\title{
ANTROPOLOGÍA Y PODER POLÍTICO \\ EL EJERCICIO DE PODER EN LAS POLÍTICAS PÚBLICAS DEL ESTADO: \\ LAS UNIVERSIDADES INTERCULTURALES
}

TESIS DE DOCTORADO EN CIENCIAS ANTROPOLÓGICAS PRESENTA: ALFONSO BARQUIN CENDEJAS

DIRECTOR: DR. PABLO CASTRO DOMINGO

UNIVERSIDAD AUTÓNOMA METROPOLITANA

UNIDAD IZTAPALAPA

CIUDAD DE MÉXICO, OCTUBRE DE 2012 
ANTROPOLOGIA Y PODER

POLITICO. EL EJERCICIO DE

PODER EN LAS POLITICAS

PUBLICAS: LAS UNIVERSIDADES

INTERCULTURALES
En México, D.F., se presentaron a las 14:00 horas del día 16 del mes de octubre del año 2012 en la Unidad Iztapalapa de la Universidad Autónoma Metropolitana, los suscritos miembros del jurado:

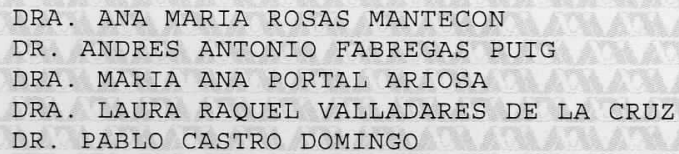

Bajo la Presidencia de la primera y con carácter de Secretario el último, se reunieron a la presentación de la Disertación pública cuya denominación aparece al margen, para la obtención del grado de:

DOCTOR EN CIENCIAS ANTROPOLOGICAS

DE: ALFONSO BARQUIN CENDEUAS

y de acuerdo con el artículo 78 fracción IV del Reglamento de Estudios Superiores de la Universidad Autónoma Metropolitana, los miembros del jurado resolvieron:

$$
\text { APROBAR }
$$

Acto continuo, la presidenta del jurado comunicó al interesado el resultado de la evaluación $y$, en caso aprobatorio, le fue tomada la protesta.
LIC. JULIO CESAR DE LARA ISASSI DIRECTOR DE SIS AMUS ESLOLARES
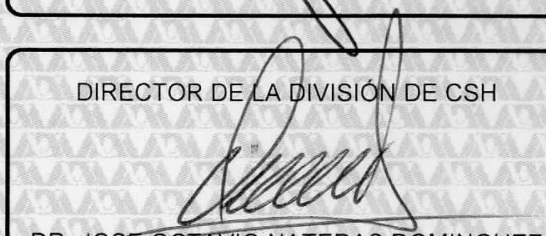

DR. JOSE OCTAVIO NATERAS DOMINGUEZ

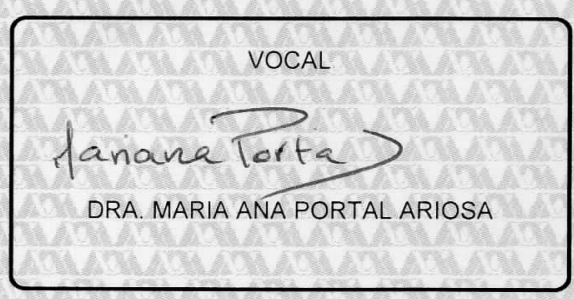

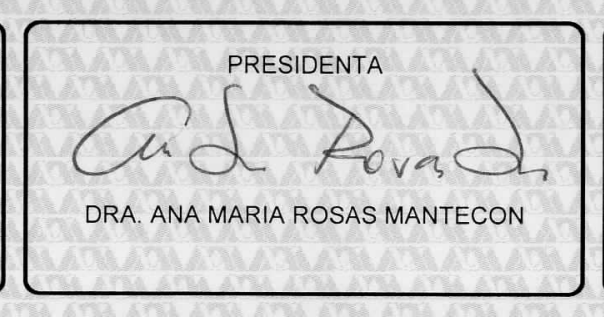

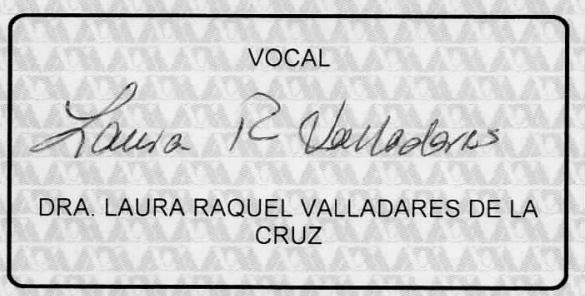

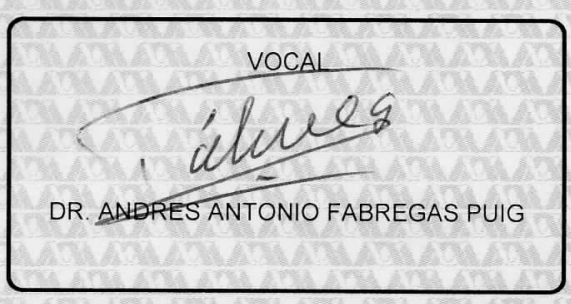

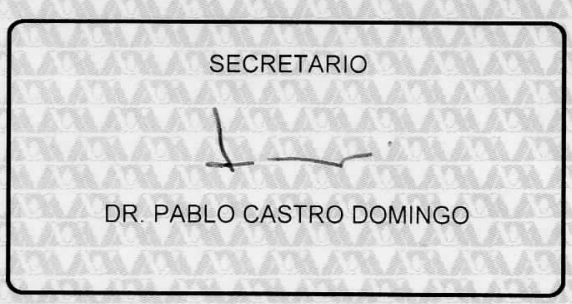




\section{Índice}

Introducción.

.7

1.- Sobre el papel de las diferencias y las asimetrías en la construcción del poder. 23

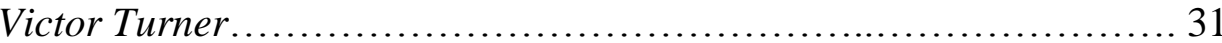

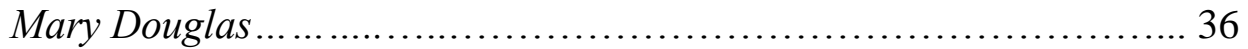

Marcel Mauss y Emilio Durkheim...................................... 40

Ferdinand de Saussure ............................................ 47

Claude Lévi-Strauss............................................. 53

Corolario.......................................................... 62

2.- El intercambio y el poder............................................... 71

El intercambio y sus efectos........................................ 77

Otros enfoques.................................................. 83

Los principios básicos........................................... 91

Complementos y precauciones......................................111

Corolario........................................................... 137

3.- El orden y las órdenes nacionales e internacionales.................. 143

El marco internacional ........................................... 145

El marco nacional ......................................................... 179

Corolario........................................................... 198

4.- El deber ser de las políticas de educación intercultural............... 203

La intervención antes de la reforma constitucional de 2001 ..............204

El marco nacional de las políticas educativas interculturales..........216 
Fundamento y estructura de la educación superior intercultural........221

Intermedio teórico-filosófico: Interculturalidad y Antropología.........247

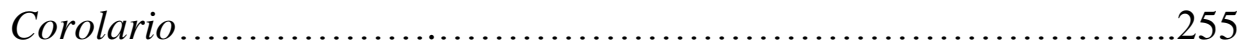

5.- Los hechos en las políticas de educación intercultural................. 259

La creación Universidad Intercultural del Estado de México............259

Condiciones generales de operación de la UIEM .......................273

El campus-símbolo.............................................288

La estructura de las carreras.....................................299

El salón de clases y la vida interna....................................306

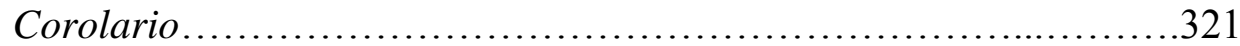

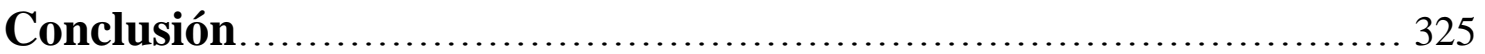

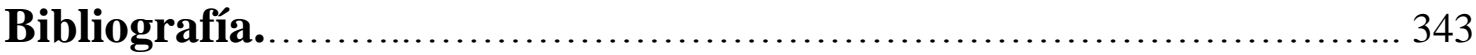

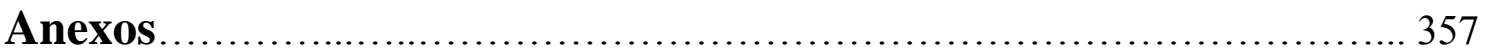




\section{Agradecimientos}

La culminación de este largo proceso, casi quince años de formación profesional en Antropología Social, ha sido de duro trabajo y gran satisfacción personal. En esta última etapa, tengo mucho que agradecer a todas las personas que contribuyeron para la conclusión de este trabajo.

En primer lugar al Dr. Pablo Castro, director de la tesis, que siempre me facilitó el proceso leyendo y comentando las sucesivas etapas del documento además de la certera comprensión de mi atareada situación personal que por la duración del doctorado fue algo muy importante. Al Dr. Juan Castaingts que estuvo a cargo de la dirección de la primera etapa de del trabajo; sus comentarios atinados y con gran hondura, me permitieron comenzar a darle forma a todo este esfuerzo, además las taurinas charlas paralelas hicieron muy agradable el trabajo conjunto.

Quiero agradecer todas las personas que han leído este documento y cuyos comentarios fueron ponderados con gusto e interés. En primer lugar al Dr. Andrés Fábregas que leyó la versión final y participa como sinodal. Por su trayectoria profesional, sus comentarios son de un interés especialmente profundo para mi trabajo presente y futuro. A la Dra. Laura Valladares, sinodal también, que ha trabajado de manera activa en la evaluación de mi trabajo académico y profesional, y cuyas opiniones han enriquecido esta obra. A la Dra. Ana Rosas Mantecón, tengo que agradecerle sus emotivos comentarios, que para este proceso final son muy importantes.

Otros cuatro comentaristas son de particular importancia y les debo también mi agradecimiento. El Dr. Héctor Tejeda leyó partes preliminares de este trabajo y por su importancia en el campo de la Antropología Política, sus observaciones son de obligada ponderación. El Dr. Luis Reygadas, certero lector, pues sus comentarios impactaron de forma tangible la estructura expositiva de la versión final. El Dr. Alejandro Gonzales Villaruel, que revisó la parte teórica y de quien incorpore algunos argumentos y la Dra. Patricia de Leonardo, también leyó algunas partes del documento y por su interés en la educación, espero que esta versión final sea de su interés.

Un agradecimiento especial al Dr. Fernando Salmerón, que me sugirió enfocarme en este tema y por su amistad, apoyo y acompañamiento profesional, que prácticamente ha permanecido a lo largo de toda mi carrera. 
A la Universidad Autónoma Metropolitana de Iztapalapa, que ofrece condiciones inmejorables para la elaboración de trabajos de tan larga duración; en especial a Socorro Flores, cuya atinada guía y permanente buen humor, hacen ligero el enredado proceso administrativo. Al Consejo Nacional de Ciencia y Tecnología (CONACYT), pues con su apoyo, faculta e induce a culminar este proceso de trabajo doctoral.

En el trabajo de campo las amistades son en ocasiones fugaces, pero por el alejamiento de del hogar, son profundamente entrañables y difíciles de olvidar. Además, colaboran con información invaluable para el trabajo y por ello es un placer agradecerles buen trato e información certera. En primer lugar al Dr. Francisco Monroy, rector de la Universidad Intercultural del Estado de México, que desde el inicio me recibió y apoyo de buena gana, esperando que este trabajo sea de utilidad para el mejor funcionamiento de la unidad. También al Mtro. Luis Acevedo, por su interés en los aspectos políticos de la tesis y los enterados comentarios sobre la universidad. Quiero agradecer también, al rector anterior, el Dr. Felipe González, por su generosa información sobre las condiciones de funcionamiento inicial de la universidad.

Dentro del cuerpo de profesores tuve buenos amigos y generosos informantes, sin su aportación conocedora, este trabajo habría sido imposible. No tengo menos que un profundo agradecimiento a los siguientes profesores: Dr. Mindahi Bastida, Mtro. Sergio Gutiérrez, Mtra. Lourdes de la Cruz, Mtro. Saúl García, Mtro. Alonso Reyes, Lic. Guadalupe Hipólito, Mtro. Antoni Servín y Dr. Salvador Aldama.

Un agradecimiento especial y fraterno al Mtro. Antolín Celote, profesor comprometido y entusiasta participante del planteamiento general de la UIEM. Su reflexiva y crítica visión de lo que la educación intercultural debe significar y el papel que las comunidades indígenas deben jugar en este proceso, oriento de manera fundamental mis reflexiones. Además debo agradecer su amistad y buena conversación informal.

Un agradecimiento general al personal administrativo y a los alumnos de la UIEM y a los alumnos, que aportaron información y documentación para este trabajo, deseando que el esfuerzo presente, contribuya en algo al mejor desempeño de la UIEM.

Finalmente, quiero agradecer de manera profunda y amorosa a mis dos cimientos, Mariza y Marco, que aguantaron con entereza, las obligadas y lluviosas ausencias que producían mis viajes a San Felipe del Progreso. 
La historia confirma que los pueblos indígenas han sido objeto de formas de subordinación, desigualdad y discriminación que les han determinado una situación estructural de pobreza, explotación y exclusión política. Confirma también que han persistido frente a un orden jurídico cuyo ideal ha sido la homogeneización y asimilación cultural.

Acuerdos de San Andrés

\section{Introducción}

La Antropología es una vía sólida para el estudio del poder político. La evidente fortaleza del cuerpo de conocimiento labrado por la disciplina desde el siglo XIX no deja duda: ¿cuál es entonces el propósito de iniciar con tal afirmación? El sentido es por demás simple: que siendo el poder un fenómeno ubicuo en la historia humana, su estudio en nuestra época, se entrevera, cada vez más, con la situación actual de la sociedad global. Hay un fuerte sentido de urgencia en la descripción de los mecanismos factibles de conducir la acción social, pues los niveles de desigualdad entre los miembros de las sociedades regionales y entre éstas, arrojan un saldo tremendo en distancias por salvar y en número de individuos que nada tienen, frente a quienes lo tienen todo. De ahí la urgencia por encontrar mecanismos que puedan llevar a las sociedades a un punto más equilibrado y justo; menos desigual.

Los organismos centralizados y centralizadores que los humanos han desarrollado a lo largo de la historia, en particular el Estado, son los que sufren actualmente las presiones más fuertes para "equilibrar" la balanza, pues cuentan con los mecanismos para lograrlo y por ende “deben” hacerlo. Para ello, se diría, habría que ejercer el poder en aras de la equidad y la justicia. Sin embargo, ronda en este mismo sentido, una aversión profunda al ejercicio de poder, pues en el fondo, entraña procesos de exclusión, de desigualdad, de diferencia. La presión por llevar los mecanismos democráticos a todos los ámbitos, donde todos deciden, donde todos participan, ha generado felices resultados de equidad, como pueden constatar las notables transformaciones en la ruptura de barreras de clase, de género, de razas, de culturas, de 
sexualidades, de capacidades. Pero este impulso de igualdad entre los hombres, reseñado en documentos celebérrimos, se confronta con la imposibilidad de todos conduciendo la acción social; en este sentido es que el Estado enfrenta una contradicción insoluble. Así pues, el ejercicio del poder político en su raíz profunda, comporta también una distinción entre los humanos, sin embargo, su disolución no es del mismo orden que las anteriores y de hecho es imposible; se dice siempre, que las relaciones de poder son aquel tipo de relaciones en donde no hay igualdad, en donde impera la diferencia, se dice pues, que toda relación de poder, es una relación asimétrica.

Aquí es donde la Antropología expresa su potencial para comprender el fenómeno del poder político, pues pocos casos permiten poner en práctica de manera más eficaz, el credo de la distancia entre aquel que busca comprender la circunstancia del otro, respecto de la suya propia. En este sentido, es que la disciplina nos faculta para seguir explorando nuevas vías en la comprensión de los fenómenos resultantes de las diferencia humanas, en una época donde variadas fuerzas sociales empujan de manera constante por cualquier tipo de solución, permitiendo así moderar la urgencia desbocada e inyectando un poco de reposo, mejorando con ello el conocimiento y la acción. Paradójicamente, estas "nuevas" vías surgen de una disciplina que cimentó su saber, en la comprensión de sociedades donde el poder político es menos acusado: las sociedades primitivas.

Desde luego que siendo un hombre de mi época, mantengo una posición política en torno a la búsqueda y aplicación de soluciones para los problemas que aquejan a los grupos sociales, ya sea que vengan desde el Estado, ya sea que ocurran en contra o a pesar de éste. En el mundo de los efectos colectivos, encuentra uno soluciones de todo tipo y en virtud de las ideas políticas personales, se juzgan adecuadas, aceptables, malas o desastrosas. Sin embargo, como antropólogo, no dejan de sorprenderme las insólitas vías o acostumbrados mecanismos, mediante los cuales, individuos o grupos, conducen las acciones o pensamientos de otros tantos. El Estado, como máxima instancia de conducción social, busca también, a partir de un marco normativo positivo y en ocasiones consuetudinario, orientar las acciones y las ideas de los grupos sociales particulares, acorde con un marco general soberano. Ello impone la necesidad de privilegiar las soluciones donde todos confluyan, sin embargo en múltiples ocasiones, las soluciones no pueden convocar a toda la población y en ese caso, la pasividad o la resistencia deben ser vencidas. Los instrumentos que poseen los Estados para vencer 
estas apatías o disonancias con el orden soberano, son los elementos centrales del ejercicio del poder político.

Así pues, este trabajo contiene como primer tema, una propuesta para entender los mecanismos básicos del funcionamiento del poder partiendo de un axioma central: las relaciones de poder son relaciones asimétricas. Esta declaración me llevó a explorar los sistemas clasificatorios, cuyo estudio es un tema de la mayor relevancia antropológica, con el objetivo de comprender cómo funciona la construcción social de sistemas de nominación y ordenación humana. Cinco propuestas clásicas son abordadas, que al final, permitieron estructurar ejes sólidos para el análisis del fenómeno. Hay que destacar la cadena diferencia-asimetría-ejercicio de poder, que acompaña tanto el desarrollo teórico como el práctico, pues determinando las posibilidades de distinción en un sistema, se pueden conocer las posibles asimetrías y de ahí, el funcionamiento del ejercicio de poder.

Esta propuesta, surgida del ámbito clasificatorio, no está alineada en ningún sentido, con una fuente o raíz simbólica del poder. De hecho, una de las conclusiones que vertebran toda la exposición, es que la contextualidad de las situaciones, determina la aparición o desaparición de asimetrías y con ello de poder. Lo que caracteriza la propuesta, es un marco analítico para entender y caracterizar ese algo que hace diferentes y asimétricos a los actores, material o simbólico, de forma tal que el uso de tales asimetrías, puede derivar en ejercicio de poder. Considero no obstante, que la Cultura en su sentido más amplio, es un complejo en donde las consideraciones entre semejante y diferente, ocurren todo el tiempo, de ahí que la base en los sistemas clasificatorios, permitió abordar satisfactoriamente el problema de las relaciones y el ejercicio de poder.

El segundo tema, es la profundización en el fenómeno del intercambio social, de la mayor importancia para comprender los fenómenos de poder. El cimiento plantado por Marcel Mauss a partir del Ensayo sobre los dones, marcó un parteaguas en la manera de considerar los hechos cotidianos de cambio más allá de la visión económica. Su propuesta global para la comprensión de lo humano, fue la base de la que partí para abordar todas aquellas relaciones asimétricas derivadas de los intercambio en la sociedad, con un acento particular: que dicho fenómeno enlaza a dos actores, en una relación de diferentes, caracterizado por la posesión de un "bien” en alguno de ellos y la ausencia en el otro en cantidad o calidad. Esta diferencia llevada al terreno de lo cotidiano constituye una posición de ventaja, asimétrica, que, mediada por la 
transferencia total o parcial del bien, permite ejercer el poder, es decir, determinar acciones o ideas.

Este proceso típico e ideal, fue la clave en la construcción del modelo para abordar el fenómeno concreto a partir de la idea de conductas y conceptualizaciones de apropiación. Acciones desplegadas o procesos mentales detonados, que ocurren como consecuencia de la apropiación del bien que media el intercambio. Partiendo de un carácter intencional del hecho, estas conductas y conceptualizaciones son justo el centro del ejercicio del poder, pues están condicionadas a la apropiación del bien. Además, tal concepto permite salvar la dificultad analítica de centrar el intercambio en el donatario, pues a diferencia del modelo maussiano, no importa quién da primero o quién “devuelve" primero; lo relevante, es quién está condicionado de manera asimétrica, a llevar a cabo conductas o conceptualizaciones en el proceso de intercambio. Este proceso puede caracterizarse de manera semejante, si ocurre con la mediación de bienes materiales o no materiales; ello, simplemente los define como intercambios homogéneos o heterogéneos.

La caracterización del poder como un fenómeno surgido del proceso diferenciaasimetría-ejercicio de poder y el uso del concepto de conductas y conceptualizaciones de apropiación, constituyen dos aportaciones básicas de este trabajo. Todo el análisis de los casos a presentar, estará centrado en estos dos ejes analíticos, poniendo en evidencia su fortaleza.

Paralelamente, se fortaleció a lo largo de todo el proceso, la caracterización de exógeno, que debe tener todo fenómeno para ser considerado como ejercicio de poder. Esta ontología, deriva de la asunción de que en los hechos que ocurren entre dos actores, algunos pueden ocurrir, únicamente por decisión o intención de uno de los actores y que no ocurrirían sin su intervención; es decir, el carácter necesariamente externo de las intenciones de un ego sobre un alter, que derivan en un comportamiento específico del segundo, pero preconcebido fuera de él. Esta condición de exterioridad y preconcepción, permite discriminar los hechos de poder, de los que no lo son. Es decir, simplificando el proceso, se reduce a conocer las intenciones del ego y cotejarlas con los comportamientos del alter; su convergencia o divergencia dará evidencias de si el poder fue ejercido o no. 
Con estas ideas en mente, es que se emprendió el estudio de las políticas de educación dirigidas a los pueblos indígenas, producto de la reforma al artículo segundo de la Constitución Mexicana. El primer intento fue justo acudir a uno de los planteles emanados de dicho esfuerzo, la Universidad Intercultural del Estado de México, para conocer lo que ahí ocurría, en concordancia con el articulado constitucional. En la estancia de 2009 se constató, que en distintos rubros sus mandatos eran llevados a cabo tanto por el personal de la universidad como por los estudiantes; es decir, los efectos del ejercicio del poder eran evidentes; también existían rubros donde no había tal concordancia. Pero en el continuo de ambos extremos, lo que destacaba era la juventud de la institución y la pasión que inspiraba en los involucrados, ese intento novedoso y generoso.

Sin embargo, al tratar de dar sentido a las formas de "descenso", desde de los dichos constitucionales hasta los hechos consumados, es decir al ejercicio del poder político, me topé con complicaciones de tipo histórico, jurídico y administrativo, que determinaron un cambio en el abordaje del problema. Había que hacer un alto para analizar estas dimensiones que me impuso el "objeto", pues si bien tenía previsto considerar estas temáticas, me era imposible ponderar lo complejo del asunto.

Del proceso quedaron tres cosas: En primer lugar, que el debate de la interculturalidad, tocaba más ángulos de los que había yo considerado, y que el peso del Multiculturalismo como paradigma rector era imposible de esquivar. En segundo lugar, se me reveló la profunda y creciente imbricación que la legislación internacional tiene sobre la nacional en torno a este tema, al grado de resignificarse, al funcionar de pactos entre Estados a motor de actividad política, que enfrenta colectivos internos con gobiernos. Y tercero, que el modelo para la comprensión del ejercicio de poder, se mostró sorprendentemente adecuado para abordar estos temas sin mayores adecuaciones, lo que fue una agradable sorpresa.

Desgranando desde este último aspecto, quiero destacar que al enfrentar el cuerpo legal nacional e internacional, las discusiones y los motivos, me vi casi orillado a utilizar el modelo que inicialmente había diseñado solamente para una contrastación empírica. Ello porque los documentos hablaban todo el tiempo de diferencias culturales, respeto entre culturas, integración, diferenciación, asimetrías, eliminación de asimetrías y mantenimiento de diferencias, todo ello, para dictar cuáles debían ser las acciones o conceptos de los Estados hacia las poblaciones indígenas, con el objetivo de mejorar su nivel de desarrollo, de ciudadanía, de acceso a la justicia y de preservación o defensa de 
su cultura. Es decir, que se tenía una relación estructural y centenaria de poder, basada en una clasificación racial y cultural, y que vía el ejercicio de poder estatal, se buscaba cambiar conductas y conceptualizaciones de la población criollo-mestiza para con los indígenas, pero también, ejercer el poder político en dichas poblaciones, pues los niveles de desventaja con el resto de la Nación eran imposibles de romper únicamente desde dentro; es decir, requerían la intervención exógena del Estado. El cambio paradigmático, que hizo pasar a los Estados desde una visión integracionista hasta una de respeto legal de la diferencia cultural, determinó un "descubrimiento": en términos jurídicos es posible dictar la aparición de diferencias y asimetrías legales, que permiten el ejercicio de poder; eso todos lo saben; lo que me sorprendió, fue el procedimiento inverso, es decir, que las leyes están posibilidad de determinar la imposibilidad de usar diferencias reales entre los individuos para ejercer el poder. Claramente, eso responde a las declaraciones de derechos iguales ante la ley, de vieja memoria, pero que no entraban en mis cálculos. Esto produjo la aparición de los términos, un tanto onomatopéyicos pero metodológicamente obligados, de asimetrizaciones y desasimetrizaciones, y que se refieren a la capacidad jurídica de crear o destruir, por decreto, asimetrías legales para beneficiar a los desaventajados o impedirles un daño. Éstas fueron las únicas adecuaciones al modelo para el abordaje de los textos, de donde se rescataron fundamentalmente, las acciones que obligaban a los Estados firmantes a crear conductas y conceptualizaciones de apropiación, para dispersar los derechos instituidos y obligar a su cumplimiento, tanto a poblaciones mestizas como indígenas. El único limitante era el de la diferencia cultural, imposible de transformar en asimetría que facultara ese ejercicio de poder; de ahí que la asimetría central elegida, fue la que enlaza al Estado como poseedor de recursos de diversa índole, frente a los indígenas desposeídos. En este sentido, es que todo el análisis del tercer capítulo es profundamente antropológico, pues buscó determinar qué cosas de las culturas son diferentes, y cómo se construyen y destruyen asimetrías a partir de esas diferencias

De las otras dos dimensiones, he de mencionar que fue muy enriquecedor el proceso, ya que se pudo observar cómo las acciones políticas de los actores nacionales, determinan en múltiples ocasiones, el establecimiento de pactos internacionales, que obligan a los signatarios a cumplir dichos pactos, pero únicamente entre ellos, es decir, que resultaba en aquella época, mucho más fácil firmar compromisos internacionales, que comprometerse con las poblaciones nacionales. Esta característica determinó que instrumentos como el Convenio 169 de la OIT, entre otros firmados por México, no 
sean cumplidos en los términos signados por el país. Así de manera general, la legislación internacional sobre el tema, avanza más allá que en el nivel nacional. Fue justo la presión nacional -armada y social-, y no la internacional, la que obligó al Estado Mexicano a modificarse en términos constitucionales, quedando la Carta Magna distante de los Acuerdos de San Andrés, pero imponiéndole una serie de compromisos entre los que aparece la educación bilingüe e intercultural. Esta nueva forma del Estado, si bien es claramente insatisfactoria para los grupos que la promovieron, es la que tiene hoy. El ejercicio de poder político mediado por el intercambio a propósito del tema, no derivará entonces, ni de la falta de inclusión de las demandas ignoradas, ni de la conducción del Estado, sus tres poderes y tres órdenes de gobierno, de acuerdo con los temas sí incluidos, pues en términos teóricos, dichas conductas y conceptualizaciones, no ocurrirían en ellos de manera exógena, sino como derecho reconocido, que era lo que demandaban. El poder político del Estado, vendrá de la modelación que en el proceso de implementación política, va tomando la educación bilingüe e intercultural, cuyo eje central responde a problemas de orden estatal, a saber: el de una asociación política -la central de nuestro tiempo-, que tiene, no solo el monopolio de la fuerza sobre un territorio, sino la capacidad administrativa y certificadora, y de ahí, la facultad de que sus determinaciones las cumplan todos los incluidos en éste. Esta capacidad global, le permite al Estado dar dimensión territorial total a los dictados constitucionales y también lo condiciona a seguir dinámicas estatales. Como consecuencia, la construcción concreta de las políticas públicas que instrumentan los gobiernos, "pasa" por muchas manos, que le van dando forma real al espíritu de la ley. Ese es justo el nivel en donde el poder político es ejercido de manera concreta, pues comporta una serie adecuaciones, intervenciones, limitaciones, ignorancias y hasta contraindicaciones, a la letra constitucional. Pero esa dimensión, no está en control de los destinatarios, pues se construye de manera exógena a la población de destino. Aun en el caso concreto de las universidades interculturales, las muchas consultas a representantes de las comunidades indígenas, no impiden dicha exterioridad -aunque si la mitigan notablemente-, pues la decisión política es por definición unitaria y se impone por igual sobre las distintas opiniones en las comunidades concretas, al margen de las opiniones de sus élites consultadas.

Esta dimensión exterior, es notable de apreciar en el último de los puntos, a propósito del Multiculturalismo, pues expresa una visión de cómo "deben" ser las relaciones entre las culturas. Este tema, en el cual los antropólogos son ahora 
acompañados y en ocasiones desplazados, me permitió profundizar de una manera "muy" antropológica, para tomar una posición al respecto de esta ideología política de impulso hegemónico. Y mi conclusión es ambivalente al respecto, pues concuerdo, políticamente, en dos los tres temas centrales que propugnan para una relación plenamente intercultural: hay que comprender y respetar las distintas culturas para vivir en un horizonte de justicia plena. Sin embargo, la tercera: conservar, genera desde mi perspectiva, muchas distorsiones en la implementación de políticas públicas. Y esto surgió justo por un tema constante en el modelo, pues si desde el exterior, se busca animar o reanimar una práctica perdida, no la pureza, pero si el vigor de dicha cultura, queda claramente expuesto en el nivel nivel endógeno y desde luego, condicionado al ejercicio de poder exógeno. Por otro lado, las intervenciones políticas pueden generar muchos beneficios, pero también daños profundos, pues el horizonte de intervención es el de la vida de una cultura, es decir centenario, de forma tal que efectos imprevistos o perversos acechan el proceso, con la peculiaridad que dichos "efectos" son visibles sólo en el largo plazo; si existen errores en el diseño, aparecerán una o dos generaciones después, cuando el daño esté hecho. No concluyó con una posición específica, pero definitivamente, las opiniones vertidas por Claude Lévi-Strauss en la discusión, son profundamente inquietantes desde un punto de vista técnico-antropológico.

Solventadas las dificultades históricas y jurídicas en los términos reseñados, restaban las administrativas. De nueva cuenta, hubo que postergar el abordaje del hecho in situ, para indagar y comprender como se da el proceso técnico, administrativo y político, que da forma concreta a las instituciones de educación superior en zonas indígenas: las Universidades Interculturales.

Con la experiencia y seguridad en la eficacia del modelo para el tratamiento del tema anterior, y simultáneamente, sabiendo que este nivel constituye el de dar forma real a los enunciados que determinarán las conductas y conceptualizaciones del bien educativo, no tuve duda de usar sus herramientas desde el principio. No me generó mayores problemas y sí obtuve en cambio, una gran consistencia interna, pues los tres momentos: teórico, normativo y administrativo, "hablaban" con el mismo lenguaje.

En esta fase, se analiza brevemente la historia que relaciona al Estado y los pueblos indígenas en el tema educativo. Los tres grandes momentos: el indígena como 
individuo subordinado; como individuo a integrar y como agente, están conectados por un hilo conductor en el que el Estado, toma decisiones externas sobre los métodos, forma, contenido y utilidad de la educación en zonas indígenas. Desde el inicio, lo reseñó Gonzalo Aguirre Beltrán, el conflicto reside en que la educación contiene fuerzas contrarias en su transmisión: aquellas que tienden a la conservación y aquellas que empujan a la innovación. En todo fenómeno de poder político que involucra la educación, las determinaciones exógenas impactan centralmente estas dimensiones. En el caso de México, desde el inicio colonial, las conductas y conceptualizaciones para conservar o innovar, estuvieron caracterizadas por dos temas: las necesidades derivadas del tipo de estado imperante; y la relación entre culturas distintas. En este sentido, es que los recursos que el Estado destina al tema educativo, interesan a sus necesidades de época pero también, a la forma en que se perciben los elementos culturales de los grupos diferentes. Deben ser fortalecidos, conservados, ignorados o combatidos. Tanto en las épocas anteriores como en la actual, el Estado ejerce el poder político en términos educativos, buscando formar individuos con distribuciones de conocimiento específicas, y las políticas educativas, operan de manera exógena de acuerdo con esos cuatro ejes. Sólo como ejemplo, en la actualidad se combaten prácticas culturales indígenas asociadas al comportamiento de los hombres hacia las mujeres y los menores de edad; la educación estatal está plenamente comprometida en ello.

Reseñada la historia en esos términos, se expone todo el marco institucional y organizacional que se desprende de la reforma constitucional del 2001. Ya no es el impacto del marco internacional o nacional en términos amplios, sino las determinaciones específicas al nivel educativo, tanto normativas como por los órganos encargados de la implementación. Ahí destaca claramente el papel de la Coordinación General de Educación Intercultural Bilingüe (CGEIB), como el órgano rector de todo el proceso de diseño, creación, certificación y acompañamiento de las Universidades Interculturales (UI).

En el tratamiento de este Órgano de Gobierno, resaltan dos dinámicas centrales. En primer lugar, la discusión técnica y filosófica que busca responder: ¿Qué cosa es la interculturalidad? ¿Cómo debe ser entendida en la educación? ¿Cuáles son las especificidades de la educación intercultural en zonas indígenas? ¿Cuál debe ser la forma y el contenido de la educación intercultural en zonas indígenas a nivel universitario? Las respuestas generadas por la CGEIB comportan dos ámbitos: ajustarse al mandato constitucional en materia de derechos y cultura indígena para cumplir 
legalmente, pero también, generar insumos concretos que den forma real a las UI; esta segunda dimensión filtra ya, muchos contenidos exógenos, es decir, el ejercicio del poder político. Adelantando, únicamente con el propósito de dar sentido a toda la exposición, tres son los problemas que generan estos insumos: la escasa cobertura a la población indígena en educación superior; las crecientes demandas de sectores de la población indígena; y el desequilibrio geográfico del desarrollo nacional. Las soluciones concretas a esta problemática, no son generadas al margen de los actores no estatales de la sociedad, pero son requisitos ineludibles en el funcionamiento de las UI y caracterizan de manera determinante, las conductas y conceptualizaciones de apropiación del bien educativo.

En segundo lugar aparece la otra dinámica: las formas administrativas concretas, que enlazan a la Federación con las Entidades Federativas en cuanto a las condiciones del Convenio de Coordinación que suscribirán para fondear las UI y la normativa legal y administrativa que va a caracterizar la operación concreta de las unidades en su dimensión educativa, administrativa y laboral. Dos ejes modelan de manera particular estas dimensiones. El primero consta en las tensiones entre los diseños institucionales existentes y las necesidades de innovación del proyecto de las UI. Resulta ilustrativo como al interior del Estado y en las interacciones políticas concretas, los diseños institucionales existentes tienden a permanecer, sobre los intentos de adecuar o reformular los marcos operativos para la nueva institución; mucho de la forma de las UI quedó determinado por lo existente, al margen del intento de los actores por transformarlo. El segundo eje, discurre por las tensiones entre el Gobierno Federal y el del Estado de México. Este campo político se transforma en arena, por la confrontación en dos niveles: el de la diferencia de escala, pues mientras para la Federación impactan los intereses nacionales, los regionales son los básicos para la Entidad; y por otro lado, el enfrentamiento político partidista, por ser el Gobierno Federal de origen panista, frente al estatal, profundamente priista.

La forma concreta resultante, es la forma que el Estado Mexicano dio a la Universidad Intercultural del Estado de México. En este sentido, el ejercicio de poder político mediado por el intercambio, se define por dos pares de oposición asimétricos que enlazan al Estado con los pueblos indígenas: Estado poseedor/individuos desposeídos y Estado certificador/estudiantes descertificados. Las conductas de apropiación de los bienes gubernamentales: educación y certificación, serán intercambiados con los dos modos descritos teóricamente: Primero el bien (educación) y 
después las conductas y las conceptualizaciones de apropiación (aprendizaje); o primero las conductas y conceptualizaciones (aprendizaje mínimo) y después el bien (certificación). En estos dos momentos, el tema de la aprehensión de contenidos y comportamientos, acordes a los principios de la interculturalidad son los centrales en la acción exógena del Estado.

De los cuatro momentos descritos: el clasificatorio, el del intercambio, el normativo y el administrativo, que conforman los cuatro capítulos iniciales del trabajo, los dos últimos no estaban contemplados como tales. Se consideraba al comienzo de los trabajos abordar esos temas, pero como complemento para encuadrar cuáles eran las conductas y las conceptualizaciones de apropiación, que conformarían el ejercicio del poder político en el tema. Lo que no se previó, fue la densidad temática y la influencia que dichos ámbitos iban a tener en el resultado final, es decir, en la unidad estudiada.

Inicialmente, el diseño teórico-metodológico estaba enfocado en dos momentos. Transformar, pulir y complementar, el trabajo teórico previo sobre el tema de las relaciones de poder y de las relaciones de poder mediante el intercambio. Como segundo, realizar dos estudios de caso y compararlos. Sin embargo, el motor principal de todo este esfuerzo, nunca fue indagar cómo se implementan las políticas sobre derechos indígenas descritos constitucionalmente, ni la educación intercultural en particular, sino comprender, describir y explicar, los mecanismos a través de los cuales el poder político es ejercido exitosamente.

Esta meta, parecía cercana en la estancia de tres meses en 2009, en San Felipe del Progreso, Estado de México, sede de la primera Universidad Intercultural fundada. Sin embargo como he reseñado, tenía las dos puntas de un "hilo" demasiado largo. En un extremo, el modelo; en el otro, el hecho crudo de poder. El trabajo etnográfico me condujo a conocer y ponderar, la importancia que los actores daban a otros temas que rondaban el proceso de la implementación, y que impactaban y determinaban las conductas y las conceptualizaciones observadas. Más aun, una estancia de 20 días en Pátzcuaro, Michoacán, sede de otra de las universidades interculturales, me llevó a complejos problemas de comparación, justo por las características diferentes que adoptaba un modelo en apariencia igual. La política local y regional, y el vigor de la cultura indígena, eran temas que impactaban de manera distinta en cada unidad. Así que 
lo que pensaba de inicio como una comparación de la efectividad del poder político en términos de resultados, se tornó imposible, pues la trayectoria particular en cada región era incomprensible, sin el desarrollo de los temas intermedios. Estas ausencias en la comprensión del proceso completo del ejercicio de poder político, es decir, lo de "en medio", se detectó por las constantes referencias de estudiantes, maestros y directivos, al denso mundo de los fines; ya como alabanza al proyecto, ya como presión por las deficiencias. Ello en virtud de que, en efecto, dicho ámbito determina la inscripción constitucional de los mandatos al Estado y por ende, qué cosas y con qué espíritu ocurrirán como derecho y cuáles como acción exógena. El otro ámbito, el marco institucional y administrativo que determina la forma real, subordinada a las estructuras de acción gubernamental cotidiana en el contexto de los intereses políticos más relevantes, aparecía también frecuentemente, sobre todo entre el personal directivo o académico, en relación a las dificultades y trabas operativas, que impedían el desarrollo pleno del aspecto normativo, pero que, se observó, impactaba de manera determinante lo que los estudiantes recibían como "bien" final.

Subsanar las ausencias, determinó tomar la decisión de olvidar la dimensión comparativa y también, de abandonar el formato de "estudio de caso" y enfocarse en un producto de visión más amplia. Esto permite afinar la comprensión del proceso general, que va desde el deseo por un futuro diferente; a la construcción mediante herramientas tipo "Estado"; pasa por el "embudo" de la maquinaria gubernamental; y aterriza en los individuos concretos que "tendrán" ese futuro diferente. Estoy cierto que esta ampliación, modificó para bien la comprensión, la descripción y la explicación, del poder político que ejerce el Estado, en el tema de la educación superior intercultural en regiones indígenas. La decisión tomada, impactó también, el espacio dedicado aquí, a los resultados en la Universidad Intercultural del Estado de México. Por ello era fundamental esta aclaración, pues el reporte de los hechos empíricos de poder, quedará encuadrado en este marco general, reduciéndose en extensión, pero ganando en generalidad. El presente trabajo es en este sentido, más un estudio de "tema" que de "caso". Dada la importancia que la Antropología otorga al trabajo de campo en el sitio, el reporte de tales datos, a pesar de quedar únicamente en el último capítulo, complementan adecuadamente el planteamiento general, que está influenciado en su totalidad por dicha experiencia. 
En la quinta sección, se caracteriza por supuesto, la historia, el sitio, la región, y las condiciones generales de operación de la Universidad Intercultural del Estado de México (UIEM). Para todas estas entradas, el criterio expositivo es claramente demostrativo. Las determinaciones constitucionales, que motivaron la acción del Estado, tomaron una forma concreta luego del mentado proceso técnico-administrativopolítico. Así, se pondrá en evidencia, todo lo que sí ocurre de lo planeado como ejercicio de poder, es decir, las disposiciones exógenas a la población universitaria y los niveles concretos en los que ocurre: directivo, académico, laboral o estudiantil. Uno de los primeros hechos que destacan, es la presión estatal para "plantar" una universidad intercultural, por sobre el deseo de sus gestores locales, de una universidad indígena. Esta acción exógena inicial, expone de manera práctica la implantación desde fuera, de una serie de insumos que van atados a los recursos que el Estado pone a disposición, pero que han de ser apropiados de acuerdo con ordenaciones específicas. Un efecto concreto de la ubicación en San Felipe del Progreso, en el corazón de la zona mazahua, es la distribución étnica de los indígenas en la unidad, pues en promedio, los mazahuas constituyen dos de cada tres estudiantes, dejando a la población otomí -la segunda en importancia- en sólo un 5\%, abajo del $25 \%$ de los mestizos, lo que muestra a la universidad como fundamentalmente mazahua y mestiza.

Todas las condiciones planteadas como modelo de las UI, determinan el tipo de estudiantes, de profesores, de saberes y de procesos educativos que ocurren en la UIEM. El perfil de edad, socioeconómico, de sexo, de opciones académicas, de permanencia en la unidad, de calidad académica, están también determinadas por la ubicación geográfica, por la fecha de las convocatorias, por las carreras ofertadas y por los recursos destinados a la operación de la UIEM, los salarios, las formas de contratación de los profesores, y el monto y disponibilidad de las becas estudiantiles. En todo esto, está claramente caracterizado, cuáles son las asimetrías determinantes, cuáles son las conductas y conceptualizaciones de apropiación esperadas y cuáles son los resultados efectivos.

Una sección particular da cuenta del fenómeno particular del diseño arquitectónico de los edificios de la UIEM, tanto los construidos como los que se van a construir. Todos tienen un diseño anclado en una mezcla de elementos prehispánicos y mazahuas, expresado con un lenguaje contemporáneo. El deseo de mostrar el orgullo del ser indígena desde los edificios, tiene efectos y busca efectos en la población 
estudiantil y local. Este efecto particular de poder, permite exponer una forma teórica no asociada al intercambio, pero relevante por su importancia en el sitio.

Se describe el efecto del modelo, desde la implantación de la idea misma de interculturalidad, su dispersión en las clases, en las curriculas y en las carreras. Destaca peculiarmente, la presión por la horizontalidad en las relaciones entre culturas, que lleva a dispersar la idea de la horizontalidad en todo, determinando que $<<$ el ejercicio de poder es algo que no debe formar parte de la interculturalidad>>; fenómeno que llamó comprensiblemente mi atención.

Uno de los impactos más notables, es la constatación de que al interior de la universidad, los muchachos, experimentan y refieren el orgullo creciente o naciente por ser indígenas; se vive y se expresa abiertamente. En este sentido el mandato constitucional se cumple. Llama la atención que en el caso de la lengua, el orgullo de hablarlo está ausente y no ocurre de manera pública; su presencia se da únicamente en los salones, durante las clases de lengua indígena.

En las clases, la presencia y manifestación de la cultura indígena es constante, como parte o ilustración de los conocimientos impartidos; de nuevo, el cumplimiento del mandato constitucional. Llaman la atención, sin embargo, las dificultades para implementar lo que se denomina "epistemología intercultural", que supone la relación horizontal entre los saberes indígenas y los "occidentales"; entre conocimiento tradicional y científico. Esta dimensión es una de las más problemáticas y aun no resueltas de las UI. Frecuentemente en las aulas, lo que ocurre es la caracterización de $<<$ Occidente $>>$ como un enemigo o entidad opuesta al mundo indígena, y la dispersión y aprehensión de sus conocimientos ocurre entreverada con esta ideología política un tanto radical.

Esta dimensión tiene su expresión concreta en las curriculas de las carreas, que diseñadas de manera exógena, han tenido un impacto desigual en la formación e inserción laboral de los egresados. La carrera base de las UI: "Lengua y Cultura", que busca formar agentes para el rescate y fortalecimiento de la lengua y la cultura indígena, ha formado agentes expertos en la materia y convencidos de la importancia del rescate y orgullo de la herencia tradicional, sin embargo, los egresados han experimentado severas dificultades de inserción en el mercado laboral. Ese efecto, es un poco menos acusado con los egresados de la carrera de "Comunicación Intercultural", pero semejante en futuro laboral, un tanto por el perfil y un tanto por lo escaso de fuentes local-regionales de empleo en el sector de la Comunicación. Esa realidad está llevando a 
la UIEM, a considerar la pertinencia de fusionar estas dos carreras para ampliar las posibilidades de empleo de los muchachos, exponiendo que el diseño en "escritorio" del perfil, en ocasiones es inviable en términos laborales. De ahí destacan dos cosas: que las conductas y conceptualizaciones de apropiación determinadas por el Estado, de manera externa a las necesidades laborales concretas, fueron desarrolladas a cabalidad exponiendo el éxito en el ejercicio del poder político, pero el fracaso en términos laborales, y la relación desigual con el espíritu constitucional. Y en segundo lugar, que la transformación de dichas carreras en una sola, modificando el planteamiento estatal original y que surge desde "abajo", no altera en nada la capacidad de poder político del Estado, pues la aprobación de tal fusión está condicionada a la certificación del órgano director: la CGEIB. Si ocurre esta adecuación, las nuevas conductas y conceptualizaciones de apropiación, seguirán estando determinadas de manera exógena con los nuevos estudiantes, configurando la continuidad del ejercicio de poder político, que mejora su adecuación al espíritu de la Constitución.

Las carreras más exitosas en términos laborales, son la de "Desarrollo Sustentable" y la de "Salud Intercultural", cuyo campo de aplicación más claro y necesario, produce mayores oportunidades de empleo o autoempleo. En éstas es también más clara y sencilla, la relación con el conocimiento científico, de tal manera que la epistemología intercultural aparece un tanto más viable que en las otras dos carreras. Un fenómeno peculiar en la carrera de Salud, se da justo por la visión un tanto diferente y peculiar sobre la interculturalidad. Tiene que ver con la tardía incorporación de la licenciatura en 2010, a diferencia del resto, que inició en 2004; también, por la eliminación del "tronco común" con las otras tres carreras, que homogeneiza las visiones; y centralmente, con la especialidad misma: la salud humana. $<<$ Si la cura es buena, no importa la procedencia >>, parece ser uno de los vectores orientadores, de tal manera que las relaciones entre distintos saberes culturales, no es problemática en tanto sea efectiva. Esta realidad lleva a producir una visión un tanto holística de la cultura, en donde la "cultura tradicional" pasa a segundo plano y lo relevante es el método efectivo: acupuntura japonesa y china, homeopatía, herbolaria, alopatía, son tradiciones combinadas, sin jerarquía visible. Esto que no es malo en sí, porque da salud, llama la atención por generarse en una institución estatal, surgida de un deseo constitucional de fortalecimiento y conservación de las culturas indígenas, lo que resulta paradójico en un ambiente de "cultura mundial" o new age. 
Finalmente, destaca el tema de la vinculación, eje característico y motor novedoso de las UI. En la unidad del Estado de México, se ha logrado en distintos niveles, que los muchachos vayan formándose académicamente con frecuentes contactos con la población local y de las comunidades. Esto crea una convicción firme, de que al egresar, será factible trabajar vinculado al ámbito regional, con respeto a la cultura de la zona. La conexión entre diseño del modelo e implementación concreta, ha sido exitosa y el Estado ha conseguido así, detonar fuerzas de desarrollo al interior de la zona y crear frenos a la fuga de "cerebros", tan común entre los profesionistas indígenas. Un aspecto peculiar de esta voluntad local, es el tinte indigenista que tiene la vinculación, pues el tema "indígena" es de tal fuerza, que en el discurso cotidiano, las poblaciones rurales no indígenas, los antiguos "campesinos" no aparecen como sujeto de la acción de los muchachos.

En fin, que la descripción de la acción exógena del Estado Mexicano con las herramientas teóricas a presentar, muestra una capacidad más que aceptable para dispersar conductas y conceptualizaciones al nivel de los estudiantes. Los problemas parecen derivar más de la correlación de dichos efectos con las expectativas constitucionales o de la pequeña cantidad de recursos inyectados en el proyecto nacional en relación a las necesidades efectivas; esas evaluaciones, están claramente en un ámbito de mediano y largo plazo. Con apenas siete años de funcionamiento y cerca de cien titulados a fines de 2011, las valoraciones del impacto real, requieren algo de espera.

Por el momento, se invita a emprender la revisión de este trabajo con una idea en mente: que la aproximación al estudio del funcionamiento del poder político, tiene en el modelo antropológico anclado en los sistemas clasificatorios, una herramienta eficaz para caracterizar lo asimétrico de las relaciones de poder. El complemento, la adecuación para los fenómenos de poder que ocurren mediante el intercambio, es una forma específica para el análisis y comprensión de las políticas operadas mediante el uso de recursos públicos. El caso de estudio, las Universidades Interculturales, permite encuadrar esa funcionalidad explicativa, de manera efectiva. Quede pues en manos del lector, la última palabra. 


\section{1.- Sobre el papel de las diferencias y las asimetrías en la construcción del poder}

Los problemas del ejercicio del poder político definen, necesariamente, contemplar los sistemas de clasificación. La propuesta a presentar, sustenta la postura de que el núcleo de las relaciones de poder, se encuentra en la movilización de las diferencias contenidas en tales sistemas. El debate siempre vigente sobre el origen o fundamento de las "fuentes" del poder, no es relevante aquí. Lo que voy a exponer, se centra en la forma en la que una diferencia -cualquiera que sea su origen- es notada, conceptualizada y procesada para servir de eje en el ejercicio del poder. De ahí la distinción entre diferencias y asimetrías; unas son formales y las otras, políticas.

Para el análisis de las políticas sobre educación intercultural que el Estado y el Gobierno de México ponen en práctica, se utilizó el esquema referido. ¿Cuáles son aquellas características que en los hechos cotidianos, definen los mecanismos por los que se puede orientar la acción social según los supuestos contenidos en el artículo segundo de la Constitución Mexicana? La interrogante está hablando claramente, del ejercicio del poder político.

Hay entonces una serie de circunstancias que enlazan funcionarios gubernamentales con la población objetivo y que hacen factible el cumplimiento del mandato constitucional. De manera fundamental, dicha población está constituida por los miembros de las comunidades y pueblos indígenas, que son el corazón del artículo 
segundo. Se supone así, que existen una serie de diferencias significativas que permiten la construcción de asimetrías y de ahí, la conducción de los sujetos según la norma.

Hay un tema de la mayor relevancia, que rondará todo el trabajo y que constituye una gran paradoja en términos políticos y sociales. ¿Cómo es que se usan diferencias y asimetrías con la población indígena en su beneficio y paralelamente, el fundamento de la reforma constitucional es la eliminación de las desigualdades entre las poblaciones indígenas y no indígena del país? La solución provisional de este dilema está en un tema tratado constantemente en la Filosofía Política: que según un pacto original, los indígenas como mexicanos, convienen en subordinarse a la norma fundamental de la nación. Ello incluye su derecho a elevar al orden constitucional, sus demandas fundamentales; tales demandas engloban mecanismos que buscan eliminar una serie de injusticias e inequidades que los afectan y que son distintas del resto de la población. Las condiciones estructurales que determinan la subordinación histórica de los indígenas del país, están ancladas en asimetrías históricas. Pero esas condiciones particulares, no influyen los núcleos ontológicos que permiten el ejercicio del poder político del Estado. En ese sentido, la "liberación" de ciertas relaciones asimétricas frente a la sociedad nacional, no supone la liberación de toda asimetría. Los mecanismos que dan sustento al poder estatal, siguen vigentes al margen de matices locales.

Es evidente que esta asunción formal, dista mucho de las discusiones permanentes entre los límites del Estado y los pueblos indígenas, sin embargo, el mayor conflicto, está en todo aquello que no quedo incluido en la reforma constitucional. Lo anterior determina, no lo justo de la reforma, sino los limites reales en la implementación de políticas por los gobiernos. Resumiendo, se van a presentar aspectos relevantes de los sistemas de clasificación y su articulación con los sistemas de poder, en la inteligencia de que una cosa son las diferencias y las asimetrías que facultan el ejercicio del poder político en términos legales y otra cosa, son las inconformidades legítimas o ilegítimas al orden establecido. Tal orden legal no define el éxito de las políticas de educación intercultural, pero tampoco las inconformidades impiden la instrumentación de las mismas. Esta última sentencia, será materia de la exposición de los resultados obtenidos de la investigación sobre la Universidad Intercultural del Estado de México. En este capítulo, únicamente se tratarán los aspectos teóricos que embridan diferencias y asimetrías con el ejercicio del poder. 
Clasificar es un acto eminentemente humano. Dentro de los trabajos que la Antropología lleva a cabo desde sus inicios, el estudio de los sistemas de clasificación ocupa un lugar fundamental; es un esfuerzo que vale la pena rescatar. En la construcción de lo que constituía el estudio de la evolución humana y la discriminación entre la condición primitiva y la contemporánea, la comprensión de cómo se etiquetaban y organizaban los datos producto de la experiencia, fue fundamental. El Evolucionismo, como corriente teórica madre y modelo de aproximación al hecho social, tenía como expectativa, indagar las características del proceso de humanización. "Las últimas investigaciones sobre el origen de la raza humana vienen a demostrar que el hombre empieza su vida al pie de la escala labrando su ascenso, del salvajismo a la civilización, mediante los lentos acopios de la ciencia experimental", es el dicho de Lewis H. Morgan en la frase inicial de La sociedad primitiva. Dentro de ese proceso de acopio, el papel de las clasificaciones era central. El mismo Morgan considera como una de las bases de la evolución del hombre y de la construcción de la sociedad, los sistemas clasificatorios. "Al discurrir sobre el desenvolvimiento del concepto de gobierno, la organización en gentes a base de afinidad de parentesco parece indicarse naturalmente como esqueleto arcaico de la antigua sociedad; pero existe todavía una organización más vieja y arcaica, la de categorías a base de sexo, que reclama, en primer término, la atención" (Morgan, 1984: 115). Es clara aquí, la utilización de las categorías en las que se organizaban las sociedades, para construir un modelo teórico de lo social. Ya sea como sistemas de parentesco, ya como reflejo del origen social, ya como órdenes derivados de la experiencia sensible del cuerpo y la biología, ya como el nombre por sí mismo, el hecho es que los sistemas clasificatorios brindan un marco poderoso para organizar y explicar los datos sociales. Sobre esta idea se trabajara en la primera sección.

Quise remitirme a los inicios de la Antropología, no buscando un referente teórico evolucionista, sino para poner en evidencia la capacidad heurística que aporta la aproximación a lo social desde la óptica de las clasificaciones. No es la intención usar tal referente de manera exhaustiva ni buscar datos en ese sentido, pues la magnitud de la tarea está fuera de los alcances de este trabajo. Tampoco, construir un modelo de aproximación a los fenómenos de poder que sea consistente con el proceso general de 
evolución de las sociedades humanas, es decir, desde las primitivas hasta las contemporáneas.

Sin embargo, esta óptica resulta pertinente teniendo en mente algunas precauciones. Buscando propuestas o trabajos que abordaran de manera específica la mecánica o la lógica que organiza los sistemas de clasificación entre los hombres, se encontró que en general, las reflexiones o los modelos encontrados tienen un carácter "constructivista". Lo digo así pues, (y se verá en adelante con los autores tratados) independientemente del marco teórico que encuadra a los autores: evolucionismo, funcionalismo, estructuralismo o procesualismo; hay un fuerte sabor a origen de lo humano, es decir, se emiten sentencias que prefiguran un proceso de acumulación sentado en un origen remoto: aquel en el que los significados no existían y de ahí, cómo se dio la significación, a partir de qué y cuáles fueron las reglas o mecanismos para su construcción y crecimiento progresivo. Por eso es que se anota el carácter constructivista. Esta característica dista de ser marcada aquí como un defecto. Se entiende que en la reflexión de calidad sobre los sistemas de clasificación, "el surgimiento del sistema", constituye una preocupación necesaria y legitima. En este trabajo también ha surgido dicha inquietud, mas no es lo fundamental.

Lo central, consiste en establecer unas bases teóricas y metodológicas mínimas para abordar un punto específico. Se tiene por una afirmación general, que las relaciones de poder son relaciones de tipo asimétrico, es decir, que hay entre las partes, elementos o características que marcan a uno de los miembros como distinto, como diferente, es decir, no simétrico. En ocasiones el dicho suena a perogrullada. No obstante, determinar cómo es que dos entidades que no son simétricas se articulan en una relación de poder, es ya de otra dimensión. Esto quiere decir que diferencia, asimetría y poder, deben ser descritos de manera analítica precisa, para justificar el por qué la asimetría en los miembros de una relación social deriva en relaciones de poder. De ahí el interés en los sistema de clasificación.

El objetivo es entonces, presentar propuestas teóricas que abordan la manera en que los humanos establecieron sistemas de clasificación. De ahí, se pueden extraer varios aspectos: ¿De dónde surge el sistema? ¿Con que elementos se nutre? ¿Cuál es la lógica que permite ir incorporando elementos? ¿Cuál, la que define las diferencias y asimetrías en los elementos? Y finalmente, ¿Qué consecuencias tiene tal sistema en la organización social? 
Las propuestas de Ferdinand de Saussure, Marcel Mauss y Emilio Durkheim, Claude Lévi-Strauss, Mary Douglas y Victor Turner, servirán para tales efectos. En ellas, hay referencias concretas sobre cómo es que se generan los sistemas de clasificación, los elementos que los forman, cómo se diferencian, cuáles son los criterios de su organización y jerarquización y finalmente, en qué región de la vida social encarnan sus ideas.

Los ejes que abordan estos autores, se relacionan con el color de los líquidos corporales, con el cuerpo mismo como sistema, como la sociedad misma como base del sistema, o con la estructura misma del sistema de construcción de los significados, ya sea en términos formales, ya a través de evidencia indirecta vía los mitos y la experiencia etnográfica. No son las únicas posibilidades de construir sistemas clasificatorios, pero resultan más que adecuadas para los fines de este trabajo. Es muy importante destacar que de tales propuestas, se rescata la mecánica en general y no un eje clasificatorio en particular, ya que en cada uno de esos sistemas, puede haber alguna oposición especifica que pareciera articular el modelo. Los sistemas clasificatorios centrados en la Economía - basados en la oposición tener/no tener- y en la Política dominante/dominado- paradójicamente han quedado fuera de la indagación, la razón es simple: El Capitulo 2 se dedicará completamente a los fenómenos de intercambio, ya sean materiales, simbólicos o ideales, con lo que las discusiones relativas a las clasificaciones centradas en el tener o no tener, quedarán claramente abordadas. En cuanto a las clasificaciones sociales resultantes de los procesos de orden y conducción social, que separan a las sociedades en gobernantes y gobernados, tienen en el ejercicio de poder uno de los ejes articuladores del sistema, por lo que dicha óptica está tejida en todo el trabajo y expuestas sus consecuencias efectivas en los últimos tres capítulos. La doble ausencia al inicio, resultará provechosa para quitarle centralidad a estos dos paradigmas profundamente dominantes en las sociedades modernas, dándole espacio al aparato antropológico, para evidenciar su potencia heurística.

Hay que insistir que el aparato teórico resultante no tendrá como mira, establecer un modelo sobre cómo de un conjunto de características o propiedades en los inicios de la cultura humana, se originaron los fenómenos de poder. De lo que se trata es que, centrándose en la idea de las asimetrías presentes en las relaciones de poder, se puedan utilizar las evidencias y los razonamientos de las propuestas abordadas, para formar un cuerpo de herramientas que permitan una conceptualización del poder bien acabada. El trabajo producido, será eficaz para precisar los elementos que definen la asimetría en 
una relación de poder, y cómo es que se articulan asimetría y poder. Con lo anterior, se podrán establecer principios metodológicos específicos orientados a la investigación empírica. Eso implica, buscar y ubicar los datos de la realidad en un contexto definido de la relación social y cómo estos insumos definen las asimetrías que se "utilizan" para ejercer el poder, ya sea al nivel de los individuos, ya al nivel de las instituciones o de la cultura.

Las relaciones entre culturas comportan un espacio muy denso de tales fenómenos, pues no solo suponen las relaciones de poder al interior de cada una de las culturas, sino en las zonas de contacto e intromisión entre ambas. Esta última dimensión, desemboca en hechos peculiares, pues por un lado una cultura hegemónica puede ir logrando sus objetivos sociales, ignorando el porqué ocurren en los subordinados o por otro lado, ignorando las causas del fracaso en intentos recurrentes. En el pasado, desde la visión colonialista hasta la indigenista, estos eran universos comunes; el éxito con desprecio cultural y el fracaso incomprensible. Actualmente la transformación de las expectativas indígenas y su acompañamiento por amplios sectores de la sociedad, ha transformado este paisaje binario. No obstante, ambos extremos son los límites teóricos y frecuentes que se dan en la implementación de políticas hacia los pueblos indígenas.

La aparición del indígena como actor de su propio desarrollo y desde luego, la inscripción de su opinión como requisito para la acción gubernamental, ha transformado esa realidad. Las políticas de educación intercultural, con su mensaje de relaciones igualitarias, no jerárquicas, solidarias entre las culturas, y sobre todo, con el empeño en el aprendizaje entre ellas, transcurren en el borde de estas dos franjas. No obstante, estos temas siguen siendo problemáticos, pues si las relaciones de poder son una constante del hecho humano y de las culturas, ¿pueden las intersecciones entre estos órdenes ser vacías? La apuesta de las políticas interculturales es que sí, sin embargo, hay una serie de complicaciones teóricas y prácticas a esta legítima pretensión. Tal vez la mayor complicación es la dualidad del indígena como ciudadano mexicano y como miembro de una comunidad. La imposibilidad de marcar límites claros a tal hecho, impacta en diversos grados a los agentes involucrados en las políticas de corte intercultural; tanto los agentes que diseñan e implementan las políticas, como los que las "reciben" u opinan al respecto, lidian con esta imposibilidad.

Por ello es que la utilización de un modelo sobre el ejercicio de poder, centrado en las clasificaciones y sus resultados asimétricos, resulta de gran utilidad para 
comprender el fenómeno de las políticas de educación intercultural universitaria. Pues los órdenes clasificatorios, funcionan para describir los hechos de poder en el nivel ciudadano y en el nivel indígena, y permiten hacer un intento por "desentrañar" los marcos detonantes de la acción o la inacción, más allá de las percepciones subjetivas de los involucrados. Es este un campo central de reflexión de la Antropología Política, y donde una de las tareas, es exponer la relación entre los hechos políticos y los hechos culturales.

El tratamiento que se la va a dar a las propuestas clasificatorias, busca resaltar de manera central los elementos en los que se basan, cómo están organizados y cuáles son los núcleos jerárquicos, si los hay. En ese sentido quisiera anticipar, que para lograr enlazar esas propuestas generales con la óptica que planteo, hay que llevar en mente la siguiente idea: que no se tratan de manera semejante, diferencias y asimetrías. De manera preliminar, las diferencias se considerarán aquí como una determinación sobre el sentido de las propiedades de objetos, sujetos o circunstancias en un renglón específico, en relación con otro cualquiera, es decir, dos objetos son diferentes respecto de, por ejemplo, su tamaño. En cambio, la asimetría se refiere a un nivel siguiente; es la valoración de una diferencia respecto de cierto procedimiento, es decir, que las propiedades que diferencian objetos, sujetos o circunstancias en un renglón determinado, ponen a uno en ventaja o mejor posición para efectuar una operación específica respecto del otro. Es evidente entonces que la diferencia deriva de las características intrínsecas de un sistema de clasificación, mientras que la asimetría es la valoración instrumental de tales diferencias. Así, no sólo se trata de establecer la mera distinción entre dos entidades, sino el procedimiento mediante el cual uno de los elementos se desempeña como el único o el mejor. ${ }^{1}$

\footnotetext{
${ }^{1}$ En este punto puede surgir la idea de que igualdad y desigualdad pudieran funcionar de manera análoga para dicho tratamiento, sin embargo la idea de la desigualdad, remite de manera profunda a consideraciones sobre "lo injusto" de un sistema desigual y por tanto existiría, en términos generales, un deseo o tendencia a generar condiciones para eliminar dichas diferencias. Partiendo de la desigualdad, no obstante, también se construyen sistemas de clasificación que determinan las causas y consecuencias de las diferencias entre los hombres. Ya Rousseau realizó un esfuerzo en ese sentido en el Discurso sobre el origen de la desigualdad (2002) que entiende de manera muy diferente las naturales diferencias que existen entre los hombres. Por otro lado, Luís Reygadas (2004), expone de manera certera los tres sistemas que se han utilizado para clasificar los fenómenos de desigualdad: con base en la capacidad y recursos de los individuos; con base en las relaciones sociales; y con base en las estructuras sociales.
} 
Es claro que desde este punto de vista, puramente formal, no existe un criterio único para valorar una asimetría; existirán tantas asimetrías como procedimientos. El “tamaño", como diferencia entre dos elementos permanecerá como criterio constante de clasificación, mientras no se altere en uno de ellos esa propiedad. No es el caso de la asimetría, pues es factible encontrar ciertos procedimientos en los que el mayor tamaño sea ventaja y ciertos otros, en los que sea desventaja. Así, las diferencias siempre serán constantes; las asimetrías no.

Si bien el concepto "jerarquía” también da una idea parecida al de asimetría, es desechado aquí por una razón: en general, define un sentido amplio de clasificación. Es decir, se refiere comúnmente a las gradaciones entre una variedad de elementos, desde el primero hasta el último, estructurando así, un sistema. ${ }^{2}$ Se pueden jerarquizar todos los colores respecto de un único criterio; las asimetrías son, en cambio, término a término. En este sentido, las asimetrías son necesariamente anteriores. Las jerarquías en los sistemas de castas, por ejemplo, clasifican desde el nivel social más alto hasta el más bajo; nadie escapa al sistema que tiene la pretensión de ser inmutable. Las jerarquías proyectan estabilidad; las asimetrías, contingencia.

Aclarado lo anterior, queda un punto pendiente: ¿qué relación existe entre asimetría y poder? Como se dijo arriba, la asimetría como concepto, es una enunciación puramente formal; al hablar de poder, se establece una pretensión de carácter operativo, para explicar fenómenos observados empíricamente. Si la asimetría se construye a través del desempeño, respecto de un procedimiento específico, en el caso que nos ocupa -el ejercicio de poder-, estará siempre atada a individuos en particular. Así, siempre habrá un sujeto o grupo de éstos, que por los objetos que posee, por sus características intrínsecas o por la circunstancia en la que se hallan, estarán en mejor o única disposición, que otros, respecto ese procedimiento específico. Lo anterior, define ya, una asimetría en términos sociales. No obstante, aún no hay poder: ¿qué falta? Falta instrumentalidad y visión de futuro.

Las asimetrías ocurren al margen de lo que los actores opinen uno del otro. Pueden ser objetivas o subjetivas, pero no implican un nexo, pues la única relación entre ellos es el procedimiento que las determina. Pueden ser enunciadas o descubiertas, pero están, por así decirlo, "inactivas". Cuando los actores evalúan o notan, que en un

Dado el centro en los fenómenos de poder, que tienen como requisito la existencia de diferencias, se utilizará la idea de asimetría y no la de desigualdad.

${ }^{2}$ Se tiene aquí en mente, la definición de "jerarquía" del Diccionario de la Real Academia del Lengua Española (1992) 
futuro dichas asimetrías pueden ser usadas como criterio en la modificación de la acción o la conceptualización de los involucrados, ahí, existe poder. Entonces, en un primer momento, se entiende el poder como la condición de una relación social en donde una o varias asimetrías, prefiguran la posibilidad de conducir la acción social. El concepto anterior es central, pues responde a la convención muy extendida de que el poder "...no es una cosa, o su posesión: es una relación entre hombres" (Stoppino, 2002a: 1191). De tal suerte que nadie tiene el poder, sino que éste, se construye en la posibilidad instrumental de las asimetrías; de ahí que se pueda decir que el poder es una forma social que toman las asimetrías (Barquín, 2007: 92). No obstante, las asimetrías no son suficientes para la aparición de fenómenos de poder, sí, necesarias. Por ello los criterios de futuro y de instrumentalidad. Dada una relación asimétrica entre actores, éstos pueden "leer" dicha condición como factible de ser usada para originar o modificar acciones y conceptualizaciones; entendiendo la primeras como parte de lo que los actores "hacen" y las segundas, de lo que piensan. Desde luego que no se procederá de la misma manera si el actor es subordinado o superordinado. Para uno, la relación es ventajosa; para el otro, desventajosa. Uno determina, el otro es determinado. Uno ejerce el poder, al otro, se le ejerce.

Estos son pues los criterios de exploración de los modelos de clasificación a presentar. Se expondrá de manera muy esquemática los núcleos que definen el sistema de clasificación y cómo tales criterios definen las diferencias en el sistema. De ahí, cómo es que se construyen las asimetrías y finalmente, su aterrizaje en relaciones de poder. No es lo anterior el programa de los autores a presentar; será sí, la estructura de exposición de sus propuestas, en función de resaltar y rescatar lo indispensable de los sistemas de clasificación en la comprensión de los fenómenos de poder.

\section{Victor Turner}

En el trabajo "La clasificación de los colores en el ritual ndembu: un problema de clasificación primitiva", Victor Turner (1999) aborda el problema de los sistemas clasificatorios en sociedades primitivas, con una actitud crítica respecto del resurgimiento del interés por este tema hacia inicios de los años sesenta. La propuesta se enfrenta a un reto básico: demostrar que los sistemas clasificatorios no están basados en una lógica binaria, sino que existen razones para pensar que lo central es la organización ternaria. Argumentaba Turner que a pesar de la abundante evidencia de que la base de las clasificaciones presenta divisiones del tipo de las oposiciones izquierda/derecha o 
masculino/femenino -de ahí su importancia para la clasificación de los grupos sociales-, asevera que “...no sólo el simbolismo de los sexos, sino también cualquier otra forma de dualismo se hallaba integrada en un modo de clasificación más amplio, de carácter tripartito" (1999: 65). La declaración es un ataque frontal a un gran conjunto de evidencias en el que las clasificaciones por pares binarios y opuestos, articulan las diferencias en las que se pueden categorizar los hechos del mundo.

Para Turner, la evidencia encontrada en los datos centrales de los rituales y los mitos ndembu, producía una lógica diferente en la concatenación de los elementos clasificatorios. Cualquier par de oposición tenía siempre, en la sombra, un término intermedio, que se colocaba entre la transición de los opuestos. Este elemento intermedio, también diferente, es ambivalente, indefinido, como lo son para Turner las formas de transición. Da evidencias rastreadas en ritos de iniciación y de paso en el África Central y no sólo de los ndembu, para fundamentar su lógica ternaria. Esta lógica la ve Turner claramente expuesta en los tres colores que están presentes en el cuerpo de los ritos analizados: el blanco, el rojo y el negro. Con estos tres elementos se representan, a través de metáforas, las diferencias entre los humanos o los elementos en el ritual. Así, el blanco representa la fertilidad, por su asociación al semen o la leche y el negro la infertilidad, por ello el semen infértil es negro (p. 73). También la fertilidad puede estar asociada al rojo, en virtud de su nexo con la fusión de la sangre materna y paterna para la concepción de los hijos (p. 70). Más aun, el negro, puede ser fertilidad, en aquellas regiones áridas donde lo negro de las nubes, presagia la lluvia (p. 92). Esta característica de mutar de las etiquetas clasificatorias, la concibe Turner en virtud de la capacidad polisémica de símbolos y metáforas, es decir, de ser susceptibles de muchos significados (Turner, 2002a: 40). No obstante la polisemia, es posible establecer asimetrías a nivel social respecto de estas clasificaciones; así presenta una lista de la significación de los colores en el proceso ritual, donde es fácil ver que definen roles diferenciados o mejor dicho, asimétricos. En ella el blanco es el color de la autoridad y negro, el de la brujería (Turner, 1999: 76-9)

Aquí surge el primer punto a reflexionar. El sistema turneriano de clasificación, deriva sus diferencias del color de ciertos líquidos corporales. Estas diferencias son inmutables en tanto que los colores de tales fluidos son una constante biológica y que existen de manera ubicua en todos los puntos del sistema. El rojo es diferente del blanco. No obstante, hay un paso adicional: la relación entre los fluidos y un procedimiento. El color del fluido es determinante para clasificar su desempeño; en 
términos de la fertilidad por ejemplo. Así, la capacidad de engendrar de un líquido, estará atada al "verdadero" color que tiene, independientemente de lo que indiquen los sentidos. Si un hombre no puede engendrar hijos es porque, "evidentemente", el semen se le ha ennegrecido. No son percibidos iguales frente a la comunidad de referencia, dos hombres con diferentes capacidades generativas y la asimetría derivada de tal característica, es clara respecto del procedimiento específico. El control de las condiciones para animar la reproducción material o social del cosmos (fertilidad de la tierra o de las mujeres), está atada entre los ndembu al color blanco, definiendo por tanto a aquellos que tienen tal característica, como individuos con autoridad; tal autoridad es necesariamente asociada a la relación que tiene el sujeto con las propiedades generativas del blanco. Algo semejante ocurre con relación a lo negro y la condición de brujo de un individuo (muerte y degeneración). Es claro que en la exposición de Turner, están presentes los tres niveles anticipados: la diferencia como condición para la estructuración de un sistema clasificatorio; la asimetría que separa tales diferencias con relación a un procedimiento específico; y finalmente, el aterrizaje de tales asimetrías en términos sociales, posibilitando a los individuos la conducción de la acción social.

No en todos los autores la relación se muestra tan clara. En Victor Turner, la claridad deriva de su preocupación por los problemas surgidos en el conflicto social y la simbolización del mismo: "Puesto que una de mis líneas fundamentales de investigación era la relacionada con el problema del conflicto social y su resolución, me hallaba al mismo tiempo interesado por la simbolización y formalización de dicho conflicto" (1999: 65). Es clara la dimensión política que se le asigna a los sistemas de clasificación, pues la representación de órdenes clasificatorios está en el corazón de los conflictos y su resolución. Con ello prefigura el tema de las asimetrías derivadas de las diferencias entre los colores, es decir, los conflictos surgiendo de las controversias entre los diferentes órdenes sociales. En el caso que documenta Turner, los resultados de este razonamiento se siguen de su exposición de los rituales de paso, fundamentalmente los de niñez a adultez y los de salud a enfermedad. La conceptualización de esto dos extremos, se expresa en los ndembu a través de las referencias míticas a los tres colores y es articulado, o mejor, experimentado, en la representación ritual. Retomando lo argumentado anteriormente, aquellos que conocen y controlan los "poderes" emanados de los líquidos fundamentales y conocen su posición en los procedimientos en el ritual, están en relación asimétrica respecto de los no iniciados y respecto, desde luego, de los 
individuos en transición. Dirigen y deciden los tiempos del ritual, como por ejemplo en la circuncisión de los muchachos -el mukanda-, al determinar cuándo ha llegado el tiempo preciso de transformar a los niños, en hombres y disponer dónde y cuándo se realizan tales procedimientos (Turner, 2002b: 21-24). Para Turner, esta transición entre dos estados sólo es posible mediante el paso por un estado liminal, indeterminado, que es, sin embargo fundamental, pues ahí está el núcleo de la creación social. "Lo liminoide pertenece a un sistema latente de alternativas que puede designarse como protoestructura, ya que precede a las formas innovadoras" (Geist, 2002: 10).

Es importante destacar que la lógica procesualista en Turner, lo lleva a centrarse básicamente en el paso de un estado social a otro: el proceso. Esta concepción culmina, según Roberto Varela, en un sobredimensionamiento del proceso y una pérdida del objeto de investigación (Varela, 1984: 27). La referencia es importante, pues si bien no se enfoca en el pensamiento clasificador, sí toca lo que aquí se quiere demostrar: que parte del modelo expuesto por Turner, se encuadra en la resonancia del paso entre dos estados rituales y lo que ocurre en el medio, lo liminal. De ahí que resulte lógico, que las referencias a sistemas binarios deban estar articuladas siempre con un tercero. "De los tres colores, el blanco parece ser el dominante y el más unitario, el rojo ambivalente, porque es fecundo y <<peligroso〉>, mientras que el negro parece ocupar el papel de compañero silencioso, <<el tercero en la sombra〉> opuesto en cierto sentido tanto al rojo como al blanco" (Turner, 1999: 75). Fortaleciendo su hipótesis, refiere que los ndembu ordenan en pares antitéticos propiedades como bondad/maldad, vida/muerte, salud/enfermedad, etcétera, siempre con relación a la oposición blanco/negro, a la que representan como la antítesis suprema de su sistema. Sin embargo, rojo y blanco frecuentemente aparecen en conjunción y el negro, en cambio, raramente aparece expresado de manera directa. (ibid: 82).

Así pues, las herramientas de Turner: la experiencia, el proceso y el cambio ritual, están en el corazón del diseño ternario, que se da en el sistema clasificador originado por el pensamiento mágico-religioso humano y la base, surge de los tres colores diferentes. "En mi opinión, esto es debido a que los tres colores resumen los tipos fundamentales de la experiencia universal humana de lo orgánico" (ibid: 98). Tal es su apuesta, que aclara lanzar audazmente, “...yo postularía que el organismo y sus experiencias cruciales son la fons et origo de toda clasificación” (ibid: 100).

Con esta declaración, Turner enfoca sus baterías a dos propuestas previas: aquella que postula a la sociedad como origen de los sistemas clasificatorios y aquella 
que le da un sentido binario, es decir, la propuesta de Marcel Mauss y Emile Durkheim y la de Claude Lévi-Strauss. Quise, no obstante comenzar con la de Victor Turner por una razón específica: antes de cualquier articulación con el exterior, el hombre toma conciencia de los líquidos corporales, que son, desde luego, anteriores a la sociedad. De ahí, que la clasificación del mundo esté basado en esta experiencia primitiva y triple. Deja sin embargo cabos sueltos. ¿Por qué la transparencia de saliva, sudor y lágrimas no entra al sistema si es simultánea a la experiencia de los otros tres colores? ¿Por qué los otros datos inmediatos de la experiencia, simultáneos a leche/semen/sangre-heces, no están presentes, es decir: frió/caliente, suave/rugoso, hambre/saciedad, aliento/desaliento, sonido/silencio, o la central en muchos mitos de origen, luz/obscuridad? Qué criterios uso para discriminar la ocurrencia temporal de las experiencias, es decir: ¿en la socialización del niño se percibe igual leche que sangre? Todos estos datos, son información básica de los sentidos o de la percepción de la corporeidad, que no están explicados en la propuesta de Turner, más que cierta información de la vista, o sea, el color (dejando al margen también, lo datos inmediatos de la geometría de los objetos: la circularidad del Sol y la Luna o la linealidad o rugosidad del horizonte, por ejemplo). La centralidad de la experiencia en su propuesta, obliga a justificar estas exclusiones. Más aún, por qué la forma o disposición de las partes del cuerpo no es importante en la clasificación, si los líquidos corporales salen por ahí. Me parece que las asociaciones leche/pezón, semen/pene, sangre menstrual/vagina o excremento/ano son relaciones inseparables y lo son en términos de experiencia. En tanto a lo ternario del sistema, creo que se explica desde la lógica de tres colores y tres líquidos, pero sólo en función de la exclusión que Turner hace de otros datos. No rebato necesariamente el carácter ternario respecto del binario, sino las exclusiones que permiten su estructuración. No obstante estas inquietudes, la relación entre sistemas clasificatorios y conducción de la acción social es totalmente clara; el nexo entre diferencias, asimetrías y poder. Implica pues el modelo de Turner, una asociación entre la necesidad de imponer un orden en lo social y los conflictos derivados da tal pretensión. No se profundizó en este último aspecto, pues es claro que lo que aquí se pretende, es encontrar los núcleos clasificatorios de los fenómenos de poder; si tales derivan en conflicto o en conformidad social, representan ya, un paso siguiente. 


\section{Mary Douglas}

En armonía con la idea de la experiencia de Victor Turner, pero con perspectivas teóricas de carácter más general, la propuesta sobre los sistemas de clasificación de la antropóloga británica Mary Douglas, también los aborda con centro en la experiencia del cuerpo, pero sin esquivar la idea de los pares de oposición, que anteriormente Turner rebatiera.

El cuerpo es un modelo que puede servir para representar cualquier frontera precaria o amenazada. El cuerpo es una estructura compleja. Las funciones de sus partes diferentes y sus relaciones ofrecen una fuente de símbolos a otras estructuras complejas. No podemos con certeza interpretar los ritos que conciernen a las excreciones, la leche del seno, la saliva y lo demás a no ser que estemos dispuestos a ver en el cuerpo un símbolo de la sociedad, y a considerar los poderes y peligros que se le atribuyen a la estructura social como si estuvieran reproducidos en pequeña escala en el cuerpo humano (Douglas, 1973: 156)

El eje que articula la relación entre cuerpo somático, cuerpo social y las fronteras que se establecen al paso de elementos entre las fronteras de los cuerpos, es la idea de pureza y contaminación. Para Douglas, la experiencia que los sentidos brindan sobre el cuerpo, permiten estructurar una visión de los procesos orgánicos y de manera contundente, definen al cuerpo como fuente de significados Así la relación entre aquello que tiene contacto con el cuerpo y aquello que sale o entra al cuerpo, delimitan un conjunto de relaciones, un sistema. Este sistema, esta articulado por la mencionada idea de pureza/contaminación, par de oposiciones que permite decidir si los elementos están “donde deben" y los procesos ocurren "como deben". El planteamiento, respecto del lugar adecuado, prefigura un sistema de clasificaciones, puesto que los objetos, sujetos y hechos del mundo, son puros en función de su ubicación adecuada, y contaminantes fuera de su contexto habitual. Así, el enfoque de lo contaminante como materia puesta fuera de su sitio “... es muy sugestivo. Supone dos condiciones: un juego de relaciones ordenadas y una contravención de dicho orden. La suciedad no es entonces nunca un acontecimiento único o aislado. Allí donde hay suciedad hay sistema. La suciedad es el producto secundario de una sistemática ordenación y clasificación de la materia, en la medida en que el orden implica rechazo de los elementos inapropiados" (ibid: 54-5). Verdaderamente la idea es sugestiva y poderosa. Plantea, en los términos que aquí se buscan, que todo un sistema de clasificaciones bien puede estar anclado en la idea de contaminación y pureza. Ese par, es capaz de articular materiales, procedimientos, personas o jerarquías a través de la percepción subjetiva del individuo, expresada en la 
idea de contacto con lo puro o lo contaminante. Más claro aún, en la idea de la intrusión de lo puro o lo contaminante, más allá de las meras fronteras del cuerpo físico. En función de los que aquí nos ocupa, supone que las relaciones de clasificación de los hechos del mundo están definidas en virtud de su "acomodo" a un orden o la ruptura del mismo, pero no se detiene ahí. Si lo normal es el orden, los actores que detectan una ruptura y tienen el interés o la capacidad de corregirla, apelaran a los elementos que representan o fomentan dicho orden para emprender la restauración social. Así, una diferencia expresada en términos de oposición, se transforma en asimetría por su representación de una ventaja respecto de un procedimiento: poner el objeto en su sitio. Si tal condición permite encauzar la acción social para mantener o acomodar los elementos en su sitio, entonces hablamos ya de poder.

La propuesta de Douglas, evita acertadamente, cosificar lo corporal como centro de las concepciones de pureza y contaminación. Resonando con Turner y la idea de lo polisémico de los significados, argumenta que "lo sucio", sólo lo es cuando está atado a un sistema, es decir, que su significación es de carácter secundario y atada a un conjunto de relaciones espacio/conceptuales; es decir el paso de la mera diferencia a la asimetría. Ejemplos del razonamiento anterior, son las atribuciones de sagrado y puro al excremento de vaca en la India, derivadas de la sacralidad del ser: la vaca; y no de la impureza del excremento como esencia. En Mesoamérica, el oro era clasificado como excremento de los dioses. La saliva tiene efectos antagónicos según el lugar donde se tiene contacto con ésta: dentro de la boca o fuera de la boca. Atinadamente, remata el argumento postulando que el sistema de relaciones del lugar de lo corporal, con el lugar de lo social, prefigura el orden del sistema y consecuentemente la idea de desorden. La expresión más acabada de su sistema, se centra en el par de oposición orden/desorden, pero se expresa en la idea de la higiene como el orden y la suciedad como el desorden. Si existiera mediación entre las oposiciones, para suprimir el sistema binario a la manera de Turner, se daría en la idea de ambigüedad y peligro, pues a través de ésta se define la frontera no atravesada ente el orden y el desorden. El peligro de la contaminación o los beneficios del contacto con lo sagrado, organiza pues, el sistema de clasificación de los hechos del mundo: de objetos diferentes, pero en su sitio, a asimetrías funcionales en virtud de su capacidad purificadora o contaminante.

...sostengo que las ideas acerca de la separación, la purificación, la demarcación y el castigo de las transgresiones tienen por principal función la de 
imponer un sistema a la experiencia, que de por sí es poco ordenada. Sólo exagerando la diferencia entre adentro y afuera, encima y debajo, macho y hembra, a favor y en contra, se crea la apariencia de un orden. En este sentido no temo la acusación de haber dado una imagen a la estructura social excesivamente rígida $^{3}$ (Douglas, 1973)

Así pues, la exageración de las relaciones entre lo que está fuera de sitio y lo que está en su sitio, delinea diferencias entre los objetos y los actores. Significadas estas diferencias en función de una estructura social determinada, delinean ya asimetrías. El aterrizaje de este sistema sobre la sociedad, es uno de los puntos notables de la propuesta de Douglas. No es claro, si la fons et origo turneriana, se encuentra en la sociedad que se monta en los procesos corporales para buscar un soporte "duro" y significarse o si por el contrario, es que la significación mana del cuerpo brindando los cimientos para la construcción de la sociedad. La interdependencia entre los dos órdenes, la encuentra un poco después del origen de lo humano, pues las evidencias están enraizadas en las sociedades primitivas. Dado que el destino de toda mi argumentación es el estudio contemporáneo de los fenómenos de poder, la primacía de un orden sobre otro es irrelevante. Lo sorprendente de su propuesta, es el lugar donde desemboca: los procesos políticos y de poder.

Si se tiene un orden clasificatorio y aparece un hecho (cosa o persona) fuera de su sitio, se le llama anomalía. No es desestabilizadora pues se suprime por eliminación, purificación o poniéndola "en su sitio". Lo que desestabiliza es lo ambiguo, pues no está clasificado, creando con esto peligro en el sistema (Douglas, 1973: 59-60). En este orden de ideas, la profanación ocurre en una ruptura en los ordenamientos, ya sea como anomalía, ya como ambigüedad, es decir, el desorden que destruye una configuración simbólica. Sin embargo, para Mary Douglas esos razonamientos dibujan una teoría política: todo orden implica restricción, por tanto materiales limitados, en cambio el desorden implica series ilimitadas con las que se puede "crear" configuraciones no existentes. "Tal es la razón por la cual, aunque pretendemos crear el orden, no condenamos sencillamente el desorden. Reconocemos que es destructor con respecto a las configuraciones simbólicas existentes; igualmente reconocemos su potencialidad. Simboliza el peligro y el poder" (ibid: 129). ${ }^{4}$ La relación entre la creación de orden donde no lo hay o la posibilidad de su transformación, es el núcleo de lo que Douglas postula como poder. Aquí resulta muy interesante darse cuenta de que las asimetrías

\footnotetext{
${ }^{3}$ El subrayado es mío

${ }^{4}$ El subrayado es mío
} 
existentes, no provendrían sólo de lo que está clasificado y ordenado; la riqueza de lo contextual aparece de nuevo. Se puede conducir la acción social mediante sentencias de orden, es decir, “ordenar" a la sociedad hacer lo que está establecido. Pero más intrigante, es la posibilidad de ordenar la sociedad mediante sentencias de desorden, es decir, aquellas propuestas que reordenan las configuraciones sociales y que no existían anteriormente; que son propuestas surgidas de la nada, de lo indeterminado. Pero por no existir precedentes, tal apuesta es peligrosa. De ahí la afirmación de Mary Douglas del poder como potencialmente contaminante; puede producir nuevas configuraciones, que son estables, pero también, inestables y destructoras. Así queda claro según se había previsto, que las diferencias transformadas en asimetrías, son las bases del ejercicio de poder.

De ahí que, y concluye, un poder limitado es aquel que mantiene el orden establecido, pero un poder ilimitado es aquel capaz de transformar o instituir un orden. Estos dos tipos difieren en un punto: el poder controlado es bueno, pues impone un orden a todos aquellos que lo rompen, por tanto se debe aprobar su uso; en cambio, aquel que desestabiliza las configuraciones establecidas, es un poder incontrolado y por tanto peligroso y contaminante (ibid: 135). Recuerda con ello la célebre sentencia de Lord Acton, de que el poder corrompe, pero el poder absoluto corrompe absolutamente, basándose el famoso lord, en la idea del contacto con una cosa que es contaminante por naturaleza. Si bien De Vos criticó la asociación que Douglas hizo entre ambigüedad y poder (Lindholm, 2000), es sorprendente la confluencia con otra teoría política, aquella postulada por Carl Schmitt. "Cada orden se basa en una decisión [...y ] la decisión nace, considerado normativamente de la nada [...] Soberano es quien decide sobre el estado de excepción". 5 Ante la incertidumbre sobre cómo proceder frente a un hecho no descrito en los procedimientos normativos, aquel que puede decidir, sin referentes, y es capaz de crear una salida novedosa, es aquel que ejerce un poder soberano.

El sistema clasificatorio que Mary Douglas propone, se estructura con base en una idea, la pureza y la contaminación referida a los procesos corporales. Las derivaciones de tal modelo, resuenan con aquellas que ocurren en la sociedad como una metáfora del cuerpo. Las diferencias así establecidas, suponen asimetrías que se delinean según el contexto, ya como puras, ya como contaminantes. La ambigüedad en la clasificación, es

\footnotetext{
${ }^{5}$ Cit. en: Serrano (1998:23)
} 
el proceso del que surgen los fenómenos de poder, capaces de restaurar el orden alterado o instituir uno nuevo.

Las inquietudes que deja la propuesta, derivan fundamentalmente de la centralidad en la contaminación como referente de las asimetrías sociales. Es por tanto un modelo particular, que impide clasificar otro tipo de asimetrías no centradas en el cuerpo, por ejemplo, aquellas derivadas de las diferentes capacidades o posesiones a nivel individual o grupal. También, aquellas en las que dos entes considerados puros o impuros, se relacionan en un proceso, pues si la pureza es un valor, por ejemplo, no se puede jerarquizar en sus mismos términos. La diferencia entre "el cuerpo y la sangre de Cristo", no deriva de ser uno más sagrado que otro, en el mismo tenor que los oficiantes en una ceremonia. Es decir, la propuesta resulta limitada para las relaciones que son de tipo horizontal según el modelo puro/impuro.

Finalmente, se colocó esta propuesta luego de la de Turner, en virtud de su nexo con el tema de la experiencia derivada del cuerpo y por su idea -no aclarada del todode la convivencia entre experiencia corporal y categorías sociales. Si bien nunca postula la primacía de alguno de estos órdenes, la centralidad en la idea de pureza/contaminación, la acerca más a lo somático que a lo social como origen de los sistemas de clasificación. La propuesta que veremos a continuación, se construye totalmente desde lo social

\section{Marcel Mauss y Emilie Durkheim}

El trabajo de referencia elaborado por estos dos franceses, De ciertas formas primitivas de clasificación, aborda desde una posición enteramente social el origen de los sistemas de clasificación y confronta de manera directa, las opiniones de las dos propuestas anteriores. Basados en un gran cuerpo de evidencia empírica que se articula mediante las relaciones en los sistemas totémicos y las relaciones de distribución espacial, Mauss y Durkheim niegan categóricamente la posibilidad de un germen preexistente, la fons et origo turneriana, que provenga del individuo o de la naturaleza. "En un principio, la humanidad carece de las condiciones más indispensables para la función clasificadora; por consiguiente, el hombre se encuentra muy lejos de clasificar espontáneamente y mediante una especie de necesidad natural. Por otra parte, basta con analizar la idea misma de clasificación para comprender que el hombre no podía encontrar en sí mismo los elementos para ello" (Mauss y Durkheim, 1971: 16-7). 
No hay duda de su posición. Las referencias a particularidades del cuerpo, ya sea por los líquidos que en el circulan, ya por las relaciones que por su biología producen un cierto "sentido", no son capaces de explicar el por qué el hombre crea sistemas de clasificación, ni los núcleos para su estructuración ni para la jerarquización de los elementos que los componen. Confrontan también a Frazer, quien plantea la posibilidad de ser las relaciones lógicas entre las cosas, las que han servido como base de los sistemas sociales (ibid: 68). La renuncia a considerar las relaciones causales entre los fenómenos naturales, como marcos para un sistema clasificatorio, colisiona con las posiciones de Turner y Douglas; no hay mucho que abundar. El semen y la leche son fértiles pues permiten la creación y el desarrollo; el alimento que entra por arriba sale por abajo. Estas relaciones causales pueden ser necesarias, más no suficientes, para producir sistemas clasificatorios. Entonces, ¿cuál es su propuesta?

Tiene que ver fundamentalmente con lo que entienden por un sistema clasificatorio. Para ellos, las clasificaciones sobre las que se estructuró el pensamiento humano, no son simples etiquetas de las cosas, representan algo más.

...clasificar no significa solamente constituir grupos: significa disponer estos grupos según relaciones muy especiales. Nosotros los presentamos como coordinados o subordinados los unos a los otros, decimos que éstos (las especies) están incluidos en aquellos (los géneros), que se subsumen a los primeros. Hay unos que dominan, otros que son dominados, unos, terceros que son independientes los unos respectos de los otros. Toda clasificación implica un orden jerárquico, del que ni el mundo sensible ni nuestra consciencia nos ofrece modelo alguno. Así pues, hay motivo para preguntarse dónde hemos de ir a buscarlo (ibid: 17)

Hay aquí la primera pista importante en función del objetivo que se busca alcanzar. Para Mauss y Durkheim no existe la necesidad de profundizar en el tema de la diferencia por sí misma, es decir, la búsqueda de un principio de discernimiento de los hechos del mundo. El establecimiento de diferencias entre las cosas, supondría un principio lógico de demarcación, principio que los autores rechazan de manera tajante. Así pues, el principio es de otro orden, aquel en el que los elementos están diferenciados, pero ya, desde una jerarquía previa. Es decir, es la asimetría y no la diferencia, lo que genera los principios de su sistema clasificatorio. Inversión curiosa, pero consecuente con la renuncia de buscar en la naturaleza o en el individuo la base para el sistema. Es importante notar que la utilización de los autores del término "jerarquía" no perturba en nada el marco propuesto, pues al inicio, aclaré que tal concepto se define en función de toda una escalera clasificatoria y compartamentalizada 
de elementos; por ello no es problemática su consideración de géneros y especies, y no de elementos en particular. El concepto de asimetría, utilizado a la luz de su trabajo, se entenderá como la ponderación jerarquica de las diferencias de carácter social, pero únicamente como pares de oposición, termino a término; es decir, de manera restringida.

Ahora bien, ¿de donde proceden los cuadros para el sistema? Mauss y Durkheim dan un núcleo generador y dos ámbitos de aterrizaje. El núcleo: la sociedad; los ámbitos: el parentesco y el espacio. Centrados en el enunciado de que la sociedad es la que se objetiva y no el individuo y su entorno, exponen gran cantidad de evidencia para argumentar la relación entre los objetos y el parentesco, es decir los clanes, y el totemismo. Para ellos, las asociaciones entre animales, plantas, materiales y el origen del clan, sólo ocurre de una manera: objetivando lo que ya preexiste como relaciones parentales. "Así pues, la clasificación de las cosas reproduce esta clasificación de los hombres" (1971: 19). ${ }^{6}$ Este punto es evidente, pues aunque suene a perogrullada, los humanos no descienden del canguro o la zarigüeya. La asociación y clasificación de estos animales, pasa por la objetivación de los clanes que componen una fratría, y las relaciones con estas criaturas se objetivan de las relaciones sociales y no de las naturales. La clasificación, a su vez, de los objetos en dos grandes grupos, procede de las divisiones en dos fratrías existentes, derivadas del estudio de los sistemas australianos de parentesco. De esta forma, las relaciones jerárquicas y políticas, están representadas en las relaciones entre animales o cosas. Refiriéndose a los encuentros rituales para una convocatoria de caza entre clanes, y los procedimientos estrictos para contactar y cambiar objetos, aseveran: "De este modo, todo se verifica en esta ceremonia a la manera de un teorema: el expedidor, el destinatario, el objeto y la escritura del mensaje, la madera empleada, representan a todos los parientes" (ibid: 23). Esta representación parental, llevaría aparejada desde luego, las jerarquías existentes entre padres, madres, hijos, hermanos y demás parientes. La clasificación jerárquica de los objetos del ritual de caza entre los Wakelbùra australianos, procedería pues, de las mismas fratrías y sus relaciones internas, corporeizándose así, en objetos sin clasificación previa. Un punto en el cual coinciden con los autores anteriores, se refiere

\footnotetext{
${ }^{6}$ Esta idea de lo social como origen de un sistema de clasificación es expuesto por Juan Jacobo Rousseau (2002) en el Discurso sobre el origen de la desigualdad. Desde su punto de vista, la diferencia determinante que estructura la sociedad se encuentra en la propiedad: tener o no tener. Si bien Rousseau tiende a naturalizarlo, al referirlo a un deseo de posesión en el hombre, la propiedad como fenómeno social, es su núcleo básico para la clasificación de la igualdad y la desigualdad entre los hombres.
} 
a la asignación de jerarquías en virtud de los contextos. Así, si para un australiano wotjoballuk, el pelicano sería su tótem y el sol su subtótem, para otro, existe el caso inverso (ibid: 34), reafirmando con ello lo convencional y contextual de las jerarquizaciones y por ende, de las asimetrías.

El otro ámbito de aterrizaje del pensamiento clasificador es el espacio. De la misma manera que los clanes y las fratrias, condensan sus relaciones de tipo parental en los objetos del mundo, la disposición geográfica y geométrica de dichos grupos también crea ordenamientos factibles de entrar en un sistema de clasificaciones. Los clanes que tienen asignado cierto animal o planta, se reparten sobre el territorio o mejor, se reparten el territorio, creando con esto los diferentes rumbos cósmicos. Dependiendo del número de clanes o fratrías, así el número de rumbos o puntos cardinales. Conjuntado con el sistema totémico anterior, permite a los autores aseverar: “...el reparto de los mundos es exactamente el mismo que el de los clanes en el seno del pueblo" (1971: 42). Para los zuñis de Norteamérica existen siete puntos cardinales y los clanes (19 en número), se reparten en esos siete rumbos. Esta multitud de clanes y rumbos no siempre ha sido así, pues la división ha sido precedida por la de seis y por la de dos, que abarcaban de manera prístina las fratrías iniciales; esto porque según los autores: "Hay un hecho que muestra a las claras que la clasificación de los puntos cardinales se ha superpuesto, más o menos tardíamente, a la clasificación por clanes..." (ibid: 46). Con ello quieren decir, que necesariamente, la asociación con objetos o animales precede a la de los rumbos del cosmos. Dejan sin responder de manera convincente, a que se debe tan peculiar ordenamiento, esto es, por qué un clan tiene que etiquetarse primero con un animal, por ejemplo, y después, con una región espacial.

Hasta aquí, refieren pues, que las relaciones jurídicas y religiosas de la tribu, aterrizan sobre las clasificaciones totémicas mientras que las morfológicas, sobre el territorio. Como una es primero y la otra después, están definidas inicialmente por las diferentes jerarquías parentales y posteriormente, por las jerarquías entre tribus. Esto ocasiona que en los términos en que se han venido analizando los diferentes sistemas de clasificación, la propuesta de Mauss y Durkheim esté centrada en las asimetrías, más que en las diferencias. Lo relevante de su propuesta para una investigación sobre los fenómenos de poder, es que se deben tomar múltiples precauciones al momento de indagar y caracterizar las asimetrías que fundamentan su ejercicio. La lógica de clasificación, en múltiples ocasiones, no deriva de propiedades intrínsecas del sistema de diferencias, sino como refieren los autores, forma una pantalla del verdadero sistema 
de diferencias (y asimetrías) que se encuentran, no en las jerarquías de objetos o propiedades, sino en las que se observan entre los individuos que sostienen tal sistema. ${ }^{7}$ De tal suerte que las asimetrías que fundamentan el ejercicio de poder, pueden ser de carácter evidente (derivadas de un sistema de clasificación socializado) o substitutas (derivadas de una asimetría real en el sistema social, que se materializa en una diferencia no representativa).

En este punto hay que hacer una consideración. Lo que los autores proponen es en primer término, una explicación de lo que representan las clasificaciones de seres, objetos y territorios: representan a la sociedad misma. No es que la naturaleza tenga una lógica preestablecida e inmutable. Es más bien, la superposición de la dinámica social sobre los accidentes naturales, lo que le da sentido a los segundos. Las relaciones jerárquicas, políticas, de poder, normativas, si se quiere hasta económicas o lúdicas, se empalman en conexiones arbitrarias post facto, estructuradas en el mundo no humano. Resuenan con fuerza sorprendente, con las palabras de Karl Marx en el célebre "Prologo": No es la conciencia de los hombres la que determina la realidad; por el contrario, la realidad social es la que determina su conciencia (1976:37). Un ejemplo de lo referido, serían las relaciones de tipo parasitario en el mundo animal, que de manera consecuente, pasarían a representar una relación humana político-económica, en donde un miembro extrae trabajo y recursos a otro, sin retribuirlo de manera equivalente. Así, el mundo de las clasificaciones de Mauss y Durkheim aborda el origen de las clasificaciones en el mundo natural, como diferencias irrelevantes (que se transformarían en asimetrías y) que posteriormente representan a las jerarquías sociales. No dan, sin embargo, una explicación convincente del origen y funcionamiento de las clasificaciones sociales mismas. A lo más, apuntan al sistema de parentesco de manera general, y a la posterior distribución espacial que deriva de ello, al aumentar de manera notable el número de miembros de un grupo humano. La lógica original de diferencias, asimetrías y poder, puede leerse de manera indirecta en su propuesta: analizando las clasificaciones, las jerarquías y los procedimientos respecto de los órdenes clasificatorios, únicamente como un resultado del statu quo. El porqué del estado de cosas, no es aclarado.

\footnotetext{
${ }^{7}$ Maurice Godelier (1998: 25) refiere a propósito del don, que hay diferencias que aparecen entre donante y donatario, pero que si estas ya existen previamente al hecho del don, el procedimiento viene tanto a expresarlas como a legitimarlas.
} 
Como corolario, presentan un tipo de clasificación que ya no está arraigado en la organización social: aquella que procede de la liberación individual de las ataduras colectivas y que mediante el proceso de racionalización, crea el pensamiento científico. “...la historia de la clasificación científica es, en definitiva, la historia misma de las etapas en el curso de las cuales ha ido debilitándose progresivamente este elemento de afectividad social, dejando cada vez más el campo libre al pensamiento reflexivo de los individuos" (ibid: 72). Esto lo argumentan basándose en los sistemas clasificatorios chinos, donde las relaciones entre el sistema clasificatorio y los órdenes sociales ya no guardan las líneas de articulación mostradas anteriormente; las categorías proceden en cambio, de la actividad reflexiva de agentes individuales, que no tienen ya las presiones colectivas de la costumbre para emprender su actividad mental; es decir, están liberados de la comunidad.

Pero esta tercera etapa, necesariamente viene precedida de las dos anteriores, que están determinadas por la sociedad y no por los esfuerzos individuales. Culminan diciendo:

La sociedad no ha sido simplemente un modelo sobre el cual haya trabajado el pensamiento clasificador; sus propios cuadros han servido de cuadros al sistema. Las primeras categorías lógicas han sido las categorías sociales; las primeras clases de cosas han sido clases de hombres en las que se integraban dichas cosas. Los hombres han agrupado idealmente a los otros seres porque previamente estaban ellos agrupados y se veían a sí mismos bajo la forma de grupos; los dos modos de agrupaciones han empezado confundiéndose para terminar siendo indistinguibles (1971: 69)

La cita anterior resume de manera contundente la propuesta de los autores. Quedan en el aire algunos temas. El principal se refiere al lugar que asignan a la toma de conciencia del individuo. Sólo en él se objetiva la sociedad. Si bien la sociedad da cuadros objetivadores ¿Qué efectos tuvo la corporeidad en la percepción? ¿Qué efectos, los instintos, pulsiones y líquidos corporales? Es decir, en qué lugar pondrían Mauss y Durkheim los argumentos de Turner y Douglas, soportados, curiosamente, con evidencias etnográficas procedentes de pueblos con grados de desarrollo semejante. Por otro lado, si las relaciones parentales son la base del sistema, el germen padres/hijos, brinda, al menos, un esquema lógico para entender la generación biológica de los nuevos cuadros de la sociedad. Ese esquema lógico, procedente de la naturaleza y no de 
la sociedad, puede ser llevado al terreno de los sistemas clasificatorios, sin ningún problema; los mitos de origen dan cuenta de ello.

Un corolario al origen puramente social de las categorías del pensamiento, es que como el actor de referencia es el clan o la fratría, es obligatorio conducir el razonamiento centrado en estos, por tanto, toda categorización que los considera, tendrá desde luego, un origen social. Esquivan o ignoran, los procesos de invención y los diferentes niveles de inteligencia individual, que facultarían a un individuo particular a desarrollar razonamientos lógicos que enraizaran en clasificaciones del mundo, siempre y cuando fueran sancionados positivamente, ahora sí, por el colectivo. Tal, no invalida el proceso lógico sino que lo ubica.

Si bien para el estudio de las relaciones de poder, la primacía de las asimetrías sobre las diferencias es muy conveniente, no estoy de acuerdo en restringirlo únicamente a ese aspecto. Dicen los autores: “Acabamos de ver, en efecto, que están representados [los vínculos lógicos] bajo la forma de vínculos familiares, como relaciones de subordinación económica o política; quiere decirse, pues, que los mismos sentimientos que se hallan en la base de la organización doméstica, social, etc., también han presidido esta repartición lógica de las cosas" (1971: 70). Con esto determinan la imposibilidad lógica y mental de los humanos a establecer diferencias entre los objetos y hechos del mundo, al margen de las jerarquías que perméan los órdenes sociales. Más aún, si la evidencia empírica en muchos pueblos primitivos, habla de sociedades poco jerárquicas, es decir un sistema muy restringido, entonces las clasificaciones del mundo tenderían a ser sobre la base de las diferencias y no sobre la de las asimetrías. Finalmente, generan un problema central: las clasificaciones que postulan, se refieren a categorías sobre grandes hechos: ritos, mitos, tótem, divisiones geográficas, etcétera, entonces, ¿con que sistema se clasificaban, los pequeños objetos y hechos de la vida cotidiana? Herramientas, utensilios, materiales, procedimiento, por poner ejemplos. No es funcional indagar la dureza de un material de trabajo de acuerdo a sus nexos con el clan o la familia. Si bien se pudiera argumentar ex post que la dureza corresponde al padre o a lo masculino, la resolución del problema no proviene de la clasificación de la propiedad del material en términos del clan, sino de la relación lógica entre el material y su eficacia técnica.

Hemos pasado pues, de una propuesta restringida a los líquidos corporales, a una puramente social, a través de una intermedia. La siguiente, es de un tipo puramente formal y está referida al corazón del pensamiento clasificador mismo: el lenguaje. 


\section{Ferdinand de Saussure}

La consideración de los trabajos que emprendió Ferdinand de Saussure, resulta obligada para lo que aquí se está abordando. En primer lugar, porque construye, a partir del estudio de los fenómenos del lenguaje y más concretamente de la lengua, una propuesta sobre el origen mismo del sistema de diferenciación de los sucesos del mundo, es decir, que antes del lenguaje, nada es claro ni discernible; después, las cosas toman sentido y se esclarecen las unas de las otras. En segundo lugar, porque constituye una influencia determinante en el pensamiento de Claude Lévi-Strauss, cuya propuesta sobre el pensamiento clasificador, será también abordada. Funciona pues el estudio de Saussure con un doble propósito: como propuesta y como antecedente. Por consecuencia de estos dos puntos, es necesaria una aclaración en el contexto general de todo el trabajo.

Para Saussure, lengua y lenguaje, no son del mismo orden. La lengua es una institución social dentro del sistema mayor de los hechos del lenguaje. La lingüística se ocupa de la lengua y la semiología deberá ocuparse de la vida de los signos en el seno de la vida social (Saussure, 1989: 42-3). En este sentido, pudiera surgir la idea o haber dejado ya la impresión, que por el desarrollo de toda la exposición, me encamino hacia el establecimiento de bases para abordar los fenómenos de poder desde un punto de vista lingüístico o semiótico. No es la intención. Si bien es cierto que hay una corriente importante en Antropología o en otras disciplinas, que abordan el estudio de los fenómenos de la sociedad a través de la metáfora de "la sociedad como texto", el enfoque teórico-metodológico que busco establecer toca sólo tangencialmente esta concepción.

La labor de exponer y analizar las propuestas que sobre la aparición y el funcionamiento de los sistemas clasificatorios, no culmina como se pudiera aventurar, en la adopción de algunos de los modelos y menos aún, que por finalizar con aquel que postula Lévi-Strauss, se le tenga por determinante en el trabajo. Como lo he ido señalando, el orden de presentación de los autores obedeció en los tres primeros casos, a su atadura respecto de la relación cuerpo físico-cuerpo social. Se estableció así, un debate respecto de los límites y las definiciones que la percepción de lo individual, ocasiona en los sistemas de clasificación. Para Victor Turner, todo; para Mauss y Durkheim, nada; en la intersección, Mary Douglas. 
En el caso de Mauss y Durkheim, su parentesco académico es determinante por compartir su aislamiento de lo corporal. Definen con ello un ámbito de explicación más general, pero, no necesariamente mejor que el de los otros autores. Es evidente que cada modelo plantea soluciones a temas específicos y es ahí donde el poder heurístico de su propuesta es más explotable. Por eso marco aquí mi distancia con la aproximación puramente simbólica a los hechos de poder. Existen múltiples fenómenos que desde otra ópticas (estructural-funcionalismo, neoevolucionismo, materialismo cultural, neoinstitucionalismo), resultan más fáciles de explicar y con mayor hondura. El asunto es que las realidades de todo tipo, "entran" necesariamente dentro de un sistema de significación, que las clasifica de acuerdo a distintos parámetros. Tales clasificaciones, y su derivación en asimetrías, son funcionales para explicar la articulación de fenómenos de poder, mas no son su origen exclusivo, pues el marco duro, son las características intrínsecas de las diferencias y su movilización instrumental, en muchas ocasiones, al margen de lo que "signifiquen" para los actores. Muchos fenómenos de poder serían imposibles de explicar, pero sobre todo de ocurrir, si la sola significación fuera la base. Un caso general, que nos ocupa, sería el de las relaciones de poder entre culturas, que, a pesar de presentar sistemas clasificatorios distintos, la que ejerce el poder en un caso, puede lograrlo al margen de la compatibilidad entre significados, pues hay insisto, fenómenos que se dan precisamente desdeñando el sistema clasificatorio de la otra cultura, para la cual resultan incomprensible, pero ocurren notablemente como fueron planeados.

Quise presentar esta aclaración para no crear una falsas impresiones o expectativas no cumplidas, pues por la potencia del paradigma lingüístico-semiótico, pudiera "leerse" que me sumerjo en éste sin darme cuenta; nada más alejado. Estoy cierto que toda óptica tiene sus limitaciones, pero por las bases de las que parto, pudiera argumentarse que me aparté, extrañamente, de una vía con múltiples posibilidades. Coincido con Derrida cuando, refiriéndose a la lejanía de los gramatólogos con la moderna ciencia del lenguaje, asevera: "Esto sorprende más por cuanto la lingüística es, entre las 'ciencias del hombre', aquella cuya cientificidad se ofrece como ejemplo con urgente e insistente necesidad" (Derrida, 1978: 39). Los sistemas clasificatorios, son en gran medida, sistemas de significación; su articulación con los sistemas de poder, no. El origen de las jerarquías que los estructuran y su imbricación con los grupos concretos para determinar la acción social, rebasa con mucho, los planteamientos generales de la 
semiología en el sentido de lo planteado por Saussure. Hecha la aclaración, pasemos a su propuesta.

El aspecto fundamental del trabajo de Saussure que se rescata aquí, es el relativo a la estructura formal de la lengua y su funcionamiento en abstracto. De ahí, se puede comprender mejor la lógica por la que postula que la lengua es un sistema de clasificación, de hecho, el sistema mayor.

La idea más relevante para la argumentación general, es el germen a partir del que se define el origen y la naturaleza del signo lingüístico. Para Saussure, el lenguaje es un sistema complejo, producto de las condiciones intrínsecas de existencia del hombre, “...es a la vez físico, físiológico y psíquico, pertenece además al ámbito individual y al ámbito social; no se deja clasificar en ninguna categoría de los hechos humanos, porque no se sabe cómo sacar su unidad" (1989: 35). En cierta medida lo que plantea, es que resulta irrelevante emprender la labor de discernir la mecánica de su funcionamiento y la de su origen; es un círculo sin salida (ibid: 34 ).

Establecido lo anterior, lo que realmente interesa es, cómo dada la capacidad de los individuos en sociedad de "hacer" sistema, la lengua se presenta como una posibilidad objetiva: como la unidad del lenguaje. Ahora bien, supone que tal sistematicidad se enfrenta a un entorno sin conceptos:

Psicológicamente, y haciendo abstracción de su expresión por las palabras, nuestro pensamiento no es más que una masa amorfa e indistinta. Filósofos y lingüistas han coincidido siempre en reconocer que sin la ayuda de los signos seríamos incapaces de distinguir dos ideas de una forma clara y constante. Considerado en sí mismo, el pensamiento es como una nebulosa donde nada está delimitado necesariamente. No hay ideas preestablecidas, y nada es distinto antes de la aparición de la lengua" (ibid: 159). ${ }^{8}$

Desde este punto de vista, es claro el centro que articula la idea nuclear de los sistemas de clasificación: el establecimiento del carácter distintivo entre entidades. Las diferencias de la índole que sean, solo pueden realmente existir, dice Saussure, si están expresadas mediante la asignación de un significado claro y distinto, en un significante verbal concreto, es decir, a través de la construcción de un signo lingüístico. La construcción de los signos de la lengua permite entonces, establecer un principio de

\footnotetext{
${ }^{8}$ Los subrayados son míos
} 
discriminación para los hechos del mundo, definiendo a la lengua, como “...un todo en sí y un principio de clasificación" (1989: 35).

Esto es fundamental en la exposición. De todas las propuestas presentadas sobre los sistemas de clasificación, la de Saussure es la de carácter más general y también, la más abstracta. No importa la magnitud del proceso, sea corporal, social, ritual, mítico, técnico, estético o lúdico; la lengua interviene en todos ellos como marca para el establecimiento de sistemas de clasificación de, llamémosle así, segundo nivel. “...no es el lenguaje hablado lo que es natural en el hombre, sino la facultad de construir una lengua, es decir, un sistema de signos distintos que corresponde a ideas distintas" (ibid: 36).

La diferencia entonces, está construida por la asignación de un significante acústico a un significado conceptual, que lo discrimina o separa de la masa amorfa de ideas, pues para Saussure, la lengua es una subdivisión concreta entre el continuo amorfo de sonidos y significados (ibid: 159-60). Los signos son definidos de manera arbitraria $^{9}$ y culminan su significado en virtud de las asociaciones con otros signos. Es pues el contexto, el que determina el sentido del signo: "Lo que de idea o materia fónica hay en un signo importa menos que lo que hay a su alrededor en los demás signos. La prueba es que el valor de un término puede modificarse sin tocar para nada ni sus sentidos ni sus sonidos, sino solamente el hecho de que tal término vecino ha sufrido una modificación" (ibid: 169).

El sistema de clasificación que supone la lengua, está basada pues, en un conjunto de signos que agrupan diferencias conceptuales discretas, generadas de la conjunción de ideas y sonidos. La definición de estas diferencias está fuera de los hechos concretos del habla, que al realizarse, dejan de ser diferencias de tipo puro, pues de compararse las unas con las otras lo que se encuentra son, ya no las entidades diferentes que generaron el signo, sino signos distintos entre sí. Las oposiciones entre términos, que toman sentido, según lo que se tienen enfrente, enmarca una especie de algebra compleja correspondiente a un hecho de gramática, definiendo una unidad a partir de la oposición de términos. “...unidad y hecho de gramática no son más que nombres diferentes para designar aspectos diversos de un mismo hecho general: el juego de las oposiciones" (1989: 171); sobre esta mecánica de oposiciones, dice Saussure, descansa todo el mecanismo del lenguaje.

\footnotetext{
${ }^{9}$ Aunque es muy conocida la crítica de Émile Benveniste a la idea de arbitrariedad del signo lingüístico (1978: 49-55)
} 
Para este trabajo, la propuesta de Saussure expone de manera contundente el mecanismo de un sistema clasificatorio: donde hay ambigüedad, la construcción de significados claros, delinea las diferencias del mundo; estas diferencias solo toman sentido, en virtud de enlazarse con muchas otras, en un conjunto de oposiciones. De tal manera que lo que postulé como diferencia, para Saussure es una distinción, pues la diferencia en su sistema es una construcción abstracta que define el sistema y no su organización. Respecto del tema de las asimetrías, no muestra interés. Para él, no hay términos, que sean más funcionales o mejores en el juego de las oposiciones. La supuesta funcionalidad provendría de accidentes exteriores a la lengua; en cierta manera, vendría del proceso concreto de las relaciones sociales. Esta ausencia es conspicua, pues resulta que el modelo de clasificación que postulan Mauss y Durkheim es antagónico respecto del de Saussure. En los primeros, la lógica del sistema está basada en las articulaciones concretas de la sociedad y se construye con asimetrías. En el segundo, la lógica del sistema está al margen de las estructuras sociales, es abstracto, y se construye con diferencias.

Si es tan abstracto, ¿por qué recuperar el pensamiento de Saussure sobre las clasificaciones? Principalmente porque constituyen una propuesta estructurada en términos formales y que no duda en aseverar el orden de aparición de los fenómenos de clasificación. Ideas, conceptos no formulados o expresados mediante procesos simbólicos, no existen para los sistemas de clasificación. Mediante el hecho de la lengua, se le asigna una imagen a un significado, en su caso, sonora. Aparece así un concepto claro, diferente a los demás existentes. El proceso culmina en la comparación con otro, al oponerse entre sí, mostrándose como distintos. Los signos significan según lo que los antecede o los sigue, es decir son contextuales y valdría decir, polisémicos (hasta aquí Saussure). Enfrentados respecto de un procedimiento, estas distinciones derivarían en el establecimiento de diferencias funcionales, es decir, lo que yo llamo asimetrías. Asignando las asimetrías a las características, posesiones o situaciones de los sujetos, se tornan de formales a sociales. Las asimetrías sociales, prefiguradas como útiles para conducir la acción social, conforman ya relaciones de poder.

La limpia exposición esquemática y secuencial de lo que sería una aproximación saussureana a los fenómenos de poder desde su perspectiva clasificatoria, no culmina en postularlo como el modelo más efectivo; si como el más económico. No lidia con las complejidades en las que se inscribe la real construcción de los significados. Para muestra, la distancia entre Turner y Mauss-Durkheim, entre Douglas y el mismo 
Saussure. No le interesan las piezas de las que se construye el pensamiento, sólo la lógica del sistema; no le interesan las experiencias corporales, los accidentes sociales, las asimetrías, la abundancia o escasez de significantes. La utilidad de su propuesta, estriba en que es un desarrollo muy fino del proceso de construcción-representación de los significados en un esquema clasificatorio. Los actores que enfrentan relaciones de poder, si meditan sobre la lógica asimétrica en la que se encuentran, es muy probable que desarrollen una exposición convergente con lo que Saussure prefigura. Una muestra de lo dicho serían las explicaciones de individuos no expertos, respecto del origen del valor del dinero y las leyes de la oferta y la demanda, donde el patrón oro representa la semilla original del valor y las condiciones simbólicas del mercado, lo que dan su valor contextual al dinero; finalmente, el porqué no todos los poseedores de la misma cantidad de dinero, recibirían la misma cantidad de mercancías; es decir, las asimetrías efectivas en los significados del dinero.

De la propuesta clasificatoria de Ferdinand de Saussure, hay sólo un par de argumentos por anotar. El primero se refiere a la centralidad exclusiva de los hechos del habla para estructurar el pensamiento mediante la eliminación de la ambigüedad. No toma en consideración la posibilidad de otros grupos de significados que sean diferentes de los del sonido. Jacques Derrida en una meditada crítica al trabajo de Saussure por su exaltación del sonido, anota la necesidad de considerar el concepto de "huella" como generador del sentido, indistintamente de ser por vía de los sonidos, las imágenes o cualquier otro estimulo en los sentidos. "La huella es, en efecto, el origen absoluto del sentido en general [...] La huella es la diferencia que abre el aparecer y la significación" (Derrida, 1978: 84-5). ${ }^{10}$ En oposición, la experiencia acústica en Saussure aparece aislada de las demás sensaciones del cuerpo y la naturaleza. Más aún, Roberto Varela con un breve pero perspicaz argumento, cuestiona la pura determinación de los significados para describir el hecho humano, es decir la sobre determinación de la cultura. Para Varela no todo comportamiento está condicionado por la cultura y la consciencia del actuar. Cultura y comportamiento guardan una relación bidireccional (2005: 87-9). Esto es una crítica frontal a Saussure en cuanto a que solamente a través de signos acústicos, se pueden objetivar las diferencias de sentido. En segundo lugar, lo mencionado sobre la aparición o existencia de asimetrías a partir de la lengua misma.

\footnotetext{
${ }^{10}$ Esta crítica alcanza también a Victor Turner, pues para él, los procesos primitivos de significado se construyen únicamente, a partir de tres colores y algunos líquidos corporales.
} 
Como referí, esto es no necesariamente un defecto, sino una condición de su marco de referencia. No obstante, se mantiene en un plano tan formal, que resulta en ocasiones incomodo, enlazar lo social en términos de un sistema clasificatorio, pues en la sociedad, coexisten semejanzas y oposiciones; los efectos que esto pudiera tener, son por él ignorados. Culminaremos con la presentación de la última propuesta. En ella aparecen elementos de todas las anteriores, ya como precedentes, ya como consecuencias

\section{Claude Lévi-Strauss}

Complejo resulta, en pocos párrafos, hacer abstracción de los trabajos del gran antropólogo francés. Sobre todo, en función de lo especifico del razonamiento que hemos venido siguiendo. Existen en Lévi-Strauss dos núcleos generadores del principio organizador de la sociedad. El primero, se refiere a la prohibición del incesto como eje de la construcción de la idea de prescripción/proscripción, que articula el sistema de reciprocidad entre los humanos. Este punto es toral, pues marca un cimiento de organización basado en la distinción naturaleza/cultura: "La prohibición del incesto constituye cierta forma $-\mathrm{y}$ hasta formas muy diversas- de intervención. Pero antes que cualquier otra cosa, ella es intervención; aún más exactamente, ella es la Intervención" (Lévi-Strauss, 1969: 68). ${ }^{11}$ La estructuración de la sociedad, es decir lo que es ya la cultura, se construye a través de la noción de orden inicial que introduce este principio en los agrupamientos puramente naturales. De ahí, la condición de intercambio y prohibición de intercambio, que el tabú del incesto dispersa en los demás materiales a disposición; es pues un comienzo de organización (ibid: 80).

Pero el segundo punto, que es el que interesa aquí, también define principios de organización. Estos principios están basados no en una forma específica, sino en la lógica en la que se organizan las formas. Según Lévi-Strauss, la capacidad de significar, es decir, aquello que nos hace humanos y nos separa de la naturaleza, apareció de una sola vez y sin matices, pues las cosas no han podido ponerse a significar de manera progresiva; la consecuencia de esto, es que la categoría del significado y la de lo significado se construyeron de manera simultánea (Lévi-Strauss, 1979: 38-9). El razonamiento sobre este inicio simultáneo entre significación y significante, determina

\footnotetext{
${ }^{11}$ El subrayado es mío.
} 
cierta estructura para la construcción de un sistema clasificatorio, o mejor, del sistema clasificatorio.

El universo ha tenido significado mucho antes de que se comenzara a saber lo que significaba, y esto no ofrece ninguna duda; ahora bien, del análisis precedente resulta que ha significado todo lo que la humanidad puede confiar en conocer; lo que llamamos el progreso del espíritu humano, o, en todo caso, el progreso del saber científico, no ha podido jamás consistir en otra cosa que en rectificar las divisiones, proceder a agrupamientos, definir la pertenencia a uno u otro grupo, así como descubrir fuentes nuevas en el seno de una totalidad cerrada que se complementa consigo misma (ibid: 39)

El argumento anterior, condensa toda la propuesta lévi-straussiana sobre la formación/acumulación del pensamiento, partiendo de la ausencia de pensamiento. Es evidente, que la idea formulada en torno a divisiones, agrupamientos y pertenencias de los hechos del mundo, define necesariamente la construcción de un sistema clasificatorio. Este sistema, parte de la base de lo sensible: el pensamiento salvaje; y llega a la racionalización de ese mundo: el pensamiento científico. La transición o mejor, la convivencia perpetua entre ambos mundos es lo que estructura el corazón de los sistemas clasificatorios. Por tanto, de los dos núcleos organizadores de la sociedad que plantea el trabajo de Lévi-Strauss, es sobre el segundo que vamos a trabajar.

Como menciona Lévi-Strauss, al principio no había conocimiento ni significación de las cosas; en un momento apareció la capacidad de significación. Esta saussureana idea, tiene un primer núcleo organizador: el construir los nombres de las cosas. Dicha "necesidad" tiene según el autor un origen claro, documentado de manera etnográfica, en virtud de los propósitos para nombrar especies vegetales o animales, que “...no son conocidas más porque son útiles, sino que se las declara útiles o interesantes porque primero se las conoce" (1964: 24). La importancia de las piezas del pensamiento se define en función de construir y ampliar los límites del conocimiento; pero esta "etiquetación" no es suficiente para completar el sistema, pues aun teniendo las partes, falta explicar su organización y aclara:

En su esfuerzo por comprender el mundo, el hombre posee un exceso de significados [...] Este reparto de la ración suplementaria, si estos términos fueran válidos, es absolutamente necesaria para que el total de los significados disponibles y las cosas significadas señaladas, guarden entre sí la relación de 
complementariedad que es condición esencial para el ejercicio del pensamiento simbólico (1979: 40) ${ }^{12}$

Hay en este punto algunos aspectos interesantes que se pueden destacar. El primero se refiere a la ausencia de un referente utilitario en el proceso de construir la totalidad cerrada de los significados. Esta no-utilidad, bosqueja la escena de los primeros humanos, en la que sin jerarquización de especies, van nombrando hechos y objetos del mundo. A Lévi-Strauss no le interesa reflexionar en torno que clase de cosas se nombraron primero, no obstante es factible pensar que es lo que se tiene presente de manera inmediata: el cuerpo y sus sensaciones, el "otro" y el entorno espacial. En todo caso, para nuestro autor es irrelevante, pues no hay todavía una lógica articulatoria; el espíritu es el del bricolage que utiliza "lo que se tiene a la mano". De aquí el segundo punto: a diferencia de Turner, Douglas o Mauss y Durkheim, que introducen un principio organizador inicial (el cuerpo, la suciedad o la sociedad), LéviStrauss comparte argumentos con Saussure: no hay un principio determinado del "nombre". A pesar de eso, entre estos dos últimos hay una gran diferencia, pues al lingüista no le interesa la materia con la que se estructuró el sistema y al antropólogo sí; la evidencia antropológica está construida en torno al pensamiento totémico y mitológico de pueblos primitivos.

Bien. Si los nombres no bastan para articular un sistema de clasificación, es decir las diferencias entre los elementos, ¿qué es lo que falta? Falta el núcleo que haga de estos elementos discretos pero desorganizados, parte de un sistema claro y discernible. "El principio lógico es el de poder oponer siempre términos, que un empobrecimiento previo de la totalidad empírica permite concebir como si fueran distintos $^{13}$ " (Lévi-Strauss, 1964: 115).

Hemos llegado al principio organizador de la totalidad de los significados. Para poder establecer una organización, es necesario hacer abstracción de la riqueza en significados y posibles matices de un objeto o hecho del mundo. Sólo así es factible compararlo con otro, previamente empobrecido. Al oponerlos entre sí, se construye el principio lógico de organización que los define como distintos. La denominación de "distinción", lo que aquí llamamos diferencia, ocurre en Lévi-Strauss por razones claras: el uso de la terminología de Saussure, basada en necesidades propias de los argumentos lingüísticos. Pero como anoté anteriormente, para la conceptualización con

\footnotetext{
${ }^{12}$ El subrayado es mío

${ }^{13}$ Este subrayado es mío
} 
la que vamos a trabajar, y que es más coloquial, la llamada distinción en ambos autores, es lo que manejo como diferencia.

La construcción de entidades sobre el sistema de clasificación postulado es muy interesante en Lévi-Strauss. Contempla desde los sistemas totémicos y su aplicación para el reparto de grupos familiares, clanes y tribus, al parejo que dispone una lógica para la sistematización de objetos, fenómenos y sus relaciones con las categorías anteriores. Estos subsistema clasificatorios, tiene en el rito y el mito, su despliegue más contundente y al mismo tiempo, la estructura para su reafirmación, ya con base en la experiencia ritual, ya mediante el relato mitológico.

Un ejemplo contundente que da el autor, se refiere a la comparación entre rito y juego. El juego, es disyuntivo, pues culmina con la creación puramente contingente, de diferencias entre individuos que al inicio del procedimiento no se distinguían para nada. Exactamente lo contrario del rito, que a través de un procedimiento específico, iguala a los participantes que al inicio eran diferentes (1964: 58-9). Los tipos de diferencias que operan tanto en juegos como ritos, pueden ser de tipos muy variados, enlazando lo vivo y lo muerto, lo sagrado y lo profano, lo joven y lo viejo, lo masculino y lo femenino, ganadores y perdedores, por poner algunos ejemplos.

En el mito ocurre algo semejante. A través de un lenguaje específico y una estructura definida, el relato que se cuenta brinda elementos para la resolución de una contradicción, mediante el enfrentamiento de otras relaciones contradictorias. "La imposibilidad de conectar grupos de relaciones es superada (o más exactamente remplazada) por la afirmación de que dos relaciones contradictorias entre sí, son idénticas, en la medida de que cada una es, como la otra, contradictoria consigo misma" (Lévi-Strauss, 1976: 196). “...el pensamiento mítico procede de la toma de conciencia de ciertas oposiciones y tiende a su mediación progresiva" (ibid: 204-5). Así pues, la agrupación de diferencias y su comparación entre sí, permite ir transformando unas en otras, mediante un proceso lógico de homologías. ${ }^{14}$

Este procedimiento hace que al interior de un sistema clasificatorio se puedan ir transformando, como se dijo, unas diferencias en otras de acuerdo a necesidades ya no de tipo formal, sino en concreto, del grupo social que construye o utiliza dicho sistema y más aún, como medio de comprensión y traducción de otros sistemas clasificatorios. Lévi-Strauss culmina asegurando que “...un sistema cualquiera de separaciones

\footnotetext{
${ }^{14}$ El proceso lo toma de la idea de analogía en Saussure
} 
diferenciales -en cuanto ofrece el carácter de sistema- permite organizar una materia sociológica 'trabajada' por la evolución histórica y demográfica, y que consiste, pues, en una serie teóricamente ilimitada de contenidos diferentes" (1964: 115). ${ }^{15}$

Expuesto lo anterior, se pueden ya enunciar los usos de su modelo de clasificación en el tratamiento de fenómenos de poder. En primer lugar, está desde luego el proceso de construcción de las diferencias como pares de oposición. Está idea se ha venido trabajando en todo el tratamiento y no merece mayor explicación, excepto en un punto. La idea de "empobrecimiento" de los términos a comparar, como mecanismo simplificador del proceso de construcción de las diferencias. La densidad de los hechos empíricos, hace complejo su tratamiento y esquematización cotidiana, de ahí que los sujetos procedan a "limpiarlos" de aquellos elementos que no presentan interés para la oposición con otro cualquiera. Esto quiere decir, que se busca su mínima expresión al oponerlos. No obstante, dicho empobrecimiento es una maniobra puramente subjetiva y enmarcada en el contexto específico del cual surgió la necesidad de la oposición. Lo anterior, que no es ya una aseveración de Lévi-Strauss, supone que las oposiciones construidas para efectos de poder, se realizan "empobreciendo" los elementos en el marco de un uso específico, en nuestro caso, el ejercicio de poder. Las diferencias así construidas, pueden ser llevadas al terreno de las asimetrías, al enfrentarlas a un procedimiento específico. En gran medida, la construcción de asimetrías es también un proceso de empobrecimiento conceptual, pues la extracción de propiedades para el desempeño en el procedimiento seleccionado, aísla o excluye características irrelevantes de los elementos involucrados. Es en esta idea, que el tratamiento de Lévi-Strauss difiere grandemente respecto de las tres primeras propuestas: no hay un germen específico de la clasificación. Es la construcción de los significados, lo que dirige el proceso. No hay primacía de la experiencia, de lo social o de la lógica; lo importante es el hecho clasificatorio por sí mismo. Tal planeamiento lo alinea, como se anticipó, con la propuesta de Saussure.

Otro punto es el concepto de bricolage. Su importancia estriba en que la sobreabundancia de objetos nombrados está por encima de la utilidad. Habla, en términos de poder, de que la posibilidad de significar diferencias preexistentes para llevarlas al terreno de las asimetrías y de ahí al ejercicio de poder, está enmarcada en la capacidad o necesidad de los individuos por redefinir o resignificar realidades. El

\footnotetext{
${ }^{15}$ El subrayado es mío.
} 
ejercicio de poder no supone necesariamente, una constante creación o redefinición conceptual. Existen asimetrías socialmente estables, las cuales son presentadas en innumerables propuestas teóricas, como los gérmenes del poder. Me parece, sin embargo, que en tales propuestas se confunde la idea de estabilidad con la de inmutabilidad. Como se ha venido reiterando, el contexto y la diferente lectura de las condiciones específicas de cada situación de poder, definen la inmutabilidad, como una imposibilidad. Lo que aquí esté implícito o explicito como Teoría del poder, renuncia de manera expresa a considerar un germen único o un conjunto de ellos, como necesarios y suficientes para ejercer el poder. En primer lugar, porque la lista de los elementos, dados los casos de uso, sería tan grande que terminaría por incluir todas las diferencias -distinciones diría Saussure- conceptualizadas en la lengua. En segundo lugar y como argumento fundamental, porque supondría que dicho germen o gérmenes usados correctamente y con la intensidad necesaria, culminarían en la conducción de las acciones o conceptualizaciones según el plan del superordinado, independientemente de los pensamientos, acciones o previsiones que el otro actor tome con relación a dicho plan. Es decir, como si el actor fuera un objeto. Con esto no se quiere decir y lo reitero, que no ocurren fenómenos de poder al margen de la voluntad de los actores; ello sería negar un conjunto de hechos regulares en las sociedades humanas. Lo que se está afirmando, es que los gérmenes por los que ocurre los hechos de poder, no pueden ser determinados ex ante, como si fueran resultados ex post. No hay condiciones suficientes y necesarias, que garanticen que en los fenómenos de la conducción de la acción social, algo va a ocurrir inexorablemente, a la manera que se pronostican las trayectorias de los astros o las partículas. Siempre el contexto y las condiciones que todos los involucrados introducen en el supuesto germen inmutable del poder, conllevan fuerzas de indeterminación y error.

Por eso el rescate de la idea de bricolage. Muestra que la circunstancia humana, estriba en "echar mano" de lo que se tiene disponible, dado un contexto. Esto supone dos cosas. Por un lado, que en los esfuerzos individuales o colectivos para "tener"16 poder, la búsqueda de nuevas asimetrías o nuevos procedimientos que originen o

\footnotetext{
${ }^{16}$ Se aclaró anteriormente que en términos teóricos, la idea del poder como una substancia o esencia que puede ser poseída por un actor, es equivocada. La expresión, frecuente coloquialmente, es derivada de la percepción subjetiva de quienes observan al actor superordinado, al margen de las condiciones del subordinado. Tal apreciación errónea, lleva a suponer que cada vez que el dominante enuncia una orden, ésta será automáticamente obedecida, en virtud de que el dominante "libera" frente al dominado, un poco de tal esencia, que se entiende en ese discurso, como "irresistible". Por ello, cada vez que sea mencionada la idea de posesión del poder, estará entrecomillada.
} 
potencien una relación de poder, es una práctica constante. De tal suerte que se puede echar mano de diferencias que están ahí, y que por múltiples razones no han sido utilizadas asimétricamente. Pero, por otro lado, el proceso inverso es un hecho. Dada una asimetría específica, la búsqueda por desmontarla, es decir, la búsqueda de condiciones para su trivialización o anulación a través de la igualación, es también entre los subordinados, una práctica constante. No es el interés aquí, describir o culminar con el tratamiento del conflicto por el ejercicio del poder; es decir la realidad política en sentido amplio. En general, las líneas de reflexión abordan las condiciones por las cuales se da, de manera efectiva, tal ejercicio. Si bien aquellos sujetos identificados como los "poseedores" del poder, enuncian constantemente órdenes, las acciones o conceptualizaciones que prescriben en innumerables ocasiones no se ajustan a lo enunciado. Parte de esa imposibilidad son los fenómenos de resistencia, pero otra, substancial también, son las imposibilidades fácticas, aun cuando se intente por norma, cumplir tales órdenes. ${ }^{17}$

Retomando. Los dos elementos anteriores que se pueden desprender del trabajo de Lévi-Strauss, tienen como complemento un tercero. Este insumo es uno de los más útiles en la comprensión de los fenómenos que nos ocupan. Se refiere a la estructura discursiva que toman las diferencias para dar cuenta de su oposición: el relato mítico. En éste, se acomodarían las asimetrías para mostrar una contradicción fundante: la diferencia entre quienes determinan la acción social y quienes la ejecutan. La idea es pues, un método para seguir los relatos en los que se imbrican asimetrías y acción social. La herramienta usada así, parece de gran productividad, pues permitiría enlazar, asimetrías, conducción de la acción-conceptualización social y los relatos acerca de tal estado de cosas. El seguimiento de dichos relatos en una comunidad o grupo específico, daría como posibilidad, no solo el conocimiento de las asimetrías que soportan la relación de poder, sino delinear una matriz de transformación de tales asimetrías. Simultáneamente, la convergencia o divergencia de las versiones en función de la posición del relator: superordinado o subordinado. Adicionalmente, esta dimensión pudiera arrojar datos de carácter histórico, en virtud de la profundidad del relato y el alcance temporal de las oposiciones utilizadas. Así, estas tres dimensiones hacen que el

\footnotetext{
${ }^{17}$ Respecto de los fenómenos de resistencia, James C. Scott $(1985,2000)$ ha trabajado el tema de manera certera. Por lo que respecta a la idea de imposibilidad fáctica, en un trabajo anterior (Barquín, 2007: 11729) se abordó esta idea mediante el concepto de desgaste, como determinación de la distancia conceptual entre lo que se enuncia como orden y lo que realmente ocurre.
} 
modelo lévi-straussiano de clasificación, sea de gran utilidad para el estudio de los fenómenos de poder en particular y de los políticos de manera general.

Con todo lo anterior, se diría que Lévi-Strauss abre una puerta amplia para la confrontación de fenómenos sociales con los sistemas de clasificaciones; y lo hace en gran medida. Queda aún una interrogante por responder: por qué Claude Lévi-Strauss desarrolló una obsesiva evitación de lo político. Esta interrogante es de gran peso, porque como bien lo intuyó Mary Douglas, existe una relación genética entre los fenómenos de clasificación y los de poder. El desorden, sólo a través del poder, puede ser transformado en orden. Entonces, el nexo entre lo político y los sistemas de clasificación es necesario, independientemente del peso que se le quiera dar en cualquier argumentación. Por eso llama la atención la ausencia de reflexiones de ese tipo en Lévi-Strauss. Si la diferencia es de capital importancia para la construcción de su sistema teórico, ¿por qué evita dar el paso y reflexionar sobre su efecto en la organización social? Esa pregunta queda sin responder. Constantemente, la consecuencia lógica de los argumentos que expone, es la de abordar la articulación o el resultado de las oposiciones en la organización social; es decir, las asimetrías. Sin embargo difícilmente profundiza en la cuestión, a pesar de asegurar que las categorías del totemismo son una base para la convertibilidad ideal de los diferentes niveles de la realidad, y citando a Durkheim, define el fenómeno como una "socio-lógica" (1964: 116). Conociendo pues esos trabajos, es enigmático que evitara líneas como aquellas de Mauss y Durkheim, en donde el sistema de clasificación tiene al menos, relación con la clasificación efectiva de los grupos humanos. La utilidad del trabajo de Lévi-Strauss para abordar la dinámica de las relaciones de poder en tanto relaciones asimétricas, es fundamental, no obstante, que ese objeto y su derivación en lo político, se perciban en su trabajo no de manera directa, sino como proyección de sus razonamientos; a la manera de sombras.

Las observaciones sobre la propuesta clasificatoria de Claude Lévi-Strauss son básicamente tres. La primera es específica y viene de las críticas que Maurice Godelier desarrolló en El enigma del don. Atinadamente, señala lo desconcertante del dicho lévistraussiano de la aparición completa y de un golpe, del lenguaje y asimismo, de la dictadura de lo simbólico sobre lo imaginario (1998: 41-9). En sus argumentos, cuestiona el aislamiento del lenguaje articulado respecto de cualquier otro proceso sensible o mental, resonando con la crítica derridiana a Saussure. Sigue diciendo, que la 
capacidad de simbolizar de la mente, contiene al menos otra en su interior: la capacidad de imaginar aquello que simboliza. Y de ahí, que por consiguiente, están ausentes aquellos procesos que permiten la construcción de lo imaginario, es decir, los procesos efectivos de la vida misma, que aportarían los elementos a imaginar y simbolizar por medio del lenguaje articulado.

En segundo lugar, hay una crítica muy generalizada a Lévi-Strauss en el sentido de que soslaya los procesos históricos, en virtud de la permanencia de la estructura, independientemente del grado de desarrollo de las culturas específicas. Este argumento, al menos desde mi punto de vista tiene bases sólidas en un aspecto: aquel asociado al problema del desarrollo temporal de los procesos y los acontecimientos. El dicho de que el universo se significó todo y de un sólo golpe, aísla las etapas del desarrollo humano y las actividades asociadas a ello. A lo largo de la vida, se va teniendo contacto con diferentes procesos, espacios y sensaciones, pero ello, no ocurre 'todo de un solo golpe'; tales sucesos dispersados temporalmente forman al individuo y al grupo, pero más importante, son esenciales en su pensamiento. El proceso de desarrollo del significado es a mi ver, tan importante como el significado mismo. La constante presencia de ritos de paso en todas las culturas, resume esta realidad, en virtud de que la experiencia, es un eje central de lo humano.

Finalmente, y siguiendo la línea turneriana, si la experiencia invade la conformación del sentido y por tanto la historia del desarrollo individual es un núcleo duro del proceso de socialización, ¿cómo fundamentar hasta el límite, la idea lévistraussiana de que no hay líneas de utilidad en la conformación de nombres y sistemas de clasificación? El dicho de que no se clasificaron las cosas porque son útiles, sino que se les declaró útiles porque primero se las conoce, implica la ausencia de interés en el individuo por aquellas situaciones que le afectan de manera inmediata, incluyendo el cuerpo y sus procesos. Se diría entonces que da lo mismo, clasificar los distintos tipos de rocas sobre el terreno, que los diferentes líquidos corporales, los alimentos de la dieta o los parientes prohibidos. Más aun, deja sin responder todo el cúmulo de argumentos planteados por Marx, respecto de la importancia de las actividades transformadoras de la naturaleza como base de los procesos de construcción del sentido. Coincido con Lévi-Strauss en que la idea económico-termodinámica de utilidad, en la construcción simbólica del mundo, es un absurdo; pero de ahí a que la jerarquización instrumental de datos fundamentales del entorno, sea irrelevante, hay un gran trecho. Esto último 
implicaría la jerarquización del universo con algunas consecuencias de tipo político; consecuencias que, el autor, persistió en ignorar.

\section{Corolario}

El estudio de los sistemas clasificatorios tiene, como se ha visto, una gran potencia heurística como modelo de aproximación a lo humano. En el caso de las relaciones de poder, las clasificaciones son imprescindibles al menos en el punto que se postuló al inicio: si se focaliza el poder como conjunto de relaciones asimétricas, la definición de lo simétrico y lo asimétrico está enmarcado necesariamente en un patrón de clasificación. No es una coincidencia que en tres de las propuestas, la discriminación entre diferencias y asimetrías desemboque o defina conjuntos de relaciones de orden social, es decir, de relaciones políticas; y desde luego que el ejercicio del poder se presenta como uno de los núcleos centrales de la actividad política. Más aun, Mary Douglas ve un nexo constitutivo entre clasificación y poder, esto es, el orden clasificatorio del cosmos es producto directo del ejercicio de poder, en el contexto de la ambigüedad y el desorden. Sólo una decisión dirigida, puede eliminar tal ambigüedad e instaurar el orden.

¿Cuáles son entonces las conclusiones o resultados de la exposición anterior? Un primer punto de orden muy general, es que el estudio de los sistemas clasificatorios centrado en la idea de la asimetría, produce pistas del más puro carácter antropológico sobre las posibles raíces del surgimiento de los fenómenos de poder en las sociedades humanas. Las conjeturas resultantes tienen dos caras que destacar. La primera se refiere a una regularidad en la lógica de los sistemas clasificatorios: la polisemia o contextualidad de lo clasificado. La percepción del valor de las diferencias para estructurar asimetrías, está atada a los diferentes niveles de interpretación que realizan los individuos o que definen las situaciones objetivas de la realidad. Ejemplo muy socorrido en la literatura sobre este tema, es "el valor" de un vaso de agua de acuerdo al contexto: selvático o desértico. Es decir, se debe renunciar a encontrar en un solo concepto, el origen del sistema clasificatorio humano. Las teorías contractualistas -por ejemplo- en donde la violencia generalizada desembocó en el orden social, mantenido a partir de la violencia legítima del Estado y entonces de ahí, postular que la violencia es la semilla primitiva de todo poder, son definitivamente reduccionistas. El segundo aspecto, es que las asimetrías que definen la posibilidad de ejercer el poder, tienen gérmenes tan disímbolos que es de una gran audacia definir a uno de ellos como el big 
bang del poder. La importancia de todas las experiencias corporales, de todas las propiedades corporales y mentales, de las estructuras sociales o de las estructuras lógicas, encuadran la densidad "infinita" de la vida. Como atinadamente afirmó Max Weber:

...la infinitud absoluta de esta multiplicidad [la de la vida] para nada disminuye, en su dimensión intensiva, cuando consideramos aisladamente un objeto singular -por ejemplo un acto de intercambio-, tan pronto como procuramos con seriedad describirlo de manera exhaustiva en todos sus componentes individuales; tal infinitud subsiste todavía más, como es obvio, si intentamos comprenderlo en su condicionamiento causal (1973: 61-2)

Es decir, los órdenes clasificatorios definen relaciones de poder de manera específica, según el principio particular de cada orden. Resulta imposible aprehender las dimensiones intensivas y extensivas de un fenómeno social de manera tal que logren acercarse con exactitud a todas sus determinantes. Por tanto, se puede enunciar con prudencia que una asimetría específica está basada en un cierto principio clasificatorio, pero aseverar que una asimetría sea la base de todo un sistema es una imprudencia; la totalidad del fenómeno es pues, inaprehensible. Lo anterior busca dar salida a las inquietudes, siempre presente, sobre el surgimiento de los fenómenos de poder en los humanos primitivos, inquietud que como enuncié al principio, es una presencia deseable de discernir, metodológicamente imposible de solucionar y marginal en el presente trabajo.

Surgen sin embargo herramientas de gran utilidad, tanto explicativas como susceptibles de aterrizar, para el desarrollo de una investigación empírica. La primera tiene que ver con la muy discutida lógica de lo binario en la simplificación analítica de los fenómenos. El tema es demasiado vasto para resolverse aquí. Únicamente quisiera rescatar lo substancial de las propuestas tratadas; tanto Douglas como Lévi-Strauss dieron pautas que voy a seguir. Refieren ambos autores -en posiciones que extrañamente parecieran contrarias- que al conceptualizar dos fenómenos y enfrentarlos unos a otros, se debe, o bien exagerar las diferencias entre éstos o bien empobrecerlos para poder compararlos. El punto central es que lo complejo de sujetos, objetos o fenómenos hace imposible aprehenderlos de manera sencilla. De ahí que postulen un principio que en realidad es complementario: abstraer de la riqueza de lo contemplado, elementos que lógicamente puedan lograr presentar a dos entidades como distintas y de ahí, potenciar esa distinción, a través de la exageración; con eso puede lograrse un 
principio definido de clasificación. Los otros tres planteamientos, también convergen en ese punto. Inclusive, Victor Turner reconoce que sus sujetos de investigación, ordenan el sistema de manera subjetiva como oposiciones; lo ternario de su propuesta es de carácter analítico y no empírico. De tal suerte que en este trabajo se usará dicho planteamiento, al indagar la lógica clasificatoria que permite la construcción de asimetrías: empobrecimiento y exageración.

Otro de los temas generales que aparecen en las propuestas es el de la reacción entre las clasificaciones basadas en, llamémosle, creencias o principios abstractos de clasificación y aquellas basadas en razonamientos lógicos. Se vio una fuerte discusión respecto del papel que el pensamiento lógico jugaba en la estructuración del sistema. En términos de Saussure, la lógica está atada orgánicamente al origen del sistema; en el tratamiento opuesto -el de Mauss y Durkheim- en nada; todo deriva de la estructura de la sociedad. Esta divergencia toma en Lévi-Strauss un punto intermedio: pensamiento salvaje y pensamiento científico conviven en la mente humana. De ahí se desprende la utilidad del ejercicio, pues en la investigación empírica de las asimetrías que definen relaciones de poder, resulta central separar los datos producto del análisis racional, de aquellos que definen un sistema de manera fundante, que no es susceptible análisis y agrupa a los individuos en conjunto sociales. Un ejemplo claro del argumento anterior, se refiere al desarrollo de una política que busca un curso de acción específico y que los actores juzgarán como atinada o inviable según su procedencia clasificatoria: de izquierda o de derecha. Resulta en múltiples ocasiones imposible o irrelevante, hacer un análisis lógico de tal política. La pertenencia al sector opuesto del que la postula, define -casi siempre- de manera inmediata, el rechazo al curso de acción; se dirá, de hecho, que por su origen es "ilegitima" o sea, de una especie que contamina a todo aquel que la aprueba. Al aproximarse a los fenómenos de poder, resulta básico desde este planteamiento, distinguir el origen de la categoría clasificatoria que estructura la asimetría. Ya sea que provenga del resultado de un análisis lógico, de procesos de aglutinamiento social o puramente clasificatorios. ${ }^{18}$

Estos dos temas de carácter general: lo binario expresado en pares de oposición, y el origen lógico o sistémico de los pares, deben rastrarse necesariamente en campos separados. Uno se refiere a las percepciones de los actores expresadas en juicios imputables a los hechos del mundo y el otro, a los detectados mediante el análisis de los

\footnotetext{
${ }^{18}$ Esto último a la manera de lo que refiere Lévi-Strauss, es decir, el ejercicio clasificatorio con el objetivo inicial de "hacer sistema", independientemente de su utilidad práctica; el llamado bricolage.
} 
datos empíricos, como resultado del proceso de investigación. Estos campos son aquellos definidos de manera ya tradicional en la Antropología como emic y etic o más coloquialmente como aquello que los individuos "dicen que hacen" y aquello que el antropólogo asevera que "realmente hacen". Así pues, con estos principios del trabajo antropológico y la base de los sistemas clasificatorios, es que se va a abordar el estudio de las relaciones de poder.

Otro tema a destacar se refiere al origen específico del sistema de clasificación. La mencionada atadura al origen primero de los sistemas de clasificación debe ser dejada del lado aquí. En el enfrentamiento con relaciones de poder contemporáneas, las propuestas de los autores expuestos se refieren a campos muy específicos, imposibles de abarcar por la expansión contemporánea de temas. Son, no obstante, de utilidad invaluable para establecer la articulación de todo ese conjunto ampliado de temas. El primero se refiere al nexo entre estructura o jerarquías sociales y el sistema clasificatorio. Así, la división de los individuos por nacionalidades, razas, adscripciones étnicas o religiosas, niveles de ingresos, campos laborales, regiones geográficas de trabajo, genera órdenes clasificatorios específicos que conceptualizan ideologías políticas, jerarquías de personas y cosmovisiones, por poner algunos ejemplos. Estas divisiones primarias, alcanzan también a los objetos de uso cotidiano en estos grupos sociales; las etiquetas de "naco" o "fresa" a prácticas u objetos son demostrativas. Así mismo, siguiendo el espíritu de Mauss y Durkheim, la posición geográfica de los grupos o individuos sobre el terreno, define una clasificación específica que puede o no intersectar con las anteriores. ${ }^{19}$ No es despreciable en ningún sentido, los modelos de origen corporal basados en la experiencia; sobre todo aquel que fue llevado a las regiones conceptuales que aquí estamos discutiendo. La noción de orden/desorden::higiene/contaminación, tiene un solidó planteamiento y múltiples vías para explicar la utilización de clasificaciones asimétricas para ejercer el poder. Adicionalmente a la idea de "contaminación ideológica", el concepto de asco o repulsión a lo que "está fuera de sitio", condensa multitud de prácticas sociales que han estructurado épocas completas y trágicas de la humanidad. El racismo y los sistemas de castas, están basados sistemas clasificatorios corporales y de ahí, la necesidad de separar y evitar el contacto con el diferente. En múltiples ocasiones históricas, la mera existencia de uno de esos órdenes es a tal grado contaminante, que no basta con ser

\footnotetext{
${ }^{19}$ Por ejemplo la división por barrios, colonias, rumbos de la ciudad o regiones del país, define en muchos casos, caracteres o prácticas sociales.
} 
puesta en su sitio; debe ser suprimida del sistema. ${ }^{20}$ Mucho de los conceptos de etnia, nación o civilización, se basan en esta idea de higiene/contaminación. Adicionalmente los grupos de interés (político, económico, religioso, deportivo, etcétera), establecen con sus homólogos del campo, clasificaciones de este tipo. Esto nos lleva al otro nivel propuesto en los autores. Existen clasificaciones producto de ejercicios lógicos de conceptualización, en donde los individuos o prácticas se clasifican en un orden específico. Luego de un proceso de racionalización de las condiciones del sistema, se enuncia una clasificación definida, construida ex nihilo. Un ejemplo muy ilustrativo de lo anterior, fue la clasificación emitida por Carlos Marx de los individuos enlazados en relaciones de producción en términos de clases sociales: burgueses y proletarios. No es que no hubiera tal clasificación. La novedad en ese par de oposición -y su dispersión a la vida cotidiana- se debió al armazón teórico que definía de manera novedosa la lógica del valor y la ganancia, mostrando los intereses diferentes y opuestos de tales grupos. Un último caso es el que plantea Lévi-Strauss con la idea de bricolage: conjuntos de pares de oposición realizados sin ningún interés de utilidad y como un mero ejercicio del pensamiento clasificador, que posteriormente pueden ser usadas, "cuando se les necesite". En el caso de las relaciones asimétricas esta idea es muy poderosa. Muestra como en la expresión de relaciones de poder "que ya está ahí", es factible ir acumulando pares de oposición por homologías, que se transforman y que expresan de manera distinta, lo que de hecho, ya es. Las diferencias entre ricos y pobre al nivel del ingreso, también se expresa en los productos que consumen como de buen o mal gusto. Los sistemas de transformación encerrados en mitos y ritos, dan cuenta adicional de las posibles vías para rastrear la trayectoria de una oposición fundante y los sucedáneos que la enriquecen sin perder nada de su condición original; parafraseando al antropólogo francés: una relación de poder son todas sus versiones.

Es claro que los materiales con los que se elaboraron las propuestas, son apenas algunos ejemplos de los que se pueden derivar principios clasificatorios o pares de oposición. Lo corporal nos llevó de los líquidos básicos del cuerpo a la totalidad de las experiencias orgánicas. Del eco entre clasificaciones sociológicas y materialización de las mismas, al uso de las relaciones de parentesco y la distribución espacial de los clanes para clasificar los objetos y regiones del cosmos. De la formalidad pura del lenguaje y la necesidad de clasificar todo, a la posición derivada de la aparición "de un golpe" de tal

\footnotetext{
${ }^{20}$ Tan sólo el nazismo y las "limpiezas" de clase, a lo largo del siglo XX, son un ejemplo trágico y doloroso de la aplicación desmesurada de estos principios de clasificación.
} 
facultad. Estos elementos sirvieron para proyectar la totalidad de los sistemas humanos de clasificación. Las ambiciones más modestas en este trabajo, buscan solamente enumerar tipos de elementos y posibles consecuencias clasificatorias en las relaciones de poder. Esto es, desde la construcción o tipificación de diferencias, a su transformación en asimetrías funcionales con un objetivo específico: la conducción de la acción social. Es evidente que la lista de diferencias y asimetrías puede ser muy larga, pero por lo planteado aquí, resulta irrelevante desarrollarla toda, pues dado el carácter polisémico y/o contextual de las diferencias, es imposible asegurar si se podrá llevar a una diferencia al terreno de las asimetrías y de ahí, más complejo aun, culminar en un ejercicio de poder. ¿Cuáles son los tipos de elementos que estructuran diferencias y asimetrías? Podemos citar tan solo algunos ejemplos. Los asociados a la posesión de recursos materiales; los asociados a las fuentes de energía; aquellos que se refieren a la "posesión" de conocimientos, tanto de tipo teórico o práctico o informativo. Este nivel puede referirse a conocimientos de cualquier campo: empíricos, científicos, tecnológicos, religiosos, estéticos, organizativos, deportivos, triviales, etcétera. También puede considerarse el acceso a materiales de alto valor simbólico, es decir los objetos sagrados o preciosos y la capacidad de transmutar objetos comunes en sagrados o preciosos. $^{21}$ La condición de determinar el paso entre estados sociales, es decir, la capacidad de fungir como conductor en ritos de paso y determinar a los elegibles. El reconocimiento social de ser un individuo u organización, que sanciona y definen las tradiciones, o en términos contemporáneos, aquellos en posibilidad de enunciar reglas sociales de carácter positivo. Y así. No pretendo agotar la lista, pues el esfuerzo por enunciarla es únicamente el bosquejo de actores, objetos, procesos o campos, en los que es factible la definición de diferencias y su transformación en asimetrías. Es necesario que lleguen a este nivel para culminar de manera exitosa en un ejercicio de poder. Tal es el carácter de este documento. Bosquejar herramientas y modos de uso, que se puedan confrontar con una realidad específica y con esa idea se desmenuzaron las propuestas teóricas.

Para culminar, resta comentar los aspectos políticos y de poder que se desprenden de los autores. Tres propuestas abordan, con diferente profundidad, las consecuencias políticas de la institución de sistemas clasificatorios: Victor Turner, Mary Douglas y Marcel Mauss con Emilio Durkheim. La de Ferdinand de Saussure está al

\footnotetext{
${ }^{21}$ Esto de acuerdo con las categorías enunciadas por Maurice Godelier (1998) y que se precisarán en el siguiente capítulo
} 
margen y la de Claude Lévi-Strauss, como anticipamos, se adentra en el terreno de lo que llamé "evitación de lo político". Para este último caso hay un comentario. La fertilidad del trabajo de Lévi-Strauss insinúa algunas consecuencias de los sistemas clasificatorios que desembocan en ideas sobre política y ejercicio de poder. No obstante estas son de un carácter muy restringido en la obra que trata sobre el tema que nos ocupó. ${ }^{22}$ Caso parecido al de Las estructuras elementales del parentesco, aunque ahí se trata con un poco más de extensión. Las luces sobre la organización política y el ejercicio de poder, están vinculadas a la lógica del intercambio, básicamente de mujeres. Así, en la reflexión sobre los intercambios asimétricos se tratarán estos temas, pero respecto a los sistemas clasificatorios y las relaciones políticas y de poder, sus juicios son más bien escasos.

En las otras tres propuestas hay algunos puntos que se presentan como fundamentales. En primer lugar, que el tema de las clasificaciones es en sí mismo causante de polémicas sociales y por tanto de relaciones políticas con elementos de poder. Como se anotó, Turner declara que su interés en las clasificaciones deriva de la simbolización de los conflictos sociales y su resolución. Esto desde luego toca a la política y al poder. En el trabajo de referencia y en parte de su obra, estas inquietudes son constantes. Si los procesos rituales implican pasos entre un estado y otro, importa tanto el sistema usado para definir ambos estados, como los encargados de decidir y realizar dicho paso. Estas inquietudes están tratadas de manera ampliada en todo el trabajo sobre el Mukanda, rito de paso asociado a la circuncisión de los muchachos (Turner 1999 y Geist 2002). Investigando los aspectos políticos de un ritual no político, Turner aborda lo que está centrado en la oposición básica muchacho/adulto o circunciso/no circunciso y las condiciones que definen el tránsito entre ambos términos. Existe pues ahí, la necesidad de regular dicha transformación social y por tanto la determinación de los procedimientos rituales comporta ejercicio de poder. Mary Douglas por su parte, es todavía más contundente. Reconoce la fuente del poder en la eliminación de lo indeterminado, de lo caótico. Sólo mediante el poder es posible dictar un orden social que elimine el desorden imperante. No obstante, el poder mismo es sujeto de clasificación, ya que un poder sin dirección, ilimitado, es altamente contaminante y por tanto peligroso. Así, el poder debe también ser regulado en sus capacidades de "crear sistema"; solo el poder controlado puede ser considerado

\footnotetext{
${ }^{22}$ La referencia es desde luego a El pensamiento salvaje.
} 
higiénico. ${ }^{23}$ Finalmente, las opiniones de Mauss y Durkheim parten de un modelo político inicial: no hay clasificaciones sin jerarquía. La "lógica" de los sistemas de clasificación esta necesariamente atada a la subordinación de unas especies sobre otras. Esto desde luego procede de lo que se encuentra en la misma sociedad: jerarquías y subordinación. Más contundentes no pudieron ser. Es cierto no que profundizan sobre lo peculiar de sus aseveraciones y cómo, sin clasificaciones iniciales, se construyó un sistema social jerárquico que luego diera origen a las clasificaciones que presentaron. En todo caso, la vinculación entre jerarquías sociales y clasificatorias, está mediada necesariamente por la operación del poder y la política, aunque sólo tocan tangencialmente tales temas.

Hasta aquí el tratamiento teórico de lo que me interesa decir sobre la relación entre los sistemas clasificatorios y el ejercicio del poder. Solo resta realizar un nexo conceptual entre tal desarrollo y la investigación empírica de los fenómenos de poder, en torno de las políticas de educación universitaria intercultural en regiones indígenas. De inicio, los sistemas de clasificación permiten encuadrar, antes de pensar en los fenómenos de poder mismos, el profundo conflicto humano que ocurre entre la sociedad mexicana mestiza y los pueblos indígenas. El trasfondo histórico de esta relación, está conformado por una situación constante de dominación, donde los indígenas han sido sujetos de diferentes tipos de políticas, que van desde las que se encaminan hacia su desarrollo, hasta su desaparición. La constante, hasta hace pocos años, era su nula participación en el diseño de tales políticas. En la actualidad esa situación es distinta. La Constitución Mexicana determina su participación y las condiciones para reducir y eliminar las profundas desigualdades que se observan con respecto al resto de la población. Justo aquí los órdenes clasificatorios permiten ir aclarando el fenómeno. En primer lugar la clasificación de ciudadano mexicano, supone derechos, pero también mecanismos mediante los cuales, el Estado puede conducir sus acciones y conceptualizaciones. Esta oposición mayor y fundacional entre el Estado y los ciudadanos, delimita muchas cadenas de diferencias-asimetrías que son herramientas

\footnotetext{
${ }^{23}$ Esta aseveración de Douglas, recuerda un problema constante en la Ciencia Política: aquel que declara que existe una relación constitutiva entre poder y norma: la norma sin poder, carece de sentido; el poder sin normas de control es ilegítimo.
} 
gubernamentales y que permiten llevar a buen puerto las políticas diseñadas. Más adelante se presentarán las cadenas fundamentales, sin embargo, se puede adelantar que la posesión/carencia de recursos es la central en esta investigación y delinea los fenómenos de poder por intercambio.

Por otro lado, dentro del panorama de los "ciudadanos mexicanos" se ha instituido constitucionalmente, una pareja un tanto peculiar: ciudadano indígena/resto de los ciudadanos mexicanos. Ésta surge por la creación de derechos especiales para los indígenas, en función de la desigualdad con el "resto" de la población, en los órdenes que el Estado debe tutelar. La peculiaridad deriva de que si bien legalmente se pretende equiparar a los dos miembros de la oposición, el origen empírico de la ley es justo motivado por la diferencia entre estos dos órdenes.

Ahora bien, para el "resto" de la población el ser mexicano no es opuesto al ser indígena $^{24}$, sin embargo, para los indígenas, dado el proceso histórico de dominación, el resto del país si es una oposición. En este sentido clasificatorio, las políticas públicas hacía los pueblos indígenas contienen siempre una tensión, que supone: o que no están siendo iguales a las del resto de la población; o que no son suficientemente diferentes con las del resto de la población, para lograr igualar su condición desigual o, sorprendentemente, mantener esa desigualdad. Estas aseveraciones, se desprenden del discurso regular en todos los foros presenciados, donde se discuten temas relativos a las políticas indígenas.

La implementación de políticas públicas hacia los indígenas, lidia con esta peculiar situación. Por un lado tienen que ejercer el poder vía las asimetrías, pues le permiten conducir las acciones y las conceptualizaciones de los sujetos sociales, desde luego en los términos que marca la Ley. Los sujetos indígenas son una parte de ese conjunto nacional y por ende, deben ser tratados de manera igual al resto de la población. Sin embargo, la legislación mandata un trato especial, lo que se conoce comúnmente como "discriminación positiva". De tal manera que no todas las asimetrías existentes entre gobierno e indígenas pueden ser utilizadas. Esta simple oración es causa de muchas de las disputas en función de la implementación de políticas públicas, pues de manera recurrente, en los foros mencionados, los actores indígenas o en favor de los

\footnotetext{
${ }^{24}$ Esto es desde luego una conjetura, que sin embargo tiene cierta fortaleza en función de la caracterización de la mexicanidad a lo largo de la historia, que si bien surgió de un choque con los indígenas, en la actualidad, la identidad nacional no se construye básicamente como oposición con ellos. De hecho es aceptado que hay fuerzas mayores en la conformación de la identidad nacional en los siglos XIX y XX, y que son constituidas por ámbitos de tipo mundial: criollo/mestizo, "gachupín"/mexicano o "gringo"/mexicano, comportan fuerzas mayores en la delimitación de la identidad nacional.
} 
indígenas, cuestionan las políticas, justo en virtud de que son implementadas contra la voluntad de los pueblos indígenas. Ese es uno de los conflictos centrales, pues el ejercicio de poder, como ontología, se realiza en aquellos ámbitos donde la "voluntad" de los individuos, es dispersa, divergente o contraria con las acciones o conceptualizaciones, que con la política que se quieren implementar. La percepción subjetiva de ser dominado por el ejercicio de poder de los distintos órdenes de gobierno, aparece constantemente en la investigación, independientemente de las motivaciones y los efectos benéficos o perjudiciales de la política; la oposición indígenas/resto del país es una constante.

Así pues, si lo central del trabajo que se presenta, es comprender los mecanismos del ejercicio de poder vía las políticas gubernamentales y mediante un instrumental profundamente antropológico, la identificación y comprensión de las asimetrías, juega un papel determinante. Las políticas de educación superior intercultural, son el objeto de trabajo, por ello, las asimetrías que permiten su implementación constituyen la base. No obstante, dado que se implementan con una población que de manera injusta, padece asimetrías desmedidas con el resto de la población, el proceso de las políticas se torna complicado, pues se apela a las asimetrías para ejercer el poder y concurrentemente, se ejerce el poder para eliminar las asimetrías. La percepción subjetiva de este enunciado, enmarca la investigación en la Universidad Intercultural del Estado de México, ya que los sujetos tienen diversos grados de percepción sobre dicho conflicto. Ello, independientemente de que muchas de las asimetrías que se utilizan para la implementación, son diferentes de aquellas que se quieren eliminar, sin embargo, los mecanismos que Lévi-Strauss denomina de "transformación" de las oposiciones, confunden y enturbian el proceso general.

Hasta aquí, el bosquejo de la relación entre la teoría expuesta y su aplicación al caso. En el siguiente capítulo, se expondrán las características efectivas del ejercicio de poder, centradas en un procedimiento específico: el intercambio. La lógica clasificatoria de diferencias y asimetrías, estará confrontada con la conducción de la acción o la conceptualización social, que surge de los intercambios entre individuos o grupos; en nuestro caso, gobierno y sociedad. Hay no obstante una diferencia central con otros tratamientos teóricos que abordan el tema. La utilización del aparato conceptual de los sistemas clasificatorios, permitirá mostrar que la complejidad de los fenómenos de poder asociados al intercambio, es de tal densidad, que la sola utilización de las 
asimetrías asociadas a la posesión de recursos, no basta para explicar el fenómeno de manera convincente. 


\section{2.- El intercambio y el poder}

Poseedores y desposeídos se encuentran cotidianamente. No todos esos encuentros culminan en intercambios y no todos esos intercambios generan una relación de poder. La definición del hecho como una relación en donde se ejerce poder, está asociada a lo que se trató en toda la sección anterior: la transformación de la diferencia entre aquellos que tienen y quienes no, en asimetría, al relacionarla a una operación que muestre alguna ventaja derivada de la posesión. Tal ventaja culminaría en la posibilidad de que el caracterizado como poseedor, aporte al que no posee, todo o alguna porción de aquello que fundamenta la diferencia: si dicha transferencia está condicionada a la realización de alguna cosa por parte del desposeído, se tiene una relación de poder.

Es evidente que esta descripción se ajusta a lo que Max Weber caracterizaría como típica ideal. ${ }^{25}$ Está separada de la densidad de la realidad con el ánimo de caracterizarla en un punto específico, la realización del ejercicio de poder a través del intercambio. Como norte conceptual en todo este trabajo, me focalizo en ese modo típico de ejercer el poder. El modelo general de poder por intercambio no es nuevo en ningún sentido. La asociación entre el condicionamiento y la transferencia de elementos, al desarrollo de conductas o conceptualizaciones por aquel que los recibe es una forma humana común. Como modelo descriptivo o teórico tiene también larga tradición. La innovación que se busca en este trabajo, consiste en potenciar la

\footnotetext{
${ }^{25}$ Como refiere Weber: "No constituye una exposición de la realidad, pero quiere proporcionar medios de expresión unívocos para representarla [...] Se le obtiene mediante el realce unilateral de uno o varios puntos de vista y la reunión de una multitud de fenómenos singulares, difusos y discretos [...] escogidos unilateralmente, en un cuadro conceptual en sí unitario" (1973: 80).
} 
explicación de los mecanismos con la profundización en los sistemas clasificatorios que están presentes y que, en gran medida, definen el fenómeno.

En ese sentido, el tipo de relaciones de poder que interesan aquí, sí son definitivamente aquellas que enlazan a poseedores con no poseedores; es decir, únicamente los procesos en los que aparecen condicionamientos para la transferencia de elementos entre actores relacionados. Por tanto, la asimetría que imperará en todo el planteamiento, será aquella que tiene que ver con el par poseedor/desposeído. ${ }^{26}$ Sin embargo, y esto es lo que permite hacer una propuesta más amplia, en las interacciones cotidianas entre personas, está asimetría no siempre es suficiente, aunque sí, necesaria. Me explico. En los sistemas de clasificación, diferencia y asimetría juegan papeles distintos. La diferencia es fija y atada a la lógica que articula el sistema de clasificación. La asimetría en cambio se articula con un tercer elemento exterior, el "procedimiento", que coloca a un miembro de la diferencia como superordinado y a otro como subordinado; si cambia el procedimiento cambia la lógica de la subordinación. Entonces, la posición ventajosa del que posee no es una cosa fija, a la manera de una esencia inmutable. Ello deriva de la consideración del contexto en el que se enmarca la relación o como se mencionó, la multiplicidad de significados asociados a un mismo hecho o elemento. ${ }^{27}$

Una relación de poder que surge de la posesión como asimetría fundante, puede en realidad estar acompañada de otras asimetrías que "arman" el sentido que tiene frente a los actores. Un ejemplo muy claro de lo anterior, es la asimetría entre los propietarios del producto de la mano de obra individual y aquellos a los que les es enajenada parcialmente; las consecuencias súper estructurales expresadas en asimetrías de tipo ideológico, no definen la relación pero la acuerpan. Más dramática aun, es aquella

\footnotetext{
${ }^{26}$ Como adelanté en el final del primer capítulo, esta oposición poseedor/desposeído, se expresa en términos de políticas estatales, en la posesión y uso de los recursos humanos, materiales y simbólicos que se movilizan para la puesta en marcha de los procesos de educación intercultural en zonas indígenas. La "desposesión" de recursos, es relevante en al menos dos puntos: la carencia de muchos individuos indígenas, de los recursos necesarios para pagar su educación universitaria y la carencia de recursos en las comunidades indígenas para costear un proyecto colectivo de educación en las regiones indigenomestizas. Esto excluye, como es evidente, la obligatoriedad del Estado de proporcionar educación universitaria, pues constitucionalmente, no es obligatorio para el Estado, aunque amplios sectores de la población lo demandan -y consideran- así.

${ }^{27}$ Una opinión convergente con este tratamiento es la que expone Alejandro González Villaruel, pues le asigna a las relaciones de poder una característica peculiar y definitiva: la de servir de enlace entre aquellos que están separados o diferenciados. "Así, las relaciones de poder ponen en contacto y articulan aquello que la economía y la sociedad separan" (González Villaruel, 2005: iii). Desde luego que la separación económica deriva de la diferencia de capacidades o recursos en términos de la vida productiva; los individuos con tales diferencias pueden así relacionarse, sin embargo, la consecuencia de lo anterior, es la construcción de una asimetría; es el poder.
} 
circunstancia en la que la posesión es sólo un vehículo de otras asimetrías en verdad determinantes: “... donar parece instaurar una diferencia y una desigualdad de estatus entre donante y donatario [...] si ya existía previamente entre ellos, el don viene tanto a expresarla como a legitimarla" (Godelier, 1998: 25).

Aquí vale la pena rescatar las ideas de "empobrecimiento" y "exageración", que mostré como atadas a los sistemas de clasificación. En gran medida, la percepción de los actores concretos de ser el par posesión/no posesión el definitorio de una relación de poder, estriba en la actitud de simplificar la complejidad de la realidad y potenciar la síntesis realizada como la única. Está dimensión emic, es una fuente invaluable para el conocimiento del fenómeno pero insuficiente para una explicación precisa. Pudiera ocurrir que en la explicación de una relación, los hechos de empobrecimiento y exageración hubieran conducido a una curiosa inversión: el "ocultamiento" ante los actores de una relación como de intercambio, pasando esta determinación a un segundo plano o desapareciendo completamente. Esta distorsión es un insumo valioso para caracterizar de manera efectiva la relación, pues de hecho, todas las relaciones de poder que interesan en este trabajo, están enmarcadas por un intercambio, pero no en todas, se despliega como la asimetría significativa para los actores.

Estos "movimientos", se dan en torno a la lógica del sistema de clasificación que articula la relación de poder; de ahí que es fundamental tener claro el principio clasificatorio. Las asimetrías en un sistema de trabajo asalariado no tienen el mismo origen que, por decir, las que enlazan ciudadanos con órganos de gobierno o con aquellas estructuran las relaciones intrafamiliares, por poner sólo tres ejemplos. Si bien se puede apuntar la vista en los intercambios asimétricos que allí ocurren, ni el principio clasificatorio ni la lógica de organización son los mismos. Así que todas las interpretaciones, distorsiones, ocultamiento o inversiones que se producen en la relación al respecto de los condicionamientos que definen el intercambio, estarán marcados por esa especificidad. Si bien la cuantía de lo aportado entre padres e hijos puede ser un factor, la edad, el sexo, el tamaño y la existencia previa, marcan de manera característica la relación. Entre gobierno y ciudadanos, criterios como legitimidad, legalidad, justicia y coerción, son en cambio los fundamentales.

Aquí se pude hablar ya de los temas que se presentarán en este capítulo. Las secciones que lo componen tratarán los siguientes aspectos: la definición de un concepto que permita construir la relación entre poder e intercambio; el porqué de la riqueza de la perspectiva y cuáles son sus fundamentos antropológicos; cómo controlar la veta 
economicista que ha inundado muchas propuestas anteriores; qué propuestas anteriores han permitido estructurar la presente y cuáles son las discusiones sobre el tema; y finalmente, qué características debe tener la aproximación empírica al fenómeno, es decir, las relaciones de poder que implica el intercambio entre gobierno y ciudadanos.

Nexo temático. Las políticas educativas para los indígenas, que el Estado Mexicano ha implementado desde principios del siglo $\mathrm{XX}$, constituyen un objeto relevante de estudio, y desde luego, pueden ser abordadas con los dos ejes mayores de este trabajo: las clasificaciones y el intercambio.

Los aspectos centrales de este tema centenario, tienen raíces históricas de la mayor dimensión, pues desde los mismos inicios de la conquista española, esfuerzos honestos y generosos se confrontaron con empresas bárbaras y etnocidas. Las implicaciones del origen contradictorio de "Nuestra América", rebasan con mucho los alcances de lo que aquí se trata. Sin embargo existió una constante, que apenas comienza a desaparecer: la calidad de ente pasivo, que los indígenas se vieron obligados a soportar, en virtud de las condiciones políticas del orden colonial y posteriormente, del Estado-Nación Mexicano. La reforma constitucional que se dio en el año 2001, modificó esta condición en el plano legal y normó los qués y los cómos de la acción gubernamental. En cualquiera de los dos casos, ya discrecionalmente, ya normativamente, los que diseñan políticas para la población indígena, ejercen ciertos recursos humanos, materiales o simbólicos, factibles de "intercambiar" con la población indígena y nacional, y mediante este procedimiento, lograr el efecto diseñado.

La calidad de agente de los indígenas, frente a la acción del Estado es muy distinta en los dos momentos, sin embargo, no se puede evitar (ni se debe, se diría en términos constitucionales) el ejercicio de poder político, como ocurre de manera general con el resto de los ciudadanos. Por ello el enfoque de este estudio sobre los fenómenos de poder, está situado en la eficacia gubernamental frente a los mandatos constitucionales. Es muy común en los estudios sobre políticas indígenas, las referencias a "lo no hecho" o "lo mal hecho" y que tienen un acento crítico sobre la gestión y la deuda histórica del Estado Mexicano con los indígenas; valido desde luego y necesario, sin duda. Sin embargo, dado el foco analítico en los fenómenos de poder, es decir las referencias a "lo hecho", en el capítulo que se presenta, se anima al lector a 
seguir el discurso teórico con una idea de aterrizaje empírico en mente: que en la búsqueda de efectos para la conducción de la acción y la conceptualización social, definidos como obligatorios constitucionalmente, los agentes del Estado, utilizan ciertas herramientas para conseguir estos objetivos legales y legítimos. El artículo segundo de la Constitución Mexicana es un caso particular de la anterior declaración general, pues mandata una serie de obligaciones a los tres órdenes de gobierno y declara una serie de mecanismos para lograrlas, entre ellos, la utilización de los recursos a su disposición para que se cumplan los derechos que tiene la población indígena y que el mismo artículo enuncia. Hay un sistema clasificatorio implícito en el texto constitucional, que permite la construcción o la "destrucción" de asimetrías; estas últimas enmarcan los efectos que, vía los recursos gubernamentales, se buscan producir. ${ }^{28}$

Las políticas públicas se toman aquí como procedimientos mediante los cuales, los gobiernos transforman los dichos legales en hechos sociales; en este esfuerzo, es central el ejercicio del poder político, como una de las herramientas fundamentales del Estado. Para la comprensión de tal procedimiento y sobre todo de los mecanismos por los que funciona y no funciona el ejercicio del poder político, se necesitan caracterizar las herramientas y los fundamentos teóricos que lo soportan y articulan. Las políticas de educación superior desarrolladas en las Universidades Interculturales, están desde luego inscritas dentro de los mecanismos generales que se van a plantear. Sea pues este breve bosquejo empírico, un complemento básico para la comprensión del marco teórico a presentar.

\section{El intercambio y sus efectos}

El primer paso para abordar el estudio del fenómeno, es la construcción de un concepto de poder, que permita definir de manera precisa lo que sucede durante el proceso de los

\footnotetext{
${ }^{28}$ El análisis de los hechos de poder desde el enfoque de los sistemas clasificatorios, desemboca, en el abordaje de los órdenes constitucionales, en un fenómeno muy interesante: las constituciones en su sentido más puro, crean clasificaciones y asimetrías obligatorias, que permiten al Estado y a la sociedad funcionar. Sin embargo, también declaran que ciertos fenómenos sociales ocurren en virtud de desigualdades e injusticias y que, conforme al orden constitucional instituido, no se pueden tolerar. En ese contexto es que se plantea la idea de la destrucción de las asimetrías, es decir: a) la prohibición expresa, de llevar al terreno de los fenómenos de poder, diferencias entre los miembros de la sociedad, imposibles de eliminar; b) la observación obligatoria de mecanismos para matizar tales diferencias o más ambicioso aun; c) la implementación de mecanismos para eliminar las diferencias existentes. Las constituciones, contienen consistentemente, mecanismos de los tres tipos, que pueden denominarse según el propósito que toman con relación a las diferencias, como asimetrizaciones o desasimetrizaciones.
} 
intercambios asimétricos. Para lo anterior, hay que considerar que existen una serie de conceptualizaciones sobre el poder como fenómeno; en éstas el intercambio ocupa una porción importante. Lo copioso y diverso de la bibliografía respecto al estudio del poder, hace innecesario para este trabajo, describirla de manera intensiva; basta con referir algunas fuentes que son síntesis interesantes y productivas. ${ }^{29}$ En todas ellas la idea de poder por intercambio está presente; en todas ellas el mecanismo es más o menos semejante al descrito en esta sección: el condicionamiento de la transferencia a la realización de alguna acción específica. Creo sin embargo, que es necesario definir de manera más restringida este proceso. Habrá que contemplar alguna idea precisa de poder y su relación con los procesos de intercambio. El problema surge debido a que los intercambios con poder, no siempre relacionan materias de tipo homogéneo, pues no siempre tienen un equivalente en valor. ${ }^{30}$ Es decir, tanto la homogeneidad como la heterogeneidad, son ideas que deben incluirse en la conceptualización de las consecuencias de la apropiación del bien a transferir.

En primer lugar, hay que referirse a una definición que va a ser útil para el tratamiento; tiene gran influencia en los trabajos sobre el tema, por su precisión y sencillez. "A tiene poder sobre $\mathrm{B}$, en la medida en que consigue que $\mathrm{B}$ haga algo que, de otro modo, no haría" (Dahl, 1957: 203). ${ }^{31}$ Con ella, Robert Dahl plantea un punto de vista central: la direccionalidad. Aquel que ejerce el poder, lo hace en función de conseguir que el alter, actúe de un modo diferente o nuevo al que lo haría si no hubiera una interacción con el ego. Es fundamental ver, que aquel que genera la actuación es $A$, de acuerdo a sus intereses específicos. $B$ en cambio, actúa desde luego motivado por sus intereses, pero en la interacción aparecen como secundarios y consecuentes con los de $A$. Habría que hacer dos precisiones a tal definición y que no aparecen consideradas por Dahl: 1) Remarcar la idea de intencionalidad, pues es importante notar que la actuación que $A$ consigue de $B$ debe ser una esperada ex ante, es decir, definida de antemano. En la medida que el planteamiento inicial y el final concuerden, se puede hablar de ejercicio de poder. 2) Como aclaré en la primera sección, considero erróneo

\footnotetext{
${ }^{29}$ Dentro de estos esfuerzos aglutinantes, vale la pena destacar los trabajos de: Stoppino (2002a); Portinaro (2000); Lukes (2005); Barret (2002); Boulding (1993); De Jouvenel (1974); Barnes (1990); Wolf (2001); y Galbraith (1986). También se puede encontrar una síntesis personal en Barquín (2007).

${ }^{30}$ Esta idea surge del trabajo de Anthony Downs, pues en los intercambios de "políticas por votos" que plantea, refiere que es un intercambio no homogéneo (1973: 179), a causa de que el dinero que aporta el gobierno en forma de políticas, espera ser pagado por los ciudadanos con un dinero distinto: votos (ibid: 189).

${ }^{31}$ El subrayado es mío.
} 
analíticamente, plantear que alguien tiene el poder; el poder se ejerce si existen las condiciones específicas. $^{32}$

A propósito de la algebraica definición de Dahl, que para mí es la manifestación de un ejercicio de poder al estar focalizada solamente en el actor "poderoso", quiero recordar que al inicio de este trabajo, expresé la intención de mantener la óptica relacional sobre el tema. Así, si el poder es una relación social, o en todo caso una manifestación de ciertas propiedades de ésta, consideraré al poder específicamente, como la condición de una relación social en la que las asimetrías facultan la conducción de la acción o la conceptualización social. Como complemento, el ejercicio del poder sí es atribuible a uno de los miembros, pues sólo uno de ellos aprovecha las asimetrías existentes con objetivos definidos; tal ejercicio puede definirse propiamente, como el aprovechamiento de condiciones particulares por un actor, para tratar de alcanzar metas, resolver problemas y necesidades, mediante la producción en otro actor, de conductas o conceptualizaciones, diseñadas previamente y que de otro modo no ocurrirían. Dicho uso está fundamentado en la transformación de las diferencias entre los actores, al plano de las asimetrías. ${ }^{33}$

Las dos definiciones anteriores, y que parten del planteamiento Dahl, consideran algunas de las críticas que se le hicieron. En primer lugar, que su foco centrado en la conducta, fue cuestionado atinadamente por Bachrach y Baratz (1962), quienes argumentaron la existencia de una "segunda cara del poder": aquella derivada de los esfuerzos del ego, para limitar o impedir las acciones o expectativas del alter. Con ello, buscaban eliminar las incertidumbres de la focalización en los comportamientos de tipo positivo y no en la idea de los comportamientos frustrados, pues en los fenómeno de poder, importa tanto lograr que las intenciones que alguien tiene se impongan, como impedir las que son contrarias a sus intereses. En segundo lugar, Steven Lukes plantea una tercera perspectiva que incluye, no solo las intenciones exitosas o el impedimento a las intenciones ajenas, sino que un actor ejerce el poder de manera exitosa al evitar que

\footnotetext{
${ }^{32}$ Con su idea de que "A tiene poder..." Dahl se asume como sustantivista en función de que la materia poder, encarna como algo que el individuo tiene, a diferencia del otro miembro, que no lo tiene; es decir, es un objeto o substancia poseída por un sólo miembro de la relación.

${ }^{33}$ Esta perspectiva analítica, fue la que utilice en un trabajo anterior con resultados, a mi ver, aceptables (Barquín, 2007). La definición de poder en términos puramente relacionales, abre la puerta a los fracasos empíricamente observables, en los intentos por conducir los procesos sociales; por ello se habla en la definición de "tratar de". Hay poder, hay relaciones de poder, pero el ejercicio que mana de ello, es únicamente la expresión de un intento unilateral; de ahí la necesaria apertura a las consideraciones o actuaciones del otro miembro. Las divergencias entre la orden y los efectos producidos, se englobaron en el concepto de desgaste (ibid: 117 y ss), como la manifestación empírica de la distancia entre lo que se ordena y lo que realmente ocurre.
} 
las intenciones contrarias a sus intereses, lleguen a construirse o a expresarse en el ámbito público (Lukes, 2005: 25-9).

Este comprimido panorama, no busca agotar los conceptos que sobre el poder existen. Se presentan aquí, porqué expresa de manera resumida varias de las consideraciones que se han hecho, para tener la posibilidad de abordar el intercambio asimétrico de manera efectiva. El centro de mi argumento consiste en que, cuando dos actores intercambian, ocasionalmente se estructura entre ambos una o varias asimetrías, determinadas por sus cualidades internas, por los recursos que poseen o por sus posiciones sociales. $^{34}$ La decisión o intención de uno de los miembros de aprovechar las asimetrías existentes, para conseguir que el otro haga algo que, de otro modo, no haría, transforma esa relación de simple intercambio, en una relación de poder. Resulta una consecuencia de lo planteado arriba y que integra en las dos definiciones anteriores, las criticas expuestas, que ese "algo" que haría el subordinado, conlleva conductas convergentes: aquellas que condicionan el intercambio a la realización de una acción observable de acuerdo a los deseos del superordinado, ${ }^{35}$ conductas divergentes: son aquellas que se realizan como producto de la disuasión de una conducta del subordinado, que al superordinado le interesa evitar (este punto incluye desde luego la inactividad, es decir, que la evitación de la conducta no produce alguna substituta); conceptualizaciones convergentes: el conjunto de ideas o conocimientos que el subordinado internaliza y que el superordinado busca que se formen o introyecten y; conceptualizaciones divergentes: que supone la formación de ideas falsas o imprecisas en el subordinado y que al superordinado le importa que se formen (aquí se incluye la ausencia de conceptualización, es decir, el éxito del superordinado en impedir que el subordinado conozca de determinadas ideas o conocimientos o las forme a través de un proceso reflexivo).

Con estos antecedentes es factible definir, como una herramienta útil para describir los fenómenos de poder por intercambio, la idea de conductas y conceptualizaciones de apropiación. Mediante este par de conceptos, se pretende dar cuenta de ese "algo" que se produce en el intercambio y que estaba definido de

\footnotetext{
${ }^{34}$ De manera general al referirme a los actores, contemplo tanto aquellos que son individuales, como colectivos.

${ }^{35}$ Es fundamental que se recuerde, que la calidad de superordinado y subordinado, se refiere únicamente al nivel de las asimetrías que articulan un intercambio específico y no, con referencia a un sistema social de jerarquías. Esto es fundamental, pues como se dijo, las asimetrías cambian constantemente en virtud del contexto y el procedimiento que las define, y temporalmente pueden imperar e invertir las jerarquías sociales.
} 
antemano por el deseo del superordinado. Solamente se considerará que existió un ejercicio de poder mediante intercambio, si en la apropiación de aquello que se intercambia, se producen conductas o conceptualizaciones de antemano definidas. No toda interacción de poder puede contenerse en este concepto, ni el intercambio es la única manera de producir conductas o conceptualizaciones. Existen otras técnicas para influir a los actores y se definirán más adelante. De ahí, que las conductas y las conceptualizaciones de apropiación, puedan estar influidas por asimetrías que no estén determinadas con referencia a lo cambiado, y sin embargo resulten centrales para la explicación de la relación. Los conceptos se presentan únicamente como el eje de giro del ejercicio de poder por intercambio; siempre será necesario considerar los demás elementos que definen los hechos de poder y que no están impactados directamente por el intercambio.

Una aclaración pertinente es la referida a las normas, instituciones o cultura en torno de las cuales se desarrollan las interacciones. Este conjunto complejo, que funciona como estructura para las interacciones, no es consciente para los actores todo el tiempo. Por tanto, determinan conductas o conceptualizaciones "estandarizadas", entre actores enlazados asimétricamente en una estructura de poder. En este caso, no existe un actor concreto que defina lo condicionado, sin embargo, existiría algún tipo de sanción o llamada de atención al actor que no se conduce de acuerdo con esas normas, instituciones o patrones culturales. La diferencia con las interacciones conscientes, es que todos están "sumergidos" en tal estructura de poder, de tal forma que o se actúa en consecuencia o se reciben las llamadas de atención o sanciones. En este caso, hay pues una relación de poder, pero, nadie lo ejerce. ${ }^{36}$

En cuanto al ejercicio de poder, es decir intencional, no es necesario que el que se apropia del bien, tenga conciencia de aquello que se presupone para el intercambio. El contexto puede ser de tal naturaleza que sea imposible la apropiación del bien sin la realización de la acción o la conceptualización esperada, independientemente de la reflexión individual. Se rescata con ello el argumento de Varela (2005: 87-97), que separa la conducta del conjunto de significaciones atadas al acto en sí, de tal manera que

\footnotetext{
${ }^{36}$ Un ejemplo que ilustra lo anterior, es lo planteado por Giovanni Sartori, en donde el efecto antecede a la causa. Cayo obra a causa de lo que Tizio le pide, pero en otra ocasiones "...Cayo hacía muchísimas cosas que no le eran ordenadas por Tizio [...pues prevé lo que Tizio desea] Si prevé bien y actúa bien, después habrá una recompensa" (Sartori, 2002: 60-1). Las previsiones están necesariamente atadas a las normas, instituciones y cultura de Cayo y Tizio. En oposición a lo dicho por Sartori, no siempre habrá recompensa o sanciones a estas anticipaciones. Está en la potestad del superordinado llamar la atención sobre el incumplimiento de las convenciones sociales y la aplicación de la sanción correspondiente. Tenemos entonces como dije, una relación de poder, pero no necesariamente su ejercicio.
} 
no toda acción estará determinada directamente por un conjunto de significados (la cultura). La ocasional ausencia de reflexión en el subordinado, es imposible en el otro miembro.

Como se dijo, la intencionalidad previa es requisito indispensable para considerar un acto como ejercicio de poder. La expresión subjetiva de esa intención, es lo que se llamará "una orden". ${ }^{37}$ La concordancia entre la orden, y la conducta o conceptualización resultante, hablaría del ejercicio exitoso de poder. Es evidente que no toda orden puede ser cerrada, es decir, que defina de manera específica en tiempo y forma las conductas o conceptualizaciones conducentes; tales órdenes se cumplen o no se cumplen. En cambio, puede conocerse desde el principio que hay un conjunto de conductas o conceptualizaciones posibles, que son deseables y en ese sentido se hablará de órdenes abiertas, ya que pueden cumplirse de manera parcial.

El enfrentamiento de los actores a las circunstancias, siempre cambiantes, de las asimetrías que fundamentan una relación de poder, expresa que es imposible saber si la orden será exitosa de manera consecuente. La precisión anterior es básica, pues puede ocurrir que algún actor se apropie del elemento intercambiado y no realice, en la apropiación, lo supuesto por el superordinado. No existe ningún substrato "duro" que garantice el cumplimiento a priori de una orden. Así, la investigación de los fenómenos de poder por intercambio debe contemplar necesariamente, el por qué y el por qué no del cumplimiento de las ordenes enunciadas. Estos "porqués", estarán enmarcados por la idea central de conductas y conceptualizaciones de apropiación.

\footnotetext{
${ }^{37} \mathrm{La}$ idea de "la orden" tiene en términos coloquiales, un carácter peyorativo. En ocasiones se plantea que lo propio es la petición, el favor o la solicitud. Esto, a propósito de que el superordinado en la relación "piense" que lo que enuncia no es una orden. En realidad, lo que define el carácter imperativo de una sentencia no depende sólo de la forma, sino principalmente del contexto. Una sentencia que define acciones o conceptualizaciones condicionadas al proceso de intercambio, contempla una disposición específica de los hechos y los objetos, como un orden del mundo. Dicho orden, toma forma discursiva en aquello que llamamos "la orden". De ahí, que para efectos analíticos, todas las formas que puedan tomar las sentencias se definen como ordenes, a despecho de las percepciones subjetivas del nombre y desde luego, de las formas de expresión discursiva que se utilicen para enunciarla. Más aún: existen ocasiones en las que el subordinado, puede ignorar el enunciado de la orden. Ello no impide el cumplimiento de la misma. Tal situación aparece, cuando por la forma que se realiza el intercambio, el subordinado está condicionado a la realización de ciertas acciones para apropiarse del bien en cuestión. Ejemplos de lo anterior, pueden ser los traslados para recibir el bien intercambiado, la permanencia temporal para recibir el bien, las disposiciones espaciales para la recepción o la forma en la que se recibe dicho bien, de tal manera que su uso o transferencia está condicionada por las características contextuales de lo dado.
} 


\section{Otros enfoques ${ }^{38}$}

No es el intercambio, la única técnica en la que el poder funciona, ni la única perspectiva teórica. Las tres formas que presentaré son en este caso, formas tipológicas, que es difícil o raro encontrar de manera pura. En todo caso se puede hablar de la forma dominante en una interacción; ello no anula la construcción de la tipología, sino que la demarca. Por tanto, quiero argumentar de manera muy breve en qué consisten las otras dos formas, el porqué de la elección del intercambio y cuáles fueron las ópticas desestimadas.

La perspectiva desde el intercambio, tiene en Antropología una rica tradición. Sobre todo, por la certeza de ser el intercambio una de las regularidades humanas imprescindibles y por estar necesariamente atada al origen mismo de la especie; deriva de una comprensión colectiva del hombre. Se rechazan los modelos contractualistas, en donde los hombres subsistían de manera desintegrada en la hobbesiana guerra de todos contra todos. Esto es importante, pues en un tema tan peculiar, la tendencia a aislar las decisiones que unos toman sobre la actuación de otros, culmina en modelos de corte individualista y voluntarista, anulando metodológicamente al otro miembro de la relación. Por ello la insistencia en la forma relacional y dejar las imputaciones subjetivas del poder como substancia, sólo para encuadrar las opiniones individuales. El colmo de esos modelos, son aquellos en los que se hacen analogías directas entre el poder y el dinero: objetos poseídos por los usuarios, que se transfieren de manera discreta y que se gastan en la medida que se usan. ${ }^{39} \mathrm{Si}$ bien la perspectiva empleada en mi trabajo, supone un modelo "costoso" del poder, es decir, atado a la transferencia de elementos como vehículo, no descansa el poder en el vehículo transferido, sino en los procedimientos que enmarcan el sistema de clasificación de referencia, pues

\footnotetext{
${ }^{38}$ En un trabajo anterior, argumente la división de los fenómenos de poder en tres partes, en el llamado "triángulo del poder" que intenta agrupar el abanico de formas que se tienen consideradas para el poder, en únicamente tres. En este apartado se consideran varios de los puntos tratados ahí (Barquín, 2007: 104117).

${ }^{39}$ Las visiones de Peter Blau (1964) y Talcott Parsons $(1967,1973)$ son un ejemplo de lo anterior. En el caso de Parsons, la analogía no es necesariamente simplista y merece consideraciones separadas. Equipara al poder como un medio de circulación para las transacciones que ocurren en el sistema político, de forma semejante al dinero en el sistema económico (1967: 306).
} 
transforman a los cambiantes o a lo cambiado, de entidades diferentes a entidades con asimetrías; por tanto, se desecha la perspectiva económica como fundante. ${ }^{40}$

Se debe aclara que en el modelo de poder por intercambio, lo relevante es el nexo que se establece entre las partes por la modificación de las conductas o las conceptualizaciones como condición y consecuencia de la transferencia del elemento. Casos altamente simbólicos como la transmisión de conocimiento por ejemplo, comportan aspectos de poder, cuando el individuo debe quedar "dispuesto a" transformar su situación, que de otro modo no haría, para estar en posibilidades de aprehender elementos de carácter inmaterial: adquirir, transformar o reordenar los elementos en su mente, ya sean definitorias o concomitantes al proceso. En lo anterior, es evidente que existe una intención anticipada de quien posee el conocimiento, por producir determinadas conductas y sobre todo, conceptualizaciones en el "aprendiz". Su realización son condiciones expresas del proceso de intercambio, pues permiten cerrar el ciclo de dar-recibir-devolver. Esto quiere decir, que lo central del poder por intercambio es la conexión conceptual entre los dos momentos: dar y devolver. ${ }^{41}$

Existen otras dos formas que serán consideradas aquí, de manera accesoria: control y violencia. El primer caso, se refiere a una forma centrada únicamente en el ego. El principio nuclear de esta forma, consiste en analizar todos aquellos elementos, ideales o materiales que un actor posee o "controla", es decir, que está en posibilidades de manejar de acuerdo a la naturaleza específica del elemento. Lo anterior implica, que el ejercicio de poder deriva de esa sola característica y no está asociada a otros actores, ni a la transferencia de dicho elemento. El poder en este caso se ejerce, como resultado de la expresión ante otros de tal posesión. Está forma comprende todos aquellos casos conocidos como persuasión, manipulación, secreto, disuasión, amenaza, acaparamiento, que derivan de la movilización de los elementos controlados con el objetivo específico de producir conductas o conceptualizaciones $\sin$ transferir el elemento en cuestión. De ahí que formas como la persuasión o la manipulación, implican la presentación de

\footnotetext{
${ }^{40}$ Charles Lindblom (1991), presenta un modelo tripartito del poder centrado en tres formas: Intercambio, autoridad y persuasión. Él es quien plantea la idea de "lo costoso" (pág. 68), pues el poder por intercambio implica necesariamente transferencias de entidades que es muy probable que sean limitadas, por tanto susceptibles de terminarse. Lo contrapone con la autoridad, que para él es inagotable mientras sea aceptada como norma de obediencia en aquellos regidos por tal autoridad.

${ }^{41}$ Se adelantó este aspecto, en virtud que una parte relevante de las políticas educativas hacia los indígenas, comportan un proceso de apropiación de los bienes simbólicos e inmateriales que supone la educación intercultural. No obstante plantea una relación de intercambio, pues hay una evaluación de la forma en la que dichos bienes deben internalizarse; no son solo expuestos para su apropiación de manera discrecional por el sujeto.
} 
informaciones al subordinado para crear en él un efecto, pero sin establecer con él, un nexo de devolución; lo que importa es el efecto, no el establecimiento de una relación ni la apropiación de la información. Caso parecido al de la amenaza, el secreto, la disuasión o el acaparamiento, en el que los elementos se muestran o se ocultan para la consecución de efectos pero sin la transferencia de los mismos. En el caso del acaparamiento, por ejemplo, el ocultamiento intencional de mercancías para producir una falsa impresión de escasez, ocasiona que en el intercambio comercial, los que carecen del bien estén dispuestos a pagar por la mercancía más que lo habitual. La disuasión o la amenaza son control y no formas violentas, pues su efecto deriva no del daño, sino de la "presentación" ante el subordinado, de los medios o los procedimientos para el daño, pero nunca de su ejecución. Un caso particular de lo anterior, es la enunciación de leyes que presuponen sanciones a ciertas acciones; las penas comprendidas en la misma, disuaden dichas acciones antes de que ocurran pero no se aplican si la ley opera exitosamente, es decir, si evita dichas acciones. También comprende esta forma, las transformaciones e indicaciones del espacio. Un ejemplo de lo anterior es el trazado urbano o el diseño arquitectónico de obra pública, que tiene efectos específicos en los comportamientos de los individuos sin que realicen, evidentemente un intercambio con los autores de la transformación. El efecto y no la relación, es lo que interesa. Un caso interesante es el ejercicio de poder mediante el control de individuos. A través de movilizar individuos, se crean efectos en otros individuos que de otro modo no ocurrirían. Las manifestaciones, los plantones, la presencia policiaca, el acomodo de jugadores en las canchas deportivas, son ejemplos de cómo se puede ejercer el poder controlando individuos. ${ }^{42}$ En resumen, el control implica

\footnotetext{
${ }^{42}$ Para Richard Adams, control es el proceso físico y energético de manipular los elementos del medio ambiente. Mediante el control de tales elementos es que se ejerce poder, ese sí, sobre las personas (Adams, 1978: 22). La diferencia central entre control y poder estriba en la capacidad de razonamiento del "objeto" intervenido: "El poder a diferencia del control, presupone que el objeto posee capacidad de razonamiento y las suficientes dotes humanas para percibir y conocer. Sólo puede ejercerse poder cuando el objeto es capaz de decidir por sí mismo que le conviene" (ibid: 23). Esta diferenciación entre poder y control basada en razonamiento del individuo para actuar, de acuerdo con lo que aquí llamamos la orden, ignora que en múltiples ocasiones los efectos del ejercicio de poder, aparecen al margen del razonamiento del actor. Por ello se quiso mencionar a Bachrach y Baratz con su segunda faceta del poder: aquella que menciona la disuasión de conductas; y a Lukes y la tercera faceta del poder: aquella en la que se evita siquiera, que se formen conceptualizaciones sobre un tema. La presencia selectiva o ausencia de ciertos elementos, impide el razonamiento sobre los mismos; con ello se ejerce el poder exitosamente. En las situaciones cotidianas del ejercicio del poder existen múltiples casos en los que el razonamiento del actor es irrelevante. Al controlar elementos del medio como dice Adams, se evita la producción de conductas o conceptualizaciones deseadas; la efectividad del ejercicio deriva en esos casos, de la evitación que supone la orden, independientemente de los cálculos racionales (o emocionales) del actor. La censura selectiva, por ejemplo, impide no la indignación en aquellos que se dan cuenta del hecho, sino simplemente, la formación de un juicio sobre aquella parte eliminada. La desaparición "misteriosa" de
} 
la búsqueda de efectos sin culminar un proceso de dar y recibir. Se centra en el efecto y no en la relación. Utiliza o no las relaciones existentes, pero no las produce, pues busca satisfacer sólo los intereses del ego y no los del alter.

Finalmente está la violencia. El ejercicio de poder mediante la producción de un daño real o simbólico sobre los elementos que posee, que interesan al actor o sobre el actor mismo, es un medio costoso socialmente, pero efectivo para quien lo utiliza. La característica principal de la violencia como forma de poder, estriba en que se le emplea de manera intencional y premeditada, con el objetivo de producir, igual que con los otros medios, algo que de otro modo los actores no harían. Resulta desde luego problemática en términos éticos, la discusión sobre la pertinencia social o individual de la aplicación de la violencia; no así la descripción de su uso frecuente o su efectividad. Aquí se considera la violencia, como la define Emmanuel Marx, desde el punto de vista de su uso "... racional y de una manera premeditada y controlada, como un medio extremo pero a menudo efectivo para alcanzar un objetivo social" (Marx, 1976: 2). Con ello se equipara en tratamiento a los medios anteriores. Es básico diferenciarla de las formas anteriores, sobre todo de la forma control. No es violencia la amenaza de su producción, sino el efecto ocasionado por su aplicación. Las conductas o conceptualizaciones ocasionadas deben ser consecuencias posteriores a la aplicación. Si bien el actor puede sentirse "dañado" por una amenaza, no es la presunción del daño, sino el daño efectivo lo que conlleva este medio.

Referí, que el daño puede ser real o simbólico, pues lo que el actor es o posee, no siempre es de carácter físico. Más aun, muchas propiedades asociadas a los elementos físicos del entorno, son también, simbólicas. Por ejemplo, el daño parcial o destrucción total de los bienes materiales de un actor, puede impulsarlo para actuar en la dirección que el superordinado planeó. Este tipo de daño físico difiere del que puede ser simbólico, por ejemplo, a través del contacto del elemento con substancias contaminantes. Las maldiciones, los hechizos, el "mal de ojo", la difamación o cualquier otra forma de pronunciamiento que por el solo hecho de ocurrir, constituye un daño. Desde luego, incluye las formas de violencia física, tanto de manera directa, como los dispositivos de control corporal, como el encierro, el control de la sexualidad o el

una bicicleta o del fluido eléctrico, impide no el deseo del niño por ver la televisión o salir a pasear, sino llanamente, la conducta. Así pues, en el planteamiento que utilizo sobre el control, lo considero no como diferente del ejercicio de poder, sino como una forma de ejercerlo, donde lo característico es la manipulación del elemento y no, la presencia o ausencia de reflexión en el actor. 
aislamiento de enfermos y "anormales". ${ }^{43}$ Un caso particular de violencia es el robo, que comprende la apropiación real o simbólica de los bienes de un actor: real, mediante la toma física de los bienes; simbólica, a través del cambio de dueño en los sistemas de sanción de la propiedad (por ejemplo el suelo o los fondos monetarios). Como en los casos anteriores, existe la posibilidad de que las conductas o las conceptualizaciones producidas, ocurran tanto de manera consciente para el actor, pero también sin que éste se dé cuenta de los motivos reales del daño. ${ }^{44}$ La forma violencia es, sin duda, socialmente destructiva. No intenta formar relaciones, sino dañarlas o eliminarlas. De ahí que normativamente, su uso esté severamente vigilado y cuestionado. Y no es para menos. En todo ejercicio de poder mediante la violencia, además del efecto producido y de la satisfacción en el superordinado por la consecución de sus objetivos, queda en el otro actor un daño que no es reparado. Incluso en las intervenciones "moralmente

\footnotetext{
${ }^{43}$ Por supuesto que estas consideraciones derivan de los trabajos de Michel Foucault. "El dominio, la conciencia de su cuerpo no han podido ser adquiridos más que por el efecto de la ocupación del cuerpo por el poder [...] El poder se ha introducido en el cuerpo, se encuentra expuesto en el cuerpo mismo" (Foucault, 1992:104).

${ }^{44} \mathrm{Si}$ se quiere evitar la actuación de una persona, por ejemplo, se le puede encerrar. Es irrelevante lo que piense sobre su encierro; está físicamente impedida para realizar un sin fin de actividades, entre ellas, la que específicamente se eligió. Las penas físicas a la comisión de delitos, tienen este efecto. Así, la idea de que sólo se ejerce poder cuando el actor es capaz de decidir por sí mismo que le conviene, como plantea Adams, no opera aquí. Esto tiene que ver con un debate erróneo (normativo a mi ver) que crea definiciones sobre el poder que se basan en la exclusión de la violencia. La forma en la que se define al individuo y los sistemas de actuar en el contexto de una sociedad determinada, propone formas de actuación de los mismos. Lo que se incluye o se excluye, aporta elementos de una filosofía política. Esto claramente lo expone Foucault al referir el objetivo de sus últimos 20 años de trabajo: "No he estado analizando el fenómeno del poder, ni elaborando los fundamentos de este tipo de análisis. Mi objetivo, en cambio, ha sido crear una historia de los diferentes modos a través de los cuales, en nuestra cultura, los seres humanos se han transformado en sujetos [...] Así que no es el poder, sino el sujeto, el tema general de mi investigación." (Foucault, 2001: 241-2). La diferencia entre Adams y Foucault, es la consciencia en el segundo, que los modos de comprensión del poder tienen como contexto la idea que el hombre tiene de sí; de ahí que excluir formas de poder en donde la opinión del actor es irrelevante, concuerda con ciertas posturas filosóficas. Un ejemplo muy evidente de lo anterior, es la visión de Niklas Luhman sobre el poder, que lo enuncia como basado en la comunicación y en un código compartido. Por tanto, el ejercicio de poder consiste en la información proporcionada a un alter, para crear alternativas probables o improbables de selección, en función de la seguridad que le aporta tal alternativa. No obstante, tal definición elimina de manera implícita a la violencia "La violencia física ejercida intencionalmente contra la gente tiene una conexión con el medio del poder orientado por la acción, en que elimina la acción por medio de la acción y, con esto, excluye una transmisión comunicativa de premisas reducidas de toma de decisiones. Con estas cualidades, la violencia física no puede ser poder..." (Luhman, 1995, 91). Es clara la trampa en la que Luhman se encierra: lo que le interesa (valido desde luego) es el ideal normativo, pero no, la naturaleza de la cosa. Eliminar a la violencia como forma de poder, desconoce los hechos empíricos. Si bien, la violencia constituye la forma socialmente destructiva, no por ello deja de ser, ni teórica, ni metodológica, pero sobre todo, cotidianamente, una forma de producir conductas o conceptualizaciones. Atinadamente, Amara (1998: 336) define a la violencia como un "atajo" para llegar a la posesión o a la posición, sin cuestionar la efectividad que en ocasiones tiene. Es Federico Nietzsche, quien plantea de manera más que certera, el absurdo de evitar caracterizar a la violencia como una forma de poder: "Exigir a la fuerza que no se manifieste como tal, que no sea voluntad de dominar, una red de enemigos, de resistencia y combate es tan insensato como exigir a la debilidad que se manifieste como fuerza" (2001: 37).
} 
buenas", donde la violencia tiene una presunción de legitimidad, como en la violencia ejercida por el Estado, el daño subsiste. Los individuos, difícilmente internalizarán los efectos objetivos de la violencia para avalarlos, por encima de sus percepciones subjetivas Por ello el papel problemático de la violencia en la sociedad. Sin embargo, desconocerla analíticamente como forma de poder, torna su tratamiento y disminución en la sociedad, mucho más complejo y en ocasiones, infructuoso.

Las tres formas anteriores, dado su carácter tipológico, no siempre se presentan en la realidad de manera pura. Frecuentemente aparecen relacionadas entre ellas. Su articulación define lo que se llamó “el triángulo del poder” (Barquín, 2007: 114-16). Tal articulación resulta útil en el abordaje empírico de fenómenos de poder por intercambio, pues aunque este medio es el central, la influencia que los otros dos aportan para la descripción plausible del fenómeno, es esencial. Lo que interesa es conocer: el sistema de clasificación, la transformación de las diferencias en asimetrías, los procedimientos involucrados y los resultados de los intentos por ejercer el poder. En ese condensado proceso, tanto el control como la violencia, pueden acompañar a la forma intercambio, de ahí su necesaria su caracterización.

Como colofón al tratamiento de los medio a través de los que se ejerce el poder, quisiera hacer una brevísima aclaración: se refiere al concepto de autoridad. Existen diferencias de origen entre poder y autoridad. En el caso del poder, están en la naturaleza de la relación entre las partes, pues en los comportamientos causados, resulta irrelevante el tema de la conformidad del subordinado. De hecho, la búsqueda de elementos, materiales, situaciones y características especiales, es la condición necesaria para el ejercicio del poder, y esta búsqueda, emana o inicia en quien intenta ejercer el poder, es decir en el superordinado.

Con la autoridad la situación es en cierta manera la inversa. Dado un estado de una relación social, cuando el actor toma para sí los enunciados del superordinado como norma de comportamiento, se puede hablar de autoridad. ${ }^{45}$ Es precisamente el hecho de la sujeción en cierta manera, autónoma del sujeto a la autoridad, lo que caracteriza el fenómeno. Hay una gran aceptación sobre esta idea (Stoppino, 2002b; Swartz, Turner y Tuden, 1994: 106-12; Claessen, 1979: 7 y ss; Gallino, 1995). Max Weber es una de las fuentes principales al respecto. Caracterizando la autoridad como dominación, refiere que fundamentalmente descansa: “...en un estado de cosas por el cual una voluntad

\footnotetext{
${ }^{45}$ Esto de acuerdo con la definición de Charles Lindblom (1991: 66).
} 
manifiesta (mandato) del dominador o dominadores influye en los actos de otros (del dominado o de los dominados) de tal suerte que en un grado socialmente relevante estos actos tienen lugar como si los dominados hubieran adoptado por sí mismos y como máxima de su obrar el contenido del mandato" (Weber, 1964: 699). Por tanto, es central el hecho de la voluntad en el funcionamiento de la autoridad. En cierto modo, la autoridad es una concesión o dadiva del dominado, pues si no está interesado en obedecer bajo este modelo, tal autoridad no descansa en ningún otro apoyo extra. "Un determinado mínimo de voluntad de obediencia, o sea de interés (externo o interno) en obedecer, es esencial en toda relación auténtica de autoridad" (ibid: 170). Así, el sustento de la autoridad, mana o inicia en el subordinado de manera endógena, lo contrario de los fenómenos de poder. Por ello, poder y autoridad no son la misma cosa y en consecuencia, se mantendrá la distinción. ${ }^{46}$

Vale la pena aclarar, que una cosa es el estudio de los fenómenos de poder y otra, el estudio de los fenómenos políticos. Tanto autoridad como poder, permiten y definen la producción de acciones y conceptualizaciones en los colectivos, de ahí que en términos humanos, se busque de manera focal concentrar ambos mecanismos, ya sea para la dirección de individuos o de comunidades hacia un objetivo definido. Lo central en este caso de lo político, es el objetivo y no el mecanismo, de ahí que en la acción cotidiana, aparezcan de manera combinada y en ocasiones, indiscernible. No obstante, como se aclaró, analíticamente no son iguales. La confusión surge, de que conviven y se potencian complementariamente de manera sorprendente. "Tener" autoridad, constituye una diferencia clasificatoria inicial, que llevada al terreno de las asimetrías, permite el acceso a los medios del poder, de tal suerte que cuando la autoridad falle, el ejercicio del poder suple la falta de autoridad. De manera inversa, el ejercicio de poder con beneficios al subordinado o el ejercicio por un periodo sostenido de tiempo (y su internalización como "costumbre"), detona la aparición de cierta autoridad, que permite

\footnotetext{
${ }^{46}$ Dos concentrados importantes de esta opinión, se encuentran en Gallino (1995) y en Stopinno (2002b). El primero asevera tajante: "La autoridad no debe confundirse con un tipo de poder [...] de hecho se pueden observar formas de autoridad sin poder así como formas de poder carentes de autoridad" (Gallino, 1995: 70).
} 
en múltiple casos, prescindir del mecanismo diferencia-asimetría que caracteriza el proceso de poder.

En términos analíticos es irrelevante clasificar un proceso como mejor y otro como indeseable. En términos de Filosofía y Teoría Política sí existe diferencia, pues las formas sobre las que se estructura inicialmente la vida de una comunidad, sí tienen impacto sobre la legitimidad del sistema de control social. Los límites al ejercicio del poder o la autoridad son de la mayor relevancia para una comunidad. Una "autoridad" puede ser recompensada con la atribución de ciertos medios para ejercer el poder. Para las sociedades contemporáneas, el ejercicio social del poder sin autoridad, aunque sea socialmente benéfico, arranca como ilegítimo. Pero independientemente del inicio, el caso es que su confluencia, puede ir aumentando la posibilidad de impacto social, de manera cada vez más potente, al grado que ocurra un uso descontrolado de poder y autoridad; lo que se conoce como "uso extendido". 47

En el caso de las políticas de educación intercultural, hay una convivencia orgánica -como en toda política-, entre la autoridad que tiene la dupla Estado-Gobierno y los medios específicos para detonar efectos sociales vía el ejercicio del poder. Uno está enmarcado en el otro. En mi planteamiento base, el foco está en los efectos concretos que se dan en la apropiación de los bienes que aporta la política, que sin embargo, están encuadrados en la legitimidad de la autoridad del orden estatal. No obstante, puede ocurrir que subjetivamente, los individuos rechacen la autoridad y únicamente operen de manera convergente, motivados por los fenómenos de apropiación. Es una tensión constante, el debilitamiento de la autoridad del Estado, sobre todo por su origen remoto con relación a la población indígena, es decir: la conquista española de los territorios y las comunidades de los pueblos originarios. En este caso, los indígenas tienden a conceptualizarlo como ejercicio inicial de poder; a contrapelo, el orden criollo-mestizo se asume como legítimo por su aparición mediante un proceso constitucional legal. Esta disputa se seguirá en el estudio del caso, al ver las atribuciones subjetivas a las conductas o conceptualizaciones de apropiación. Ahí, la diferencia entre poder y autoridad es clara, aunque, no necesariamente atinada.

\footnotetext{
${ }^{47}$ Originada la autoridad, constantemente se presenta el riesgo de que al ser ejercida, rebase lo que se tiene aceptado por norma. Es lo que Lindblom llama el 'uso extendido' y es un fenómeno constitutivo de la autoridad, pues una de sus características fundamentales, es la ausencia de evaluaciones racionales $<<$ cada vez〉> que se usa y por tanto, se ejercerá en casos no contemplados. Estos casos pueden ser útiles socialmente o no. Sobre todo la disyunción deriva de que la autoridad mana de un ente individual que se confronta a una colectividad de opiniones; la pugna es pues, constitutiva (Lindblom, 1977: 24-5).
} 


\section{Los principios básicos}

Se han delineado hasta aquí, algunos conceptos y herramientas para el tratamiento de los intercambios, cuya consecuencia es la producción de conductas o conceptualizaciones en uno de los miembros de la relación. Es necesario, no obstante, señalar por qué la centralidad del intercambio permite comprender de manera amplia fenómenos empíricos, cuya densidad rebasa ese solo hecho. Desde la perspectiva antropológica, el fenómeno del don es central, sin embargo, a pesar de la importancia teórica e histórica que dicho concepto encierra, quiero aclarar que no se consideran "don" e "intercambio" fenómenos iguales. La categoría intercambio permite abordar un numero inmenso de fenómenos en los que lo central resulta la relación existente entre dos actores que se aportan de manera mutua, simultánea o diferida, algún elemento posible de ser transferido. De inicio, no son relevantes ni las motivaciones, ni los efectos de tal cambio; lo central es el hecho mismo. Dependiendo de la perspectiva disciplinar, será el tratamiento del fenómeno. En el don esto es diferente. Contempla una forma particular de intercambio, que analíticamente arranca con el don, es decir cuando el actor da algo. Las consecuencias se describen a partir de ello. El tratamiento es mucho más particular, pues el don no se aborda como fenómeno general, sin contexto, sino como una práctica cultural especifica. Es pues evidente, que intercambio y don no son lo mismo. Sin embargo, los trabajos sobre la mecánica de los dones, han producido un cuerpo fundamental para abordar los hechos del intercambio. Hay una larga tradición sobre ello y tomaremos como base analítica ese potente conjunto de ideas. Desde luego que la referencia disciplinar procede de la Antropología y el ejemplo seminal, de Marcel Mauss.

El ensayo que sobre la lógica de los dones, publicó hacia 1924, ha sido fuente inagotable de inspiración teórica y discusiones de todo tipo, acerca del buen tino en la explicación del fenómeno que implica el dar-recibir-devolver y también, en torno a los errores de método y explicación sobre el abundante material etnográfico utilizado. La perspectiva que hemos visto a lo largo de este trabajo, tiene una deuda de origen con el artículo de Mauss. El interés por esa óptica me llevo a seguir una línea conceptual que enlaza trabajos notables y de gran influencia en el campo antropológico. Todos ellos se inspiran en lo argumentado por Mauss; también, rectifican o disienten en puntos 
substanciales. Y el avance se dio ahí mismo donde la senda del francés se detuvo. Aquí se pretende aprovechar partes de esa discusión para enriquecer un fenómeno particular, que se enlaza con esa gran tradición a causa de los intercambios que producen conductas o conceptualizaciones de manera intencional.

Lo central que se retoma de Mauss, es la perspectiva "ampliada" que presentó sobre los intercambios. No es una simple transacción comercial o una dadiva lo que ocurre cuando dos personas interactúan mediante dones. La densidad del fenómeno es de tal magnitud, que se puede describir como un hecho social total, que en cierta medida, pone en juego a toda la sociedad y sus instituciones (Mauss, 1971b: 258-9). Esta es desde luego la idea más polémica y criticada de Mauss (Allen, 2000: 343), no obstante, la asume como un eje rector. "En este fenómeno social $<<$ total $>>$, como proponemos denominarlo, se expresan a la vez y de golpe todo tipo de instituciones: las religiosas, jurídicas, morales -en éstas tanto las políticas como las familiares- y económicas, las cuales adoptan formas especiales de producción y consumo, o mejor de prestación y distribución..." (Mauss, 1971b: 157). Esta perspectiva ampliada, total, permite incorporara a la mecánica de los intercambios, elementos tanto homogéneos como heterogéneos. "Estas instituciones sirven para expresar un hecho, un régimen social, una determinada mentalidad. La de que todo, alimentos, mujeres, niños, bienes, talismanes, tierra, trabajo, servicios, oficios sacerdotales y rangos son materia de transmisión y rendición" (ibid: 170-1). Este es el punto central que interesa del trabajo de este antropólogo francés: los intercambios expresan algo más que la transacción empírica y subjetiva. La lectura atenta del fenómeno, pone en evidencia consecuencias de orden más profundo. No estoy de acuerdo con Robert Lowie que plantea que la perspectiva ampliada de los hechos económicos que presenta Mauss y que profundiza en campos como el social, religioso o estético, era ya común en otros autores y su valor, estriba en estar muy bien "ilustrado" (Lowie, 1946: 264).

Mauss trata de desentrañar la lógica, y si se quiere, la esencia de los intercambios en la vida social, más allá del ámbito económico. No es como Lowie dice una mera ampliación de la visión económica a otros campos. Es un esfuerzo por trascender las herramientas de la economía, al colocarlas en el estudio, con mismo nivel que otras perspectivas; como Weber argumentaba, encontrar las determinaciones no económicas de lo económico . Este cambio epistemológico y si se quiere paradigmático, fue lo que llevo a Claude Lévi-Strauss a aseverar que: 
Mauss parece, y con razón, estar dominado por una certeza de orden lógico, la de que el cambio es el denominador común de un gran número de actividades sociales, aparentemente heterogéneas entre ellas, aunque este cambio no llega a encontrarlo en los hechos [...] El único medio de superar el dilema habría consistido en darse cuenta que es el cambio lo que constituye el fenómeno primitivo y no las operaciones concretas en que la vida social lo descompone (1979: $32-3)^{48}$

Tampoco Lévi-Strauss ve en el trabajo del don, una simple ampliación o enriquecimiento de la perspectiva económica de los intercambios. Enuncia que la conceptualización como origen y motor de la vida social, fue el paso no dado, aunque si anunciado, por Marcel Mauss. Es la relación del cambio con todas las instituciones y con todos los elementos que enunció, y la supremacía del intercambio en sí mismo sobre visiones disciplinares específicas, lo que a mi ver constituye la gran valía del trabajo de Mauss. Permite eliminar, para el caso de los fenómenos de poder que ocurren mediante intercambios, la rectoría de la visión económica. Como dice Lévi-Strauss, el cambio es tan determinante por él mismo, como para pensarlo "el fenómeno primitivo". 49

Ahora bien, existen ciertas reservas sobre los argumentos planteados por Mauss. La primera, se refiere al hecho de que en el tema del poder por intercambio, no estoy interesado por el "hecho social total" como metodología; únicamente con su espíritu. Aquel que invita a pensar los fenómenos de intercambio como involucrados con un gran conjunto de instituciones sociales. Desde luego que la focalización en los hechos de poder, acota ya de inicio, la amplitud anunciada por Mauss. No obstante, el espíritu relativo a la densidad del fenómeno, incita a buscar las demás determinaciones del entorno; en nuestro caso, la lógica que fundamenta los sistemas de clasificación que permiten el surgimiento de asimetrías y el consecuente ejercicio de poder. Como atinadamente advierte Maurice Godelier: “...el análisis de un don, sea cual fuere, exige siempre tener en cuenta la relación existente entre el que da y el que recibe antes de que el primero done al segundo" (1998: 27).

Respecto a la idea de hau o mana como las esencias que iniciaban y obligaban el proceso de don/contradón, no tengo ninguna observación, pues como aclaré de inicio, no existe ningún interés en explicar las condiciones de intercambio-poder en el inicio de la humanidad, más aún porque critique la idea del poder como una "esencia” que está en

\footnotetext{
${ }^{48}$ El subrayado es mío.

${ }^{49}$ Pierre Clastres valida: "El hombre es un animal político, la sociedad no se reduce a la suma de sus individuos, y la diferencia entre la adición que ella no es y el sistema que la define consiste en el intercambio y la reciprocidad mediante la cual están ligados los hombres (1978: 114).
} 
el actor identificado subjetivamente como "poderoso"; simplemente se trata de aprovechar las herramientas derivadas de esas reflexiones. Adicionalmente, porque esa esencia mística, derivó de una mala traducción-interpretación de los juicios del famoso informante Tamati Rainapiri, como Sahlins puso en evidencia en "El espíritu del don" (1983).

El otro aspecto que inquieta es, paradójicamente, el político. Mauss culmina el ensayo refiriendo que su estudio es del tipo de los que permiten entender la dirección consiente de la sociedad en el sentido socrático del término política. Lo cierto es que poco se interesa de las causas y efectos políticos en términos modernos. Es decir, que el aspecto obligado e interesado que asigna al fenómeno, no aborda las dinámicas propiamente políticas y parte substancial de los hechos sociales, a saber, la competencia entre intereses diferenciados y la búsqueda porqué prevalezcan, en el contexto de los valores fundamentales de una sociedad. Si bien refiere que la autoridad emana de las diferencias en lo dado/devuelto, no explica en ningún momento tal dinámica, es decir, cómo se ejerce tal autoridad o para qué, en relación al intercambio. Más notable aun, es el hecho de que no todos los elementos intercambiados tienen el mismo efecto político: coloca personas, rangos, trabajo y servicios, al mismo nivel que alimentos, tierra o bienes. Los segundos, no “contienen” acción social, los primeros sí. El hecho de que en los cambios y su devolución, los individuos mismos, deban desempeñar acciones o conceptualizaciones de manera socialmente obligada, define lo que las relaciones de poder comportan. Si en un cambio de acciones por bienes, se está obligado devolver más que lo que se recibió ¿no se observa una relación de poder? ¿Cómo se determinan las acciones específicas de devolución? ¿Cuál es el interés de dar para que las acciones de devolución sean unas y no otras? En las sociedades que Mauss describe, los intereses individuales no son los predominantes, pero ante la novedad de las circunstancias de la vida, siempre se deben tomar decisiones y los intercambios que implican acción social, necesariamente entrañan una oportunidad para definir un rumbo social. ¿Por qué Mauss se sustrae de esas problemáticas de la política, que ocasionan conflictos y lucha?: por su formación de origen. La influencia del pensamiento de Emile Durkheim en su obra es determinante (Lowie, 1946: 259). La centralidad en el estudio de la armonía social y la tipificación de los conflictos como "anomia", lo determinaban a evadir estos temas. Como bien refiere Héctor Tejera: "La principal preocupación de la sociología durkhemiana se inscribe en la dimensión ideológica burguesa del mantenimiento del 
orden social" (1996: 32). ${ }^{50}$ De ahí que inicie el apartado de conclusiones con referencias "morales", prescribiendo la construcción de una nueva moral mediante la cual se recupere el placer de dar en público y eliminar el egoísmo y el riesgo de guerra (Mauss, 1971b: 246-52). Así pues, la influencia de Mauss en torno a los intercambios es determinante, sin embargo, la no consideración de los fenómenos políticos en su aspecto cotidiano, determinó que no abordara las consecuencias que en la conducción del orden social, producen los intercambios asimétricos. La visión que se presentó aquí, busca rescatar de la obra de Mauss tales aspectos, un tanto en el espíritu de Singh Uberoi quien hablando del kula, lo reconoce como un sistema de intercambio, pero también, como un modelo de organización política (1971: xiii).

Se adelantó: la consecuencia en Lévi-Strauss del trabajo del don, fue llevarlo a postular el intercambio, no como un hecho principal, sino como el hecho de la vida social. Este cambio lo centralizó en bienes, mujeres y símbolos. Estos elementos, circularían de manera diferente que en el dominio de la naturaleza donde solo se da lo que se recibe, "En el dominio de la cultura, por lo contrario, el individuo recibe siempre más de lo que da y al mismo tiempo, da más de lo que recibe" (Lévi-Strauss, 1969: 66). Con lo anterior, se refiere al hecho peculiar de la influencia de la cultura en los intercambios, en la que intervienen los contenidos simbólicos, de tal suerte que la definición del valor de lo cambiado, siempre está sujeto a valoraciones contextuales que no son simplemente mecánicas. ${ }^{51}$

\footnotetext{
${ }^{50}$ También Giddens (1997: 118-19) anota la centralidad de Durkheim en las fuerzas de cohesión y orden social antes que la capacidad individual de influir causalmente en los fenómenos. Más aun, que destaca a las ideas morales como la fuente de la conducta intencional.

${ }^{51}$ Desde la perspectiva ampliada con que se tratan los intercambios, el tema del valor es central. Para fijar el valor de los elementos en una transacción de tipo mercantil, se da la determinación (aproximada) del precio absoluto y de ahí se derivan los precios relativos. En las interacciones donde se ejerce poder, no siempre es determinante la idea del valor absoluto, incluso, la de valor relativo. Lo anterior debido a que las peculiaridades en las que se contextualiza la interacción, definen que la asimetría que fundamenta el ejercicio del poder, no necesariamente se encuentre en el valor de los objetos cambiados. Como se comentó arriba: los intercambios o instauran asimetrías o las expresan, por tanto, no siempre el valor de lo cambiado es lo substancial. Por ello la visión antropológica enriquece, mejor aún, transforma de manera importante las posibilidades explicativas y comprensivas del fenómeno. El trabajo Simbolismos del dinero de Juan Castaingts (2002) explora en el capítulo tres, justo, problemas de ese orden. Resume en un cuadro sinóptico de manera efectiva, las relaciones de tipo paradigmático y sintagmático que definen o afectan las configuraciones del valor y que concentran todo el complejo cultural en el que se desarrollan los intercambios (pág. 124).
} 
Del intercambio, es el de mujeres el que le más le interesa, sin embargo lo aborda desde una perspectiva muy particular y que constituye una de las grandes aportaciones de su trabajo: la prohibición del incesto. Realiza un trabajo muy intenso de reflexión sobre la lógica de las reglas del parentesco culminando, en el caso del incesto, con aseveraciones sorprendentes:

Considerada como interdicción la prohibición del incesto se limita a afirmar, en un campo esencial para la supervivencia del grupo, el predominio de lo social sobre lo natural, de lo colectivo sobre lo individual, de la organización sobre lo arbitrario. Pero incluso en este momento de análisis, la regla, al aparecer negativa, ya engendra su opuesto, ya que toda prohibición es, al mismo tiempo y con otra relación, una prescripción (1969: 82)

La prohibición del incesto no sólo es, como se sugirió en el capítulo precedente, una prohibición, ya que al mismo tiempo que prohíbe, ordena. La prohibición del incesto, como la exogamia, que es su expresión social ampliada, constituye una regla de reciprocidad (ibid: 89)

El contenido de la prohibición no se agota en el hecho de la prohibición; ésta se instaura sólo para garantizar y fundar, en forma directa o indirecta, inmediata o mediata, un intercambio (ibid: 90$)^{52}$

El sentido de este conjunto de razonamientos es muy claro. Para Lévi-Strauss, la esencia de una prohibición no es únicamente, la delimitación de lo que no se debe o puede hacer. Aparejada a la prohibición, se abre un campo específico de posibilidades dentro del mismo ámbito de operatividad de la regla: la definición de ciertas mujeres como prohibidas, exhibe a las demás como posibles; de ahí que también prescriba. Pero además, al definir mujeres posibles y no posibles, el tabú instaura obligadamente una regla de reciprocidad, pues se obliga a dar y aceptar con direcciones específicas, tanto al interior del grupo, como hacia afuera. Por ello uno de los núcleos de su trabajo en Las estructuras elementales del parentesco, es la certeza de que el intercambio constituye la esencia misma del proceso social y de ahí que el tabú del incesto, una regla, tenga como fin, estructurarlo.

Las consecuencias políticas del argumento y su utilidad aquí, saltan a la vista, pues enlazan prohibición y prescripción, intercambio y alianza. En el abordaje de los fenómenos de poder mediante intercambio, aparecen también los mismo aspecto, sin embargo, si usamos los términos de Lévi-Strauss, tendríamos que invertir el proceso. En el inicio, analíticamente, no aparece la obligación social, como prescripción o proscripción, sino la propuesta de intercambio, que como consecuencia de la toma de lo

\footnotetext{
52 Todos los subrayados son míos.
} 
ofrecido, deriva en un conjunto de conductas o conceptualizaciones de apropiación, al final, que son obligatorias. Esta "puesta de cabeza", no pretende enmendar los resultados del trabajo de Lévi-Strauss. Es producto de las necesidades del tema de poder. La intención de un actor por causar acciones en otros actores, que de otro modo no harían, surge de los medios que pone en movimiento para lograr su objetivo. Lo que constituye un aporte central de Lévi-Strauss al tema, es la transformación de la óptica sobre el hecho de las obligaciones en sociedad. No constituyen una simple obligación o prohibición, se inscriben en un ámbito mayor en donde la obligación tiene sus complementarios y está ubicada en un proceso general de intercambio y relaciones sociales. Así, en el análisis de los fenómenos de poder mediante intercambio, importa conocer no únicamente los elementos intercambiados y la orden que los enlaza, sino, el contexto más amplio en donde tales intercambios ocurren, ahora sí, para saber cuáles son los sistemas de prescripciones o prohibiciones en los que se da tal intercambio. Vale la pena recordar, que no existe ningún interés particular en encontrar la determinación en última instancia, del proceso social real donde se ubica el fenómeno empírico de estudio; si fue primero la prohibición o el intercambio. Se tienen intercambios y reglas sociales que los enmarcan; de ahí se parte. Y el autor da una pauta para seguir tal proceso:

Las mercaderías no sólo son bienes económicos sino, vehículos e instrumentos de realidades de otro orden: potencia, poder, simpatía, status, emoción; y el juego sabio de los intercambios (en los que, a menudo, no hay más transferencia real de la que se encuentra entre los jugadores de ajedrez, al avanzar las piezas alternativamente sobre el tablero, únicamente con la intención de provocar una respuesta) consiste en un conjunto complejo de maniobras conscientes e inconscientes, para ganar seguridades y precaverse contra riesgos, en el doble terreno de las alianzas y las rivalidades (Lévi-Strauss, 1969: 93)

Es claro que nuestro autor, evitó a lo largo de su vida profundizar en la mecánica explícita de la política. Aquí, sin embargo, da una pista sobre algunos aspectos de ese mundo y de manera específica, sobre los efectos políticos de los intercambios; es lo que se buscaba rescatar. Más aun, en unos breves párrafos del capítulo IV de Las Estructuras, reflexiona sobre las consecuencias del monopolio de los ancianos sobre la distribución de mujeres y en particular sobre la posibilidad de éstos para acceder a la poligamia. Refiere que comprometer el equilibrio demográfico al

\footnotetext{
${ }^{53}$ El subrayado es mío.
} 
interior de una banda, tiene cierta lógica en el contexto de "las pesadas responsabilidades que tiene el jefe", imposibles de cumplir sin el auxilio de varias compañeras: "La pluralidad de las mujeres es, pues, a la vez la recompensa del poder y su instrumento" (Lévi-Strauss, 1969: 81). Es notable la declaración, pues en el espíritu de esa obra, el autor implica que el germen de los fenómenos de poder en la humanidad, deriva del control de las mujeres. Desde nuestra posición, llama la atención la nula reflexión sobre el hecho de que "tomar" mujeres desemboca en obligaciones sociales a cumplir, es decir en conductas de apropiación. Si bien para Lévi-Strauss lo relevante es el control de las mujeres y no su toma, destaca el nexo entre poder, intercambio y acción social, pues como un todo, el grupo no es víctima de un "atesorador" de mujeres, sino que en el intercambio obligado que el tabú define, se le dan más mujeres a aquellos que tienen tareas importantes para la existencia del grupo.

Retomé entonces todos esos argumentos, pues enlazan este capítulo con el primero, en donde se postuló la importancia de los sistemas de clasificación para ubicar el aspecto asimétrico de las relaciones de poder. Las "realidades de otro orden" que interesa destacar, son las lógicas de clasificación de los elementos intercambiados, que contienen algo más que el simple valor material. De ahí que las maniobras conscientes a las que hace referencia el autor, necesariamente consideren esas realidades de otro orden. Por ello la utilidad de los argumentos de Lévi-Strauss: enlazan el intercambio y los efectos sociales obligados, con la riqueza simbólica que portan los elementos intercambiados. Las críticas al autor, sobre la exclusividad del intercambio como la operación fundamental de la vida social (Clastres, 2004) o sobre la primacía de lo simbólico sobre los demás hechos del mundo (Godelier, 1990; 1998) son atinadas; no anulan, sin embargo, lo valido de los argumentos escogidos para la delimitación de los fenómenos de poder mediante el intercambio. ${ }^{54}$

Maurice Godelier constituye el tercer eslabón de esta cadena temática, pues considera el hecho del don un enigma a resolver. Lo central de su tesis, reside en indagar no sólo por qué se devuelve, sino por qué se da; cómo son las relaciones sociales involucradas en el

\footnotetext{
${ }^{54} \mathrm{El}$ argumento poco usual de Clastres sobre el papel de la guerra en las sociedades primitivas, ataca de manera frontal el de Lévi-Strauss, de ser la guerra una forma de intercambio frustrado. Para Clastres no hay duda: "...la guerra es una estructura de la sociedad primitiva, no el fracaso accidental de un intercambio malogrado" (2004: 55).
} 
proceso; y cómo son las motivaciones individuales. Declara que su inquietud inicial, surgió de la característica del don de funcionar para compartir y para combatir, asimismo, que en sus estudios previos en Guinea, comprobó que el poder de los grandes hombre no provenía de la acumulación de bienes o su repartición, sino de la posesión de objetos sagrados; por tanto, le intrigaba conciliar estos dos hechos (Godelier, 1998: 1820). ${ }^{55}$

Concuerda con Mauss que el proceso de don/contradón genera relaciones de solidaridad, derivadas de la disposición de las partes a dar lo que tienen y al mismo tiempo, relaciones de superioridad que provienen de la deuda instaurada y la obligación de devolver, y en un segundo momento, por la devolución mayor al bien recibido: “Así pues, donar parece instaurar una diferencia y una desigualdad de estatus entre donante y donatario, una desigualdad que en ciertas circunstancias puede transformarse en jerarquía" (ibid: 24-6). ${ }^{56}$ Esta superioridad instaurada ocasiona que el proceso del don contenga aspectos políticos, en los cuales la diferencia que surge de tener y no tener, dar y recibir, se transforma en asimetría que faculta, como hemos visto, el ejercicio de poder. Es de notar que el trabajo de Godelier, se centra en el intercambio de mujeres o de objetos relacionados con lo sagrado. Así las asimetrías instauradas, quedan en su tratamiento, atadas fundamentalmente al parentesco y lo religioso. Le ocurre igual que a Mauss, quien aseguran que los intercambios son de muchos elementos, entre ellos las actividades; ninguno repara que hay necesariamente una gran diferencia en el intercambio de actividades y lo demás. En términos de procedimiento, los intercambios de elementos cualesquiera por una actividad o de actividades entre sí, son de un orden cualitativamente diferente. Los otros elementos que listan los autores, no conducen por si mismos la acción social, salvo el mero hecho del intercambio. Lo que cambia de condición es el elemento transferido, ya sea en términos de localización, estatus, propiedad o clasificación, por ejemplo. En contraposición, los intercambios que

\footnotetext{
${ }^{55}$ Quiero hacer notar, que en términos de teoría política, Godelier parece hablar la mayor parte de su obra de autoridad y no de poder. Es importante destacar este hecho, que aclaré anteriormente, pues Godelier parece confundirlos o por lo menos, no hace un intento por demarcarlos. Para él, lo sagrado "tiene" tal poder, que por su sola sacralidad se torna irresistible a los hombres; lo que deviene en un tratamiento substancialista del fenómeno. O en su defecto, deviene en autoridad pura, pues las conductas ocurren, como dice Weber, ocasionadas por la voluntad del subordinado en reconocer en el poseedor, una conexión con el objeto sagrado. Lo anterior, aporta legitimidad para enunciar deseos que el subordinado internaliza para sí, a causa del nexo que ambos comparten con el objeto sagrado. Lo que rescataré de su obra, son los efectos que el intercambio tiene sobre conductas o conceptualizaciones y no, la esencia en la que descansa el poder -lo sagrado-, pues desde el inicio de este trabajo, aclaré mi rechazo por encontrar el origen del poder o la autoridad.

${ }^{56}$ El subrayado es mío.
} 
involucran actividades, son acción social misma, por eso el interés de aprovechar los análisis sobre el don, pero caracterizarlo cuando tiene consecuencias en la acción social; de ahí el concepto de conductas de apropiación. Vale algo parecido para lo que se llamó conceptualizaciones de apropiación, pues aunque el tema es tratado en términos del efecto que el intercambio tiene para el mundo de las ideas, no aborda el aspecto de la intencionalidad sobre tales conceptualizaciones y menos aún, el efecto de tales conceptualizaciones en la acción social.

La vía que sigue Godelier no incluye reflexiones sobre el hecho, políticamente relevante, en el que se está obligado a realizar acciones por algo que se recibió. Más aun, que con la lógica del don, tales acciones deben contener un poco más que lo recibido. Esta humana forma de cooperación, conocida en México bajo el concepto de "tequio" o "mano vuelta" no es en sí un fenómeno de poder, pero comienza a acercarse a dicha idea, cuando, como dice Mauss, la devolución no es libre sino obligada.

¿Qué aspectos son relevantes para Godelier? Fundamentalmente, que en los fenómenos de intercambio, la representación del valor o esencia de los objetos que circulan, está atado a objetos que no circulan, es decir, “...puntos fijos o realidades sustraídas (provisional pero duraderamente) a los intercambios de dones o a los intercambios mercantiles" (1998: 20). Estos ejes son los objetos sagrados, elementos de la vida grupal que son atesorados por ciertos individuos y que funcionan como representación de toda la comunidad y de la potencia de los seres divinos. Dichos objetos ni deben ni pueden circular, lo único que circula son sus efectos, atados a otro tipo de objetos, los objetos preciosos. Estos, circulan en los intercambios de dones a la manera de substitutos de los sagrados y también, como sustitutos de los individuos que los intercambian (Godelier, 1998: 108-9). La diferencia entre sagrado y precioso estriba en la unicidad del primero, frente a la multiplicidad del segundo. Así, el ayate de la Virgen de Guadalupe es sagrado por su origen divino y por su carácter singular. Las reproducciones de dicha imagen, sólo serán preciosas si existe un proceso de transmisión de ese carácter sagrado, mediante, por ejemplo, la bendición o mejor, el contacto con lo sagrado. En todo caso, lo relevante para lo que aquí se trata es la diferenciación que Godelier hace de los procesos de intercambio: el contrato y la transmisión. "La sociedad humana ha extraído su existencia de dos fuentes: por una parte, el intercambio, el contrato y por la otra la no contractual, la transmisión. La sociedad continua avanzando sobre esas dos bases, apoyándose en esos fundamentos que le son tan necesarios, y que no pueden existir por separado" (1998: 58-9). Aquí se 
acerca el autor a su culminación, pues como argumentó, deben existir puntos fijos que funcionen a manera de valores absolutos, los objetos sagrados, a partir de los cuales los intercambios de objetos cotidianos puedan darse. Los objetos preciosos que "portan" algo de esa condición, sirven como mediadores al aparecerse como sustitutos. De ahí, que pudieran tomar carácter de "moneda", por su doble condición de representar a lo sagrado y a lo humano:

...esa doble naturaleza nos permite comprender por qué esos objetos funcionaban como moneda sin serlo plenamente, así como el hecho de que a menudo se convirtieran en monedas despojándose de una gran parte de sus antiguas funciones y transformaciones en un instrumento impersonal del desarrollo de relaciones mercantiles impersonales, en un instrumento que no circula más que estampillado, acuñado con el sello de la institución que representa a la comunidad como un todo, y que es la fuente de todo poder y de la ley, a saber, el Estado (1998: 109)..$^{57}$

De esta exposición, se sigue que los objetos sagrados son el referente simbólico sobre el que gira toda sociedad y por lo tanto controlarlos, otorga "poderes" a sus poseedores que los distingue de los demás miembros. "Poseer esos objetos significa detentar una parte de los poderes de esos seres más poderosos que el hombre, supone satisfacer un deseo de poder, manifestar una voluntad de controlar las fuerzas que se imponen a los hombres, de actuar sobre el curso de las cosas, sobre el destino (ibid: 250). Esta suerte de "moneda" de poder que se asigna a los objetos sagrados, culmina con la aseveración contundente de Maurice Godelier de que uno de los mecanismos básicos de la sociedad es: "Guardar para (poder) donar y donar par (poder) guardar. Adoptar este doble punto de vista permite, a nuestro entender, captar la verdadera medida del ser social del hombre y de las precondiciones de la sociedad" (Godelier, 1998: 58)..$^{58}$

Del trabajo de Maurice Godelier importa rescatar algunos puntos de vista. Fundamentalmente, la dimensión estratégica que surge en el proceso de los intercambios, es decir, que socialmente, no implica un acto mecánico de cambio o puramente económico. Siguiendo la tradición de Mauss encuentra algo más; ese extra se

\footnotetext{
${ }^{57}$ Hay que hacer notar, la relación que Godelier marca entre tipos de intercambios y formas de relación social. El modelo transaccional de Karl Polanyi, antecede a esa posición al afirmar que la reciprocidad está asociada con relaciones de tipo amistoso, de parentesco, de estatus o jerarquía, mientras que la redistribución, únicamente se asocia a la afiliación de tipo religioso o política; finalmente, las relaciones de mercado, en su estado puro, no contiene ningún otro tipo de relación más que la mercantil misma (Dalton, 1969: xiv).

${ }^{58}$ El subrayado es mío.
} 
ve en el ámbito, a mi parecer, temporal/institucional. Al revisar con cuidado lo que ocurre, Godelier ve tres fenómenos centrales: Primero, que el hecho en sí, no ocurre de un solo golpe, de manera inmediata. Implica un proceso en el que alguien que da, puede haber estado guardando lo que dio o no dar todo y conservar una parte; el que recibe, no recibe el objeto todo y de un golpe, hay partes que tarda en recibir por haber sido guardadas y hay partes que probablemente nunca recibirá expresamente, sólo sus efectos. Esta es la dimensión que expone la diferencia entre contrato y no contrato; cambio y transmisión

El segundo punto se refiere al contexto que encuadra el cambio. Existen valores de referencia que le dan sentido los objetos. En Godelier este mecanismo lo brinda la tercia de objetos sagrados, objetos preciosos y objetos comunes. La posición social que controla esos valores absolutos, está ligada a los guardianes de lo sagrado mediante la transmisión que instituye a los objetos preciosos como moneda de cambio; estos guardianes se introducen "por la puerta de atrás" en los intercambios comunes y corrientes. Por ello la sanción social de los objetos sagrados y todas las ideas y prácticas asociadas al hecho sagrado, aparecen como evidentes. Desde la perspectiva que se ha visto, el sistema de clasificaciones que da origen a los intercambios sociales, se encuentra en la representación de lo divino como valor absoluto y su descenso al mundo de los hombres mediante la transmisión. Son los guardianes de tales objetos sagrados, quienes "detentan" el poder en esa sociedad por el control que ejercen sobre tales objetos. La subordinación de los poseedores al código social que gira en torno a la posesión de tales objetos sagrados es necesaria y constitutiva; de ahí que obedezcan a la tradición y conforme a la tradición, ordenen. ${ }^{59}$

El tercer punto revela la dimensión política del hecho. Heredero de la tradición de Marcel Mauss y Claude Lévi-Strauss, Godelier rompe en un punto significativo: los fenómenos políticos. Se ha puesto en evidencia la refractaria actitud que los dos primeros experimentaban sobre el mundo de la política y los fenómenos de poder asociados constitutivamente a los intercambios; probablemente por convicción, pero es evidente que sí por omisión. En contraposición, Godelier entiende la existencia de tal

\footnotetext{
${ }^{59}$ En los párrafos más conmovedores que he leído de un antropólogo, Maurice Godelier relata la escena en la que un anciano baruya accede a mostrarle, después de varios años de espera, los objetos más sagrados que la tribu posee: los kwaiimantnié. Ante la vista de algunas piedras y huesos, el anciano “...rompió a llorar, silenciosamente, evitando mirar lo que presentaba ante sus ojos. Continuo así durante algunos minutos, cabizbajo, sollozando, con la frente apoyada sobre sus manos que descansaban en el borde de la mesa. A continuación, levantó la cabeza, enjugó sus ojos hinchados, contempló a su hijo y cerró con la misma delicadeza y las mismas precauciones el paquete que luego envolvió con el ypmoulié rojo. Había acabado" (Godelier, 1998: 179-80).
} 
dimensión por su atadura al hecho de dar y guardar, que constituye en gran medida, la lógica profunda de los fenómenos de poder por intercambio. Esta dimensión es imprescindible y la influencia de su trabajo en algunas de las ideas que expongo aquí es determinante. En la tradición del estudio de los dones en particular y los intercambios en general, Godelier marcó un viraje y por ello su trabajo es fundamental.

Pero, ¿realmente aborda la lógica de poder asociada al intercambio? Mi opinión es que no. Para empezar, ignora de manera significativa los efectos que sobre la conducta tienen los intercambios. Si las actividades son una de las cosas que son factibles de "dar" y "devolver", la intensidad y dirección de tales actividades es algo que merece ser destacado. Estoy cierto que tal problema es un caso particular y no es obligación en el autor. Llama la atención no obstante, que la influencia que a propósito de los intercambios se puede tener en la acción social -y que es mucha-, no merezca en Godelier ninguna reflexión o demarcación. Lo anterior es grave pues uno de sus ejes temáticos en El enigma del don es el poder, sin embargo, sólo se ocupa de la idea del qué, nunca de los cómo o los para qué. Entonces, en el argumento de que la fórmula de lo social es dar y guardar, Godelier sólo se ocupa de lo último: de guardar.

Para que un objeto precioso circule como moneda, es preciso que su valor <<imaginario〉> sea compartido por los miembros de aquellas sociedades que comercian entre sí. Una moneda no puede existir y tener <<curso〉> legal, si no tiene <<fuerza de ley〉>. Y la ley no es un hecho del individuo. Una moneda debe manifestar en sí misma la presencia de los dioses, los símbolos de los dioses deben marcarla, o debe marcarla el sello del Estado, o la efigie de un rey. Incluso hoy en día, el dólar, ese billete verde que es la única moneda conocida y aceptada en todo el mundo, lleva impresa la referencia a Dios, al dios de la Biblia (1998: 239)

Para Godelier, la posesión de una conexión con lo sagrado es la fuente de todo poder y legitimidad; es la fuente primaria del orden social. Todo aquel que gobierne o ha gobernado, necesariamente tiene que tener conexión con lo sagrado, creando un código en el que la diferencia sagrado/profano es la fons et origo de toda clasificación; chocando con Turner quien la veía en los líquidos corporales, con Mary Douglas y su división puro/impuro o con Mauss y Durkheim que lo derivaban de los cuadros de la sociedad misma. Para Godelier, sí se puede "tener el poder"; basta con controlar los objetos que para una sociedad son sagrados. De hecho, afirma que ese aspecto de su análisis sobre los baruya “...es válido para todas las sociedades humanas” (1998: 178), refiriéndose al nexo entre poder social y el mundo de lo sagrado. Pues para que ciertas relaciones sociales se reproduzcan, tienen que estar “...cargadas de legitimidad, como 
las únicas relaciones posibles, y semejante evidencia sólo se impone plenamente si estas relaciones parecen tener sus orígenes más allá del mundo humano, en un orden inmutable y sagrado, o mejor aún, inmutable por ser sagrado" (ibidem). ${ }^{60}$ Hay pues, un desplazamiento del mecanismo a la esencia, del proceso al origen, del intercambio al hau. Lo que a Godelier le preocupa, es cómo se fundamentan los punto fijos que dan el control (externo) del intercambio, no cómo es que aparece el control (interno) en el intercambio. Atinadamente, Castaingts (2007a) expresa lo limitado de la focalización de Godelier en lo sagrado: "Es cierto que su análisis sobre los objetos sagrados que no se donan, es importante para comprender muchas facetas del don, pero de ahí no se puede concluir que lo que se dona se explica por la existencia de lo sagrado..." (pág. 9). Asimismo, que la existencia de argumentos de tipo estratégico y táctico rondan los intercambios y por ello, las motivaciones individuales en el proceso son ineludibles; su propuesta de enlazar el enigma del don con el dilema del prisionero es una muestra (pág. 9 y ss).

La posición que Godelier asume aparece pues, no como errónea, pero sí como insuficiente para el estudio de los fenómenos de poder mediante el intercambio. La primera ausencia es, como expuse, la reflexión sobre los efectos que la toma de los elementos tiene sobre las conductas, tanto en términos individuales, como sociales. La segunda reserva, deriva de la incapacidad del modelo de Godelier, para explicar el rechazo a lo sagrado como eje de acción. En el ejercicio del poder, en su obediencia, pero también en la desobediencia, la contextualidad y la polisemia, es decir, lo estratégico de las situaciones y las múltiples facetas de la realidad, presentan vías para que las asimetrías existentes, se reconfiguren, redefinan o resignifiquen: para ejercer el poder o para ignorarlo. ${ }^{61}$ Finalmente, la focalización en las conexiones entre poder y sacralidad, ignora un vasto campo de la acción humana que está sujeto a otras determinaciones que también definen el ejercicio de poder. Sobre todo es errónea la conexión necesaria y suficiente, fundante e ineludible, entre "lo sagrado" y sus efectos en la acción social. De hecho, seguir la propuesta de Godelier hasta sus últimas consecuencias, pondría sobre la mesa un hecho a todas luces inconsistente: el fin de la vida política de las sociedades, pues dado que los poseedores de los objeto sagrados los

\footnotetext{
${ }^{60}$ El subrayado es mío.

${ }^{61}$ James Scott ha trabajado de manera exitosa las situaciones en donde la aceptación de un orden inmutable y sagrado, no es necesariamente determinante de la acción. Su concepto de infrapolítica, atado a la idea de resistencia, pone en evidencia que la aceptación pública de los órdenes inmutables y sagrados, es en muchas ocasiones un acto de conveniencia, que no necesariamente define de manera determinante, las acciones sociales de un sector basto de la población: los dominados (Scott, 2000).
} 
controlan según su visión particular, los colectivos no pueden evadir conducirse de acuerdo a las interpretaciones que sobre el orden sagrado, tiene el poseedor o los poseedores. En ese sentido la cristalización de la vida política, se daría, de acuerdo con Godelier, en marcos de acción <<inmutables por ser sagrados >>.

Es necesario buscar en otra propuesta, las ausencias que las tres anteriores han mostrado. Por ello, falta exponer el efecto de la materialidad misma de lo cambiado, las circunstancias en que ocurre y reflexionar si el orden "dar, recibir, devolver" es el único posible.

En los países en que impera el régimen de producción capitalista, la fuerza de trabajo no se paga nunca hasta que ya ha funcionado durante el plazo señalado en el contrato de compra, v.gr. al final de cada semana. Es decir, que el obrero adelanta en todas partes al capitalista el valor de uso de la fuerza de trabajo y el comprador la consume, la utiliza, antes de habérsela pagado al obrero, siendo, por tanto, éste el que abre crédito al capitalista (Marx, 1999: 127).

Entre derechos iguales y contrarios decide la fuerza. Por eso, en la historia de la producción capitalista, la reglamentación de la jornada de trabajo se nos revela como una lucha que se libra en torno a los límites de la jornada; lucha ventilada entre el capitalista universal, o sea, la clase capitalista, de un lado, y de otro el obrero universal, o sea, la clase obrera (ibid: 180).

Alargando desmedidamente la jornada de trabajo puedes arrancarme en un solo día una cantidad de energía superior a la que yo alcanzo a reponer en tres. Por este camino, lo que tú ganas en trabajo lo pierdo yo en sustancia energética. Una cosa es usar mi fuerza de trabajo y otra muy distinta desfalcarla (ibid: 179$80){ }^{62}$

Las herramientas para el estudio del ejercicio de poder mediante el intercambio, no están atadas, como he aclarado, a ninguna pretensión esencialista, es decir, a definir el origen del fenómeno. Por ello resulta factible enlazar pueblos primitivos con obreros y capitalistas universales, pues lo que interesa, es rescatar las situaciones en las que las diferencias de clasificación, generan asimetrías y que en el proceso de intercambio, definen el poder y su ejercicio.

El acercamiento de Carlos Marx a los fenómenos de intercambio difiere grandemente de aquellos expuestos anteriormente. Es claro que los tres autores anteriores, evitan entrar en las regiones conflictivas de los intercambios; en oposición,

\footnotetext{
${ }^{62}$ Los subrayados en las tres citas son de Carlos Marx.
} 
Marx aborda el conflicto como eje epistemológico, metodológico y político. ${ }^{63} \mathrm{El}$ conflicto, como se expuso arriba, proviene de la batalla resultante del intercambio de salario por trabajo, es decir, de un elemento material por actividad humana. Esta particularidad es la que distingue a Marx de los antropólogos presentados, pues al mirar de cerca el hecho, se enfoca en describir, comprender y explicar, las circunstancias y contradicciones que se dan en esté particular y heterogéneo intercambio. ${ }^{64}$ Dado que el dinero por un lado, y la intensidad, calidad y duración de la actividad humana por el otro, no son equivalentes en todos sus términos todo el tiempo, las tensiones son una consecuencia lógica. Más aún si como expone Marx, hay una batalla de desigualdades, en la que el capitalista intenta, por todos los medios, "extraer" más trabajo, del que en realidad pagó. Pero esta lucha de rendimientos no es pareja. No se asemeja a la mecánica del don, libre y desinteresada, ni tampoco al segundo momento que expuso Mauss, interesada y obligatoria.

La forma de intercambio que presenta Marx, es aquella en la que una de las partes está obligada, no sólo socialmente, sino individualmente, a cambiar su fuerza de trabajo por un salario. Aquel que da primero, el trabajador, no lo hace motu proprio, ni con el deseo de instaurar una superioridad con el donatario; está individual y socialmente determinado, a dar de manera obligatoria y en los términos que define el poseedor del capital. Esta es, a mi ver, la principal utilidad del discurso de Marx en torno a la problemática del don y de los intercambios con poder. Si bien desde Mauss se reconoce la arbitrariedad analítica de estudiar el proceso de intercambio arrancando con el que da, nunca se interesa en el proceso inverso, esto es, que mediado por relaciones de poder, lo que en realidad pasa, es que la devolución va primero que el don. ¿Cómo es que esto ocurre?

Si lo que determina la lógica del don, es la instauración de una alianza y una diferenciación positiva, aquel que da es el que de inicio queda en mejor posición; el que recibe queda en subordinación, obligado a devolver y además, en mayor cuantía, para restaurar la igualdad o invertir el estatus. Desde la lógica marxiana, el que da, está obligado y subordinado de inicio; el que recibe, puede devolver si quiere y como Marx

\footnotetext{
${ }^{63}$ Randall Collins lo coloca como el eje paradigmático de la llamada tradición del conflicto. "Marx es el centro de una tradición que dramatizó el conflicto más que ninguna otra" (1996:53).

${ }^{64}$ Desde la perspectiva marxista, Nicos Poulantzas asevera que a pesar de que no hay un estudio profundo sobre el poder en Marx, Engels, Lenin o Gramsci, se ve en éstos que: "El concepto de poder tiene como constitución el campo de las prácticas de clase [... pues] las relaciones de clase son relaciones de poder" (Poulantzas, 1974: 117). Y desde luego que desde nuestra perspectiva, se desprenden dos hechos: la lógica clasificatoria centrada en las clases, asimétrica siempre; y las conductas obligatorias que supone la transferencia de capital, es decir, el trabajo.
} 
aclara, tiende a hacerlo con menor cuantía, sin pérdida de su estatus, sino contrariamente incrementándolo (esto desde luego, en la lógica capitalista).

Por eso digo que en Marx, la devolución va primero. En términos de la visión liberal, las relaciones de poder por intercambio, se presentan como una relación de intercambio de acciones por recursos, pero tienen un dejo de simultaneidad, de contrato acordado mutuamente, aislado de las condiciones sociohistóricas que paradójicamente, obligan una de las partes a dar sin recibir. "Esto es lo que propone cualquiera que ofrezca a otro un trato. Todo trato es: dame esto que deseo y obtendrás esto otro que deseas tú; y de esta manera conseguimos mutuamente la mayor parte de los bienes que necesitamos" (Smith, 1994: 45-6). Aquí hay un acuerdo que sucede cuando conviene a las partes. Si existiese una diferencia de rendimientos, derivaría del proceso mismo del cambio, ya sea porque a las partes no les importa, ya por que no se den cuenta. El modelo de intercambios comerciales que Adam Smith presenta ocurre de manera cotidiana y no es criticable por sí mismo. Sus preocupaciones son de orden económico y no políticas. Lo presento, como muestra de un intercambio libre e igualitario, donde las partes no están obligadas a cambiar, ni a dar más por menos. Llevada al terreno político y de las relaciones de poder, esta idea de la libre concurrencia y del aislamiento temporal del cambio, resulta limitada para la descripción del fenómeno. Fundamentalmente porqué desde esa visión, el ejercicio de poder deriva de la conducción de la acción social mediante los recursos intercambiados en el trato: "si haces tal cosa, te doy tanto" o en su expresión negativa, "si no haces tal cosa, no te doy tanto". El que ejerce el poder, siempre va primero, el que obedece, siempre segundo; la acción, siempre es una consecuencia, nunca un antecedente. En este modelo, la estructura de la obediencia, descansa en la conveniencia de obedecer decidida de manera libre. El tratamiento del "don" como lo presentan Mauss, Lévi-Strauss y Godelier, tiene esta forma. No se deduce de ello, que el modelo analítico de don, sea de corte liberal, pues el mismo Tamati Rainapiri centra su análisis del hau, como iniciando en el "dar" (Mauss, 1971b: 166-7); simplemente que es una perspectiva que los liberales han tomado para sí, en detrimento de otras. Un autor que argumenta de esta manera es Peter Blau. Para él, poder desde la perspectiva del intercambio, “...es la habilidad de personas o grupos para imponer su voluntad en otros, [...] en la forma de retener las recompensas regularmente aportadas [...] constituyéndose como sanción negativa" (1964: 117). Es clara la forma: existe un intercambio regular, el que inicia es quien está en posibilidad de ejercer el poder; al otro miembro le toca por tanto, actuar en 
consecuencia de ese intercambio, mediado, eso sí, por la amenaza de retener el intercambio regular. Es la visión negativa del contrato. Una visión parecida sobre el poder y los fenómenos políticos mediante el intercambio, es la presentada por Anthony Downs en el clásico Teoría económica de la democracia, en la que los partidos gobernantes de los regímenes democráticos, “....se comportan de manera análoga a la de los empresarios de las economías lucrativas. Para conseguir sus fines privados formulan las políticas que, a su juicio, les reportaran el mayor número de votos, lo mismo que los empresarios producen los productos que, a su juicio, les rendirán mayores beneficios" (1973: 318).

El modelo que se construye desde el dar, procede de la focalización en el sujeto como agente, es decir, que la actividad que el individuo despliega tiene consecuencias en los otros; así, inicia de manera libre. El modelo que se centra en la devolución, focaliza su análisis en que de inicio, el individuo está obligado a actuar, como consecuencia de una estructura que se le impone; no da libremente. Aunque para Mauss, dar no es un hecho libre y desinteresado, las evidencias y el discurso, siempre se centran en las consecuencias que desprenden del actor que decide iniciar. Desde la perspectiva de Marx, lo que interesa son los fenómenos estructurales en los que se ubica el intercambio; las consecuencias en el actor que debe devolver; por ello el adelanto del trabajo sobre el salario. Ya de inicio, el individuo está determinado a dar, de manera obligatoria, sabedor que si se le retribuye, será en menor cuantía, es decir, con un desfalco. Tampoco Marx tiene el proceso de intercambio obligado -devolver primerocomo el inicio real, únicamente como eje analítico: "El resultado al que llegamos no es que la producción, la distribución, el intercambio y el consumo sean idénticos, sino que constituyen las articulaciones de una totalidad, diferenciaciones dentro de la unidad" (1980: 56$).^{65}$

La diferencia entre los dos tratamientos es a mi ver, de tipo político. En la visión desde el que da, el actor es considerado superordinado. La consecuencia de la manifestación de su actuar, lo que da, lo coloca en posición de superioridad frente al otro. Mientras que desde la óptica de la devolución, el actor es considerado subordinado. La consecuencia de la manifestación de su actuar, lo que da, lo coloca en posición de subordinación frente al otro. El primer razonamiento, culmina en la formulación del fenómeno del don, el segundo con algo que bien podía llamarse el anti-

\footnotetext{
${ }^{65}$ El subrayado es mío.
} 
don. Lo anterior, una metáfora que no busca constituir una nueva categoría de análisis, tiene simplemente la pretensión de dar cuenta de todos los efectos que las relaciones de poder tienen en los intercambios. Pues desde la óptica de la economía política marxista, los razonamientos generales sobre el don, aparecen en cierta medida, como complementarios y "de cabeza".

Es fundamental aclarar, que en el tratamiento de los fenómenos de poder, ninguna de las dos ópticas es la dominante o la más correcta. Ambas afirman ver el fenómeno como integral y sólo expositivamente se centran en una dinámica. Lo destacable es que cuando dos actores enlazados por una relación de intercambio, se encuentran en situación asimétrica y uno de ellos decide orientar las conductas o las conceptualizaciones del otro, será la naturaleza específica del contexto, la que determine quién es el que da primero y quién después; quién resulta superordinado o subordinado. En suma, quién manda y quién obedece. El aspecto del contexto resulta así de la mayor importancia para el correcto entendimiento del fenómeno, porqué como es evidente de la exposición, no es la posesión de recursos o su aporte lo que define de antemano, la posibilidad de ejercer el poder. Tener no es suficiente; dar a veces subordina; y dar más, a veces, subordina más.

El concepto de conductas y conceptualizaciones de apropiación se diseñó justo, para abordar tanto una mecánica como la otra. No presupone un orden de acción. Permite enlazar intenciones y consecuencias. Si la toma del bien es primero y la obediencia después o en su defecto, si primero se obedece y posteriormente se espera el bien, el concepto se muestra efectivo; incluso si el fenómeno es simultaneo. Lo central es que si existe una relación de intercambio, esta ocurra en condiciones asimétricas que permitan el ejercicio de poder; lo que suceda primero, elementos o hechos, no afecta la pertinencia del concepto.

La puesta en marcha de políticas públicas, coincide en muchas ocasiones con la asignación de recursos, para activar procesos de acción social, ya sea mediante el aporte directo a los ciudadanos objeto de la política, ya por el aporte a terceros que incidirán posteriormente en los ciudadanos o también, vía la ampliación de las capacidades de los gobiernos en la dirección definida y que los impactan. En todos los casos anteriores, ocurren fenómenos en los que los grupos de destino, están en la condición de "tomar" 
ciertos recursos, pero siempre condicionados a la realización de conductas y conceptualizaciones de apropiación. Si ello ocurre, se culmina el proceso del ejercicio del poder político.

Es claro que la implantación de un centro de educación superior en una región determinada, conlleva una serie de efectos y expectativas, que van de la mano de efectos de poder. No se crea una infraestructura física, académica y administrativa, para que los individuos que concurran al centro, hagan uso de los recursos ahí dispuestos, de manera libre y casuística. Hay requisitos de ingreso, progreso y salida del proceso educativo. La conducción convergente con los supuestos mínimos (las ordenes), culmina en la emisión de un certificado de aprovechamiento.

Desde luego, el proceso de educación intercultural universitaria en la región mazahua del Estado de México, es un caso particular de las generalizaciones anteriores. Muchos bienes públicos gubernamentales son puestos a disposición de los jóvenes de la región, y no todos comportan ejercicio de poder por su disfrute. En el caso de la Universidad Intercultural del Estado de México, esto ocurre también así; pero lo que interesa resaltar es que hay otro sector de bienes y servicios, ya sean materiales o simbólicos, que establecen acciones y conceptualizaciones para su disfrute.

La Constitución Mexicana, en su artículo segundo determina las bases mínimas con las que se debe atenderse a la población indígena, sin embargo, hay también en el artículo tercero, determinaciones generales sobre el proceso educativo. En este sentido, hay ámbitos distintos de apropiación, por un lado, la apropiación debe ser privilegiada y no condicionada para los indígenas, por otro lado, la certificación universitaria exige mecanismos de exclusión y condiciones de reconocimiento.

Justo estos dos niveles -además de otros específicos de la operación gubernamental y que serán vistos en los capítulos de análisis-, son los que aparecen como susceptibles de abordar desde la lógica del don-intercambio. Para el Estado, el aporte de recursos es una obligación y no obstante, los individuos generalmente se reconocen subordinados ante tal hecho, pues están impedidos para influir -en contextos inmediato- en las formas necesarias para la apropiación de tales recursos. Hay una disputa constante, sobre quién es el poseedor inicial de los recursos: el Estado o el Pueblo. Así el espíritu de Mauss ronda la lucha por la jerarquía y la subordinación en el dar.

¿Qué cosas se prohíben y que cosas se permiten en los intercambios? El orden constitucional, busca precisamente, mediante ciertas prohibiciones y obligaciones, una 
nueva relación de los indígenas frente al conjunto nacional. No obstante, en ese proceso, las diferencias y las asimetrías preexistentes, impiden en muchos casos, que los efectos que supone la Ley Suprema y que se realizan vía la toma de los recursos dispuestos, "igualen" a los que en el inicio eran diferentes. La tensión siempre presente, entre "Estado impuesto" y "Pueblos indígenas originarios", determina, que exista una actitud conflictiva entre los recursos que se dan con ejercicio de poder político y aquellos que se dan -o se retienen- justo para ejercer el poder de facción o grupo (los mestizos; los caciques, los criollos, o cualquier grupo específico, que discrimina y pretende dominar extralegalmente a los individuos o comunidades indígenas). Útil pues la perspectiva de las asimetrías en torno a los intercambios que Godelier refiere y que se enmarcan en el ejercicio de poder vía la "donación" o la "retención" de los recursos sociales y su uso conforme a la ley o a las necesidades de las facciones.

Finalmente, es importante señalar la perspectiva abierta por Marx, relativa a las condiciones del proceso de intercambio asimétrico: aquello que se plantea a los individuos como orden para la apropiación de los recursos estatales, ¿qué va primero: el bien público o la conducta o conceptualización? Hay situaciones de ambos casos, pues la educación en general, es un bien público que va primero y que los individuos pueden disfrutar de inicio para después retribuir con ciertas conductas o conceptualizaciones, sin embargo, si tales hechos, no son de la calidad acordada, el segundo momento, que es la certificación, va después y por tanto, puede ser negada, a pesar de haber ocurrido las acciones previas.

No se va a abundar más sobre el particular, simplemente se busca no perder la tensión entre el diseño teórico de los fenómenos de poder mediante intercambio y los nexos empíricos con las políticas educativas interculturales, implementadas con el aporte de recursos gubernamentales.

\section{Complementos y precauciones.}

Se han presentado entonces, los aspectos básicos para la aproximación a las relaciones de poder mediadas por intercambios que están definidos por su centralidad en el don. Asimismo, los elementos que considero correctivos o mejor, complementarios, para que la propuesta sea satisfactoria. Se mantuvo necesariamente, un nivel abstracto, pues las herramientas para ser pertinentes debían ser de carácter general. Para esta sección, se 
comenzará a perfilar el foco principal de tales utensilios: las políticas gubernamentales mediadas por el intercambio. De ahí que existan algunos aspectos cuyo origen no está necesariamente atado a la mecánica del don, por lo que se buscará señalar defectos o imprecisiones, siempre apuntando la visión al tema de referencia. En el primer inciso se abordaran las consecuencias que surgen al extender la lógica de los intercambios para las explicaciones integrales; en el segundo, las herramientas complementarias y específicas para el contexto gubernamental.

\section{I) Precauciones.}

Larga es la tradición que busca explicar la realidad social desde un punto de vista racional e individualista. En la época moderna, arranca con los trabajos de John Locke y se prolonga hasta nuestros días. ${ }^{66}$ Forma un gran cuerpo teórico y el paradigma que la orienta, reside en los efectos que tiene en los grupos humanos, la búsqueda de satisfacer los intereses individuales mediante argumentos racionales. Esta visión ha tenido momentos de gran vigencia; en particular a partir de la Segunda Guerra Mundial y en la escuela norteamericana. Tres son al menos, los aspectos que potenciaron su dispersión: a) El interés por fortalecer a las Ciencia Sociales -en particular a la Ciencia Políticacon criterios de cientificidad que fueron encontrados en la Economía; b) El modelo capitalista como paradigma opositor al comunismo; así, las razones del individuo prevalecían sobre las de la colectividad y finalmente; c) El crecimiento urbano, industrial y de los aparatos burocráticos del Estado desde principios del siglo XX, que imponían una lógica de administración científica y que derivo en la transición de lo racional utilitarista, de ser herramienta operativa a herramienta explicativa. ${ }^{67}$

La influencia poderosa de los temas de la Economía para la explicación de lo social, tiene, no obstante, razones de peso. Uno de los aspectos centrales, es el proceso de imbricación de las relaciones de tipo monetario con las relaciones sociales; de ahí que aparezcan para los individuos, como las relaciones sociales mismas. Como asevera Castaingts desde la perspectiva antropológica: en el dinero se da una transformación de lo valorado en valorante, pues es el factor usado para conciliar tiempos y movimientos en la sociedad contemporánea, además, que muchos procesos de objetivación del individuo se desarrollan a través del consumo (2002: 22-36). Más aun, que "El dinero es

\footnotetext{
${ }^{66}$ La síntesis de Collins (1996) constituye un trabajo de gran calidad y describe de manera concisa los principales argumentos y autores, que agrupa en lo que llama "La tradición racional/utilitarista".

${ }^{67}$ En Barquín (2006), se trataron con más amplitud estos temas.
} 
el instrumento fundamental del cálculo y de la orientación racional de la vida social" (ibid: 30$){ }^{68}$ Esto quiere decir, que se tiende a monetarizar lo social y por ello se privilegia la perspectiva racional. Todos esos aspectos, colocan a la Economía como básica para describir tales temas, pero ¿de ahí se sigue que lo racional/utilitarista basta para explicar el aspecto económico lo humano?

Este trabajo se alinea con las opiniones de que tal paradigma es insuficiente. Hay una gran cantidad de temas en los que la modelación económica pasa del uso al abuso, al llevar la idea del intercambio y el interés como ejes básicos de todo tipo de interacción. El problema parece pues, no que la lógica económica sea una especie presente en las situaciones de la vida cotidiana, sino la expansión de las situaciones específicas de los intercambios materiales, a todos los ámbitos de actividad humana, resultando con ello, una serie de "mercados" de la más diversa índole. Godelier, al criticar el trabajo de Leclair, critica de manera general lo que llama pensamiento formalista:

"El avance formalista pertenece, por lo tanto, a la reflexión epistemológica de la ciencia económica sobre sí misma. El error de Edward Leclair no es elaborar un modelo de este tipo, sino pensar que al hacerlo construyó una 'teoría general' y [...] que las leyes de la economía política elaboradas para nuestro sistema de economía de producción mercantil capitalista son el núcleo de esta teoría general y adquieren así un campo universal de validez" (Godelier, 1970: 258-9).

La expansión del discurso y la lógica económica aparecen pues, como la teoría de lo social. Llama la atención que dicha lógica formalista, en ocasiones traspasa lo prudente, para invadirlo todo. George Homans, por ejemplo, al referir la lectura del Ensayo sobre los dones, destaca no la búsqueda de la dimensiones no económicas en el cambio, derivadas del tratamiento de hecho social total, sino que expandiendo la lógica de las interacciones en laboratorio y en pequeños grupos, culmina diciendo que el comportamiento social es un intercambio de bienes; que el proceso de dar y recibir, tiende al equilibrio; y que los individuos buscarán maximizar sus rendimientos en el intercambio, más aún: "De todos nuestros 'acercamientos' al comportamiento social, aquel que lo entiende como 'economía' es el más abandonado y sin embargo, es el único que usamos en cada momento de nuestra vida" (Homans, 1958: 606). ${ }^{69}$ En términos de Godelier, formalismo puro. El problema, resulta de la naturalización de las

\footnotetext{
${ }^{68}$ El subrayado es mío.

${ }^{69}$ El subrayado es mío.
} 
relaciones económicas, es decir, que el "pensamiento" individualista y maximizador, está presente en la naturaleza, incluso, antes de la aparición del hombre como especie. La crítica de Marshal Sahlins aborda este aspecto: "Adopt[o] como cualidad distintiva del hombre no el hecho de que deba vivir en un mundo material, circunstancia que comparte con todos los demás organismos, sino el que lo haga según un esquema significativo, concebido por él mismo, de lo que sólo la humanidad es capaz" (1997: 9). Desde luego, que constituir a lo económico como "la determinación en última instancia", es uno de los posibles esquemas de significación.

Dos críticas en torno a la presentación de la teoría del intercambio como la teoría social, son las que presentan Jeffrey Alexander y Alvin Gouldner. En el caso del primero, se realiza con la crítica a los trabajos de Homans. De inicio plantea que fueron útiles por su rescate de lo utilitario y racional en un panorama académico, dominado por la visión normativa y que tuvo éxito porque “...se parece mucho a la perspectiva del sentido común acerca de la vida cotidiana en las sociedades occidentales" (Alexander, 2000: 131). No obstante ve varios problemas: Que percibe a los individuos actuantes en igualdad de condiciones en los intercambios (nada de asimetrías ni poder); que plantea a las interacciones sociales como un proceso de negociación continua; que se basa en supuestos subjetivos tales como decir que solicitar algo por nada es humillante; que plantea únicamente interacciones diádicas; que utiliza reactivos de la actividad animal (naturaliza el pensamiento humano al compararlo con el de las palomas) para hablar de las decisiones sobre opciones, olvidando la posibilidad de la valoración de los recuerdos sobre opciones desechadas; finalmente, que el punto anterior desembocaría en una teoría interpretativa sobre las estructuras mentales, aspecto que Homans ignora, por lo que le resulta imposible explicar el origen de las normas, quedando este aspecto como una categoría residual (Alexander, 2000: 139-59). Esta crítica, sobre todo la que se refiere a lo normativo como categoría residual, asevera Alexander, alcanza a los trabajos de Peter Blau, James Coleman y -en cierta medida- los de Alvin Gouldner (ibid: 1589). ${ }^{70}$

Este último autor presenta, a pesar de la crítica, un aspecto que vale la pena rescatar. Abordando las posibilidades de la reciprocidad desde el punto de vista funcionalista, Gouldner se enfoca en la importancia de "dar algo por nada". Como

\footnotetext{
${ }^{70}$ Esta crítica roza los trabajos de Richard Adams. Es de notar, que una reflexión frontal sobre el papel de los valores, aparece sólo como apéndice en uno de sus últimos trabajos (“Apéndice B: La energía y los valores", en: Adams, 2001: 361-72).
} 
resultado del análisis del aspecto normativo de la reciprocidad, afirma que la dinámica de intercambios consecuentes en la explicación total de lo social, presenta algunas dificultades: "Una de ellas surge de la incertidumbre que a menudo existe en lo concerniente al balance de la deuda en toda relación prolongada. Después de un tiempo, puede ser difícil para las partes determinar quién está en deuda con quién" (Gouldner, 1979: 246). ${ }^{71}$ De ahí la ocurrencia de situaciones en las que dar algo por nada sea común. La reglamentación de lo que Gouldner llama "la norma de la beneficencia" busca llamar la atención, sobre el tipo de relaciones sociales que se sostienen no sobre la base de los intercambios, sino, sobre la base de que alguien da todo y otro, todo recibe. Este esquema, resulta difícil de explicar en términos de las teorías totalizadoras del intercambio, pues habrá relaciones en las que la devolución jamás ocurrirá. El autor, se enfoca en un solo eje de análisis, aquel tocante a la posición superordinada del que da, respecto a la subordinada del que recibe: “...el precio de la ayuda incondicional es el desamparo y la dependencia incondicional del receptor respecto al donante, cuyo paradigma es la relación entre progenitor e hijo" (ibid: 255). La focalización en la asimetría originada por dar, acusa en Gouldner la influencia del trabajo de Mauss. A pesar de lo anterior, las consecuencias de tratamiento son relevantes, pues establece una clasificación interesante: Que existe una idea de justicia en el que recibe, por considerar que aquello que se le da, en alguna medida, le pertenece; y que los deberes de beneficencia no se aplican con igual fuerza a todos, pues quien tiene riquezas o ejerce el poder, está necesariamente más obligado (Gouldner, 1979: 252-66). De ahí que el tratamiento, resulte útil para comprender las relaciones entre el Estado y la Sociedad, pues al margen de una lógica del intercambio, presenta una lógica de la justicia que surge de la redistribución de la riqueza en forma de obligación estatal, pero también, permite entender las situaciones en las que se pasa de las percepciones del Estado benefactor al Estado paternalista, en donde los individuos lo merecen todo sin la obligación de dar a cambio. "Si bien el rechazo de algo por nada es antiguo, el anhelo oculto de él -y a veces no tan oculto- es igualmente viejo y profundo [...] Así el deseo de algo por nada se convierte en la trama de la que están hechos los sueños y las fantasías" (ibid: 252).

\footnotetext{
${ }^{71}$ Llama la atención, la notable convergencia con los juicios que, años después, formulara Jurgen Habermas, respecto de que al crecer la unidad de cooperación, a los individuos, "...se les escapa del campo de visión la reciprocidad entre prestaciones y recompensas" (Habermas, 1999: 42). Por tanto, "Aceptar obligaciones reciprocas resulta racional sólo para aquellos que tienen interés en una interacción sometida a reglas. Así puede extenderse el círculo de contratantes sólo a aquellas personas de quienes cabe esperar contraprestaciones porqué quieren o tienen que cooperar" (ibid: 43).
} 
Las dos advertencias, la de Alexander y la de Gouldner, sumada a la de Godelier, las utilizo aquí con el objeto de hacer una precisión fundamental: En el estudio de las relaciones de poder mediadas por un intercambio, en ningún momento pretendo alinearme con aquellos para los que la teoría del intercambio es el paradigma de lo social; menos aún, que la visión económica es la central para entender dichos cambios. Tal monocausalidad, está en abierta contradicción con la multiplicidad de ópticas desde las que se puede abordar lo social y que Weber mostró de manera convincente. Lo que se busca aquí es generar algunas herramientas básicas para explicar y entender el fenómeno, cuando ocurre a causa de un intercambio. Es de notar que en un artículo muy interesante, David Baldwin analiza la relación entre poder e intercambio. Luego de revisar diversos tratamientos sobre el poder y sobre la teoría del intercambio, asevera que existen una serie de convergencias, que no están exentas de problemas y concluye diciendo: "La discusión ha mostrado, por tanto, la posibilidad de usar la terminología del poder para describir las relaciones de intercambio y la posibilidad de usar la terminología del intercambio para describir muchas clases de relaciones de poder" (Baldwin, 1978: 1239). Esta conclusión es valiosa, pues refiere una práctica común y que por tanto tiene que ser manejada con sumo cuidado. De hecho, en general, aquíi se trata de evitar tanto lo uno como lo otro. No se busca usar dos terminologías distintas para explicar los fenómenos contrapuestos, sino, fundamentalmente, definir formas de abordar de manera específica la intersección de los dos fenómenos: el poder y el intercambio. ${ }^{72}$

Derivado de los argumentos anteriores, en todo el razonamiento se tomaron tres precauciones necesarias. Primero: hay que evitar que se tenga la impresión que las otras formas de poder, que postulé como "control" o "violencia", son formas como diría Alexander, residuales. Desde mi punto de vista son constitutivas del fenómeno, aunque, menos frecuentes por su impacto negativo en las relaciones sociales. Segundo: se debe considerar la posibilidad de aquellos fenómenos en los que las transferencias no son bidireccionales, sino unidireccionales, es decir, lo que Gouldner plantea como la

\footnotetext{
${ }^{72}$ Una práctica común es la de llevar la idea de mercado político democrático a sus extremos discursivos. De ahí surge la idea de funcionario como empresario y ciudadano como cliente, que impacta a la Administración Publica como disciplina: "Es importante destacar que el público consumidor no es una simple abstracción, retórica o idealista o guarismo alguno. Es, ante todo, la suma de actores que, organizados de manera diferenciada pueden escoger en términos de calidad, el costo y la eficiencia de las satisfactores que les son útiles en la vida civil y la vida pública [...] La Administración Publica no es un autorreferente institucional, sino un sistema de intercambios, satisfactores, preferencias y respuestas que vinculan de modo significativo a los ciudadanos con el gobierno" (Uvalle, 2003: 38-9). Como se ve, la transposición de lenguajes es el leit motiv del planteamiento.
} 
diferencia entre reciprocidad y beneficencia. Puede ocurrir que un gobierno intercambie con los ciudadanos -impuestos por políticas- y no obstante, en términos subjetivos, ser percibido como beneficencia. Tercero: que del análisis costo/beneficio que ocurre en las relaciones de intercambio, no se debe seguir que la teoría primordial es la económica, ni que el lenguaje básico sería el del mercado, pues como he venido argumentando, la lógica de los intercambios trasciende las dimensiones puramente mercantiles, en consonancia con la idea de "hecho social total" que Mauss presentó; ello desembocaría como bien dice Godelier, en un tratamiento de tipo formalista, manejo que se evitó desde el principio, al colocar los sistemas de clasificación como eje primario y no, los modelos de elección racional.

Una propuesta que buscó aproximarse desde la lógica de los intercambios a los fenómenos de políticos y de poder, es la corriente de la Elección Publica o Public Choice. Originada en las ideas de Keneth Arrow (1991), Anthony Downs (1973) y James Buchanan (1980, 1990), esta corriente busca generar herramientas teóricas para comprender y orientar el funcionamiento de las democracias contemporáneas, con base en la idea de los intercambios gobierno-ciudadanos y en un individuo racional y calculador. Esta aproximación no es por definición, errada. Sin embargo, sus bases metodológicas están colocadas en instrumentos de la Economía, en donde los individuos necesariamente tratan de maximizar su utilidad. ${ }^{73}$ Como lo que tratan de entender es el Estado y no, el Mercado, funden sus argumentos con los de la Teoría Política. Esta sugerente combinación, aparece al enfocarse en las consecuencias políticas de la competencia por los recursos provenientes del Estado. En el caso de Downs, lo que le llama mayormente la atención es la competencia por votos que fundamenta la lógica de las políticas gubernamentales. En el caso Buchanan, lo que importa es la actitud de los individuos interesados, frente a las reglas constitucionales, construidas como decisión colectiva por la suma de decisiones individuales; de ahí la influencia de Arrow. Buchanan y Tulock definen el objetivo básico: “...analizar el

\footnotetext{
${ }^{73}$ En el prólogo al Cálculo del consenso (Buchanan y Tullock, 1980), se cita a Gary Becker en su obra The Economic Aproach to Human Behavior: “....todo comportamiento humano puede ser visto como comprendiendo participantes que maximizan su utilidad [...] Si esta argumentación es correcta, el enfoque económico suministra una estructura unificada para la comprensión del comportamiento humano" (pág. 10).
} 
cálculo individual racional cuando se enfrenta con cuestiones de elección constitucional [concibiendo...] a los individuos como únicos responsables finales de la determinación de la acción del grupo así como de la acción privada" (1980: 22). Para Buchanan tal determinación, procede de los intercambios en las cámaras del congreso y de los ciudadanos con el gobierno, al representárselos como un juego, de tal forma que los conceptualiza como una perspectiva ampliada de los intercambios del mercado. Esta postura la enuncia con el nombre de catalaxia, es decir, la concentración del esfuerzo teórico, no en la búsqueda de la maximización o en la escasez de los recursos intercambiados, sino en el proceso mismo de intercambio (Buchanan, 1990: 27). Ello le permite, decir que su expansión hacia la política incluye los intercambios con poder; no obstante, mantiene en toda su obra, la maximización del interés como "norma" de actuación de los individuos, dejando lo valorativo al resultado de las decisiones colectivas.

El resumen anterior, busca poner en evidencia que el tratamiento que propongo sobre los intercambios en los que se ejerce poder, no se origina como una vertiente de la "Elección Publica". Básicamente, porque desde esa perspectiva, las consideraciones de tipo normativo, surgen del resultado de la agregación de voluntades, en un proceso que Keneth Arrow declaró como lógicamente imposible. Es decir, que de acuerdo a la Paradoja de Condorcet, es imposible un resultado racional de la agregación de las preferencias individuales, por causa de la aparición de ciclos de indecisión, que aumentan de probabilidad en función del aumento de participantes (Shepsle y Bonchek, 2005: 53-9). Por ello, Arrow postula que no existe un mecanismo de agregación de preferencias que cumpla cuatro condiciones mínimas para que sea justo, centrado en la “Constitución” como modelo normativo (Arrow, 1991: 507). ${ }^{74}$ De ahí, asevera que “...en la vida social, existe un equilibrio entre la racionalidad social y la concentración de poder". ${ }^{75}$ Este punto es central aquí, pues las relaciones de poder, representan a mi ver, la desarticulación del sistema de preferencias individuales como modelo único de acción y de elección. La imposición que comportan dichas relaciones, frecuentemente trascienden las preferencias individuales; tanto para el que obedece como para el que manda, pues las estructuras de poder, están por sobre los individuos y constantemente

\footnotetext{
${ }^{74}$ El corazón del trabajo de Kenneth Arrow, postula que es imposible obtener una función de bienestar común, única e intransitiva a menos que una parte de la sociedad imponga su voluntad al resto (Downs, 1973: 19). El teorema de la imposibilidad refiere: "No puede existir constitución alguna que satisfaga simultáneamente las condiciones de racionalidad colectiva, el principio de Pareto, la independencia de las alternativas irrelevantes y la no-dictadura" (Arrow, 1991: 511).

${ }^{75}$ Cit. en: Shepsle y Bonchek (2005: 71).
} 
determinan su acción. Así, lo que interesa del análisis anterior, es que si bien desde la perspectiva de la instrumentación de políticas gubernamentales, los que diseñan o instrumentan tal política son individuos con una intención determinada, no en todas las ocasiones las conductas de apropiación o conceptualización que el bien comporta, provendrán de un diseño racional. Ideales como la justicia o la posición ideológica, por ejemplo, distorsionan esa pretendida racionalidad absoluta. En los sujetos de tales políticas, las conductas de apropiación o conceptualización, pueden o no obedecer al esquema diseñado para el intercambio; los argumentos para la apropiación, pueden responder a determinaciones racionales, pero no siempre. Por ejemplo, la obligatoriedad de la beneficencia estatal, por la cual, un ciudadano no estará obligado a ninguna acción por la toma del bien, ya que de inicio los recursos administrados, "le pertenecen". Este ejemplo, corresponde al caso en que ambos actores -superordinado y subordinado-, comparten el sistema clasificatorio que origina las asimetrías y que fundamenta el ejercicio de poder. No obstante, como se expuso anteriormente, la contextualidad, la polisemia y las diferencias culturales, hacen todavía más inútil la modelación con base en la maximización individual y su correlativo colectivo, pues ante la enunciación de una orden, fundamentada en una asimetría, puede seguir la indiferencia o la inacción, causada por la aparición de otra asimetría no contemplada, o paradójicamente, por la inversión de ella misma, con base en un contexto diferente.

\section{II) Complementos}

En el inciso anterior se señalaron las precauciones que se deben tener respecto del paradigma del intercambio y del abuso de las herramientas derivadas de la Economía. Quise sin embargo, señalar primero estos aspectos, pues por la naturaleza del tema trabajado, siempre aparecen como un riesgo y pudiera flotar una sombra de duda sobre si se han tenido tales precauciones. Mas el peso específico de los instrumentos no está en duda y en adelante se les incluirá, junto con otros, para culminar de perfilar las herramientas sobre el tema.

En primer término se quiere destacar el argumento sobre la intencionalidad o no de los comportamientos y las conceptualizaciones que ocurren en las relaciones de poder. Como se había mencionado, las órdenes son aquellos supuestos de acción que van aparejados con el bien aportado. Pero, en términos de acción gubernamental que es el destino final de estas herramientas, muchos de los bienes aportados, no parten de una 
decisión individual tomada ex profeso para el aporte del bien. La decisión, puede derivar de los procedimientos gubernamentales emanados del cuerpo de atribuciones y obligaciones legales o administrativas que habitualmente realizan los funcionarios que gestionan los procesos de aporte de los bienes; esto proviene de la estructura de poder en la que está colocado el individuo. En otras ocasiones en cambio, desde el diseño se planea de manera racional el conjunto de transformaciones que se supone derivarán de la toma del bien. Como contraparte, aquellos que se apropian del bien pueden realizarlo a través de un proceso de conveniencia, es decir que la orden, supone un efecto posterior a la toma del bien, el cual se debe usar para propósitos definidos; por ejemplo, créditos al fomento de actividades específicas. En cambio habrá modelaciones en las que la misma apropiación del bien, es ya lo que se busca; este es el caso, por ejemplo, de las conceptualizaciones derivadas de los procesos de transmisión de conocimientos, en los que no interesa el uso de tales conocimientos, sino su internalización como herramienta conceptual. Tanto para quien enuncia la orden, como para quien la sigue, existen situaciones en las que las acciones se realizan en torno a órdenes y decisiones explicitas y en otros casos, los procedimientos están imbricados con fenómenos en los que los individuos, no reflexionan sobre las implicaciones de sus actos. Lo anterior, es una reflexión del último trabajo de Roberto Varela, en donde, al tratar el tema de la cultura en torno a los fenómenos políticos, enuncia contundente: “¿Todo comportamiento es el resultado de la cultura? No necesariamente. Algunas veces sí, otras no: a priori no sabríamos decirlo. Conviene precisar más: la cultura -conjunto compartido de signos y símbolos- no necesariamente es la causa de un comportamiento determinado [...] Si nos aferramos a que la cultura es la causa del comportamiento, llegaríamos a un impasse para explicar el cambio cultural" (Varela, 2005: 87). Si no toda acción está impulsada por la cultura [o por la razón], ¿cómo explicarla? Varela plantea la idea de dispositivos habituales, para referirse los procesos no casuales en los que de manera automática se siguen ciertas pautas no determinadas en primera instancia por una conexión con los símbolos y signos compartidos de una colectividad (ibid: 8994). Es decir, los argumentos de Varela nos permiten profundizar en el proceso de la conducción social de los comportamientos y las conceptualizaciones, al eliminar no sólo la racionalidad asociada, sino la conexión obligada con procesos de significación compartida. Quiero ser claro: no estoy diciendo que todo el proceso de conductas y conceptualizaciones asociados al ejercicio de poder pueda estar aislado de los argumentos de racionalidad o de cultura compartida; lo que quiero decir es que tal 
puede ocurrir, con respecto a lo que se supone deriva de la toma de los bienes, es decir, del enunciado de la orden. Esto es relevante en términos de los nuevos temas de la Antropología Política, pues como plantea Pablo Castro (2006), no es únicamente la cultura el puesto de mira antropológico para los fenómenos políticos. Lo argumenta al analizar la propuesta de Marc Abélès para una renovación de las cuatro formas tradicionales en las que la Antropología estudiaba los fenómenos políticos, a seis nuevos temas, pasados todos ellos por el eje de la cultura; ahí, clava la advertencia de Varela afirmando: "De tal manera que es importante no exaltar a la cultura como el factor más relevante para entender los patrones de comportamiento, pues existe una serie de factores más globales que inciden en la configuración de las prácticas cotidianas" (Castro, 2006: 48).

Dado que el foco de interés del ejercicio de poder, está en la actividad de los gobiernos, conviene precisar el tema relativo a la denominación de los elementos que intercambia el gobierno con los ciudadanos. En un lenguaje muy coloquial podemos denominar a esos elementos, como bienes. De estos, interesan fundamentalmente, aquellos que al ser aportados implican conductas o conceptualizaciones en su apropiación. No obstante, hay diversas formas de conceptualizar tales bienes; el modelo más común es el de "bien público”. Este se entiende como un tipo de bien con dos características centrales: “...el productor no está en condiciones de excluir del goce del bien a quien quiera procurárselo aun sin pagar un precio de compra; y quien goza de él lo hace conjuntamente con otros" (Ricossa, 2007: 62). La "gratuidad" que suponen tales bienes, está en función de la imposibilidad de cobrar por su disfrute. Sin embargo, en términos de Teoría Política, se supone que los ciudadanos deben aportar en forma de impuestos, los insumos necesarios para la construcción general de tales bienes. Tal hecho, deriva en la posibilidad del gorrón: ciudadano que nunca paga los servicios que recibe, pues por su carácter público puede disfrutarlos sin ningún tipo de compromiso. Por otro lado, se entiende, que los bienes públicos una vez liberados, están a disposición de todos aquellos que quieran disfrutarlos.

La definición es a todas luces, insuficiente e inadecuada para describir los fenómenos de poder por intercambio. Básicamente porque desde su ejercicio, precisamente se busca eliminar las ambigüedades o indefiniciones en el aporte de 
bienes. El poseedor original de los bienes, el gobierno, en múltiples ocasiones, sí está en condiciones de excluir, tanto a aquellos que en términos ciudadanos han pagado por la construcción del bien, como a los que no; lo que importa es el efecto y no los derechos del goce. Por tanto, no necesariamente todos deben "caber" en una política, es decir, que el disfrute puede ser o no universal, dependiendo del objetivo que se persigue. Las políticas de fomento a una actividad empresarial específica, por ejemplo, no son destinadas a todos, ni a todos los empresarios.

El otro aspecto interesante, es que surge un tipo de "gorrón" diferente. No importa si tal individuo ha pagado o no la construcción del bien; su tipificación deriva de que en términos públicos, la apropiación del bien debería realizarla mediante la conducta de apropiación supuesta; no obstante, evade el cumplimiento de la orden, pero toma el bien. El desvío de los créditos al fomento agrario, para fondear otro tipo de actividades, es un ejemplo. No todos los procesos en los que el gobierno aporta recursos, deben estar encadenados al aporte ciudadano, es decir, la devolución en servicios urbanos derivados del pago del impuesto predial, en nada se parece a lo que aporta el gobierno, resultado de los bienes o servicios que produce de manera interna y autónoma.

No es lo principal del tema si el actor contribuye o no contribuye a la construcción del bien, aunque resulta básico conocer las opiniones subjetivas al respecto. Lo relevante es que "nacen" de la actividad gubernamental y que llevan un propósito definido en su apropiación. Si tal propósito se logra, caracterizará el ejercicio del poder; caso contrario, quedará como un intento frustrado. Así, en este trabajo, se denominará como bienes gubernamentales, a los elementos que aporta el gobierno y que en nuestro caso particular, se limitan a aquellos que presuponen conductas o conceptualizaciones en su apropiación.

El aspecto de la racionalidad, en todos aquellos intercambios que implican conductas o conceptualizaciones de apropiación, juega un papel importante. De inicio, manifesté que mi principal interés residiría en la búsqueda intencional de producir un cambio en las acciones de otros actores. Ello implica planeación, información, análisis, síntesis y recursos, que al ser apropiados derivaran en el propósito definido y no en otro. La enunciación concreta del tal propósito se encierra en la orden. Desde el punto de vista 
racional, aquel que se adueña de los elementos aportados, debería culminar con el desarrollo de lo que la orden plantea, pues al evaluar todo el esquema, lo vería como aceptable. Este modelo, supone pues, la convergencia de criterios entre el que emite la orden $-\mathrm{y}$ el bien-, y aquel que obedece en la apropiación, es decir, supone una clasificación homogénea de los elementos involucrados, para culminar en razonamientos convergentes.

En la planeación de políticas gubernamentales desde esta perspectiva, hay un conjunto de criterios que se supone se deben valorar y que epistemológicamente, proceden de la tradición económica. Se refieren a que en los intercambios de tipo mercantil, hay que considerar varios aspectos: la información, el tiempo para manejarla, el algoritmo para procesarla, el costo de procesamiento, la dispersión geográfica de los recursos y los actores, y el costo de los procesos de negociación para el intercambio. Estos aspectos son los que Douglass North considera fundamentales en la elaboración de una teoría sobre los intercambios de tipo político (North, 1990; 1993). Su propuesta se acoge a los supuestos de la racionalidad limitada que Herbert Simon enunció, pues desde una racionalidad acrítica, se consideraban los aspectos anteriores, pero sin las dificultades o limitaciones inherentes a cada punto; North lo cita:

Si aceptamos los valores como dados y constantes, si postulamos una descripción objetiva del mundo como es realmente, y si asumimos que las capacidades de cálculo del que toma las decisiones son ilimitadas, entonces se desprenden dos importantes consecuencias. Primeramente, que no necesitamos distinguir entre el mundo real y la percepción que de éste tiene aquel que decide: él o ella perciben el mundo como es en realidad. En segundo lugar, podemos predecir enteramente las elecciones que serán hechas por el que toma decisiones racionales, de nuestro conocimiento del mundo real, sin un conocimiento de las percepciones o modo de evaluar del que toma la decisión (sabiendo, por supuesto, su función de utilidad) ${ }^{976}$

Simon plantea cuan ridículos son los requisitos para instrumentar una planeación puramente racional que implica a dos actores enlazados: la perfección en todos los puntos del proceso tanto para uno como para otro. Así, solo es posible una racionalidad limitada. Por ello, es fundamental saber cuáles son los ejes de evaluación de los actores que, mediante el aporte de bienes gubernamentales, esperan reacciones específicas en la

\footnotetext{
${ }^{76}$ Citado en North (1990: 356). Desde un ámbito distinto, la literatura, Fedor Dosyevski supremo conocedor de la subjetividad humana asevera una veta diferente respecto a la posibilidad del cálculo de todas las variantes del hacer humano "En ese caso, podría calcular toda mi vida por adelantado para los próximos treinta años [...] no nos quedaría nada por hacer". Frente a ello el individuo se revelaría ante la razón "...para ejercer el derecho a desear incluso lo muy estúpido y no estar sujeto a la obligación de querer para sí solo lo inteligente" (2006: 49-50).
} 
población de destino. Así, se podrá confrontar el contenido de la orden, con la medida de su efecto y de ahí, la efectividad en el ejercicio de poder. Por ello era importante esta aclaración, puesto que el diseño que fundamenta la intención previa, puede basarse en un supuesto de racionalidad perfecta, de racionalidad limitada o no tener su origen en supuestos de racionalidad. Por último, hay que considerar que el esfuerzo intelectual que emprende un actor, puede ser deficiente en diversos grados; no se plantea que sea irracional, sino que es ineficaz, es decir, que el actor considera -subjetivamente- sus juicios como racionalmente pertinentes, pero desde otra posición son notablemente erróneos. $^{77}$

Hay un último aspecto que conviene mencionar. Los puntos en los que se considera aplicar los criterios para el intercambio, pueden tener una aplicación diferente en aquellos que se apropian del bien gubernamental. Suponiendo que luego de valorar racionalmente la conveniencia de ejecutar las conductas o conceptualizaciones implicadas en la apropiación, el actor decide que son adecuadas, puede ocurrir que se vea ante la imposibilidad real de ejecutarlas. Con ello me refiero a las limitaciones de tiempo, recursos, información, procesamiento, etcétera, que surgirían en el proceso y que impedirían de facto la ejecución de la orden, no obstante la buena disposición de dicho actor.

Richard Adams amplía el panorama de los criterios a considerar en torno a las relaciones de intercambio y además, a las relaciones de intercambio en las que se ejerce poder. La ampliación de Adams consiste en colocar como criterio básico, los esfuerzos globales de los hombres para enfrentarse al medio ambiente y controlarlo, con vistas a mejorar sus posibilidades de supervivencia (Adams, 1978: 19). Esta perspectiva, básicamente retoma los avances del campo de la termodinámica para tratar de explicar la evolución de las sociedades en términos energéticos. En consonancia con lo anterior, Leslie White asevera que para satisfacer las necesidades básicas, “.... se requiere energía. De allí que la función primordial de la cultura, sea la de embridar y dominar la energía a fin de que pueda ser puesta a trabajar al servicio del hombre" (White, 1982: 340-1).

\footnotetext{
${ }^{77}$ Un ensayo notable, "Las leyes fundamentales de la estupidez humana", de Carlo Cipolla (1992), constituye una crítica lúdica a los excesos del pensamiento racionalista, pero también, a la falta o ausencia de valoración del efecto de la estupidez en los esfuerzos humanos por actuar con inteligencia.
} 
Aparece así, una perspectiva mucho más rica en el análisis de los fenómenos de poder, pues se busca una lógica que, siendo de carácter racional, está más allá de la ganancia monetaria. Sin embargo, hay que reconocer la mira mucho más alta de Adams. El horizonte que se plantea, es la explicación de las tendencias generales de procesamiento energético, en las que el hombre es el eje central, pero no el único, pues está inmerso en los flujos energéticos generales. La lógica de la sociedad está atada en la lógica de la termodinámica de los procesos irreversibles. Aproximarse desde ahí a los fenómenos de poder por intercambio tiene algunas ventajas. Sobre todo porqué para Adams, el poder juega un papel central en la búsqueda del manejo racional de la energía. Así, las evaluaciones para la toma de decisiones en la construcción de una política, estarían inmersas en el aprovechamiento de tal energía: se ahorra tiempo, porque se ahorra energía; obtener información gasta energía y procesarla, también; etcétera. La energía aparece como una moneda más general que el dinero para la toma de decisiones y por tanto, para la conducción de la acción y la conceptualización social. Adams asevera:

En general el hombre no trata a sus semejantes como objetos ni les aplica tecnología. Más bien los reconoce como seres humanos pensantes y procura encontrar formas de convencerlos de su posición o al menos de impedirles el rechazo de sus deseos. Para lograrlo utiliza su control sobre partes del medio ambiente que son valiosas para los demás. El hombre manipula el medio ambiente, procurando que los demás concuerden racionalmente con lo que desea para ellos. Cuando hace esto, no ejerce control directo sobre ellos; más bien está ejerciendo poder (Adams, 1978: 23)

Las capacidades heurísticas del punto de vista energético, toman en la afirmación anterior, un rango más limitado y se adentran en el ámbito de la teoría política. Para Adams, el poder deriva de la posesión de bienes sujetos de control energético, es decir plantea un ejercicio de poder con la forma de don o esquema contractual liberal. El poder se ejerce por aquel que acuerda con los demás, lo que harán para conseguir el citado bien; la jerarquía viene del tener, la subordinación del recibir. $\mathrm{Su}$ propuesta olvida aquella otra visión que denominamos anti-don, en donde la subordinación está en aquel que da los recursos y que da más, en un proceso ineficiente energéticamente. La correlación general entre tiempo y acumulación energética, no describe el desfalco obligado que un capitalista realiza sobre un obrero, por poner solo un ejemplo. Adicionalmente, desconoce cómo poder a las otras dos formas: el control 
(diferente del control adamsiano) y la violencia. ${ }^{78}$ El modelo de Adams es muy útil en términos de amplio espectro. Acercarse a los fenómenos cotidianos desde la visión adamsiana, tiene que realizarse con mucha precaución para no caer en un determinismo energético que, puesto como absoluto, resulta inoperante; ni siquiera Adams plantea tal posibilidad. Es decir, sus planteamientos son útiles como teoría evolutiva; como teoría política, tiene problemas insolubles.

Adicionalmente hay que señalar, que el sistema de clasificación que permite la construcción de las asimetrías adamsianas está basado, a mi ver, en tres pares de oposición: energía/no energía, eficiencia/ineficiencia y control/no control. Desde ahí se teje la lógica de poder en Richard Adams. Son las fontis et origo de su sistema clasificatorio. El tratamiento que se ha expuesta, rechaza contundentemente considerar los núcleos definitivos del poder. Para mí, la contextualidad y la arbitrariedad determinan la posibilidad de las relaciones de poder, independientemente de cualquier núcleo duro, incluyendo desde luego, la energía.

Las evaluaciones racionales mostradas anteriormente, están construidas sobre categorías estables, es decir, que los juicios que se emiten, tanto en un lado como en el otro, están relacionados con un concepto clave: el de preferencia. Según Charles Lindblom, hay cuatro formas de discriminación entre opciones: a) La preferencia simple (escoger un sabor: 'me gusta la vainilla'); b) una elección basada en datos, hechos, probabilidades y crítica del conjunto - no es una simple preferencia; c) de acuerdo a juicios morales o éticos; d) y semejantes a las simples, pero de tipo 'irracional. (1977: 134). Para el autor, la teoría económica se centra en la primera y en la última. Sin embargo en la política, las elecciones son siempre interdependientes, implican simples preferencias, pero también valores y juicios y más importante aún, proyectos de futuro. Por eso le parece errado, que se trate a las <<preferencias〉> políticas de la misma manera que la preferencia por un sabor, pues esto no contiene ningún tipo de expectativa a futuro o valores morales (1999: 462). Así, es fundamental considerar que en las políticas gubernamentales, la pura idea de preferencias es insuficiente para abordar los núcleos

\footnotetext{
${ }^{78}$ En las notas 42 y 44 de este trabajo, se discutieron las diferencias entre estos conceptos y el porqué de las ausencias en la obra de Adams.
} 
de decisión. De ahí que elige el concepto de volición como más adecuado, para describir tales decisiones. Las voliciones implican no tanto un descubrimiento, sino, la creación de un futuro posible, es decir, lo que se quiere que ocurra: "Si pienso en preferencias, me inclino a creer que yo soy lo que soy. Si pienso en voliciones, me inclino a juzgar que aún no soy lo que puedo llegar a ser" (1999: 464). Por ello la idea de volición resulta pertinente, pues en todo diseño de política gubernamental, hay algo más que la pura planeación de conductas o conceptualizaciones. Hay ideas acerca de cómo se debe llegar a un mejor mundo, más aun, sobre cuál debe ser ese mundo. Es claro que en el ámbito de la política, la polémica respecto de los dos puntos anteriores es constitutiva. Se abre así una vía para la evaluación no racional de la acción política. Los aspectos normativos juegan un papel poderos. Los argumentos de Lindblom son importantes, pues resultan de la corrección de un economista que busca explicar la política. Esta transición fue analizada en otro trabajo (Barquín, 2006), donde destacó principalmente, la transformación que en Lindblom sufrió el término preferencia al de obediencia, en el marco del concepto de conductas de apropiación. Es decir, que en los intercambios donde existe una intención política, no sólo operan las preferencias, sino también, las voliciones. Los deseos, las ideologías, la historia, la justicia, el futuro, aparecen como criterios, tanto en la aportación del bien como en su apropiación; desde luego que las conductas o conceptualizaciones, estarán definidas por tales influencias.

Estos aspectos, aunque no son centrales en mi propuesta, son ponderados de manera cuidadosa. Me explico. El eje central de análisis, es la emisión de la orden, el aporte del bien, la toma del mismo y la realización o no, de la orden supuesta en la apropiación. Sin embargo, los criterios para la distribución, asignación y toma de los bienes gubernamentales, están impactados fuertemente por la posición política de los actores. Son al mismo tiempo, argumentos de tipo subjetivo y condiciones estructurales. De acuerdo a la posición ideológica, el reparto de bienes gubernamentales tendrá el objetivo de fomentar ciertas conductas o conceptualizaciones, acordes con las expectativas del desarrollo del país, por poner un caso. Existirán no obstante actores, como partidos políticos o grupos de la sociedad, que consideren tal reparto no sólo inadecuado, sino profundamente injusto y que pone en riesgo la idea de nación o bien común. Cierto es, que las perspectivas políticas de reparto de bienes y de ordenes consecuentes, tiene un sin fin de temas en los que estas determinaciones confluyen en un esfuerzo cooperativo. Desde la lógica clasificatoria que se postula, resulta fundamental aclarar que los temas en los que se centra el ejercicio de poder 
gubernamental, constituyen uno de los núcleos básicos de las asimetrías que fundamentan tal ejercicio. Existen múltiples pares de oposición, que definen asimetrías en la sociedad y que no derivan de un solo sistema clasificatorio. Las políticas de gobierno, pueden ser clasificadas en torno a la idea derecha/izquierda, nacionalista/entreguista, estatalista/neoliberal, capitalista/comunista, ecologista/ depredadora, obrera/empresarial, machista/feminista, populista/neoliberal, mestiza/indígena, etcétera. ${ }^{79}$ Estos pares de oposición, pueden también aglutinarse por grupos de transformaciones, en donde derecha, neoliberal, machista e mestiza, se oponen a izquierda, populista, feminista e indígena. Lo relevante es que la forma en la que se aporta el bien gubernamental, encuentra argumentos del mismo tipo, en ocasiones convergentes, en ocasiones contrarios. Así, los argumentos racionales sobre el monto del bien y las acciones conducentes -el mundo de las preferencias-, se confronta con los valores en los que se encuadra la política gubernamental, ya por la forma, ya de quien proviene, es decir, el mundo de las voliciones.

Lo político, como espació conceptual en donde recursos, acciones e intenciones sociales aparecen, ya como operaciones cooperativas, ya como conflictivas, permite que los fenómenos de poder mediante intercambio, puedan ser encuadrados en lo que Victor Turner denominó como campo político. El campo es un espacio conceptual que concentra "...la totalidad de relaciones sociales entre actores orientados a los mismos premios o valores” (Turner, 1974: 127) Y el campo político “...está constituido por grupos de acción con metas decididas, y no obstante contiene tanto conflicto como coalición, donde las acciones cooperativas a menudo son hechas para servir a propósitos de confrontación" (ibid: 128). Llaman la atención dos puntos fundamentales. Primero: que el campo contempla el conjunto de relaciones sociales que mantienen los actores con respecto metas o valores específicos aunque, es claro que dichas metas pueden ser las mismas pero de signo contrario, es decir, que generan una polémica no sobre la

\footnotetext{
${ }^{79}$ Es básico recalcar, que la construcción de pares, no anula la riqueza clasificatoria que surge de la vida política, y que no está centrada en el pensamiento dicotómico. Un ejemplo claro es la existencia de partidos de izquierda, de derecha y de centro. Sin embargo, evidente que la ideología "centro" construye su propuesta exitosamente de manera negativa, es decir, no se define por proponer, sino por no ser, pues se posiciona como no izquierda y no derecha, en una tendencia que busca, captar a los votantes que no se identifican con los extremos puros. La consideración de la estrategia política, no anula la construcción dicotómica de la clasificación, sino que la define como viable.
} 
primacía de la meta, sino sobre su instrumentación y la perspectiva de mira. Segundo: que es patente la idea de cooperación, tanto como la de conflicto. No plantea pues, el campo, un escenario únicamente de lucha, sino, de esfuerzos convergentes en términos de vida social. Ello resulta central, pues desde mi punto de vista, las relaciones de poder no son por definición conflictivas. Las conductas y las conceptualizaciones de apropiación, pueden desarrollarse en muchos casos sin fricción alguna.

Adicionalmente, hay que aclarar que cuando una orden no es llevada a cabo, no necesariamente el conflicto de metas o valores fue lo que imperó. Como argumenté anteriormente, hay un sinnúmero de circunstancias en las que a pesar de la aceptación de la orden por el actor subordinado, está nunca llega a cumplirse. La contextualidad es desde luego una propiedad del campo "Debe, también notarse, que los recursos que los actores comprometen y gastan en los procesos de campo [...] cambian según los eventos se suceden uno a otro en el particular campo bajo estudio o en otros campos en los que los mismos actores operan concomitantemente" (Turner, 1974: 128). Con ello se fortalece la idea de que las asimetrías que afectan a los actores (y a los recursos, que aunque Turner no lo menciona, parece evidente de sus dichos), cambian de un momento a otro, alterando la lógica de las relaciones del campo y por ende, las de poder. Lo anterior porqué el campo, además de ser un conjunto de relaciones, es “... un continuum espacio-temporal con algunas características sistemáticas" (Swartz, Tuden y Turner: 1994: 119). Esto plantea que las asimetrías en el campo, están atadas, además de a las relaciones de los actores y los recursos, a las influencias del territorio y la ubicación temporal. Ello es fundamental para caracterizar de manera adecuada, tanto objetiva como subjetivamente, las circunstancias que fundamentan el ejercicio de poder.

El concepto complementario al campo, se encuentra en la arena: “...marco institucionalizado o no- que funciona como ambiente para las interacciones antagónicas que se esfuerzan por llegar a una decisión públicamente reconocida" (Turner, 1974: 133) Respecto de su relación con el campo, plantea: "Yo me inclinaría por tanto a ponerla dentro del campo, hablando claro, y a hacerla menos abstracta que el campo" (Turner, 1974: 132). Ello, porqué el origen del concepto lo ubica en la plaza de toros, donde hay una confrontación entre actores antagónicos -toro y torero-, en un espacio definido y delimitado, y donde se tiene como marco para esta lucha un conjunto de espectadores. La metáfora que usa Turner, se basa en que el objetivo de la lucha es, como señaló, la búsqueda de una decisión pública reconocida. Si bien he argumentado que no toda relación de poder es conflictiva y antagónica, el concepto de arena resulta 
central para complementar el de campo, en torno de los fenómenos de poder por intercambio. La razón es simple: en muchas relaciones de poder, se dará una controversia entre el monto, valor o calidad del bien gubernamental aportado y la profundidad, calidad o duración de las conductas o conceptualizaciones derivadas de la apropiación. Y tal controversia es necesariamente pública, pues atañe a las expectativas de futuro tanto desde la perspectiva del gobierno con desde la de los ciudadanos. Por ello campo y arena, se contemplan como herramientas básicas para el encuadre pertinente del fenómeno. ${ }^{80}$

En este apartado quisiera referirme a una disputa no aclarada, que constantemente surge en torno a los fenómenos de poder. Se refiere a lo justo o injusto de las acciones tomadas por aquellos que están en posibilidad de conducir la acción social. Esta es una de las polémicas que, me aventuraría a decirlo, están atadas al surgimiento mismo de la humanidad y sólo con ella acabarán. No es para menos. Ya hemos visto toda la serie de consideraciones que rondan los fenómenos de poder, desde evaluaciones racionales en términos de costo monetario o energético, hasta presunciones de bienestar general, ideologías específicas y futuros "necesarios". Quien enuncia una orden, ya sea producto de evaluaciones específicas individuales o grupales, o por otro lado, requisito de una posición estructural de poder, presenta ante los demás un enunciado que hace suyo, que postula una visión con la que ese actor concuerda por muy diversas razones. Desde el otro lado, desde la subordinación, la lectura de las razones y motivaciones difícilmente podría coincidir en todos los puntos, porqué aunque suene a perogrullada, se trata de otro actor. Dado que lidiamos con políticas de gobierno, las opiniones referentes a la pertinencia de un aporte de bienes específicos y la orden que suponen, tendrán que ver con la idea que se tiene del papel social que desempeña el funcionario, el órgano de gobierno o el gobierno mismo. Esto ocurre en múltiples casos, cuando la orden es percibida de manera explícita, de tal suerte que se confrontará la expectativa de desempeño institucional, con el enunciado de la orden. Esta idea surge de un

\footnotetext{
${ }^{80}$ En el trabajo "Economía política de la política económica" Castaingts (2007b) desarrolla una interesante propuesta de aplicación de los conceptos de campo y arena para el estudio de las políticas económicas de tipo gubernamental. Delinea de manera atractiva, el campo en el que se ubican tanto las políticas del Estado, como aquel en el que se encuadra el gasto público. Asimismo, esquematiza la arena y los contendientes, que surgen de la disputa en torno a la distribución social del gasto público.
} 
planteamiento muy acertado que desarrolla Federico Engels en el Anti-Dühring. Para él, independientemente de las opiniones particulares sobre el origen y funcionamiento de las instituciones políticas, si estas perduran, es porqué cumplen algún papel social relevante. Esta visión de corte funcionalista, resulta provechosa para enriquecer mi propuesta, en virtud de que recalca la necesidad de no ideologizar las tareas que han dado estabilidad a un órgano específico de gobierno. "Lo único que nos interesa aquí es comprobar que en todas partes subyace al poder político una función social: y el poder político no ha subsistido a la larga más que cuando ha cumplido esa función social" (Engels, 1968: 173). Dos precisiones. En primer lugar, la óptica funcionalista que declara el autor, es útil para lo que hemos visto, no en términos de origen o fundamento del órgano en cuestión, sino únicamente respecto de su desempeño hacia la población. En segundo, que desde luego, el trasfondo epistemológico de Engels se ubica en el origen estructural de los órganos del Estado, derivado del papel que cumplen en la coordinación de las relaciones de producción, que mantienen aquellos que aportan la mano de obra y aquellos que administran dicho desempeño. En la perspectiva anotada, las ordenes llevarán de manera frecuente, "atados" al cuerpo del bien suministrado, elementos de la función social que cumple la instancia que emite. Esta forma es la que se enuncia aquí como poder de función.

Ocurre no obstante, que quien enuncia la orden es un actor que tiene intereses particulares y específicos atados a múltiples determinaciones y que están imbricadas a él, no sólo en términos de jerarquía política o de clase, sino de raza, de lengua, de grupo político o de interés, o de cualquier otra índole particular. De tal suerte que las órdenes pueden, además de desempeñar un papel social, resultar útiles a un sector, grupo o individuo específico, que de manera constitutiva, pervierte el papel de carácter general que se supone debía desempeñar. Este desvío de los preceptos, tareas o bienes del Estado, en favor de intereses particulares de aquel que emite la orden, lo califica Engels como una forma de dominación:

Mientras la población que realmente trabaja está tan absorbida por su trabajo necesario que carece de tiempo para la gestión de los asuntos comunes de la sociedad -división del trabajo, puntos del estado, cuestiones jurídicas, arte, ciencia, etc.- tiene que haber una clase especial liberada del trabajo real y que resuelva esas cuestiones, y esa clase no dejó nunca de cargar sobre las espaldas de las masas trabajadoras cada vez más trabajo en beneficio propio. (Engels, 1968: 175-176) 
Como se ve, los argumentos de la clase dominante tienden a despegarse de la función social que los posicionó y buscan satisfacer intereses particulares, en este caso, de clase. El ejercicio de poder de este tipo será llamado poder de dominación. En ningún momento plantea Engels estas dos formas tipológicas de poder, pero se desprenden de sus argumentos. Hay que aclara que son herramientas de tipo ideal, pues resulta irrelevante enunciar cuanto de cada especie hay en un acto de poder. Se trata sólo de enriquecer las perspectivas de análisis, a través de posicionar los índices de utilidad social que refieren los individuos, que se encuentren a partir de la investigación o por otro lado, aquellos aspectos en donde la posición de poder, se utiliza con objetivos distintos a la mentada función. ${ }^{81}$

Así, la percepción de los actores involucrados sobre lo justo o injusto del ejercicio de poder, tiene en estas dos perspectivas, herramientas poderosas de análisis. Y es importante considerar la idea de justicia, porqué constituye un marco obligado de los fenómenos de poder social. Cierto es que poder y justicia tienen en esencia, aspectos contradictorios, pues como hemos visto, uno de los ejes del ejercicio del poder es la perspectiva de que el actor subordinado, es llevado realizar conductas o conceptualizaciones, que motu proprio no realizaría. Es decir, la motivación inicial del acto, está fuera de él. No es un acto enteramente libre o enteramente individual. Tampoco significa necesariamente un daño, pues desde una visión general, hay fenómenos de poder en los que el actor concuerda. Ello quiere decir que la inducción resultante le parecerá justa en sentido abstracto, o al ver el efecto en otros actores o al reflexionar de manera profunda en actos por él experimentados. Un ejemplo clarísimo de lo anterior es el uso legítimo de la fuerza en cualquier ámbito social. Un actor puede concordar con los reactivos que definen como legitimo un procedimiento, sin embargo, cuando el ejercicio del poder cae sobre el individuo, la cosa puede cambiar. Dependiendo de la intensidad de esa "fuerza" externa y dependiendo del grado de reflexión sobre el acto, el subordinado podría considerar que la coacción sufrida es injusta, pues se aplica de manera excesiva o inadecuada a su caso particular. No obstante la misma circunstancia en otros actores, le parecería una aplicación correcta de

\footnotetext{
${ }^{81}$ Un aspecto muy particular pero que vale la pena considerar en términos del ejercicio de poder de dominación, es la constitución orgánica del poder, con grupos subordinados a los que mediante el aporte de bienes gubernamentales, se induce u obliga a realizar conductas o conceptualizaciones que nada tienen que ver con la tarea específica del aparato. Este fenómeno, conocido como clientelismo, tiene al menos, dos caras evidentes. La primera se refiere a un fenómeno limitado, no regular. Cuando se torna constante y orgánico con el poder político, pasa de ser una forma, en cierto sentido peyorativa, a una de carácter socioantropológico. Gonzáles Alcantaud (1997) refiere estas peculiaridades en su trabajo sobre el clientelismo.
} 
la norma. Por ello la idea de justicia es problemática, pues los ideales que la orientan y las circunstancias de su evaluación, no permanecen constantes en el tiempo, ni tampoco son únicas.

De ahí, que la idea de velo de ignorancia inunde la propuesta de John Rawls al proponer una Teoría de la justicia (2002: 135-40). Supone que los individuos acepten un orden normativo, imaginando no saber en qué posición social se encuentran. Esta propuesta resume el conflicto señalado arriba, pues para tener estabilidad en el sistema de justicia, esa debería ser la norma. El sistema de poder es de otro orden y en la constatación empírica del fenómeno, justicia y poder chocan frecuentemente. Por ello la idea de poder de función y poder de dominación, puede resultar útil para encuadrar los ejes de justicia, que necesariamente, subyacen al ejercicio del poder político mediante el aporte de bienes gubernamentales.

La idea anterior da pie al último punto de este trabajo. Se refiere a las circunstancias en las que un gobierno reparte los bienes con los que desempeña su función. Un criterio muy general es el postulado por Theodore Lowi, quien resume en tres modos generales los mecanismos mediante los cuales el gobierno ejerce el poder: políticas regulatorias que restringen o limitan el acceso a recursos; políticas redistributivas, que definen que unos paguen lo que otros reciben; y finalmente las políticas distributivas, mediante las cuales se reparten recursos sin considerar las limitaciones de los mismos, ni quien <<paga>> el costo (Lowi, 2000: 89-117). ${ }^{82}$ Estas tres formas de implementación de políticas, mediadas por el poder, resultan centrales en el tratamiento. Todo reparto gubernamental puede implicar en primer término una exclusión, pues salvo contadísimos ejemplos, es imposible dar un bien accesible para todos y en todo momento. Así, existen múltiples limitaciones, y que van más allá del mero concepto de escasez, por las que resulta imposible repartir todo a todos. Ello resulta central, sobre

\footnotetext{
${ }^{82}$ Cada forma de reparto de bienes gubernamentales tiene aspectos de justicia ínsitos. Para Rawls, condensan la forma básica de sus principios de justicia. O la justicia es distributiva, lo que define el acceso libre e igualitario a cierto conjunto de bienes sociales, o es redistributiva en función de compensar a aquellos que por cualquier causa son desiguales (2002: 67-85). En cambio, Norberto Bobbio condensa la división clásica en justicia conmutativa y justicia distributiva. La primera se refiere a la que regula los intercambios para que se den entre cosas de igual valor y que las condiciones del cambio sean justas, es decir, lo que deriva del derecho civil; para el segundo caso se refiere a la que inspira a la autoridad pública para el reparto de honores y gravámenes, dando a cada quien según criterios que pueden cambiar, según merito, necesidad o esfuerzo (Bobbio, 1989: 20-21).
} 
todo para encuadrar la circunstancia de aquellos que reciben bienes gubernamentales y por ende, las asimetrías probables. Un eje básico de las políticas es la "puerta de entrada". Los mecanismos de selección de aquellos candidatos a recibir un bien, es factible encuadrarlos en un orden clasificatorio o al menos en un par de oposición, que clasifique los posibles de los excluidos. Consecuencias sociales se dibujan tanto en el gobierno, para la fundamentación del diseño de aporte a los posibles candidatos, como entre la población, pues independientemente de si tiene acceso o no, puede considerar justos o injustos los mecanismos de reparto del bien. Esto desde luego impacta los efectos de poder

En cuanto a los otros dos tipos, su utilidad es patente. La mecánica de la relación de poder tiene mucho que ver con la procedencia de los bienes gubernamentales o la percepción de la procedencia. Son no obstante, niveles diferentes. La construcción del recurso como fenómeno de gobierno, define la lógica del diseño y la implementación. $\mathrm{Su}$ origen está o en una lógica redistributiva o en una distributiva, dependiendo cómo se argumentó administrativamente su construcción. Ello desde luego, corre al parejo de las consideraciones de justicia social que motivaron tal política, pero los procesos de aporte y apropiación del bien, se pueden describir de manera más precisa si se consideran estos aspectos.

Desde la perspectiva del que recibe el recurso, también es relevante. Pues en términos de evaluación del gobierno, o inclusive del Estado, la percepción del origen de los bienes aportados en una política, en muchas ocasiones afecta las posturas y las actuaciones que suponen tal aporte; puede llegar a impactar incluso la toma misma del bien. Se mencionó anteriormente, como para Gouldner, la norma de reciprocidad (o de intercambio) y la de beneficencia definen aspectos muy diferentes. Lo primero es una relación consecuente, la segunda es obligatoria para una de las partes. La percepción del origen de los bienes que una política aporta, impacta en un grado importante lo que los individuos hagan al respecto del aporte. No es lo mismo considerar que un bien se construyó con contribuciones ciudadanas, vía impuestos, a considerar cualquier bien gubernamental, como "del pueblo". Desde la primera perspectiva, muchos pudieran caer en la cuenta de no tener derecho a la apropiación del bien, ya que no forman parte de su construcción; desde la segunda, los individuos pueden rechazar las conductas o conceptualizaciones de apropiación, pues dado que los bienes son del pueblo, el gobierno - percibido cono sujetos concretos o como clase política- no tiene derecho a condicionar en forma alguna, la toma del bien. 
Los puntos anteriores, son ejes generales en el aporte de bienes, pero ¿qué peculiaridades implican? En un trabajo muy interesante, Jon Elster (1998) aborda estos aspectos. En su propuesta, hay dos aspectos muy adecuados a lo que aquí se trabaja. La primera es que para Elster la justicia debe ser un término de tal naturaleza que “...en su sentido amplio incluya la distribución de bienes escasos con el propósito de maximizar algún conjunto de características de los receptores o, más generalmente, de todos los ciudadanos" (Elster, 1998: 18). Por otro lado, reconoce que: "Se podría escribir la biografía ficticia de un ciudadano típico, para describir como su vida es modelada por sucesivos encuentros con instituciones que tienen el poder de otorgarle o negarle los bienes escasos que busca" (ibid: 14).

Como se ve, todo aporte de bienes gubernamentales puede ser sujeto de una evaluación pública en términos de los supuestos de justicia que implica su asignación. Pero de manera fundamental, Elster reconoce el papel que el poder juega en el fenómeno. Diferencialmente, el foco de su atención estriba en que para los organismos de gobierno, el poder deriva de la circunstancia de dar y retener. No desde el punto de vista que aquí interesa: que la modelación del individuo ocurre, como fenómeno de poder, como consecuencia del aporte de bienes y su apropiación dirigida; es decir no de la posesión, sino de la aportación.

Esta diferencia de enfoque, no impacta los usos de algunos de los conceptos que Elster presenta. En general, se enfoca en las formas de justicia que llama "locales". Se refieren a las decisiones sobre el reparto de bienes que toman instituciones de manera restringida, que dependen de regulaciones del gobierno, pero que cuentan con autonomía para decidir libremente, muchos aspectos del reparto. Sus decisiones son de tipo compensatorio, es decir reparan en las personas algún tipo de infortunio y las asignaciones son no monetarias; se refiere a cosas como riñones donados, entrada y servicios de instituciones académicas y exenciones del servicio militar. La justicia global por el contrario parte desde el gobierno central, es completamente compensatoria y generalmente toma la forma de asignaciones en dinero (Elster, 1998: 15-6).

La justicia local tiene tres consecuencias básica: un impacto desigual, pues hay beneficiados y excluidos; que la suma de las justicias locales, puede dar una injusticia global; y un efecto de incentivo, al animar a la transformación de la conducta para acceder al bien (ibid: 26-7). Este último punto llama la atención, pues Elster aborda los efectos en la conducta para la toma del bien, pero no como efecto intencional, sino oblicuo. Los problemas en la asignación derivan de la naturaleza del bien asignado. 
Pueden ser escasos de manera intrínseca o artificialmente escasos (por ejemplo las becas) y pueden ser divisibles o indivisibles (ibid: 33-5). Para repartir un bien existen los principios, que son los conceptos de justicia que definen la asignación del bien; los criterios para seleccionar a los beneficiarios y que consideran la circunstancia individual; los mecanismos, que son formas de asignación no individualizada (se refiere a fenómenos como las filas y los sorteos); y los procedimientos, que son la versión operacional de un principio. Finalmente, que los principios tienen dos esferas de acción, es decir, que dependen de propiedades de los individuos o que son independientes de sus propiedades (ibid: 77-82). Los principios son de seis tipos

- Igualdad: todos tiene derecho los bienes que son repartidos por igual (divisibles o indivisibles); si no es posible, se sortean.

- Relacionados con el tiempo: hacer "cola", listas de espera, por antigüedad.

- De estatus: edad, genero, preferencia sexual, etnicidad, características físicas (edad, peso, estatura), estado civil, residencia, situación laboral, religión, grado de estudios, etcétera.

- Por otras propiedades: niveles de ingreso, necesidad, eficiencia en el aprovechamiento del bien

- Por relación al poder: quién paga más por ellos (por ejemplo concesiones), influencias, etcétera

- Mixtos: generalmente los procedimientos no son solo de un tipo y confluyen dos o más principios. (ibid: 84-122).

Como se ve, estos insumos son útiles en la comprensión general de los fenómenos de poder mediante intercambio, pues en muchos casos, la circunstancia de la apropiación, tiene que ver con la circunstancia de la asignación. Por ejemplo, en los servicios educativos, el nivel de conocimiento, es un criterio para la asignación del bien, sin embargo, para irlo recibiendo paulatinamente, se tiene que ir demostrando constantemente cierto nivel, que en este caso será progresivo, es decir, asignación y apropiación van al parejo. En otras ocasiones, la asignación únicamente define "el puerto de entrada" y los efectos son posteriores. En cualquier caso, conocer los argumentos para la discriminación de los posibles sobre los excluidos es básico, pues constituye un insumo clasificatorio con base en el cual, se construyen las asimetrías que sostienen el ejercicio de poder. Esa clasificación inicial, no necesariamente es la única 
que conforma el complejo total de las relaciones de poder, pues ya "adentro del sistema" las asimetrías pueden tener relación con la clasificación inicial o ser independientes, pero no obstante, su consideración necesaria.

\section{Corolario}

Las relaciones de poder, ocurren como se expuso al inicio, en la movilización de las asimetrías entre actores, centradas en uno o varios sistemas de clasificación. De las formas típicas de ejercer el poder, se escogió profundizar en la forma intercambio. Por ello la relevancia de la discusión inicial, que retoma autores y tradiciones de una raíz antropológica muy profunda. Las reflexiones de Marcel Mauss sobre el impacto de los hechos de intercambio en el conjunto total de los hechos sociales, son de una hondura sorprendente, por la apertura de variables no económicas sobre hechos que, a simple vista, parecerían llanamente "económicos".

No interesa mencionar las limitaciones o errores que pudo cometer Mauss en un trabajo considerado fundante en la disciplina. Sólo tal vez, que evadió las consecuencias políticas relacionadas con dar y tomar, y se limitó a pensar como inherentes, efectos de instauración de jerarquías, que curiosamente, consideraba como motores poderosos en el fenómeno. Claude Lévi-Strauss, profundizó en la importancia de tales razonamientos, al llevarlos al plano de la generalización antropológica, es decir, que los fenómenos de cambio, constituían el germen central de la vida social, pues el otro eje, el normativo, estaba anclado a la <<prohibición de la autarquía〉>, es decir, que la prohibición del incesto, tenía sentido en tanto condicionaba a los hombres a relacionarse con otros, al cambiar mujeres. Sin embargo, caminó la misma senda de su antecesor al evitar ahondar en las consecuencias políticas que implicaban el cambio y la jerarquía instaurada. Es más notable aun en su caso, pues el cambio básico, determinaba "mover" personas de un lado a otro, invadiendo el campo de los efectos en la conducta de los colectivos y los individuos; esto comporta efectos políticos, y desde luego, de poder.

Maurice Godelier arranca su reflexión sobre la senda abierta por sus colegas franceses, pero incorporando de inicio los efectos políticos y de poder. Dar, guardar y devolver, supone controlar bienes, tiempos y movimientos sociales, que quedan anclados al arranque del cambio o a su culminación. Así, aporta un cuerpo teórico notable para la reflexión de los efectos de poder en los procesos de "don" y de “intercambio". Sin embargo, centrado en el objeto que va y viene y no en los actores que dan y toman (entrando en la región que tanto criticaron Mauss y Durkheim sobre el 
origen de los conceptos clasificatorios), plantea que hay una relación originaria entre todos los bienes que circulan y unos cuantos, los sagrados, que no. Supone con ello, una fuente originaria e inmutable del poder: el mundo sagrado y sus objetos. Se han expuesto las reservas a tal ontología y no se abundará más sobre ello. La ausencia verdaderamente notable, y que comparte con los otros dos autores, es que en los fenómenos de don-intercambio, resulta lo mismo cambiar objetos, personas o actividades. Desde luego que para los intereses que aquí se abordan, la reflexión sobre el intercambio de bienes por servicios es central, no obstante, más allá de este trabajo, el impacto de cambiar objetos por actividad humana es un hecho densísimo y que no puede ser pasado por alto. Como las inquietudes de los autores expuestos, corrieron en otra dirección por razones que no impactan ni su obra ni su utilidad aquí, hubo que buscar en otro lugar, el elemento faltante.

La economía política, en su vertiente marxista es un campo que tiene entre sus fundamentos, justo reflexionar sobre los fenómenos políticos atados al intercambio, ya sean estos entre bienes homogéneos o heterogéneos. Los últimos, cuyo caso más conspicuo es el intercambio de dinero por trabajo, son tratados en extenso por Carlos Marx. La revisión de sus trabajos, permitió profundizar en el proceso mismo del intercambio y desde luego, evidenciar su relación con la jerarquía instaurada. Sin embargo, como Marx estaba preocupado por el origen del valor y su relación con el intercambio, no se contenta con las explicaciones comunes -que en Adam Smith son un ejemplo- de que los intercambios inician entre individuos que concurren libremente e intercambian de manera más o menos equilibrada, de tal manera que al final, el cambio es aproximadamente equivalente en virtud de ser producto de una negociación entre pares. El enunciado, que muestra abreviado algunos de los núcleos del credo liberal y que, es de recalcar, ocurre en innumerables situaciones de intercambio, deja sin abordar la otra cara de la moneda: la concurrencia obligada y el intercambio sin equilibrio, donde al final, la negociación ocurre sobre las tasas del desequilibrio permanente. Más allá de la pertinencia ideológica de cada postura, el trabajo de Carlos Marx, se centra en las causas y los efectos de las relaciones de intercambio, donde dinero y actividad son los bienes regulares y la peculiaridad de las asimetrías existentes, redunda en un ejercicio de poder más contundente. Es, recordando a Godelier, la otra cara del don: no la de compartir, sino la de combatir. Abre además la puerta para considerar, desde la Antropología, un fenómeno no abordado especialmente por los autores citados: que el que da, obligadamente, queda en subordinación y el que devuelve, queda superordinado, 
a pesar de que devuelve menos. Este caso particular, que llamamos metafóricamente "antidón", resume justo las circunstancias inversas de lo descrito por Mauss: no una espiral permanente de superordinaciones, sino una cadena fija de subordinación. El cerrojo antropológico a los trabajos de Marx, parte no obstante, de que para este alemán, los sistemas clasificatorios son inmutables y centrados en un punto único: la propiedad de los medios sociales de producción, cristalizando las posibilidades culturales de otros sistemas de diferencias, que fundamenten relaciones de poder distintas, vía el intercambio. Los cuatro autores tratados aportan entonces, modelos para entender mecánicas de poder diferentes, según las circunstancias (asimétricas) de lo cambiado y los cambiantes.

Sistemas de diferencias y sistemas de intercambio, caracterizan lo básico del ejercicio de poder que se trata aquí, no obstante, se enunciaron un serie de precauciones y complementos, que eliminan el esquematismo teórico, al mostrar ángulos adicionales que rondan la aproximación empírica al fenómeno del poder político vía el intercambio. Como es costumbre, no se glosarán todos los aspectos referidos, sino únicamente aquellos cuya ampliación fortalece la discusión en torno al caso de estudio elegido.

Uno de los temas más polémicos en torno a las políticas públicas, es la relación que guardan con el beneficio que aportan a un sector de la población o a la totalidad nacional. Por ello los ejes que se desprenden de la "creación” y aporte de los bienes públicos o gubernamentales, abre el campo inmenso de la Política en su sentido más amplio. ¿Cómo se jerarquiza que bienes deben aportarse primero? ¿Quiénes tienen derecho? ¿Quiénes deben esperar? ¿Quiénes quedan excluidos? ¿Quiénes los reciben y muy importante, quiénes los pagan? Estas preguntas están enmarcadas en el campo de la Filosofía Política y tienen la forma particular en el concepto de Justicia.

Hay una vasta región del comportamiento humano, que está englobado en el conjunto de valores normativos que refieren las ambiciones y anhelos de las sociedades. Estos valores pueden ser aceptados por todos o por un sector de la sociedad. En todo caso, para el tema de este estudio, lo central, no es porque tales valores son mejores o más fundamentales que otros, sino, que dado un estado axiológico determinado, existe una disputa sobre si los mecanismos para lograr que dichos supuestos se cumplan, concuerdan con el fin último y si en las partes intermedias del proceso, se apegan o parten de los ejes generales. 
Por ello es que las reflexiones sobre los bienes gubernamentales; los mecanismos para su creación; los ámbitos en donde se disputa su pertinencia; las atribuciones a una política pública de "justa" o "injusta"; y los individuos y procedimientos concretos que materializan tales dichos abstractos, son relevantes, pues determinan, como se expuso en el desarrollo, quiénes y cómo van a apropiarse de los recursos que el Estado libera para el acceso pleno al orden contemplado.

Una precisión a este respecto, es que para el tema del ejercicio del poder político vía el intercambio, lo primordial es conocer las condiciones suficientes y necesarias, por las que los supuestos iniciales -nuevamente, las ordenes- concuerdan con las conductas o conceptualizaciones de apropiación. Ello, en un primer momento, independientemente de su mayor o menos relación con el marco normativo estatal mayor o derivado, es decir, la Constitución y las Leyes Secundarias. Sin embargo en un segundo momento, es decir, aquel de los efectos en la población de destino, se buscará valorar si los supuestos constitucionales que originan la acción gubernamental, son alcanzados al ejercer tal poder político.

Dicho lo anterior, se pueden enlazar los supuestos teóricos con el tema de estudio elegido. Las políticas de educación superior las poblaciones indígenas, exploradas a propósito de las Universidades Interculturales, dan un marco adecuado para confrontar el modelo propuesto con un hecho concreto de poder. La reforma constitucional al artículo segundo, estableció diferentes mecanismos para llevar determinaciones de justicia a los pueblos originarios de la nación mexicana; estos, como se mencionó anteriormente, plantean la destrucción de ciertas asimetrías -y la creación de otras- para eliminar la condición de subordinación y desigualdad en la que viven todavía, muchos indígenas. $^{83}$

El mecanismo y la asimetría central para este trabajo, parte de la posesión de recursos por parte del Estado y su carencia en los ciudadanos, específicamente, los indígenas. Las conductas y conceptualizaciones que se espera ocurran como producto de la apropiación de los bienes y servicios materiales, ideales y simbólicos, constituirán el núcleo del ejercicio exitoso del poder político, en virtud de que tanto gobernantes como

\footnotetext{
${ }^{83}$ En la nota 28 se introdujo esta idea de la creación y la destrucción constitucional de las asimetrías.
} 
gobernados, convergen en la pertinencia del orden supremo del país. Ahí están las órdenes que deben cumplirse por los dos grupos de individuos. El asunto, como se mencionó anteriormente, es qué tanto de lo supuesto se consigue y qué tanto de eso, abona el ideal fundamental de justicia para esa población.

Por ello, los insumos teóricos para evaluar la política, aparecen en este punto, como pertinentes. Buscan compaginar, la forma específica que toman dichos bienes en el marco del proceso educativo, con las acciones conducentes a su apropiación. Adicionalmente, indagar si en la apropiación se realiza lo supuesto o si no ocurre, ya sea por imposibilidad fáctica o por fenómenos como el del mencionado "gorrón". Enriquece el proceso, el conocimiento de la percepción subjetiva respecto a la condición de superordinado o subordinado, qué queda antes y después del cambio, por qué define las actitudes convergentes o divergentes hacía el bien suministrado y su apropiación; ello, independientemente de que se rechacen las condiciones jerárquicas del cambio, pero se tome el bien.

La disputa anterior, se encuadra en los valores que se desprenden de la reforma constitucional y que enmarcan el hecho de la desigualdad existente entre indígenas y el resto de los ciudadanos. Entonces, la insuficiencia, inadecuación o inviabilidad del diseño de la política son, ideas constantes entre los receptores del bien y en aquellos que están cercanos a los ideales de dicha población. Esto impacta en cierta medida el intercambio y por tanto, la efectividad de la política. De ahí, que establecer un marco mínimo de los valores y anhelos que los indígenas tienen en torno a las políticas que los afectan, resulta básico para delimitar la investigación y también, la confluencia y eficacia de las acciones gubernamentales con el marco constitucional. Así, en el capítulo siguiente, se establecerán los fundamentos de los valores normativos básicos que inciden en el diseño y la implementación de las políticas hacia los pueblos indígenas, considerando dos vetas existentes: el orden nacional y el orden internacional. Ambos contextos fueron determinantes para culminar con la forma final, que a la fecha tiene el artículo segundo de la Constitución Mexicana. Forma muy cuestionada en el campo político indigenista, pero que, sin excepción, constituye el marco obligatorio desde el que los tres órdenes de gobierno tienen que trabajar. La eficacia y la pertinencia en el ejercicio del poder político, legal y legítimamente determinado, son los núcleos empíricos de esta investigación y por ello, las características de ese marco legal, en el contexto de las clasificaciones y el intercambio, son las que se van a desarrollar. 


\section{3.- El orden y las órdenes nacionales e internacionales}

El orden global contemporáneo, constituye una suma no aritmética de fuerzas con necesidades de orden nacional pero también, de carácter internacional. Esta composición binaria es un insumo relevante a partir del comienzo del siglo XX y cobra después del fin de la Segunda Guerra Mundial una relevancia tal, que no es posible entender los procesos locales o globales si se excluye alguno de sus componentes. La creación y existencia estable de la Organización de las Naciones Unidas constituye uno de los crisoles de tales fuerzas. En su seno, las naciones expresan sus necesidades, exigencias y anhelos particulares, con objeto de armonizarlos frente al resto de la comunidad internacional. En ese sentido, representa un espacio para la negociación y la resolución de conflictos y también, un centro normativo mundial, cuyo eje fundamental es expresar condiciones mínimas deseables para todas las personas que habitan el globo y desde luego, los mecanismos para lograrlo.

Los estados miembros han formulado desde su inicio, diversos cuerpos normativos respecto de los distintos campos de la vida humana que deben respetarse con una forma determinada. En consecuencia, han signado instrumentos vinculantes y no vinculantes y establecido los mecanismos en caso de ruptura o incumplimiento de los acuerdos. El universo de los derechos de los pueblo indígenas, forma parte de tales acuerdos internacionales. Su pertinencia se expresó desde la declaración del primer principio fundamental global, la Declaración Universal de los Derechos del Hombre, pero no como parte, sino como exclusión, al ser expresada por la Asociación Americana de Antropólogos (AAA), la lesiva ausencia de la dimensión colectiva de los individuos, 
es decir, que la protección a sus derechos fundamentales es incompleta si no se considera la matriz cultural que los acrisola; dimensión indispensable para los miembro de los grupos indígenas.

Por lo tanto, la elevación de los derechos de los indígenas al nivel de norma global, inició con una disputa acerca su presencia en el cuerpo general de derechos humanos. La batalla por su inclusión, se ha escenificado en el frente internacional, y desde luego, en los distintos ámbitos nacionales donde los grupos indígenas tienen presencia. En el caso mexicano, diversas iniciativas políticas se gestaron ya independientemente, ya complementariamente a los procesos internacionales, siendo el punto culminante, la irrupción del Ejercito Zapatista de Liberación Nacional, que llevó las demandas que los indígenas habían enarbolado de manera centenaria, al plano de lo inevitable, es decir, que terminaron por cuestionar al Estado y modificarlo. Luego de siete años de tensiones se legisló en el año 2001, la forma final que tendría el artículo segundo de la Constitución Mexicana, forma altamente cuestionada por los actores indígenas, pues difiere en gran forma de lo que se firmó con el gobierno federal en los Acuerdos de San Andrés en 1996, pero forma obligatoria para los tres órdenes de gobierno en el campo de las políticas hacia los pueblos indígenas.

Todo el proceso de discusión de los “Acuerdos", estuvo impactado por la legalidad internacional, que avalaba las demandas de los indígenas levantados, en particular, destacó el Convenio 169 de la Organización Internacional del Trabajo, instrumento internacional que el Estado Mexicano signó en 1989 y que contenía disposiciones legales relacionadas con los indígenas, incumplidas o cumplidas de manera deficiente. Quedaba en evidencia así, la señalada convivencia e interrelación entre los órdenes nacional e internacional.

Este breve y esquemático panorama, tiene la pretensión de encuadrar el análisis de los cuerpos legales que positivamente determinan la actuación de los funcionarios mexicanos, ya sea por la vía nacional (la Constitución y las leyes secundarias) o por la internacional (acuerdos y convenios, obligatorios al nivel de las leyes secundarias). Estos marcos, encierran las consecuencias sociales que se busca producir y lo que intentra significar el título del capítulo, por su referencia a las "órdenes" nacionales o internacionales. Resulta obvio en este punto, mencionar el corte metodológico que se va a realizar en la mayor parte de los aspectos en torno del panorama mentado. La densidad política, social, legal, histórica, axiológica, que tuvo y tiene lugar en relación con este 
tema, rebasa necesariamente el nivel de análisis que se tiene considerado. La mira principal del tratamiento del cuerpo normativo, apunta a tres blancos: las características del sistema de clasificaciones considerado; las asimetrías creadas o destruidas legalmente; y la forma intercambio que las políticas planteadas toman o pueden tomar y que culminan, desde luego, en el ejercicio del poder político.

Es claro que estos tres ámbitos, tienen impactos decisivos en la manera en la que se conciben o reciben las políticas indigenistas; de ahí que la polémica en torno a la forma específica de tales políticas sea intensa. Sin embargo, los argumentos que determinan ambas posiciones son, como ya dije, inútiles en este punto. El trabajo principal de este capítulo, desarrolla la forma en la que se da el proceso diferenciaasimetría-poder por intercambio, para mantener la congruencia teórica general y mostrar la utilidad de sus herramientas para encuadrar el fenómeno. Desde luego, más adelante, cuando se expongan las consecuencias de las determinaciones constitucionales en los mecanismos concretos de implementación del sistema de educación intercultural universitaria y en aulas de la Universidad Intercultural del Estado de México, ambos universos -el de las razones de la forma concreta que toman las políticas de educación intercultural y el de las opiniones sobre la utilidad de dichas políticas-, quedarán evidenciados de manera clara. Por el momento, regresemos a la discusión de las fuerzas normativas presentes en el orden internacional y nacional, y su caracterización y efectos en términos del ejercicio de poder mediados centralmente por el intercambio.

\section{El marco internacional ${ }^{84}$}

El primer cuerpo legal internacional del moderno orden contemporáneo, lo constituye la Declaración Universal de los Derechos del Hombre. Si bien esta declaración no constituye un instrumento de naturaleza vinculante, su carácter universal deriva de su aceptación por los estados miembros de las Naciones Unidas en Asamblea General (1948). El carácter normativo de la declaración, tiene su origen en dos cuerpos distintos de sentencias: aquellas que definen los temas a los que tienen derecho los individuos y aquellos que definen lo que es imposible causarles. ${ }^{85}$ En ambos casos, el garante de

\footnotetext{
${ }^{84}$ Una relación pormenorizada de todos los instrumentos internacionales de derechos humanos que confluyen con los de los derechos indígenas, se encuentra en Stavenhagen (2002).

${ }^{85}$ Hay que hacer notar que existe un principio que supone que los principios jurídicos tienen que ser expresados en términos negativos, es decir, sancionar únicamente hechos que no deber ocurrir y que con base en ello, se norma la conducta de los individuos y los órganos del Estado. Esta posición es la defendida intensamente por Hans Kelsen (2007), que entiende dichas normas como primarias. Contrasta con otras voces, que plantean que se deben declarar cosas a ocurrir como norma primaria y que
} 
estos derechos es en última instancia, el Estado miembro en donde se encuentra el individuo vulnerado, ya sea en su propio territorio, ya en los territorios a su cargo; en su defecto, los estados miembros los harán valederos donde quiera que se vulneren, en virtud de su dimensión universal extensiva "a todos los miembros de la familia humana". ${ }^{86}$

Las clasificaciones centrales de este documento, desde la perspectiva que se ha planteado, contiene ciertos principios clasificatorios que permiten enunciar lo que se quiere lograr o prohibir: derechos/barbarie; libertad/esclavitud; justicia/injusticia; igualdad ante la ley/desigualdad; paz/guerra; vida/muerte; individuo/colectivo. En estos insumos, el primer término conforma valores que son los de necesaria ocurrencia, y si bien no son equivalentes, discursivamente son enunciados homólogos, de acuerdo con los mecanismos de transformación referidos.

Estas oposiciones que tipifican hechos o valores, se complementan con las otras diferencias que están centradas en los individuos y que los artículos de la declaración, reconocen como existentes, pero que no deben ser un criterio de acceso a la lista primera, es decir, que los derechos para una vida libre, justa y pacífica no pueden ser limitados a los individuos en función de su “...raza, sexo, idioma, religión, opinión política o de cualquier otra índole, origen nacional o social, posición económica, nacimiento o cualquier otra condición" (Art. 2). Para efectos prácticos, diferencias consubstanciales a los individuos, que derivan ya de su naturaleza intrínseca, ya de su origen social, ya de sus talentos o los efectos de estos, no deben ser invocadas bajo ninguna circunstancia para privarlos de sus derechos. El sentido de esta declaración, surge de que “...el desconocimiento y menosprecio de los derechos del hombre han originado actos de barbarie ultrajantes para la conciencia de la humanidad" (Considerandos) y desde luego, de la fundamentación para una estructura de poder, que aquí se define como ilegítima e ilegal, en virtud de originarse en asimetrías que vulneran los derechos humanos. Son claros en este punto, cuatro aspectos de la Declaración: 1) Que las diferencias individuales tipificadas, funcionan como asimetrías que culminan en ejercicios de poder, dado que son éstas, las que individuos o grupos movilizan para causar efectos en los individuos o grupos de la sociedad; 2) Que la

constituyen acciones deseables de los individuos (Fix-Zamudio 1969: 108-9). Sin embargo, me parece que para el debate presente, el ejercicio de poder, puede armonizarse con ambos extremos, pues lo "empírico" del hecho de poder, es la conducta o la conceptualización causada de acuerdo con la orden y no, la forma afirmativa o negativa en la que se expresa dicha sentencia.

${ }^{86}$ En los Considerandos. 
movilización de las asimetrías es condenada, siempre que vulnere el acceso de los individuos a los derechos establecidos; 3) Que no se condena necesariamente el ejercicio de poder con base en las diferencias individuales establecidas, sino cuando su “asimetrización" conduce al punto dos; 4) Que la destrucción de asimetrías postulada -la desasimetrización-, enuncia rubros en los que no es permitido el uso de tales diferencias o mecanismos para neutralizarlas; empero, las diferencias subsisten. ${ }^{87}$

Ejemplo de lo anterior es la enunciación del artículo primero según el cual, "Todos los seres humanos nacen libres e iguales en dignidad y derechos...", refiriéndose justo al campo de los derechos (asimetrías ante la ley) y no de sus diferencias consubstanciales. Oposiciones como hombre/mujer, blanco/de color, castellano/náhuatl, católico/protestante, liberal/conservador, rico/pobre, son ejemplos de pares que existen en los colectivos, que caracterizan sistemas sociales, pero que deben ser extirpadas del campo de los derechos a los que deben tener acceso todos los hombres.

Finalmente, se mantienen y enuncian diferencias y asimetrías específicas: aquellas que sustentan el poder del Estado: "La voluntad del pueblo es la base de la autoridad del poder público..." (Art. 21) que es expresada por medio de elecciones democráticas, en un sistema representativo en el cual algunos miembros del pueblo se incorporan “...a las funciones públicas de su país" (ibidem). Las diferencias individuo/colectivo, votante/votado y administrador/administrado, subsisten como bases del ejercicio del poder y la autoridad política; con base en ello, el Estado puede garantizar la conducción ordenada de la sociedad, para los fines que ésta anhele, entre ellos, el acceso pleno a los derechos universales. En realidad, el artículo 28 garantiza el derecho de toda persona "...a que se establezca un orden social e internacional en el que los derechos y libertades proclamados en esta Declaración se hagan plenamente efectivos". Tiene que haber un Estado justo, pero Estado al fin. Los mecanismos reales que sustentan al Estado, pasan por hechos, tanto de autoridad como de poder; es imposible e inviable neutralizar las asimetrías que les permiten funcionar, aunque, se debe mencionar, los mecanismos estatales se han transformado a lo largo del tiempo y las asimetrías que los sustentan, también. Para culminar este razonamiento, no hay que dejar pasar un dato muy relevante y que a menudo se olvida en todo tipo de discusiones sobre derechos humanos en general e indígenas en particular: que los compromisos signados en la Declaración, son, formalmente y de hecho, compromisos para los

\footnotetext{
${ }^{87}$ La descripción básica de los conceptos: asimetrización y desasimetrización, está reseñada en la nota 28.
} 
Estados y con los Estados. Esto quiere decir que los fundamentos y mecanismos para el cumplimiento de los derechos humanos, llegaron al nivel que tienen, en foros de naturaleza internacional, es decir entre naciones-estado y que las llamadas de atención a las violaciones que ocurren, o son denunciadas ante un Estado particular o son denuncias a un Estado particular. Ello no invalida ni anula la vía central que en este tema jugó la sociedad civil histórica en los diferentes Estados miembros o la que pudiera desempeñaren el futuro. El asunto es que el tema de las violaciones, se centra en el campo estatal, en función de que si un individuo vulnera algún derecho de otro, su sanción debe ocurrir en tribunales estatales contemplando a los particulares. La dimensión estatal subsiste, al ser dichos tribunales incompetentes o parciales en la resolución de la injusticia entre particulares. Es entonces que el orden internacional se activa para reclamar el cumplimiento de los derechos convenidos. ${ }^{88}$

En cuanto a los mecanismos de poder por intercambio, que la Declaración enuncia y que están suscritos con el objetivo de cumplir sus normas básicas, destacan aquellos que implican recursos estatales y conductas y conceptualizaciones en su apropiación. El artículo 22 lo enuncia claramente: "Toda persona, como miembro de la sociedad, tiene derecho a la seguridad social, y a obtener, mediante el esfuerzo nacional y la cooperación internacional, habida cuenta de la organización y los recursos de cada Estado, la satisfacción de los derechos económicos, sociales y culturales indispensables a su dignidad y al libre desarrollo de su persona". ${ }^{89}$ Está implícito, pero claramente entendido, que los Estados deben destinar recursos y movilizar órganos administrativos para que los individuos puedan tener satisfechos los derechos enunciados. Por lo tanto, parte de los recursos tiene por objeto, mediante su apropiación, que los ciudadanos hagan acciones que tienen como satisfactorias de sus derechos económicos, sociales y culturales. No se trata de forzar la Declaración para que sirva a los propósitos particulares de mi propuesta. Hay múltiples rubros en los que los individuos están impedidos de facto para llevar a cabo acciones que están dentro de sus derechos fundamentales. Esta visión igualitarista de la justicia, que tiene una gran tradición, es precisamente lo que la Declaración ordena a los Estados realizar.

\footnotetext{
${ }^{88}$ En la Constitución Mexicana, norma suprema de la Nación, se tiene contemplada la importancia de los compromisos internacionales signados por el país, al tenerlos como segundos en relevancia en el orden estatal mexicano, es decir, que los compromisos internacionales están en segundo lugar de jerarquía, solo después de la constitución federal, según resolución de la Suprema Corte de Justicia de la Nación (2009), del 13 de febrero de 2007.

${ }^{89}$ El subrayado es mío.
} 
Otro aspecto semejante, es el educativo, pues la Declaración mandata la asignación de recursos para que los individuos se eduquen de manera gratuita en el nivel básico pero obligatoriamente, en el entendido de que tal educación “...tendrá por objeto el pleno desarrollo de la personalidad humana y el fortalecimiento del respeto a los derechos del hombre y a las libertades fundamentales; favorecerá la comprensión, la tolerancia y la amistad entre las naciones y todos los grupos étnicos o religiosos" (Art. 26). Describe llanamente, conductas y conceptualizaciones de apropiación.

Los dos ejemplos anteriores, no coinciden necesariamente con los objetivos y supuestos de la investigación presente, pero sí muestran, como se articulan sus ejes básicos, que como adelanté, contemplan diferencias, que estructuran asimetrías, que son aceptadas o desechadas en términos normativos, y que de dicho orden, surgen "órdenes" a cumplir. Muchos de estas sentencias son viables de llevar a cabo mediante el ejercicio del poder político, a través del intercambio de recursos; las conductas y conceptualizaciones de apropiación, son el núcleo de tal ejercicio.

Este resumido panorama sobre la Declaración de los derechos del hombre, termina aquí, pues cumplió el objetivo de evidenciar los principios generales que sentaron las bases para los instrumentos internacionales, referentes a los derechos de los pueblos indígenas. No se buscó señalar las ausencias o contradicciones con las reivindicaciones indígenas, porque como he argumentado, los instrumentos positivos son los que norman de manera efectiva las políticas gubernamentales. Mas esta ampliación viene a cuento, porque la Asociación Antropológica Americana (1947), emitió un año antes de la votación en la Asamblea General, su "Declaración sobre los Derechos Humanos". En ésta, llama la atención a la comisión que estaba redactando la declaración para que subsanara una deficiencia fundamental y que definía la Declaración como evidentemente parcial, diluyendo su pretensión de universalidad. La deficiencia provenía de que, si tal instrumento pretendía ser universal, necesariamente tenía que considerar las bases culturales desde donde se emitía tal orden universal. Caracterizó el problema en estos términos: “¿Cómo puede ser aplicada a todos los seres humanos la Declaración propuesta y no ser un pronunciamiento de derechos concebidos únicamente en los términos de los valores que prevalecen en los países de Europa Occidental y Estados Unidos?” (p. 539). Es decir, problematizaban un hecho ilógico e imperialista, pues se imponían derechos incompatibles con otros sistemas culturales, pero también, se excluían otros, esenciales para esa porción de la universalidad. 
Al argumentar las evidencias sobre los aspectos en los que la unidad de la especie humana es incongruente con postulados normativos únicos -en su forma o en su fondo-, cuestionan que se deje del lado tal evidencia y se impongan unos valores sobre otros. La conclusión del documento plantea que los valores y derechos que tienen los individuos, están atados a los valores que imperan en su cultura, de ahí que si se busca el respeto a los individuos y sus diferencias, se deben respetar las diferencias culturales; más aun, los estándares y los valores son relativos a la cultura de la que derivan, así que cualquier intento de formular universales desde una posición cultural única, es inviable en términos generales. Sólo cuando un pronunciamiento sobre el derecho de los hombres a vivir en términos de sus propias tradiciones, sea incorporado en la Declaración propuesta, es posible dar pasos firmes en la definición de los derechos y las obligaciones de los grupos humanos, considerándose entre ellos en la base firme del conocimiento científico del hombre (p. 543).

Como es sabido, la petición de la AAA no fue considerada y los argumentos sobre la diferencia cultural fueron desechados. La Declaración se hizo desde los criterios normativos de los países mencionados, incorporando el tema en el artículo 22, respecto de que los individuos pueden obtener del Estado recursos para la satisfacción de sus derechos culturales y en el artículo 26, según el cual la educación: “...favorecerá la comprensión, la tolerancia y la amistad entre las naciones y todos los grupos étnicos o religiosos". En ambos casos la dimensión cultural es secundaria. En el primero, en virtud de que los derechos culturales están explícitamente colocados por fuera y por abajo de los derechos universales. En el segundo, porque se habla de favorecer la tolerancia eliminando el carácter obligatorio y, paradójicamente, porque el tema de la cultura no es "favorecido". Más allá de las circunstancias políticas, lo que se quiere rescatar del señalamiento puntual de la AAA, es que evidenció la necesidad de destruir una asimetría adicional a las otras suprimidas: que las diferencias culturales no deberían ser usadas para vulnerar los derechos humanos. En ese sentido, la diferencia: culturas "occidentales" hegemónicas/culturas indígenas, siguió como asimetría luego de la declaración. $^{90}$ También, se resignificó una diferencia ya contemplada, pues la

\footnotetext{
${ }^{90}$ Es de la mayor importancia, señalar los problemas que se generan al hablar en términos reduccionistas del concepto "Occidente". Es un concepto de uso constante, frecuentemente de manera irreflexiva por legos y expertos. La caracterización de dicha entidad, no está entre los problemas sustantivos de este trabajo, sin embargo, en concordancia con el discurso cotidiano que he observado, cuando se use tal sustantivo o su adjetivación, "occidental", me referiré principalmente al orden cultural, cuyo núcleo generador está ubicado en las formas y contenidos acostumbrados en las naciones o estados hegemónicos o colonialistas de la Europa del siglo XVI y su apropiación o transformación por otros colectivos. Esta
} 
Declaración eliminaba la ambigüedad de los derechos que los Estados históricamente vulneraban, justo por su dilución en el colectivo, de ahí que la diferencia individuo/colectivo, fue asimetrizada en términos normativos, para privilegiar al individuo por encima de la comunidad, de acuerdo con el credo liberal. Sin embargo, este fenómeno ocurrió en un contexto culturalmente homogéneo. La incorporación de "todo el mundo" al ámbito de los derechos universales, modificó, en términos polisémicos, la naturaleza de la oposición, porque en muchas culturas la dimensión individual es secundaria en los cánones normativos, centrados en la comunidad. Si se quería o se quiere que los derechos universales, sean realmente universales y justos, es necesario, destruir la asimetría mencionada, no en términos liberales -una "cultura" como cualquier otra-, sino con la diversidad cultural en mente.

El propósito de rescatar el pronunciamiento de los antropólogos norteamericanos, es que justo desde el nacimiento de los instrumentos sobre derechos humanos, la tensión individuo/colectivo en el contexto de la pluralidad cultural, ha sido un motivo de disputa y revisión a la fecha. Resulta compleja la asimetrización y, simultáneamente, la desasimetrización de esta diferencia, porque enlaza dos ejes incompatibles. La defensa del individuo frente a la acción del Estado, que naturalmente opera con mentalidad colectiva y la defensa de una colectividad especifica frente a la hegemonía del Estado, que tiende a ver sólo una colectividad -la nación, en el más puro espíritu weberiano- y no varias. Hay que considerar, además,la peculiaridad de que la incompatibilidad cultural entre el primero y las segundas, determinaría la exclusión del poder del Estado en áreas que éste considera de su única competencia. Lo interesante

asunción, supone colocar otras hegemonías culturales derivadas de dicha tradición, en ese crisol problemático, como pueden ser Estados Unidos, Canadá o Australia. Finalmente, está la hegemonía de carácter colonial interno, es decir, que el orden cultural se impone a una población indígena, con la que se funden los colonizadores, generando poblaciones mestizas, en las que conviven partes de ambas tradiciones culturales. No obstante, la focalización en las asimetrías surgidas de dicho choque, y que sustentan el mantenimiento de la hegemonía con múltiples elementos del orden colonial inicial, designan a ese orden como "occidental". Aquí surge el problema real, pues muchos de los individuos que se inconforman o reclaman el establecimiento o existencia de dicho orden, "llevan" en su ser, elementos que ya conforman su Cultura -con mayúscula- y que tienen una matriz "occidental". La imposibilidad de determinar cuantitativamente tal complejo, es la que genera los problemas efectivos de la definición. Más aun, cuando el concepto de "autoadscripción" a una cultura definida crea confusiones, al suponer que una declaración política, tiene efectos antropológicos de la misma intensidad. Guillermo Bonfil (1991), intentó esclarecer el problema, separándolo en función del carácter de las decisiones y los elementos culturales: como propios o como ajenos. El asunto es: ¿hasta dónde una tradición cultural extraña, pero mezclada con la colonizada y vivida por siglos, puede definirse como ajena? En términos políticos, insisto es viable y desde luego, valido y necesario. El problema es que su tratamiento antropológico, no genera de manera automática las certezas de lo político, sino problemas de ardua demarcación. El esquema de Bonfil (p. 50), es un ejemplo de lo anterior, ya que políticamente es rescatable. Antropológicamente, constituye un análisis lucido, pero instantáneo, pues ignora los efectos de tales situaciones luego de décadas o siglos de cambio y fusión cultural. 
del fenómeno es que en los dos casos, se busca refrenar la acción del Estado: frente a los excesos contra individuos o frente a los colectivos. El problema son las bases individualistas del Estado contemporáneo y del orden internacional, que chocan con los fundamentos colectivos de los grupos culturalmente diferentes. Mucho se ha avanzado desde entonces, pero la tensión subsiste. En adelante, se van a exponer los cambios realizados desde ese primer intento.

El Convenio sobre poblaciones indígenas y tribales (C-107) de la Organización Internacional del Trabajo (1957), firmado por 27 Estados (todos ellos del denominado "Tercer mundo" o "Países en vías de desarrollo", a excepción de Bélgica) se concretó con la pretensión expresa de: “...adoptar diversas proposiciones relativas a la protección e integración de las poblaciones indígenas y de otras poblaciones tribales y semitribales en los países independientes..." (Considerandos). Lo primero que llama la atención, es el cambio de foro, de la Asamblea General a una rama de las Naciones Unidas y en segundo lugar, la dimensión particular del acuerdo, es decir, sólo países interesados o involucrados en el tema.

A diferencia de la dimensión universal de la "Declaración", aquí de lo que se trata es, no de crear derechos, sino de eliminar los impedimentos para alcanzar los derechos que todos los individuos tienen, pues: “...en diversos países independientes existen poblaciones indígenas y otras poblaciones tribales y semitribales que no se hallan integradas todavía en la colectividad nacional y cuya situación social, económica o cultural les impide beneficiarse plenamente de los derechos y las oportunidades de que disfrutan los otros elementos de la población..." (Considerandos). ${ }^{91}$ Supone en este caso un proceso que busca más centrarse en la eliminación de la diferencia, que conservarla y entonces no es en ese sentido una desasimetrización. Destaca de inicio, que se dan por sentados los derechos universales que dichas poblaciones no tienen o ejercen, pero que deben llegar a ello. En segundo lugar, se advierte que las desigualdades en las comunidades de referencia, están empatadas para los términos sociales, económicos o culturales, equiparando órdenes incompatibles y adicionalmente, esquivando el problema concreto de la diversidad

\footnotetext{
${ }^{91}$ El subrayado es mío.
} 
cultural. Finalmente, que se declara explícitamente el carácter "integrador" de los supuestos normativos y las políticas a implementar, determinando con ello, la reiteración del conflicto de origen, esto es, la visión monocultural centrada en el orden hegemónico internacional.

Estos aspectos iniciales desembocan en las diferencias definidas como centrales en el texto, que tienen mucha relación con las oposiciones básicas de la "Declaración". bienestar material/carencia material, desarrollo espiritual/subdesarrollo espiritual, libertad/esclavitud, dignidad/degradación, igualdad/desigualdad. Estas oposiciones enmarcan las dos que resultan centrales: Estado/pueblos; e indígenas o tribus/resto de la población. De la primera no hay mucho que abundar: de frente a la comunidad internacional, los Estados declaran su voluntad de implementar mecanismos que culminen en la integración de los indígenas y tribus; hecho que no ocurriría si el statu quo se mantiene, de ahí que la integración constituya un hecho general de poder. De la segunda, ya en el final del "Corolario" al capítulo 1, se había resaltado la peculiaridad de oponer poblaciones indígenas con la "otra parte" de la población. El primer miembro está positivamente identificado, el segundo no, por ello se infiere que el primero es opuesto al segundo, pero el segundo es un término en cierto sentido vacío, porque engloba a todos aquellos no indígenas (blancos, mestizos, extranjeros, colonizadores, etcétera) que gozan, como grupo, de mejores condiciones de vida. Un punto que resalta en esta oposición, es que en el Convenio se reconoce la existencia de un hecho sociológica y antropológicamente relevante: la existencia de semitribales: “...grupos y personas que, aunque próximos a perder sus características tribales, no están aún integrados en la colectividad nacional" (Art. 2). Esto es notable, porque abre la puerta a la dimensión del cambio social y cultural que ocurre en el contacto entre culturas. Si bien tiene un carácter claramente unilineal, es decir, que estos colectivos o grupos <<aún〉> no se integran pero que eventualmente lo harán, lo que es notable, pues define un fenómeno empírico. Ello contrasta con la tendencia normativa posterior, que eliminó las gradaciones de cambio, al incluir el concepto de "autoadscripción" y evitar las referencias a pasos intermedios: se es o no se es indígena. Nuevamente, la naturaleza política del hecho, no elimina las dinámicas intermedias, culturalmente relevantes. ${ }^{92}$

\footnotetext{
92 En México profundo Bonfil Batalla (1994) expone un fenómeno que tiene cierta relación con lo mencionado: hay un México profundo que se comporta con elementos culturales indígenas, parcial o totalmente. Ello se opone a la idea de un México imaginario. Sin embargo, la parte profunda no es totalmente indígena a pesar de tener muchos elementos de lo anterior -el ejemplo de los campesinos-, la transición o cambio cultural hacia <<otra cosa $>>$ genera necesariamente, una identidad particular,
} 
Se plantea entonces en el Convenio un eje central: crear las condiciones necesarias para que las desigualdades entre indígenas y tribus y el resto de las sociedades de los países firmantes, se empaten en el ejercicio de sus derechos y posibilidades de desarrollo y se integren paulatinamente a ese resto. Por ello se instrumentan mecanismos de atención especial o discriminación positiva; en términos de este trabajo, se definen asimetrías. Los Estados crearán medidas especiales para que los pueblos indígenas y tribales se igualen. Estas medidas no deben crear un "estado artificial de segregación" y por ende, deben de terminar cuando ya no exista la necesidad de una protección especial (Art.3).

Las medidas que buscan impulsar la acción de los Estados o la acción de los individuos indígenas o tribales, crean condiciones específicas para romper la marginación y demoler las injusticias, pero también, integrarlos al resto del país. El aspecto integrador del instrumento es problemático, ya que declara que para alcanzar ese objetivo se deberá: “...tomar debidamente en consideración los valores culturales y religiosos y las formas de control social propias de dichas poblaciones [...y] tener presente el peligro que puede resultar del quebrantamiento de los valores y de las instituciones de dichas poblaciones” (Art. 4). Si se tiene en cuenta que el artículo 5 declara que los gobiernos deberán: “...buscar la colaboración de dichas poblaciones y de sus representantes [...y] ofrecer a dichas poblaciones oportunidades para el pleno desarrollo de sus iniciativas", las posibilidades normativas del programa integrador son formalmente escasas, a menos que se considere como dada la voluntad-necesidad de los afectados por integrarse. Este supuesto ontológico, deriva de la visión estatal sobre el tema, que se expuso anteriormente en el tratamiento de las asimetrías en la "Declaración": el Estado tiende a ejercer su acción respecto de una comunidad única y con valores homogéneos. Desde luego que los pueblos indígenas y tribales, no fueron consultados al respecto de la visión uniformadora plasmada en el texto del Convenio.

Los artículos del siete al diez, refieren las medidas que se deben tomar en relación al ámbito jurídico. Sus códigos de normas y sanciones, deberán ser respetados en tanto no afecten el orden jurídico nacional o los objetivos del programa. Es decir la diferencia derecho indígena-tribal/derecho positivo, se mantiene como asimetría en favor del Estado, salvo en los casos no previstos por la legislación nacional o en todo caso, que no la vulnere.

transicional, pero que es a mi ver, justamente una realidad que puede ser estable y por tanto, no se le debe tratar, necesariamente, como lo que fue o como lo que será. 
“Artículo 11. Se deberá reconocer el derecho de propiedad, colectivo o individual, a favor de los miembros de las poblaciones en cuestión sobre las tierras tradicionalmente ocupadas por ellas”. El contenido de este artículo, motivo de duras y conflictivas disputas en el presente, por el activismo y participación de indígenas en foros nacionales e internacionales, en 1957 aparece como no problemático para los Estados firmantes. Desde luego, la conjugación -se deberá, abre un periodo al futuro, que no establece ni plazos ni mecanismos, de forma tal que las disputas entre pueblos originarios y colonos de todo tipo, tienen una resolución indeterminada hacia el futuro, Aunque, es relevante, se reconoce la titularidad territorial desde el pasado, al aseverar que el derecho es sobre los territorios tradicionalmente ocupados. En este sentido, se desasimetriza la diferencia entre mecanismos para sancionar la titularidad sobre el territorio, al reconocer como válidos los procedimientos indígenas o tribales, simultáneamente a los estatales. En términos laborales -artículo 15- no se declara nada en particular, salvo la voluntad de que los derechos que gozan los trabajadores en el orden social regular, lleguen a los pueblos indígenas y tribales.

Caso especial es el de la capacitación y la formación profesional en la cual se refiere que deben tener los mismos derechos que el resto de la población. Sin embargo, se especifica que deberán crearse programas especiales en aquellas: “....actividades para las cuales las poblaciones [...] se hayan mostrado tradicionalmente aptas. Estos medios especiales de formación se deberán proveer solamente mientras lo requiera el grado de desarrollo cultural de los interesados; al progresar su integración, deberán reemplazarse por los medios previstos para los demás ciudadanos" (Art. 17). Caso particular de lo anterior es el campo de las artesanías y las industrias rurales, que mediante el fomento y capacitación se busca: “...elevar su nivel de vida y a adaptarse a métodos modernos de producción y comercio" (Art.18). Aquí no queda en duda la intención integradora estatal. Los bienes gubernamentales sólo se aportaran, en función de que produzcan conductas y conceptualizaciones que lleven a los ciudadanos disminuidos a un nivel igual a los demás; al llegar ese punto, la política cesa.

El tema educativo tiene una forma semejante y por ello se enlaza con el anterior. Los Estados deberán instrumentar políticas educativas para que los individuos reciban educación del nivel y calidad que los demás ciudadanos (Art. 22). Se deberá brindar una educación básica en su lengua (lecto-escritura) para posteriormente llevarlos a dominar la lengua oficial; adoptando, [no obstante] políticas para la preservación de la primera (Art. 23). Los contenidos generales deberán impulsar conocimientos y habilidades 
tendientes a la integración, haciendo énfasis en el conocimiento de sus derechos y obligaciones (Arts. 24 y 26). Interviniendo también en la población general, para eliminar los prejuicios existentes respecto de dichas poblaciones (Art. 25).

En términos de salud, se buscará que cuenten con los servicios que el resto de la población disfruta, implementándolos de manera progresiva hasta la cobertura total “...cuando sea factible" (Art. 19).

La exposición anterior mostró dos temas centrales en el trabajo: las diferencias o las asimetrías existentes y la posición frente a éstas. En general lo que se busca en el Convenio es eliminar dos asimetrías: el bajo nivel de desarrollo y el trato desigual a los pueblos indígenas o tribales. Pero este supuesto, se emprende sin la eliminación del procedimiento que las fundamenta -la asimetría-, sino básicamente, eliminando la diferencia. Esto quiere decir, que existe una condición dada que caracteriza a estas poblaciones impide su mayor desarrollo y acceso a derechos. La propuesta del Convenio es implementar en ellas, mecanismos para reducir y desparecer dicha distancia. Este credo de integración final, permite preservar las diferencias culturales, siempre y cuando no impidan el fin último: alcanzar la homogeneidad nacional. No es clara la intensidad de esta integración, pues como se mostró, en el instrumento se previene de la imprudencia que supone suplantar valores o instituciones, sin remplazarlos por otros pertinentes y con el consentimiento de los interesados (Art. 4). Deja la puerta abierta, sin embargo, a una suplantación progresiva y consentida por los pueblos.

No obstante: ¿de qué medios disponen los Estados para lograr tal fin?; ¿tienen una forma progresiva y consentida los mecanismos dispuestos? El sentido general como he mostrado es empatar en derechos y desarrollo a los pueblos citados, para ell, y por ello, es que habrá medidas tendientes a que los individuos se integren. En el caso del primer tema, los Estados habrán de vigilar que todas las instancias a su cargo, se encarguen de que se cumplan los derechos que no se observan por diversos motivos, ya por sus propios órganos, ya por el resto de la población. También, habrá que instrumentar medidas para que ellos ejerzan sus derechos, ya por su misma situación no están en posibilidad de conocerlos. Así, se implementaran medidas: “...que promuevan el desarrollo social, económico y cultural de dichas poblaciones [...] El objetivo principal de esos programas deberá ser el fomento de la dignidad, de la utilidad social y de la iniciativa individuales (Art. 2). Los mecanismos del Estado se moverán para llevar dichas poblaciones al mismo nivel que el resto, con un objetivo principal que sean de 
utilidad social (de los pueblos y del total nacional) y la potenciación del espíritu individual. En esa dirección es que se plantea: “...estimular por todos los medios posibles entre dichas poblaciones el desarrollo de las libertades cívicas y el establecimiento de instituciones electivas, o la participación en tales instituciones" (Art 5). En este caso la orden es evidente: si en el proceso de implementación se aportan recursos a estos pueblos la apropiación debe privilegiar el espíritu individual, el desarrollo de las libertades cívicas [no indígenas] y la implantación y plena participación en elecciones democráticas [mecanismo no indígena de elección y decisión social].

Un ejemplo de este argumento es el hecho de que la capacitación que reciban, puede ser especial en función de sus necesidades particulares, pero en el caso de las artesanías y las industrias rurales: “...deberán fomentarse como factores de desarrollo económico, de modo que se ayude a dichas poblaciones a elevar su nivel de vida y a adaptarse a métodos modernos de producción y comercio" (Art 18). ${ }^{93}$ Es decir, la apropiación de los recursos pasa, necesariamente, por la transformación de conductas y conceptualizaciones de la producción: adaptándose a la lógica del mercado, con centro en las iniciativas individuales. Resulta evidente que en la implementación de los recursos, la violencia o coacción está prohibida expresamente, pero los mecanismos de apropiación en este tipo de programas están conformadas de tal manera, que solo con las formas diseñadas se podrán tomar y ejercer los recursos; es decir, el ejercicio de poder político vía el intercambio. En este mismo sentido se canalizan los recursos al sistema educativo, pues los bienes educativos que el gobierno ofrece a la población, solamente podrán ser apropiados por los pueblos indígenas o tribales, en un mecanismo que: “...deberá asegurar la transición progresiva de la lengua materna o vernácula a la lengua nacional o a una de las lenguas oficiales del país" (Art. 23). Se respeta de inicio su lengua, pero con la orden expresa de adoptar gradualmente a la lengua oficial, si el individuo quiere apropiarse de los bienes gubernamentales para la educación. De modo adicional, la instrucción primaria: “...deberá tener como objetivo inculcarles conocimientos generales y habilidades que ayuden a esos niños a integrarse en la colectividad nacional" (Art. 24). No sólo se substituirá, progresivamente la lengua en la que se imparte la educación, sino que esta tendrá como centro, contenidos con un carácter eminentemente dirigido a la educación; se trata nuevamente de las conductas y

\footnotetext{
${ }^{93}$ El subrayado es mío.
} 
conceptualizaciones de apropiación por las que los Estados crean realidades sociales, que de otro modo no ocurrirían, ejerciendo el poder mediante el intercambio. ${ }^{94}$ En síntesis, los gobiernos deberán crear programas tendientes a los objetivos marcados y para ello deberán: “...crear organismos o ampliar los existentes para administrar los programas..." (Art. 27), para administrar los recursos destinados a tal fin o las medidas de carácter gubernamental; en cualquier caso, el desarrollo integrador es el objetivo.

Un aspecto final del Convenio se refiere al carácter obligatorio que supone. El hecho central es que obliga no a los Estados frente a sus ciudadanos, sino formalmente a los Estados frente a otros Estados; son producto del Derecho internacional, en el que "el tratado" es la forma concreta que toman. ${ }^{95}$ Son ellos los que se imponen obligaciones, quienes vigilan su cumplimiento y toman medidas frente a los desacatos. En este orden de ideas, es que el artículo 28 del Convenio toma su justa dimensión al declarar: "La naturaleza y el alcance de las medidas que se adopten para dar efecto a este Convenio deberán determinarse con flexibilidad para tener en cuenta las condiciones propias de cada país". ${ }^{96}$ Esta disposición matiza los ordenamientos generales, correspondiendo a cada país, evaluar la profundidad y características que tomaran las medidas implementadas. Si bien la Convención de Viena determina que los acuerdos entre naciones deberán ser firmados e implementados de buena fe (artículo 26), es un hecho en la realidad internacional, que existan múltiples visiones para interpretar una disposición como la precedente. De hecho, esta libertad, determinó que a la fecha, en muchos de los países firmantes, existan disputas sobre cuestiones que ya deberían estar superadas desde el Convenio 107 y en las cuales subsisten problemas a pesar de que se han firmado nuevos instrumentos (como el Convenio 169 o la Declaración de las Naciones Unidas sobre los Derechos de los Pueblos Indígenas). La dimensión geopolítica del asunto, es que los países firmantes no se recusaron entre ellos por las

\footnotetext{
${ }^{94}$ En México fue, prácticamente una política de Estado, impedir el uso de las lenguas indígenas en los salones de clase. Llamadas de atención, castigos, golpes, arrestos a los padres, formaron parte, hasta hace apenas pocos años, de los mecanismos de integración. Ello muestra que las órdenes que el Estado Mexicano dio a la población indígena, sí coincidían con los supuestos de la Convención, no obstante vulneraban algunos de sus artículos, porque prácticas como las descritas estaban expresamente prohibidas, no así el objetivo.

${ }_{95}$ En términos generales puede entenderse el derecho internacional, como: “...el conjunto de normas jurídicas que regulan las relaciones entre los Estados y los organismos públicos internacionales, como sujetos reconocidos con capacidad para obligarse en ese ámbito" (Suprema Corte de Justicia de la Nación 2009: 15) y el tratado, en consonancia con los supuestos de la Convención de Viena sobre el Derecho de los Tratado, como: “...todo instrumento jurídico, sin importar su denominación, en el que se plasma el acuerdo de voluntades de dos o más sujetos del derecho internacional, firmado y ratificado por ellos, para crear, transmitir, modificar o extinguir derechos y obligaciones en ese ámbito" (ibid: 24)

${ }^{96}$ El subrayado es mío
} 
responsabilidades internacionales no cumplidas y de ahí la inoperancia y necesidad de nuevos instrumentos. ${ }^{97}$ Los individuos que viven en los países firmantes, si bien pueden exigir el cumplimiento o señalar las violaciones a los pactos internacionales firmados, solo sus pares, otros Estados, son sujetos de derecho para exigir su cumplimiento. En concordancia con esta visión, Rodolfo Stavenhagen declara que: “...el problema de fondo siguen siendo los procedimientos para que estos tratados [los relativos a derechos humanos o de pueblos indígenas] sean cumplidos efectivamente. Ni la ONU ni los organismos regionales [...] están dotados de mecanismos que obliguen a los estados a cumplir sus compromisos internacionales" (2002: 179). El sistema de justicia global avanza lentamente, y si bien los organismos de justicia o derechos humanos internacionales ganan terreno, los procesos son lentos y en general son de tipo casuístico, es decir, implican violaciones concretas que son reparadas de esa manera.

Para terminar, el objetivo de este último argumento, fue mostrar las características mínimas en las que los países se comprometen entre ellos y la naturaleza de las dificultades para alcanzar que dichos pactos se cumplan. Este precedente va a ser fundamental, porque al abordar el tratamiento de la reforma a la Constitución Mexicana en el año 2001, el fantasma de los pactos internacionales flotó todo el tiempo. Las discusiones jurídicas sobre la preeminencia de los órdenes jurídicos, el internacional y el constitucional, serán abordadas en ese punto. Únicamente se buscó enmarcar la lógica global de los compromisos nacionales y su incorporación a la Constitución o las leyes secundarias en materia de derechos indígenas.

El Convenio 169 sobre Pueblos Indígenas y Tribales en Países Independientes de la Organización Internacional del Trabajo (1989) es un documento multilateral, originado por la revisión del Convenio 107 y firmado por 20 países, de los cuales nueve repiten; todos ellos de América Latina. De 1957 a la fecha de redacción del nuevo Convenio, muchos cambios notables ocurrieron, y originaron la nueva visión sobre los temas indígenas: la aparición de países de reciente creación o la consolidación de los ya independientes, producto de la descolonización durante el siglo XX; la presencia de

\footnotetext{
${ }^{97}$ Danilo Zolo ha expuesto de manera brillante, las complicaciones y realidades para llegar a la justicia internacional, tanto entre países, como en la responsabilidad internacional de los hechos individuales: Ver: Cosmópolis. Perspectivas y riesgos de un gobierno mundial (2000) y La justicia de los vencedores. De Nuremberg a Bagdad (2007).
} 
pueblos originarios en muchos países del globo y su incorporación progresiva a la vida política, derivada de los procesos de democratización global; la ampliación notable de las comunicaciones de todo tipo: terrestres, aéreas, marítimas, radiales, telefónicas, satelitales, redes globales, que potenciaron la comunicación entre los individuos en los territorios y al mismo tiempo, el conocimiento de los procesos mundiales; la existencia de un periodo de relativa paz y progreso, posterior a la Segunda Guerra Mundial, que determinó una sensible mejora en la condiciones de vida mundiales y sobre todo, la aparición del deseo de mejora en esas condiciones.

Este último punto, una culminación de los procesos anteriores, es la base sobre la que se gestó el cambio que se aprecia en el C-169. En los "Considerandos", se refiere específicamente dicha circunstancia, al expresar dos puntos centrales que motivaron el nuevo tratado: la aparición de nuevas visiones sobre los derechos de los pueblos y los individuos, posteriores a la Declaración Universal de los Derechos del Hombre, entre ellos, el Pacto Internacional de Derechos Económicos, Sociales y Culturales y el Pacto Internacional de Derechos Civiles y Políticos, que engloban la aparición de los derechos llamados de "segunda" y "tercera" generación; ${ }^{98}$ y más notablemente, el cambio de visión, dentro y fuera de los pueblos, de que el planteamiento de integración nacional, postulado en el Convenio anterior era francamente inaceptable, pues el deseo de preservar las culturas indígenas en un entorno de pluralidad cultural había madurado. Este cambio en términos de Filosofía y Teoría Política, fue lo que determinó que los Estados parte, se comprometieran a romper con las visiones anteriores y asignarse nuevas y diferentes obligaciones internacionales, con referencia a los pueblos indígenas y tribales existentes en su interior.

El cambio central y más notable del C-169, es la transformación de la visión de un estado uniforme y homogéneo culturalmente, a la posibilidad de una nación en donde la diversidad de culturas no funciona como un impedimento para la vida armoniosa de la sociedad, sino que el reconocimiento de dicha variedad, facilita la convivencia. En los términos expuestos, esto supone una transformación substancial, ya que dentro del sistema estatal de clasificaciones, la oposición: población indígena/resto de la población, ya no es una diferencia a suprimir, sino un par que va a caracterizar los procesos de asimetrización y desasimetrización.

\footnotetext{
98 Para ampliar aspectos de estos tratados, sigue siendo muy recomendable la revisión realizada por Stavenhagen (2002).
} 
De manera general, la eliminación de las asimetrías, gira en torno a que se buscan proscribir los procedimientos que impiden a los indígenas, acceder a los derechos o recursos que gozan los otros miembros de la población. Paralelamente, debido a las condiciones históricas de desigualdad y marginación, se van a enunciar disposiciones en las que se crea un trato especial y ventajoso respecto del resto de la población, con el objetivo de acortar y eliminar la brecha existente, es decir, la creación de ciertas asimetrías. ${ }^{99}$

Ahora bien, el punto culminante de esta nueva visión, surge de la disposición adoptada en el Convenio, de que, además de la caracterización histórico-antropológica de los pueblos o tribus que residen en el país, "La conciencia de su identidad indígena o tribal deberá considerarse un criterio fundamental para determinar los grupos a los que se aplican las disposiciones del presente Convenio" (Art. 2). Éste es el cambio central en términos de clasificación, de políticas y desde luego de ejercicio de poder. Desde la visión anterior, las disposiciones para los indígenas tenían un carácter exógeno, es decir, se les aplicaban desde fuera. Si bien estaba determinado en el C-107 que su opinión se debía respetar, resultaba marginal para el punto central: el arranque de las disposiciones de integración; ya que eran incluidos de manera forzada, porque la naturaleza homogeneizadora del diseño legal, impedía que opinaran sobre otra forma de las políticas indigenistas. Con el nuevo formato, además de cambiar hacia una visión de respeto cultural, se da cierto control a los individuos o comunidades: si se quieren adscribir a las disposiciones o recibir los bienes mencionados, es requisito indispensable autoadscribirse como "indígena". Esto, como se mencionó anteriormente, elimina "de

\footnotetext{
${ }^{99}$ Las asimetrías generadas, sobre todo en lo que se refiere a los mecanismos de acción estatal hacia la población, no supone la creación de una asimetría estructural entre los miembros de las comunidades indígenas y los demás, sino ámbitos específicos cuyo objetivo es neutralizar, justo las asimetrías globales. Para la posición liberal eso resulta criticable, ya que genera la posibilidad de que tales asimetrías legales, se transformen en sistemas de privilegios o en el peor de los casos, ser un freno al impulso de "igualarse" con el resto de la población. En todo caso, independientemente de los argumentos de las dos posiciones, desde la visión que aquí se propone, es una consecuencia posible, que las asimetrías artificiales, se naturalicen en las relaciones sociales y faculten una inversión en las estructuras de poder. Estas asimetrías "artificiales", derivarían, no del uso dado a la diferencia cultural como tal, sino de las condiciones especiales dictadas para igualar a los individuos en temas de diferencias no culturales pero derivadas en un inicio de éstas: la falta de desarrollo motivó la creación de cierto régimen especial, que debería terminar, justo, cuando los pueblos se igualaran en desarrollo. En el C-107 se declara en el artículo tres, que las medidas compensatorias, “...se apliquen solamente mientras exista la necesidad de una protección especial y en la medida en que la protección sea necesaria". Esta característica -lo provisional de ciertas medidas especiales- se perdió en el C-169, por una confusión a mi ver, entre el deseo de rechazar la medidas integracionistas y la perennidad de los derechos culturales. El derecho a la diferencia cultural no debe cesar, sin embargo, las asimetrías secundarias, es decir las que resultaron injustamente del trato asimétrico a las culturas indígenas, deben cesar, en tanto dichas asimetrías aparezcan como inexistentes, pues las diferencias en desarrollo, educación o riqueza, habrían desaparecido, es decir, que las condiciones de los pueblos indígenas serían iguales a las del resto de la población.
} 
un plumazo", el reconocimiento de estadios parciales de cambio sociocultural. En el C107 se reconocía la existencia de fases intermedias (ni indígena ni mestizo, por poner un ejemplo). La eliminación parece pertinente desde un punto de vista que matiza los excesos del pensamiento evolucionista. No necesariamente los estadios intermedios deben "evolucionar" a la integración nacional como se suponía en el convenio anterior, sin embargo, no necesariamente todos los que se autoadscriben como indígenas, son indígenas formalmente. Esto de explica por razones de dos tipos: antropológicas y políticas. Las antropológicas no tienen mayor complicación, pues las formas culturales no son fijas, están en constante cambio, y el surgimiento de formas sincréticas no necesariamente culmina en la transición a una de las dos originales; el mestizo, forma sincrética inicial, se opone a lo indígena en la actualidad, como "cultura”. De ahí que las razones políticas se tornen relevantes, porque la apertura a los fenómenos de autoadscripción para ser sujeto de beneficios estatales, cierra la puerta a dichas formas intermedias: o se es indígena o no se es; eso desde el punto de vista púramente formal, pues desde el lado técnico de la justicia origina otros problemas, que son motivo de críticas a las legislaciones que crean regímenes especiales. ${ }^{100}$ No es este trabajo un espacio para definir una posición sobre la pertinencia o no de dichos regímenes, que en esencia buscan reparar una injusticia a todas luces evidente. Lo que se quiere argumentar, es que en la implementación de las políticas que toman a la Cultura como el motor inicial, se llegan a confundir los aspectos antropológicos con los políticos o de justicia, de tal suerte que en los intentos por reparar a individuos o grupos por los daños que sufren en virtud de su identidad, es muy factible cometer errores de implementación y consecuentemente, producir efectos perversos o esfuerzos inútiles respecto de lo que se buscaba inicialmente, justo por confundir el hecho antropológico con el político.

La delegación en los individuos de controlar su adscripción, caracteriza el otro punto de vista importante del Convenio: que controlen los aspectos sustantivos de las políticas que los afectan. Ello quiere decir, que: “Los gobiernos deberán asumir la responsabilidad de desarrollar, con la participación de los pueblos interesados, una acción coordinada y sistemática con miras a proteger los derechos de esos pueblos y a

\footnotetext{
${ }^{100}$ Como se mencionó en la nota anterior, dichas críticas proceden generalmente de puntos de vista liberales e individualistas, pues suponen que si no tienen "candados", dichos regímenes pueden derivar en sistemas de privilegios, pervirtiendo el motivo inicial de justicia. Los argumentos de Elster (1998) sobre los efectos de disposiciones especiales para la impartición de lo que llama "justicia local" y que fueron expuestos al final del capítulo II son dignos de consideración. El más relevante, es que dichos mecanismos en ocasiones fracasan, “...porque los encargados de las asignaciones suponen ingenuamente que los aspirantes al bien escaso son ingenuos, es decir, que los candidatos actuarán como si ignoraran las reglas que gobiernan la asignación de esos recursos" (p. 140).
} 
garantizar el respeto de su integridad" (Art 2). El enunciado encierra los dos aspectos mayores que están planteados en el convenio: la creación de condiciones para que pueblos indígenas accedan a los derechos ciudadanos en condiciones de igualdad y; que se deben crear condiciones para lo que caracteriza a los pueblos como tales, entorno, instituciones y cultura, sea respetado y preservado en el contexto del Estado-Nación contenedor. La diferencia con el Convenio anterior es abismal. En el pasado, la idea de acceso a la los derechos estaba imbricada con la eliminación, llanamente, de la diferencia y no sólo de la asimetría. El cambio en el C-169 es diametralmente opuesto: lo que se busca es mantener la diferencia, eliminando la asimetría. De ahí que las oposiciones que encierra el sistema de clasificaciones, mantiene las consideradas en la "Declaración" y en el C-107 al incorpor el cambio mencionado. La oposición Estado/Pueblos deja de ser problemática, en virtud de que ya no se busca su disolución, sino simplemente su desasimetrización. La otra dicotomía mencionada: pueblos indígenas/resto de la población, o busca neutralizar en términos asimétricos o francamente, asimetrizar en favor de los pueblos indígenas, para neutralizar las condiciones sociohistóricas que enmarcan el proceso general. Adicionalmente queda establecido que debe realizarse toda intervención con la participación de los pueblos. En el artículo seis se expone de manera más clara: “... consultar a los pueblos interesados, mediante procedimientos apropiados y en particular a través de sus instituciones representativas, cada vez que se prevean medidas legislativas o administrativas susceptibles de afectarles directamente".

Ahora bien, ¿qué campos son en los que interviene el Estado para conseguir lo anterior. El primero que se refiere al campo jurídico, establece que deberán tomarse en cuenta sus instituciones jurídicas y costumbres, “... siempre que éstas no sean incompatibles con los derechos fundamentales definidos por el sistema jurídico nacional ni con los derechos humanos internacionalmente reconocidos" (Art. 8). En este caso, la diferencia derecho indígena-tribal/derecho positivo, se mantiene como asimetría en favor del Estado, de manera semejante al C-107. Para el caso de las tierras el enunciado es prácticamente el mismo que en el Convenio anterior. "Deberá reconocerse a los pueblos interesados el derecho de propiedad y de posesión sobre las tierras que tradicionalmente ocupan" (Art 14). Su ejecución o cumplimiento, queda atado a dos aspectos ya tratados: la preeminencia de la legislación nacional y la no aplicación de la norma por la falta de instrumentación de mecanismos de sanción a los Estados que incumplen el Convenio. 
En cuanto a los aspectos laborales y de capacitación para el trabajo, se mantiene el mismo tenor que en el C-107: tomar todas las medidas necesarias para que se respeten sus derechos de manera semejante al resto de la población, preservando sus especificidades culturales. Describe de manera casuística campos y actividades laborales en las que los miembros de los pueblos se desempeñan, como por ejemplo las producidas por la migración y que pudieran vulnerara sus derechos, que formalmente ya están protegidos de manera general.

Hay que hacer notar que las similitudes con el C-107 mencionadas anteriormente y las que vendrán, surgen de que existe un proceso general de respeto a sus derechos humanos <<como el resto de la población〉>. Eso en términos globales cambio poco. La novedad deriva de que la dirección de dichas políticas, no debe tener contemplada la integración, sino el respeto a su diferencia cultural y en muchos casos, el fomento a la permanencia de dicha especificidad.

En el tema de la salud sí hubo una ampliación substancial, pues anteriormente se declaraba que se debían tomar medidas para que los servicios generales de salud llegaran a dichas poblaciones, sin ninguna consideración a sus condiciones particulares. En el C-169 se declara que: "Los servicios de salud deberán organizarse, en la medida de lo posible, a nivel comunitario. Estos servicios deberán planearse y administrarse en cooperación con los pueblos interesados y tener en cuenta sus condiciones económicas, geográficas, sociales y culturales, así como sus métodos de prevención, prácticas curativas y medicamentos tradicionales" (Art. 25). ${ }^{101}$ Adicionalmente, en el cumplimiento de dicho punto, deberá considerarse la formación de personal local, para que atienda los aspectos primarios de la salud.

En el tema educativo se insiste nuevamente en que se tomarán las medidas necesarias para que tengan acceso a todos los niveles educativos en plena igualdad. El cambio substancial, deriva de que se plantea que los programas y los servicios de educación destinados a los pueblos,

deberán desarrollarse y aplicarse en cooperación con éstos a fin de responder a sus necesidades particulares, y deberán abarcar su historia, sus conocimientos y técnicas, sus sistemas de valores y todas sus demás aspiraciones [...deberán] asegurar la formación de miembros de estos pueblos y su participación en la formulación y ejecución de programas de educación, con miras a transferir progresivamente a dichos pueblos la responsabilidad de la realización de esos programas [...y] deberán reconocer el derecho de esos pueblos a crear sus propias instituciones y medios de educación, siempre que tales instituciones satisfagan las normas mínimas establecidas por la autoridad competente en

\footnotetext{
${ }^{101}$ El subrayado es mío.
} 
consulta con esos pueblos. Deberán facilitárseles recursos apropiados con tal fin (Art. 27).

En cumplimiento de lo anterior, se deberá buscar que el aprendizaje de la lectura y la escritura sean en la lengua materna y paralelamente, que dominen la lengua nacional. Es necesario además, que se tomen las previsiones necesarias para que las lenguas indígenas se preserven y se practiquen (Art. 28). De manera semejante al C107, se insiste en la necesidad de tomar medidas de carácter educativo con la población general, con objeto de eliminar los prejuicios que pudieran tener con respecto a esos pueblos. Adicionalmente y de manera novedosa, se propone que: “...deberán hacerse esfuerzos por asegurar que los libros de historia y demás material didáctico ofrezcan una descripción equitativa, exacta e instructiva de las sociedades y culturas de los pueblos" (Art. 31).

Hasta aquí la exposición de los temas en los que se interviene con el objetivo de alcanzar un estatuto de igualdad de derechos, supresión de las desigualdades y preservación de las diferencias culturales. Y se plantea nuevamente la pregunta: ¿cuáles son los medios de los que disponen los Estados para alcanzar estos objetivos renovados?

De manera inicial, se plantean en el Convenio la creación de mecanismos u órganos administrativos para implementar los dichos referidos, además de la transformación legislativa necesaria a tales fines, siempre en concordancia con la opinión de los pueblos (Art. 31). Para los efectos aquí planteados, interesan los mecanismos de conducción social a través del intercambio: ¿en qué órdenes se interviene? El artículo dos, declara que los recursos se deberán enfocar en el objetivo de llevar a los individuos indígenas a una situación de igualdad; en que los demás lleguen a esa conclusión; en que se instrumenten medidas para eliminar las diferencias socioeconómicas; $\quad$ y en que se implementen medidas para la conservación de su cultura. Estas consideraciones incluyen igualdad de género (Art. 3) y la relación de la cultura con los territorios o el medio ambiente. "Tales medidas especiales no deberán ser contrarias a los deseos expresados libremente por los pueblos interesados” (Art. 4). Para lograr lo anterior, se deberán crear mecanismos de consulta cada vez que existan medidas que les afecten de manera directa; se deberán integrar a los pueblos a los mecanismos de adopción de decisiones que les conciernen y; se deberán asignar recursos para implementar sus propias iniciativas (Art. 6). 
En general, es claro lo que los Estados deben conseguir en la población indígena y en el resto de la población a través del ejercicio del poder político vía el intercambio. Mediante el ejercicio de recursos, se deberá llevar a la población indígena a que: se perciba con derechos iguales -tanto frente al resto de la población como de manera interna-; a que dicho "resto" asuma la igualdad de derechos con los indígenas; a que participen en las consultas sobre los asuntos que les competen; a que se implementen dichos acuerdos y se apoyen con recursos; y finalmente, que se anime la preservación y fortalecimiento de la cultura indígena, reafirmando en los indígenas la importancia de su cultura y en el resto de la población, el respeto a la diversidad cultural.

Si los pueblos indígenas conocen tales derechos, los recursos se tornan en acción social para el cumplimiento del Convenio, y el Estado únicamente conduce el proceso general. Si en cambio ignoran los acuerdos internacionales, el Estado deberá implementar los recursos, detonando el conocimiento de la nueva situación y de ahí, conducir el proceso general. En ambos casos, eso se logra ejerciendo el poder político que el Estado detenta de manera legítima, al ser la instancia máxima de coordinación social, tanto en conductas como en conceptualizaciones.

En este punto aparece una tensión que se mantendrá a lo largo de los acuerdos o reformas a analizar: que la acción gubernamental, deberá ocurrir en concordancia con el deseo de los pueblos, conocido en consultas. Ello determina un sistema de consulta imperfecto en virtud de ser un sistema, en última instancia de búsqueda de mayorías. La decisión de esta "mayoría indígena" deberá imponerse a toda la comunidad, tanto a la que está de acuerdo, como a la que no. El poder por intercambio como hemos visto juega un papel fundamental en dicho proceso. Ejemplos de lo anterior, son las determinaciones en la Convención, para que el Estado asigne recursos a los siguientes rubros:

- Protección y desarrollo de sus territorios, con base cultural

- Capacitación e incorporación al campo labora; creación de programas especiales para los campos donde la cultura tradicional difiera de la nacional, con el objeto de fortalecer y preservar dichas actividades

- Creación de sistemas de salud con perspectiva comunitaria y de medicina tradicional

- Implantación de un sistema de educación de calidad, que contemple la dimensión cultural grupal, preserven y fortalezcan su lengua y cultura al mismo 
tiempo que los incorpora al contexto nacional; asignaciones presupuestales para que administren sus propias instituciones educativa

Como se ve, los rubros son muy similares a los del C-107, con la salvedad, mayor, de que la perspectiva asimilacionista está eliminada y por tanto, lo que son específicamente las políticas públicas -se supone- estarán acordadas con los integrantes de los pueblos indígenas. El dicho "se supone" atiende a dos dimensiones centrales. Que en muchos casos, por no poder o no querer, los gobiernos actuarán sin dicho acuerdo. Y segundo, que el acuerdo con una parte de los grupos, deje insatisfecha a otra. En cualquier caso, es factible evaluar lo que se planteó de inicio: el establecimiento por parte del gobierno, de órdenes tendientes a detonar conductas o conceptualizaciones en línea con los mandatos del Convenio y posteriormente, si tales órdenes, imbricadas con la toma de los recursos, se cumplen según el diseño previo. Para terminar, el "Convenio 169" constituye el primer escalón de un nuevo tipo de posiciones frente a las poblaciones indígenas por parte de los Estados-Nación. En este contexto, el internacional, es que tiene lugar en la ONU una declaración "universal" en el año de 2007 y que se va a abordar en la siguiente sección.

La Declaración de las Naciones Unidas sobre los derechos de los pueblos indígenas emitida por la Asamblea General de las Naciones Unidas (2007a), constituye la posición más acabada de la comunidad internacional sobre los derechos de los pueblos indígenas. Es de notar, que para los efectos de las políticas públicas en México, dicho documento carece de influencia formal, pues está firmado por toda la comunidad internacional con un carácter no vinculante y en segundo lugar, porque fue signado posteriormente a la reforma constitucional del año 2001. Sin embargo, su relevancia deriva de que es producto de discusiones regulares en la ONU desde 1982. ${ }^{102}$ Ello determina que en todo su cuerpo, se encuentren conceptos avanzados y trabajados por la comunidad internacional; de ahí que su influencia indirecta o informal es profunda en el presente. Esta fuerte presencia, encierra también los debates y las polémicas existentes sobre el

\footnotetext{
${ }^{102}$ Centralmente, en el llamado "Grupo de Trabajo sobre Poblaciones Indígenas" creado en 1981 dentro de la Subcomisión de Prevención de Discriminación y Protección a la Minorías, a su vez nacida en el seno de la Comisión de Derechos Humanos de las Naciones Unidas (Stavenhagen, 2002: 186-94).
} 
tema, pues los conceptos están plasmados con la forma que aceptan los Estados firmantes de la Declaración y no como en ocasiones parece ser el deseo de los pueblos indígenas. En ese sentido, destacan las precisiones de cada país a la firma del documento, las abstenciones y los votos en contra (ONU, 2007b). En el caso específico de México, la delegada ante la Asamblea General a nombre del país, aclaró que México celebraba los puntos generales de la Declaración y "...sin embargo, que los derechos de los pueblos indígenas sobre autodeterminación, autonomía y autogobierno deben ser ejercidos en concordancia con la Constitución de México, para garantizar su unidad nacional y su integridad territorial" (ibid). Por tanto, la somera revisión que se hará de la Declaración, buscará principalmente destacar los conceptos centrales, su relación con los documentos expuestos anteriormente y los puntos de conflicto, para encuadrar el campo en el que se materializan los derechos signados en políticas públicas.

De nueva cuenta, lo central de la revisión es el entorno clasificatorio en el que se encuadra la Declaración y las asimetrías que se crean o suprimen. No difiere mayormente de lo que ya se había tratado antes. Se declara en primer lugar, la eliminación de las diferencias que impiden o determinan el acceso inequitativo a la justicia o el desarrollo; esto en concordancia por lo aceptado en la Declaración Universal de los Derechos del Hombre de 1948. Se incorporan todas las diferencias incluidas en la Convención 107 y en la Convención 169 de la OIT. Se mantiene el espíritu declarado de esta última convención, al transformar el espíritu integracionista al de respeto cultural, es decir, se privilegia el mantenimiento de la diferencia y no su eliminación; y se asimetriza dicha diferencia con el resto de las poblaciones con la intención de una igualación en derechos sociales, legales, políticos y económicos, y con la intención adicional de fortalecer la permanencia de la diferencia cultural.

No hay que desarrollar en extenso, los artículos de la Declaración 2007, pues en general, tienen una gran semejanza con lo analizado de la Convención 169. El aspecto sustantivo deriva de dos temas enlazados. En primerísimo lugar, la pretensión universal de la Declaración y en segundo lugar, su carácter no vinculante. En cuanto lo primero, hay que adevtir que las Convenciones anteriores son obligaciones que se dan los Estados frente a otros y por ende, tienen fuerza vinculante entre ellos, y que pueden terminar si un Estado firmante decide denunciar el instrumento. En el caso de la Declaración 2007 (igual que la Declaración de 1948), su validez está por encima de la responsabilidad estatal, dado que se definen como derechos intemporales e imprescriptibles, atados al individuo o al colectivo indígena y que se "clasifican" en 
oposición no sólo del resto de la población de un Estado, sino llanamente, frente al resto de la humanidad. Como se reconoce en los Considerandos: “...los pueblos indígenas son iguales a todos los demás pueblos y reconociendo al mismo tiempo el derecho de todos los pueblos a ser diferentes [...] todos los pueblos [los indígenas y los demás] contribuyen a la diversidad y riqueza de las civilizaciones y culturas, que constituyen el patrimonio común de la humanidad" (ONU, 2007). ${ }^{103}$

Es bien cierto que el garante general de tales derechos es el Estado-Nación en donde se localizan los indígenas y que cualquiera puede reclamar su aplicación a cualquiera otro, en virtud de su universalidad. No obstante, y esa es la segunda característica, no constituyen obligaciones legales formales en tanto existan solamente en la Declaración. Su materialidad jurídica, deriva de su inscripción, como norma en los instrumentos legales de cada Estado particular. De ahí que se asuma, de manera principal, la intervención de los Estados para lograr el respeto a sus artículos, animando las conductas o las conceptualizaciones ahí descritas; es decir, ejerciendo el poder político. Este último aspecto, resuena con los ámbitos de intervención, vía el poder por intercambio, reseñados a propósito del C-107 o el C-169.

Se señaló arriba, que la Declaración tenía un carácter de "pretensión universal" en virtud de su nacimiento polémico. Así como se reconocieron las inconsistencias en la Declaración de 1948 -sobre todo lo referente a la posición de la AAA- y por ende, las fallas en la visión universalista, así se citan los conflictos mentados a propósito de la presente. De inicio, la votación en la Asamblea General no fue unánime (143 a favor, 4 en contra y 11 abstenciones), es decir, no fue aceptada de manera "universal". Esta circunstancia, la oposición o abstención de algunos, que podría aparecer como marginal, toma su justa dimensión cuando se conocen las razones de aquellos que se opusieron y que encierra el verdadero conflicto para lograr el cumplimiento de la Declaración. Los aspectos centrales de este conflicto, expuestos por los representantes de Australia, Estados Unidos, Nueva Zelanda y Canadá, resumen las oposiciones reales al cumplimiento de algunos puntos específicos. Los delegados de estos países, expresaron su rechazo ya que:

\footnotetext{
${ }^{103}$ Esta peculiar asimetrización de una diferencia étnica o cultural, está en línea con la creación a nivel mundial de derechos de segunda o tercera generación para grupos específicos, cuya particularidad, les impide alcanzar los "de primera". Como declaran Fix-Zamudio y Valencia: "Este tipo de derechos exigen el concurso de la comunidad internacional [...pues] se inspiran en principios generales o universales cuyo respeto reclama la humanidad" (2009: 433-4).
} 
- Se confunde el carácter aspiracional de la Declaración con la ley o el derecho internacional.

- El concepto de autodeterminación definido en abstracto, genera conflictos e interpretaciones diversas.

- La referencia a los derechos territoriales tiene carácter intemporal y al margen de derechos de terceros.

- Existe la posibilidad real de que las consultas y el consentimiento previo, libre e informado, se constituya en una forma de veto, incompatible con el sistema de gobierno representativo y que además, otros grupos poblacionales no tienen.

- Es evidente la inoperancia del concepto de propiedad intelectual de los pueblos

- Plantea la superioridad en ciertos ámbitos de la ley de la costumbre sobre las leyes estatales.

- Deja francamente desbalanceado el aspecto de la relación entre derechos y obligaciones indígenas.

- Las ambigüedades en muchos conceptos, definen el riesgo de interpretaciones sin fin y por ende, el origen de conflictos.

- En algunos de los puntos anteriores, tanto por lo declarado, como por su amplitud o ambigüedad, lesionan o es factible que lleven a lesionar los derechos de terceros.

Los puntos anteriores (ONU, 2007b), representan no sólo las razones por las que los países mencionados se opusieron, sino además, la posición de otros que se abstuvieron o que votaron a favor pero con reservas en lo mencionado. De ahí que varios delegados fijaron la posición de que se debió lograr un documento con total consenso para darle un carácter plenamente universal. Exponer esta polémica de origen tiene un objetivo central: poner en evidencia la forma que tiene el rechazo a ciertos aspectos de la Declaración. No es este espacio, el lugar para discutir la pertinencia o impertinencia de las reservas o rechazos expresados a los artículos del documento, es decir, si son justos o inadecuados los derechos para los pueblo indígenas. La relevancia, deriva del carácter abierto y específico con el que se expresa el rechazo o la reserva hacia algunos temas de la Declaración, pues por su carácter polémico, aparecen velados en las discusiones caseras. ${ }^{104}$ En México, fundamentalmente en la reforma al artículo

\footnotetext{
${ }^{104}$ La tensa discusión en torno al tema aparece en un sinfin de obras y autores, inviables de listar. Lo que vale la pena referir es que, en todo ese corpus académico, el carácter deriva hacia aspectos puramente ideológicos, pues las razones de unos y otros, a pesar de tener argumentos importantes, terminan en
} 
segundo de la Constitución, tales reservas surgieron en el debate público y legislativo, y rondan toda la exposición de motivos del nuevo artículo. Sin embargo, lo polarizado del caso mexicano, en el contexto del conflicto nacido en Chiapas en 1994, hace difícil exponer las reservas de manera abierta, así que aparecen como "matices" o "eufemismos", pero en franca resonancia con lo expresado en la Asamblea General. Estas similitudes derivan en esencia, de los problemas que supone la creación de un estatus especial no igualitario, diferente al resto de la población, que limita la soberanía del Estado-Nación clásico, y simultáneamente, de que para romper la situación de injusticia y desigualdad que impera hacia las poblaciones indígenas, es necesario abordar los aspectos anteriores en alguna medida.

Esta fuerte discusión, ha tenido como centro de gravedad lo que se conoce como el Multiculturalismo. Conjunto de saberes teóricos y posturas filosóficas y políticas relativas a los derechos de los pueblos que teniendo un especificidad cultural, están subordinados o subsumidos en el contexto de una cultura diferente, mayoritaria, hegemónica o francamente dominante. Así que para culminar lo relativo al ámbito internacional, se hará una revisión resumida de los aspectos más relevantes del Multiculturalismo y que impactan el campo de las políticas públicas con enfoque cultural.

Antropológicamente, el tema de las relaciones entre las culturas es altamente complejo y rico. En el cimiento de la disciplina, figura tal hecho: el interrogante sobre el otro, diferente y desconcertante. Entender los cómos y los porqués de dicha diversidad y cuál fue el camino por el que se dieron tales diferencias, empujó la curiosidad de mentes brillantes y culminó con la creación de nuestra disciplina. Sin embargo, dicho proyecto no estuvo nunca al margen del contexto político. En general, las reflexiones antropológicas seminales surgieron del contacto diferenciado, asimétrico, entre poblaciones diferentes. De ahí, el pecado original de la disciplina como "hija bastarda" del colonialismo y el ejercicio de poder transcultural.

ruptura, quedando la posición liberal como un defecto de origen y la posición indigenista, como intolerante y sectaria. Dos ejemplo de lo mencionado, se pueden encontrar en Sartori (2001) y Díaz Polanco (2006). 
A pesar de ello, una parte substancial de sus resultados, teóricos y empíricos, ocurrió y ocurre al margen de tal nexo "pecaminoso". Esta precisión es de la mayor importancia al hablar de la relación entre Política y Cultura. Y es que dicha relación es intensa y en ocasiones confusa, cuando se abordan los problemas de la convivencia entre culturas y, sobre todo, entre culturas que guardan una relación asimétrica, hegemónica o dominante. Los esfuerzos por eliminar los conflictos por la convivencia o la subordinación entre culturas, igualarlas en derechos y desarrollo, y mantener su especificidad, son en su sentido más puro, un proyecto político. Dicha empresa, contiene elementos de justicia evidentes, legítimos y necesarios; las declaraciones y convenios expuestos anteriormente, son una muestra. Justo, intervenir para modificar el statu quo de las relaciones entre culturas, ha derivado en el desarrollo de un aparato jurídico y en la implementación de políticas públicas para conseguir una convivencia pacífica, igualitaria y con respeto a la diversidad; este expediente es el que aquí se denominará como "Multiculturalismo" (más cerca de la idea de paradigma que de la de corriente o proyecto). Si bien es cierto que muchos autores que reflexionan sobre el tema y proponen diversos tipos de proyectos para armonizar la convivencia entre culturas, rechazan formar parte de tal corriente, lo cierto es que lo que los hermana es la idea de intervención sobre realidades de contacto y conflicto cultural; las direcciones ideológicas para abordar dicho problema son las que difieren. ${ }^{105}$

En general, los trabajos concuerdan en dos supuestos básicos: que en la historia de la humanidad, la diversidad cultural siempre ha existido y ha definido las relaciones entre los grupos humanos; y por otro lado, que tales relaciones pueden y deben ser igualitarias y por tanto, no estar orientadas por una cultura dominante o universal. ${ }^{106}$ Estas dos asunciones, tienen como colofón, que la especificidad cultural de los grupos humanos debe ser comprendida, respetada y conservada. Tal declaración, un argumento novedoso en la historia de la humanidad, deriva paradójicamente, de que esa historia muestra como la noción de "Cultura", surge en la búsqueda por diferenciarse del otro de manera singular y privilegiada:

\footnotetext{
${ }^{105}$ En este trabajo, no se busca generar una propuesta sobre cómo resolver el "problema", sino sobre los efectos reales de dicho proyecto; en ese sentido considero que las reflexiones generales no son de tipo multiculturalista. Sin embargo, si a "vuelo de pájaro" se percibe que está inscrito en sus problemáticas comunes, en consistencia con lo dicho, no puedo rechazar mi inscripción al paradigma.

${ }^{106}$ Los argumento básicos para armar la discusión proceden de las consultas a: Barie (2000), Santos (2004), Santos y Rodriguez (2007), Diaz Polanco (1991; 2006), Bonfil (1981), Krotz (2008), Sartori (2001), Kymlicka (1996), Sierra (1997), Van Cott (2004), Hale (2004), Gutierrez (2004), Martuccelli (2004), Touraine (2004), Valladares (2009), Zapata-Barrero (2004), Dietz (2003), Colom (2001) y Ordoñez (1994).
} 
Periódicamente cada cultura se afirma como la única verdadera y digna de ser vivida; ignora las otras; las niega incluso como culturas. La mayoría de los pueblos que llamamos primitivos se autodenominan con un nombre que significa «los verdaderos», «los buenos», «los excelentes» o, simplemente, «los hombres», y aplican a los demás calificativos que les niegan la condición humana, como «monos de tierra» o «huevos de piojo». (Levi-Strauss, 2000: 113)

Esta regularidad de las culturas, su autoafirmación, tomó un carácter dramático a raíz de las expansiones coloniales del siglo XVI y en el contexto del proyecto moderno. Las dificultades insalvables para conseguir las promesas de desarrollo que justificaba ideológicamente dicho proyecto en todo el mundo, hicieron ver los problemas que surgían de imponer una homogeneización cultural con centro en "Occidente". ${ }^{107}$ Pero esa dinámica de cambio cultural asimétrico, que es una parte substancial del cambio cultural general, transcurre al parejo de las dinámicas de difusión, préstamo o intercambio que ocurren en las fronteras culturales. En el proyecto multiculturalista se rechaza, de acuerdo con los valores de justicia, derechos humanos y culturales que rigen en el presente, dichas formas de imposición cultural, pero también aparece encadenada, la idea de que la diversidad cultural debe manterse, pues es una riqueza patrimonio de la humanidad: "El multiculturalismo [...] refleja el ideal de un programa político de acción, y no una característica de nuestras sociedades pues ellas siempre han sido diversas" (Gutiérrez, 2006: 10). Esto da lugar a un problema fundamental, en virtud de que la exposición de un hecho general a nivel histórico y mundial, se extrapola al presente a nivel nacional o regional, derivando en la exigencia política de aplicar "ahí”, los dichos generales multiculturalistas, que conllevan comprender, respetar y conservar las diversas culturas humanas.

“Comprender" es un expediente científico, pero también social, derivado del corpus de la investigación antropológica y su difusión a la población general. "Respetar" es un expediente jurídico y ha tomado cuerpo general en los compromisos internacionales arriba listados. "Conservar" está incluido en los dichos jurídicos, pero formalmente y sobre todo empíricamente, es un hecho antropológico que no se dirige por decreto, y de ahí los conflictos de su inclusión en el segundo orden. Adicionalmente los dos primeros puntos, la comprensión y el respeto son hechos, por así decirlo, instantáneos, pues cuando ocurren, sus efectos se ven o perciben de manera inmediata.

107 Como refiere Enrique Dussel: "La modernidad no es un fenómeno de Europa como sistema independiente, sino de Europa como centro", cit. en: Hardt y Negri (2002: 375) 
En cambio, la conservación no puede ocurrir en el presente, y las medidas que se toman para conseguirla, pueden derivar o no en la permanencia de una cultura particular, tanto por su efectividad como por el hecho de que es necesaria una intervención exógena para mantener un fenómeno humano que, por definición, es vital de manera endógena.

Este último argumento es, en mi opinión, el corazón problemático del multiculturalismo y el núcleo de sus fallas desde una dimensión puramente antropológica. El avance en las regulaciones sobre derechos humanos primarios y posteriormente los de segunda o tercera generación, hace que la especificidad cultural vaya acompañada de otras diferencias humanas que son internas a las sociedades y no externas. ${ }^{108}$ No obstante, son protegidas de manera semejante, en el contexto de la falta de equidad y acceso a los derechos generales. Sin embargo, proteger "una cultura" supone tomar acciones de una escala mayúscula y cualitativamente diferente. El problema reside en el balance y alcance de tal protección, pues la conceptualización de lo que es cultura, aparece como el núcleo de grandes esfuerzos y polémicas en el seno de la disciplina y en cambio, las políticas de conservación tienen un carácter necesariamente casuístico. ¿Se deben proteger la lengua más que las instituciones, el territorio más que los mitos, o los elementos materiales más que las estructuras de producción?

Se dirá que existe la obligación legal y jurídica de proteger todo eso al mismo tiempo, pero la complicación reside en la limitación de recursos, la restricción del efecto en tan inasibles materias y la transformación cultural derivada de las elecciones personales o grupales que adoptan elementos externos. ¿Hasta que punto una cultura se mantiene como sujeto de una política pública, si al haber perdido muchos de esos elementos, se estaría hablando antropológicamente de otra, pese a la autoadscripción política del individuo o grupo a una cultura base? Estos dilemas no son los únicos encarados cuando se toma por expediente el defender y conservar la diversidad, pero constituyen una muestra de los límites antropológicos de tal programa político. En 1971, Claude Lévi-Strauss conmocionó en la UNESCO al público reunido para su conferencia inaugural "Raza y cultura" al afirmar que: "...la intolerancia no se basa en ideas falsas sobre la raza, sino que tiene un fundamento más profundo: la saturación

\footnotetext{
${ }^{108}$ Es decir, diferencias religiosas, de género, de preferencia política, de preferencia sexual, etcétera, que están en el interior de un grupo social. Así el planteamiento del reconocimiento diluye las especificidades del fenómeno cultural en términos amplios y equipara "Cultura", con subcultura. Un ejemplo evidente de lo anterior, es la mención de estas divisiones particulares al mismo nivel que las culturales, por la mayoría de los autores presentes en la edición del Fondo de Cultura Económica al trabajo de Charles Taylor: $E l$ multiculturalismo y "La política del reconocimiento" (2009).
} 
demográfica de nuestro planeta; y estas ideas falsas sólo son el disfraz ideológico revestido para ocultar los conflictos que emanan de esa saturación (Stoczkowski, 2008: 6). Más aún, aseveró que la UNESCO “...se equivocaba al tratar de reconciliar dos tendencias antinómicas: por un lado, el progreso civilizador que genera un aumento de la población y de los intercambios culturales; y por otro lado, conjuntamente, el desvanecimiento de la diversidad cultural ocasionado por esos intercambios y la saturación demográfica provocada por el crecimiento de la población" (ibid: 7). ${ }^{109}$ Es decir, para Lévi-Strauss los conflictos culturales y la intolerancia contemporánea, derivan de la novedad de la ocupación masiva y total del globo por los grupos humanos, "saturando" el territorio. Dicha saturación procede del avance civilizatorio, que potencia la reproducción, la supervivencia humana y los intercambios entre grupos. Pero esta realidad contemporánea, empuja el desvanecimiento de la diversidad cultura. Es decir, las consecuencias del avance tecnológico y social contemporáneo, frente al mantenimiento de la diversidad como la conocemos, son fenómenos antitéticos en una magnitud extremadamente difícil de evaluar.

La intolerancia que mana de los conflictos del contacto tan cercano, puede y debe combatirse según el antropólogo francés (a pesar de su pesimismo expresado en "Raza y Cultura"). Sin embargo, lo que destaca de su dicho, es la dirección que observa el proceso y sobre todo, la magnitud de los insumos que generan, tanto el cambio humano como la transformación de la diversidad. En este punto hay que notar que una de las simientes centrales del Multiculturalismo, consiste en que justo por la desaparición efectiva de la diversidad cultural, es que hay que tomar acción política. Lo legítimo del esfuerzo no elimina en grado alguno los hechos empíricos; por lo tanto, la evaluación del efecto real de las políticas de rescate cultural debe realizarse con cuidado y sin pasión política.

\footnotetext{
Ahora bien, no se puede negar que a despecho de su urgente necesidad práctica y de los elevados fines morales que se asigna, la lucha contra todas las formas de discriminación participa de ese mismo movimiento que arrastra a la humanidad hacia una civilización mundial, destructora de esos viejos particularismos en los cuales recae el honor de haber creado los valores estéticos y espirituales que dan su recompensa a la vida y que recogemos preciosamente en las bibliotecas y en los museos porque nos sentimos cada vez menos capaces de producirlos (Lévi-Strauss, 2000: 140-1) ${ }^{110}$
}

\footnotetext{
${ }^{109}$ El subrayado es mío.

${ }^{110}$ El subrayado es mío.
} 
Me parece que la clave del asunto, es la notable afirmación de que gran parte de la riqueza cultural del hombre, deriva de "viejos particularismos" y la búsqueda por conservarlos mundialmente, tal cual, enfrenta problemas antinómicos evidentes. Estos problemas son identificados y expuestos claramente por el genio francés al declarar que:

Sin duda nos acunamos con el sueño de que la igualdad y la fraternidad reinarán un día entre los hombres, sin que se comprometa su diversidad. Pero si la humanidad no se resigna a transformarse en la consumidora estéril de los únicos valores que supo crear en el pasado, capaz solamente de dar a luz obras bastardas, invenciones groseras y pueriles, deberá aceptar que toda creación verdadera implica una cierta sordera a la llamada de otros valores, pudiendo llegar hasta el rechazo y aun a su negación. Porque no se puede, a la vez, fundirse en el goce del otro, identificarse con él y mantenerse diferente. Plenamente lograda, la comunicación integral con el otro condena en un plazo más o menos breve la originalidad de su creación y de la mía (ibid: 141) ${ }^{111}$

El problema pues, es grande y no tiene solución fácil. Sin embargo, la Antropología como la única ciencia que cuenta con las herramientas para entender y explicar la diversidad o la uniformidad cultural, tiene la obligación de dar cuenta de los efectos culturales de las medidas políticas, atendiendo no a la nostalgia por la pérdida de tal o cual elemento o hecho cultural, sino llanamente, al comportamiento de las culturas como consecuencia de la intervención dirigida o del cambio histórico. La tentación de hacer del Multiculturalismo, la ideología de la diversidad sempiterna de la humanidad es grande, sin embargo, hay que contener la pasión política en la evaluación de los efectos sobre la Cultura, pues los excesos de un expediente ideológico siempre suponen un riesgo grande en otra dirección. ${ }^{112}$ No obstante, la Antropología como tal, no puede pontificar sobre la distribución de las medidas para la construcción de tal o cual futuro, tan sólo le corresponde evidenciar los hechos o postular las probables consecuencias.

Por eso se acude a un terreno externo, la Teoría Política, para comprender las posibilidades o límites de la acción política en fenómenos de tan grande escala. Ernesto Laclau y Chantal Mouffe utilizan el concepto de Hegemonía para entender y explicar las particularidades de los grandes proyectos políticos. Según ellos, la acción política

\footnotetext{
${ }^{111}$ El subrayado es mío.

${ }^{112}$ Análisis de las consecuencias del exceso en la aplicación del credo multiculturalista pueden verse en Martuccelli (2004), Touraine (2004) y Diaz Polanco (2006). Gunther Dietz expone un efecto especialmente notable y que, adelantando, ocurre consistentemente al interior de las aulas de la Universidad Intercultural del Estado de México: "El relativismo cultural [...] como recurso heurístico y metódico indispensable para el estudio de la diversidad cultural, paulatinamente adquiere matices de recurso ideológico empleado para 'camuflar' todo tipo de desigualdades bajo el manto de la cultura" (Dietz, 2003: 77).
} 
profunda deriva en aspiraciones hegemónicas, en virtud de que los actores que ocupan posiciones diferenciadas y particulares respecto del total de discursos en una sociedad, se mueven en dirección de la consolidación de su discurso particular, como estructura universal.

Esta relación, por la que una cierta particularidad asume la representación de una universalidad enteramente inconmensurable con la particularidad en cuestión, es lo que llamamos una relación hegemónica. Como resultado, la universalidad es una universalidad contaminada: (1) ella no puede escapar a esta tensión irresoluble entre universalidad y particularidad: (2) su función de universalidad hegemónica no está nunca definitivamente adquirida, sino que es, por el contrario, siempre reversible. (Laclau y Moufe, 2004: 13-4)

El planteamiento en Hegemonía y estrategia socialista avanza en la dirección de profundizar el credo democrático, es decir, la culminación hegemónica de los axiomas de la democracia, llegando por ende, a todos los ámbitos donde no se encuentra. Sin embargo, Laclau y Mouffe no se extravían de sus postulados al llevar siempre en mente la tensión particularidad/universalidad, base de los antagonismos sociales, y consubstancial a lo político. De ahí que asuman “...que no puede haber política radical sin la identificación de un adversario. Es decir, que lo que se requiere es la aceptación del carácter inerradicable del antagonismo" (ibid: 17). ${ }^{113}$

La conclusión para lo que nos ocupa, es casi transparente. Una cosa es el hecho histórico de la universalidad de la diversidad cultural y otra muy diferente, hacer de tal hecho, un credo político particular con pretensiones universales. Para los autores no hay duda: lo segundo es una universalidad contaminada, pues no representa la totalidad de los discursos, sino solamente una parte. La defensa de la diversidad cultural como proyecto y la intención expresa de que se extienda y domine en todo el globo es, llanamente, un proyecto hegemónico. Tomando como fondo las diferencias entre los hombres y las culturas, plantea medidas para su conservación, su eliminación, su asimetrización o desasimetrización. Dicho expediente político, es legítimo en toda la extensión de la palabra, pero lógicamente particular. Apropiarse del hecho universal de la diversidad, para extenderlo como proyecto al comportamiento de las culturas, resulta en la contaminación política de un hecho empírico. Más aun, ignora la legitimidad formal de los antagonismos a dicho proyecto, al colocarlos como opuestos, no al

\footnotetext{
${ }^{113}$ El subrayado es mío.
} 
proyecto político de la comprensión, respeto y conservación de la diversidad, sino, al hecho histórico y empírico de la diversidad humana. ${ }^{114}$

Concluyendo. La Antropología como ciencia estudia el universo de los fenómenos culturales. Para ésta, resultan igualmente un objeto de estudio, tanto las miles de culturas que existen o han existido en la historia de la raza humana, como una hipotética cultura global única; de hecho, la encendida respuesta a las tendencias globales homogeneizadoras, pone en evidencia la factibilidad de dicho objeto. ¿Debe la Antropología "oponerse" a tal posibilidad? Claramente, no. Su deber es definir herramientas para comprender lo que va sucediendo y postular consecuencias o efectos de los cambios culturales. ¿Pueden o deben los antropólogos manifestarse frente a la pérdida de la diversidad? Definitivamente, sí. Sin embargo, la enunciación de un futuro específico como deseable, abandona los terrenos de la Ciencia y se adentra en los de la Política; es decir, el estudio científico de las diferencias y las asimetrías humanas, termina donde empieza el credo de su transformación o eliminación. ${ }^{115}$

En cambio, la Teoría o la Filosofía Política, deben abordar y definir las herramientas para los "diseños" del futuro. En ese sentido, el Multiculturalismo está menos interesado en comprender "lo que va ocurriendo" y mucho más en "lo que debe ocurrir". Es por tanto, un proyecto legítimamente hegemónico. La búsqueda de la Ciencia por otro lado, es una búsqueda hegemónica de la verdad de los fenómenos, es decir, de su explicación. La brillante simplicidad de la Tesis once sobre Feuerbach: Los filósofos no han hecho más que tratar de interpretar de diversos modos el mundo, pero de lo que se trata es de transformarlo (Marx y Engels, s/f: 403), no elimina la frontera formal entre los mundos de la comprensión/explicación y los de la acción. Por ello es que se compendió este breve apartado, buscando clarificar lo que hay de acción política en los instrumentos internacionales y su frontera con las disciplinas antropológicas. Esto

\footnotetext{
${ }^{114}$ Dicho supuesto es antagónico e insostenible con las aseveraciones regulares de que <<el capitalismo se opone a la diversidad pues se opone a su existencia > y que <<el capitalismo fomenta la diversidad pues le sirve a su existencia >. Más aun, destacan las expresiones de daño y ofensa que motivaron las declaraciones de la canciller de Alemania Angela Merkel en octubre de 2010, en el sentido de que el intento de construir una sociedad multicultural en su país “...es un fracaso". El problema es que la declaración es política, pero los reclamos también, pues la integración multicultural, no depende de los buenos deseos de los cancilleres de Alemania, pero tampoco, de los críticos multiculturalistas. Las relaciones entre los grupos musulmanes y los alemanes, no han llegado al respeto y comprensión por ambos lados, sino a cierto grado de aislacionismo y tensiones resultantes. Resuenan pues, las palabras de Lévi-Strauss en torno a la evidente tasa de aislamiento que requiere una cultura para ser tal.

${ }^{115}$ Como anota limpiamente Luis Villoro: "Esa es la paradoja de toda ideología: captar la realidad pero, al interpretarla con un aparato conceptual determinado, disfrazarla. Las concepciones indigenistas sufren la misma mistificación: describen una realidad parcialmente verdadera con conceptos que la distorsionan. No nos comunican, pues, una historia imaginaria, sino una historia real pero disfrazada" (Villoro, 1984: 10). Sustitúyase "indigenistas" por "multiculturalistas" y el argumento se sostiene, invariable.
} 
significa que muchos de los contenidos antropológicos de dichas normas están "contaminados" por su particularización política. Considero de utilidad dicha aclaración, pues en el abordaje de las políticas públicas de corte cultural, en este caso la de la educación intercultural en México, la evaluación reposada de los efectos de dichas intervenciones, no puede estar influenciada bajo el estigma ineludible del expediente multiculturalista. Lo pertinente es confrontar los supuestos jurídicos de la acción política del Estado mexicano, con los efectos logrados, en el contexto del artículo dos de la Constitución. Si ello lleva a la comprensión, respeto y conservación de las culturas indígenas, será reseñado, independientemente de la "necesidad" de una dirección determinada. Se busca por tanto, determinar la causalidad de la relación entre política y cultura en un caso mexicano. Precisamente, en la siguiente sección, se van a exponer los instrumentos legales nacionales, que marcan el deber ser de las intervenciones del Estado mexicano, respecto de los pueblos indígenas de la Nación.

\section{El marco nacional}

El tratamiento que el Estado ha dado a los indígenas en el territorio nacional ha sido en general, duro, injusto, paternalista y sobre todo, con una tendencia notable a la integración. ${ }^{116}$ Esto es resultado lógico de la situación de las diferencias entre

${ }^{116}$ Claramente, el problema en la definición de la forma específica de organización social llamada Estado, comporta complejos problemas de demarcación, tanto técnicos como disciplinares, pues la etiqueta a dicha forma política, nombrada primeramente por Nicolás Maquiavelo en El príncipe, avanza y retrocede en el tiempo y las disciplinas, desde los "Estados prístinos" que trabaja la Arqueología (Ver Manzanilla, 1986); el Estado como resultado del proceso "función/dominación" (Ver Engels, 1968); el "Estado moderno" surgido del análisis de Maquiavelo (1999) y que es una forma histórica surgida en Europa hacia el siglo XIII (Ver Schiera, 2002); el "Estado contemporáneo", como la forma actual de organización social (Ver Gozzi, 2002); y el "Imperio", forma global, máxima y final que dicha forma de organización puede tomar (Ver Hardt y Negri, 2002). En este abigarrado paisaje, resulta cándido establecer una definición "dura" de Estado, pues si bien se trabaja un estado contemporáneo -el Estado Mexicano-, desde el enfoque antropológico, se privilegia la naturaleza estructural de las relaciones de poder que esa forma define en cuanto a que se ejerce: sobre grandes poblaciones; por encima de realidades comunitarias locales o regionales; en un contexto de supremacía económica, tecnológica, administrativa y militar; con pretensiones a la homogeneidad cultural, lingüística, pero sobre todo, normativa; y que esa homogeneidad normativa, brinda legitimidad a las acciones que ese Estado tiene que imponer sobre un territorio definido. La posición sostenida aquí, resalta dichas características, y de éstas, el balance interno entre clasificaciones y asimetrías, con lo cual, se le da una dimensión holística, antropológica, por sobre las particularidades histórico-administrativas que impactan a las otras disciplinas. Estas características mínimas, independientes de intereses politológicos, sociológicos o jurídicos, se contraponen en cierta medida al expansivo orden global, el Imperio, que adelanta a los estados geográficos, instituyendo un poder máximo, no localizado, pero al cual apelan las poblaciones concretas para neutralizar la porción del Estado con la cual no están de acuerdo. Todo lo anterior, enmarca pues, las dimensiones analíticas de este trabajo sobre el poder político que el Estado Mexicano ejerce o busca ejercer, para aplicar los mandatos constitucionales en materia de educación superior en poblaciones indígenas. Como se ve, la definición de Estado requerida, es totalmente factible de instrumentar. Sin embargo, tiene características de categoría y no de concepto, por lo que su esclarecimiento requiere más de las ocho líneas del bosquejo conceptual que aquí presento. 
conquistadores españoles y pobladores originales del territorio mexicano, pues derivó en el desarrollo de asimetrías y poder de acuerdo con los intereses e intenciones imperiales. Aun con las notables tendencias a dispensar un trato justo, de "hombres", a los que se miraba como diferentes, el esfuerzo siempre fue en el sentido de amoldarlos a los esquemas culturales europeos, es decir, a los valores que se tenían por más preciados: aquellos derivados del Derecho imperante y del Evangelio cristiano.

No es necesario hacer un recuento histórico ni reseñar bibliográficamente las barbaridades cometidas -en aras, primero, de explotar y aniquilar a la población amerindia (mediante las encomiendas) y luego, al tornarse el esquema más racional, iniciar un proceso de "administración" de dichas poblaciones-, porque la literatura especializada está llena de tales trabajos y el horizonte temporal de esta investigación, es netamente contemporáneo.

Sin embargo, luego de siglos de tal esquema, el resultado fue derivando en la situación demográfica mayoritaria que se estabilizó en el siglo XX: Un sector pequeño de "criollos", una creciente población mestiza y un porcentaje significativo de indígenas, afro-descendientes y campesinos. ${ }^{117}$ Esta realidad es el marco en el que se gesta lo que es bien conocido como el Indigenismo. La historia del indigenismo mexicano es basta, pero tiene momentos centrales, como la obra de Manuel Gamio "Forjando Patria", la declaración conjunta de países latinoamericanos que crea el "Instituto Indigenista Interamericano" a través de la Convención de Pátzcuaro (1940) y la creación del "Instituto Nacional Indigenista" (Diario Oficial de la Federación, 1948). Estos documentos, resultado de la transformación del país luego de la Revolución Mexicana, pero también de la transformación de las condiciones internacionales, sobre todo en países del "Tercer Mundo", culminaron en la necesidad de conceder un énfasis especial en la eliminación de las condiciones de pobreza y marginación en la que vivían las poblaciones indígenas en América Latina, pero también, a que dicha transformación fuera con un horizonte integrador al proyecto de un Estado-Nación fuerte y homogéneo. ${ }^{118}$ La gestión del INI fue la rectora de dichas políticas durante la segunda mitad del siglo. ${ }^{119}$

\footnotetext{
${ }^{117}$ Este último sector, lo que Bonfil (1994) llama el "México Profundo".

${ }^{118}$ Llama poderosamente la atención, que en las discusiones para la aprobación de la "Ley que crea el Instituto Nacional Indigenista" se enfrentaron dos posiciones contrarias: por un lado las que estaban en favor de soslayar el objetivo básico del INI como integrador de las poblaciones indígenas y los que estaban a favor de inscribirlo expresamente en dicha ley. El diputado Ramírez Munguía declaraba: "En ese artículo [el segundo, donde se describían las funciones del INI] únicamente se habla de las medidas por las cuales se faculta al instituto por crearse y en ellas no encontramos, principalmente, dentro del
} 
Esta característica integradora y homogeneizante, y la creciente aparición de una conciencia política indígena y pro indígena, provocaron las protestas y el activismo en el último cuarto del siglo. Dan cuenta de este cambio, las declaraciones del Primer y Segundo Congreso Nacional de Pueblos Indígenas (INI, 1978: 361-81); todos los documento compilados en el volumen Utopía y revolución (Bonfil, 1981), en particular la "Declaración de Barbados II"; los célebres Cuadernos del CADAL (Centro Antropológico de Documentación para América Latina) y el gran cúmulo de documentos de corte antropológico, que analizaban los movimientos indígenas a la luz de las ideologías dominantes en la época: las presiones democratizadoras de corte liberal o la liberación como clase, de corte marxista; pero sobre todo el creciente y pujante movimiento indígena que en organizaciones colectivas o reuniones periódicas, comenzó a manifestar sus intereses como pueblos y culturas diferentes. Las más notables fueron el Consejo Nacional de Pueblos Indígenas (CNPI) y la Alianza Nacional de Profesionistas Bilingües A. C. (ANPIBAC) surgidas en los años setenta. ${ }^{120}$

La resonancia internacional con estos temas, obligó al Estado Mexicano, a responder a las presiones internas y externas. Muestra de ello fue la firma del Convenio 169 ocurrida en 1989. Su adhesión frente a la comunidad de naciones culminó, en el nivel interno con la modificación al artículo cuarto constitucional realizada en el año de 1992. Este brevísimo bosquejo histórico, no tiene otra pretensión que encuadrar las circunstancias nacionales en las que se desarrrolla la reforma constitucional y que permiten dar sentido a los conceptos que se han venido manejando en todo el documento: diferencias, asimetrías y ejercicio de poder vía intercambio. En la siguiente sección, se analizarán con ello, los aspectos centrales de dicha reforma conservando el mismo método de análisis usado en los documentos internacionales.

concepto de mejoría de estos núcleos indígenas, la verdadera incorporación de los mismos a la hispanidad [...] que tienda a incorporar a la sociedad mexicana a estos indígenas" (INI, 1978: 343). Pese a las reticencias a expresarlo de manera abierta, es un hecho que las políticas desprendidas del INI sí tenían un carácter integrador. La declaración del diputado expresa pues, una posición que legislativamente fue minoritaria -tres votos contra 76- pero que representaba el verdadero sentir de la clase política mexicana durante gran parte del Siglo XX. Ese expediente se hará presente igualmente, en las discusiones de la reforma constitucional del año 2001, en la cual opiniones aisladas y duramente criticadas, sobre los peligros de la autonomía, no obstante son imperantes en la operación de las políticas públicas estatales, tanto porque están mandatadas constitucionalmente, pero también, porque exponen las tensiones entre los limites funcionales del Estado y las autonomías indígenas.

${ }^{119}$ Un recuento panorámico del primer periodo se encuentra en: "INI 30 años después. Revisión Crítica" (INI, 1978).

${ }^{120}$ Una bibliografía panorámica de lo reseñado se encuentra en: INI (1954), Villoro (1984), Stavenhagen (1969; 1992), Bartolomé (1997), Bengoa (2000), Diaz Polanco (1991), Ordoñez (1994) y Valladares (2009). 
La nación mexicana tiene una composición pluricultural sustentada originalmente en sus pueblos indígenas. La ley protegerá y promoverá el desarrollo de sus lenguas, culturas, usos, costumbres, recursos y formas específicas de organización social, y garantizará a sus integrantes el efectivo acceso a la jurisdicción del Estado. En los juicios y procedimientos agrarios en que aquellos sean parte, se tomarán en cuenta sus prácticas y costumbres jurídicas en los términos en que establezca la ley (Diario Oficial de la Federación, 1992: 5)

El compendio de lo signado por el Estado mexicano en el Convenio 169 y la larga exposición de motivos, se comprimen en este breve primer párrafo del artículo cuarto de la Constitución, vigente en 1992. Siguiendo los procedimientos acostumbrados, se puede hacer su análisis que, dada la extensión, resulta sencillo.

En concordancia con lo firmado por el Estado mexicano en el C-169, se reconoce constitucionalmente que el país está formado por una multiplicidad de culturas cuya base descansa, de origen, en los pueblos indígenas. Esto define la primera oposición: pueblos indígenas/resto de la población. Lo segundo que enuncia, es que dichos pueblos tienen características culturales diferentes, por lo que mediante procedimientos enunciados en la ley, se protegerá y promoverá su desarrollo. Se asume pues la necesidad de crear una asimetría legal que derivará en políticas especiales para la protección de dichas características. ${ }^{121}$ Se insiste en que tales diferencias culturales no pueden resultar en un acceso deficiente a la jurisdicción del Estado, es decir, que no justifican la construcción de asimetrías. Finalmente, que en los temas agrarios, sus prácticas y costumbres jurídicas serán consideradas en los términos de ley. Se instaura así una clasificación antes inexistente: derecho positivo mexicano/prácticas y costumbres indígenas, cuya asimetrización o desasimetrización, estará regida por el primer término del par. En concordancia con el método de trabajo, se declara pues que las diferencias culturales en la población mexicana, no deben facultar la construcción de asimetrías que impidan el acceso a los derechos que goza el resto de la población. Se mantiene sin embargo, la asimetría entre los sistemas legales, por los problemas que genera la renuncia del Estado a su soberanía. Para el ejercicio del poder político, la citada protección y preservación deberá encarnar en políticas públicas, que serán factibles de operar mediante el intercambio, al poner recursos al servicio de dicha

\footnotetext{
${ }^{121}$ Como expone Valdivia (2009), la reforma del Estado Mexicano a partir de la firma del convenio $196 \mathrm{y}$ la reforma constitucional de 1992, culminó en un exiguo resultado en leyes secundarias.
} 
promoción y protección, que al apropiarse, derivarán en las conductas o conceptualizaciones elegidas.

No hay pues, gran novedad. Lo más interesante surge del contexto. Para comenzar, se instaló una Comisión Nacional de Justicia para los Pueblos Indígenas en el INI, que analizó la posibilidad de la reforma constitucional, convocando para ello, a foros con participación de representantes indígenas; los cuales aportaron el $40 \%$ de las propuestas (Gaceta Parlamentaria, 1990). Los trabajos de la Comisión arrojaron un documento que contenía siete puntos básicos:

1. El reconocimiento de la realidad pluricultural del país y de los pueblos indígenas como una parte del total

2. El derecho de los pueblos a la protección, preservación y desarrollo de su cultura

3. El reconocimiento legal, para los tres órdenes de gobierno, del punto anterior

4. Que las disposiciones sean de orden público

5. La creación de normas especiales que garanticen su acceso a la justicia individual y colectiva

6. La declaración de que el juzgador tome en cuenta las especificidades culturales de los indígenas en los tribunales

7. Que se harán legislaciones estatales específicas para el tema (Ordoñez, 1994: 23)

El resultado constitucional, retoma algunos de estos aspectos, pero no todos. La presentación de la iniciativa por el Ejecutivo Federal al Congreso de la Unión, contiene en la exposición de motivos, argumentos sobre todos estos puntos, que en el resultado final no se tomaron en cuenta (Gaceta Parlamentaria, 1990)

De la "Exposición de Motivos", destaca el análisis de la población indígena en términos de pobreza y falta de desarrollo. Su caracterización demográfica, está atada a la lengua $y$ en ningún punto se declara expresamente el concepto de <<autoadscripción〉>. Se describen las injusticias legales y la incompatibilidad de los sistemas legales, declarando que: "La solidaridad entre los propios indígenas, que se expresa a través de su organización social, mitiga conflictos y ofrece protección que resulta insuficiente. Está sustentada en prácticas jurídicas arraigadas y respetadas entre ellos, que en la mayoría de los casos no sólo no contradicen sino que podrían complementar las normas del derecho positivo" (Ibidem). ${ }^{122}$ Esta declaración,

\footnotetext{
${ }^{122}$ El subrayado es mío.
} 
problemática a todas luces y motivo en el presente de duras polémicas por la aceptación formal pero no legal del argumento, busca en el contexto de la reforma, subrayar un hecho: la armonía imperante entre los indígenas y el resto de la población. Es decir, el marco de la reforma es la convivencia pacífica entre los mexicanos. Se entiende la declaración en el marco del régimen priista, en el cual la "paz revolucionaria" sólo necesitaba de pequeños ajustes en sus imperfecciones. Contrasta notablemente, con lo que sucederá en la exposición de motivos para la reforma del 2001, en el marco de una insurrección indígena, que claramente se buscaba atenuar o terminar.

En contraposición al C-107, que postulaba la existencia de pueblos "semitribales", la reforma resuena con la eliminación política de las gradaciones culturales que tuvo lugar en el C-169. Se declara: "La identidad se precisa de manera diversa y se modifica con el tiempo y circunstancias. Los indígenas mexicanos se transforman y redefinen sin que su identidad se disuelva o debilite [... la reforma] No establece ni prefigura el destino de los pueblos indígenas, lo deposita en sus propias manos. No se traduce en la preservación de lo viejo por viejo ni en el cambio forzado para adoptar lo nuevo sólo por serlo" (Ibidem). ${ }^{123}$ Se tiene muy claro ya, el respeto a la diferencia cultural y el abandono del expediente integracionista; pero aparece, de manera implícita, la idea de identidad política, es decir la autoadscripción, que como se argumentó, reduce las posibilidades identitarias a dos: indígena o no indígena. Adicionalmente, establece políticamente, la intemporalidad de su identidad, al referir que al margen de cómo se transforme, siempre será indígena. ${ }^{124}$ Por último, se va desarrollando en el texto, otra de las grandes objeciones a los regímenes especiales: la vulneración de los derechos de terceros o la creación de regímenes de privilegios. "La reforma propuesta parte de reconocer diferencias y desigualdades. En el marco de nuestra ley suprema, respeta las primeras pero rechaza las segundas. Proporciona una base jurídica para proteger las diferencias que enriquecen al conjunto de la nación, pero no crea ningún privilegio ni establece una categoría diferente entre los mexicanos" (Ibidem). ${ }^{125}$

\footnotetext{
${ }^{123}$ El subrayado es mío.

${ }^{124}$ Resuenan aquí, las críticas a la Declaración sobre derechos indígenas del 2007, en donde la creación de regímenes especiales, puede derivar, no en la ruptura de las condiciones de marginación, sino en su prolongación y fortalecimiento.

${ }^{125}$ Esta baja voluntad del Ejecutivo, tuvo eco en las discusiones para su aprobación en la Cámara de Diputados, en donde mayoritariamente, o se rechazó la reforma o se negó la posibilidad de mejorarla (Burguete, 1991: 37-9).
} 
Es insólito como embonan los postulados teóricos de origen, sobre clasificaciones, asimetrías y ejercicio de poder, con esta declaración, y también, como niega lo mismo que acaba de declarar. Mencioné que a partir del C-169, ya no se buscó eliminar las diferencias como en el pasado C-107, sino sólo las asimetrías. Sin embargo, las asimetrías eliminadas se refieren a las que impiden el ejercicio igualitario de los derechos ciudadanos, es decir aquellos de los que goza el resto de la población. No obstante, el fenómeno indígena trae aparejado condiciones de pobreza y bajo desarrollo; para romperlas, hace falta asimetrizar ciertas condiciones de la acción del Estado, pues de otro modo es imposible lo que se pretende: igualar a lo diferente. La segunda parte de la declaración, la negación de que crea regímenes de privilegios es cierta en el contexto de la reforma constitucional del 92. Es tan exigua, que no plantea mecanismos legales para romper la desigualdad no cultural, pero derivada de lo cultural. En ese sentido la frase es completamente congruente -pues no crea ningún régimen especial, lo que la muestra como inútil- y recuerda las objeciones expresadas en el debate del 2007 de Naciones Unidas. ${ }^{126}$ En la reforma constitucional del 2001, esta tensión, la de los regímenes especiales y la lesión de derechos de terceros, será más intensa y conflictiva, en virtud del cambio de la realidad política del país: de indios pacíficos a “transgresores" de la ley. ${ }^{127}$ En adelante abordaremos la reforma al artículo segundo de

\footnotetext{
${ }^{126}$ Esta característica del Derecho que relaciona diferencias, asimetrías, igualdad, desigualdad, privilegios y poder, tiene un origen complejo desde el modelo de poder aquí expuesto, en virtud de la característica "polisémica" de los pares de oposición, en relación con las condiciones concretas de la realidad. De tal suerte que, como se expuso en el capítulo I, no hay asimetrías estables ni inmutables, y tampoco es posible declarar, que una diferencia jamás se usará como asimetría. Esto explica la tensión creada por los regímenes especiales, que, en el más puro sentido de la Teoría sobre el poder, pueden ser y son usados para la creación de privilegios. No es materia de una declaración de buena fe, sino de la naturaleza intrínseca de los fenómenos de poder. Llama la atención en ese contexto, el insoluble argumento del Ayuntamiento de San Pedro Quiatoni, Oaxaca, que en la argumentación de la controversia constitucional presentada ante la Suprema Corte de Justicia de la Nación, a propósito de la reforma del 2001, declara: "En países multiétnicos, como México, el Convenio 169 pretende impulsar un marco jurídico diferenciado para lograr un plano de equidad, aunque parezca contradicción. Lo especial no implica privilegio sino referencia específica a la identidad diferenciada de los diversos pueblos que conforman nuestra nación" (Suprema Corte de Justicia de la Nación, 2001: 29). Resulta, pues, insoluble el planteamiento del enunciado. Crear diferencias jurídicas para lograr la igualdad jurídica; crear regímenes especiales, que no implican trato especial; la salida efectiva de la antinomia ocurre en el campo político, pero no en el de la lógica formal. La solución de estos problemas pudiera ocurrir en una dimensión que no está presente: la caracterización ciertas condiciones sociales en los indígenas, que determinarían el fin de la aplicabilidad del ordenamiento, al haberse alcanzado la "igualdad". Como ello es políticamente muy complicado de enunciar y gestionar, y jurídicamente genera problemas de justicia, se contentan con una declaración de buena fe, en el sentido de que las asimetrías que benefician a los indígenas, no serán usadas como asimetrías; declaración a todas luces contraria, insisto, al planteamiento teórico sobre el origen y funcionamiento de las relaciones de poder.

${ }^{127}$ Las diferencias en el tratamiento de tema de la diversidad cultural, según el "tono" en el que se piden los derechos, está caracterizado de manera muy interesante en: "Rethinking Indigenous Politics in the Era of the 'Indio Permitido' ", de Charles Hale (1994).
} 
la Constitución, poniendo un énfasis especial en ese cambio político, producto de la irrupción del EZLN y los Acuerdos de San Andrés.

Si hay un hecho extraordinariamente denso en la historia contemporánea de México, necesariamente estamos hablando del levantamiento armado del Ejercito Zapatista de Liberación Nacional (EZLN). Justo el día en que entraba en vigor el Tratado de Libre Comercio firmado con Estados Unidos y Canadá, los “zapatistas” irrumpieron en el escenario nacional, definiendo la agenda política del convulsivo año de 1994. Las negociaciones que siguieron al alto al fuego entre el EZLN y el Gobierno de México, con la ayuda de la Comisión de Concordia y Pacificación (COCOPA) y la Comisión Nacional de Intermediación (CONAI), estuvieron enmarcadas en un insólito contexto de actores sociales "tradicionales" y "nuevos" actores sociales, cuyo activismo, influyó en el cese de las hostilidades, en el acompañamiento de las negociaciones de paz y en la consecución de los “Acuerdos de San Andrés” en 1996.

El más buscado y notable efecto de todo el fenómeno, fue llevar al primer lugar de la agenda nacional, la reflexión sobre los derechos indígenas y desde luego, su posterior inscripción en la Constitución. Dos ejes de la mayor relevancia, definieron el debate a lo largo de los siete años que van de la rebelión armada a la inscripción de los “derechos indígenas" en el artículo segundo de la Constitución: una revisión profunda y crítica de las causas históricas y contemporáneas del estado de pobreza, marginación y desigualdad en el que se encontraban los pueblos indígenas; y una puesta al día en las consideraciones jurídicas y políticas para el reconocimiento y otorgamiento de derechos a los indígenas. Con esto dos ejes en mente fue posible articular una propuesta consensada, que partiendo del diagnóstico mencionado, retomara las tendencias actuales en términos de derechos culturales y sobre la diversidad.

No obstante la convergencia entre el Gobierno Mexicano y el EZLN expresada en los Acuerdos de San Andrés (Gobierno del Estado de Chiapas, 2003), el primero nunca presentó dichos acuerdos al Congreso de la Unión como iniciativa constitucional. Fue hasta el cambio de gobierno, cuando se concretó dicha presentación, rodeada nuevamente por la presión social y del EZLN, en su larga marcha hasta la tribuna de la Cámara de Diputados. La reforma constitucional, "como está", retoma puntos de los "Acuerdos", modifica otros y excluye algunos. En adelante, se analizará dicha reforma a 
la luz de los conceptos referidos anteriormente: diferencias, asimetrías y poder por intercambio. Hay que aclarar, que se obvia el análisis especifico del texto acordado en San Andrés Larrainzar, pues lo central es el texto constitucional, ya que constituye el orden del Estado y los mandatos al Gobierno. Este preámbulo únicamente buscó encuadrar la reforma, no obstante se irá confrontando con los "Acuerdos" o con los otros documentos trabajados cuando sea necesario. ${ }^{128}$

Dos aspectos son relevantes de considerar, al abordar la reforma constitucional del 2001. El primero, es su carácter vigente y el segundo, su naturaleza polémica. La vigencia es central para el tema del ejercicio del poder político del Estado, pues la norma constitucional, declara de manera inapelable lo que "es", lo que "debe ser" y lo que "se debe hacer". En segundo lugar, como todo orden político normativo, la Constitución es cuestionada, apelada y "apaleada" por no representar los intereses legítimos de un grupo específico o mayoritario de la nación. Sin embargo, dada mi focalización en los problemas del ejercicio del poder político, tomaremos como centro de las "órdenes" a los gobiernos y a la población el texto constitucional, y se dejará del lado el carácter polémico como contrapunto, para explicar o entender, porqué los objetivos de las políticas se logran o no, en virtud de tener el sentido de fundamentación o aclaración en los motivos de la reforma; de inconformidad manifiesta con el texto; de insuficiencia efectiva, ya que carece de definiciones o medios para lograr lo que se pretende; o de un exceso de expectativas, pues pretende alcanzar cosas que no se pueden lograr. Estos últimos órdenes se expondrán entreverados con el análisis del texto constitucional.

Lo primero que llama la atención, es el enunciado inicial del artículo segundo: "La Nación mexicana es única e indivisible" (Diario Oficial de la Federación, 2001: 2). Declaración ausente en el texto de San Andrés, engloba la pugna central de toda la reforma. Como lo enuncia el propio titular del Poder Ejecutivo:

...debe subrayarse que la libre determinación y autonomía de los pueblos indígenas -reconocidas en la redacción propuesta para el párrafo segundo del artículo $4^{\circ}$ constitucional-, se proponen sin menoscabo de la soberanía nacional y siempre dentro del marco constitucional del Estado Mexicano. La libre determinación no debe ser un elemento constitutivo para la creación de un Estado dentro del Estado Mexicano. La Nación mexicana tiene una composición

\footnotetext{
${ }^{128}$ Para un marco más fino y crítico sobre el contexto de la rebelión zapatista y su desarrollo hasta antes de la reforma ver: Harvey (2000); Leyva (2001); Ansaldo (1998); Diaz Polanco (1997); Gilly (1997); Moguel (1998); Guerra (1998); Pérez Ruiz (2000); Womack (1999) y Valladarez (2009).
} 
pluricultural, pero un solo Estado nacional soberano: el Estado Mexicano. (Gaceta Parlamentaria (2000: 9). ${ }^{129}$

Es decir, se suprime la posibilidad de oposiciones del tipo nación mexicana/nación indígena o nación mestiza/nación mazahua, por poner unos ejemplos. Es cerrado el texto constitucional a otro orden fundamental que no sea el emanado del proceso histórico que culmina en la formación del Estado-Nación que conocemos a la fecha. Si bien se reconoce en un segundo nivel la diversidad de culturas particulares, una unidad identitaria superior, "la mexicana", impera sobre dichas particularidades. El motivo de enunciar tal asimetría cerrada, parte de la disputa sobre la soberanía del Estado en los pueblos y comunidades indígenas, y el miedo a que si se comparte dicha soberanía, habrán movimientos de separación o escisión. En la reflexión de la reforma que les envió la Cámara de Diputados, los senadores en la minuta:

...no puede ignorarse que se ha producido la inquietud, seria, fundamentada con argumentos, que el reconocimiento de las demandas indígenas tal como fueron resueltas en los acuerdos COCOPA-EZLN que conforman la iniciativa del $\mathbf{C}$. Presidente, implique la división de la Nación y que la apertura política con que la República está dispuesta a responder, conduzca a movimientos de desagregación (Gaceta Parlamentaria, 2001: s/p). ${ }^{130}$

Esta tensión, entre los derechos de igualación ante la ley y los derechos inherentes a la calidad de ser indígena, expresados en la figura de la autonomía, fue contemplada por los miembros del EZLN como inexistente, pues en ningún momento han afirmado- tal autonomía derivaría en la aparición de dos o más Estados o Naciones. En la tribuna del Congreso de la Unión, la comandante Esther aseveró:

Aquí en ese Congreso, hay diferencias notorias, algunas de ellas contradictorias, $\mathbf{y}$ hay respeto por esas diferencias. Pero aun con esas diferencias el Congreso no se divide en partes, no se balcaniza ni se fragmenta en pequeños congresos. $Y$ es justamente que debido a estas diferencias $y$ por el respeto que existe entre los legisladores, que la reglamentación se hace presente. Y sin perder lo que a cada uno hace diferente, la unidad se mantiene y con ello la posibilidad de avanzar mediante lo acuerdos. Este es el país que los zapatistas queremos (GimateWelsh, 2010: 113-4). ${ }^{131}$

\footnotetext{
${ }^{129}$ El subrayado es mío.

${ }^{130}$ El subrayado es mío.

${ }^{131}$ El subrayado es mío.
} 
Si tal es la opinión mayoritaria, la Cámara de Senadores -generadora de las modificaciones finales a la iniciativa presidencial- postula entonces que fue "Crucial la unanimidad de todos los grupos y organizaciones en el sentido de que la demanda de autonomía indígena no significa, de ninguna manera, intención de separarse de la nación mexicana o de organizarse al margen de las instituciones y las leyes del Estado Mexicano" (Gaceta Parlamentaria, 2001: s/p). ${ }^{132}$

De lo anterior, se observa como núcleo de la discusión sobre la reforma al artículo segundo constitucional, la creación de un régimen especial, que permita subsanar las injusticias y desigualdades históricas que los indígenas han sufrido. Esto genera un proceso de asimetrización de las diferencias entre indígenas y el "resto" de la población, buscando que por medio de dichas ventajas, los pueblos y comunidades puedan igualarse a los demás en derechos y desarrollo. Sin embargo, la "especialidad" del dicho régimen, no puede conducirlo más allá de los márgenes de la Nación y el Estado Mexicano; esto es una opinión general de todos los actores. Con base en ello, es que los cambios a la minuta del Ejecutivo, tomaron sentido para la mayoría de los miembros del Congreso de la Unión. ${ }^{133}$

El asunto central es la definición de lo que constituyen los límites del Estado y la Nación; y no quedó duda, el Estado-Nación existente, discriminó lo que podía y debía otorgar en la reforma; es decir, sus propios límites. Es verdad que dicha interpretación corrió a cargo de individuos concretos que tomaron posiciones orientadas por una ideología, pero también es cierto que la propuesta de San Andrés se confeccionó de la misma manera, pues así discurre la práctica política. En ese sentido destaca la polémica surgida, respecto de la representatividad que los participantes en la confección de los Acuerdos de San Andrés, tienen frente al Poder Legislativo. Ésta es una confrontación problemática, en virtud de que la legitimidad final que se buscaba con la inclusión constitucional de los "Acuerdos", derivaría de su aceptación por dicho Poder. Sin embargo, se desestimó su proceso habitual, y por ende la legitimidad que emana del Congreso de la Unión, ya que al demandarse la aceptación en automático del texto, lo que generaría en la práctica, sería la aceptación de un Constituyente nuevo. Dado que en la historia política de México, las Constituciones y los Constituyentes han surgido de situaciones de confrontación y se han impuesto por la fuerza, la aparición de este

\footnotetext{
${ }^{132}$ El subrayado es mío.

133 En el Senado: 96 a favor y 12 en contra; en la Cámara de Diputados: 385 a favor y 60 en contra (Gimate-Welsh, 2010: 272, 284)
} 
"nuevo constituyente", en la práctica, no tuvo la fuerza suficiente para "imponer" la totalidad de sus resoluciones y quedo en el Órgano habitual, la culminación del proceso de legitimación constitucional. ${ }^{134}$

El asunto no es un problema menor, pues intersecta cuestiones de justicia, de derecho y de política, que no necesariamente resultaron en una reforma a la altura de lo requerido. Sin embargo, el Poder Legislativo emitió su resolución y así fue publicada por el Poder Ejecutivo. La distancia con la iniciativa inicial es variable según el tema, pero los cambios derivan de la citada tensión entre los límites y acción del Estado, y las demandas de respeto a la cultura y territorio de los pueblos indígenas.

¿Cómo se comporta el ordenamiento constitucional, al analizarlo con los procedimientos empleados en los otros cuerpos normativos? En primer lugar, aparece el sistema de clasificaciones desplegado en el texto. Culturas diversas/Nación Mexicana; culturas indígenas/resto de la población; indígenas con conciencia de su identidad/indígenas sin conciencia de su identidad; pueblo indígena/comunidad indígena; autonomía indígena/Estado constitucional; orden federal/orden estatal y municipal; sistemas normativos indígenas/leyes mexicanas; cultura indígena/cultura del “resto". Estas oposiciones están consideradas en el primer apartado (A), que incluye formalmente los derechos de los pueblos, las comunidades y los individuos indígenas; suponen también, diferencias inmutables. En el segundo apartado (B), se enlistan las obligaciones de los órdenes de Gobierno, para dar cumplimiento a tales derechos: igualdad/desigualdad; valoración/discriminación; desarrollo/subdesarrollo; abundancia/carencia; educación intercultural/educación monocultural; alfabetismo/analfabetismo; bilingüismo/monolingüismo; medicina tradicional/medicina científica; mujeres indígenas/hombres indígenas; comunicación/incomunicación. Estas oposiciones adicionales, se plantean no en términos de derechos intrínsecos o diferencias inmutables, sino de diferencias superables y producto de la asimetrización colonialista e integracionista de las del primer apartado, es decir, las asimetrías construidas a partir de las diferencias culturales, derivaron en asimetrías en el desarrollo de individuos y comunidades, necesarias de eliminar.

\footnotetext{
${ }^{134}$ Este es el espíritu de las declaraciones de los legisladores en los documentos consultados. Destaca la de la minuta de dictamen a la propuesta del Ejecutivo en la Cámara de Senadores: "La iniciativa de Ley sobre Derechos y Cultura Indígenas que presentó el C. Presidente de la República, es la misma que elaboró la Comisión de Concordia y Pacificación a finales de 1996. A casi cinco años de distancia y con la experiencia que ha brindado la discusión que se generó alrededor de la propuesta de dicha comisión de coadyuvancia, los legisladores tuvimos las condiciones para elaborar un dictamen que recupera todos los derechos que los indígenas demandaron, así como legislar para lograr el consenso y la aceptación de los sectores más representativos del país" (Gaceta Parlamentaria, 2001: s/p).
} 
Las asimetrías ancladas a las diferencias culturales, -las del apartado "A" del artículo segundo- son en términos constitucionales eliminadas, al declararlas ilegales, es decir se desasimetrizan, ya que sus fracciones contemplan rubros que el Estado enuncia como diferencias anticonstitucionales de asimetrizar. Los indígenas tienen derecho a decidir de manera interna: I) sus formas de convivencia y organización; II) aplicar sus sistemas normativos a la solución de sus conflictos internos; III) elegir a sus autoridades tradicionales; IV) preservar y enriquecer sus cultura; V y VI) acceder a la propiedad y conservar las tierras donde habitan; VII) elegir representantes ante los ayuntamientos; y VIII) acceder con plenitud a la jurisdicción del Estado. En concordancia con lo expuesto en el C-169, lo que se busca es la eliminación de las asimetrías, manteniendo las diferencias, porque ello deriva en la plena igualdad con el resto de la población. Hay no obstante, una diferencia enunciada que permanece como asimetría, que es la relación entre indígenas como parte de la población y el Estado mexicano como monopolio de la administración de la justicia y el gobierno. Todos los derechos enunciados, están subordinados al orden constitucional vigente, el cual no puede rebasarse en el ejercicio de la establecida libre determinación y autonomía, en ninguno de los casos expuestos. Autonomía de individuos y comunidades indígenas/Estado constitucional mexicano, sigue siendo una diferencia con clara asimetría hacia el segundo término. La pretendida desasimetrización expresada en los Acuerdos de San Andrés en su propuesta constitucional como: "Los pueblos indígenas tienen el derecho a la libre determinación y, como expresión de ésta, a la autonomía como parte del Estado mexicano" (Gobierno del Estado de Chiapas, 2003: 113), fue limitada por el Estado Mexicano, en el que están incluidos de manera forzada, ${ }^{135}$ con: "El derecho de los pueblos indígenas a la libre determinación se ejercerá en un marco constitucional de autonomía que asegure la unidad nacional" (Diario Oficial de la Federación, 2001: 2). No existe pues manera que los derechos concedidos a los pueblos

\footnotetext{
${ }^{135}$ Este argumento, en concordancia con el punto de vista weberiano de que el Estado es una asociación política -la central de nuestro tiempo-, que tiene el monopolio de la fuerza sobre un territorio y de ahí el derivado, de imponer leyes que se cumplan a los incluidos en éste (Weber, 1998: 81-4). En tal sentido, los indígenas y los que se solidarizan con su causa, constituyen una asociación política al igual que todos los demás grupos sociales, incluidos de manera forzada, ya que el mentado monopolio no es cuestionable, pues de otro modo, dice Weber, se instauraría la anarquía entre todos los grupos. Más allá de los cambios en el funcionamiento del Estado en términos teóricos o filosóficos y las aperturas a regímenes menos estrictos o más participativos o autonómicos, la renuncia de un Estado al monopolio por sobre las demás asociaciones políticas, sigue siendo problemática. Por lo tanto, esperar que el Estado Mexicano aceptara sin modificar una reforma constitucional que reduce su monopolio en algunos aspectos, resultó en una esperanza frustrada, en virtud de que los medios empleados a tal fin, no eran lo suficientemente grandes como para limitar de facto, tal monopolio.
} 
indígena, se ejerzan de forma tal que invadan las competencias exclusivas del Estado. Esta sentencia, de carácter puramente jurídico, pone en evidencia, no que los indígenas no puedan ejercer facultades de tipo autonómico a pesar de que el Estado las prohíbe, sino la correlación de fuerzas -es decir las asimetrías movilizadas en ejercicio de poderexistente en el momento de la reforma constitucional, que no consiguió "imponer" cambios en el Estado jurídico, independientemente de que en la realidad, ocurran muchas manifestaciones autonómicas de contención o exilio del Estado sobre el territorio que supuestamente monopoliza. ${ }^{136}$

El campo de las diferencias que deben subsistir -las culturales- y las asimetrías a eliminar, queda entonces claro. Pero tal expediente no es suficiente. Producto de la asimetrización del fenómeno cultural en detrimento de los indígenas, hay instaladas otras diferencias y asimetrías que deben eliminarse, porque siguen impidiendo la incorporación de los indígenas al resto de la población; son las oposiciones desprendidas del apartado "B" del articulo dos. No es que tales diferencias existan únicamente entre los indígenas y el resto. Toda la población mexicana presenta dichas diferencias en alguna medida. Su presencia en la reforma constitucional obedece a que si no se eliminan, reafirman de manera estructural las condiciones de atraso en el desarrollo de los indígenas; tienen la forma discriminatoria: <<son pobres por ser indígenas >> o <<son ignorantes por ser indígenas >>. Ni la pobreza ni la ignorancia, están, por supuesto, atadas a la condición del ser indígena; la asimetrización de la “indianidad" como diferencia, deriva de la limitación de acceso a la riqueza nacional o a la educación, por motivos colonialistas, racistas o discriminatorios. En consecuencia, se deben generar asimetrías legales y de caso, que al incorporarse en la administración cotidiana del Estado, neutralicen las asimetrías estructurales, derivadas de la diferencia cultural. Así, se declaran en el segundo apartado, mecanismos que los tres poderes del Gobierno: Federal, Estatal y Municipal, deberán obedecer en la atención a los pueblos indígenas.

\footnotetext{
${ }^{136}$ Dos ejemplos notables de fenómenos de autonomía efectiva y que interesa a miles de individuos y vastos territorios, son los municipios autónomos en las regiones donde apareció el EZLN, conocidos como "Los Caracoles" o la creación de un órgano de vigilancia no estatal, como la "Policía Comunitaria de Guerrero"; ver: Gasparello y Quintana (2009). En ese sentido resulta extraordinariamente sensata y clarividente, la declaración de Héctor Diaz Polanco: "Por lo demás, que la autonomía se pueda convertir en un arreglo adecuado no depende de algún misterioso imperativo categórico o de un designio teleológico, sino de la acción concreta de fuerzas sociopolíticas que, al asumirla como proyecto, la hagan realidad. En ese sentido, la autonomía es sólo posible, no necesaria" (1991: 11). Adicionalmente resuena toda esta discusión con la planteada por Lasalle al aseverar que: “...lo que es, en esencia, la Constitución de un país: la suma de los factores reales de poder que rigen un país” (2002: 19).
} 
Este régimen especial, es declarado como un proceso de asimetrización, en el sentido de que implica la creación de condiciones particulares, que de manera puramente jurídica, sí constituyen un trato diferente y ventajoso respecto del resto de la población. Se ha insistido, que el matiz general al supuesto privilegio, deriva de que al ser un grupo mayoritariamente deprimido, este tratamiento especial, busca detonar la ruptura con la desigualdad histórica y estructural y está lejos de constituir un régimen de privilegios. $^{137}$

Los ejes en los cuales los órdenes de gobierno actuarán para cumplir con el mandato constitucional, según las nueve fracciones del apartado "B”, comprenden: I) el impulso al desarrollo regional en las zonas indígenas; II) garantizar e incrementar los niveles educativos, favoreciendo la educación bilingüe e intercultural y los contenidos culturales locales; III) asegurar el acceso a los sistemas de salud, aprovechando la medicina tradicional; IV) mejorar las condiciones de las comunidades y de sus espacios recreativos, con apoyo especial para construcción y mejoramiento de la vivienda; V) propiciar la incorporación de las mujeres al desarrollo; VI) extender la red de comunicaciones de todo tipo y propiciar condiciones para que los indígenas puedan adquirir y administrar medios de comunicación; VII) apoyar el desarrollo sustentable y

\footnotetext{
${ }^{137}$ La disputa, ya tratada, según la cual los regímenes especiales constituyen situaciones de privilegios, tiene algunos puntos a su favor y su discusión es pertinente, aunque las fronteras entre privilegio y compensación para grupos disminuidos en las sociedades, son verdaderamente complejas de trazar. Un ejemplo de lo anterior, es que la reforma determina a las comunidades indígenas "...como entidades de interés público", para lo cual, los órdenes de gobierno se coordinarán en su atención. Esta ventaja -la nombrada transversalidad- es adicional a los derechos que legalmente gozan los indígenas como ciudadanos. También, dentro de las enmiendas realizadas a los Acuerdos de San Andrés, destaca la efectuada en el artículo 18 constitucional, que proponía: "Los indígenas podrán compurgar sus penas preferentemente en los establecimientos más cercanos a su domicilio, de modo que se propicie su reintegración a la comunidad como mecanismo esencial de readaptación social" (Gobierno del Estado de Chiapas, 2003: 120). El texto final, con algunas modificaciones técnicas, retomó ese espíritu, pero eliminó a los indígenas como sujeto, suplantándolo por "los sentenciados". Es decir, lo que constituía un privilegio sólo para los indígenas, se incorporó, igualitariamente, para todos los sentenciados. Si bien el espíritu de San Andrés era justo sin regateo, el blanco legislativo no era el "interés general", sino el de un grupo. Algo similar sucedió con la propuesta de que los indígenas tienen libre determinación y autonomía para: "Adquirir, operar y administrar sus propios medios de comunicación." (ibid: 115), derecho que ningún grupo como tal, gozaría. Hay que aclarar que en términos constitucionales, las asimetrías en la gestión de gobierno hacia los indígenas como grupo, quedan neutralizadas como privilegio, en virtud de que al final del artículo segundo se declara que: "Sin perjuicio de los derechos aquí establecidos a favor de los indígenas, sus comunidades y pueblos, toda comunidad equiparable a aquellos tendrá en lo conducente los mismos derechos tal y como lo establece la ley" (Diario Oficial de la Federación, 2001: 4). Esto significa que se están estableciendo derechos colectivos, no contemplados anteriormente en la Constitución, pues cualquier grupo, que se equipare a los indígenas gozará en automático de tales derechos. Comportan como están, sin embargo, un trato especial a los grupos, pues un ciudadano no puede, de manera individual, exigir los derechos constitucionales declarados en el artículo dos. De acuerdo con el planteamiento teórico, esta diferencia: ciudadano/grupo, puede derivar en una asimetría y desde luego, soportar un sistema de poder. En ese sentido, se podría hablar de un régimen de privilegio para los grupos, en detrimento de los individuos que no quieren, no pueden o no saben organizarse.
} 
el empleo productivo; VIII) establecer políticas de protección a los indígenas migrantes; y IX) consultar a los pueblos en la elaboración de los planes gubernamentales.

Es claro del mandato constitucional, que las tareas descritas contemplan la asignación de recursos monetarios, la asignación o reasignación de tareas a funcionarios de gobierno, la creación de organismos específicos para tal atención y la creación de nuevos puestos de trabajo y funciones burocráticas específicas.

"B. La Federación, los Estados y los Municipios, para promover la igualdad de oportunidades de los indígenas y eliminar cualquier práctica discriminatoria, establecerán las instituciones y determinarán las políticas necesarias para garantizar la vigencia de los derechos de los indígenas y el desarrollo integral de sus pueblos y comunidades, las cuales deberán ser diseñadas y operadas conjuntamente con ellos [...] Para garantizar el cumplimiento de las obligaciones señaladas en este apartado, la Cámara de Diputados del Congreso de la Unión, las legislaturas de las entidades federativas y los ayuntamientos, en el ámbito de sus respectivas competencias, establecerán las partidas específicas destinadas al cumplimiento de estas obligaciones en los presupuestos de egresos que aprueben, así como las formas y procedimientos para que las comunidades participen del ejercicio y vigilancia de las mismas" (Diario oficial de la Federación, 2001: 3, 4) ${ }^{138}$

Es evidente todo lo que debe cambiar. En tal sentido, se está hablando de la concreción de los impulsos sociales que motivaron la reforma constitucional y la imposición de "órdenes" a las instituciones del Estado y a los Gobiernos; es pues la manifestación del poder soberano de la sociedad sobre el Estado. Su intención es clara y se expresa por la inscripción en el cuerpo legal de la Nación.

Sin embargo, ¿cómo se logra el otro aspecto: lo que los gobiernos deben producir en las poblaciones, para cumplir con el mandato del soberano, es decir, el ejercicio de poder político sobre la sociedad? El texto constitucional refiere que se deberán garantizar los derechos de los individuos, pueblos y comunidades indígenas derivados de la diferencia cultural y eliminar la desigualdad en su acceso a las oportunidades de desarrollo. De manera paralela, en el resto de la población se deberán eliminar las prácticas discriminatorias, y fomentar el respeto y conocimiento de las diversas culturas en el país. Para el interés que aquí se ha expuesto y en concordancia con los análisis precedentes, se hablan de los mecanismos para lograrlo.

A través de los mecanismos del poder, es factible que la población, ya no los gobiernos, cumplan con las órdenes emanadas de la Constitución y materializadas en políticas públicas. Del texto constitucional se desprende que los recursos que los

\footnotetext{
${ }^{138}$ El subrayado es mío.
} 
gobiernos ejerzan, deberán llevar a los indígenas, como un primer tema, a conocer y aprehender los derechos expresados en el apartado "A": ya sea mediante su promoción en pueblos y comunidades; mediante material impreso en vías públicas o instituciones de gobierno; a través de su difusión en medios masivos de comunicación; o por la realización de talleres y foros relativos al conocimiento y ejercicio de tales derechos. En este nivel, se busca generar conceptualizaciones distintas, pues la materialización del gasto público debe ocurrir en una forma tal, que lleve a los individuos a aprender y a pensar cosas que "de otro modo no harían" (como reza el núcleo básico de la definición de ejercicio de poder); si lo logra, un gobierno habrá conducido la acción social en una dirección determinada constitucionalmente y antes no existente, es decir, habrá ejercido el poder político.

Una aclaración altamente pertinente, en la relación entre poder político y derechos constitucionales, con un sentido púramente empírico, es que no a todos los individuos se les debe llevar a conocer y ejercer sus derechos, vía el ejercicio de poder. Entre las poblaciones indígenas existirán individuos altamente politizados que, inmediatamente después de que una ley que los impacta entre en vigencia, estarán en capacidad para cumplirla o exigir que se cumpla según el caso; ello porque son ciudadanos plenos. El problema es que las poblaciones indígenas son muy heterogéneas en niveles de ciudadanización, justo por las asimetrías tejidas injustamente alrededor de la diferencia cultural. Con niveles bajos de educación, pobreza crónica y debilidad ante los poderes del Estado, las posibilidades de que un individuo conozca una reforma legal, los canales para exigir su cumplimiento y esté emocionalmente dispuesto a enfrentar la discriminación por su condición de indígena, son muy bajas. De ahí que las políticas gubernamentales deben de llevará a las poblaciones indígenas marginadas, como una de sus tareas sustantivas, al conocimiento de la reforma constitucional, a la comprensión de los mecanismos por los que se implementa y a inyectarles confianza para denunciar el racismo y la discriminación.

Un segundo tema, distinto de la "publicitación de la ley" es la materialización de la ley con los nuevos supuestos. Los recursos en los programas públicos deberán llevar a los indígenas, al parejo de que se apropian de ellos, a ejercer los nuevos derechos. Son los casos de programas de: desarrollo regional y sustentable; inversión y capacitación en actividades productivas comunitarias; validación y capacitación para el ejercicio renovado de la medicina tradicional; establecimiento de programas educativos bilingües e interculturales con contenido local o regional; fortalecimiento y promoción del uso de 
las lenguas indígenas; mantenimiento y fortalecimiento de las tradiciones culturales fundamentales; incorporación de las mujeres a una situación de plena igualdad ante los hombres en las comunidades, tanto productiva como políticamente; impulso a las formas de representación indígena ante los poderes del Estado; formación y capacitación de expertos en derechos indígenas; establecimiento de mecanismos para la integración de representantes indígenas a los órganos de consulta.

De esta segunda lista, resulta muy evidente que para cumplir los mandatos constitucionales y dirigir las conductas y conceptualizaciones sociales, los programas deberán contener dos aspectos centrales: I) que el individuo o grupo se apropie de los recursos puestos a disposición según el programa del que se trate y; II) que dichos actores se apropien de acuerdo con las reglas de operación o espíritu del programa, que deberá estar alineado, por obligación, con la Constitución.

No necesariamente el cumplimiento de estas dos condiciones deriva en el ejercicio exitoso del poder político; es decir, son condiciones necesarias pero no suficientes. En primer lugar, porque la conducta detonada puede estar atada estructuralmente a los recursos provenientes del Estado. Ejemplos de lo anterior pueden ser los casos de las publicaciones en lengua indígena o la capacitación para la producción artesanal; al acabarse los recursos, el fenómeno no ocurriría más, por carecer ciertas comunidades de recursos para fondearlas; comportan un ejercicio de poder real, pero instantáneo, distante del espíritu de justicia supuesto. En segundo lugar, porque en el plano de la conceptualización, puede suceder que no haya transformación en el contenido o estructura cognitiva del sujeto, no obstante haberse apropiado de los recursos movilizados según el diseño; lo que denominé como un nuevo tipo de "gorrón". 139

Algo semejante ocurrirá con el "resto" de la población del país, ya que una parte de ésta, es precisamente la que desprecia, margina y minimiza a los miembros de los pueblos indígenas y su cultura. Resultan irrelevantes las motivaciones para tal actuación; dolo, ignorancia o costumbre. Lo significativo, es que las políticas instrumentadas deberán llevar a este sector de la población, a cambiar sustantivamente sus conductas y actitudes hacia lo indígena. Entre los aspectos fundamentales destacan: la promoción de los valores de la reforma constitucional; el impulso a una nueva actitud hacia la diversidad cultural; la exposición de la importancia del dialogo entre

139 En el Capítulo 2, en la sección "Complementos" se habló del tema del gorrón de manera más detallada. 
culturas; y lo importante de apoyar el rescate y fortalecimiento de los hechos culturales indígenas, que también forman parte de la cultura y de la identidad nacional. Los temas ejemplificados pueden ser "inyectados" en la sociedad, a través de la puesta a disposición de materiales impresos, de festivales culturales, de difusión de las manifestaciones culturales diversas, de integración del tema de la interculturalidad en los cursos escolares regulares, etcétera. Nuevamente, si dicho cambio de actitud, surge de la apropiación de recursos que los gobiernos movilizan, se estará hablando de ejercicio de poder político mediante el intercambio.

El asunto de fondo no es por lo tanto, que se produzcan ciertas conductas y conceptualizaciones vía el intercambio, ejerciendo un poder empíricamente observable, pero estructuralmente irrelevante, sino dotar a los mecanismos de apropiación, con las características necesarias y suficientes, para generar una nueva óptica nacional respecto de los derechos que los indígenas tienen, como consecuencia de su diferencia cultural. En esto estriba centralmente la diferencia entre ejercicio de "poder" y de "poder político".

El primero es, sabemos, un hecho factible de detectar por su ocurrencia fenoménica, ya sea mediante la observación empírica de las conductas, "lo que los individuos hacen"; ya mediante la entrevista u otra técnicas indirectas para detectar las conceptualizaciones, "lo que los individuos piensan". ${ }^{140}$ Lo anterior está desde luego, atado a que la intervención sea predeterminada y que el fenómeno empuje a los individuos a realizar tareas "que de otro modo no harían". En contraparte, el poder político, de manera muy general, sí tiene éxito cuando ocurre de acuerdo al enunciado anterior, es decir, respecto de un sujeto, pero que ocurre de manera relevante y semejante en otros sujetos, hasta alcanzar dimensiones significativas en el actor social o grupo político al cual está destinada la orden; pasando del efecto personal, al efecto político. Más aún, no es necesario que se proceda con esa disposición, o sea, de un diseño individual a su replicación colectiva. Puede ocurrir que el planteamiento sea el de ordenar de manera no individualizada a un colectivo y los fenómenos singulares se darán como consecuencia. En ambos casos, pero sobre todo de manera notable en el segundo -el poder político-, existe la pretensión de darle a las disposiciones de poder, una estructura tal, que deriven en fenómenos de autoridad, es decir, que se internalicen entre los colectivos, de manera que la repetición de la orden, requiera cada vez menos la

\footnotetext{
${ }^{140}$ Ambos mecanismos relevantes y factibles de constatar desde la perspectiva antropológica.
} 
utilización de medios específicos para que se cumpla. Este último mecanismo, trasciende el proceso de evaluación que los sujetos dan a lo imperativo del enunciado, quedando instalado finalmente, como norma de acción de los individuos en el colectivo. De forma adicional, esto lleva a eliminar la distinción superordinado/subordinado, pues ambos habrán internalizado dicha "orden" como valor propio, ya sea que deban ejecutarla o que deban conformar las condiciones para que ocurra.

\section{Corolario}

Se ha realizado el procedimiento de exponer el sistema de clasificaciones, que engloba las diferencias descritas en los códigos nacionales e internacionales elegidos. También, se han listado las asimetrías que resultan de ello y de que modo puede darse el ejercicio de poder a través del intercambio, para conseguir lo que ordenan dichos instrumentos. He mostrado pues, la manera en que los planteamientos teóricos de los primeros dos capítulos, pueden ser aplicados a casos reales; no de manera formal, sino efectiva. Considero el resultado satisfactorio, sobre todo al exponer casos donde las declaraciones de actores concretos, organizan las ideas sobre diferencias y poder, en maneras que refuerzan la pertinencia de los planteamientos teóricos.

La confrontación efectiva del modelo, ha ido de los instrumentos internacionales a los nacionales, para contrapuntear la forma en que ocurre la convivencia entre los Estados-Nación del mundo y las exigencias de sus sociedades locales. Esta relación, acontece en el marco de una nueva ideología política que se ha desarrollado desde mediados del Siglo XX. El Multiculturalismo tuvo un impacto determinante, tanto en la transformación política del país antes de 1994, pero sobre todo, luego del alzamiento del Ejercito Zapatista y durante el proceso de reforma al artículo segundo de la Constitución Mexicana.

Lo central de dicho proyecto político, fue elevar a rango de paradigma la improcedencia de eliminar la diferencia cultural. Lo procedente, es mantener las especificidades culturales, pero eliminando las asimetrías construidas sobre dichas diferencias. Este planteamiento, como se habrá visto, está esquematizado en términos de la teoría sobre el poder que defiendo en este trabajo; no obstante, embona de manera productiva, pues el Multiculturalismo se centra en el tema de las diferencias culturales y su uso -injusto- para ejercer un poder estructural sobre las comunidades culturales minoritarias en todo el mundo. Dicha circunstancia, deriva en la construcción de otras diferencias -ancladas en temas de desarrollo-, que fortalecen la imposibilidad de los 
indígenas, de ser ciudadanos con plenos derechos. En consecuencia, se debe romper el uso de las diferencias culturales para construir asimetrías y poder, pero también, se deben tomar medidas especiales para restaurar los daños históricos.

Las políticas descritas en los instrumentos analizados, hablan precisamente de tal necesidad. Implementan medidas específicas para borrar la marginación en la que los indígenas vivían, y viven. Aun en el caso del polémico Convenio 107, había tal búsqueda; paradójicamente, se enfocaba en la desaparición del sujeto beneficiado. Así, se fueron exponiendo las posibilidades de materializar las medidas consideradas en dichos instrumentos, sobre todo, cuando sus efectos se conseguían mediante la toma dirigida de recursos gubernamentales; el remachado poder por intercambio.

Si bien se abordaron algunos aspectos de Filosofía y Teoría Política: ¿qué lograr y por qué lograrlo?, se insistió y se insiste, en que las limitaciones, aciertos o defectos de las legislaciones consideradas, no son un aspecto substancial en este trabajo. El foco en el ejercicio del poder político, me empuja a centrarme en la cristalización legal de las legítimas aspiraciones de las culturas indígenas del mundo y los mecanismos obligados para conseguirlo. Es por ello que se tomó una vía lo más neutral posible, que considere las demandas del actor, pero también, los matices o negaciones legales a dichas aspiraciones, pues representan voces significativas, pero sobre todo, argumentos presentes en la implementación de las políticas públicas.

Tales voces expresan en cierta medida, la postura que motiva las reformas legales. Sin embargo, también expresan tensiones reales en la instrumentación gubernamental de las políticas, que comportan procedimientos particulares, al parejo que demandan la acción generalizante del Estado. Más allá de exponer si el Estado ha sido excesivamente cauto en la cesión de partes no sustantivas de su soberanía o si las fuerzas indígenas han demandado derechos que "rozan" el fantasma de la escisión efectiva, lo fundamental en este trabajo reside en determinar cómo es que se logran implementar las normas establecidas. Ahí también existen fallas y aciertos. Las primeras deben ser expuestas y explicadas, mostrando de manera convincente, por qué los medios puestos al servicio de fines constitucionales, entreverados en lo que se ha llamado la orden, no logran conducir la acción de los colectivos blanco de las políticas. De forma semejante, los aciertos deben ser expuestos, pero sobre todo, y de manera primordial por el argumento defendido, explicados en su determinación causal, pues si se plantea un modelo para el ejercicio del poder, es fundamental detallar cómo es que 
las diferencias presentes se transformaron en asimetrías y llevaron de manera ineludible, a lograr el objetivo enunciado.

Vale la pena aclarar que la "ineludibilidad" del ejercicio del poder no ocurre ex ante, sino únicamente ex post. Ello porque, como se expuso cuidadosamente en el primer capítulo, no existe una configuración de medios y procedimientos que desemboque obligatoriamente en el cumplimiento de una orden. Es decir, la cadena de causalidades puede reconstruirse, pero no construirse. En términos epistemológicos y metodológicos, colocan la enunciación de una orden, en la posición de hipótesis y el ejercicio de poder exitoso, como su comprobación. Sin embargo, de ahí es imposible concluir, que la enunciación de la misma orden en un contexto distinto, se comporte a la manera de una ley.

En la Educación Superior Intercultural en México, los blancos son claramente los desarrollados a lo largo de este capítulo. Inscritos en el texto constitucional y en algunas leyes secundarias, se encuentran una serie de disposiciones que afectan la acción de los poderes de gobierno; afectan también, las conductas y conceptualizaciones de la población. Este segundo universo constituye el campo de las interrogantes a develar, mediante los instrumentos teóricos presentados.

Las políticas públicas en educación intercultural, parten de considerar, tanto las diferencias que deben conservarse -las culturales-, como las diferencias y asimetrías tejidas injustamente a causa de la "indianidad". Consecuencia de ello, es la movilización de medios gubernamentales, para dar cumplimiento a los ordenamientos legales, que prescriben mecanismos para la consideración, defensa y conservación de los pueblos y las culturas indígenas.

La consideración, parte de que se deben movilizar las estructuras gubernamentales para dar y generar espacios en los que la diferencia cultural pueda expresarse plenamente, en los ejes que le son fundamentales o históricamente relevantes. La defensa supone la generación de condiciones para eliminar las diferencias y asimetrías derivadas de la diferencia cultural, centralmente en temas de desarrollo, pero también, en torno a la relación de los indígenas con el resto de la población, para neutralizar el trato discriminatorio y desigual. Por último, los temas de la conservación, conforman el ámbito que busca revertir el daño a las culturas indígenas, inflingido por 
el trato injusto y discriminatorio, tanto en relación a su diferencia cultural, como a su diferencia en desarrollo.

Así pues, diferencias, asimetrías y poder, construyen una relación constitutiva con las políticas públicas hacía los pueblos indígenas. Hay que hacer notar, que además de tener importancia para el avance hacía una Teoría sobre el poder, dicha relación plantea temas netamente antropológicos. Ello, porque la confrontación entre Antropología y Poder, toma una dimensión mayúscula, pues la movilización de los mecanismos considerados, atañe al choque entre diferencias culturales, es decir, con el otro; tema este, de importancia primordial y definitoria de la Antropología como ciencia.

De manera complementaria, el proceso de desarrollo de políticas que inciden en la Cultura de un colectivo, también tiene que ser tratado por la Antropología, pues las fuerzas que demandan o imponen impactos directos sobre esta dimensión de los colectivos, regularmente no toman en cuenta todas las complejidades de los procesos culturales humanos, sino fundamentalmente, criterios políticos. En ese sentido, los efectos a largo plazo del expediente descrito: "comprender", "respetar" y "conservar", puede no ajustarse a los deseos que lo motivan. No es que estos tres temas sean soslayables. Concuerdo vitalmente, en el tema de la comprensión, el respeto y (el deseo de) la conservación de las culturas humanas. De lo que no estoy tan seguro, es que las formas políticas para lograr dichos insumos, sean las más efectivas o que en algunos puntos, dicho intento sea si quiera pertinente. En todo caso, estas reflexiones son a las que la Antropología está obligada a realizar desde siempre: la Cultura, su aparición, su dispersión, su transformación y su desaparición; y en un segundo momento, el impacto de las políticas que buscan ahondar, mantener o detener dichas dinámicas

Así pues, en los dos capítulos siguientes, se expondrá la materialización de los dichos legales del artículo segundo de la Constitución, en el tema de la educación universitaria. Para ello, se describirá en el capítulo cuarto, la naturaleza del sistema de educación indígena nacional, su particularización en la educación superior intercultural, los mecanismos de asignación de recursos, los mecanismos de gasto y los efectos que se buscan. Finalmente en el capítulo quinto, se expondrán los efectos de dichas políticas en la población universitaria, esto es: ¿cuál es el resultado de la apropiación de los recursos públicos, que buscan un efecto acorde con la Constitución? Con ello se logrará mostrar si ocurrió un ejercicio de poder político y si tal ocurrencia, se dirige o se aparta del núcleo central de la reforma constitucional. 


\section{4.- El deber ser de las políticas de educación intercultural}

Como se ha desarrollado a lo largo de este trabajo, el proceso mediante el cual se conduce la acción social es un hecho de gran complejidad, y la mirada antropológica sobre este particular abarca sólo una porción. No obstante, dicho segmento se expande de manera notable, al considerar las intervenciones que los gobiernos realizan, para dar cumplimiento a mandatos constitucionales que impactan dimensiones culturales de los colectivos. Se ha perfilado un esquema para la comprensión de los fenómenos de poder y centralmente, del ejercicio de poder político; de forma adicional, se ha insistido en lo paradójico que resulta el fenómeno cuando se lidia con el insumo básico que caracteriza al poder: la diferencia.

El manejo de este insumo es de una dificultad suprema, ya que si se intenta atender a poblaciones distintas del común de un país, se apelaría a algunas de esas diferencias para construir el poder político, sin embargo, las demandas justas de una nueva relación con los diferentes, hace más complejo su uso y por lo tanto, plantea nuevos modelos y patrones en aras de una eficacia gubernamental y la justicia nacional.

Las políticas educativas hacia los pueblos indígenas de México, pasaron de la primera fase a la segunda. El carácter integrador, paternalista e instrumental que caracterizó el esfuerzo hasta bien entrado el siglo XX, se fue transformando hacia nuevos esquemas con pretensiones distintas: desarrollar sin integrar, gobernar sin avasallar y acuerpar respetando la especificidad indígena.

En este capítulo se describen aspectos particulares de las políticas educativas hacia los indígenas de México. En la sección anterior se trató de manera amplia el marco legal, nacional e internacional, sin soltar en ningún momento el hilo conductor: 
cómo, mediante asimetrías existentes con la población, los gobiernos pueden conducir la acción social a través de fenómenos de intercambio, usando las referidas conductas y conceptualizaciones de apropiación. En la convivencia de las fuerzas nacionales e internacionales, se enmarcaron temas de acción como justicia, salud, educación, territorio. En adelante, se analizarán de forma detallada las características específicas, que derivadas de tal marco general, toma la educación superior enfocada en los pueblos indígenas, en su veta contemporánea: lo intercultural.

Previo a este esfuerzo, voy a caracterizar algunos de los puntos más relevantes de la historia moderna de la educación hacia los indígenas, a partir de la fundación del Instituto Nacional Indigenista (INI). Cabe aclarar que el foco de los contenidos a presentar, se halla en las dinámicas de instrumentación de la política educativa, derivada de la relación que en aquellos años se tenía con las poblaciones indígenas. En este sentido, la descripción histórica destacará esencialmente los aspectos que abonen al planteamiento general.

\section{La intervención antes de la reforma constitucional de 2001}

Gonzalo Aguirre Beltrán plantea de manera prístina todo el problema: el proceso de transmisión cultural, mejor conocido como educación, encierra fuerzas contrarias que tienden a la conservación de lo tradicional, su renovación o su transformación. Los dos últimos procesos pueden derivar desde dentro -por invención o descubrimiento- o desde fuera, por la transferencia cultural derivada del contacto de culturas diferentes (1992: 9). En el caso de los procesos de conquista y dominación, el grupo dominante tiende a planear el fenómeno educativo, "inyectando" o manteniendo lo que conviene a sus intereses; este proceso lo denomina Aguirre "educación dominical”. El asunto es que en los contenidos y mecanismos educativos que implementa el Estado dominante “...se torna indispensable la educación de las masas para aprovechar más ventajosamente su esfuerzo de trabajo" (ibid: 18).

Aquí se encuentra la génesis del conflicto educativo, dado que si las poblaciones indígenas interesaban al sistema dominante, era superlativa la castellanización y la capacitación laboral. Esto crea un sistema de educación dual con contenidos y finalidades distintas en cada uno de los segmentos de población: indígena o criollomestizo. Y declara Aguirre Beltrán de manera por demás contundente y visionaria: "La sociedad nacional, al confrontar el problema de la heterogeneidad étnica y cultural, presionada por los requerimientos de integración, no advierte otro modo de atacarlo que 
el de apegarse al modelo de educación dominical heredado de la colonia" (1992: 18). Este juicio es central, ya que muestra las tendencias de tipo institucional que se encuentran en las políticas implementadas por los funcionarios y que presentan escasas posibilidades de elección en vista de los marcos institucionales. ${ }^{141}$

Para los fines de este trabajo, interesa el carácter exógeno de la educación que tuvo el objetivo de moldear a los indígenas a las necesidades estatales, para lograr que los individuos aprendieran a hablar y leer en español, mediante la presencia de agentes externos que intentaron alcanzar dicho objetivo. Es decir, mediante el uso de recursos (infraestructura física, administrativa, humana $\mathrm{y}$ de contenidos educativos programáticos), se implementan políticas que llevan a los individuos a emprender acciones y formarse conceptualizaciones, que de otro modo no harían.

Es de la mayor importancia recalcar, que el ejercicio del poder político referido a lo largo de todo este trabajo, se centra en los mecanismos de poder por intercambio, lo cual significa, que el individuo a educar se embarca en las conductas o conceptualizaciones que supone el programa dispuesto, de manera más o menos libre, en función de los recursos que le representa el intercambio de comportamientos por recursos. Sin embargo, la historia de la educación indígena no es precisamente un panorama de "libre" intercambio. Historias complejas de violencia y subordinación imperan a lo largo de todo el siglo XX. En ese contexto, los indígenas, o fueron obligados por la fuerza a integrarse a la escuela derivando en aceptación pasiva (Aguirre Beltrán, 1992: 19) o fueron y son obligados a recibir educación en español a pesar de ver a la escuela como un símbolo de progreso y movilidad social (Aguilar et al., 1996: 12-3). ${ }^{142}$ Estas historias de violencia escolar, están documentadas y comentadas ampliamente; lo dramático del hecho es la cercanía de historias de violencia ocurridas apenas en los años setenta u ochenta. ${ }^{143}$

Hacia el fin del régimen porfirista, el proyecto de nación busca de manera decidida incorporar a todos los sectores de la población a un proyecto único y general,

\footnotetext{
${ }^{141}$ El trabajo de Powell y DiMaggio (1999) está lleno de ejemplos de resistencia institucional a las intenciones transformadoras del funcionamiento del Estado

${ }^{142}$ El mismo Aguirre Beltrán refiere cómo en la década 1910-1920 funcionarios de gobierno pensaban que el servicio de las armas era un mecanismo "eficacísimo" para lograr la dispersión del español (1992: 60-1). Es claro que la leva formaba parte de ese mecanismo

${ }^{143}$ Testimonios de estudiantes indígenas de la carrera de Educación en el medio indígena, en la Universidad Pedagógica Nacional de Puebla, fueron levantados en 2004. Basta una muestra: "Un día llegué y salude a mis compañeros en mi lengua sin darme cuenta que ella, la maestra, nos estaba escuchando [...] Me dijo que 'por qué estaba platicado en mi lengua'. Yo le dije que simplemente había saludado y porque desde niños nuestros padres nos inculcaron nuestra lengua materna. Entonces la maestra agarró la vara y me empezó a pegar” (Rodríguez, 2006: 27)
} 
pues la Revolución Mexicana determinó el fin de los localismos y regionalismos autárquicos que caracterizaron al porfiriato. En ese contexto de unidad nacional, es que la visión integradora se enfoca de manera decidida en las poblaciones indígenas, bajo el manto de la visión campesina. ${ }^{144}$

En esa época es que aparecen las primeras instituciones de educación indígena del régimen revolucionario, con la creación en 1921 del Departamento de Educación Indígena en la Secretaría de Educación Pública. Desde ahí se coordinaban las "Casas del pueblo", la primera de las cuales apareció hacia 1917. Su objetivo era el de "socializar al campesino" y ahí se instruía a los maestros rurales de manera ambulante por capacitadores a lo largo de todo el país. Como dice Sáenz:

En 1925 los maestros misioneros se convirtieron en inspectores instructores; las escuelas dejaron de llamarse, lástima grande, 'Casas del Pueblo' y adquirieron el más convencional y prosaico título de escuelas rurales, iba pues, tomando cuerpo el sistema [...] De las 3,392 escuelas rurales que existen, 1,417 están establecidas en pueblos netamente indígenas, 95,000 niños de estos grupos asisten y 20,000 adultos, es decir, poco menos de la mitad de las escuelas federales están sirviendo exclusivamente a indígenas (1964: 115)

Hacia 1930 se consolidan las misiones culturales que buscan preparar a los maestros rurales de manera integral, siendo la educación un tema central. Suprimidas en 1938 y restablecidas en 1942, operan con el principio básico de que “...el pueblo debe ser ayudado a resolver por sí mismo sus problemas” (Comas, 1964: 72). En 1931 asume Narciso Bassols la dirección de la SEP y declara que “...la escuela sólo es útil si se convierte en una palanca del desarrollo económico, capaz de introducir aptitudes de producción y métodos de trabajo nuevos entre los indígenas" (cit. en: Aguirre Beltrán, 1992: 93); ${ }^{145}$ es decir, la introducción de patrones para la conducta y conceptos nuevos para entender su realidad productiva y desarrollarse.

Lo expuesto hasta aquí, puede mostrar con claridad, cómo del nuevo orden constitucional de 1917, el Estado mexicano implementa una política educativa integradora y de tipo desarrollista en las poblaciones indígenas. La inversión en salarios de profesores, su capacitación, la generación de manuales y libros de texto, la implantación de infraestructura física en sitios elegidos y la dispersión de contenidos

\footnotetext{
${ }^{144}$ El perfil social que asumió el régimen revolucionario hacia 1920, cuando se alcanzó la paz, quedó encriptado en la ideología campesinista y obrerista que asumió el régimen revolucionario para la legitimación de su proyecto hegemónico (Medina, 1995: 51).

${ }^{145}$ El subrayado es mío.
} 
tendientes a "mejorar" la situación económica y social de los indígenas, es claramente un impulso exógeno, que introduce en la población conductas y conceptualizaciones vía la inyección de los recursos materiales e ideales mencionados. Un dato interesante es la opinión de que los indígenas deben, "por sí mismos" resolver sus problemas; sin duda, el impulso exterior y el ejercicio de poder estatal, mana de la caracterización exógena de los problemas indígenas y los recursos que implementó el gobierno federal en aquellos años, se alineaban con esta visión externa del "problema" indígena

La influencia internacional sobre los gobiernos en el tema indígena, que fue expuesto ampliamente en el capítulo precedente, se profundiza en México y América Latina con el desarrollo de una serie de reuniones tendientes a uniformar el estudio científico y el desarrollo de las comunidades indígenas. La reunión de 1933 en Montevideo, la de 1938 en Lima, pero sobre todo la de 1940 en Pátzcuaro, que culminó en la fundación del Instituto Indigenista Interamericano, tuvieron en México un efecto claro, con el decreto de creación, en 1948, del Instituto Nacional Indigenista, el célebre "INI".

El INI y su órgano operativo, los Centros Coordinadores, tuvieron el objetivo de estudiar los núcleos indígenas para determinar las medidas de mejoramiento requeridas, gestionando ante el Ejecutivo la aplicación de éstas y coordinando la acción de los órganos de gobierno necesarios, según reza el Artículo II del decreto de creación (INI, 1978: 359). De este modo, la confluencia del INI y la SEP modeló el esfuerzo educativo hacia las comunidades indígenas, que en 1963 tenía ocho Centros y un Sub-centro (Comas, 1964: 80). Así, “...[1]a educación nacional está orientada a la consecución de los fines propios de un sistema capitalista e individualista que camina rápidamente a la industrialización. Las sociedades indígenas [...] tratan de conservar modos de vida que ellos consideran aceptables pero que constituyen un obstáculo en la integración de una nacionalidad y patria común" (Aguirre Beltrán, 1992: 169). Es claro el dualismo en este punto: la tradición interna frente al cambio en lo exterior. Se consideraba en esa época que era imposible mantener la cultura indígena al parejo del desarrollo de tipo capitalista y por ende, las tensiones y las presiones de tipo integracionista eran máximas. Las asimetrías entre desarrollo y subdesarrollo, riqueza y pobreza, y cultura indígena frente a cultura mestiza, fueron las que caracterizaron las intervenciones educativas en esa época, además de las regulares que el Estado mantiene con la población en general. El ejercicio del poder político en términos educativos tenía un objetivo, si se quiere paradójico: utilizar las asimetrías mencionadas para eliminar las 
diferencias que lo alimentaban. Ello supone igualar en desarrollo y en recursos pero también, culturalmente. Di cuenta de que los instrumentos internacionales de la época (Convenio 107 de la OIT de 1957) hicieron tabla rasa del credo igualador: integrar al diferente, eliminando la diferencia; en este sentido, el proyecto del INI resuena armónicamente.

El modelo integracionista de diseño externo con tinte evolucionista generó en los decenios de 1950 y 1960 una discusión entre técnicos en educación indígena y antropólogos sobre si la educación debiera ocurrir con un método directo -enseñanza del español y alfabetización en español- o con un método indirecto -enseñanza del español y alfabetización en lengua indígena (Aguilar et al., 1996: 23). ${ }^{146}$ Estas discusiones evidenciaron las tensiones emergentes, que colocaban a la cultura indígena, pero sobre todo al indígena mismo, en el centro de la discusión. Esto significa que en la conducción del proceso educativo, el Estado Mexicano se veía obligado a considerar a la cultura indígena y a los propios indígenas. Este proceso de carácter centralmente histórico esta remachado por la transformación del indígena: de sujeto pasivo de las políticas a agente de su educación.

Resulta vano indagar si el indigenismo revolucionario hubiera podido seguir por más décadas como estaba, pero la transformación mexicana ocurrida a raíz del Movimiento del 68 fue un impulso transformador de la mayor significación. Este cambio se concretó en el tomo colectivo De eso que llaman Antropología Mexicana (Warman et al., 1970) que planteaba una nueva relación del Estado con los indígenas y, desde luego, una transformación de la visión estatal y de sus políticas. Esta transformación se puede glosar en un dicho de Guillermo Bonfil Batalla: "Si algún

\footnotetext{
${ }^{146}$ La referencia al tinte "evolucionista" es fundamental, porque la percepción de un cambio inexorable, necesario o consecuente, que estaba disperso no sólo en antropólogos, sino en la sociedad de la época, contrasta con el viraje al credo "relativista" que articula las reflexiones presentes sobre la educación intercultural y que delinea un mundo de permanencia y diversidad cultural en todos los puntos del sistema. Así mismo, destaca que el viraje en torno de los temas sobre la forma de la educación indígena en América Latina -ya bilingüe, ya intercultural-, es según Gunther Dietz un debate “...por educadores para educadores" (Dietz, 2003: 62). Vale la pena el rescate de la discusión sobre el Multiculturalismo que se realizó en el Capítulo III por una razón: el expediente "comprender, respetar, conservar" relativo a las culturas indígenas es insostenible, políticamente, desde una posición evolucionista. Las culturas van a perdurar; deben perdurar. El Relativismo como corriente teórica, tiene insumos que permiten acuerpar técnicamente el expediente político de la conservación cultural. No es que la gente sea experta en las especificidades teóricas; es que en los discursos que se rescatan a todo nivel en la Universidad Intercultural del Estado de México (UIEM), existe la certeza de que las culturas deben permanecer, pues la humanidad siempre ha sido diversa. El tema antropológico no es si deben o no deben permanecer, sino cuáles son los mecanismos y consecuencias de la permanencia o desaparición de las culturas. La comunidad de la UIEM está exenta de realizar tales reflexiones, sin embargo, está alineada con los principios de la escuela relativista, que centrada en la especificidad cultural, evita pensar sobre las direcciones de la cultura humana como un todo, que son las que claramente abordan los evolucionistas.
} 
reproche debe hacerse a los indigenistas de esa época [de Manuel Gamio a Gonzalo Aguirre Beltrán] es el haber abandonado el ejercicio indeclinable de la crítica" (1983: 143). ${ }^{147}$

Por lo tanto, la crítica de las políticas hacia los indígenas transformó el panorama y permitió que en 1975, en el marco del "Primer Congreso Nacional de Pueblos Indígenas", los actores afectados enunciaran una serie de demandas reunidas en las “Conclusiones” del Congreso (López y Velasco, 1985: 123-5):

- Que las comunidades indígenas fueran atendidas a nivel primaria por maestros bilingües con una perspectiva bilingüe y bicultural.

- Un aumento de 50\% para los maestros en función de que su labor no sólo incide en lo escolar sino en las actividades comunitarias y que dominan dos lenguas, con el objeto de evitar la deserción o la migración.

- La creación de escuelas normales en el medio indígena.

- La creación de universidades indígenas con internado, que generen universitarios enfocados a mejorar el medio indígena.

- Que se declaren lenguas oficiales a las lenguas indígenas.

- Que las instituciones educativas estén controladas y dirigidas por profesionales indígenas.

- Que se incremente el número de escuelas albergue.

- La "urgente" necesidad de ubicar en lugares estratégicos, escuelas tecnológicas agropecuarias, becando al mayor número de indígenas, para dar oportunidad al mayor número de indígenas de participar en el desarrollo regional y del país.

El correlato de estas demandas, es el documento resultante de la reunión de 1977, denominado "Pacto del Valle Matlatzinca" (Garduño, 1983: 152-8), en el que se reiteran los puntos de vista anteriores y se adicionan algunos más, abriendo nuevas perspectivas: ${ }^{148}$

- La ampliación del carácter de educación bilingüe de la educación a la consideración de la dimensión "pluricultural".

\footnotetext{
${ }^{147}$ González Apodaca lo plantea en estos términos: desde los años setenta, comenzó un proceso de acción política potencialmente contrahegemónica que cuestionó el proyecto nacionalista existente y las asignaciones identitarias previas (2008: 39).

${ }^{148}$ Hay que hacer notar que en el caso de los acuerdos del Valle Matlatzinca, independientemente de su carácter nacional, comportan una dimensión regional importantísima, que va a proveer el marco históricoideológico para demandar una universidad indígena al candidato a la presidencia Vicente Fox, lo que redundará en la primera universidad intercultural de México.
} 
- Que los programas deben realizarse dentro de los valores indígenas.

- Que las normales dejen de utilizar métodos didácticos europeos.

- La creación de una editorial en los idiomas nativos.

- La creación de un centro de documentación e información sobre los grupos étnicos.

- La adecuación de los libros de texto al contexto socio-lingüístico de cada pueblo.

Estos puntos, sólo representan los relativos a la educación, pero como es evidente recogen demandas significativas que se van a mantener hacia el futuro y tienen sobre todo, un carácter endógeno, es decir, los indígenas ya no hablan al estado mestizo como sujetos de beneficencia, sino con el espíritu de un grupo que busca conducir su destino de acuerdo con sus intereses particulares.

Rechazan en primerísimo lugar el mantenimiento de las políticas educativas como están; deben cambiar. Pero además, piden su sustitución por acciones que incidan en las comunidades de manera diferente a como lo hacían hasta esa fecha. No sólo es detener un proceder sino sustituirlo por uno nuevo. Esperan que los recursos materiales, ideales y simbólicos que el gobierno mexicano habría de invertir de manera diferente a la acostumbrada, mejoren el desempeño de los maestros y alumnos, mejoren su rendimiento, eleven su presencia en el sistema educativo y que todo lo anterior se realice con una óptica diferenciada, en atención al respeto y fortalecimiento de su diferencia cultural, respecto de la población en general

¿Cómo entonces puede hablarse de ejercicio de poder, si las acciones a implementar son acciones deseadas de manera convencida y razonada por los propios indígenas? ¿En dónde se puede acomodar el enunciado general de esta tesis, que refiere que el ejercicio de poder ocurre cuando u actor lleva a cabo conductas o conceptualizaciones que de otro modo no haría?

La respuesta tiene al menos dos ejes evidentes: en primer lugar, los que enuncian ambos pronunciamientos, son representantes indígenas. Conforman una parte importante de dicho colectivo, pero no son el colectivo. Son así mismo un grupo diferente, educado, políticamente instruido y con pretensiones hegemónicas -esto último desde el más puro espíritu gramsciano. Son pues una parte de los indígenas, pero no son todos los indígenas. "En México, los indígenas que luchan por destruir el mito de 
la inferioridad de unas culturas con relación a otras, forman parte de una élite instruida y con acceso a corrientes de pensamiento que, a nivel mundial, sostienen los principios de igualdad social y el respeto a la diferencia cultural" (Aguilar et al. 1996: 10). ${ }^{149}$

En consecuencia, las políticas a implementar no van a recaer en quien las solicita de manera expresa, sino en la población indígena en general, que en su gran mayoría no consideraba la reforma al sistema educativo en esos términos. Ello explica la idea de la dirección moral, intelectual y cultural que la hegemonía supone. Esto quiere decir que representantes indígenas solicitan la intervención gubernamental, ya que la gran mayoría de los indígenas del país no están en posición de imaginar o implementar localmente las medidas solicitadas. ${ }^{150}$ Cualquier núcleo de población requiere en múltiples ocasiones del apoyo económico y organizativo que el Estado supone. Sobre todo, si dichas poblaciones están atrapadas en un ciclo muy difícil de romper de manera endógena; en ese sentido es que el Estado debe intervenir de manera exógena. En contraposición, existe un gran debate en la actualidad sobre de la capacidad de una población de gestionar su propio desarrollo, toda vez que no es necesario que el Estado aporte todo a todos de manera paternalista, además de que en la actualidad los estados contemporáneos sufren un "sobrecalentamiento" derivado de la ampliación de demandas y del notable crecimiento poblacional en los últimos 50 años. ${ }^{151}$ A pesar de ello, la intervención estatal sigue importando e impactando de manera fundamental; de ahí la petición de su intervención para transformar los procesos educativos que en todo caso, el Estado conducía con espíritu "indigenista” vía el poder político.

En segundo lugar, este proceso -la demanda de un grupo específico para que el Estado transforme las políticas que lo impacta- no difiere en nada de la dinámica que el Estado moderno viene enfrentando desde su maduración. El orden constitucional o una política acostumbrada por un Estado, en innumerables casos se generan, transforman o desaparecen por las demandas, presiones o inconformidades de un grupo específico de la sociedad. Sin embargo, muchos detalles de forma y fondo, no son definidos, imaginados o controlados por los demandantes. Están subordinados a las características específicas del sistema Estado-Sociedad y de la propia dinámica del funcionamiento gubernamental. Todo ello será decidido y encauzado por los órganos de gobierno y

\footnotetext{
${ }^{149}$ El subrayado es mío.

${ }^{150}$ Ello aun considerando que dentro de los principios pedagógicos contemporáneos se afirma que "...la verdadera transformación de la educación sólo puede proceder de dentro, es decir, desde la escuela" (Schmelkes, 2010: 207).

${ }^{151}$ De 3,000 millones de habitantes en 1960 a 7,000 millones en 2011.
} 
culminará en conductas o conceptualizaciones de los individuos o grupos demandantes, pero bajo el ejercicio del poder político estatal, que es lo que centralmente exigieron. Además, aparece el tema de la dimensión anterior, según el cual muchos de los miembros del grupo demandante, no participaron ni en la construcción de la demanda ni en su proceso de instrumentación y que sin embargo, serán afectados por las políticas gubernamentales. En términos de poder por intercambio, se hace referencia a que los individuos, al tomar los recursos que las políticas educativas movilizan, modificarán su conducta de acuerdo con la forma y el fondo implementado en la política, que desde luego resuena con las demandas presentadas, pero también, con la dinámica particular del órgano implementador o con la del Estado en general. ${ }^{152}$

El cambio social que experimentó el país, alteró directamente el funcionamiento del Estado en la época. Hacia 1971 se creó la "Dirección General de Educación Extraescolar en el Medio Indígena", que en 1978, derivó en la actual "Dirección General de Educación Indígena". La misión central era la de ofrecer educación básica en las comunidades indígenas y responder a las demandas expresadas por ese sector: “...constituye el reconocimiento oficial de la educación bilingüe y bicultural materializado en la DGEI, a quien se encomienda instrumentar el subprograma de educación indígena para la primaria" (Guzmán Gómez, 1991: 23). Pero esta misión, que comenzó el impulso de transformación del subsistema indígena, tratando de cambiar la óptica e iniciar el mecanismo de generación de materiales bilingües para la enseñanza primaria, fue un proceso duramente cuestionado, pues el cambio in situ, difícilmente se apegaba a las expectativas oficiales de “...tomar en cuenta la cultura materna de los educados en la planeación educativa, tanto en el contenido como en los métodos pedagógicos" (Calvo y Donadieu, 1992: 40). Por ello, el deseo indígena incorporado a las instituciones educativas de la época, no culmina en su instrumentación y únicamente queda en lo formal. De ello dan cuenta las críticas e inconformidades que empezaron a

\footnotetext{
${ }^{152}$ Para estos dos puntos cabe considerar que son un apretado resumen del proceso general de la política. Luis Villoro expone que en todo discurso político existen dos tipos de lenguaje: El primero se refiere a un estado social deseable, mientras que el segundo atañe a características de la sociedad existente; el primero juzga a la sociedad desde lo posible y el segundo la explica por factores reales; el primero está basado en una ética de la acción política, pero el otro, “...[e]n su forma más sistemática y rigurosa, aspira a formular una ciencia o técnica del poder" (1997: 75). Claramente, mi trabajo se alinea con la segunda perspectiva, con una precisión: no se busca formular una ciencia o técnica del poder, sino explicar el funcionamiento de dicha ciencia o técnica cuando tiene éxito, es decir: cuándo funciona y por qué funciona.
} 
surgir en a finales de los ochenta pero que maduraron hacia los noventa (Ramírez Castañeda, 2006: 169-74).

Dos análisis de la época así lo señalan: "Se ha podido constatar mediante una investigación en numerosas comunidades que todos los maestros utilizan el castellano como lengua de comunicación en todos los aspectos de la vida escolar [...] De hecho, en las escuelas que operan en el medio indígena se usan los mismos programas, filosofía, contenidos, metodología y formas de evaluación que la utilizada para el resto de la población" (Aguilar et al.,1996: 33, 35). Por otro lado, a pesar de estar desarrollado “...con el consenso de las organizaciones indígenas, de los maestros bilingües, del sistema de los científicos sociales y técnicos [...] La educación bilingüe bicultural tiene sus defensores y también sus impugnadores pero, sobre todo, está plagada de dificultades técnico-pedagógicas aún no resueltas” (Rodolfo Stavenhagen cit. en: Guzmán Gómez, 1991: 16). ${ }^{153}$

La firma del Convenio 169 de la OIT y la reforma al artículo cuarto de la Constitución en 1989 y 1992, respectivamente, impulsaron el cambio y reafirmaron las deficiencias en el tratamiento dado a los indígenas en el tema educativo. Aquí se abre el parte aguas histórico que la aparición del Ejercito Zapatista de Liberación Nacional supuso. Empujó claramente el cambio, que se venía considerando, pero que se había postergado por décadas. El impulso integracionista y exógeno del estado revolucionario, no cesó hasta que se le paró de manera armada. A partir de tal paradigma, comenzó una reconfiguración de arriba a abajo, motivada tanto por la urgencia del régimen de desactivar la situación de guerra, como por el empuje de la sociedad civil y la voluntad de no negociar en temas en los que antes cedía. Los acuerdos de San Andrés, firmados entre el EZLN y el Gobierno Federal, consideraban para el texto de la reforma constitucional, que entre los derechos que los pueblos indígenas poseen, se encuentran:

- La preservación y el enriquecimiento de su lengua y cultura;

- La promoción de la educación bilingüe e intercultural;

- La definición y desarrollo conjunto, con los tres órdenes de gobierno, de programas educativos con contenido regional que reconozca su herencia cultural;

\footnotetext{
${ }^{153}$ En una investigación que realicé el año 2010 en el estado de Guerrero en escuelas primarias del subsistema (Zona Chilapa-Tlapa), pude observar que dichos problemas subsisten, al no usarse la lengua como vehículo, sino únicamente como fenómeno casuístico, centrado en el aprendizaje de sustantivos. Por los horarios pegados en los salones (los efectivos), se le asigna a la clase de lengua indígena una o dos horas a la semana, reconociendo los profesores que frecuentemente, no se cumple con dicha programación.
} 
- Asimismo, que el Estado establecerá las instituciones y políticas necesarias para garantizar la vigencia de los derechos;

- De manera simultánea, la adecuación de constituciones estatales y leyes que garanticen los principios declarados (Gobierno del Estado de Chiapas, 2003: 113-6).

Las propuestas de texto para la reforma constitucional, estaban sustentadas en principios comunes acordados entre el EZLN y el Gobierno Federal. Un principio central lo conformaba "El Pluralismo", puesto como el número uno para redefinir la relación del Estado con los pueblos indígenas.

El trato entre los pueblos y culturas que forman la sociedad mexicana ha de basarse en el respeto a sus diferencias, bajo el supuesto de su igualdad fundamental. Como consecuencia, ha de ser política del Estado normar su propia acción y fomentar en la sociedad una orientación pluralista que combata activamente toda forma de discriminación y corrija las desigualdades económicas y sociales. Igualmente, será necesario avanzar hacia la conformación de un orden jurídico nutrido por la pluriculturalidad, que refleje el diálogo intercultural, con normas comunes para todos los mexicanos y respeto a los sistemas normativos internos de los pueblos indígenas (Gobierno del Estado de Chiapas, 2003: 32). ${ }^{154}$

Es clara aquí la aparición, nuevamente, de los temas analizados en el Capítulo III. Existe un colectivo cultural diferente, el cual no ha logrado sus derechos ciudadanos, en virtud de que dicha diferencia, ha caracterizado inequidades en temas no culturales, como los económicos o de desarrollo social. El Estado debe respetar las diferencias culturales y eliminar las asimetrías instauradas a partir de éstas, al reconocer el carácter plural de la Nación. En ese contexto, es que toma carta de nacimiento, el concepto de interculturalidad, como el campo o mecanismo, en el cual o mediante el cual las relaciones entre las diferentes culturas del país pueden darse en un entorno de respeto y reconocimiento mutuo.

Como un dramático colofón, la reforma constitucional que se promulgó en el año de 2001, ha sido impugnada hasta la fecha. Los actores que la impugnan, no dejan de reconocer que la aparición de los nuevos temas que se enunciaron en los Acuerdos de San Andrés, han modificado sustancialmente el comportamiento del Estado Mexicano, pero no han dejado de señalar las deficiencias, derivadas de la exclusión de varios de los temas que el Gobierno Federal se había comprometido a elevar a rango constitucional y que no aparecieron finalmente. Sin embargo, la reforma constitucional, tal y como se

\footnotetext{
${ }^{154}$ El subrayado es mío.
} 
promulgó, constituye el único marco en el que se puede y debe de mover el Estado en su conjunto, y consecuentemente, las políticas que implementa deberán seguir dicho marco. Por ello es que no se ahonda mayormente en el análisis de lo que los "Acuerdos" implican, sino de las demandas que alcanzaron nivel constitucional. ${ }^{155}$

El somero recuento histórico presentado no buscó tocar todos los puntos relevantes de la discusión, sino mostrar un marco conceptual acerca de la forma en que el Estado Mexicano ha ejerciedo los recursos con los que cuenta, para conducir la política educativa y, desde luego, las conductas y conceptualizaciones de los individuos que se apropian de los bienes gubernamentales puestos a disposición de la población indígena. Hay que hacer notar que los efectos políticos que más llaman la atención en este trabajo, son aquellos que impactan el concepto "Cultura". Debe destacarse por consiguiente, que las políticas educativas produjeron, en términos del ejercicio de poder político, un empuje muy fuerte para lograr que individuos hablantes de lengua indígena hablaran español, es decir, una conducta que de otro modo no harían. Paralelamente indujo a estas poblaciones a considerar que su cultura materna era un lastre, un residuo del pasado o un impedimento para su desarrollo, incorporación o tránsito en la sociedad mestiza. Configuró con ello, un entorno ideacional que muchos indígenas introyectaron a lo largo del proceso educativo; esto es, conceptualizaciones que no tenían.

Claro que el éxito en estos dos puntos, no culminó en el objetivo central del Estado, que era educar e integrar, puesto que la imposición externa de lengua, valores y procedimientos, generó exclusión en muchos puntos y exhibió como fallida la esperanza posrevolucionaria de integrar a todos los grupos en una masa de obreros y campesinos exitosos. Las regiones de refugio descritas por Aguirre Beltrán (1967), mostraron cierto grado de resistencia a este propósito, dando al traste con dicha expectativa. Ello fue lo que motivó los reclamos sociales y la adecuación estatal. El nuevo mandato del Estado es ahora buscar nuevas vías para desarrollar a las poblaciones indígenas, sin sacrificar su especificidad cultural, potenciar las ventajas que brinda ese patrimonio y abrir el tema de la justicia hacia y en las comunidades.

En la siguiente sección se expondrán los instrumentos legales y procedimientos que el Estado debe aplicar en el tema de la educación en el medio indígena, para caracterizar, los objetivos que busca lograr mediante el ejercicio del poder político,

\footnotetext{
${ }^{155}$ Reitero que el expediente de la justicia postergada para los pueblos y comunidades indígenas es un expediente abierto y por tanto, la adecuación del marco constitucional es todavía una asignatura pendiente; sin embargo, esos hipotéticos hechos futuros, no pueden ser considerados al evaluar el desempeño gubernamental obligatorio en términos legales; de ahí el vago tratamiento.
} 
donde los individuos se embarquen en proceso que de otro modo no harían. Con ello se acota el interés antropológico en la conducción de las acciones y conceptualizaciones sociales, en su dimensión exógena, es decir, de poder.

\section{El marco nacional de las políticas educativas interculturales}

En el capítulo anterior se analizó de manera extensa la circunstancia en la que ocurre el ejercicio de poder político como resultado de la reforma constitucional de 2001. De los puntos que vale la pena retomar para la discusión, se debe mencionar:

- Que existen diferencias de tipo cultural que tienen que mantenerse y respetarse, declarando ilegal su asimetrización.

- Que existen otras diferencias, atadas a temas de desarrollo, que deben eliminarse de la población indígena, ya que constituyen trabas para el ejercicio de derechos ciudadanos específicos del artículo segundo constitucional.

- Que se crean algunas asimetrías especiales para lograr "emparejar" a los indígenas con el resto de la población.

- Que se determina un conjunto de temas en el que los tres órdenes de gobierno deben intervenir, para que se conozcan y ejerzan los derechos reconocidos y se impida la asimetrización de las diferencias culturales.

- Que a través del ejercicio del poder político se debe llevar a la población indígena a conocer y ejercer sus derechos, o a impedir que el resto de la población los vulnere, ya por desconocimiento, ya intencionalmente.

- Finalmente, que lo anterior puede lograrse cuando los distintos grupos de la población se apropian de los recursos gubernamentales, cambiando sus conductas o conceptualizaciones, en línea con las disposiciones gubernamentales y que no ocurrirían de otro modo.

La forma poder político se ajusta a todo lo expuesto en el planteamiento general. Ahora se enfocará la dimensión de poder en tema educativo, comenzando por la Constitución. ${ }^{156}$

\footnotetext{
156 Todas las referencias a la Constitución Política de los Estados Unidos Mexicanos (CPEUM), corresponden a la versión en línea vigente al 13 de octubre de 2011, consultada en la página www.ordenjuridico.gob.mx
} 
En el artículo tercero se enlistan la forma y el contenido de la educación a nivel nacional. En éste se determina la capacidad rectora del Estado, para vigilar que se ajuste a los principios de amor a la patria, respeto a los derechos humanos, democracia, carácter laico, científica, además de luchar contra los prejuicios y fanatismos, privilegiar el interés general y evitar privilegios de razas, religiones, grupos, sexos o individuos. Sobre todo, destaca el carácter rector del Estado, para otorgar validez oficial a los estudios realizados en planes y programas de estudio. El punto es claro para el ejercicio de poder: si no se imparten o realizan los estudios de acuerdo con los planes aprobados, no se emitirá la certificación de tales estudios; con ello se obliga a la población, a realizar las conductas necesarias y las transformaciones conceptuales consideradas, a fin de conseguir la certificación correspondiente. ${ }^{157}$

En segundo lugar se establecen dos hechos: "IV Toda la educación que el Estado imparta será gratuita [...y] VIII. El Congreso de la Unión, con el fin de unificar y coordinar la educación en toda la República, expedirá las leyes necesarias, destinadas a distribuir la función social educativa entre la Federación, los Estados y los Municipios, [y] a fijar las aportaciones económicas correspondientes a ese servicio público..." (CPEUM, 2011: 4,5). Este insumo es imprescindible para comprender el proceso desde la perspectiva propuesta. Arriba se mencionó que la certificación de los estudios, está subordinada a la conformación del alumno a los planes y programas de estudio, no obstante nada se dice de cómo el alumno obtendrá dicho servicio. Las fracciones IV y VIII aclaran que cuando es proporcionada por el Estado, mediante transferencias económicas a la Federación, los estados y municipios para su materialización, será gratuita. El "bien" educativo estará a disposición de los alumnos para que se apropien de éste, aun sin aprehenderlo; sin embargo, la certificación de su apropiación únicamente es posterior a todo el proceso. ${ }^{158}$

\footnotetext{
157 Es a todas luces evidente, que las conductas y conceptualizaciones de los alumnos, tenderán a conformarse a las de los planes y programas de estudio, y la convergencia con dicha orden, será determinada en función de la emisión de una calificación. Claramente es un juicio que asigna el profesor de acuerdo con criterios de tendencia objetiva - en las conductas esperadas- y de tendencia subjetiva -en las conceptualizaciones esperadas.

${ }^{158}$ Aquel que se apropia de todos los bienes que un gobierno dispersa, sin realizar lo dispuesto por su apropiación, lo denominé "gorrón”. Así, un individuo que acude a la educación pública gubernamental, sin hacer lo que se le dice y sin aprender lo dispuesto, es claramente un gorrón. Con ello no ignoro dos fenómenos: 1) que el típico gorrón, es aquel que accede a un bien público sin aportar, vía impuestos, una porción para su materialización; en este caso, dado el carácter gratuito de la educación estatal, no es un tema importante y constituye lo que se mencionó en el Capítulo II a propósito de Lowi, que definiría la educación estatal en México como una política de tipo "distributivo"; 2) que la función social de la educación, está más allá de la pura eficiencia terminal y todos los individuos que concurren a un aula, se apropian de una porción de lo que ahí se despliega y con ello mejoran su calidad de vida y sus
} 
De esta manera están descritos los dos tiempos del fenómeno indisoluble del poder por intercambio: primero va bien y luego la obediencia (tipo "Don"); o primero va la obediencia y luego el bien (tipo “Anti-don”). El gasto y los procesos educativos son del primer tipo; la certificación del segundo.

Ahora, ¿qué carácter toman las obligaciones educativas del Estado en la población indígena según el artículo segundo de la Constitución y qué forma de poder suponen? La fracción IV del apartado A, plantea que los individuos de pueblos y comunidades indígenas tienen derecho a "Preservar y enriquecer sus lenguas, conocimientos y todos los elementos que constituyan su cultura e identidad" (CPEUM, 2011: 2). Considerando este derecho y el de cualquier mexicano a la educación, descrito en el artículo tercero, la forma que tomará esta combinación jurídica estará caracterizada por el mandato del apartado B del articulo dos, que considera que <<para promover la igualdad de oportunidades y eliminar cualquier práctica discriminatoria, los tres poderes determinarán las política necesarias y establecerán las partidas específicas destinadas al cumplimiento de estas obligaciones, que deberán ser diseñadas y operadas conjuntamente con ellos > (Ibid: 3 ). El desglose constitucional no deja dudas:

II. Garantizar e incrementar los niveles de escolaridad, favoreciendo la educación bilingüe e intercultural, la alfabetización, la conclusión de la educación básica, la capacitación productiva y la educación media superior y superior. Establecer un sistema de becas para los estudiantes indígenas en todos los niveles. Definir y desarrollar programas educativos de contenido regional que reconozcan la herencia cultural de sus pueblos, de acuerdo con las leyes de la materia y en consulta con las comunidades indígenas. Impulsar el respeto y conocimiento de las diversas culturas existentes en la nación (Ibidem). ${ }^{159}$

La educación que imparta el Estado en pueblos y comunidades debe favorecer las prácticas bilingües y el enfoque intercultural, incluida la educación media superior y superior. Así, planes y programas de estudio, deberán considerar las formas y contenidos adecuados al espíritu constitucional, pero además -se infiere-, deberán invertir recursos para generar los materiales necesarios y buscar los mecanismos para que se cuente con personal capacitado en dicha elaboración. Como está escrito

expectativas sociales; no obstante, no es el propósito central del proceso educativo en términos de política pública, pues la estructura supone una tasa mínima de eficiencia y por tanto de rendimiento por parte del alumno.

${ }^{159}$ El subrayado es mío. 
expresamente, se deberán asignar montos específicos para becar a los estudiantes indígenas, de forma tal que una situación económica precaria, deje de ser un factor en la inasistencia o deserción escolar. De manera adicional, caben aquí los requerimientos de infraestructura donde no la haya, el mantenimiento y ampliación de las plantas académicas y administrativas, la conservación de la infraestructura y los demás gastos asociados e indispensables para el buen desempeño de una institución educativa.

Reitero aquí dos ángulos de la acción de gobierno que abordé en el capítulo anterior: no en toda acción del gobierno, se lleva a los individuos a comportarse en términos "que de otro modo no harían"; muchos indígenas conocen sus derechos y el tipo de educación que desean y, en ese sentido, concurrirán convencidos y competentes al desarrollo de la educación superior bilingüe e intercultural que el Estado ofrece en cumplimiento de su obligación constitucional. Sin embargo, sociológicamente, la población indígena presenta muchas carencias educativas y es víctima del sistema "tradicional"; de ahí que la novedad de la propuesta, y por lo tanto la acción gubernamental busca que esta población conozca sus derechos, los ejerza y se eduque con una visión distinta a la que conoce o espera, conduciéndose en maneras que de otro modo no haría.

En el proceso de reforma constitucional, en pugna con los Acuerdos de San Andrés, no se transformaron otras legislaciones secundarias, especialmente la de educación, pues “....en 2001 se hace un nuevo dictamen de la ley y el rubro educativo queda sin reformas puesto que el Senado considera que no contradice la ley general de educación; no se observa en este nivel ninguna contradicción insuperable" (Ramírez Castañeda, 2006: 183). ¿Qué contenido tenía la Ley General de Educación y qué reformas posteriores apoyan el fenómeno de la educación superior intercultural?

En primer lugar, el articulo sexto, reitera la forma de política distributiva ya mencionada, al afirmar que: “Artículo 60. La educación que el Estado imparta será gratuita. Las donaciones destinadas a dicha educación en ningún caso se entenderán como contraprestaciones del servicio educativo" (Ley General de Educación, 2011: 2). La promulgación de la Ley General de Derechos Lingüísticos de los Pueblos Indígenas (13 de marzo de 2003), trajo una adecuación a la Ley General de Educación, que en el artículo séptimo, fracción cuarta, refiere que la educación que imparta el Estado deberá: "Promover mediante la enseñanza el conocimiento de la pluralidad lingüística de la Nación y el respeto a los derechos linguíísticos de los pueblos indígenas. Los hablantes de lenguas indígenas, tendrán acceso a la educación obligatoria en su propia lengua y 
español" (Ibidem). Los demás aspectos de la Ley General de Educación concuerdan, en efecto, con los puntos presentados a propósito del artículo tercero de la Constitución. Finalmente, la mencionada Ley de derechos lingüísticos, contiene algunos insumos que los tres poderes deberán observar en la atención a los pueblos indígenas y que atañen al tema educativo.

Todo esto viene incorporado en el artículo $13:<$ Incluir en planes y programas educativos en materia de educación y cultura indígena, acciones tendientes a la protección, preservación, promoción y desarrollo de las lenguas indígenas; incluir en dichos planes, el origen y la evolución de las lenguas indígenas; supervisar que en la educación pública y privada se fomente o implemente el enfoque de la interculturalidad y el multilingüismo; garantizar que los profesores que atiendan la educación básica en las comunidades, hablen y escriban en su lengua; impulsar la investigación, difusión y documentación sobre las lenguas indígenas; crear bibliotecas, hemerotecas y cualquier institución que conserve los materiales en las distintas lenguas; apoyar la formación y acreditación de intérpretes y traductores >> (INALI, s/f: 6-7).

La revisión documental del marco legal en materia de pueblos indígenas muestra que los primeros años del sexenio de Vicente Fox fueron especialmente vigorosos en términos de reformas legales y decretos presidenciales. Dentro de lo más importante, destaca la Ley de la Comisión Nacional para el Desarrollo de los Pueblos Indígenas. Se crea la Comisiín Nacional para el Desarrollo de los Pueblos Indígenas (CDI), en sustitución del Instituto Nacional Indigenista (INI), como un organismo descentralizado, no sectorizado con el objeto de "[Artículo 2]...orientar, coordinar, promover, apoyar, fomentar, dar seguimiento y evaluar los programas, proyectos, estrategias y acciones públicas para el desarrollo integral y sustentable de los pueblos y comunidades indígenas de conformidad con el artículo 2o. de la Constitución Política de los Estados Unidos Mexicanos" (CDI, 2011: s/p). Es una entidad independiente, de coordinación de las políticas públicas en el sector indígenas, con las facultades de: <<asesorar en la formulación, ejecución y evaluación de las políticas, dado que las dependencias y entidades federales deberán solicitar su opinión en la materia; servir de apoyo y asesoría a comunidades y pueblos indígenas; instrumentar programas y acciones, que no afecten atribuciones de otras dependencias o entidades para lo cual podrá establecer acuerdos y convenios de colaboración, con éstas o con estados y municipios. Para lo anterior está facultada para apoyar en la formulación del presupuesto de egresos de la Federación. Su acción se basará considerando carácter multiétnico y pluricultural de la nación, 
promoviendo la no discriminación y el dialogo intercultural; deberá impulsar la integralidad y transversalidad de todas las políticas en la Administración Pública Federal y muy notable, podrá aprobar y adecuar las partidas presupuestales de acuerdo a sus necesidades, sin necesidad de autorización del Poder Ejecutivo>> (Ibidem).

Es importante mencionar a la CDI, pues aunque no está directamente involucrada con el tema educativo, en todas las políticas educativas del sector indígena, la entidad funciona como asesora, mediadora, y lo que es muy significativo, como proveedora de fondos adicionales, excepcionales o complementarios de los programas o instituciones involucradas. ${ }^{160}$ En este caso, dichos fondos permiten a las instituciones del sector, apoyar acciones prioritarias que de otro modo serían inviables, imposibles o de lenta respuesta, porque una característica central de la CDI, es justo su liberación de autorizaciones hacendarias para el ejercicio flexible de los recursos.

\section{Fundamento y estructura de la educación superior intercultural}

Todo el marco legal anterior se presentó con el ánimo de encuadrar el sentido y actuación de la Coordinación General de Educación Intercultural Bilingüe en la creación, funcionamiento y consolidación de las Universidades Interculturales del país. $\mathrm{Su}$ origen se encuentra en las primeras acciones que el titular del Poder Ejecutivo implementó en relación con el tema indígena, luego de la presentación ante el Senado de la República de la propuesta de reforma constitucional al artículo segundo, el 5 de diciembre del año 2000. El decreto de la Coordinación General de Educación Intercultural Bilingüe (CGEIB), se publicó en el Diario Oficial de la Federación el 22 de enero de 2001. Destaca así la elección de un tema educativo como central en la respuesta del Ejecutivo, a las presiones por el impasse que existía en el tema desde el año de $1995 .{ }^{161}$

¿Cuáles son los aspectos centrales de la misión y funcionamiento de la CGEIB? En primer lugar, en los "Considerandos" se reconoce que en el impulso reciente al tema

\footnotetext{
${ }^{160}$ En el caso de la Universidad Intercultural del Estado de México, las transferencias presupuestarias, desde su creación en 2003 hasta octubre de 2011, son de alrededor de 39 millones de pesos (INFOMEXCDI, 2011).

${ }^{161}$ Es imposible evitar referirse a la simplona propuesta de "arreglar el problema indígena en 15 minutos", que Vicente Fox repetía como lema de campaña hacia la Presidencia de la República. No obstante lo trivial de la frase, desde su inmediata creación, la CGEIB ha desempeñado un papel central en la transformación de las relaciones entre el Estado mexicano, la población indígena y el resto de la población. En el reciente festejo por sus diez años de creación (noviembre de 2011), más allá de alabanzas o críticas, sorprende la rectoría que la CGEIB desempeña en las demandas y el discurso de los agentes educativos, ya pidiendo apoyo, ya asesoría, ya una guía hacia lo que falta por hacer; es claramente un núcleo coordinador en la solución del problema educativo.
} 
educativo en pueblos y comunidades indígenas [luego del alzamiento del EZLN], la calidad, equidad y pertinencia del servicio es una asignatura pendiente. Por ello, es necesaria la creación de una instancia que garantice la transformación del servicio educativo federal, incorporando la visión de un país pluricultural y multilingüe, reconociendo por tanto esa diversidad (Diario Oficial de la Federación, 22 de enero de 2001: 58).

Lo primero que destaca del articulado es su localización dentro de la Secretaría de Educación Pública y en cuyo seno, “...tendrá como propósito asegurar que la educación intercultural y bilingüe responda con un alto nivel de calidad a las necesidades de la población indígena" (Ibidem). Entre sus atribuciones destacadas y relevantes al tema de la educación superior hacia los indígenas, se debe mencionar: <<Su capacidad de promover y evaluar la política educativa intercultural y bilingüe (EIB) en las diferentes instancias del Sistema Educativo Nacional; de animar la incorporación de las entidades federativas y los municipios, así como las comunidades indígenas, en el desarrollo de la EIB; diseñar mecanismos de supervisión y vigilancia que aseguren la calidad de la EIB; promover y asesorar la implantación de programas innovadores de EIB, especialmente en los modelos curriculares, la formación de personal docente y la producción de materiales en lenguas indígenas; buscar que en los servicios educativos en general, se reconozca la diversidad cultural y lingüística de la Nación y; evaluar y certificar los estudios en materia de EIB>> (Ibidem). La ampliación legal y fuerza obligatoria que adquirió el tema de la educación indígena luego de la reforma al segundo constitucional, terminó por dar a este "Acuerdo" la fuerza vinculante que le faltaba. Es claro que en sus temas y redacción, se avizoraba la posibilidad de que el proyecto de reforma, donde el Ejecutivo presentó al Congreso los Acuerdos de San Andrés, llegara a buen puerto.

¿Qué significó el remache constitucional y cómo se puede "leer" la capacidad operativa de la CGEIB en los términos que venimos revisando? La idea de la educación intercultural o llanamente, de la interculturalidad, puso a la CGEIB en el papel de coordinar los esfuerzos para aplicar y explicar, qué contenía ese término de densidad simbólica mayúscula y compleja polisemia. Lo primero que debe aclararse es que se buscó, y se ha buscado, crear un cuerpo teórico y administrativo, que defina lo qué es la “interculturalidad", cómo se aplica en educación y cómo se puede articular en una política que considere lo teórico, los mandatos constitucionales y, algo que resulta central, lleve a los indígenas (estudiantes y maestros) a vivir la educación de manera 
diferente a la acostumbrada, y a la población no indígena a comprender la importancia de las relaciones interculturales equitativas y armónicas.

Estos planteamientos, notablemente, eran nuevos en el país. La CGEIB se dio a la tarea de generar modelos de EIB en los distintos niveles, y esto es importante, realizando foros donde los involucrados en el proceso, fundamentalmente profesores y funcionarios del sector educativo indígena, fueron aportando ideas, pero también fueron conducidos a tomar la interculturalidad como la ideología central de la nueva relación del Estado mexicano con los indígenas. ${ }^{162}$ Esto no es complejo de aseverar, pues el neologismo, si bien refiere la idea normativa de que las relaciones entre culturas deben ser horizontales, armónicas, respetuosas e interesadas en el "otro", es muy frecuente que políticas que inciden en poblaciones mayoritariamente indígenas, se denominen o traten como interculturales; en ese sentido, la "mezcla" entre políticas interculturales y políticas indigenistas o hacia los indígenas converge constantemente. ${ }^{163}$ Interculturalidad funciona frecuentemente, más como eufemismo de políticas indígenas que como el neologismo mencionado. Una muestra de lo anterior son las fuerzas que, provenientes de la capacidad rectora del Estado, han llevado a los indígenas a desistir de ciertos impulsos endógenos, "tener una universidad indígena", para aceptar ya en las negociaciones, que su universidad acabe por ser "intercultural", en virtud de las presiones exógenas. ${ }^{164}$

\footnotetext{
${ }^{162}$ De las publicaciones destacadas que constituyen guías para la educación intercultural en los distintos niveles se encuentran: Experiencias inovadoras en educación intercultural. México, SEP-CGEIB, 2004; Universidad intercultural. Modelo educativo. México, SEP-CGEIB, 2006a; El enfoque intercultural en educación. Orientaciones para maestros de primaria. México, SEP-CGEIB, 2006b; Modelo educativo del bachillerato intercultural. México, SEP-CGEIB, 2006c; Líneas de investigación en educación intercultural. México, SEP-CGEIB, 2009.

${ }^{163} \mathrm{La}$ complejidad y las disputas en torno del significado del término, evidencia varios aspectos: su novedad, su carácter político, su facilidad de apropiación y su uso excesivo; González Apodaca lo expone de manera certera: "La polisemia del término educación intercultural en sus diferentes ámbitos de aplicación ha generado un vacío connotativo que, sin embargo, también abre múltiples posibilidades de significación y debate. A los discursos oficiales de educación intercultural en distintos contextos nacionales se suman las formulaciones elaboradas por los movimientos indígenas, vía sus líderes e intelectuales, que lo retoman y contextualizan en propuestas locales y regionales de escuela culturalmente pertinente. La educación intercultural representa, en esta mirada inicial, un campo de significación disputado por los diferentes actores que participan en su construcción" (Gonzales Apodaca, 2008: 31). En ese sentido lo comprende como una "... arena política donde se disputan los bienes materiales y simbólicos asociados a la escuela" (Ibid: 54).

${ }^{164}$ Actores centrales, que estuvieron desde el inicio del proceso para conseguir la implantación de una universidad en la zona mazahua y que participaron en las reuniones y los foros iniciales con la CGEIB, para la culminación del proyecto, refieren que su deseo inicial era el de lograr una "Universidad Indígena" o una "Universidad Mazahua". Durante los trabajos, se les "convenció" de lo importante que era cambiar a la dimensión intercultural: "Por cierto, quien propuso que la institución de educación superior debería ser intercultural fue Silvia Schmelkes, [Coordinadora] de la Coordinación General de Educación Intercultural Bilingüe" (Celote, s/f: 15). Desde la posición de la coordinadora, el punto estaba bien claro, pues relatando las objeciones a las universidades indígenas y su posible carácter
} 
Más allá de esta circunstancia, a la fecha funcionan nueve universidades interculturales (UI) públicas, que dan cuenta del impulso que la CGEIB ha dado a estas instituciones. ${ }^{165}$ El motor inicial quedó expresado en el Programa Nacional de Educación 2001-2001, en el cual se expresa con claridad que una de las metas del sexenio era elevar la cobertura en educación superior para indígenas del $1 \%$ al $3 \%{ }^{166}$ En consecuencia, la CGEIB se dio la tarea de coordinar este esfuerzo de manera conjunta con la Subsecretaria de Educación Superior Federal, buscando resolver tres problemas centrales: la escasa cobertura a la población indígena en educación superior; las crecientes demandas de sectores de la población indígena; y el desequilibrio geográfico del desarrollo nacional (Schmelkes, 2008: 329). Para mitigar estas constantes, las UI deberían dar respuesta:

- Formando intelectuales y profesionales comprometidos con el desarrollo económico, social, cultural y lingüístico de las regiones de ubicación.

- Abordando tres áreas sustantivas: docencia, investigación y vinculación.

\begin{abstract}
segregacionista, aseveró que desde el inicio “...se señaló que las universidades nunca serían exclusivamente para indígenas - desde la CGEIB se tenía claro que no se quería una universidad que segregara a los indígenas..." (Schmelkes, 2008: 329). La posición institucional es contundente: "En cuanto a la vocación y denominación de la institución que se proyectaba crear, se acordó omitir el término indígena a fin de evitar la idea de segregación de los grupos étnicos del resto de la sociedad mexicana, a la que generalmente se asocia el término. Dada la vocación y los propósitos a cumplir por la nueva institución, se optó por calificarla como intercultural" (CGEIB, 2006a: 131). Claramente el ejercicio del poder político funcionó aquí en los dos sectores: en los mestizos, llevándolos a conceptualizar la posibilidad de instituciones educativas en donde se integren los indígenas con pleno derecho, sin estar segmentados o marginados, sino en el "centro" del proyecto; y a los indígenas negándoles la posibilidad de alcanzar un proyecto largamente acariciado y obligándolos a renunciar a la denominación indígena si deseaban apropiarse de los servicios educativos brindados por las UI . Desde 1977 se buscaba que en la zona de San Felipe del Progreso se implantara una universidad indígena; esta visión netamente local, indígena y endógena, contrasta con la visión global, multiculturalista y exógena del proyecto estatal. El planteamiento desde la CBEIB resultó "irresistible", en virtud de la experiencia académica, administrativa, el marco constitucional y los recursos necesarios para lograr el anhelo. El Estado mexicano llevó a los solicitantes a tener una conceptualización nueva, relativa a la introyección de la ideología intercultural y el abandono del credo indigenista, todo ello en el macro del ejercicio del poder político vía el intercambio. De manera lógica, un participante este proyecto del Estado, reconoce que otros actores del Estado, son los que introdujeron la idea central: “...la Coordinación General de Educación Intercultural y Bilingüe que fue puesta bajo la responsabilidad de Silvia Schmelkes, a quien, junto con Julio Rubio Oca, deben acreditarse como los introductores del principio de interculturalidad en la educación superior y media superior de México" (Fábregas, 2008: 342). No es en este caso, que se busque aprovechar una palabra para sustentar una hipótesis de trabajo, es que el ejercicio del poder político tiene ciertas constantes que definen la acción de los sujetos. Así, el subrayado de "introductores" del proyecto, resalta, no una pretendida forma impositiva o autoritaria de accionar, sino el carácter exógeno que define todo el ejercicio de poder; ya sea respecto del órgano estatal, ya en los estudiantes y profesores incorporados a las universidades.

${ }_{165}$ Las universidades en funciones son las siguientes: 1.- Universidad Intercultural del Estado de México; 2.- Universidad Intercultural de Chiapas; 3.- Universidad Intercultural del Estado de Tabasco; 4.Universidad Intercultural del Estado de Puebla; 5.- Universidad Indígena de México; 6.- Universidad Veracruzana Intercultural; 7.- Universidad Intercultural del Estado de Guerrero; 8.- Universidad Intercultural Indígena de Michoacán; 9.- Universidad Intercultural Maya de Quintana Roo.

${ }^{166}$ Secretaria de Educación Pública (2001: 203)
\end{abstract}


- Atendiendo principalmente, pero no exclusivamente, a población indígena.

- Definiendo su oferta a partir de las necesidades y potencialidades de la región.

- No seleccionando a sus estudiantes con criterios académicos; dedicando en cambio el tiempo necesario para formar $\mathrm{y}$ fortalecer competencias para enfrentar críticamente los estudios universitarios.

- Vinculándose orgánica y formativamente con las comunidades.

- Favoreciendo una educación de muy alta calidad (Ibid: 330).

Estos puntos sustantivos, son la forma concreta que la normatividad que rige a la CGEIB, supone para la educación superior hacia los indígenas, expuesta anteriormente en el "Acuerdo" de creación. Definirán la manera en la que la Secretaría de Educación Pública va a conducir a los actores concretos que desean recibir fondos y certificación federales para fundar una universidad intercultural en las diversas entidades estatales y posteriormente, el resultado instrumentado, dirigirá las conductas y las conceptualizaciones de los estudiantes indígenas a lo largo del proceso de apropiación de los servicios educativos. ${ }^{167}$ El alumno quiere educación, regularmente de la mejor calidad y pertinente hacia él, pero carece de elementos para imaginar qué forma específica y alcance local o regional debe tener; asimismo, ignora la forma estructural que debe tener el proyecto educativo hacia los indígenas como grupo poblacional. En todo caso, le bastaría conocer, que ocurrió una reforma constitucional y que el Estado está obligado por tanto a conducirse con ese nuevo marco legal; pero el ejercicio del poder político por el Estado, legítimo y exitoso, precisamente ocurre al conseguir que este alumno, se comporte de acuerdo con los conceptos planeados por la CGEIB, que en un grado sociológicamente relevante, no hacía o no conocía. ${ }^{168}$

En ese sentido, los recursos que la CGEIB “invierte" en esa dimensión, son empleados para impactar ambos mundos: el de los miembros académicos, administrativos y directivos de las nuevas universidades, y el de los alumnos de la

\footnotetext{
${ }^{167}$ Es preciso advertir cómo empatan estos puntos particulares con los expuestos al inicio de la sección: El marco nacional de las políticas educativas interculturales.

${ }^{168}$ Esta descripción tipológica, se ajusta en gran medida al perfil del alumno de nuevo ingreso a la Universidad Intercultural del Estado de México (UIEM), en tres puntos importantes: la gran mayoría de los alumnos entrevistados no tenían a la UIEM como su primera opción y entraron luego de ser rechazados en otras instituciones "tradicionales"; en segundo lugar, no tenían la menor idea sobre las carreras y eligieron, luego de un año en el que cursaron un tronco común; desde luego, conocían vagamente o no conocían, los valores político-filosóficos alrededor del concepto "interculturalidad". De ahí, los alumnos titulados, contentos con su carrera y con el perfil intercultural de su alma mater, claramente son una muestra del ejercicio eficaz del poder político estatal, pues condujeron a los estudiantes a conductas y conceptualizaciones que de otro modo no harían.
} 
institución. En su papel de coordinación, los agentes de la CGEIB ejercen recursos federales: visitando las posibles sedes; presentando las características esenciales del modelo; organizando foros y debates; coordinando la creación y publicación de materiales relativos; suministrando esos materiales a los individuos involucrados; garantizando el apoyo federal para el sostenimiento de las unidades académicas (entre $80 \%$ y $50 \%$ ); asesorando en la construcción del modelo y los currículos; garantizando la aprobación de los currículos cuando se ajusten a los requerimientos anticipados; y participando con voz y voto en el órgano directivo máximo de las universidades: el Consejo Directivo. En este sentido, la apropiación de dichos recursos federales por las unidades académicas en los distintos estados de la República, sólo se dará plenamente, si las conductas y conceptualizaciones de los participantes se ajustan a los puntos sustantivos -mencionados arriba- para el funcionamiento de las universidades interculturales. $^{169}$

La convergencia de las unidades universitarias, en términos de lo que el corazón del modelo supone, deberá ajustarse a un conjunto de valores, ideas y procedimientos mínimos. El primer tema en general es el que se refiere a la baja incorporación de los estudiantes indígenas a las universidades existentes. En general el problema se deriva del bajo nivel educativo imperante en las zonas rurales-indígenas del país. ${ }^{170}$ Paralelamente, de la presión para la castellanización y la integración a la cultura mestiza, que dificultan profundamente el aprendizaje de los niños y jóvenes. En ese sentido, la educación intercultural busca “...la creación de espacios académicos que permitan establecer las bases para promover relaciones paralelas entre individuos de diferentes culturas y que contribuyan a fortalecer la autoestima cultural y personal de los jóvenes de este origen, desplazando las actitudes de asimilación y sometimiento a culturas ajenas" (CGEIB, 2006a: 34). ${ }^{171}$ Esta sentencia general, tiene su aterrizaje en la

\footnotetext{
169 El monto total de los recursos presupuestados para la CGEIB desde su creación hasta estas 2011 aparecen en el Anexo 1.

${ }^{170}$ El diagnóstico general de la situación para la época, al margen del conocido rezago histórico, puede verse en SEP (2001).

${ }^{171}$ El subrayado es mío. Una definición de educación intercultural anterior (de los noventa) ya perfila uno de los ejes muy consistentes del interior del proceso; es decir en el aula: "La Educación Intercultural por su parte apunta a un proceso de aprendizaje entre iguales [...] en ese sentido no es una educación para los indígenas, sino para toda la población la cual debe dejar atrás su perspectiva de la relación superior/inferior y folclórica hacia los indígenas y cambiarla por una relación de sujeto a sujeto que implica la reflexión mutua de la asimetría actual y sus causas" (Klesing-Rempel, 1996: 11). En el 3er Encuentro Regional sobre Educación Superior Intercultural de América Latina y del Caribe, desarrollado en Pátzcuaro, Michoacán en noviembre de 2009, el rector de una UI, hizo especial énfasis en el asunto:
} 
educación superior, al establecer que se deberá generar un diálogo intercultural “...orientado a hacer compatibles las procesos de estudio, análisis y generación de nuevos conocimientos que beneficien a las poblaciones que sustentan, y contribuyan a librar barreras de comunicación entre el conocimiento práctico y místico acumulado en la sabiduría indígenas y el conocimiento científico generado en las universidades convencionales" (Ibidem).

Estas ideas de paralelismo en el contacto cultural al nivel de los conocimientos, van a ser una constante en el diseño e instrumentación del discurso educativo en las UI, porque a causa de la hegemonía criollo-mestiza en amplios niveles de la vida nacional, los individuos indígenas, su cultura y su conocimiento, se encontraban efectivamente, desvalorizados o invisibilizados, del sistema educativo nacional. La interculturalidad busca reducir o empatar estos tres niveles para lograr a mediano o largo plazo, relaciones igualitarias y paralelas, donde el conocimiento tradicional y el científico, convivan de manera armónica, o más aún, “...impulsar un proceso de complementación $\mathrm{y}$ enriquecimiento entre la ciencia moderna y otros saberes $[\ldots y]$ fomenta[r] la formulación de una síntesis entre los conocimientos que aporta la visión científica occidental y los saberes tradicionales que no han sido reconocidos desde esa perspectiva" (Ibid: 38$).{ }^{172}$

Estas loables ideas buscan dar salida al complejo problema que supone formar indígenas para integrarse a la vida productiva del país a través de la educación superior, conservando y enorgulleciéndose de su cultura materna. Así, se obliga a una necesaria

\footnotetext{
$<<$ Un maestro que se cimiente en las relaciones de poder, no tiene lugar en las universidades interculturales $\gg$. Claramente, la ideología intercultural, que busca valer para todos exponiendo su impulso hegemónico, tiene un problema político central, pues en la aplicación rigurosa de su credo, no caben las relaciones de poder de ningún tipo, con la consiguiente parálisis de todos aquellos expedientes sociales que fundamentan la conducción social en las asimetrías sociales. Esta confusión deriva en parte a mi ver- de que se mezcla la necesidad de igualdad jurídica y de convivencia entre culturas, con lo igual como esencia, pues se imagina un mundo en donde ninguna diferencia será llevada al mundo de las asimetrías y de ahí al ejercicio de poder, cosa que por todo el planteamiento teórico desarrollado aquí, es imposible que ocurra. Resulta muy difícil pensar que los discursos sobre la igualdad a ultranza que imperan en el mundo de la educación intercultural, sean reflexionados profundamente por los actores que los impulsan; desde la CGEIB, los rectores de las UI, los maestros y los estudiantes. El asunto grave, es que la debilidad institucional de los profesores en la unidad del Estado de México, proviene de que ese discurso limita los controles que regularmente se utilizan en la docencia y que vienen del control del profesor del conocimiento y la certificación del mismo. Se han constatado múltiples quejas de profesores, de su debilidad de reprobar alumnos que faltan o no trabajan. Sin embargo, la necesidad por aparentar un modelo educativo exitoso, recae en los profesores que son presionados -sin referir desde donde- para no reprobar a aquellos que no se ajustan a la norma. El conocimiento del hecho por los alumnos y su sustento en el discurso de igualdad a ultranza, ha derivado en un problema importante en la unidad que ya busca ser resuelto; la ideología igualitaria es un freno potente al proyecto educativo, al menos en el tema de la calidad.

${ }^{172}$ El subrayado es mío.
} 
convivencia entre los conocimientos científicos (individuales) y los tradicionales (colectivos), buscando crear una síntesis entre ellos, ya sea al nivel del conocimiento como tal, ya sea al de un plan de estudios que busque conjuntar de manera no conflictiva estos dos tipos de saberes.

Sin embargo, el conflicto no sólo se da entre operatividades de conocimiento; son conflictos ideológicos, derivados de la encarnación arbitraria de los sujetos históricos indígenas y criollo-mestizos, en los individuos concretos: indígenas y mestizos. La deseable transformación del mundo, a través de la desasimetrización de las diferencias existentes en la sociedad, pasa en muchos casos por la maniobra ideológica, tanto social como personal, de desvalorizar y defenestrar algunas o todas las características de la entidad dominante. No es un proceso analítico, sino fundamentalmente político; busca dar sustento a un legítimo deseo de justicia y recomposición social. ${ }^{173}$ Esta reflexión, intenta exponer algunos juicios de la CGEIB, que resuenan en varios aspectos con lo que ocurre en la Universidad Intercultural del Estado de México (UIEM), sobre todo al nivel de la tradición del conocimiento en las universidades y en el sujeto histórico que las "creó": Occidente.

Refiere el texto de la CGEIB, Universidades interculturales. Modelo Educativo (2006a: 37-8), que <<es central el deseo de modificar el esquema "tradicional" de universidad y de educación, pues es un proyecto monopolizado por "Occidente". Que el conocimiento generado en ellas, es desde una perspectiva epistemológica europea, "que ha excluido otros saberes". Que las universidades se organizan bajo el esquema clásico surgido del medievo, determinando qué y cómo se enseña, y también, cómo debe valorar la sociedad los conocimientos que ésta ofrece. Que la elite política y cultural decide lo que los estudiantes deben aprender y coordina los sistemas de evaluación de saberes, privilegiando su utilidad económica >>. "Las universidades convencionales se apoyan en el poder de la escritura; a través de sus práctica, el saber se hace ley. En sus métodos se privilegia la transmisión de conocimientos, no de procesos de pensamiento o discernimiento" (Ibidem). ${ }^{174}$

En toda estructura mítica, existe una contradicción entre pares opuestos irreconciliables; el relato busca "explicar" dichas contradicciones, pero sobre todo, exponer relaciones lógicas entre las cosas. El sesgo mitológico del relato histórico de

\footnotetext{
${ }^{173}$ Es casi mecánico referirse aquí, a las tesis expuestas por James C. Scott en Los dominados y el arte de la resistencia (2000), que dan cuenta de este proceso y que Scott denomina "discurso oculto".

${ }^{174}$ El subrayado es mío.
} 
los procesos educativos en Occidente, busca poner un piso duro, a partir del cual, reinventar la educación. Para ello son necesarias dos maniobras ideológicas. Primero, desconocer la naturaleza intrínseca y real del proceso educativo occidental, con todas sus lacras, pero fundamentalmente, con todos sus éxitos y avances. Todos los intelectuales que pensaron y construyeron los insumos para fundamentar el discurso multiculturalista y de la diversidad cultural, generaron su pensamiento en dichos centros. Sin caricaturizar, están más cerca del pensamiento o del discernimiento, que de la transmisión mecánica del conocimiento. Segundo, postular que la salida de la contradicción, ocurre en términos del proyecto que da origen y sentido al relato.

Tal salida es claramente el proyecto de las universidades interculturales. $<<\mathrm{Se}$ encuadra en las demandas de los movimientos sociales por la reivindicación de los derechos humanos y en particular de los derechos de los pueblos indígenas. Es una oportunidad para construir una nueva imagen y función social de las instituciones educativas, especialmente de la universidad como promotor del progreso social incluyente. Donde, al abrir nuevos espacios de educación superior, se generen las condiciones para la inclusión de la población indígena en la construcción de conocimientos y disciplinas científicas, en complementariedad con los saberes tradicionales >> (CGEIB: $38-9$ )

Las necesidades expositivas del argumento, reconozco, les permiten estas licencias literarias. Lo sorprendente es que filtran contenidos mitológicos para dar espacio al proyecto político-filosófico que sustenta la universidad cultural. Lo que falta decir, es cuál es la contradicción insoluble a la que este relato busca dar sentido. Evidentemente, como en cualquier mitología de tipo político, la oposición central se observa entre dominantes y dominados, que por las consabidas transformaciones, generan pares análogos que complementan $\mathrm{y}$ arman el relato: ${ }^{175}$ Occidente/Mesoamérica; Criollo-mestizos/pueblos originarios; individualismo/comunitarismo; conocimiento científico/conocimiento tradicional; Universidades tradicionales/Universidades interculturales.

Destaca que el primer término de las oposiciones, corresponde a Occidente y sus transformaciones y el segundo, a la derivada del proyecto civilizatorio surgido de la América anterior a la conquista española. Lo interesante de este análisis somero, es que la cadena de transformaciones culmina con la transformación de las universidades,

\footnotetext{
${ }^{175}$ Estas transformaciones, están de acuerdo con lo presentado en el Capítulo 1 sobre la propuesta lévistraussiana.
} 
todas, en interculturales, dado que las tradicionales, corresponden a un molde viejo, no adecuado a los tiempos presentes. Esta proyección que hago de manera conjetural, tiene algunos puntos fuertes, expuestos en el capítulo anterior, respecto de las características hegemónicas del multiculturalismo y su concepto básico, la interculturalidad. ${ }^{176}$ La proyección de un mundo en el que las universidades deben confluir en un punto de interculturalidad dominante, resuena sorprendentemente con la descripción de Ernesto Laclau sobre la hegemonía: búsqueda de una de las partes del sistema, no por imperar frente a las otras, sino por aparecer fuera de las pugnas entre proyectos particulares y ser la característica que englobe a todos los demás, de manera hegemónica.

¿Por qué le concedo importancia a este análisis tan provisional sobre el discurso que fundamenta la pertinencia de las UI frente a las "tradicionales"? De manera central, porque desde la óptica que aquí se ha venido exponiendo, las diferencias fundamentan la creación de asimetrías y de ahí, la posibilidad de ejercer el poder. En ese sentido, la contradicción insoluble entre dominantes y dominados, no cesa por el cambio de formas. Por lo tanto, la instrumentación de políticas interculturales, derivadas de la reforma al artículo segundo de la Constitución, es justa, es necesaria y de deseable expansión. No obstante, el proyecto intercultural apunta de manera expansiva, ideológica, hacia la transformación de las relaciones sociales, vía su credo, en un mundo puramente horizontal en todos los aspectos. No existe manera en que dicho proyecto se expanda a través del poder político estatal, si al parejo se va desasimetrizando todo en la sociedad. Este juicio, formal, teórico y si se quiere, ontológico, quiero hacerlo evidente, no porque corresponda a las expectativas globales de la educación intercultural, sino porque en la instrumentación de las políticas educativas in situ, en San Felipe del Progreso, Estado de México, muchas de las contradicciones entre conocimiento científico y tradicional, Occidente y los pueblos originarios, la sociedad mexicana y las comunidades indígenas, no son resueltas de manera eficaz, pues la dificultad de conciliar aspectos problemáticos del contacto cultural asimétrico, hace que en las aulas, se tome recurrentemente el camino más corto, degradando o negando el valor o pertinencia del primer término de las oposiciones. Esto es especialmente dramático al nivel del conocimiento como tal. La novedad y juventud de las UI permite suponer, que a medida que madure el proyecto se encontrará una epistemología y una ideología

\footnotetext{
${ }^{176}$ Esta convivencia en términos políticos la describe Gunther Dietz: "La interculturalidad y su sustento ideológico, el multiculturalismo, requiere un análisis de los discursos y las "políticas de identidad" que interculturalizan, a la vez que intraculturalizan, las prácticas de los miembros de cada uno de los grupos de la sociedad contemporánea" (2003: 79).
} 
intercultural más reposada, que sea capaz de pensar en las aulas a los elementos de la cultura "occidental" "177, como eso, como elementos de una cultura cualquiera y no, como hasta la fecha, como la oposición constitutiva del proyecto.

Para conseguir la viabilidad del proyecto educativo, era necesario darle estructura institucional de centro de educación superior. El conocido isomorfismo institucional, determina la dispersión de estructuras exitosas de organizaciones dominantes a otras organizaciones que buscan competir o compartir un nicho social. ${ }^{178}$ En ese sentido, gran parte de la estructura, funciones y financiamiento de las UI, se asemejará o copiará modelos ya operativos. Claro que existe un cúmulo de razones pertinentes para la "copia", que no se enlistarán aquí. El motivo de esta precisión es mencionar que lo central en las UI, no es el isomorfismo puro en términos de instituciones de educación superior, sino la modificación, renovación y transformación de esas estructuras fuertemente institucionalizadas, para que se adecuen al imbuirlas del espíritu fundamental del proyecto: la búsqueda de convivencia armónica entre saberes e individuos de culturas diferentes; la construcción de un modelo educativo más horizontal; la importancia del trabajo comunitario y coordinado; el dialogo permanente y la vinculación con la comunidad. ${ }^{179}$ Todas las funciones sustantivas y adjetivas deberán estar subordinadas a los principios rectores de las UI, mencionados desde el inicio de esta sección. Así, se expondráer en adelante la urdimbre institucional y operativa que da cuerpo al funcionamiento de las UI. Tres temas serán muy importantes en la exposición: la focalización de las estructuras y temas que buscan incidir en el tema

177 Quisiera recordar que "Occidente" y "occidental" son términos de compleja, acaso imposible demarcación en términos antropológicos, pero políticamente, su uso no genera mayores problemas. En la nota 91 traté de hacer un avance de demarcación, claramente no concluyente, con el propósito de enmarcar su utilización a lo largo del texto.

${ }^{178}$ Una referencia muy adecuada para este tema lo constituyen los excelentes trabajos "Organizaciones institucionalizadas: la estructura formal como mito y ceremonia" de Meyer y Rowan; "Retorno a la jaula de hierro: El isomorfismo institucional y la racionalidad colectiva en los campos organizacionales" de DiMaggio y Powell; y específicamente en el tema educativo, el notable: "Los orígenes y las transformaciones institucionales: El caso de las escuelas locales de los Estados Unidos" de Brint y Karabel. Este trabajo en particular reseña el esfuerzo por modificar dichas escuelas, de un perfil abstracto en Humanidades a una capacitación profesional, y refieren los autores: "Desde los años veinte, los administradores de las escuelas locales y los expertos en educación comenzaron a apoyar esa transformación. En consecuencia se debe explicar el fracaso durante 40 a 50 años para transformar las escuelas y el éxito de los esfuerzos de fines de los sesenta y principios de los setenta" (p 413-4). Los tres trabajos se encuentran en Powell y DiMaggio (1999).

${ }^{179}$ Esta aseveración está en el espíritu de lo comentado en entrevista (Noviembre, 2011) por Fernando Salmerón, actual coordinador de la CGEIB. 
de la "Cultura" de los que concurren a las UI; los mecanismos de poder político que permiten instrumentar dichas políticas interculturales; y la subordinación de las unidades a otros contextos institucionales, que imponen desde fuera de las unidades, interpretaciones sobre lo intercultural o desinterés o rechazo efectivo. ${ }^{180}$

1.- La presión social arrastrada desde 1994 por el Estado mexicano, determinó que el gobierno elegido en el año 2000, comenzara a instrumentar acciones para elevar la atención gubernamental a pueblos y comunidades indígenas, independientemente del proceso que tomara la reforma constitucional en la materia. La instrumentación de estas políticas en educación superior, corrió a cargo de la CGEIB desde el inicio del sexenio. ¿Qué marco de políticas públicas, sustentaba sus esfuerzos particulares? En primer lugar el Plan Nacional de Desarrollo 2001-2006 que, respecto de la relación con los pueblos indígenas, postula que la acción de gobierno deberá ajustarse a nuevas realidades posteriores al levantamiento de 1994. “...hoy reconocemos que la relación entre la cultura y la identidad indígena no ocurre de manera mecánica y que, por tanto, los cambios culturales en una colectividad no necesariamente implican cambios de identidad" (cit. en: CGEIB, 2006: 57). ${ }^{181}$ Además, la aceptación de que es erróneo pensar a la Nación como homogénea y que los indígenas son identificados plenamente como sujetos políticos con intereses específicos (Ibidem). Bajo el rubro de "Equidad", el Ejecutivo dispone la atención de los grupos que se encuentran en desventaja frente al resto y mediante el concepto de "transversalidad", busca la coordinación de las diferentes áreas de gobierno, para romper el ciclo de inequidad. La educación, está contenida dentro de los temas de acción transversal, en la que habrán de concurrir distintas dependencias para darle forma y viabilidad. ${ }^{182}$

El complemento al plan nacional lo constituye el Plan Nacional de Desarrollo de los Pueblos Indígenas 2001-2006, versa sobre temas similares, pero establece puntos específicos de la relación con los pueblos indígenas y los ejes concretos para su

\footnotetext{
${ }^{180}$ Los puntos a desarrollar, se ajustan en gran medida al formato expositivo que presenta el documento rector de la Coordinación de Educación Intercultural Bilingüe (2006a), para la justificación y culminación de una institución de educación superior intercultural, que atienda a la población indígena.

${ }^{181}$ Quiero hacer notar, que claramente se decanta el Poder Ejecutivo por la existencia de la identidad política, en términos de la multicitada "autoadscripción" que elimina, sobre todo, las formas intermedias; tema tratado más ampliamente en el Capítulo 3.

${ }^{182}$ Es muy interesante de señalar, que el concepto "transversalidad" corresponde de manera notable a la elección gubernamental de lo denominado en los Principios de los Acuerdos de San Andrés, bajo el rubro Integralidad (Gobierno del Estado de Chiapas, 2003: 34) y que en la propuesta de reforma constitucional fuera definido bajo la categoría de desarrollo integral (Ibid: 116). La conceptualización gubernamental ha sido exitosa y es una constante en todos los foros sobre el tema.
} 
operación. Destaca <<que se establecerán los lineamientos necesarios para la nueva relación, que será coordinada con ellos y de carácter integral. Para lo cual se promoverá el dialogo intercultural en las políticas y programas gubernamentales, para lo cual, dichas políticas, programa y los recursos gubernamentales deberán ser ejercidos de manera transversal y tener como ejes de actuación: el reconocimiento a la diversidad cultural, la promoción del desarrollo sustentable, social y humano y la cohesión social>> (cit. en: CGEIB, 2006: 59-60). Así, la estrategia de la actuación gubernamental, según la entiende la CGEIB, “...es promover la transformación y la creación de espacios institucionales en el conjunto de las entidades públicas con la finalidad de garantizar y hacer efectiva la atención a éstas comunidades" (Ibid: 60). Empieza aquí a delinearse, como a partir del deseo social y del mandato constitucional, se utilizará el gasto gubernamental en comunidades concretas para la producción de conductas y conceptualizaciones.

El Programa Nacional de Educación 2001-2006, establece que un eje fundamental es la ampliación de la cobertura educativa y el mejoramiento de la calidad para lograr la equidad en los grupos sociales con menores posibilidades, para lo cual, establece varias líneas de acción: apoyar de manera prioritaria la educación superior pública, ampliando y diversificando la oferta; en dicha ampliación, se cuidará la inclusión de diferentes expresiones culturales locales y regionales en zonas tradicionalmente marginadas; se brindará apoyo económico a estudiantes de bajos recursos para potenciar su acceso a los servicios, con prioridad a estudiantes de zonas indígenas y rurales (cit. en: CGEIB, 2006: 61-2). En este contexto es que el Programa Nacional de Becas para la Educación Superior (PRONABES), es creado para proporcionar recursos monetarios que impidan que el factor económico sea un motivo para abandonar los estudios. Dichos aportes no reembolsables se instrumentarán con el apoyo de los gobiernos de los estados. Los objetivos particulares pretenden: reducir la deserción escolar y propiciar la terminación oportuna de los estudios; impulsar la formación de profesionales en las áreas de conocimiento que requiera el desarrollo estatal, regional y nacional y disminuir la brecha entre las entidades federativas (Ibid: 63). La conducción social desde la rectoría del Estado es muy evidente. Atendiendo al mandato constitucional del artículo tercero constitucional, se dará mayor cobertura con equidad, pero la instrumentación específica al nivel de la educación superior e intercultural en pueblos indígenas, es como ya vimos, una decisión de gobierno. Más aún, es la instrumentación del PRONABES y, sobre todo, lo será en los montos 
asignados a cada proyecto institucional, de acuerdo con evaluaciones federales, y en los sitios que se considere estratégico. ${ }^{183}$ Todo ello culmina en que los estudiantes que reciben educación superior, queden determinados por esas líneas estratégicas generales y por el "fondeo" a los proyectos acordes con éstas. Si bien, la concurrencia y decisión de los ejecutivos estatales tiene un peso determinante, como veremos, la decisión final para la aprobación de un proyecto de una UI, está definida por la voluntad federal, aunque, y esto es significativo en el proyecto a mediano y largo plazo, los estados de la Federación, son los que deciden si desean o no una UI. ${ }^{184}$

El Programa de Ampliación de la Oferta de la Educación Superior 2002, es un programa del gobierno federal en coordinación con las "Comisiones Estatales para la Planeación del a Educación Superior" (COEPES), para la mencionada cobertura con equidad, pero adicionalmente, en el marco de un desarrollo regional y nacional coordinado y racional en las entidades federativas. Las COEPES definen el perfil de educación superior de su estado, con base en las necesidades futuras para “...propiciar el desarrollo, el crecimiento y la reorientación, en su caso de la educación superior en las entidades federativas, y estimar el presupuesto necesario para ello [...y] Orientar y

\footnotetext{
${ }^{183}$ El PRONABES es un programa sujeto a reglas de operación que determina el marco dentro del cual se ejerce el presupuesto aprobado por el Congreso de la Unión y es operado por la Subsecretaría de Educación Superior. De 2001 fecha de su creación, en que se registraron 44,422 becarios, se pasó a 302,671 en 2010. En ese lapso, se han gastado alrededor de 8,500 millones de pesos. La incorporación de la población indígena ha ido creciendo en estos 10 años hasta alcanzar el 13\% del padrón (Diario Oficial de la Federación, 31 de diciembre de 2010). Las condiciones para la incorporación a los becarios son que: "Los solicitantes en los dos primeros ciclos escolares los cuales no requieren demostrar un promedio ni ser estudiantes regulares; y Los solicitantes a partir del tercer ciclo escolar los cuales deberán demostrar haber cursado y aprobado con un mínimo de 6.0 la totalidad de las materias (asignaturas, módulos o créditos) que correspondan al plan de estudios del ciclo escolar previo a la solicitud de beca y haber alcanzado un promedio mínimo de calificaciones de 8.0 o su equivalente utilizando una escala de 0 a 10 " (Ibidem). Dada la posibilidad del exceso de demanda, pertenecer a una población indígena es el segundo criterio de discriminación positiva, sólo detrás de la precaria situación económica y delante de pertenencia al programa PROGRESA o mejor desempeño académico previo. La SEP, tiene la facultad de: "Aportar conforme a la disponibilidad presupuestal, los recursos que se acuerden con los gobiernos de las entidades federativas y con las Instituciones Públicas Federales de Educación Superior" (Ibidem). Como es evidente, las conductas y conceptualizaciones de apropiación de los fondos del PRONABES, son definidas por la Ley de Egresos de la Federación y puestas en operación por la SEP, en función de los criterios estatales. Todo ello conduce a los estudiantes indígenas a "dirigirse" a aquellos centros educativos que tienen estos fondos y conducirse en correspondencia con las reglas de operación, es decir el ejercicio el poder político, con enfoque importante hacia la población indígena.

${ }^{184}$ El proyecto de la Universidad Intercultural de Chihuahua, ya realizados todos los estudios de factibilidad y disposición de la SEP para firmar el convenio de colaboración con el 50\% de los fondos necesarios, fue abandonado por las autoridades estatales a principios de 2010 , quienes decidieron que lo que necesitaba su estado, en relación con la población indígena, era la instalación de una Universidad Tecnológica. El efecto en conductas y conceptualizaciones de apropiación de los bienes educativos es claro y como se ve, fue decidido de manera exógena por el gobierno de Chihuahua.
} 
en su caso, validar la creación de nuevas instituciones de educación superior públicas o privadas" (CGEIB, 2006a: 64-5). ${ }^{185}$

Ya realizados todos los estudios pertinentes (presentes y prospectivos), para que la Federación decida apoyar la creación y financiamiento de una institución de educación superior (IES), se requiere la aprobación de la COEPES, del Secretario de Educación Pública del Estado y el apoyo del gobierno del estado. Además del estudio de factibilidad se deberán presentar: los fundamentos macrorregionales que justifican la IES; el impacto dela IES en el ámbito microrregional; el estudio del mercado laboral, que justifique la unidad y los servicios que prestará; el estudio del mercado de servicios educativos en el área de influencia de la unidad; estudio socioeconómico y de expectativas de educación; y la posibilidad de integración de un cuerpo de profesores con perfil adecuado, en el entorno de la unidad (Ibid: 69-71). “...salvo justificadas excepciones, es deseable que las nuevas IES sean de pequeña escala (máximo tres mil estudiantes) y que el respectivo municipio pueda dotarlas para su creación con el terreno necesario (no menos de diez hectáreas)" (Ibid: 71). ${ }^{186}$ Desde el Estado (Federación y entidades federativas) se decide el impacto de la unidad, en función de la disponibilidad local. Las opciones para los egresados de la educación media superior son definidas por los mecanismos expuestos, y la vida social de la unidad y la comunidad huésped, quedará caracterizada por el tamaño definido de antemano. Finalmente, queda establecido que la ampliación de la cobertura “...se acordará, por iniciativa del gobierno estatal respectivo, mediante un convenio entre ambos gobiernos en el que se estipule la manera como cada uno participará en el proyecto" (Ibid: 72). ${ }^{187}$

Por último se presentan dos programas adicionales: el Programa Integral para el Fortalecimiento Institucional (PIFI); y el Programa para el Fortalecimiento del Profesorado (PROMEP), que apoyan mediante fondos federales, a través la SEP, el fortalecimiento de la IES, en términos de la propia institución, sus programas educativos y los cuerpos académicos correspondientes; o el fortalecimiento específico de la calidad de los profesores, al apoyarlos con recursos, para la realización de estudios

\footnotetext{
${ }^{185}$ El subrayado es mío.

${ }^{186}$ El subrayado es mío.

187 La cercanía de las UI a los núcleos comunitarios indígenas, tiene como es evidente dos consecuencias: la oportunidad antes inexistente, de acceder a la educación superior en la propia localidad o microrregión y la consecuencia del arraigo al sitio, en virtud de las características de los programas educativos. Así, la voluntad estatal definida constitucionalmente, se realiza de manera directa al conseguir que población sin educación superior, "se eduque" y "se quede" en el sitio de manera productiva. Las conductas y conceptualizaciones de la educación superior intercultural suponen que los indígenas descubran las opciones locales y regionales de trabajo, y las ventajas de no migrar a las ciudades.
} 
de posgrado, para el mejoramiento de sus condiciones de trabajo académico y alentando el ingreso de nuevos profesores y exbecarios (Ibid: 72-5). ${ }^{188}$

Hemos visto hasta aquí cómo se van sentando las bases del ejercicio de poder vía el intercambio, en atención a los tres ejes descritos para analizar los incisos a presentar. Hay toda una estructura a nivel del Estado y concretada al nivel gubernamental, de la cual las Universidades Interculturales no pueden sustraerse. Claro que la búsqueda del proyecto es, como mencioné, la adecuación de esas estructuras a los lineamientos mínimos del modelo intercultural y, desde luego, a las restricciones constitucionales. El punto es que el isomorfismo institucional es fuerte y las organizaciones, en este caso las UI, no pueden sustraerse del influjo que determina hasta dónde se puede avanzar en el modelo y hasta dónde no, independientemente de las resistencias políticas a nivel cotidiano. Por ende, se han expuesto varios factores que determinan el carácter exógeno de la instrumentación de la política intercultural, decidido por el Estado. En segundo lugar, se ha mostrado cómo los individuos involucrados en el proyecto, fundamentalmente los estudiantes, van siendo inducidos para la apropiación de los bienes gubernamentales, con conductas o conceptualizaciones definidas, que en el caso de las UI, estarán definidas por el modelo intercultural, pero que también lo estarán, por los moldes generales de atención estatal. Con ello se delinea la asimetría entre el Estado como poseedor, proveedor de recursos y servicios educativos, frente a los individuos que carecen de esos recursos o servicios y al mismo tiempo, la asimetría entre aquel que puede certificar lo aprendido y aquel que requiere dicha certificación. Por último se bosquejó, que para que una UI "ocurra", no basta el puro mandato constitucional: se deben de cumplir y acreditar varios pasos y requisitos, y debe también, darse la voluntad política entre la Federación y sus partes; sin esta concurrencia, no "aparecerá" la unidad y el fenómeno nuevamente escapa del control de los individuos, que jurídicamente, tienen derecho.

2.- De las características básicas de las IES, se pasa a los lineamientos generales de las UI, que de acuerdo con la CGEIB:

La misión de la Universidad Intercultural es promover la formación de profesionales comprometidos con el desarrollo económico, social y cultural, particularmente, de los pueblos indígenas del país; revalorar los saberes de los

\footnotetext{
${ }^{188}$ La que fue coordinadora de la CGEIB, Sylvia Schmelkes, asevera que hasta 2008, las UI, habían sido excluidas de participar tanto en el PIFI como en el PROMEP. (2008: 331).
} 
pueblos indígenas y propiciar un proceso de síntesis con los avances del conocimiento científico; fomentar la difusión de los valores propios de las comunidades , así como abrir espacios para promover la revitalización, desarrollo y consolidación de lenguas y culturas originarias para estimular una comunicación pertinente de las tareas universitarias con las comunidades del entorno (2006a: 145).

Como se ve de manera clara, los sujetos a impactar de manera positiva son los futuros profesionistas. Las conductas y conceptualizaciones de apropiación de los bienes gubernamentales, son aquellas que se busca "promover" durante el proceso de formación, mediante las tareas concretas que llevan a cabo en la institución educativa. Se estableció a lo largo del Capítulo 3, la naturaleza jurídica de las órdenes dictadas a la población, en torno al tema de las políticas que impactan las diferencias culturales. Y en el "Corolario", se definió que el ejercicio exitoso del poder político estaba atado a la coincidencia entre el supuesto inicial y la forma final en la apropiación. Hay que recordar, que el marco jurídico vigente, definía la asimetrización de diferencias culturales como ilegal y que respecto de los individuos indígenas, únicamente subsistían las asimetrías que el Estado mantiene con el resto de la población. Es evidente, que la CGEIB coincide con todo el espíritu multiculturalista, que resumí en los conceptos: “comprender", "respetar" y "conservar". También, que la misión de la UI, busca dispersar y consolidar, entre la población indígena, los derechos que les son inherentes de acuerdo al apartado "A" del artículo segundo de la Constitución.

Todo lo anterior, supone que si la UI logra los supuestos de su misión, con la formación de profesionales comprometidos, el Estado habrá ejercido de manera exitosa el poder político, pues en ausencia de tal institución, tales intenciones no ocurrirían localmente. Esto es más evidente si lo consideramos desde la situación hipotética inversa: que por el derecho y libre acceso a la educación que imparte el Estado, profesionistas egresen, sin modificar sus conductas o conceptualizaciones en los aspectos que son definitorios de la institución. En ese caso se respetaría su derecho constitucional, pero claramente se estaría fracasando en términos del proyecto político, y los egresados, quedarían englobados en aquellos que redefinimos como "gorrón"; individuos o actores políticos que se apropia de los recursos gubernamentales sin desarrollar ni las conductas ni las conceptualizaciones que supone su apropiación. Este marco introductorio busca mantener la tensión analítica a lo largo de la exposición de los ejes sustantivos de las UI, en su búsqueda por implementar los dictados constitucionales en materia indígena. 
Para el logro de su misión, las UI utilizan las tres funciones normales de cada universidad: docencia, investigación, extensión; y adicionalmente la vinculación con la comunidad, eje importantísimo del proyecto, que impacta las otras y que es la estructura institucional novedosa y transversal de las UI.

a) La docencia, como ya se había citado, busca ofrecer carreras innovadoras "...que ofrezcan servicios relevantes al desarrollo de los pueblos indígenas, así como nuevas perspectivas de atención a problemas emergentes" (CGEIB, 2006a: 147). La docencia permitirá formar alumnos de manera intercultural, es decir, que estén en posibilidad de incorporar los conocimientos científicos y tradicionales de las comunidades en una "síntesis", donde los conocimientos, como parte de culturas en situación de igualdad, dialoguen de manera equitativa. ${ }^{189}$ En cuanto al enfoque psicopedagógico que se busca seguir, el modelo propone la implementación a partir del "constructivismo sociocultural", el cual supone a “...la educación como un proceso en el que el conocimiento se construye colectivamente, y plantea que la enseñanza tiene una dimensión social que se apoya en el marco de las experiencias del contexto donde el individuo se desenvuelve" (CGEIB, 2006a: 155). De ahí que se rechace el papel del profesor como el "...poseedor del y transmisor del conocimiento, y el estudiante, el receptor pasivo" (Ibid: 156). Es evidente que, en este caso, la orden no recae en el alumno, sino en el personal académico de la institución, que deberá "descentrar" su papel tradicional en la educación, para llevarlo a una posición más horizontal frente a los alumnos, que de nueva cuenta, serán en su mayoría, receptores pasivos del modelo expositivo que elija el profesor.

En cuanto a los contenidos curriculares, el modelo supone un año de "Formación básica”, periodo de nivelación que repara todas las deficiencias arrastradas por el alumno a lo largo del sistema educativo rural (primarias bilingües, telesecundarias y bachilleratos), para integrarlo, ya nivelado, a los estudios universitarios efectivos. ${ }^{190}$

\footnotetext{
${ }^{189}$ Esta parte central, la construcción de una epistemología intercultural, es uno de los puntos más problemáticos y complicados, pues si bien, discursivamente se comenta mucho sobre el tema, en los salones de la UIEM, los resultados son muy diferentes; se expondrán en el capítulo siguiente.

${ }^{190}$ Esta opinión se expresa en Schmelkes (2008: 335). Al respecto, dos comentarios. El atraso educativo, que se busca subsanar, al dedicar un año para la nivelación, necesariamente, ocupa "un año" de los cuatro que comportan las carreras, dejando únicamente tres para la formación propiamente universitaria. Si bien en la CGEIB se opina que en todas las escuelas hay materias generales, el propósito mentado de "emparejar" ocupa, un año efectivo y no se consideró entonces extender las carreras a cinco años para graduar a los alumnos, de manera efectiva, verdaderamente emparejados; pero lo anterior, no es decisión de los alumnos, sino del Estado, que determina la composición curricular y la duración de manera exógena, ejerciendo el poder político. El segundo punto se refiere a que la carrera de "Salud Intercultural"
} 
Son cuatro ejes transversales en las carreras, para ajustarse a las expectativas del modelo. El primero es el eje Lengua, cultura y vinculación con la comunidad. Se busca aquí acercar al alumno al conocimiento y fortalecimiento de competencia comunicativa en lenguas indígenas, a la valoración y respeto de la cultura de las comunidades y pueblos indígenas, lo que claramente se logra al establecer mecanismos que compenetren el aula con la comunidad a través de la vinculación; ya sea elaborando diagnósticos y análisis de la situación local; ya mediante sistematización de los saberes productivos o tradicionales; ya al buscar soluciones a problemas prioritarios. De manera adicional se buscará que los resultados de todo lo anterior estén disponibles en las lenguas locales (CGEIB, 2006a: 180-1). El segundo es el eje Disciplinar, que son los aprendizajes específicos de cada carrera. El tercero es el eje Axiológico, que busca “...que la formación del estudiante esté centrada en los valores humanistas y sociales fundamentales del enfoque intercultural y no sólo del conocimiento..." (Ibid: 182). ${ }^{191}$ Aquí la propuesta no deja lugar a dudas: la institución promoverá los valores de la interculturalidad en todo el proceso de formación del alumno; la apropiación que del "bien" educación superior pueda hacer un individuo, estará "centrada" en la introyección del concepto "interculturalidad" como eje axiológico. Finalmente, el cuarto eje, el Metodológico, busca el desarrollo de competencias profesionales basadas en las “...prácticas sociales que se problematizan y se reconstruyen en el aula constituyendo esta experiencia una estrategia sustantiva del aprendizaje" (Ibid: 183). ${ }^{192}$

b) La investigación se considera un "motor vital" de las UI. Sus blancos principales serán: la lenguas indígenas y la cultura, con el propósito de alimentar proyectos de revitalización, desarrollo y fortalecimiento; problemáticas ambientales, económicas, sociales, de salud, que afecten a las comunidades con el propósito de implementar soluciones en este ámbito; la búsqueda de mecanismos para la articulación de los problemas y necesidades comunitarias con la docencia; finalmente, aquellos que surjan del proceso de vinculación con la comunidad y que reflejen el sentir más interno a nivel local (CGEIB, 2006: 149-50).

\footnotetext{
no aplica tal año inicial y desde el comienzo, los alumnos reciben formación específica de su carrera eliminando muchos de esos contenidos remediales e integrando algunos a las materias del currículo.

${ }^{191}$ El subrayado es mío.

${ }^{192}$ La descripción de las carreras concretas se expondrá al abordar la unidad educativa de San Felipe del Progreso, Estado de México.
} 
c) La extensión tiene por misión, realizar una amplia labor de preservación y difusión de la cultura y tradiciones locales y regionales, fundamentalmente las indígenas. Algunas de las líneas prioritarias son: la producción y difusión artística de las expresiones culturales de los pueblos originarios; la divulgación del conocimiento tradicional, científico y tecnológico; la producción de video, televisión y radio; entre otras. Promover la formación integral de los alumnos, colaborando con distintas instituciones y organismos locales y regionales, impulsando el intercambio académico con otras instituciones educativas. Todos estos aspectos podrán alcanzarse, mediante el aprovechamiento del servicio social, los cursos de educación continua, el intercambio con instituciones gubernamentales y no gubernamentales, la creación de centros de enseñanza de lenguas indígenas y extranjeras para fomentar su uso social, etc. (CGEIB, 2006: 151-2).

d) Ya se mencionó que uno de los temas centrales y novedosos de las UI es justamente la Vinculación con la comunidad. Todos los temas y estructuras universitarias tienen que orientarse a lograr espacios para que "desde dentro" y "desde fuera" exista una plena comunicación. Aspectos relevantes de este eje rector, refieren que dado que las prácticas culturales de la comunidad, están fuertemente vinculadas a las actividades sociopolíticas y productivas, hay una relación integral entre el ser y el hacer. En ese sentido, el modelo de las UI busca nutrirse y paralelamente, enriquecer sus prácticas socioproductivas y culturales (CGEIB, 2006: 152-3). La docencia, la investigación y la extensión, para ser plenamente interculturales, tienen por lo tanto, que estar orientadas en gran medida, por la realidad y las necesidades expresas y estructurales de las comunidades y pueblos indígenas.

3.- La creación efectiva de las UI sólo ocurre en el momento en el que el gobierno federal y el de un estado de la Federación signan un "Convenio de Coordinación" que establece los compromisos mínimos y obligatorios a los que se comprometen ambos signatarios. Dicho convenio establece un plazo máximo en el que habrá de publicarse el Decreto de Creación por parte del Ejecutivo estatal, fundando con ello la institución, e iniciando el proceso de su operación. 
El convenio establece varios puntos que merecen ser destacados: ${ }^{193}$

- Que las UI funcionarán como "Organismos descentralizados del Gobierno del Estado", con personalidad jurídica y patrimonio propios.

- Consignará la estructura orgánica, organizacional y de gobierno de la institución, en donde destacan órganos colegiados (Consejo directivo, Consejo social, Consejo de desarrollo institucional) y los unipersonales (Rector y Directores de división), así como las instancias de apoyo (Secretario académico, Abogado general, Director de planeación institucional y Director de administración y finanzas).

- Se establece que la Secretaría de Educación Pública Federal y el Gobierno del Estado signatario, aportarán a partes iguales el presupuesto anual para el funcionamiento de la UI.

- Que el Gobierno del estado gestionará que el municipio donde se asiente la unidad, aporte un terreno de mínimo diez hectáreas con todos los servicios urbanos a disposición.

- Que el modelo pedagógico será aprobado por la SEP, de acuerdo con las disposiciones de la CGEIB

- Que el consejo directivo estará conformado con diez integrantes con voz y voto: tres del Gobierno estatal; tres del Gobierno federal; un representante del Municipio; y tres representantes distinguidos de la región.

- Que el Rector será designado por el gobernador del Estado y los directores de división y área serán nombrados por el rector.

- Que habrá profesores de carrera y de asignatura, cuyo ingreso, promoción y permanencia será de acuerdo al reglamento correspondiente.

- Que el tabulador de salarios académicos se fijará en correspondencia con el establecido para la educación superior según la normatividad del estado.

- Que los requisitos para la obtención del título de grado se darán conforme a los planes y programas de estudio de cada carrera que apruebe el Consejo directivo, con la opinión favorable de la SEP, a través de la CGEIB, la cual apoyará en todo momento con asesoría académica, capacitación y definiendo los perfiles del

\footnotetext{
${ }^{193}$ Los puntos destacados son fundamentalmente aquellos enunciados en el "Convenio de Coordinación para la Creación, Operación y Apoyo Financiero de la Universidad Intercultural del Estado de México" (INFOMEX-SEP, 2011).
} 
personal académico $\mathrm{y}$, asimismo, determinará, junto con la UI los procedimientos de evaluación del servicio educativo.

- Finalmente, se describen los puntos que debe de cumplir el modelo de educación superior intercultural en el medio indígena -que coinciden con todo lo expuesto según el documento Universidad Intercultural. Modelo educativo (CGEIB, 2006a).

Postule al inicio de estos numerales que el isomorfismo institucional dispersa las formas en las que los órganos del Estado se relacionan entre sí, más allá del deseo de los actores concretos por encontrar formas que coincidan con sus deseos inmediatos. Así, aparecen claramente en los puntos del "Convenio" formas institucionalizadas que se encuentran de manera independiente al tema de la educación superior intercultural en el medio indígena. Quiero entonces destacar, el efecto que las formas regulares de funcionamiento del Estado, tienen sobre esta forma particular de educación, y por ende en los sujetos fundamentales de la acción gubernamental: los estudiantes.

De acuerdo la línea expositiva de todo el trabajo, se recordará, que existe una serie de determinaciones de carácter exógeno, que determinan la forma en la que los sujetos van a apropiarse del bien educativo. En los puntos firmados entre la Federación y los estados en particular aparece una serie de controles del proceso educativo que norman la vida universitaria. Sin embargo, me interesa destacar significativamente, aquellos novedosos, es decir, los que tipifican la especificidad de las UI.

En primer lugar, destaca que el carácter de organismo descentralizado del Gobierno del estado, define un conjunto de características operativas comunes a organismos de ese tipo. El modelo previo en el tema educativo, es el de las Universidades Tecnológicas, que teniendo el mismo carácter institucional, también imparten educación superior en las poblaciones del interior de los estados de la Federación. La búsqueda por implantar un modelo educativo novedoso, se confrontará con el modelo previo a nivel estatal, ya que las instancias estatales de educación superior que los van a coordinar, también coordinan a los "Tecnológicos". 194 Esta homologación institucional dificulta la concreción de la autonomía académica que requiere el modelo de las UI, pues la integración entre los cuatro ejes básicos del

\footnotetext{
${ }^{194}$ Es una referencia y queja común de los profesores y directivos que son "iguales" a los Tecnológicos, siendo que el modelo presiona más hacia la dimensión de una universidad autónoma. Mayores salarios y libertad académica, son los índices de queja frecuente entre el personal de la UIEM.
} 
modelo intercultural -docencia, investigación, extensión y vinculación- se ven dificultados en gran medida, por la falta de estabilidad laboral (bajos salarios y contratos anuales o semestrales), que presiona la rotación de personal, atenuando el impulso inicial por formar profesores con una mentalidad diferente, intercultural, y llevando a que el modelo se diluya en cierta medida, porque la formación de profesores para la educación intercultural, no recibe el mismo cuidado al inicio, respecto de las etapas posteriores del desarrollo universitario.

En segundo lugar, destaca la elección del sitio de la unidad por parte del Estado. Como se expuso, la Federación apoya a los estados en su decisión de ubicar, estratégicamente, una IES en donde decidan, siempre que esté sustentado con los estudios de factibilidad y aprobado en las COEPES. En consecuencia, el impacto de una UI se dará donde finalmente decida el gobierno del estado, dentro del margen que permiten la legislación y los planes nacionales y estatales en la materia, pues definida una región, la elección entre un municipio y otro, una localidad u otra, queda en manos del ejecutivo estatal; con ello determinará en gran medida las posibilidades reales de los muchachos de "apropiarse" del bien educativo, en función de la cercanía, que impacta en el costo y la movilidad necesaria para llegar a los planteles. ${ }^{195} \mathrm{Si}$ en el entorno existen dos o más etnias, las posibilidades de plantar la unidad de manera equidistante son remotas, lo que conlleva una decisión política y el impacto desigual en términos educativos.

El tercero es un punto central. El modelo pedagógico, las carreras y los planes de estudio, deben contar con la anuencia del Gobierno Federal y en específico, de la CGEIB, que impulsará la orientación conceptual en los términos que se han expuesto de manera extensa en este capítulo.

El "aire" local en el control de la unidad, también determina ciertas direcciones. El gobernador del estado designa al rector, determinando con el perfil interpretativo que se dará del modelo intercultural; además, en el consejo directivo de la universidad, las

\footnotetext{
${ }^{195}$ En el caso de la UI del Estado de México, por su particular historia, no había mucha opción de localización, pues la demanda de una unidad en San Felipe del Progreso era histórica, sin embargo había varias posibilidades en esa misma zona y al mismo tiempo, el pueblo otomí, presionaba por opciones más cercanas a su región, como Ixtlahuaca, Toluca o Temoaya. La ex coordinadora general de la CGEIB Sylvia Schmelkes proporciona una visión global: "El gobierno federal, pero sobre todo los gobiernos de los estados, entienden la creación de las UI como una forma de acallar las inconformidades entre la población indígena [...] Desgraciadamente, en algunos casos, esta 'funcionalidad política' de las UI, es llevada a expresiones que atentan también contra la calidad académica" (2008: 233).
} 
decisiones por votación privilegian lo local siete a tres frente a la Federación. ${ }^{196}$ Finalmente, el tabulador de salarios, según la normatividad del estado, como se mencionó arriba, tiene un nivel bajo frente al de las universidades autónomas, lo que determina las posibilidades de contratar el profesorado de "alto nivel" que plantea en el modelo. Esto producen un gran impacto, porque en el fond, se siguen reproduciendo algunas de las lacras del subsistema de educación indígena: la asignación diferencial de recursos y por ende el nivel diferencial entre ambos subsistemas. Según el convenio, no hay obligación, de ninguna de las dos partes, de homologar el salario de los profesores con los más altos estándares regionales sino, según la normatividad del estado, por homologación con las universidades tecnológicas con bajo salario e inestabilidad laboral. ${ }^{197}$

No creo necesario abundar más en el análisis de estos efectos exógenos que sobre la educación superior en el medio indígena el Estado, como ente máximo, imprime a este bien del que se apropia la población de destino. Únicamente quisiera reiterar, que no se olvida aquí el papel de los grupos sociales para ordenar al Estado, conducirse de tal o cual manera, mediante el activismo, la presión social o la violencia como último recurso. En virtud de la modificación constitucional, los órganos de gobierno, deberán ajustarse al mandato máximo de la nación, obedeciendo sus dictados, para disponer que los servicios que se proporcionan, permitan a los pueblos y comunidades indígenas, gozar de sus derechos ya inalienables. Pero dado el perfil real de la población indígena, deben, no sólo ajustarse a la nueva forma, sino también, llevarlos a conocer y ejercer en los hechos, los mandatos constitucionales. Es ahí donde, el Estadio ejerce el poder, delimitando y definiendo temas concretos, formas específicas, montos asignados, lugares designados, condiciones de apropiación y certificación de la relación de intercambio entre los indígenas y el Estado. Los

\footnotetext{
${ }^{196}$ En el caso de la UIEM, primero se nombró rector a un antropólogo social y a los cuatro años, a un geógrafo; el perfil y las opiniones en la universidad sobre ambas administraciones, son claramente distintas, además de sus diferentes inclinaciones de gestión. En cuanto a lo segundo, en una entrevista con uno de los principales impulsores de la universidad en el Estado de México y que perteneció al consejo directivo como representante de la región, refirió con tristeza, que la visión del gobierno del estado siempre se imponía, "pues siempre son mayoría". Esta posición, derivaba de que el personaje era de militancia panista y por tanto, opuesto al influjo general de aire priista que impera notablemente en el Estado de México.

${ }^{197}$ Una declaración sorprendente del primer rector de la UIEM, se refiere a la gran cantidad de currículos recibidos en la primera convocatoria y a su calidad académica, señal del interés que despertó el proyecto de las UI; en su gran mayoría, al conocer las condiciones laborales, declinó participar. Sylvia Schmelkes coincide para el caso de otras unidades: "A los docentes se les paga poco [...] al principio priva el entusiasmo por trabajar en un proyecto novedoso. Con el tiempo, sin embargo, las inquietudes por otras oportunidades y por el nivel de vida mejor, comienzan a pesar y los docentes exigen mejores condiciones de trabajo o terminan yéndose a buscar otros horizontes" (2008: 334).
} 
estudiantes se apropian del bien educativo, pero desarrollando las conductas y conceptualizaciones determinadas por el marco constitucional y también por el marco institucional y gubernamental, vía el ejercicio del poder político.

4.- Siguiendo el impulso definido en los tres numerales anteriores, a través los convenios de colaboración entre la Federación y sus diferentes estados, se han fundado hasta la fecha ocho universidades interculturales, en otras tantas regiones con población predominantemente indígenas. ${ }^{198}$ En cada una de ellas el proceso concreto se ha ajustado a la realidad étnica, social, cultural y política específica. ${ }^{199}$ Las fechas de los decretos de creación son los siguientes: Universidad Intercultural del Estado de México, 10 de diciembre de 2003; Universidad Veracruzana Intercultural, 26 de noviembre de 2004; Universidad Intercultural del Estado de Chiapas, 1 de diciembre de 2004; Universidad Intercultural del Estado de Puebla, 8 de marzo de 2006; Universidad Intercultural del Estado de Tabasco, 5 de abril de 2006; Universidad Intercultural Indígena de Michoacán, 11 de abril de 2006; Universidad Intercultural Maya de Quintana Roo, 30 de octubre de 2006; Universidad Intercultural del Estado de Guerrero, diciembre de $2006 .^{200}$

Existen cuatro nuevos proyectos en puerta de UI. ${ }^{201}$ Los primeros tres, corresponden a las unidades de Nayarit, Sinaloa y San Luis Potosí. En el caso de Nayarit, el decreto de creación es del 2010, pero la unidad empezara a funcionar en

\footnotetext{
${ }^{198}$ Hay que destacar aquí la fundación, el 5 de diciembre de 2001, con todo el impulso de la reforma al segundo constitucional, de la Universidad Autónoma Indígena de México. Sin embargo, en su base inicial, no está el subordinarse a todo el marco conceptual-institucional y regulatorio generado por el Poder Ejecutivo, a través la CGEIB, sino únicamente: “Artículo 3. Para el específico cumplimiento de sus fines, la Universidad tendrá como atribuciones: I.- Organizarse de acuerdo a las normas generales que establece la Constitución Política de los Estados Unidos Mexicanos, la Constitución Política del Estado de Sinaloa, el presente ordenamiento, así como las leyes y los reglamentos procedentes" (Ley Orgánica de la Universidad Autónoma Indígena de Sinaloa, 2001: 1). Tiene que notarse que el Estado tiene varias formas de ejercer el poder político, que no son únicas, aun cuando se inspiren en un único mandato constitucional. La decisión política particular de los actores concretos, modela el cumplimiento del mandato con una forma específica y, en este caso, se remacha la forma exógena que adquiere el ejercicio de poder político, pues si bien los sujetos de acción del Estado son los mismos, la forma que toma en concreto, no está en la potestad de los estudiantes, sino de los gobiernos que lo implementan. Adicionalmente, hay que destacar que el expediente "intercultural" se extiende por isomorfismo, al presentar en su portal de internet a la universidad, como subtítulo "Institución Intercultural del Estado de Sinaloa" y pertenecer a la Red de Universidades Interculturales (REDUI).

199 En Daniel Matto (2008) se encuentra una relación de experiencias del proceso inicial de las universidades interculturales del Estado de México, Chiapas y Veracruz.

${ }^{200}$ Las ocho unidades fundadas, casi alcanzan la meta inicial de la administración foxista, que inició con el “...compromiso para crear diez universidades interculturales en México durante este sexenio que termina en 2006. En este compromiso corresponde al CGEIB orientar algunas de las pautas básicas para la creación de este tipo de instituciones" (Schmelkes, 2004: 379).

${ }^{201} \mathrm{La}$ información relativa a las nuevas universidades, fue proporcionada por Fernando Salmerón, coordinador general de la CGEIB.
} 
2012. La de San Luis Potosí, es un caso interesante, pues resulta de la fusión de dos proyectos previos: la Universidad Comunitaria de San Luís Potosí y la Universidad Indígena de Matlapa. Caso semejante al de Sinaloa con la Universidad Indígena Autónoma de México (UIAM), que como se precisó, inició labores en 2001. Problemas de tipo administrativo rebasaron los aspectos novedosos y sólidos del proyecto; en ese contexto, es que se abre la posibilidad de incorporarse al modelo general, y firmar el convenio de colaboración, en los términos ya descritos. Estos últimos dos casos están en el periodo de transición, con altas posibilidades de culminarlo hacia 2012.

Estas atracciones reflejan el éxito del modelo de las UI, pues como aseveré anteriormente, existen diferentes formas de dar respuesta a la reforma constitucional de 2001 y las propuestas potosina y sinaloense son formas distintas de esa respuesta. Sin embargo, el empuje de la propuesta desde la CGEIB y la posibilidad de ampliar al doble la cobertura en el estado ejercieron presión por la extensión del modelo federal; en ese sentido, los estudiantes indígenas a nivel nacional, van siendo atraídos a las conductas y conceptualizaciones de la propuesta más exitosa, reforzando el ejercicio del poder político del Estado en este caso emanado desde la Federación y en detrimento de la visión de las entidades federativas. En ambos esfuerzos, los modelos son implantados de manera exógena sobre los estudiantes. ${ }^{202}$

El último caso, Oaxaca, destaca por ser la entidad con mayor diversidad indígena del país. Los problemas para el establecimiento del convenio de colaboración con la SEP y la elaboración del decreto de creación, son hasta la fecha dos. El primero es el de los recursos, pues como se ha mencionado, el estado de Oaxaca, tiene que aportar la mitad de los recursos necesarios para el funcionamiento, lo que, dado el nivel de pobreza en la entidad, genera una dificultas importante y ha frenado la asignación de los recursos. El otro tema, que ya se mencionó, se refiere a las dificultades de designar la sede de la Universidad, puesto que independientemente de que se puedan abrir varias unidades académicas o campus, la Subsecretaría de Educación Superior de la SEP, sólo

\footnotetext{
${ }^{202}$ Dado el foco analítico sobre los fenómenos de poder por intercambio, resalta aquí de manera clara, que en el caso de las unidades de San Luis Potosí y Sinaloa, el efecto que los recursos federales ocasionan en los proyectos en las entidades federativas está colgado de las conductas y conceptualizaciones de apropiación, que inciden directamente, sobre los órganos educativos y en un segundo momento, sobre la población estudiantil. Adicionalmente, al margen de la necesidad continua de recursos por parte de las entidades federativas, está la dispersión exitosa del modelo en términos institucionales, que presiona a la igualación isomórfica de la educación superior en el medio indígena; el crecimiento de la red de universidades interculturales, la "REDUI", es una muestra de dicho fenómeno. Tales presiones, monetarias e institucionales, refuerzan el poder político de la Federación y hacen el proyecto de educación intercultural emanado de la CGEIB, de clara tendencia hegemónica en los términos referidos de Laclau y Mouffe (2004) en el Capítulo III.
} 
acepta una UI por entidad federativa. Por ello, las negociaciones sobre el asentamiento de la unidad central, se dan entre la experiencia de la CGEIB sobre la localización e impacto de las unidades en las otras entidades, y las discusiones a nivel estatal, con sus criterios gubernamentales y las demandas de las fuerzas políticas y sociales involucradas. Más allá de estos detalles particulares, como precisé en el tratamiento del punto, Federación y entidad federativa, decidirán en última instancia la posición de la UI del estado de Oaxaca, definiendo con ello, efectos locales y regionales, y por ende, posibilidades e imposibilidades de apropiación del recurso educativo. Con ello, resulta irrelevante saber si a la larga, imperó el criterio federal o el estatal; en ambos casos, el Estado habrá ejercido el poder político en torno a la educación superior en el medio indígena, por su presencia o su ausencia.

\section{Intermedio teórico-filosófico: Interculturalidad y Antropología.}

En todo el mundo antropológico, pero particularmente en el caso mexicano, la relación entre estudios empíricos, teoría y aplicación constituye un complejo de fuerte imbricación. La historia de la antropología mexicana no puede comprenderse, si se deja al margen el importante papel que han tenido los antropólogos mexicanos en la conformación de las políticas de atención a los mismos sujetos que estudian; en tal sentido, la demarcación entre investigación y aplicación es altamente compleja. Este profundo contacto tiene consecuencias al nivel de un mundo que, formalmente, debería estar fuera de la investigación: el de las ideas políticas.

No resulta sensato pensar que algún investigador es capaz de eliminar por completo su posición política sobre los fenómenos sociales que estudia. Por otro lado, la presión teórica de la antropología fundada en el estudio "del otro", empuja a la disciplina, en México, al estudio del fenómeno indígena. En ese marco, el otro se constituye en un particular sujeto histórico: invadido, esclavizado, despojado, excluido, con bajos niveles de desarrollo, salud y educación, por señalar algunas características. Las políticas que el Estado emprendió sobre los indígenas fueron, hasta fines del siglo $\mathrm{XX}$, de naturaleza contradictoria, pues mientras en algunos puntos trataban de mitigar o eliminar las injusticias históricas, en otros puntos profundizaban las inequidades. La Antropología Mexicana, hija del siglo XX, actuó claramente de buena fe en el contexto 
de la ideología estatal posrevolucionaria -el "Indigenismo"-, pero incidiendo en políticas que generaban ambos efectos. ${ }^{203}$

El activismo político de los antropólogos mexicanos para "beneficiar" a los pueblos indígenas, tuvo muchas facetas y no todas son producto de su actividad cotidiana y orgánica, en el Estado mexicano. Sin embargo, aquellos que lo hicieron desde ahí tuvieron un impacto determinante en la instrumentación de las políticas gubernamentales. Esto produce una combinación problemática entre teoría y práctica, pasado y futuro, ciencia y política. Esto es así porque, a la luz de una determinada condición del mundo, las intervenciones "para mejor" imponen considerar cuáles vías son deseables, cuáles posibles y cuales factibles, para que la incidencia de recursos gubernamentales redunde, efectivamente, en una mejoría de las condiciones sociales de los pueblos indígenas. ${ }^{204}$ Este mundo se transformó substancialmente, con el surgimiento del EZLN. El cambio paradigmático de las relaciones entre gobierno, sociedad en general y pueblos indígenas fue mayúsculo, pero sobre todo incidió en un punto central: la asunción creciente en los dos primeros, que los indígenas son y deben ser agentes de su propio desarrollo. Esta transformación es clara e impacta a todos los sectores.

Aun así, las nuevas consideraciones antropológicas se confrontan con las políticas -como siempre-, con resultados que van desde los felices hasta los desastrosos. En esto tiene fundamental importancia el balance que cada insumo aporta a la instrumentación efectiva: qué tanto de evidencia y teoría antropológica, y qué tanto de compromiso, sensibilidad y realismo político. No es posible, ni aquí ni en ningún lado, establecer claramente el contenido de ese balance, porque la visión de lo que se debe hacer resulta altamente problemática, en función de los horizontes temporales del impacto considerado: corto, mediano o largo; y también de la escala de la intervención: pequeña, mediana o grande. ${ }^{205}$

\footnotetext{
203 Aguirre Beltrán reconoce que fue Manuel Gamio quien comenzó la “inyección” de la antropología al Estado mexicano, al fundar hacia los años veinte del siglo pasado, la Dirección de Antropología y Poblaciones Regionales, en la Secretaría de Agricultura (1992: 120).

${ }^{204}$ En estas reflexiones es imprescindible aclarar, que yo mismo he participado en el campo y considerado las interrogantes, al haber laborado durante tres años en el área de políticas lingüísticas del Instituto Nacional de Lenguas Indígenas (INALI). Así, mucho de lo que se está exponiendo es resultado de mis reflexiones, pero también, de lo que observé en los discursos y en los hechos, del gran número de colegas que confluyen en la instrumentación de políticas hacia los indígenas. Dada la presión hacia la comentada y demandada "transversalidad", el contacto supone a funcionarios-antropólogos de distintos órdenes y dependencias de gobierno.

${ }^{205}$ Giovanni Sartori en "V. La acción inteligentemente llevada" (2002: 131-187), establece criterios de gran seriedad al delinear las complejidades del fenómeno en términos de la intervención, pues si la acción
} 
Es indudable que este mundo es difícil y, en consecuencia, no hay "recetas" para intervenir. Pero, ¿cuál es el sentido de estas reflexiones iniciales y qué tienen que ver con lo anunciado: la relación entre interculturalidad y antropología? Centralmente están conectadas, porque la interculturalidad es un concepto que refiere un estado deseable del mundo, dada la existencia de culturas en un solo entorno y dado el contacto asimétrico entre dichas culturas. Así, el deseo, la búsqueda y la intervención para que tales relaciones se modifiquen a un estatus más igualitario y simétrico, involucra desde luego al mundo político, pero involucra particularmente a la Antropología, como la ciencia específica del estudio de las culturas. En esos términos, el establecimiento de qué cosas de las culturas son diferentes y cómo se construyen asimetrías a partir de estas diferencias, es un quehacer eminentemente antropológico.

Quise subrayar esta aseveración porque me va a permitir esclarecer la relación que guarda este trabajo con el creciente interés que despierta la interculturalidad y en especial, la educación intercultural. Como expresé, la relación entre culturas es uno de los motores del pensamiento antropológico y en México, no hay caso más dominante que el desarrollado por el proyecto de Estado-Nación posterior a la colonia española, con el de las culturas originarias atrapadas en su interior. No es necesario describir las diferencias entre proyectos y las asimetrías que se tejen; son de sobra conocidas y paralelamente, se han delineado en el cuerpo de este texto. Así, no es de extrañar que los antropólogos aborden en un número considerable, el estudio de la interculturalidad. Sin embargo, a nivel general, el tema presenta el conflicto perfilado arriba, dado que no sipone únicamente la descripción y explicación de las diferencias y asimetrías culturales, sino que implica un componente importante de prescripciones sobre las posibilidades de equilibrar ambos mundos, es decir, que las diferencias culturales, no deriven en la constricción de asimetrías y de ahí, en relaciones de poder.

No diría, quiero ser muy enfático, que este componente prescriptivo, el político, implique necesariamente una "contaminación” del carácter científico que la Antropología debe tener. Como ya referí, resulta inútil la búsqueda de una ciencia "neutra". Aun en el remoto caso de que se lograse, es imposible eliminar los efectos políticos que tendría dicho resultado. En ese sentido, para la dimensión pública de la

política busca efectos de corto plazo, la escala debe ser pequeña, siendo fácil evaluar sus efectos. En cambio, si la escala es grande, el efecto no puede medirse en el corto plazo y por lo tanto, si la intervención es equivocada, los efectos sólo podrán determinarse cuando ya están en marcha y son en cierta medida, imparables. Este comportamiento, debe ser tenido en cuenta al implementar políticas de cualquier tipo. 
ciencia, resulta irrelevante la neutralidad política que pudiera existir en la cabeza del investigador. El conocimiento tiene lecturas y efectos políticos, y en las ciencias sociales, los efectos son más dramáticos. Por ello resultaría cándido un investigador que, buscando la neutralidad, ignorara los efectos políticos del conocimiento producido, al margen de su simiente pretendidamente a-política.

Estas ideas vienen a colación porque mi interés en el estudio de la educación intercultural a nivel superior y en el medio indígena, no se genera desde el interior de ese campo sino, como es más que evidente, desde la comprensión amplia, antropológica, de los fenómenos de poder y en particular en los mecanismos que exponen el funcionamiento del poder político que el Estado ejerce en una sociedad. De ahí que: "el establecimiento de qué cosas de las culturas son diferentes y cómo se construyen asimetrías a partir de estas diferencias" que mencioné arriba, sea un eje común con todos aquellos que trabajan el tema de la interculturalidad y en particular la educación intercultural. Sin embargo, el destino es diferente, ya que mientras desde el campo de la educación intercultural lo relevante es comprender la educación en el contexto de la diversidad cultural y apuntar hacia relaciones equilibradas y equitativas entre las culturas, en mi caso se trata de comprender que dado el mandato constitucional de implementar una educación intercultural en el medio indígena, el poder político estatal funciona o no funciona en alcanzar dicho objetivo. Es decir, el primero es un tema de Antropología de la Educación; el segundo, de Antropología Política

Toda esta aclaración es pertinente, en virtud de que el corpus sobre educación intercultural es basto y en continuo crecimiento. ${ }^{206}$ Así, parecería que se tocan aspectos del tema, sin haber profundizado lo suficiente en el material ya existente. No obstante, es evidente que el blanco expuesto apunta al nexo entre antropología, diferencias y relaciones de poder político; de ahí que el tema de la interculturalidad en la educación, es marginal en términos generales. A diferencia de otras disciplinas que pueden interesarse sobre el tema, los problemas de las relaciones entre las culturas, definen las preocupaciones antropológicas: el abordaje desde su perspectiva debe resultar notablemente diferente.

Los importantes trabajos de Gunther Dietz sobre el tema son una muestra de la distancia entre las visiones educativas, pedagógicas o de otro tipo, y la que puede tener

\footnotetext{
${ }^{206}$ Una pequeña muestra del tema se encuentra en: Deance y Vázquez (2012) Dietz (2003), Dietz y Mateos (2011), Alteridades (2008), Juliano (1993), Klesing-Rempel (1996), Jiménez Naranjo (2011), Gonzales Apodaca (2008), Bartolomé (2006; 2008), Bertely (2009) y Mato (2009).
} 
la Antropología. Aclara el papel que ésta debe tener en el estudio del fenómeno: "La interculturalidad y su sustento ideológico, el multiculturalismo, requieren de un análisis de los discursos y las 'políticas de identidad' que interculturalizan, a la vez que intraculturalizan, las prácticas de los miembros de cada uno de los grupos que componen la sociedad contemporánea" (Dietz, 2003: 79). Reconoce el autor que no obstante nuestra disciplina ha perdido - para bien-, el monopolio de los estudios sobre la cultura, aún conserva la voz cantante en un tema que es central: el de la etnografía.

Si bien es cierto que la idea de investigación in situ de los fenómenos sociales, y sobre todo de sus productores, los hombres, es una práctica ya común a todas las ciencias sociales, el germen inicial del expediente, pertenece a la Antropología. La idea de etnografía ha invadido la pedagogía y, sin embargo, las complejidades teóricas de esta práctica a veces no aparecen y queda únicamente el fenómeno de la presencia de aquel que busca contrastar sus ideas con la realidad. La Antropología por el contrario, ha pasado por varias fases en la construcción de su método por excelencia. Dietz expone, a manera de preámbulo, las distintas fases y enfoques que sobre el trabajo etnográfico se han instrumentado hasta el presente, para después, postular el "cómo" en relación con las investigaciones sobre educación intercultural (2003: 129-47).

Ello le permite plantear la necesidad de una aproximación hibrida, entre la etnografía posmoderna y la antropología de la liberación, esto es, una etnografía doblemente reflexiva, que incorpore el proceso de reflexión del autor-antropólogo, al mismo tiempo que genera en los sujetos del medio donde se trabaja una capacidad de pensar su problemática y construir conceptos de "primer orden", es decir, aquellos que surgen de los mismos sujetos sociales (ibid: 140-3). Esta posición teórico-metodológica, aplicada al campo de las relaciones interculturales educativas, lo lleva postular la posibilidad de una “...antropología de la interculturalidad - un modelo antropológico que se basa en los ya clásicos conceptos de cultura y etnicidad para analizar los fenómenos contemporáneos de interculturalización educativa $[\ldots y$ que desde su punto de vista] la principal aportación que la Antropología puede y debe ofrecer al debate contemporáneo sobre multiculturalismo e interculturalidad reside en su potencial etnográfico" (ibid: 183-4).

Es muy difícil no estar de acuerdo con el autor, tomando en cuenta el impecable trabajo de documentación y extenso conocimiento del campo de la interculturalidad educativa; coincido con él en términos generales. Sin embargo, hay un eje en el cual debo manifestar, no extrañeza, sino distancia. La separación deriva, no de una postura 
distinta sobre lo expuesto, sino de una procedencia distinta al mismo sitio de estudio. La obra de Dietz, delinea una aproximación antropológica al estudio de los fenómenos educativos interculturales, inclusive, de los efectos de las políticas educativas interculturales. Para nuestro caso, se llega a las relaciones interculturales, no partiendo de preocupaciones educativas, sino políticas. El empeño en hacer esta precisión, surge de la necesidad de establecer de manera contundente, la potencia heurística que la antropología política tiene para acercarse a la educación intercultural, sin involucrarse en los planteamientos de una antropología de la interculturalidad o del establecimiento de unas bases especiales para una etnografía de la educación intercultural. El solo planteamiento de la naturaleza del poder: clasificaciones-diferencias-asimetríasejercicio de poder, desde la teoría antropológica y con herramientas etnográficas estándar, permite abordar el fenómeno de la educación intercultural en su dimensión de política gubernamental, sin la necesidad de construir una "antropología” específica. ${ }^{207}$

El mismo autor reconoce que el puro campo educativo no es suficiente para delinear el objeto de estudio:

Para evitar la habitual instrumentalización de la etnografía como una técnica puntual y anecdóticamente empleada para cierto tipo de 'evaluación escolar', el análisis deberá trascender por tanto el contexto estrictamente escolar e incluir la dimensión política y meta-pedagógica desde la cual se detecta, formula e institucionaliza el 'problema' educativo. El estudio etnográfico de la llamada educación intercultural ha de partir no de la escuela o del aula en concreto, sino del Estado-nación que genera y articula estas instituciones educativas (Dietz, 2003: $147)^{208}$

La investigación concreta en la Universidad Intercultural del Estado de México (en los salones, con los estudiantes, los maestros y el personal directivo), partió efectivamente, desde las preocupaciones sobre cómo el Estado genera, articula, implanta, fondea y certifica la educación intercultural en una región indígena específica. Amén de parecer reiterativo, eso no es otra cosa que el ejercicio del poder político. Ahora bien, ello no supone que toda investigación sobre políticas públicas -entre ellas la educación superior intercultural- tenga necesariamente que iniciar con el Estado. Me

\footnotetext{
${ }^{207}$ En el Anexo 2 se presenta el marco metodológico de esta investigación. Ahí será evidente, que para la comprensión de la educación superior intercultural en el medio indígena que instrumenta el Estado Mexicano, no es necesario un marco intercultural específico; el desarrollo práctico del modelo en la investigación de diferencias, asimetrías y poder, es adecuado para abordar los problemas de las relaciones de poder en sociedades que se relacionan asimétricamente, como consecuencia de sus diferencias culturales.

${ }^{208}$ El subrayado es mío.
} 
parece que el planteamiento de Dietz, que va de la educación al Estado, es muy sólido. Lo que busqué argumentar, es que cuando se "viene" desde el Estado, no es forzosamente necesario generar una "antropología" o una "etnografía" del campo al que se va. La inquietud mayor de mi trabajo es avanzar por la senda de la construcción de una teoría de alcance medio sobre las relaciones de poder. El poder político estatal es claramente el "objeto" más constante de este esfuerzo, pero no es el único. La solidez de los trabajos sobre un área específica, en este caso los de Dietz (2003) y Dietz y Mateos (2011), me permitió exponer - con su apoyo- que los estudios sobre Antropología Política, siguen teniendo gran vigor, a pesar de las especializaciones temáticas a las que todos tendemos en mayor o menos mediada.

Un punto adicional es su referencia a que la forma tradicional en la que la Antropología estudiaba lo estatal y lo político, tenía un sesgo estático y estatista. De ahí que haga referencia a un campo nuevo que se está conformando: la "Antropología de las políticas", en la cual lo importante no es sólo el ángulo exógeno y dominante del Estado, sino la vitalidad local para impulsar e instrumentar políticas (Dietz, 2003: 148). ${ }^{209}$

En este último aspecto, claramente aquí se culmina con un estudio sobre sobre políticas educativas, lo que deriva en cierta convergencia con ese tipo de aproximaciones; de hecho, un resultado secundario de los intentos y los resultados de este trabajo, es generar mecanismos para evaluar el impacto que cualquier tipo de política tiene en la población, pero no necesariamente el "impacto" deseable desde el planteamiento de la política en específico, sino desde los mecanismos concretos que supone el ejercicio del poder político, es decir, únicamente aquellos que, en el cuerpo general de la política, tienen una naturaleza exógena.

Las políticas sociales en la actualidad buscan no sólo lo que el Estado "desea", sino desarrollar agencia y ciudadanía en las poblaciones con bajos niveles de desarrollo y que sufren, socialmente, un trato inequitativo o injusto. Pero una componente importante de dichas políticas no se construye desde el agente, sino desde el Estado. En ese sentido, Alejandro Agudo pone en evidencia cómo construyen los funcionarios su visión de "lo que es" y de "lo que debe ser", derivado de su experiencia como antropólogo en la evaluación de políticas sociales, puesto que los funcionarios de

\footnotetext{
${ }^{209}$ Trabajos antropológicos en torno de este tema se pueden encontrar en: Shore y Wright (1997); Sharma y Gupta (2007); y Nugent y Vincent (2004). En el caso mexicano se puede revisar: Oemichen (1999); González de la Rocha (2006) y Agudo (2009).
} 
gobierno prefieren que los resultado se les presenten más en forma de diagnóstico que en términos descriptivos (Agudo, 2009: 77). De esto, refiere un argumento de Anthorpe que bien puede ajustarse a las políticas de educación superior intercultural y que demuestran la dimensión desde donde se busca ejercer el poder político: “...el lenguaje de las políticas sociales no es descriptivo, sino prescriptivo: aquellas no necesitan informes que hablen de algo 'como realmente es' sino evaluaciones que digan claramente 'que es lo que se necesita'" (Ibidem). ${ }^{210}$ Partes substanciales de lo que se necesita, tienen un componente exógeno, ya que surgen desde las políticas gubernamentales, caracterizando con ello el ejercicio del poder político.

Con las ideas anteriores culmina esta sección. El estudio del ejercicio del poder político define objetos de estudio claramente discernibles y se han ido presentando a lo largo de este trabajo. En éstos, el tema político queda definido de manera evidente por el concepto de "Interculturalidad" y por el sujeto de acción: los indígenas. Su instrumentación en el campo de la educación superior en regiones predominantemente indígenas, ha sido el hilo conductor de los últimos dos capítulos. Sin embargo, no ha sido mi preocupación central un estudio a profundidad de la interculturalidad, porque el blanco final no es precisar qué se entiende por interculturalidad en educación, sino qué cosas llevan las políticas en educación intercultural que son significativas para los gobiernos y que tienen una naturaleza exógena, esto es: la "toma" de los bienes gubernamentales por la población estudiantil, que deriva en las consabidas conductas y conceptualizaciones de apropiación. El impacto que se genera en términos de lo descrito en el artículo dos de la Constitución es pues la forma final del ejercicio del poder político que el Estado Mexicano tiene que producir. Sin embargo, en la Constitución, sólo aparecen líneas generales sobre los derechos de las poblaciones indígenas y obligaciones de los tres órdenes de gobierno. No tienen forma concreta y, por lo tanto, no se garantiza de ahí que las políticas que sigan determinada línea particular culminarán en el cumplimiento de las expectativas constitucionales, caracterizando con ello, las paradojas del ejercicio del poder.

Una cosa es el deseo de un determinado orden social; otra cosa es la forma que tiene la orden para lograrlo; otra, son los medios empleados a tal fin; una más es el efecto concreto logrado y, finalmente; el hecho central es si ese ejercicio de poder conseguido, deriva en los fines generales que motivaron la acción. En todas estas fases,

${ }^{210}$ El subrayado es mío. 
el estudio antropológico del poder político debe estar, lo más posible, cerca de lo que ocurre y lejos de lo que debería ocurrir. Aclarado lo primero, puede darse por finalizada la fase descriptiva y emprenderse, la fase prescriptiva, ya por el autor, ya por los interesados en el tema. En el siguiente capítulo, se emprenderá el análisis concreto de los resultados del orden constitucional en la implantación de la Universidad Intercultural en el Estado de México, siempre estando más cerca de la primera perspectiva que de la segunda.

\section{Corolario}

El importante peso que se concedió en este capítulo al aspecto normativo de las políticas de educación superior e intercultural en el medio indígena no comporta ninguna contradicción con lo declarado en la última sección. Las bases y expectativas normativas que fundamentan el accionar del Estado, presentadas -explícita e implícitamente- en la Constitución y las leyes reglamentarias emanadas de la reforma al artículo segundo, son un insumo fundamental, para comprender el ejercicio del poder político, justo en su obligación de obedecer las fuerzas sociales, materializadas a través del Congreso de la Unión; son pues, las órdenes de la Sociedad al Estado.

Como quedó expuesto en el Capítulo 3, existe una correlación importante entre las presiones y expresiones de orden nacional y las de dimensiones internacionales. Esto llevó a poner en evidencia los mecanismos de gran espectro, que determinan lo que los Estados signatarios de los convenios internacionales se obligan a cumplir, y también, lo que van a hacer cumplir a sus poblaciones nacionales.

El salto de la visión integradora global (Convenio 107) al del respeto a la especificidad cultural (Convenio 169), comportó un cambio de tareas del Estado y de su concepción de los indígenas: de entes pasivos a agentes de su propio destino. Dicho cambió tiene su correlato nacional; ése es el punto central que se buscó evidenciar en la primera y segunda secciones de este capítulo. Mostrar primero de manera general, y despues específicamente, cuáles son las herramientas legales y de política pública que se generaron como consecuencia del cambio de gobierno y de régimen político, y que van a dar soporte y sentido a las universidades interculturales.

Ya en la tercera sección se expuso la estructura institucional y política, que decidió hacer de las universidades interculturales la herramienta básica de la educación superior en las regiones indígenas. Desde ahí, se comenzaron a presentar aspectos sobre cómo la Secretaría de Educación Pública y la Coordinación General de Educación 
Intercultural Bilingüe conducen, desde fuera de las comunidades, aspectos sustantivos del diseño y operación de las UI. Se destacó también, el papel que podían tener los estados de la Federación y los órganos propios de la universidad: el rector, los consejos y los docentes.

Toda la armazón institucional de las UI, oscila entre la búsqueda de un nuevo modelo operativo y las constricciones que impone el marco administrativo gubernamental; muchas de ellas son intencionales, pero otras son de naturaleza eminentemente isomórfica, lo que remacha la supremacía del funcionamiento estatal sobre las deseables pero en ocasiones imposibles, fórmulas novedosas de funcionamiento. Es evidente que para los gobiernos, el cumplimiento del artículo segundo constitucional no sólo depende de la buena disposición personal de los funcionarios, sino de su naturaleza operativa real, que está más allá de temas de justicia o derechos de algún grupo en particular, sino de los proceso intrínsecos a la forma "Estado contemporáneo", que se refirió en el Capítulo 2.

En todo caso, y concediendo mérito al gran esfuerzo gubernamental por cumplir el dictado constitucional, en el análisis de los puntos centrales del modelo, se expusieron todos aquellos índices donde la conducción de la actuación y la conceptualización en educación superior en el medio indígena no depende de los individuos-estudiantes, sino del diseño exterior, exógeno, que proviene del Estado. En ese sentido, se resaltaron de manera particular las situaciones en las que los bienes gubernamentales disponibles en el sitio elegido solamente pueden ser disfrutados a plenitud al comportarse o "educarse" como está dispuesto en la forma definida para tomar del bien; esto es, la órden implícita en la apropiación.

Finalmente, me pareció fundamental aclarar la tangencialidad del tema de la educación intercultural en el nivel del análisis y la distancia que considero pertinente entre lo deseable de una política y la forma concreta que toma en el terreno. Esto deriva de dos aspectos desarrollados en la última sección. Mi esfuerzo central es definir, depurar, remodelar o desechar las diferentes piezas que constituyen el intento de construir un modelo que explique los fenómenos de poder político desde una posición antropológica. Ese esfuerzo, debe resultar un tanto independiente de lo que personalmente creyera que debiera ocurrir. En el estudio de los fenómenos de poder, esto es básico, pues si por un lado, ontológicamente se define al poder como un efecto exógeno, resulta técnicamente inadecuado, cuestionar en primer instancia su ocurrencia precisamente con base en esa característica. Pero más importante aún, el estudio del 
poder debe darse fundamentalmente en la explicación de porqué ocurre tal y como sucedió; ello es, si no antitético, por lo menos privilegiado respecto del momento de criticar sus efectos. En ese sentido, la comprensión del ejercicio del poder político desarrollada aquí está centrada en la eficacia del ejercicio, dejando siempre para un segundo momento, la evaluación de los efectos de tal ejercicio eficaz.

Desde luego, si se quiere ser equilibrado, se deben considerar los intentos fallidos por conducir la acción social. Esta disonancia entre lo supuesto como orden y lo que realmente ocurre, se definió en otro lado como "desgaste" del poder. ${ }^{211}$ Para el análisis de los fenómenos de poder por intercambio, el desgaste resulta, de la no ocurrencia de las conductas o conceptualizaciones de apropiación de los bienes gubernamentales en la educación intercultural, ya sea por la presencia de "gorrones" conscientes o también por por fallas en el diseño de la política, que determinarían que dada la apropiación, los estudiantes verdaderamente estarían incapacitados para obedecer la orden o peor aún, incapacitados para siquiera apropiarse del bien.

Este panorama, bosquejado someramente, es el preámbulo adecuado para abordar el último capítulo. La Universidad Intercultural del Estado de México (UIEM), es el sujeto del esfuerzo estatal para dar educación superior con pertinencia cultural y alineada con los demás aspectos del artículo segundo constitucional. Dado que el esfuerzo sustancial era la construcción del modelo teórico y su confrontación, partiendo desde el ámbito normativo y el administrativo general, la aplicación al caso concreto, consistirá en una serie de temas generales, pero que desde mi perspectiva son de la mayor importancia para evaluar si el Estado Mexicano, cumple eficazmente su parte relativa a la conducción de la acción y la conceptualización social. Claramente, se expondrá cómo y cuándo es que ocurre el ejercicio del poder político, cuáles son los actores que implementan la orden y quiénes la que la cumplen.

También se expondrá, cómo es que se ocurre la falla en el ejercicio del poder, lo que determina su desgaste y las posibles razones del fenómeno. Esta parte es importante y dramática, pues muestra -como podrá suponerse- que la implementación del modelo tiene algunas fallas por lo que las instancias de gobierno deberán revisar por qué no está "funcionando". Finalmente, y esta parte es la más compleja de abordar, se expondrán algunas situaciones en las cuales la ocurrencia del fenómeno es feliz en términos puntuales, es decir, los estudiantes se apropian de los recursos educativos y se

\footnotetext{
${ }^{211}$ En El poder y su desgaste. Un modelo para su estudio (Barquín, 2007) realicé un intento inicial para abordar estos problemas.
} 
comportan o concientizan, según está dispuesto en la orden, en el modelo o en última instancia, en la Constitución. Sin embargo, en una escala macroscópica o de largo aliento, parecen ir en contra de algunos principios orientadores del tema. El análisis de estos fenómenos es más complejo, pero sobre todo es antropológicamente lo más interesante porque deriva de los efectos que sobre las culturas indígenas busca tener el orden político. Pero las intervenciones en ese material tan inasible y vital, la Cultura, pueden tener efectos imprevistos o contrarios, que llevan a pensar si el camino elegido para la implementación o la implementación misma, debe modificarse o suspenderse. Con todas estas ideas en mente, se procede a la exposición del caso concreto. 


\section{5.- Los hechos en las políticas de educación intercultural}

La acción interventora del Estado, es decir el ejercicio de poder político, toma en el cuerpo de la Universidad Intercultural del Estado México características definidas. Todo este capítulo estará dedicado a exponer el fenómeno. Vale la pena aclarar que no representa una evaluación intensiva de la UIEM, sino de los mecanismos por los que la educación superior e intercultural, es instrumentada, de manera exógena, en una región predominantemente indígena.

\section{La creación de la Universidad Intercultural del Estado de México}

La derrota del Partido Revolucionario Institucional en las elecciones presidenciales del año 2000 por el candidato del Partido Acción Nacional (PAN) y la coyuntura política en las campañas previas, explican en gran medida por qué la primera universidad intercultural de México, se asentó en la cabecera del municipio de San Felipe del Progreso en el Estado de México.

Existía, en la historia reciente, una actividad política notable entre los distintos pueblos indígenas de la región. Con una población en el estado de 219,757 hablantes de lenguas originarias, ${ }^{212}$ de los cuales el $52 \%$ correspondía a población mazahua, el $47 \%$ a población otomí, el $3 \%$ a población nahua, el $0.6 \%$ a población matlatzinca y el $0.4 \%$ a población tlahuica, estos grupos se habían manifestado de manera contundente en el

\footnotetext{
${ }^{212}$ El número corresponde a individuos mayores de cinco años, según el XII Censo General de Población y Vivienda 2000 (Serrano et al. 2002); excluye a los hablantes migrantes de otros estados. La elección de este censo, se refiere a que eran los datos con los que se contaba para el tiempo en el que se planeó e instauró la universidad en San Felipe del Progreso.
} 
año de 1975, al elegir cada pueblo su Consejo Supremo para acudir al "Primer Congreso Nacional de Pueblos Indígena" y posteriormente, manifestarse en el ya mencionado "Pacto del Valle Matlatzinca" de 1977.

Este activismo, generó liderazgos locales y regionales que se mantuvieron en tensión durante los años 80 y 90 y culminaron en el año 2000 con la petición de la universidad al candidato Vicente Fox. Uno de esos liderazgos lo constituye el de Julio Garduño, maestro normalista, mestizo, originario de Temazcalcingo. Participó en el movimiento que logró la construcción de los Centros Ceremoniales otomí y mazahua. Abogó durante esos años, por la educación bilingüe y bicultural y por la instalación de una "Universidad Indígena" en la zona mazahua. Hacia los noventa conoce al Dr. José Dolores Garduño ${ }^{213}$ y le comenta de su experiencia educativa, respecto de distintas universidades que visitó, entre las que destacan Chapingo, Sinaloa, Nuevo México y Brasil. $^{214}$

El Dr. Garduño es oriundo del municipio de San Felipe. Mestizo de origen, desde muy joven tomó conciencia de los problemas de los mazahuas y siempre pensó que la educación era un insumo central para borrar el rezago y, al mismo tiempo, fortalecer y conservar la cultura indígena para frenar y borrar el desprecio y pérdida de su lengua y su cultura. Militante desde joven, participó en la gestión de una preparatoria en Atlacomulco. Ya en los años setenta, con un grupo de jóvenes, en reunión con Carlos Hank, gobernador del Estado de México, le solicitaron una "Universidad Indígena". Luego de una pausa para terminar sus estudios, regresó a la región y retomó su papel de gestor, logrando junto con otros la instalación del "Tecnológico de Estudios Superiores de San Felipe del Progreso". Sin embargo, no se logró el objetivo central. Se incorpora al PAN en 1996 y contiende en las elecciones del año 2000, como candidato a presidente municipal en San Felipe. Es en ese contexto, que aprovechando la gira electoral del candidato presidencial del PAN, junto con personajes importantes de la región, entre ellos varios intelectuales mazahuas, organizaron un acto donde decidieron presentarle la petición de la "Universidad Indígena". 215

El 16 de abril de 2000, a las afueras del Centro Ceremonial Mazahua, se realizó la ceremonia con el candidato presidencial del PAN. ${ }^{216}$ Entre los presentes estaban, el

\footnotetext{
213 No pariente.

${ }^{214}$ Según entrevista con la esposa de Julio Garduño, la Sra. Francisca.

215 Según entrevista con el propio Dr. Garduño.

${ }^{216}$ Es interesante que, aun habiendo realizado la petición con tiempo, les fue negada la realización del evento en el interior del centro ceremonial. Ello deriva de la pugna con los priistas del estado, pugna que
} 
poeta mazahua Fausto Guadarrama que elaboró el texto de la petición de la universidad; el maestro bilingüe Pedro Duran Segundo, quien fue seleccionado en un concurso de oratoria para leer la petición; y el Mtro. Antolín Celote Preciado, mazahua, antropólogo, líder de la región y a la postre, figura central en la UI (Celote, s/f: 2-5).

Según el Dr. Garduño, el candidato ya tenía algunas ideas sobre el tema, pero desconocía de la petición en concreto de la universidad, así que el evento fue la misma petición. El mitin se desarrolló con varios oradores, entre "vivas" y gritos de "Estamos por la universidad mazahua"; pero la petición central la hizo el orador designado ex profeso, primero en mazahua y luego en español:

Bienvenido hermano Vicente Fox a estas tierras indígenas. No tenemos que ofrecerte, solamente nuestra amistad y este bastón de mando, que por mi voz, le transmiten los pueblos mazahuas [...] Somos excluidos social, económica y culturalmente, no existe el respeto a la diferencia de los grupos étnicos de nuestro país, no respetan nuestro sistema de gobierno, nuestra creencia y valores; dicen que nuestra lengua no tiene esa categoría, sin embargo, nosotros hemos demostrado que es un sistema tan complejo como cualquier lengua, y que con ella construimos nuestra cosmovisión e imágenes poéticas de todos los días [...] Queremos vivir en este mundo globalizado, participar en condiciones iguales por la educación [...] ya hemos esperado más de quinientos años y no estamos dispuestos a seguir esperando.

Demandamos precio justo para nuestro maíz, mejores salarios para todos los trabajadores; solicitamos una universidad pública regional para que se eduquen nuestros hijos, y en ella se haga investigación y difusión de nuestra cultura... (Celote, s/f: 10).

Son evidentes del discurso, algunos temas: la característica mazahua del evento; la delegación-obligación del poder mazahua para solucionar las demandas que se le presentan; la constitución de los indígenas como diferentes del resto de la nación; la consecuente desvaloración de todos las partes de su sistema social, entre las que destaca en particular la lengua y la cultura; la consistente presencia del sujeto histórico con 500 años de resistencia y paciencia que se terminó; y desde luego, la necesidad de un centro universitario regional y público, que permita el conocimiento, la preservación y la difusión de la cultura mazahua.

Si bien no se puede sostener todo un argumento de una simple declaración, hay que destacar lo que ya se ha venido aseverando con otras fuentes: que es insostenible desestimar el papel de los agentes locales en la estructuración de las UI, pero que hay

va a perseguir y trabar la concreción de la UI. No obstante, quedarán evidencias institucionales de estas luchas y que afectan al presente, la gestión de la universidad. 
que valorarlo en su dimensión endógena-exógena, es decir, que el ejercicio del poder político ocurre acorde a la segunda característica, en resonancia con el dicho de que se ejerce el poder, siempre y cuando los agentes se comporten en una forma <<que de otro modo no harían >. En consecuencia, es evidente que el concepto de interculturalidad no está arraigado en los actores locales y por ello resulta claro, que la forma que las políticas educativas en las regiones indígenas iban a seguir, se ajustó a la dimensión "intercultural" que el Estado introdujo, vía el poder político. ${ }^{217}$

Según el Dr. Garduño, hecha la propuesta al candidato de una secretaría de asuntos indígenas, de una universidad indígena y que la primera fuera en San Felipe, Vicente Fox $<<\ldots$ en el calor del mitin anunció la creación de la oficina de asuntos indígenas y que se comprometía a crear la universidad indígena>>. Lo que siguió a este acto, que Celote (s/f, 1-11) definió como de gran entusiasmo y esperanza, fueron tres años de trabajo político, que culminó con la creación, por decreto, de la Universidad Intercultural del Estado de México, la primera del país.

La etapa del trabajo político fue muy intensa y comenzó luego de la victoria del candidato del PAN a la presidencia. Julio y agosto fueron los meses en los que el Dr. Garduño animó a todos los interesados en la universidad a integrar un patronato para no dejar en el vacío la oferta presidencial; era además fundamental, pues el Dr. Garduño había perdido frente al candidato del PRI la elección a la presidencia municipal, por lo que el esfuerzo debería transcurrir fuera de los canales gubernamentales; es decir, por vías ciudadanas. El primer asunto fue una entrevista personal que Garduño sostuvo con el candidato electo en Cocoyoc, Morelos. Ahí le recordó el compromiso educativo con los mazahuas: “...el presidente electo le comentó que lo apoyaría y que la universidad se construiría. Pero le recomienda que visite primero al gobernador del estado para sensibilizarlo y darle el anteproyecto. Entonces don Gregorio Montiel fue el enlace para concertar una cita con el gobernador Arturo Montiel [su hijo]" (Celote, s/f: 12). Así se

\footnotetext{
${ }^{217}$ No se olvida aquí, que las peticiones de una educación intercultural ya se encontraban entre los argumentos de San Andrés, sin embargo, siendo el evento en el año 2000, esos indígenas, no están pensando en una universidad intercultural, sino como he venido exponiendo, en una universidad indígena. Más aún, destaca que la petición de la universidad indígena, tampoco es producto de una gran demanda regional. $<<$ La solicitud de la universidad, no es un movimiento social, es un movimiento de ideólogos que tratan de buscar soluciones a la problemática >, declaró el Dr. Garduño en la entrevista, a pregunta sobre el empuje regional en la demanda de la universidad.

De todo lo anterior, es más que evidente que hecha la reforma constitucional, el Estado debió llevar a los individuos a comportarse en formas, que de otro modo no harían (insertarse en un modelo universitario intercultural), esto es, mediante el ejercicio del poder.
} 
hace y el gobernador instruye a su Secretario de Educación, Cultura y Bienestar Social para que siga la petición ciudadana.

A fines de septiembre de ese año se creó formalmente el patronato "Pro Universidad" con varios miembros, donde destacó el papel del padre del gobernador para conseguir comunicación directa cuando fuera necesario. ${ }^{218}$ Posterior a la toma de posesión y de la presentación ante el senado de la iniciativa de reforma constitucional en derechos y cultura indígena, el nuevo presidente decreta la creación de la Oficina de Asuntos Indígenas (que posteriormente derivará en la disolución del INI y la creación de la CDI en mayo de 2003), y la de la CGEIB en enero de 2001. Con estos dos órganos del gobierno, principalmente el segundo, es que se gestará la forma real que tomarían las universidades interculturales y en particular la del Estado de México.

Por indicaciones presidenciales directas, se le instruye al Secretario de Educación federal, de ocuparse de la petición del Patronato; éste a su vez, designa al Dr. Julio Rubio Oca Subsecretario de Educación Superior, como el encargado directo del tema de la UI en el Estado de México; entre él y Sylvia Schmelkes -como se mencionó en el capítulo anterior- buscarán los cauces teóricos y administrativos que culminarán en el modelo de educación superior intercultural en el medio indígena (Celote, s/f: 14).

En ese contexto, el Patronato fue invitando a todos los actores relevantes de la zona, sin distinción de partidos o grupos, para sumar las voluntades necesarias: líderes indígenas de la región, funcionarios públicos regionales, académicos destacados. Claramente, los representantes populares del Partido Revolucionario Institucional (presidente municipal de San Felipe, diputado local y diputado federal), evitaron sumarse; así, la interlocución estatal tuvo que ser directa, aprovechando las relaciones familiares descritas. ${ }^{219}$

Luego de varios meses de trabajo y espera, todas las instancias pudieron confluir en la organización del "Foro de Consulta a Expertos sobre Modalidad y pertinencia de Formación Profesional Intercultural", en la ciudad de Toluca el 19 de julio de 2002. Participaron profesionales, poetas, investigadores, profesores indígenas y no indígenas, rectores y directores de instituciones de educación superior, representantes de las distintas etnias y funcionarios del gobierno estatal y federal. Hubo también otro foro

\footnotetext{
218 Anecdóticamente, resalta el hecho que los Montiel siendo de Atlacomulco, conocían a la familia Garduño de muchos años, por lo que la pertenencia al grupo de individuos que hacían política desde Atlacomulco, fue superior a la diferencia partidaria.

${ }^{219}$ Según describió el Dr. Garduño en la entrevista.
} 
público que continuó los trabajos académicos, ahora en San Felipe del Progreso, del 24 al 26 de octubre del mismo año. Ahí se realizó el "Primer Ciclo de Conferencias de la Educación Intercultural: Retos y perspectivas", que buscaba afinar los detalles generales del modelo y los curriculos. A mediados del año 2003, los informes presentados por el equipo de Sylvia Schmelkes al Subsecretario de Educación Superior de la SEP, destacaban que era viable la institucionalización de centros de educación superior en el medio indígena y en particular que era viable la apertura de una UI en la zona de San Felipe del Progreso (Celote, s/ f: 14-7).

En el Estado de México, en concordancia con esto último, se generó el documento Universidad Intercultural del Estado de México (Gobierno del Estado de México, 2003), que define los lineamientos para la creación de organismos descentralizados de carácter estatal, y presenta también una evaluación del impacto y las necesidades educativas de la región. Incluye un comparativo de las propuestas de organización de las UI por la CGEIB y lo que correspondería a un órgano descentralizado a nivel estatal. También un estudio de factibilidad que delinea las poblaciones estudiantiles a incorporar, las posibilidades laborales, las distancias entre las posibles sedes de la UI y los números de estudiantes en los niveles medio superior y superior, exponiendo las unidades de educación superior y sus índices de absorción. Este documento de julio de 2003 es una muestra de que ya estaban afinados los últimos detalles, por lo que el 10 de diciembre de 2003, se firmó el "Convenio de Coordinación para la Creación, Operación y Apoyo Financiero de la Universidad Intercultural del Estado de México" y paralelamente, el Gobernador Arturo Montiel, firmó el decreto de creación que se publica en esa misma fecha en el periódico oficial del Gobierno Estado de México. Con esto concluyen los caminos oficiales que culminaron en la creación de la Universidad Intercultural del Estado de México (UIEM).

Pero, ¿cuáles fueron las disputas reales para dicha culminación? es decir, las arenas en donde se disputó el control efectivo de la UIEM y, más relevante aún, ¿cuáles fueron los efectos del resultado de esas luchas políticas, que modelaron la forma final en la que el Estado Mexicano dirige la educación superior e intercultural en el medio indígena?

Es claro que desde la perspectiva amplia de este trabajo, es irrelevante si en los "estira y afloja" de las disputas sobre el control de la UIEM, la Federación ganó, perdió o empató con el Poder Ejecutivo Estatal; en cualquier caso, se podrá analizar si el Estado en su conjunto (Federación más entidad federativa) ejerce el poder político vía el 
intercambio y cómo lo hace. No obstante, esa disputa y su resultado son relevantes, porque expondrán los efectos concretos que el diseño institucional tendrá sobre la forma final del modelo de educación intercultural y, desde luego, sobre cómo se apropian los estudiantes del "bien" educativo.

Lo primero que hay que destacar es que la labor que hizo el Patronato fue pagada en su totalidad con sus propios recursos; es claramente un esfuerzo ciudadano. Los gastos por las innumerables reuniones que sostuvieron, tanto en Toluca como en la Ciudad de México, no recibieron ningún tipo de ayuda por parte de los gobiernos estatal o federal. En contraposición, los funcionarios de gobierno realizan su trabajo con fondos del Estado. Destaca entonces que la dispersión del proyecto "Intercultural", contó con recursos para imponerse a nivel nacional, por sobre las pretensiones de carácter eminentemente local. ${ }^{220}$ Esta presencia del Estado para ir bosquejando el proyecto según su propia visión, contó pues, con el impulso de los recursos federales efectivos para implantar el proyecto. Como se anotó anteriormente, desde el Gobierno no se quería que las universidades fueran "Indígenas", así que su primera labor fue la de precisar que el proyecto federal estaba, de origen, marcado por esa característica. Queda sobrentendido que un proyecto de universidad, cuyo foco fuera puramente indígena, no contaría con el apoyo económico necesario para funcionar, ni para la construcción o certificación de las nuevas carreras a impartir.

No había, como referí, mucho entusiasmo entre los funcionarios públicos a nivel local o regional. Esta circunstancia se derivaba del origen del proyecto en un grupo panista local y también del probable cambio en la correlación de fuerzas con y al interior de los pueblos indígenas; de ahí la resistencia a cambiar el equilibrio existente. En varios de los miembros que participaron en el proceso de gestión inicial con el Gobierno del Estado de México, quedó la impresión de que tampoco había mucho

\footnotetext{
${ }^{220}$ En este aspecto, se recuerda que la información presentada en el Anexo 1, muestra los recursos que han sido presupuestados a la CGEIB del año 2002 al 2011. En el primer año se le asignaron recursos por 83.592,600.00 millones de pesos, que contrastan con los 38.908,265 millones de pesos del 2011, lo que representa apenas el $46 \%$ de los recursos iniciales. Las ocho primeras UI, surgidas durante el sexenio de su fundación, contrastan con las cuatro del segundo sexenio. Este contraste es ocasionado, en mi opinión, por la necesidad estructural de iniciar un movimiento de escala nacional desconocido. Por ende, los gastos de investigación, desarrollo, convocatoria, difusión y desplazamiento de todos los involucrados en el proyecto (funcionarios y ciudadanos) fueron muy importantes; adicionalmente, existía un impulso político "fuerte" y mucho entusiasmo por el nuevo fenómeno. En contraposición, la maduración del proyecto, la experiencia de los funcionarios y el conocimiento ya existente a nivel nacional, determinan un menor esfuerzo en los rubros mencionados y uno mayor, en el tema de la consolidación. Desde luego, esta visión es independiente de la reducción que se da, desde los presupuestos enviados por el Ejecutivo o que aprueba el Congreso, que ocurre al margen de las necesidades reales de la CGEIB. En todo caso, lo que sí es evidente, es que las posibilidades de la CGEIB para crear conductas y conceptualizaciones de apropiación, son menores que antes.
} 
interés en este nivel. ${ }^{221}$ Las razones son diversas. En primer lugar estaba la concepción de desarrollo existente en el estado, que confrontaba a la de la Federación, porque a nivel regional se consideraba que lo necesario era ampliar la educación tecnológica para animar el progreso en las regiones más atrasadas. Apoyar un proyecto cuya bandera temática era el rescate, fortalecimiento y promoción de las lenguas y cultura indígena era, desde esa perspectiva, ahondar el proceso de aislamiento y subdesarrollo que se buscaba romper, más allá del evidente sesgo mestizo de expansión del proyecto nacional monocultural. En segundo lugar, estaba la necesaria etiquetación de recursos, pues el proyecto implicaba la creación de un fondo mixto al 50\% con la Federación. En tercer lugar estaba la evaluación política que, más allá del eufemismo “intercultural", representaba la creación de un nicho de militancia indígena y por lo tanto, de conflicto político. ${ }^{222}$ Y finalmente, que dicha institución constituiría una isla de independencia y por ende, un modelo académico autonómico era francamente indeseable.

En ese entorno concreto es que se desarrollaron las negociaciones, con la circunstancia en la SEP y la CGEIB de cumplir el deseo presidencial por lograr la UI y que la primera fuera en San Felipe. Además, las trabas no derivaban únicamente de los puntos expuestos arriba o de las dificultades consubstanciales al proceso de negociación estatal-federal, sino de la creación de una institución nueva y, más aún, novedosa. En ese campo político, sin duda alguna la urgencia estaba del lado federal, presionado públicamente en el contexto del tema indígena a nivel nacional (marcha zapatista a la Ciudad de México; negociación y aprobación de la reforma al artículo segundo constitucional; rechazo de los interesados por la modificación de la propuesta de San Andrés; y no obstante, el necesario cumplimiento del nuevo mandato constitucional) y en el nivel interno, porque la recién creada CGEIB tenía que demostrar su eficacia, para acatar el mandato legal de ejercer el gran presupuesto y la responsabilidad política de hacerlo bien.

Las trabas a la UI tomaron varias formas, desde construir o ampliar el impacto de la educación tecnológica en la zona, hasta <<dar un gran número de becas a estudiantes indígenas para que accedieran y permanecieran en instituciones de

\footnotetext{
${ }^{221}$ Ya se puede mencionar, que la circunstancia real de las negociaciones, se construyó con las entrevistas y conversaciones realizadas en el trabajo cotidiano en la UIEM. Entre los entrevistados, se cuentan miembros del patronato, los dos rectores -el anterior y el actual-, varios de los profesores que se integraron a la universidad luego de los foros previos y algunos de los investigadores que también participaron.

${ }^{222}$ Un alto funcionario del gobierno estatal, le comentó a un informante al respecto: $<<$ Si de por sí ya son ladinos y tú les quieres poner una universidad>>
} 
educación superior tradicionales $>{ }^{223} \mathrm{El}$ asunto de las reticencias estatales y la prisa institucional, conformaron un escenario en el cual el gobierno federal terminó cediendo en varios de los puntos que resultaban sensibles para el Estado de México, con tal de que avanzara el proyecto. En estas condiciones es que se firmó el convenio de coordinación, acorde con el modelo educativo federal, pero atendiendo a las preocupaciones políticas del estado huésped. Los controles compuestos (Federación más entidad federativa) que el Estado ejerce sobre el proceso educativo intercultural están expresados en el convenio y fueron expuestos en el capítulo anterior.

Mostraré ahora la forma concreta que tienen las distorsiones al modelo original, emanadas desde el Estado de México y signadas como clausulas:

PRIMERA.- El presente convenio tiene por objeto establecer entre "LA SECRETARIA" y "EL GOBIERNO DEL ESTADO" las bases para la creación, operación y apoyo financiero de la Universidad Intercultural del Estado de México, en lo subsiguiente "LA UNIVERSIDAD", como Organismo Público Descentralizado de carácter estatal, que contribuya a consolidar los programas de desarrollo de la educación superior en la Entidad...

QUINTA.- "LA SECRETARÍA" y "EL GOBIERNO DEL ESTADO" se obligan a realizar un esfuerzo presupuestal para lograr una institución de alta calidad académica para lo cual convienen en aportar la primera el $80 \%$ (ochenta por ciento) y la segunda el $20 \%$ (veinte por ciento) del presupuesto de operación del primer año de "LA UNIVERSIDAD": en el caso del presupuesto de años subsecuentes se realizarán convenios específicos donde se establecerá el porcentaje de aportación.

Así mismo "LA SECRETARÍA" y "EL GOBIERNO DEL ESTADO" convienen que la estructura y tabuladores para las remuneraciones del personal se fijarán en función de los tabuladores establecidos para el ejercicio de las actividades docentes del nivel superior en la normatividad del estado (INFOMEX-SEP, 2001). ${ }^{24}$

La designación de la universidad como un organismo descentralizado bajo la tutela del Ejecutivo Estatal es una de las trabas más efectivas a la libre operación académica de la universidad. Ello determina, en primer lugar, el nombramiento y remoción del rector por parte del gobernador y en segundo lugar, el control estatal de las finanzas y la administración. Esta cadena incluye la remoción por parte del gobierno del estado de cualquier trabajador, incluidos los académicos, pues los contratos son

\footnotetext{
${ }^{223}$ Dos informantes de la universidad, por separado, comentaron que el secretario de educación estatal declaró en una reunión que <<aunque dijera el gobernador, de él corría que no se abriera esa universidad $>>$.

${ }^{224}$ Todos los subrayados son míos. Hay que hacer notar que para el Convenio 2010 (que desde el primero se firman anualmente), la cláusula referente al financiamiento, únicamente describe el mismo porcentaje, eliminando la referencia a una posible o probable negociación de la distribución asimétrica (según copia facilitada por la Dirección de Administración y Finanzas de la UIEM).
} 
temporales (de seis meses a un año, lo que implica la constante presión por la no recontratación). ${ }^{225}$ El remache en el control estatal, se observa en función de la composición del consejo directivo, ventajosa para el Estado de México, que va anclada a la característica de organismo descentralizado estatal.

El siguiente aspecto es la desigual aportación de fondos entre el gobierno federal $\mathrm{y}$ estatal, que tuvo que aceptarse para destrabar las reticencias expuestas arriba. Al margen de que la Federación "perdió” y el Estado de México "ganó”, y que esta situación no se ha vuelto a repetir en ninguna otra UI, queda un daño al funcionamiento de la UIEM. El asunto de fondo es que cualquier ampliación estructural de la universidad (física o humana), implica un aporte mayor de la Federación. Si bien la Federación transfiere múltiples fondos a la UIEM, son esporádicos, lo que no comporta complicaciones presupuestarias como sí lo es, el designar una porción presupuestaria que fuera permanente año tras año ${ }^{226}$; caso parecido con aportaciones del gobierno del estado. El actual rector reconoce las dificultades que genera este esquema desigual, pues resulta muy complicado "mover" a la Federación, si las futuras ampliaciones deben ser aprobadas por ambas partes, pero pagadas casi en su totalidad por ésta. ${ }^{227}$

Finalmente, en el rubro de los salarios, toda la cadena está claramente insatisfecha. El salario promedio neto de los académicos, es en la actualidad de alrededor de 11,000 pesos mensuales para un profesor de tiempo completo. Como ya se había comentado, este nivel determina que la captación y retención de profesores sea en general de bajo nivel. No necesariamente todos los profesores están en esa condición; situaciones personales de toda índole definen la permanencia en la UIEM (alto compromiso con el proyecto, residencia en el sitio, perfil profesional idóneo, amistades, exilios). Lo que queda claro es que si un profesor detecta un sitio donde pueda satisfacer

\footnotetext{
${ }^{225}$ Existe la certeza, tanto en el rector actual (Francisco Monroy) como en el anterior (Felipe González), de que el modelo descentralizado, tal cual está, es un mal esquema para una institución educativa. Al primero le queda la impresión de que la CGEIB no supo negociar el esquema y por lo tanto eligió mal; el segundo, refiere que en términos políticos no es tan malo, pues blinda a la universidad de las presiones políticas de los grupos locales, pero en términos de salarios y estabilidad de los profesores de tiempo completo, es totalmente inadecuado y mina la potencia del proyecto a largo plazo. Independientemente de las opiniones encontradas sobre las ventajas o desventajas del modelo de organismo descentralizado estatal, el Dr. Garduño, que accedió al Congreso del Estado como diputado local por el distrito de San Felipe (2006-2009), presentó una iniciativa de ley para decretar un régimen autonómico para la UIEM. Sin embargo, y siguiendo el impulso de control férreo característico del Estado de México, la iniciativa nunca salió de comisiones para llegar a ser votada en el pleno; <<está en la congeladora〉>, comentó el ex diputado.

${ }^{226}$ En el Anexo 4 se muestran los rubros y los montos que la CDI ha asignado a la UIEM desde su creación hasta 2011.

${ }^{227}$ El Coordinador General de la CGEIB, en entrevista, asevera que a futuro esta situación es insostenible y debe cambiar; sin embargo, dificultades de toda índole impiden la re-escritura de un convenio tan difícil de lograr; entre ellas, las condicionantes internas del Estado de México expuestas arriba.
} 
sus expectativas, pero con un mejor salario, migrará, como es una constante detectada en la UIEM y la queja más amarga de los profesores. ${ }^{228}$ La debilidad salarial del interior del país, respecto de las ciudades, es una constante histórica que permanece. Adicionalmente se combina con la determinación estatal de que las unidades estarán en comunidades pequeñas, lo que impide que estos profesionistas especializados encuentren ocupaciones complementarias, acordes con su perfil.

En todo caso como aclaré arriba, la forma estructural final es la que el Estado mexicano determina para el desarrollo del modelo de educación superior intercultural en el medio indígena. ¿Qué efectos tiene en los alumnos la apropiación del bien gubernamental con este "molde" final?

Lo que se va a establecer son las condicionantes en las conductas y conceptualizaciones de apropiación, que derivan de la forma institucional final de la UIEM. En primer lugar, destacó que la apertura, control y terminación de los contratos de los docentes quedan en manos de las autoridades del estado y de su representante, el rector. La inseguridad e incertidumbre que los profesores experimentan y que es una constante mención en las entrevistas afecta a los alumnos en dos claros temas: que los profesores luchan con su compromiso personal con el proyecto, frente a su obligación como trabajador y la incertidumbre laboral. Muchos docentes, están en un nivel de bajo compromiso y cierta apatía, pues los esfuerzos realizados por el proyecto, pueden no ser compensados si se decide no recontratarlos nuevamente. ${ }^{229}$ Esta inestabilidad laboral, se refleja en la seguridad que los profesores experimentan frente a los alumnos, sobre todo al nivel de las evaluaciones: si el profesor es estricto y tiende a evaluar alumnos con rigor académico, los alumnos se inconforman con las distintas direcciones, que presionan a los profesores para bajar el nivel y por ende, tratan a los alumnos de manera displicente; todo ello redunda en una debilidad en su formación académica. ${ }^{230}$

\footnotetext{
${ }^{228}$ En un estudio historiográfico muy interesante de los documentos sobre educación indígena en la zona de Atlacomulco, Galván (1982: 289) expone que el nivel salarial de los profesores rurales que realizan el mismo trabajo que los de la Ciudad de México hacia el año de 1927 guarda una proporción de cuatro a uno en favor de los citadinos; 240 pesos mensuales contra 60. A la fecha, la relación bien puede ser de al menos dos a uno, en los casos más bajos y de cuatro a uno en los altos; es decir, la relación asimétrica persiste.

${ }^{229}$ Un profesor lo condensaba así: <<No hay equipo suficiente; solo hay un "cañón" [proyector de imágenes de la computadora], pero ¿para qué voy a comprar uno? Con lo que nos pagan apenas si nos alcanza y si hago el esfuerzo, pues luego nos corren y ¿para qué quiero el proyector? Total, si ya no alcanzo cañón, pues ya ni modo>>

${ }^{230}$ Algunos maestros, me han contado que no pueden reprobar alumnos; incluso mencionan un supuesto oficio de la SEP, en el que se emite tal disposición. Lo que es más creíble son las informaciones en el sentido de que la inasistencia de los alumnos, ha elevado en los últimos años, los individuos sin derecho a examen o de plano, reprobados. El alto porcentaje (en algunos casos hasta del 60\%) inhibe las
} 
Otra de las consecuencias, en términos laborales que tocan al profesor, se refiere a que el éxodo de los profesores por un mejor salario, ha debilitado el capital humano de la UIEM en cuanto al proyecto intercultural. En las primeras estancias en el 2009, existía un gran ímpetu y nivel de reflexión respecto de que significaban todos los temas educativos del proyecto intercultural (axiológicos, étnicos, epistemológicos, políticos, culturales). Se discutía y reflexionaba constantemente en las entrevistas, al respecto de ese tema. Aún en estos casos, cuando se preguntaba el nivel de capacitación recibida, en general referían que era bajo y se circunscribió a dos cursos de unas horas y a la entrega del libro, que sobre el modelo, produjo la CGEIB (2006a). Para el 2011, en las tres carreras iniciales (Lengua y Cultura, Desarrollo Sustentable y Comunicación Intercultural) parecía haber pasado el "furor" intercultural y dar paso a una visión institucionalizada del tema, a pesar de no haberse resuelto los problemas más complejos. A esto se suma el diferente nivel de entusiasmo respecto de las etapas tempranas y, en términos de capacitación, al aumento de la carga de trabajo de la CGEIB, simultáneamente con la reducción de su presupuesto. Sólo en la reciente carrera de "Salud Intercultural" se detectaba ese ánimo inicial, pero paradójicamente, su visión sobre lo intercultural es diferente de las otras academias. ${ }^{231}$ En este sentido, la instrumentación de la educación intercultural a nivel superior es un tanto desigual, dependiendo de la "antigüedad" del profesor en el sistema, la época en la que se incorporó y la academia en la que labora. Los alumnos tendrán así un bien educativo de calidad desigual, característica originada de manera exógena y resultado no intencional, de la estructura administrativa de las UI.

Otro tema se refiere en concreto a los bajos salarios y por tanto al nivel académico de los profesores, en función de lo que se puede contratar. Esto se mencionó arriba y no se abundará más. Lo que quiero resaltar es el hecho de que una de las asimetrías centrales en el ejercicio del poder político en el campo educativo, la constituye el par recursos/no recursos, mecanismo por la cual el Estado administra la forma concreta de apropiación. En este sentido, es claro que el bajo nivel salarial es una condición determinada para los trabajadores académicos y no, para los estudiantes. El diseño educativo determina que los alumnos, sin recursos económicos para acceder a diferentes alternativas educativas, se apropien de los bienes educativos que se les

posibilidades de reprobación, pues tendría efectos desastrosos sobre el proyecto; por lo tanto, se ve la manera de aprobarlos. La consecuencia es un bajo nivel de aprendizaje. Todas estas condiciones de apropiación son definidas de manera exógena sobre los alumnos.

${ }^{231}$ Este tema se abordará, cuando se analicen los diferentes planes de estudio. 
proporcionan en la localidad. Si bien dentro de las condicionantes del modelo se plantea una educación intercultural de "alto nivel", el nivel salarial dificulta en gran medida contratar profesionales de un nivel alto, en virtud de los precios en el mercado laboral. En términos de este trabajo, los alumnos que se apropien del bien educativo, de acuerdo con las conductas y conceptualizaciones supuestas, mostrarán que el Estado ejerció plenamente el poder político. Sin embargo, el resultado puede no reflejar el espíritu del modelo, y sobre todo del artículo segundo constitucional, que designa claramente al trato diferencial a los indígenas, como anticonstitucional. ${ }^{232}$ Este subproducto, perverso, de la política del Estado de dar más a los que más tienen, claramente daña a las zonas del interior del país respecto de las grandes ciudades, lo que limita la idea de redistribución y más bien continua la inercia presupuestaria de siempre. La ruptura de ese ciclo centenario no es sencilla y rebasa con mucho los temas de este trabajo, pero debe ser anotado en el contexto de cómo el Estado ejerce el poder político mediante el aporte de recursos, <<donde quiere y con el monto que quiere >>. ${ }^{233}$

Por último quisiera resaltar el hecho de que la rotación de profesores, en virtud de su inestabilidad laboral y bajos salarios, tienen un efecto positivo no previsto: la posibilidad de incorporar a los pasantes o egresados en las tareas docentes de la universidad, cubriendo los huecos que deja la reseñada movilidad. Esto es positivo en el sentido que expone para todos los estudiantes, la factibilidad de encontrar trabajo dentro del mismo instituto que los formó. Ello dispersa una imagen exitosa de los egresados y refuerza el modelo intercultural, dado que ahora los profesores, serán gente convencida de que su formación es pertinente y exitosa. ${ }^{234}$ No obstante el problema de la calidad baja subsiste, pues los nuevos docentes son muchachos de licenciatura que apenas

\footnotetext{
${ }^{232}$ Aquí vale la pena destacar que el hecho de ser la universidad "intercultural" y no "indígena", libera en cierta medida, tramposamente, al Estado Mexicano de sus obligaciones constitucionales, pues tratando de evitar la estigmatización y los fenómenos de ghetto, pugnó por el proyecto intercultural, que impacta población mayoritariamente indígena. Esto dificulta la presión por la exigencia de sus derechos constitucionales, porque si bien en la práctica, "interculturalidad" es un eufemismo para indigenismo, como proyecto político-normativo incluye a todos, lo cual define que al pagar bajos salarios y por tanto dar educación de bajo nivel, no se lesiona a los indígenas específicamente, sino a "todos", diluyendo el tema étnico.

${ }^{233}$ Esta asimetría en recursos respecto de las grandes ciudades, no impide que en la UIEM se empiecen a notar muy buenos resultados en algunos egresados, que han demostrado su capacidad al incorporarse exitosamente a los nichos laborales o académicos de su interés. Ello muestra que el modelo tiene puntos muy importantes que destacar. Pero esos "éxitos", no neutralizan el desbalance de salarios, ni las dificultades de contratar mejores profesores, o en todo caso, premiar de manera equivalente a la ciudad, los buenos resultados logrados con muchos de los egresados.

${ }^{234}$ A la fecha de cierre, conozco de tres muchachos (dos mujeres y un hombre) que están incorporados a las labores docentes. En las entrevistas, refieren su satisfacción y orgullo por estar dando clases en la UIEM.
} 
comienzan su maduración y refuerza el mecanismo de expulsión de profesionista, porque así, nunca se tendrán docentes de alto nivel.

Debilidad de origen, bajos salarios e inestabilidad laboral, es la forma específica que el Estado (Federación más entidad federativa) concretó en la zona de San Felipe del Progreso, para brindar educación superior intercultural. Insisto, en todo lo expuesto en este capítulo, el Estado ejerció pleno poder político, al modelar la forma final que la educación intercultural llega a la región. No hay demérito alguno en la presión, iniciativa y seguimiento ciudadano, que el Patronato y los actores que los acompañaron, realizaron (desde el mismo presidente de la Republica, hasta los representantes indígenas o autoridades municipales) de manera entusiasta y convencida. Pero la forma Estado tiene palancas centenarias y plenamente institucionalizadas, que imperan por encima de intereses y gestiones particulares. Por eso la batalla por llevar a la Constitución, un cuerpo de reactivos lo más cercanos a lo que se desea ocurra. Sin embargo, lo decretado como norma de Estado (el artículo segundo constitucional) no es suficiente para mover rápidamente y en la dirección decretada al complejo legal, administrativo, burocrático, financiero, cultural, humano, etcétera, que conforman de manera real, cualquier Estado. ${ }^{235}$

Fue, y es, notablemente exitoso el impulso inicial; hay nueve UI alineadas con el modelo federal y cuatro más por alinearse. Se le mandató al Estado hacerlo, y el gobierno federal (anterior y presente) ha avanzado en esa dirección. Pero la forma específica que tomará el dictado constitucional, y en concreto, la oferta educativa, está

\footnotetext{
${ }^{235}$ Gilberto López y Rivas expone muy bien lo complejo que resulta transformar el Estado y la impaciencia que experimentan los individuos que esperan un cambio substancial en el corto plazo: “...el CONAPRED no obstante que reconoce la discriminación de las autoridades educativas federales, lo cual es positivo, mandata en su resolución poner en práctica políticas marcadas por el estatismo y el paternalismo, ya que son las mismas autoridades que constituyen la fuente permanente de discriminación -más que directa- contra los educandos indígenas, las que tienen que aplicarlas, sin precisar claramente el papel de los sujetos autonómicos en estas medidas supuestamente correctivas. Nuevamente los pueblos son sujetos pasivos de la acción protagónica de un Estado que "sí sabe qué hacer con los indígenas' ". Cit. en: Congreso Nacional de Educación Indígena e Intercultural (2011: 40). La demanda presentada al CONAPRED se refiere a que la prueba ENLACE en regiones indígenas, no incorpora la lengua y cultura del contexto. Más allá de la evidente falla gubernamental, que incumple el artículo segundo constitucional y la Ley General de Derechos Lingüísticos de los Pueblos Indígenas, y que por ende el Gobierno Federal, debe enmendar su conducta, resalta lo complejo del papel del Estado, pues buscando que ejerza su poder político para cumplir la Constitución, se reclama la movilización exógena del Estado, con el objetivo de mitigar su previo proceder exógeno y anticonstitucional. Esta forma de reclamo al "Estado" es típica, es decir, se busca el protagonismo estatal y se le reclaman las intervenciones exógenas que realiza. Sin embargo, como se mostró a propósito de la pugna entre el gobierno federal y estatal, el resultado que produjo el Estado no coincide con una voluntad única y preestablecida. En ese sentido el Estado es más un resultado que una hipótesis. Adicionalmente, los tiempos y los deseos futuros de individuos o grupos particulares, raramente coinciden con el resultado final de todos los procesos gubernamentales, es decir, con el Estado.
} 
determinada en gran medida por una lógica estatal. Esto quiere decir que las conductas y conceptualizaciones de apropiación del bien gubernamental están condicionadas y conformadas por lógicas exógenas. Hay que precisar que esta última aseveración, se refiere en principio a lo expuesto hasta aquí: esto es, el diseño institucional de la UIEM. En las siguientes secciones, se mostrarán los efectos directos de la existencia de la unidad en la localidad y de la apropiación en concreto, de la educación superior intercultural en zonas predominantemente indígenas.

\section{Condiciones generales de operación de la UIEM}

La primera generación ingresó a la universidad en septiembre de 2004 con 267 alumnos en un plantel rentado ex profeso por el gobierno del Estado de México. La existencia de recursos, garantizada desde el 1 de enero de ese año (según el "Convenio"), permitió ir contratando el personal necesario para el funcionamiento de la institución a lo largo del primer año de operación.

Dado el mandato constitucional y gubernamental, respecto de incidir en la población indígena, se realizó una campaña de promoción en la Región I Atlacomulco, que según el estudio elaborado por el gobierno del Estado de México (2003), comprende los municipios de San Felipe, Ixtlahuaca, Atlacomulco, Jilotepec, Temascalcingo, El Oro, Acambay, Jocotitlán, Aculco, Chapa de Mota, Timilpan, Polotitlán y Soyaniquilpan; estas localidades arrojan un total de 3,955 egresados de la educación media superior y dado que la región tiene una capacidad de absorción del $60 \%$, es decir, alrededor de 2,400 alumnos (10 instituciones de educación superior hacia 2003); las posibilidades de la UIEM están en el orden de atención de 1,500 estudiantes (Ibidem). No obstante, por el compromiso con todas las etnias del estado y la juventud institucional, se buscó al inició impactar lo más cercano, pero tratando de mantener una representatividad étnica. Así, según consta en el relato de Antolín Celote (s/f), se promovió la UIEM en instituciones de educación media superior cercanas en San Felipe, Ixtlahuaca, Atlacomulco, El Oro, Jocotitlán y al Valle de Toluca con población otomí. Pero buscando la mentada representatividad, se mandaron comisiones a la zona matlatzinca (San Francisco Oxtotilpan) y tlahuica (San Juan Atzingo), para promover la incorporación de estudiantes de esas regiones. Este último tema es recurrente en las actas y en las conversaciones con los profesores, pues refieren la dificultad de hacer promoción en la zona matlatzinca y tlahuica por la lejanía y se llega a comentar: $<<$ da flojera ir tan lejos y a nadie le gusta ir>>. 
Al principio del capítulo se presentó la distribución étnica del estado, en donde sólo el 7\% de la población es hablante de alguna lengua indígena. Moviéndose hacia la zona de la UIEM, cambia el perfil regional, pues los porcentajes indígenas son bastante más altos, destacando el 28\% de mazahuas en San Felipe, el 20\% en Ixtlahuaca, el 26\% en Temascalcingo, el 15\% en El Oro y el 17\% de Atlacomulco. También es relevante la población otomí, sobre todo en la zona de Acambay, con 16\%, Aculco 7\% y Temoaya con $35 \%$. Con ello, se tuvo una composición inicialen la primera generación de $71 \%$ de mazahuas, $8 \%$ de otomís, $7 \%$ de tlahuicas, $2 \%$ de matlatzincas, $1 \%$ de nahuas y $12 \%$ de no indígenas. Hay que destacar que a partir de 2004 la población se ha ido normalizando con la siguiente composición aproximada a la fecha: mazahuas 66\%, otomís 5\%, matlaltzincas $1 \%$, tlahuicas $1 \%$, nahuas $1 \%$, distintas etnias no originarias de la región $1 \%$ y población no indígenas $25 \%$. $^{236}$

En términos de efectos sobre la población estudiantil de la región, la implantación de la unidad en San Felipe del Progreso, no deja duda: de 7\% a nivel estatal, la población indígena alcanza el 75\%; exitoso efecto de la presión por apropiarse de los recursos gubernamentales con perspectiva "intercultural”. Pero además hay otro efecto muy contundente a nivel regional: en el proceso de decisión sobre la localización de la UIEM, se evitaba consistentemente la posibilidad de San Felipe y se explicó el porqué, sin embargo, también hay que señalar que al mismo tiempo, los pueblos indígenas no mazahuas, también presionaban para tener la unidad más cerca o francamente, $<<\ldots$ en un momento, cada uno quería su universidad $>>.^{237}$ En este

\footnotetext{
${ }^{236}$ Porcentajes elaborados según datos de Celote (s/f) y las actas del Consejo Directivo. El 12\% inicial de no indígenas ha variado desde 30\% en 2006 hasta $23 \%$ en 2011; llama la atención no obstante, que según impresión de un miembro de la Academia, en los últimos dos años, la población universitaria se ha ido $<<$ blanqueado〉>. Con ello se refería a que el éxito y prestigio de la UIEM, ha empujado a la población urbana de San Felipe y Atlacomulco a inscribirse en un número creciente, independientemente de su "autoadscripción". Ello lleva además a una creciente diferenciación por clases sociales, evidente en la implementación de un estacionamiento para alumnos que no existía en 2009 y funcional ya en 2011. Estos dos fenómenos, muestran el éxito de la dimensión intercultural e incluyente de la UIEM, pero preocupan al interior, pues la presión urbana crece y tiende a desplazar la demanda originada en el medio rural, matriz que da razón a la universidad. Un indicador evidente de este proceso, es que las facilidades para los indígenas de zonas rurales son a la fecha muy limitadas. Todo el apoyo que reciben, se reduce a la beca, cuyo máximo es de $\$ 1,000$ pesos al mes. Las posibilidades de brindar hospedaje, están restringidas al albergue que tiene la CDI en Atlacomulco, que a la fecha sólo está en capacidad de recibir a 30 muchachos; con ello queda en evidencia la presión urbana sobre lo rural.

${ }^{237}$ Según refirió el Dr. Garduño. En otra entrevista, Margarita de la Vega, otomí, coordinadora de la licenciatura en Lengua y Cultura y participante del proceso de creación de la universidad, comentó que se contempló la posibilidad de situar la unidad en Toluca o Temoaya, mucho más cerca de la zona otomí. Sin embargo, terminó en San Felipe lo que según la profesora Margarita fue injusto, $<<\ldots$ pues le da demasiada prioridad a los mazahuas $>>$. Esta decisión de Estado, ha motivado la gestión, por parte de líderes otomís, con el gobernador Eruviel Ávila, sobre la posibilidad de una unidad de la UIEM en la zona del Valle de Toluca, expresamente en Temoaya. En al menos un punto, era ventajosa la idea de localizar
} 
sentido, la decisión de carácter estatal, de localizar la unidad en San Felipe y con ello definir el sitio en donde se va a impartir la educación superior de tipo intercultural, marcó profundamente el nivel de la composición étnica de la población, pues en contraste con el 47\% de otomís en el Estado de México, en la UIEM nunca ha rebasado el $8 \%$ inicial; es por ello la población en general se refiera a la UIEM como: <<ésa es una universidad mazahua > o <<ésa es cosa mazahua〉>. Es decir, la voluntad local sobre una universidad mazahua, persiste, en virtud de la localización en una zona predominantemente mazahua y con población predominantemente mazahua.

Un efecto un tanto insospechado de su localización en una zona rural-urbana, como es la de San Felipe, es la composición por sexo de la población. La proporción de 2 a 1 entre mujeres y hombres ha sido consistente desde 2004 y hasta la fecha. Esta superioridad numérica de la población femenina, se explica, en función de al menos dos temas: la presión al sector masculino por incorporarse al sector laboral dadas las necesidades familiares de la zona, lo que determinan la imposibilidad de sostener un miembro adulto "sin trabajar" y la mayor facilidad masculina para la movilidad a centros educativos alejados de la zona, lo que implica mayor desplazamiento o de plano cambio de residencia. ${ }^{238} \mathrm{Si}$ bien, la composición de facto de la proporción por sexos, determinaría las ventajas evidentes de la universidad en la zona, existe cierta preocupación en la UIEM por este desequilibrio de género, aunque no se ha implementado a la fecha ninguna política en particular para corregirlo.

En relación con el tema de políticas de ingreso, se debe hacer notar, que en ningún lugar de los supuestos originales de las UI o de los convenios o decreto de creación, se establece la discriminación positiva como una norma para la admisión de estudiantes indígenas sobre los que no lo son. Todo el efecto selectivo, deriva como se ha expuesto, de la localización del edificio, la denominación de la universidad como intercultural, la historia regional para conseguir dicha ubicación y los lugares y temas de

la unidad en Ixtlahuaca: geográficamente presentaba mayor cercanía a con las cuatro etnias originales del estado, pero como la gestión política tenía su raíz en San Felipe, las presiones locales siempre fueron en ese sentido. No hay todavía efectos de estas gestiones, sin embargo, para la rectoría de la UIEM, no es una prioridad la apertura de nuevas unidades, sino la consolidación del proyecto.

${ }^{238}$ Estas opiniones se han vertido en las reuniones de consejo, según consta en actas. Es evidente el componente de diferenciación sexual en ambos temas. En el primero, porque se sobreentendería que los hombres son los que deben ir a trabajar y las mujeres no; en el segundo, porque se plantearía que las mujeres, si van a estudiar, deben permanecer cerca de su casa y no migrar. Esta segunda dimensión se constató en las entrevistas, pues era un caso común que las mujeres deseaban estudiar en otra universidad, pero la residencia en otro sitio (Toluca o Ciudad de México), era imposible debido a la oposición de sus padres, lo que las empujó a la UIEM, con la esperanza de que avanzando los semestres o para la maestría, sus papás les dieran << permiso >> de residir fuera del hogar. 
promoción asociados a lo indígena. En el Decreto de Creación de la UIEM, artículo cuarto, fracción xi, se establece que la universidad tiene la facultad de: "Regular los procedimientos de selección e ingreso de los alumnos y establecer las normas de su permanencia en la institución" (Gaceta de Gobierno, 2003: 3). Esta facultad, que no se había ejercido, aparece ya en 2009 en la convocatoria 2009-2010 bajo el siguiente enunciado:

Con el fin de atender el sentido de equidad que promueve la Universidad Intercultural, la admisión de los aspirantes se hará en el siguiente orden de prelación. Aspirantes provenientes de pueblos indígenas y no indígenas, preferentemente de escuelas públicas de la entidad. Aspirantes provenientes de pueblos indígenas y no indígenas, preferentemente de escuelas públicas de las entidades federativas. Aspirantes provenientes de pueblos indígenas y no indígenas de otros países. ${ }^{239}$

Llama poderosamente la atención que el orden formal de jerarquía, en sentido estricto, poco apoya la mencionada acción afirmativa, al determinar que los aspirantes de los pueblos del Estado de México y provenientes de escuelas públicas, indígenas y no indígenas, tienen preferencia sobre los demás aspirantes. Ello equipara población rural indígena y la no indígena, desplaza a indígenas provenientes de escuelas privadas o a indígenas de otros estados, sobre miembros de pueblos no indígenas, pero originarios del Estado de México. Estos problemas de selección, denominados de “justicia local", ${ }^{240}$ exponen en el nivel formal los problemas reales que aparecen cuando los bienes son escasos y hay que incluir y excluir individuos, lo que genera mecanismos modificados por criterios de justicia. En el caso de la UIEM, no ha habido estos problemas, porque, salvo la primera convocatoria (2004) que excluyó a 100 aspirantes, a la fecha se sabe por pláticas con Servicios Escolares, que no ha existido necesidad de

\footnotetext{
239 Tomado directamente de la convocatoria en la UIEM.

${ }^{240}$ Según la postura de Jon Elster expuesta en el Capítulo 2. No se han detectado tensiones evidentes, desprendidas de la dificultad de acceso a los bienes educativos, pues la oferta siempre ha estado por arriba de la demanda; sin embargo, en las entrevistas, se han detectado varios casos, en maestros y alumnos, en donde la autoadscripción como indígena (casos de mazahuas y otomís), está imbricada con un profundo conflicto identitario, producido por las condiciones de apropiación de los bienes gubernamentales. Refieren los individuos, tener parientes remotos que eran indígenas, <<un bisabuelo hablante>> <<una abuelita que algo entendía $>$, y no saber entonces si son o no son indígenas, pero sobre todo, que la búsqueda de las raíces identitarias, estuvo subordinada a las necesidades de ingreso al plantel o incluso, fue posterior. En ese sentido, el Estado ejerce claro poder vía la discriminación en la selección, al empujar a los individuos a revalorar su identidad indígena, aun en los caso en que dicha autoadscripción sea claramente estratégica y coyuntural. Este fenómeno aparece, como bien expuso Elster, al considerar las distorsiones que los individuos realizan para apropiarse de bienes "especiales" que en sentido estricto, les pertenecen más a otros individuos, desplazándolos de manera "injusta”.
} 
excluir a nadie, puesto que la demanda siempre ha estado por debajo de la capacidad de atención. ${ }^{241}$ Recientemente se comentó que en esta última convocatoria (2011-2012), los aspirantes a la carrera de Salud Intercultural rebasaron la capacidad de atención y en el curso propedéutico que tiene la licenciatura, fue necesario hacer una selección con base en el desempeño de actitudes y convicciones. Esto quiere decir que las condiciones de apropiación del bien educativo, están supeditadas a conductas y conceptualizaciones de apropiación acordes con el modelo intercultural, exponiendo, en concreto cómo en la UIEM, se va perfilando a los estudiantes con base en el ejercicio de poder vía el intercambio.

En las tres carreras iniciales, como se expuso en la parte del diseño, los alumnos cursan un tronco común denominado "Formación Básica", lo cual permite que la elección de la carrera se realice a lo largo del año de duración. Las nuevas generaciones son de alrededor de 160 alumnos, lo que determina que en cada licenciatura los grupos de tercer semestre ronden los 55 alumnos, divididos en dos grupos. Para agosto de 2011, la matricula total de las tres primeras licenciaturas es como sigue: Lengua y Cultura: 189 alumnos; Desarrollo Sustentable: 170 alumnos; Comunicación Intercultural: 130 alumnos. Por decisión del colectivo que diseñó la licenciatura en Salud Intercultural, se suprimió el tronco común. ${ }^{242}$ La consecuencia, es la separación de los alumnos en dos grupos: aquellos que llevan un tronco común y aquellos que no; eso define para los segundos, la necesidad de ingresar a la UIEM con la carrera ya elegida y la no convivencia directa con las otras carreras. Tal característica permite, como se expuso, que la matrícula de Salud, que a la fecha cuenta con 130 alumnos, se defina desde el inicio. La diferencia de número con otras carreras es notable, si tomamos en cuenta que solo corresponde a alumnos de los dos primeros años, dado que la primera generación ingresó en septiembre de 2009 con aproximadamente 70 nuevos estudiantes y la segunda generación con 71 alumnos, lo que expone una diferencia para el primer semestre, cercana al $40 \%$ respecto de las otras licenciaturas.

Para los 659 alumnos inscritos al final del ciclo 2010-2011, las condiciones de ingreso son un tanto diferentes. La forma en la que se ven determinados de manera

\footnotetext{
${ }^{241}$ No se conocen los criterios usados para el corte, sin embargo, por las distribuciones posteriores se puede concluir que se privilegió a los aspirantes indígenas sobre los no indígenas, en virtud de que al inicio, los segundos representaron sólo el $12 \%$ y que a la fecha tiene un promedio del 25\%; también se puede aventurar la exclusión de algunos mazahuas para incluir a y mayor número de otomís, tlahuicas y matlatzicas cuyos porcentajes fueron atípicos en la primera promoción.

${ }^{242}$ Las circunstancias y consecuencias de esta notable transformación institucional, se reseñarán en la sección referente al diseño de los currículos.
} 
exógena, para la aprehensión de los bienes educativos gubernamentales, es distinta porque mientras los que cursan el tronco común, construyen su visión de la interculturalidad y la elección de su carrera en contacto con estudiantes y maestros de las tres primeras carreras, los del grupo de salud, se enfocan directamente en su especialidad y con una visión sobre la interculturalidad que es exclusiva, por la ausencia de contacto externo, sobre todo con otros profesores, y también por la peculiar visión que sobre la interculturalidad produce el campo de la medicina y que se expondrá en las siguientes secciones.

Así pues, hasta este punto son claros los efectos del poder político derivados del diseño del modelo, de la localización de la unidad y de las decisiones de promoción, acceso e incorporación a la UIEM. El derecho constitucional de los ciudadanos y los ciudadanos indígenas, que modela la acción del Estado, toma una característica novedosa, al aparecer las necesidades específicas del aparato estatal para dar forma al derecho ciudadano. Recursos, conocimiento, administración y procedimientos institucionales forman parte de la asimetría que se establece entre el Estado y los ciudadanos, indígenas o no, que concurren a la UIEM, en la cual, su derecho a una educación intercultural, está modelado con disposiciones de carácter exógeno, que exponen claramente la necesidad del ejercicio del poder político para consolidar un proyecto educativo novedoso. ${ }^{243}$

Los efectos anteriores estarían incompletos si se excluye otra de las asimetrías sustantivas en la operación de las políticas educativas: la de los recursos económicos. La educación que imparte el Estado deberá ser gratuita por mandato constitucional. En ese caso, los montos y distribución de los recursos tienen efectos específicos sobre la población estudiantil. Lo primero que hay que destacar son los fondos que la UIEM recibe del convenio entre la Federación y el Estado de México (Ver Figura 1). ${ }^{244}$

\footnotetext{
${ }^{243}$ Quiero recalcar que esta idea de la "necesidad" del ejercicio del poder es un planteamiento de corte funcionalista e instrumental, sin embargo, está expresada en términos de lo que Federico Engels mencionaba como "poder de función" y que se describió en el Capítulo 2.

${ }^{244}$ Elaborado con datos de las actas del Consejo directivo. La composición concreta de las aportaciones derivadas del convenio y las exclusivamente federales, se exponen en el Anexo 5, con información proporcionada por la Secretaría de Educación Pública, a través de INFOMEX.
} 


\section{Figura 1}

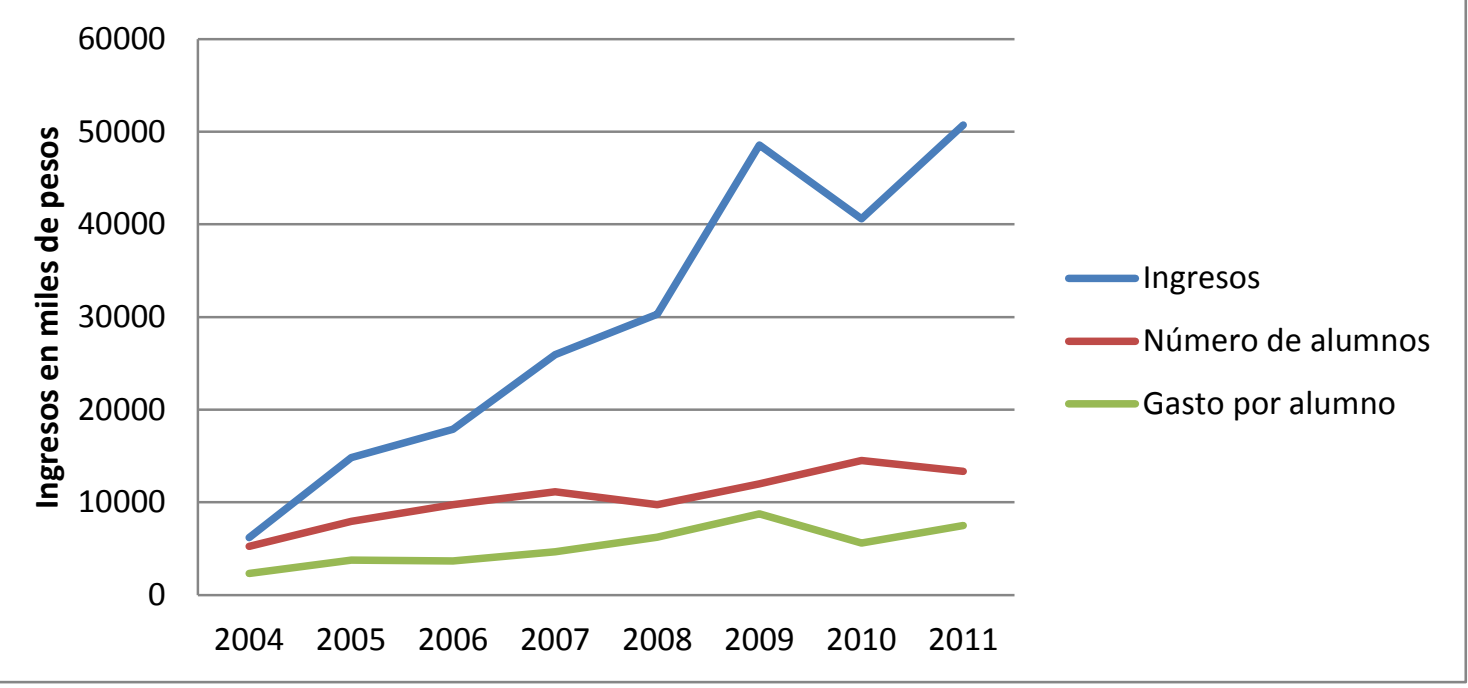

Dichas aportaciones, que van de los 6.201,000 millones de pesos en 2004 a los 50.830,069 millones en 2011, muestran un patrón creciente, de casi nueve veces, en relación con el inicio. Esta correlación expone que para el ciclo 2005-2006, el gasto por alumno se ubicó en 37,426 pesos. En un estudio de la Organización para la Cooperación y el Desarrollo Económico (OCDE), publicado en septiembre de 2008, el gasto promedio por alumno en educación superior en México, se ubicó en 6,402 dólares. ${ }^{245}$ Esto quiere decir que de acuerdo con el precio promedio del dólar para aquellos años de 10.80 pesos por dólar, el gasto por alumno en la UIEM, se ubicaba en 3,465 dólares. Este cociente creció para el periodo 2011, a 5,861 dólares por alumno con un precio de $\$ 13.00$ pesos por dólar. ${ }^{246}$ Es claro el desnivel con el que arranca el proyecto de la UIEM, de casi la mitad del promedio nacional, para acercarse en el 2011 al 90\% del promedio. Se expone así la recurrencia señalada anteriormente, del desequilibrio de las zonas rurales e indígenas respecto de las urbanas. Hay que hacer notar que la suma de los esfuerzos locales, federales y del poder Legislativo, ha definido la transformación presupuestaria de la UIEM, para mitigar el rezago respecto de otras instituciones de educación superior del país. En este sentido, el cociente expone, en términos de poder por intercambio, que las conductas y conceptualizaciones de apropiación de los alumnos

\footnotetext{
${ }^{245}$ Información según el suplemento Milenio Campus del jueves 19 de marzo de 2009, p. 7. El gasto en México, como porcentaje del gasto en países del primer mundo como Canadá, Estados Unidos o Japón, se ubica en niveles del $25 \%$ al $50 \%$ de la inversión por alumno en educación superior.

${ }^{246}$ Estos cocientes están profundamente afectados por la cotización del precio promedio del dólar, por lo que deben tomarse con mucha precaución, en el sentido de que unas cuantas décimas de unidad, arrojan relaciones de gasto por alumno muy diferentes. En todo caso, lo que se muestra es un arranque muy mediocre y una creciente mejoría en los niveles de inversión de recursos por alumno.
} 
tendrán, por un lado, una mejoría en función de que la porción neta de recursos apropiados es mayor y, en consecuencia, la efectividad del ejercicio del poder político, tiende a incrementarse, pues los individuos se ven, en términos racionales y también estructurales, más "animados" en aprender o transformar, conductas y conceptualizaciones asociadas a los procesos educativos, a los de ciudadanía y los de identidad. $^{247}$

Por otro lado y como complemento, al inicio del proyecto se contaba con ocho profesores de tiempo completo, lo que a finales de 2011 pasó a 27. Esta notable multiplicación (3.3 veces) pone a disposición de los alumnos, mejores condiciones de apropiación, ya que los profesores tienen condiciones de trabajo más adecuadas, al pasarse de 33 alumnos por profesor en la primera generación a 24 alumnos en 2011. Esta reducción mejora la atención individual, disminuye la carga semestral de materias, mejora las condiciones de preparación de las clases y la evaluación, y adiciona tiempo libre para actividades de profesionalización e investigación, que incrementa la calidad de los profesores. No obstante, una queja recurrente de los académicos es aún la gran carga de trabajo administrativo que se ven obligados a realizar, lo cual impide todavía, el mejoramiento del nivel de clases y el desarrollo de tareas de investigación, necesarias en cualquier proyecto universitario con expectativas de éxito.

La otra gran queja se refiere al bajo nivel salarial de los profesores. Según actas del Consejo Directivo, en el año 2005 los profesores recibían un salario bruto de 10,600 pesos, que en la actualidad se ubica en alrededor de $\$ 15,000$ pesos brutos, un incremento de aproximadamente 50\% faltando descontar la tasa de inflación, que desde esa época, ronda el 5\% anual. Eso representa que, a pesar del incremento en el presupuesto de la universidad, los salarios a los profesores han mantenido su bajo nivel, pues respecto a las instituciones comparables en educación superior la desventaja se ubica en parámetros de 50 a 100\% de atraso. Esta situación es claramente observable, si

\footnotetext{
${ }^{247}$ Aquí es fundamental aclarar, que el aumento de los recursos destinados para ejercer el poder mediante el intercambio, de ninguna manera genera una correlación lineal. En primerísimo lugar, porque múltiples condiciones sociales en torno de la apropiación de los recursos, pueden determinar la negativa o la imposibilidad de aumentar el comportamiento en la medida del incremento del recurso. En segundo lugar, y más profundamente, porque justo se estableció la imposibilidad de postular un núcleo duro y atemporal del ejercicio del poder, en virtud de la realidad polisémica de los hechos del mundo; en ese sentido, establecer la simplista correlación: más recursos-más poder, desconoce el funcionamiento del fenómeno en su dimensión histórica y adicionalmente, desconocería los postulados teóricos de los que se partió, invalidando el modelo o su aplicación empírica.
} 
se consideran los porcentajes dedicados a los diferentes capítulos que corresponden al gasto anual de la UIEM (Ver Figura 2). ${ }^{248}$

El capítulo 1000, que comprende el salario de los trabajadores permanentes y transitorios, las primas extras, la seguridad social, los estímulos y el material didáctico de los profesores, ha ido retrocediendo respecto del total. Esto es una clara muestra de que en el nacimiento de una institución educativa, lo central es el capital humano, que progresivamente va retrocediendo ante las necesidades de la infraestructura física y su operación. Esta natural tendencia no pudo ser contenida al nivel de los salarios a los profesores de tiempo completo, dado que la ausencia de crecimiento hacia la equiparación respecto de instituciones de educación superior de referencia (UNAM, UAM, U de G, ITESM, UIA, entre otras), debilita la planta docente en el nivel de calidad - por fugas hacia otros mercados laborales- o en su rendimiento - carga excesiva de trabajo, mala calidad en el servicio, ausentismo. El ausentismo es uno de los más dramáticos a decir de los alumnos, porque los profesores frecuentemente $<<$ llegan tarde, se 'comen' las clases, o de plano se quedan en su cubículo en quién sabe qué>>.

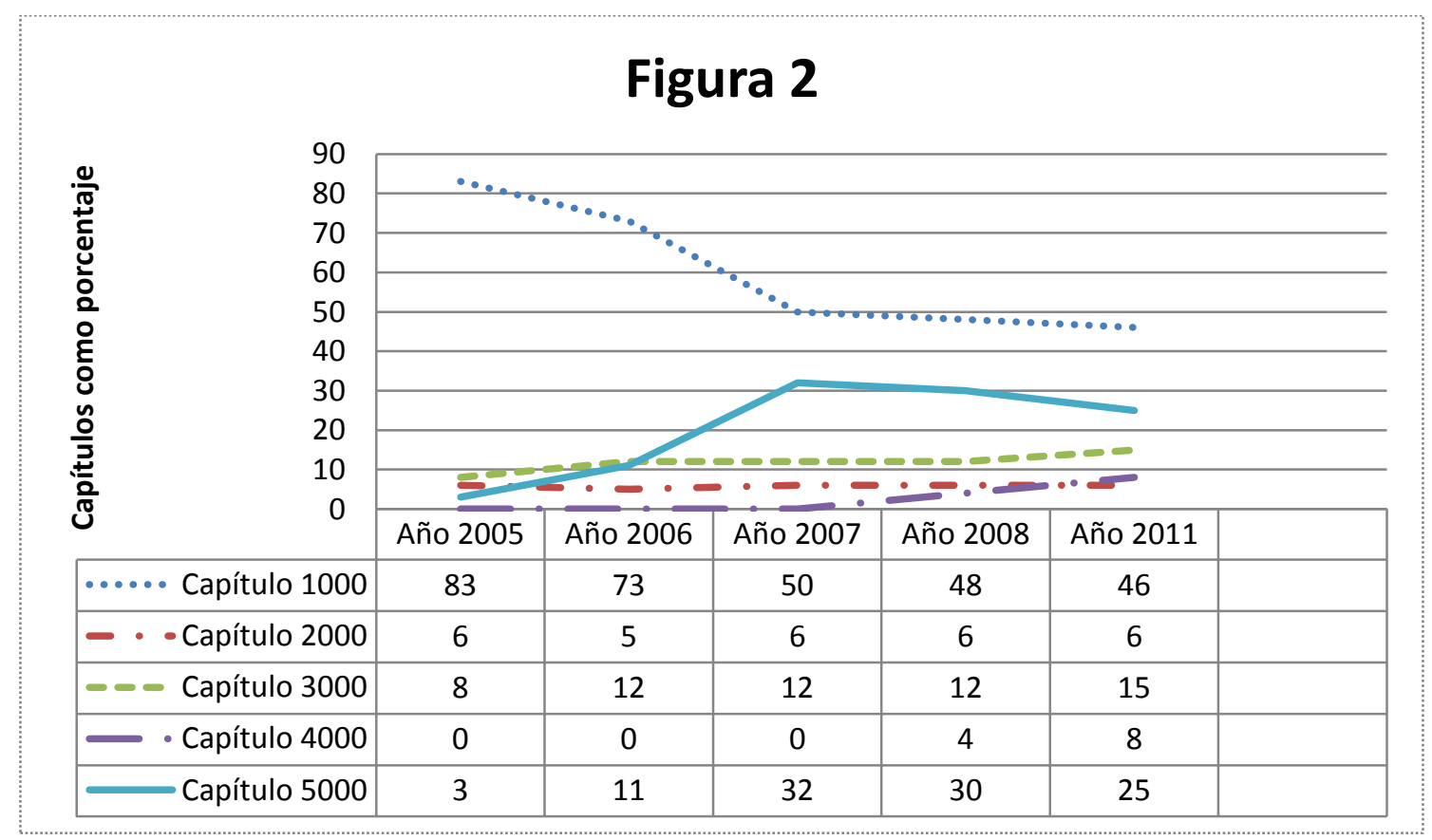

\footnotetext{
${ }^{248}$ Elaboración con datos recabados de la propia universidad, según documentos del Consejo Directivo y para 2011, según página web de la UIEM, en el enlace "TRANSPARENCIA". Los conceptos de los capítulos son grosso modo: 1000 "Servicios personales"; 2000 "Materiales y suministros; 3000 "Servicios generales; 4000 "Transferencias"; y 5000 "Bienes muebles, inmuebles e intangibles".
} 
La composición presupuestal que el Estado implementa, producto de decisiones tomadas desde la SEP, el Congreso de la Unión, el Gobierno del Estado y la propia UIEM, ha producido dicho balance, que determina las formas de apropiación de los bienes gubernamentales $\mathrm{y}$, en sentido lato, las conductas y conceptualizaciones de apropiación resultantes. Me parece que la incidencia de la UIEM en tal composición es la más importante, ya que las decisiones entre el número de alumnos admitidos, profesores contratados, creación y fortalecimiento de la infraestructura, y los gastos de operación, que competen casi exclusivamente a la universidad, han afectado al insumo central del proyecto de educación intercultural, que es el profesor. Evidentemente, las presiones institucionales y políticas, definen un margen de maniobra estrecho; sin embargo, se ha decidido en la UIEM que las prioridades están más cerca del crecimiento y la diversificación de la oferta que del fortalecimiento de lo inicial. Esta decisión política de la mayor importancia no puede juzgarse a la ligera, pero expone claramente, el ejercicio del poder político, que determina tanto las conductas y conceptualizaciones de los alumnos, como las de los profesores de la institución.

En este sentido es que podemos explicar el crecimiento de la planta total de trabajadores, que pasó de 36 en 2005 a casi 100 a fines del 2011. Es decir, la planta total de personal se triplicó desde el inicio, mientras que la población estudiantil se duplicó, lo que expone la necesidad de contar con mayor personal en todas las áreas, respecto del diseño inicial. Estas necesidades de capital humano, destacan la decisión de adelantar este indicador en relación al del salarios a los profesores, que como se mostró, tiene consecuencias muy fuertes en la calidad de la educación impartida a los alumnos; en todo caso, constituye una decisión explicita con impacto en la calidad general de la universidad.

Los bienes gubernamentales, ideales y simbólicos, que proporciona la UIEM, es decir, la educación, definen -como se ha señalado- un conjunto de conductas y conceptualizaciones que debe desarrollarse por los estudiantes, para apropiarse de manera adecuada, de acuerdo con el modelo de educación intercultural. Esta “educación”, impone una serie de prácticas, ideas y estructuras educativas que forman el corazón del modelo y, al mismo tiempo, imponen condiciones de isomorfismo institucional respecto de la educación que recibe el resto de la población nacional. Sin embargo, dado el perfil de los estudiantes de la región descrita, los niveles de ingreso económico son un freno a la integración a la universidad pero sobre todo, a la permanencia. Para eliminar las presiones económicas que determinan el abandono, se 
acude Programa Nacional de Becas para la Educación Superior (PRONABES). En el capítulo anterior se delinearon las características básicas de la operación de este programa. Lo central para la apropiación es mantener un promedio general de 8.0 en los cursos y no reprobar ninguna materia. Esto define un conjunto de conductas y conceptualizaciones de apropiación, específicas y necesarias, que determinarían la asignación por parte del profesor de una calificación, no sólo aprobatoria, sino de un nivel suficiente para mantener la beca. Este acicate al rendimiento forma parte de los bienes gubernamentales suministrados con el patrón definido anteriormente como “don", pues el monto de la beca es recibido antes de conocer el rendimiento del alumno en el curso. ${ }^{249}$ En contraposición, la certificación del esfuerzo como se ha mencionado, tiene la característica de "anti-don", puesto que las conductas y conceptualizaciones, deben ser adecuadas y suficientes, previamente a la emisión de la calificación. Para todos aquellos que tiene la beca PRONABES, el ejercicio de poder es evidente, pues su quehacer cotidiano como estudiantes debe apegarse a lo que se comprende como un "alto rendimiento". ${ }^{250}$ Estas becas, que tienen un monto inicial de 750 pesos y final de 1000 pesos, han sido asignadas a la UIEM en un monto muy pequeño al inicio que se ha estabilizado con los años (Ver Figura 3). ${ }^{251}$

\footnotetext{
${ }^{249}$ Hay aquí un balance muy interesante del ejercicio de poder asociado a las becas, ya que en el primero y segundo semestres, los alumnos son elegidos en función de condiciones económicas: provenir de una familia cuyo ingreso familiar, sea menor a cuatro salarios mínimos. Es decir, de inicio, el programa no exige ninguna conducta ni conceptualización específica, salvo, asistir e inscribirse. Para recibir la beca en el segundo semestre ya hay un requisito en conductas y conceptualizaciones de apropiación: no reprobar más de tres materias de las siete que se cursan en el primer semestre; si ocurre, se le niega la inscripción (egún reglas de la UIEM). Aquí ya es claro que si el alumno no se integra las tareas mínimas del modelo, no podrá inscribirse al segundo semestre y por ende perderá los bienes gubernamentales de los que pretendía apropiarse: la educación y la beca. Este caso, no muy común, que alcanza alrededor del 7\% en el primer semestre -es decir aproximadamente 50 alumnos-, es una muestra del fenómeno del gorrón de poder, pues los individuos se apropiaron del monto de la beca, sin desarrollar cabalmente las condiciones supuestas en las bases, es decir, la orden resultante de la apropiación.

${ }^{250}$ Sólo se hará referencia al programa PRONABES, pues es el más constante y significativo. Existen becas en la UIEM, apartadas por el Consejo Estatal para el Desarrollo Integral de los Pueblos Indígenas del Estado de México (CEDIPIEM), del gobierno del estado y de Consejo Nacional de Fomento Educativo (CONAFE)

${ }^{251}$ Elaboración de acuerdo con los motos asignados a la UIEM según datos del Gobierno Federal (Ver anexo 5).
} 


\section{Figura 3}

Gasto en beca PRONABES por alumno (en miles de pesos)

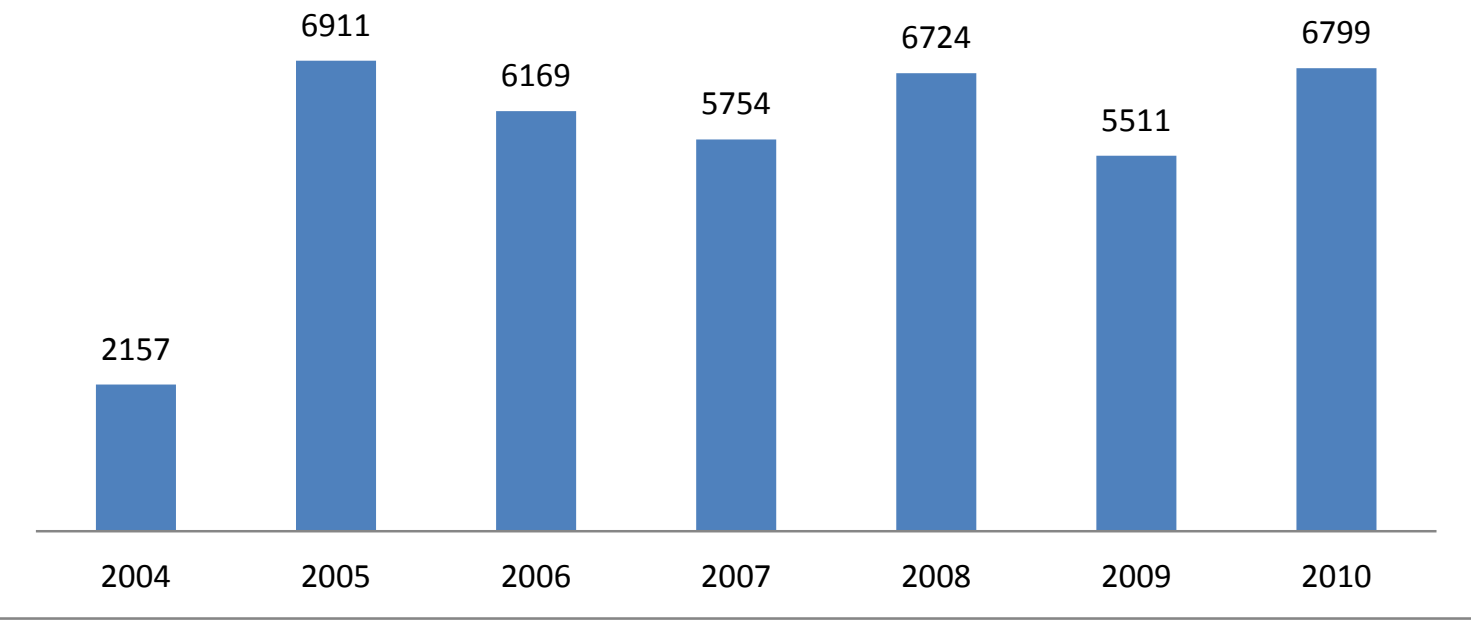

La evaluación de la efectividad de las becas para mantener a los alumnos en la institución y evitar la deserción o fuga hacia otras instituciones, es de difícil evaluación, pues el que desiste sólo es detectable posterior al hecho, sin poder determinar las causas de manera clara. En este rubro si hay una correlación más profunda entre el monto del recurso y el efecto sociológico, pues si el monto aumenta las presiones económicas para abandonar la escuela disminuyen. ${ }^{252}$ Adicionalmente, es de notar que, al margen del dictado constitucional que mandata la implementación de un sistema de becas para los estudiantes indígenas en la UIEM, inscrita en el PRONABES, el orden de asignación no privilegia a los indígenas. Se establece que el orden de asignación, coloca a aquellos con "Mayor necesidad económica [sobre los] Aspirantes que provengan de comunidades indígenas, rurales y urbano marginadas [...sobre los que provengan] de familias que se encuentran el padrón de familias del programa OPORTUNIDADES [y finalmente aquellos con] mejor desempeño académico". ${ }^{253}$ Esto quiere decir que, si bien los indígenas como grupo están en segundo lugar en el criterio de asignación, no existe un sistema de bacas para los estudiantes indígenas.

\footnotetext{
${ }^{252}$ No se cuenta con datos para determinar el porcentaje de deserción, y por ende, la efectividad del monto de las becas.

${ }^{253}$ Según la Convocatoria 2010 y 2011 del PRONABES para el Estado de México. Consultadas en línea en: www.pronabes.sep.gob.mx el 10 de octubre de 2011.
} 
Para culminar esta sección, únicamente resta decir que la aplicación del modelo para encuadrar las conductas y las conceptualizaciones de apropiación, se ha mostrado satisfactoria en este nivel. Las asimetrías generales que definen el componente de poder del proceso de educación intercultural en la UIEM: la diferencia en recursos y la capacidad certificadora del Estado, implican la facultad del ejercicio del poder político, para conducir la acción social en concordancia con el artículo dos de la Constitución. He mostrado un balance muy general acerca la forma en que afecta la decisión de escoger un sitio y no otro, que benefició al pueblo mazahua, como era la intención de los promotores de la universidad. Esta localización determina un perfil específico, que es el que va a definir el comportamiento macroscópico de la población estudiantil. La "localización" étnica determina las tareas de promoción y difusión de la UIEM, al tiempo que define la percepción local de lo que significa la relación educación intercultural-adscripción étnica, es decir, UIEM-mazahua. Simultáneamente, la clara superioridad numérica de esta etnia perfila el aire indígena de la unidad en términos muy cercanos a dicha cultura, si no en detrimento por lo menos con un sesgo favorable respecto de las otras etnias del estado y, por ende, en una disminución de las posibilidades de apoyar el efecto constitucional de comprensión, respeto y conservación para aquellos grupos indígenas del estado que no son mazahuas. ${ }^{254}$

No han surgido problemas en términos de incapacidad de atender la demanda anual, pero se recuerda que los funcionarios de la universidad aceptan que se ha incrementado notablemente el prestigio de la UIEM en la región, por la novedad de la oferta, lo que ha comenzado a atraer mayor población urbana y de un nivel económico más alto. La impresión interna de que la universidad se está <<blanqueando〉>, no es en sí un problema, pues mostraría un avance substancial en la transformación de la percepción mestiza de lo que es la cultura indígena y sobre todo de la tolerancia que implica fomentar la componente indígena de la cultura local o nacional. Es llanamente una medida del éxito del Estado en dispersar en la población no indígena, los conceptos de comprensión y respeto, que claramente potencia las posibilidades de la conservación,

\footnotetext{
${ }^{254}$ Un profesor otomí, que participó desde el inicio en el proyecto comenta que le entristece mucho que $<<$ no hay neutralidad en el terreno >> por estar localizado en San Felipe. En un viaje que realizó con la Coordinadora de la CGEIB y otras personas, con el objetivo de ver terrenos que alojarían la universidad, no se interesaron en explorar lotes en Ixtlahuaca o Toluca. Como ha quedado en evidencia, la decisión de plantar una UI para "los indígenas del Estado de México" en San Felipe del Progreso fue claramente una decisión exógena; el profesor comenta que él sintió que todo el asunto derivó del compromiso que hizo Vicente Fox afuera del Centro Ceremonial Mazahua; ejercicio de poder pues.
} 
descrita como derecho constitucional. La convergencia entre lo trazado y lo conseguido es, en este renglón, muy satisfactorio y por tanto el ejercicio del poder político ha mostrado eficacia social. El problema a futuro es justamente la debilidad de los planteamientos que la UIEM denominó como de "prelación" y que con toda probabilidad, tendrán que irse aplicando de manera más contundente, determinando la profundización de los conflictos que surgen de la búsqueda de justicia local.

Un efecto notable del diseño curricular es la diferencia entre las tres carreras iniciales y la de Salud Intercultural. Para esta última, es evidente que la supresión del módulo de Formación Básica, separa claramente a los alumnos del resto, toda vez que la "cantidad" de contenidos técnicos que los alumnos reciben desde el inicio es mayor que en aquellos que siguen el diseño institucional anterior. En el trabajo cotidiano en la UIEM, se ha observado que los alumnos de Salud se han incorporado a las labores de su profesión más pronto que los de las otras carreras. Esta separación tiene efectos muy evidentes en la "Vinculación Comunitaria" porque la implementación en este eje tiene en Salud un planteamiento muy acabado, que permite a los alumnos desde los primeros semestres, enlazarse con las comunidades con trabajos remunerados. El "éxito" de este rubro presiona la forma de "vinculación" que existe en las otras carreras y que no necesariamente deben implementar un esquema semejante. Sin embargo, las tensiones sí surgen de la separación conceptual, porque las tres carreras primeras carreras fueron diseñadas desde una óptica central y nueva, mientras que Salud tuvo más tiempo de maduración y se consolidó sin un pleno apoyo estatal. ${ }^{255}$

El efecto de los montos y la distribución del gasto, se reflejan claramente en los resultados del proyecto de educación intercultural en zonas indígenas. Por un lado, la ubicación del ingreso en relación con los promedios nacionales de la educación superior, impacta los resultados finales para los alumnos, en función de su enfrentamiento, en el mercado laboral, con alumnos provenientes de instituciones con mejores condiciones. Independientemente de la dimensión comparativa, es clara la

\footnotetext{
${ }^{255}$ Luego del planteamiento logrado entre el diseño curricular gestado en la CGEIB y las adiciones en la UIEM para las primeras carreras, la contraposición con Salud es notable. Para la estancia de 2011 eran evidentes las tensiones entre el núcleo original de carreras frente a Salud. La visión de vinculación comunitaria tenía en esta última una propuesta de apoyar la autosubsistencia o el complemento alimentario o a la salud, claramente opuesta a las necesidades que existen en las otras carreras, sobre todo en Desarrollo Sustentable, que veían la propuesta de Salud como claramente "extensionista". Las pláticas con los profesores de ambos extremos, la participación en reuniones sobre "Vinculación" y la observación directa de la implementación de ambas posturas, expone en primera instancia, no la ventaja de una sobre otra, sino fundamentalmente, que la diferencia en la génesis de ambos modelos produce fricciones y desde luego, conductas y conceptualizaciones distintas entre los alumnos de cada modelo.
} 
correlación: mejores salarios-mejores profesores. Toda la cadena institucional: SEPCGEIB-Rectoría-Profesores, está de acuerdo con esta correlación. Se expuso cómo el entusiasmo por el proyecto convocó a profesionales de nivel y cómo el salario determinó que declinaran integrarse; un suceso que todos lamentan.

Ya al interior, la relación de alumnos por maestro está definida por los recursos destinados a la contratación de profesores. Las condiciones de carga académica, administrativa y de investigación, inciden directamente en los alumnos. La mejoría en esta correlación, del inicio del proyecto a la fecha, definitivamente establece un mejor "bien gubernamental", pero no hay que olvidar que fue determinado de manera exógena por el Estado en su conjunto. La disposición a mejorar no sólo el presupuesto, sino sobre todo, la distribución del mismo, se expuso como uno de los índices donde claramente se ejerce el poder político mediante el gasto global. No es un accidente que, aún incrementándose el presupuesto, se haya disminuido la proporción destinada a salarios; esto determina que para poder contratar a más profesores se haya tenido que sacrificar el nivel salarial. Paralelamente, el capítulo destinado a bienes muebles e inmuebles ha crecido de manera notoria, en atención a las necesidades de infraestructura y equipamiento. No se puede dictaminar, desde la postura sostenida aquí, hasta dónde ha sido una buena decisión mantener bajos los salarios de los profesores, pues lo que interesa es mostrar que en términos estatales las decisiones sobre el gasto son claramente un ejercicio de poder, porque impactan las conductas y las conceptualizaciones de aquellos que toman los bienes ofrecidos por la universidad.

Por último, sobresale el papel que las becas tienen para animar la integración al proyecto universitario y su permanencia en éste. El modelo PRONABES está más allá del diseño propiamente intercultural y es isomorfo a toda la educación que imparte el Estado. El programa se va integrando a todas las instituciones de educación pública, federales o estatales, en donde los únicos rubros de decisión, son aquellos que tocan a los montos efectivos, lo que puede determinar que alumnos que cumplen con los requisitos de participación, queden excluidos por la escases del recurso, generando como se ha insistido, la necesidad de implementación de mecanismos de justicia para discriminar a unos sobre otros. 


\section{El campus-símbolo.}

En septiembre de 2004, iniciaron los cursos con rector designado, personal contratado, alumnos admitidos y plantel rentado. Era una preocupación desde esa fecha, conseguir un terreno adecuado para la edificación de las instalaciones definitivas, dado el carácter provisional de las iniciales. Tres temas mayores afectaban la culminación de este tema: conseguir el terreno adecuado; conseguir los fondos necesarios; y definir el programa arquitectónico, que supone tener clara la relación entre los servicios de la universidad, el número de usuarios, y la clase de edificio que se quiere. Dado el apasionado carácter con el que muchos de los involucrados abordaron el inicio la primera universidad intercultural de México, la construcción del edificio implicó una profunda reflexión sobre el tipo de construcción que se quería y qué relación iba a tener con los ideales del proyecto. Esto involucraba la cosmovisión indígena presente, la arquitectura prehispánica y la reflexión sobre estos temas tanto en su dimensión local como nacional. $^{256}$

Hay que hacer en este punto una precisión de la mayor importancia. Los bienes gubernamentales que han definido el interés de este trabajo son aquellos que los alumnos se apropian, con el condicionante de un comportamiento específico. En este sentido, habría que aclarar si el gasto gubernamental en un edificio, es "apropiado" de manera análoga a la de los servicios educativos. El centro del ejercicio del poder por intercambio supone la transferencia de recursos materiales, ideales o simbólicos y servicios del que los posee a un alter, con condiciones específicas. En este sentido se puede hablar de una situación en la cual los recursos que controla un actor pueden pasar al control de otro; ${ }^{257}$ llanamente, que el nuevo poseedor puede "apropiarse" o "usufructuar" los bienes o sus efectos directos, donde vaya o esté, y su posesión y uso se prolongara en virtud de la finitud, caducidad o perdurabilidad del recurso.

\footnotetext{
${ }^{256}$ Es muy interesante cómo en todas las conversaciones sobre los elementos culturales involucrados en el proyecto, al pasar del ámbito local-regional al nacional, el horizonte efectivo es claramente Mesoamérica. Tal hecho no es problemático pero sí profundamente llamativo, pues en la dimensión clasificatoria que opone pueblos originarios con Estado-nación, comporta un altísimo contenido de elementos culturales que son asociados a los pueblos "cultivadores" en oposición a los "cazadores- recolectores". La cultura agrícola, que corresponde a una porción de México y América Central, está asociada a Mesoamérica (Kirchhoff, 1992), quedando la parte semidesértica y desértica más al norte, asociada a los segundos, lo que se denomina comúnmente Aridoamérica. Sin embargo, en el discurso cotidiano en la UIEM, se empata recurrentemente Nación con Mesoamérica, así que las reflexiones sobre el origen y cimiento de las culturas indígenas y el horizonte del rescate o la revitalización, cotidianamente se empata con lo mesoamericano. Para el edificio, justo los elementos están asociados a la arquitectura mesoamericana y la cosmovisión mazahua, de pueblos cultivadores.

${ }^{257}$ Esta sentencia se alinea con la concepción adamsiana de control, distinta de la percepción de "poder por control" que he propuesto; la demarcación se encuentra en el Capítulo 2, particularmente en la nota 42.
} 
Los recursos "encapsulados" en un edificio se ajustan claramente al tipo de bienes definidos como públicos: recursos que se liberan para todos, cuyo disfrute no se puede limitar y aquel que los disfruta, lo hace conjuntamente con otros. En términos clásicos, ello supone la imposibilidad del uso privado lo que define el impedimento de apropiárselos. ${ }^{258}$ Así, las determinaciones asociadas al edificio, tanto en su materialidad, su diseño funcional y estético, como en su carga simbólica, no están planteadas para apropiarse en sentido estricto. Si bien los que habitan el edificio pueden experimentar una sensación de pertenencia o propiedad ocasionada por las características del edificio, lo que queda de tal experiencia, no es una recurso que pueda ser llevado, pues está atado a su materialidad. Ello es más evidente si se plantea cómo la experiencia, el efecto, pudiera ser transferido a otro actor; esto es totalmente imposible. Lo que se puede transferir es la memoria del efecto, pero la experiencia, como tal, está encadenada de manera indisoluble a la presencia del individuo en el sitio.

Estas aclaraciones son relevantes, en razón de que el edificio y su diseño final, sí buscan crear un efecto, y dicho efecto sí tiene una intención determinada. Pero tal efecto e intención, es decir, la orden, no ocurre como producto de un mecanismo de apropiación. Las conductas y conceptualizaciones que se generan no están condicionadas por la apropiación de "algo" sino, como expuse, por un fenómeno externo que se presenta al individuo, con una disposición tal, que detonen en él, conductas, sensaciones y reflexiones de un tipo determinado. Esta definición expresa claramente lo que llamo poder por control, es decir, que el efecto es producto de la presentación de elementos específicos -con características, secuencias y magnitudes precisas-, que no se transfieren y que no necesariamente suponen el establecimiento de una relación entre el que plantea el efecto y el que lo experimenta. ${ }^{259}$

\footnotetext{
${ }^{258}$ Es evidente que lo público de un bien se termina cuando su asignación y disfrute, es asignado a un privado; es decir, que "nace" como público pero se materializa de manera exclusiva, sacándolo de tal ámbito. De ahí que el concepto bien gubernamental es más adecuado, pues permite separar cuándo el disfrute va a ser público y cuándo va a ser privado.

${ }^{259}$ Hay que tener mucho cuidado en discriminar lo que constituye la expresión interna del sujeto y lo que constituye la búsqueda de efectos. La manifestación arquitectónica de una cosmovisión o gusto estético, ocurre al margen de cualquier efecto de poder; sin embargo, existen otras dimensiones que se dan de manera paralela a la expresión estética y que buscan efectos. Un ejemplo pertinente es el del mundo del teatro. La escritura de una tragedia o una comedia busca desde luego, la expresión estética de cierto tipo de sentimientos al margen de los demás y centrados únicamente en el autor; no obstante, la dimensión escénica tiene que estar diseñada pensando en la detonación de dichos sentimientos en otros individuos, fuera de la esfera del autor. Esto es ya un efecto social pre-determinado y que produce en los espectadores conceptualizaciones que de otro modo no tendrían. Quiero hacer mucho énfasis en este aspecto, pues conviene eliminar la percepción de que cualquier efecto social es un efecto de poder. Pero, recordando un célebre fenómeno escénico y de poder, Orson Wells desató en 1938 con la transmisión radiofónica dramatizada de una invasión extraterrestre, una respuesta social y de pánico, con dimensiones
} 
Los argumentos anteriores, buscan dar razón a lo que se va a presentar, pues abarca fenómenos de poder que no están determinados por la vía del intercambio como es la idea central, sino por la vía del control. No obstante, la importancia que tiene todo el planteamiento del edificio para la vida de la UIEM, genera un significativo número de efectos intencionales, que vale la pena rescatar y por otro lado, ejemplificar el ejercicio de poder por esta vía.

La renta de las primeras instalaciones no podía ser indefinida y existía el compromiso del gobierno federal de aportar 25 millones de pesos para la construcción del edifico propio (ver anexo 4); de hecho, se garantizó el recurso por la CDI, aun antes de contar con el terreno; el Gobierno del Estado de México aporto como complemento, siete millones y medio de pesos. La gestión del terreno fue muy complicada. Inicialmente, como se acordó en el Convenio de Coordinación, se gestionaría ante el municipio, que aporte un terreno de mínimo diez hectáreas. Como el apoyo del municipio era poco, vía los ejidatarios se propuso un terreno muy inadecuado junto al basurero municipal. Esta inutilidad derivo en la búsqueda de otros terrenos, que culminaron el en actual, ubicado en una de las nuevas avenidas de San Felipe (Ver anexo 6).

Este terreno de 15 hectareas pertenecía a la Escuela Secundaria Técnica No. 12 de los Servicios Educativos del Estado de México y había sido donado por los ejidatarios de San Felipe. Tanto la directiva de la secundaria, los padres de familia y los

increíbles. En el prólogo al guion de dicha emisión se lee: "Peter Bogdanovich preguntó a Orson si había previsto ese tipo de respuesta a lo que respondió: 'El tipo de respuesta sí...Todos lo anticipamos felizmente. Pero su extensión nos dejó pasmados a todos. A los seis minutos de estar en antena, las centralitas de todas las emisoras de radio a lo largo y ancho del país empezaron a iluminarse como árboles de navidad. Los hogares se quedaron desiertos y las iglesias se abarrotaron [...] Cuando radiábamos la fantasía de la destrucción de Nueva Jersey, descubrimos que la extensión de la capacidad de nuestro país por dejarse arrastrar por una emoción había sido infravalorada” (Koch 1996: 9). Es increíble la declaración pero sobre todo, el formato noticioso que el guionista Howard Koch y Orson Wells como director y locutor dieron a su emisión con la intención clarísima de producir una sensación de verdad en los radioescuchas y por tanto, detonar en ellos conductas y conceptualizaciones que de otro modo no tendrían. Las cuestiones del desconocimiento o no intencionalidad en la escala o las formas específicas, podrían estar relacionadas a cierta candidez sociológica o a una manifiesta irresponsabilidad en la búsqueda de un efecto púramente estético y escénico, al margen de las acciones resultantes. El punto central es que Orson Wells intentó crear en otros individuos un efecto real, con base en la presentación de elementos específicos -con características, secuencias y magnitudes precisas-, que no se transfieren y que no necesariamente suponen el establecimiento de una relación entre el que plantea el efecto y el que lo experimenta, ejerciendo llanamente, el poder por control. A la fecha, fenómenos de este tipo ocurren en las redes sociales donde se busca, por la presentación de una idea inexacta o falsa, producir sensaciones de verdad, escudados en el "aire" de veracidad que puede cosechar un mensaje al ser repetido innumerables veces y la imposibilidad de cotejarlo con una fuente externa. El rumor, de boca en boca, tiene un efecto semejante, aunque por la velocidad de propagación y la transmisión por actores no anónimos, los efectos macroscópicos son de menor intensidad y por tanto mayores posibilidades de falsación. 
ejidatarios, estuvieron de acuerdo en que se podían sustraer 13 de las 15 hectáreas, quedando 10 para la universidad y 3 para los ejidatarios. ${ }^{260}$ La donación implicaba además que la UEIM construyera en la Secundaria un salón para computación y lo dejara equipado. ${ }^{261}$ Estas negociaciones y las asociadas al proyecto arquitectónico y su construcción, fueron de mucho desgaste y ocuparon por largo tiempo la agenda del rector. Vale la pena mencionarlo de manera central, puesto que según refirió el propio rector, este "tiempo" político y administrativo, aunado a otras actividades no sustantivas, impidió la reflexión profunda del tema eje de la universidad: la construcción del modelo de educación intercultural: <<cuando el rector dejo el tema académico, los directores de división también lo soltaron>>, reconoció en la entrevista. La presión adjetiva que sufre cualquier organización, impide la implementación acabada de lo sustantivo, en cuyo caso, las determinaciones isomórficas tienden a llenar el hueco; de ahí que se han expuesto algunas de estas determinaciones contrarias al proyecto intercultural, pero que se infiltran, justo por dificultades como la descrita arriba.

El 18 de abril de 2005, en la reunión del Consejo Directivo \# 5:

...la Mtra. Sylvia Schmelkes del Valle, comenta que la UIEM por ser la primera en su tipo, sea testimonial en el sentido de tomar en consideración los materiales y formas de construcción de los saberes locales de la entidad, a su vez menciona que sostuvo una reunión con el Comité Administrador del programa federal de Construcción de Escuelas (CAPFCE), en donde se planteó la posibilidad de que las Universidades Interculturales respeten todas las recomendaciones técnicas del CAPFCE para sus universidades y se puedan tener así las variantes, que permitan respetar las formas arquitectónicas de la localidad y no romper el paisaje. Resaltando que el CAPFCE está abierto a cualquier tipo de cuestiones a este respecto y que al solicitar los planos arquitectónicos se tomen en cuenta sus recomendaciones. EI Lic. Eduardo Zarzosa Sánchez comenta que después de hacer notar la diferencia de los materiales que anteriormente se usaban, por ejemplo, el tabique, el tabicón y el block, sugiere que queden claros los términos utilizados en los puntos anteriores, a lo que la Mtra. Sylvia Schmelkes del Valle, hace mención de que se refiere a las formas tradicionales de construcción de la comunidad, que son donde están plasmados los saberes

\footnotetext{
${ }^{260}$ El primer rector, Felipe González, comentó en entrevista lo complejo que fue armonizar todo este proceso, tanto por los mecanismos legales para rehacer el proceso de donación ante las autoridades agrarias y las aprobaciones legales del Ayuntamiento y las autoridades educativas del Estado de México y federales. Adicionalmente, fue difícil, pues el primer proceso de donación, evidenció la posibilidad de la segunda, lo que determinó que los ejidatarios quisieran recuperar un poco, pues habiendo donado suelo agrícola, con los años se había transformado a un uso habitacional.

${ }^{261}$ Según recuento de hechos, plasmados en el Acta del Consejo Directivo \# 17, del 16 de marzo de 2007.
} 
propios, resaltando que el tabicón carece de ellos, puesto que es un material de importación y además se tienen muchas desventajas, el hecho de contar en el país con este tipo de materiales que no ayudan a fortalecer la cultura. El Lic. Eduardo Zarzosa Sánchez, pregunta si los muros de la Universidad tendrían que ser de adobe, la Mtra. Sylvia Schmelkes del Valle, hace notar que hay varias posibilidades para lo que sólo sería cuestión de abrirse a varias posibilidades con el CAPFCE. ${ }^{262}$

$[\ldots]$

"EI M. en C. S. Felipe González Ortiz, comenta a los integrantes del Consejo Directivo que se sostuvieron pláticas con varias empresas de arquitectos, a los cuales se les transmitió el modelo de Institución que debe estar acorde con la imagen e idea que se tiene de la Universidad, y se invitó a presentar la propuesta a la empresa que captó y aceptó las condiciones del concepto en cuanto a la interculturalidad [...] Los arquitectos inician la presentación, haciendo notar que ellos han elaborado diferentes escuelas, pero que este es un modelo especial para el cual han tomado los puntos que se les han sugerido, como son, el logotipo de la Universidad, la forma circular, la arquitectura solar, los tres edificios de gobierno que semejan las tres piedras del fogón, haciendo a la vez contraste con la simetría de los bordados de las mujeres mazahuas, aulas en forma circular con corredor fortificado, centro comunitario, centro de actividades, etc. [...] La Mtra. Sylvia Schmelkes del Valle, dice que está muy contenta con el anteproyecto y sugiere que dentro de todo esto es importante estar abiertos a todo tipo de aportaciones y experiencias para lo cual sugiere el acercamiento con la gente de la comunidad, que conoce la cultura y la región para ver los datos que ellos pueden aportar en cuanto a la Cultura Mazahua (UIEM, 2005: 4, 7-8). ${ }^{263}$

Resulta insólito lo bien que plasma el acta mencionada los problemas en torno a la construcción de un edificio nuevo y novedoso en el contexto de un proyecto de educación superior intercultural. Lo inicial es el impulso gubernamental de hacer de la construcción un hito en el sitio. Esta determinación exógena impulsa la utilización de materiales y formas de construcción existentes en los saberes de la región; pero la región ha perdido en su gran mayoría estos saberes, que en términos de edificaciones perenes se acota a construcciones de adobe con vigas de madera y cubierta de tejas. ${ }^{264}$

\footnotetext{
262 El CAPFCE posteriormente paso a conformar en 2008 el INIFED (Instituto Nacional de la Infraestructura Física Educativa). Estas instituciones a nivel federal tienen sus pares a nivel estatal: el CIEEM (Comité de Instalaciones Educativas del Estado de México), que pasó a conformar, luego de la reforma federal el IMIFE (Instituto Mexiquense de la Infraestructura Física y Educativa). Aquí hay que hacer notar que las facilidades otorgadas a nivel federal comportaban trabas a nivel estatal, en concordancia con todo el tema de la relación de tensión federal-estatal delineada anteriormente.

${ }^{263}$ Todos los subrayados son míos.

${ }^{264}$ En otras dos universidades interculturales: Chiapas y Michoacán, el peso de la tradición colonial de la ciudad, San Cristóbal de las Casas y Pátzcuaro respectivamente, imperó en la construcción de los edificios, es decir, blancos, cuadrados, con tejas y viguería de madera aparente. Dado que la tradición
} 
Sin embargo la memoria constructiva de esta técnica vernácula se da por perdida, en virtud de que en ningún momento del proyecto se la plantean; es tan fuerte esa impresión que la referencia al <<tabique, tabicón y block〉> aparece como algo "tradicional". Aclarado el punto, la referencia al adobe, confronta la idea de que entonces la universidad debe ser construida con adobe. Estas ideas muestran una interesante exposición de los debates de tipo "intercultural" en torno al estilo y técnica del edificio; nótese, sin embargo, que este debate ocurre en una instancia estatal que es la que va a tomar la decisión.

El rector refiere que se platicó con los arquitectos, en torno a los elementos y necesidades que debería presentar un proyecto de arquitectura "intercultural". Como refiere la minuta, los arquitectos consideraron centrales: el logotipo de la Universidad, la forma circular, la arquitectura solar, los tres edificios de gobierno que semejan las tres piedras del fogón, haciendo a la vez contraste con la simetría de los bordados de las mujeres mazahuas, aulas en forma circular con corredor fortificado, centro comunitario y centro de actividades.

¿Cómo fue que se decidieron estos elementos? En una entrevista sobre el tema, el primer rector refiere que su idea base era tener un edificio notable y moderno. Ello para $<<$ salirnos de la construcción gris popular de la región [...y] darle a la gente un espacio de color $>>$; $<<$ Crear un edificio digno para culturas dignas $>>$; $<<$ Un edificio diferente, hermoso, anclado en la cultura de los pueblos >>. Para lo anterior convocó a una reunión con varios actores locales y los viejos de las comunidades, para pedirles consejo acerca de la forma que debería adoptar el nuevo edificio. Menciona que de inicio $<<\ldots$ muchos hablaban de un edificio cuadrado tipo CAPFCE, pues así es la cultura>>, pero avanzando las discusiones se fueron decantando por un cambio: de cuadrado a redondo. Esto tuvo tres apoyos. En la reunión se mencionó una tradición mazahua que utiliza un palo como eje del cual salen unas palomitas y que generan un espacio circular; también la idea de la serpiente enroscada, Quetzacoaltl, que aparece en el logotipo de la universidad y que en la sala Azteca del Museo Nacional de Antropología, existe una pieza donde está la serpiente enroscada, circular y ascendente, como modelo inspirador.

constructiva en esas regiones del país es más fuerte y viva, llama la atención la falta de contundencia en la aparición de elementos arquitectónicos indígenas y el alineamiento con el espíritu "colonial". Incluso en la reunión que sostuvo el rector de la UIEMcon miembros de las comunidades, se llegó a sugerir la incorporación de faroles tipo "colonial" para la iluminación del edificio. En las otras universidades, lo que domina de manera fundamental son, como se menciona de manera un tanto despectiva, los edificios "tipo CAPFCE". 


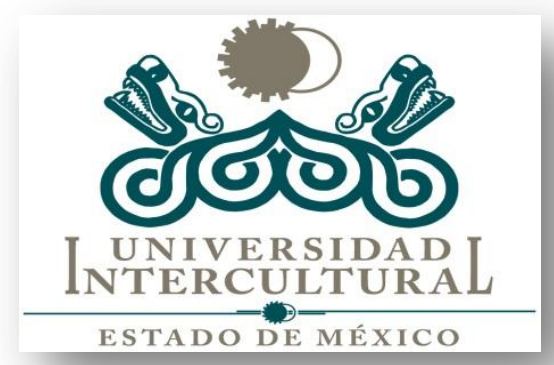

Pero tal vez la influencia más poderosa, y que remachó la idea de círculo, fue la mención por un miembro de las comunidades, de la existencia en la zona del Valle de Toluca, de una pirámide circular: Calixtlahuaca. $<<$ Con eso, dije, tiene que ser redondo >>, declaró el ex rector.
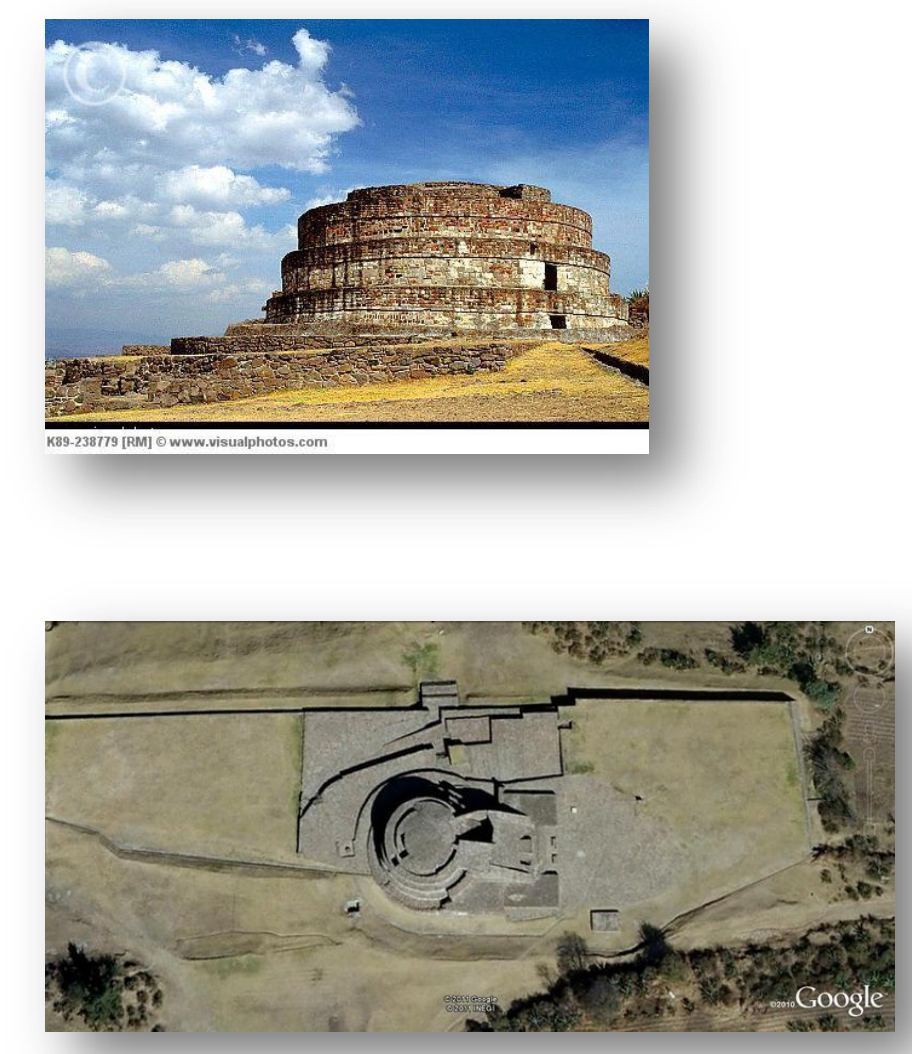

En el proceso hubo varios despachos arquitectónicos que presentaron distintos proyectos, entre ellos uno cuya planta arquitectónica era semejante a la de Teotihuacan con la rectoría en un punto central, elevado, <<como el Altepetl >> y los demás edificios subordinados. Otro era muy moderno, con diseño de $<<\ldots$ grecas y adornos muy bonitos pero tipo CAPFCE $>$. Así que se inclinaron por el diseño de serpiente enroscada. Otro de los condicionantes que pusieron a los arquitectos fueron los salones redondos. 
Menciona también el rector que se decidió esto porque en la pedagogía intercultural, el conocimiento no es cuadrado, sino infinito, fluido, producido por lo redondo. El salón redondo, permite la circulación del conocimiento, evitando una sola dirección maestroalumno, que impide el conocimiento colectivo. La morfología tradicional está remarcada por las sillas con paleta y escritorio <<cuadrado>>, base de la pedagogía tradicional; de ahí que se pensaba en un mobiliario diferente como una banca <<circular>> alrededor del salón o una mesa <<circular>> tipo seminario. ${ }^{265}$

En cuanto a la morfología circular del edificio, refiere que permite una mayor integración pues todos los salones vierten a un pasillo continuo, sin niveles, que les permite integrarse con todos y desembocar en la plaza central a donde convergen todos. En ese sentido, él ubicó la rectoría en un salón de arriba, pero no <<hasta arriba >> para eliminar esta idea de jerarquía, parte central del modelo intercultural.
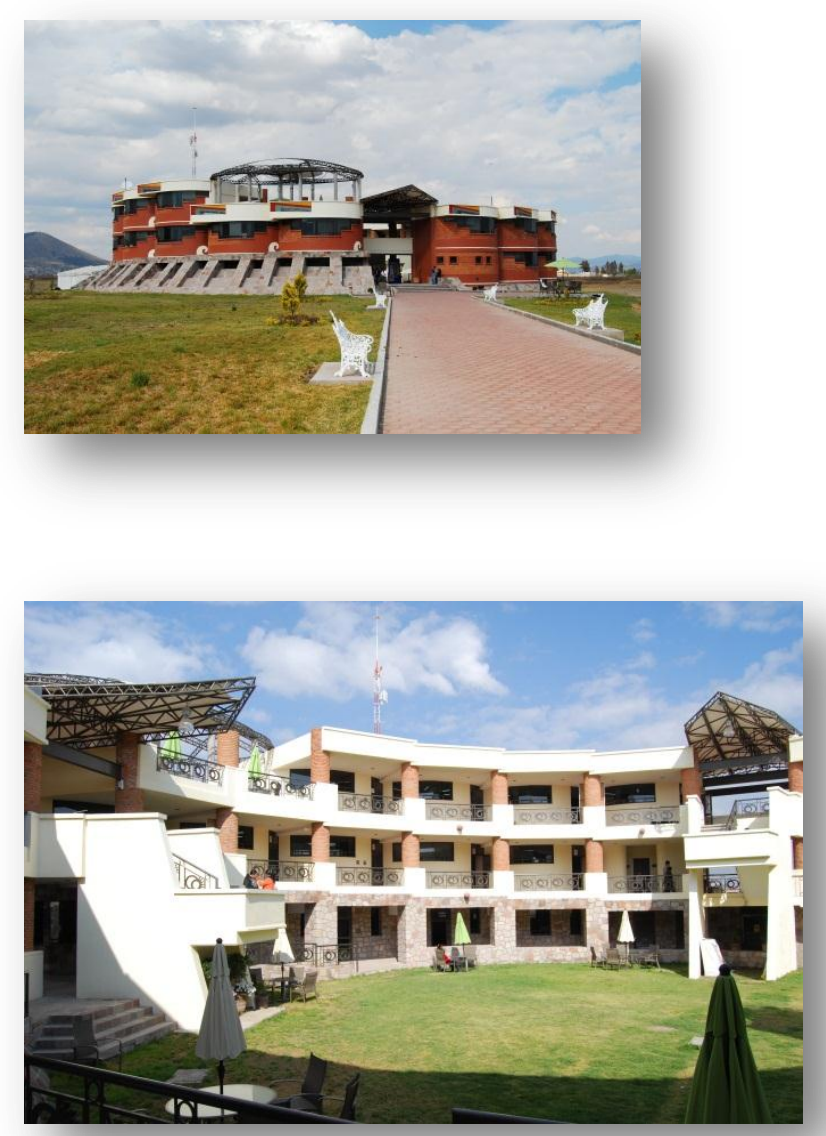

\footnotetext{
${ }^{265}$ A la fecha, los salones tienen bancas con paleta y escritorio cuadrado para el profesor. Lamenta el ex rector que las prisas en el ejercicio del presupuesto impidió diseñar un mobiliario acorde con el modelo y por lo tanto se compró algo provisional. Hay que hacer notar que en un inicio se trató de obligar a los profesores a prescindir del escritorio para quitarles jerarquía; dicha política fue un fracaso y las protestas determinaron la aparición de escritorios "cuadrados" (Ver anexo 7).
} 
El edificio principal, de aulas para los estudiantes, no era el único que debería estar en concordancia con este espíritu. Todo el conjunto ese pensó en los términos descritos. De ahí la idea de que los tres edificios circulares aluden a las tres piedras del fogón, sustento simbólico y uno de los ejes que sustentan la cultura mazahua. La comunidad de estudiantes y maestros mazahuas coinciden que el modelo piedras-fogóncomal-tortillas permite ubicar la idea del cosmos y su energía primigenia, sostenido por estas tres piedras simbólicas sostén del mundo, que dan sentido a la cultura del maíz, eje fundamental de la cultura indígena. Este núcleo generador, los tres edificios-fogón, serviría como base y determinaría la disposición subordinada de los demás edificios con cargas simbólicas semejantes. Adicionalmente, la ornamentación con referencia a la cultura local o prehispánica era obligatoria. Así, el edificio principal y los otros dos edificios ya terminados, la rectoría y la biblioteca, están llenos de detalles en este sentido (Ver anexo 7). El último edificio por construir con este esquema, es la Clínica de Salud, que está planeada sobre la planta arquitectónica del diseño de una flor mazahua de cuatro pétalos.

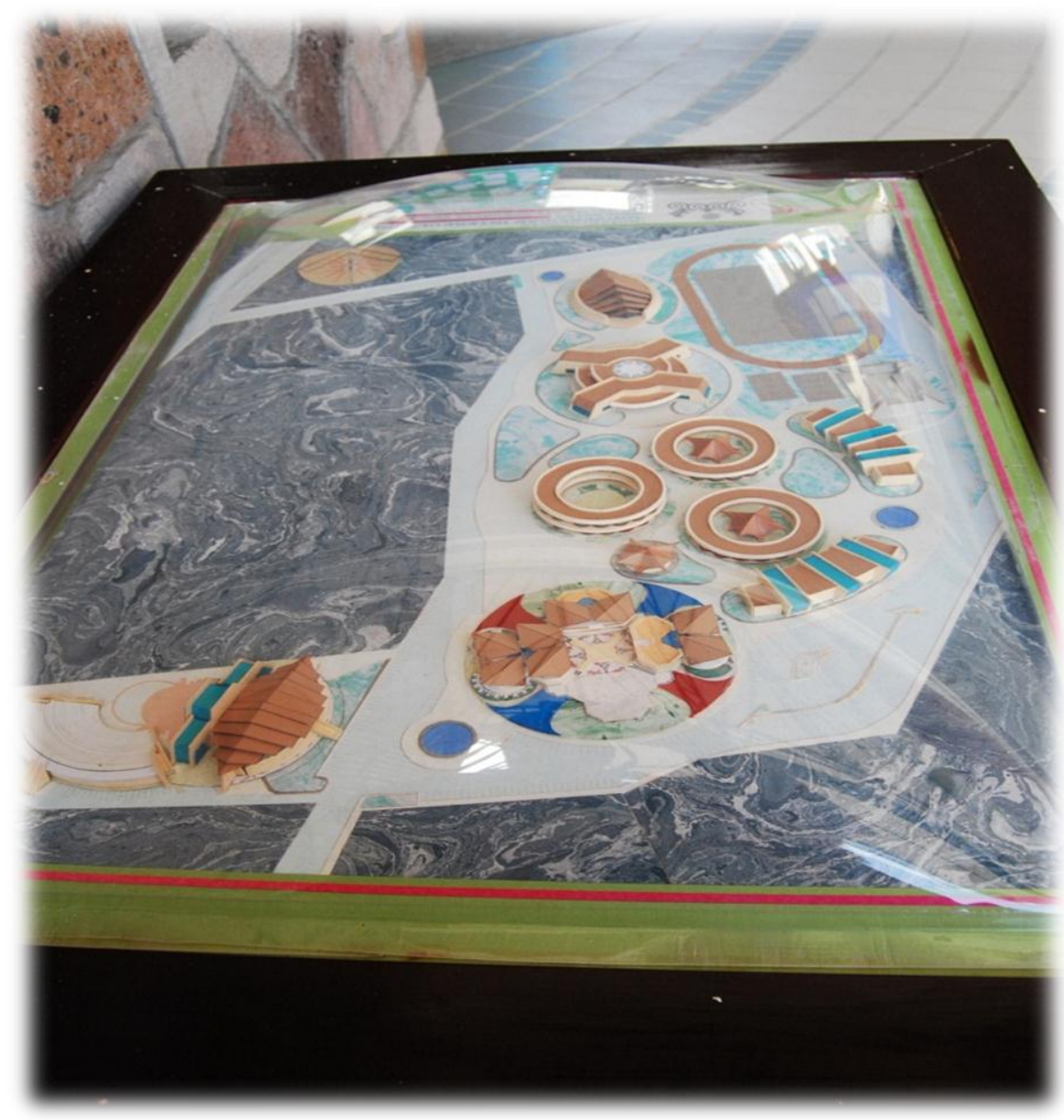


Ahora bien, ¿cuáles son los efectos de este diseño en la vida interna de la comunidad? En primer lugar se tiene que rescatar el hecho de la notable diferencia en términos de presencia, con cualquier otro edificio de la localidad. En entrevistas con alumnos que cursaron en el otro edificio, revelaron justo un sentimiento de orgullo y apropiación. Estos individuos estaban muy impresionados por todo el proceso de diseño y el relato simbólico de lo que contenía. Sobre todo, era muy recurrente la referencia a las tres piedras del fogón, la serpiente Quetzalcoatl y los detalles del sol y la luna como oposiciones originarias. También se detectó apropiación en virtud de las referencias al carácter circular del conjunto, a la manera del conocimiento en relación a que este $<<$ no es cuadrado>>. Éste es uno de los primeros éxitos del diseño, pues implanta la idea de una oposición con el conocimiento científico-occidental, de naturaleza <<cuadrada〉>. Es evidente el bajísimo número de edificios circulares entre las culturas prehispánicas, en oposición al abundante modelo de edificios de planta cuadrada; sin embargo, en este nivel, la ideología intercultural funciona eficazmente al inyectar la idea de una ruptura necesaria con el orden establecido, en términos clasificatorios: lo "occidental" es cuadrado, lo indígena e intercultural es redondo.

La circulación de los individuos en el pasillo espiral, si ocurre tal y como lo deseaba el rector: vertiendo a la circulación general y luego a la plaza. Hay que hacer notar que otros diseños no circulares podrían crear efectos semejantes, pero aquí se privilegia el escogido por sobre la dinámica que experimentan como cuadrada, rígida y no intercultural.

La plaza circular funciona efectivamente como un "centro" de reunión, a donde se confluye constantemente para diversas actividades de clase y extra clase. Destaca la facilidad con la que los alumnos y el profesor abandonan el salón de clases para ocuparla y desarrollar alguna actividad que requiere mayor espacio que el disponible en el salón. ${ }^{266}$ También, dicha disposición circular la hace muy exitosa para el desarrollo de eventos que permiten observarlo desde los corredores y hacia abajo. ${ }^{267}$ Un caso muy frecuente es el desarrollo de ceremonias o escenificaciones de todo tipo. En particular,

\footnotetext{
${ }^{266}$ Yo mismo participé en dos ocasiones en estas actividades y me sorprendió la buena disposición para salir y llevar a cabo lo dispuesto por el profesor.

${ }^{267}$ La creación de un espacio interior circular, determina la percepción de los usuarios. En una ocasión, alumnos de secundaria iban a un evento en el patio interior $<<$ Y vamos a entrar al estadio $>>$ les oí decir. Más peculiar todavía, es la referencia a un folleto anónimo que circuló en la UIEM, con motivo de ciertas inconformidades estudiantiles. En éste, se mencionaba la intolerancia de la universidad con los alumnos y el abuso de poder; para ello, se hacía referencia a la inspiración del edificio en el Circo Romano. La persona que me lo comentó también refirió que parecía ser de un grupo de estudiantes indígenas de alguna denominación protestante. Destacan pues la lectura totalmente ajena al espíritu original.
} 
destaca que regularmente se utiliza ese espacio para danzas de tradición "mexica" o comúnmente conocidos como concheros. El espacio circular es muy adecuado para estos fines y el centro geométrico del edificio es el punto que en esas ceremonias se toma como <<ombligo de la madre tierra〉> y desde donde se hacen ofrendas o agradecimientos a los distintos rumbos del cosmos; ahí se deposita el copal y los bailes ocurren en relación a dicho centro. ${ }^{268}$

Es conocida popularmente la importancia que la arquitectura prehispánica concedía a la relación del sitio con las montañas como marcadores espaciales y sagrados y paralelamente, la precisión e importancia de las orientaciones geográficas que dan testimonio de eventos astronómicos. ${ }^{269}$ Esta dimensión simbólica tan fundamental, toma en los relatos sobre el edificio una importancia central. Es una referencia común, que las tres entradas del edificio están orientadas hacia los cerros importantes de región y, paralelamente, que están orientadas a la salida del sol (la entrada Este) y las otras dos (Nor-Oeste y Sur-Oeste) a las posiciones del Sol en los solsticios de verano e invierno. Claramente, el deseo de inyectar estas conceptualizaciones exógenas en la población -lo simbólico del edificio- es profundamente exitosa, pues al preguntar sobre estas dimensiones, los "habitantes" del edificio siempre tienen una respuesta. Son insólitas no obstante, las imprecisiones reales en las que se cae: el edificio circular tiene tres entradas equidistantes, lo cual implica que el ángulo entre cada una es de $120^{\circ}$, lo cual es incompatible con los $46^{\circ}$ de amplitud máxima que tiene el sol es su desplazamiento aparente en la esfera celeste entre el verano y el invierno; así, si bien una de las aberturas, la Este, está claramente orientada en esa dirección, las otras no coinciden en nada con los solsticios astronómicos, pero se les atribuye esa cualidad. Lo mismo ocurre con las montañas, pues el Cerro de Jocotitlán, la elevación más notable de la región (3910 msnm), se considera que define la orientación de la puerta Este, sin embargo, tiene una desviación de aproximadamente $10^{\circ}$, claramente incompatible con la rigurosa precisión prehispánica en las orientaciones. Para las otras dos aberturas se relata en

\footnotetext{
${ }^{268}$ Es insólito como este efecto de apropiación simbólica, el centro como ombligo de la tierra, fue cancelado de manera exógena, al decidir cubrir la superficie de pasto de la plaza, con adoquín, impidiendo ese contacto con la tierra. Los criterios para dicha transformación, si bien pueden ser válidos, transforman de manera exógena un patrón de apropiación inicial de espíritu tradicional, roto por el adoquín, producto industrial y barato, que soluciona necesidades inmediatas, pero rompe la idea de contacto con lo tradicional que mana del edificio.

${ }^{269}$ La importancia de los cerros como sitios llenos de agua y contenedores de las semillas fundamentales y casa de los dioses: el Altepetl; en la tradición mesoamericana, es una de las constantes del diseño arquitectónico y fuente del poder político. Ver: Los orígenes del poder político en Mesoamérica, de Enrique Florescano (2009).
} 
abstracto la importancia de otras elevaciones, evidentemente menores en altura y precisión, pero no en simbolismo. Se me contó una historias sobre que la apertura NorOeste, apuntaba a un pequeño cerro, del que se cuenta, sirvió como punto de descanso al águila que posteriormente se posaría en el nopal y devoraría a la serpiente en el islote de Tenochtitlan. Las imprecisiones geográficas y astronómicas, centrales en el discurso prehispánico, nulifican la funcionalidad real del edificio en esos términos, aunque exponen la pertinencia ideológica del diseño arquitectónico y toda su carga simbólica, inyectada de manera exógena por los agentes del Estado.

Por último, se debe dar cuenta de que la diferencia entre un diseño "tipo CAPFCE" y lo que aquí se construyó representa una elevación substancial en el costo del edificio; grosso modo, el doble de la inversión. ${ }^{270}$ Esta duplicación de los recursos, necesaria para reafirmar la dimensión prehispánica, mesoamericana y mazahua del edificio, muestra la voluntad estatal de dar una dimensión arquitectónica a los supuestos formales y constitucionales del proyecto de educación superior en regiones indígenas. Esta "voluntad" de gastar más recursos no es criticable en razón de que esos montos pudieran invertirse en otras ampliaciones del proyecto; son útiles por reforzar la ideología de la interculturalidad en su dimensión espacial y en efecto, son muy exitosos en términos de inyectar esas conceptualizaciones. Las otras unidades del país no consideraron pertinente invertir tiempo y recursos en la dimensión arquitectónica. Ello no afecta el desempeño del proyecto de educación superior intercultural, pero sí lo caracteriza de manera diferente, es decir, que la voluntad exógena en el Estado de México pasó por la dimensión espacial, mientras que en otras entidades se consideró, de manera exógena, como no relevante; esto es, el ejercicio de poder ocurrió en ambos casos, ya por presencia, ya por ausencia.

\section{La estructura de las carreras}

En ningún otro insumo de una universidad, como lo son los mapas curriculares de las carreras, el ejercicio de poder se deja sentir de manera más intensa. La disposición completa de las materias y los contenidos mínimos es, en toda la extensión de la palabra, un programa exógeno. Esto no tiene nada de sorprendente: el enfrentamiento

\footnotetext{
${ }^{270}$ Esta opinión del costo al doble se desprende de una conversación con un arquitecto, en la cual refiere que la novedad del diseño, los problemas resultantes de la forma circular, las adecuaciones de puertas, canceles, herrería y detalles ornamentados y las dificultades constructivas, representan al menos un esfuerzo del doble del costo y con mayor tiempo de ejecución. Todos estos detalles pueden verse en el Anexo 7.
} 
entre quien sabe y quien no sabe, marca una diferencia fundacional en el fenómeno educativo y permite la construcción de una asimetría operativa, que lleva a los estudiantes a aprender y aprehender cosas que de otro modo no estarían en capacidad o posibilidad de saber. Desde el inicio se ha reiterado la idea de que esta oposición asimétrica, que enlaza a la UIEM con los pueblos indígenas de la región, es el corazón del ejercicio de poder del Estado. Desde la estructura filosófica y administrativa, el proceso enseñanza-aprendizaje tiene un componente exógeno de gran magnitud, pues aterriza, desde los expertos (de todo tipo), en las poblaciones locales que no conocen lo que van a aprender.

La siguiente aclaración es de la mayor relevancia, aunque se ha abordado constantemente y desde varios puntos de vista: no es que se desdeñen los elementos del modelo intercultural, que plantean la relación maestro-alumno como horizontal y que por tanto las partes pueden aprender una de la otra; el expediente intercultural, justo busca "horizontalizar" las relaciones inter-culturales. El asunto medular es que el sistema, desde su origen constitucional, no está diseñado para que el maestro aprenda del alumno, sino para que el alumno aprenda del maestro en un entorno intercultural. Aunque suena a perogrullada, ignorar este aspecto es ignorar la toda la lógica del proceso educativo; ello no implica desdeñar las retroalimentaciones alumno-maestro que en el sistema intercultural se presumen como de mayor intensidad, sino encuadrarlas en un apartado específico, para colocar en otro todos aquellos aspectos en donde los profesores conducen las conductas y las conceptualizaciones de los alumnos de manera exógena.

Aclarado lo anterior, lo primero que llama la atención es la estructura y contenidos de las diferentes carreras de la UIEM (Ver Anexo 8). Todo el esfuerzo de planeación discurrió con el personal que se contrató o consultó y que desde luego, venía de "fuera" de los estudiantes. Esta dimensión no excluye, desde luego, las peticiones originales al candidato presidencial, que estaban encarriladas claramente a formar egresados, capaces de conocer o reconocer, valorar o revalorar los elementos más queridos de las culturas indígenas de la región, para fortalecerlos, evitar su pérdida y darles un nuevo estatus frente a la sociedad y cultura mestiza del resto de la nación. Tampoco excluye la participación de profesionales indígenas o de la comunidad, que los hubo, en el diseño curricular.

El proceso comenzó con lo que se había destacado desde el Capítulo 4: que la debilidad del sistema en el medio rural e indígena y las duras condiciones de desarrollo 
de los individuos hacían necesario dedicar un periodo de la formación, para fortalecer y emparejar a los muchachos con el nivel universitario general. Este periodo de un año (dos semestres), denominado "Formación Básica", es igual para las tres carreras iniciales: "Lengua y Cultura", "Desarrollo Sustentable" y "Comunicación Intercultural". ${ }^{271}$ Incluye materias sobre "Lectura y redacción de textos" I y II; "Teoría del Conocimiento" y "Metodología de la Investigación"; "Antropología Social"; "Introducción al Desarrollo Sustentable y a la Comunicación Intercultural"; e "Informática" I y II. Esto se complementa con las materias de "Ingles" y "Lengua originaria". Ya se había mencionado que la decisión de "retrasar" la incorporación a la temática especifica de las carreras en particular era una decisión totalmente exógena con base en la idea de igualación, pero que por otro lado, dañaba a los alumnos en términos de volumen de contenido, porque la formación particular quedaba reducida a seis semestres, en demérito de los ocho que se dan en el resto del país. Al margen de las "buenas intenciones" en la igualación, es muy evidente que esta estructura inicial e igual para todos permitió a las academias de la universidad tener tiempo para pensar el contenido específico de cada carrera en un entorno desconocido, pues siendo esta la primera universidad intercultural de México, todo era novedoso. Así, la compresión de esos contenidos en el primer año, que fue una decisión clara y exógena, facultó condiciones para iniciar la UIEM sin saber la estructura final de las carreras. Esta "funcionalidad", que no es del todo claro si fue intencional o producto de las presiones de tiempo, tiene efectos profundos en el desarrollo de los alumnos. Como contraparte, permite incorporarse a la UIEM sin haber definido claramente la carrera a cursar, pues el "tronco común", ocasiona que la decisión definitiva ocurra hasta el final del primer año. Ello produce una mayor convivencia con los compañeros de otras carreras, una mayor retroalimentación y una convergencia más amplía en la idea base de la universidad: la interculturalidad y sus propósitos más profundos. El subproducto perverso, es la disminución de los contenidos profesionales y la pérdida de tiempo para alumnos aventajados cuya formación es más sólida.

Algunos de los argumentos a favor quedan refutados, al notarse que la carrera de "Salud Intercultural" decidió, de manera exógena, eliminar esta estructura inicial y, desde luego, invalidar los argumentos que le dieron sentido. Resulta ciertamente complejo dictaminar cuál modelo es mejor pues, como todo proceso de impacto social,

\footnotetext{
${ }^{271}$ Se puede cotejar la forma y el contenido similar en el Anexo 8.
} 
tiene resultados en favor y en contra. A favor está el hecho de que se fortalecen las competencias específicas de la carrera, evitando la pérdida de tiempo en materias "generales". También, que se reconoce la posibilidad del esfuerzo personal para "ponerse a nivel", en virtud de la mayoría de edad y agencia individual, que están un tanto ausentes en niveles inferiores por la natural falta de madurez personal. Y, desde luego, que no minusvaliza a los estudiantes al considerar que necesitan esos conocimientos, porque no ignora que los muchachos, con todo, han avanzado en el sistema tradicional con todas sus presiones y por ende determinar de inicio que no están listos para el conocimiento universitario. ${ }^{272}$ En los argumentos en contra se encuentra el hecho de que la eliminación del tronco común excluye una parte importante de la convivencia estudiantil, impidiendo lo que en la administración pública exigen los indígenas consistentemente, y que es conocido como "transversalidad"; si no hay transversalidad en la formación, es imposible exigirla en la ejecución. Por otro lado, se evita la convergencia filosófica y normativa en torno del concepto de interculturalidad. Esta declaración que a primera vista se presenta como púramente incidental, tiene un resultado efectivo y dañino al proyecto, en virtud de que la visión de lo que es interculturalidad en la carrera de Salud Intercultural se acerca mucho a una mezcla homogénea de elementos culturales provenientes de distintas partes del mundo, y paralelamente de distintas tradiciones culturales mesoamericanas o "aridoamericanas". En la composición de sus principios filosóficos, importa más la unidad humana que la cultura local; lo holístico sobre lo particular; la India o China sobre Mesoamérica. ${ }^{273}$

\footnotetext{
${ }^{272}$ Esta presión por remachar el carácter de desventaja en los individuos desiguales, fue descrito atinadamente por Charles Erasmus (1969) como el "síndrome del encogido". Paralelamente, en el proceso de entrevistas y platicas con los estudiantes, respecto de las inconformidades con el modelo de la UIEM, varios alumnos refirieron el bajo nivel como uno de los defectos, pues las clases abordan temas muy básico, lo que las hace aburridas; estos muchachos provenían de instituciones de áreas urbanas como El Oro, Atlacomulco o San Felipe.

${ }^{273}$ Destaca aquí la declaración de un profesor de la carrera de Salud, desde mi punto de vista, muy capaz y comprometido con el proyecto, que sin embargo refirió en entrevista: <<La interculturalidad es una "hoja del árbol" que representa la unidad humana; es una idea más para la burocracia del Estado que para su aplicación. El principio fundamental es la unidad humana; el tronco es la medicina de China y la India; la Azteca es nada más una rama. La relación entre todas es circular, pues el concepto de "energía" es universal〉>. Llama poderosamente la atención no lo sensible y profundo del argumento, sino su distancia con el mandato constitucional del artículo segundo, cuyo espíritu es el fortalecimiento y rescate de las culturas indígenas, en este caso la mazahua, y no su dilución en el fluir universal de la energía humana, cuyo efecto final, es justo lo que se quiere evitar: lo global barriendo lo local. Se confunde la dominación de Occidente, con su moderación o neutralización por culturas alternas, aunque provengan de China, Japón o la India. De hecho, destaca la declaración de un miembro de la UIEM, que cuando se propuso la materia de "Teorías del Conocimiento", insistió en la necesidad de incorporar lógicas alternas a la de Occidente, y mencionó, sorprendentemente, en concordancia con el ejemplo anterior, al pensamiento chino o hindú como una manera de neutralizar lo "occidental" sin reparar en la debilidad que inyecta, en el proyecto de rescate y fortalecimiento de las culturas indígenas, las epistemologías foráneas, ya sean
} 
Las academias de las tres carreras iniciales, aprovecharon el lapso de un año del tronco común para desarrollar la estructura efectiva del mapa curricular; los trabajos se dieron durante todo el ciclo 2004-2005. Este proceso involucró tanto a los profesores de las academias, como a los asesores externos y los de la CGEIB (Celote, s/f: 70). ${ }^{274}$ La determinación del resultado final de estos trabajos puede entenderse en el perfil de egreso que definieron las academias:

El perfil de egreso de la licenciatura de Desarrollo Sustentable

El profesional será capaz de implementar proyectos productivos de investigación-acción, ya que una de las funciones sustantivas de la Universidad Intercultural es la investigación y la transferencia de los conocimientos a la realidad; además el estudiante será capaz de manejar los recursos naturales y generar servicios enfocados a la promoción del desarrollo sustentable para el mejoramiento integral de las funciones de su comunidad o de la región como para el enriquecimiento del marco teórico del desarrollo sustentable; tomando en cuenta que el desarrollo sustentable tiene tres dimensiones, la dimensión económica, los proyectos productivos de toda índole y la dimensión cultural (Celote, s/f: 72)

El perfil de egreso de la licenciatura de lengua y cultura

El perfil de egreso es la de un profesional que sepa reflexionar su lengua, investigar su cultural, serán capaces de traducir textos escritos de las lenguas indígenas al español y del español al mazahua y estará capacitado de continuar estudios de postgrados, los estudiantes tendrán una formación al terminar la carrera que les permita enseñar lenguas con un enfoque intercultural en los niveles de primaria a educación media superior. (ibid: 73)

El perfil de egreso de la licenciatura de Comunicación Interculturales el siguiente

Formar profesionistas e intelectuales capaces de analizar y usar los medios de comunicación en sus diferentes modalidades (oral, impresos, electrónicos y/ o multimedia), para interactuar, comunicarse y crear redes de información y comunicación, a partir del uso de las tecnologías de información y comunicación (tic), como una posibilidad, entre muchas otras para difundir, proyectar y revitalizar la existencia cultura y conocimiento de los pueblos originarios de México ante el mundo global del siglo XXI y que tendrían en su manos la responsabilidad de escribir y compartir con el mundo nuestras culturas, ritualidades y los iconos de nuestros pueblos. (ibid: 75)

Lo específico de cada una de estas licenciaturas se encuentra comprimido en el eje disciplinar de los mapas curriculares. Destacan de las carreras los siguientes

occidentales u orientales. Lo dañino al espíritu constitucional, es justo la progresiva aproximación a una cultura global y new age, que presiona a lo local desde todos los puntos del globo y todas las culturas del globo.

${ }^{274}$ Recordar que está última tiene que aprobar su forma definitiva. 
aspectos. En Desarrollo Sustentable, un eje económico-productivo, que busca formar en técnicas de producción para el mercado agrícola, pecuario, silvícola, piscícola y ecotecnias. Un eje vinculado al contexto de la diversidad biológica y su asociación con la cultura. Un eje relativo al análisis geográfico de la información, tanto territorial como social y uno político, en el que se abordan teorías antropológicas, legislaciones sobre la propiedad del patrimonio de los pueblos originarios y las técnicas de producción.

En la carrera de Lengua y Cultura destacan de manera preponderante los aspectos asociados a la lengua. Todo un eje de teórico dedicado al contenido específico de la Lingüística; otro, dedicado a las materias sobre traducción escrita y hablada y el diseño para la difusión de esos materiales. Finalmente, un eje dedicado a la teoría antropológica y la cosmovisión de los pueblos, que como en el caso anterior, contiene insumos relativos a la propiedad intelectual del patrimonio cultural, los derechos asociados y su defensa; como complemento, se les prepara en la organización mecanismos de rescate de las expresiones culturales y artísticas y la gestión de proyectos culturales.

En Comunicación Intercultural, lo específico reside en una línea relativa a las técnicas de producción y difusión de los distintos géneros del fenómeno comunicativo: periodismo, radio y locución, audiovisual e internet. Asimismo, un eje dedicado a la cultura, que contiene teoría antropológica, de comunicación intercultural, semiótica y teorías sobre la comunicación. Finalmente un campo sobre historia política y económica de México y expresiones literarias.

La evaluación de la pertinencia de los planes de estudio es claramente una tarea pedagógica y profesional, específica de cada campo. Lo que se tiene que destacar es que el diseño y replicación de las estructuras de aprendizaje fueron y son, un producto exógeno y, claramente, un producto del Estado. No se pueden desestimar las contribuciones de los asesores o los miembros de las comunidades en el debate de los contenidos; sin embargo, la rectoría estatal, para dar forma al mandato constitucional es evidente y desde luego resalta el papel de consentimiento final, que la CGEIB desempeñó en tal construcción y que está centrado específicamente en el carácter intercultural que deberían tener las carreras. De manera adicional está el papel de aprobación final que la Dirección General de Profesiones de la Secretaría de Educación 
Pública otorgó a estas carreras y que remacha el otro eje de poder. ${ }^{275}$ Dada una estructura de conductas y conceptualizaciones, que el alumno tiene que realizar para apropiarse del bien educativo puesto a su disposición, aparece el espectro de las condiciones mínimas de aprovechamiento que tiene que ir alcanzando un alumno para aspirar a tener la certificación que emite el Estado -el Título Profesional-, para todos aquellos que cumplen dicho mínimo. Con esto se completa la cadena de intercambios de poder, tipo don y tipo antidón.

La carrera de Salud Intercultural tiene una historia distinta e independiente de las otras carreras. En sentido estricto, a diferencia de las primeras que son nuevas y novedosas, la de salud es una actividad que viene realizándose desde hace mucho tiempo. En el caso específico de la UIEM, las cimientos se remontan a la fundación del Centro de Desarrollo Humano y Comunitario (CEDEHC) en el año de 1982 en el estado de Morelos. En este centro se trabaja con una óptica integral sobre la salud, donde distintas visiones conviven, de manera horizontal y sin jerarquías, con el propósito de lograr un estado de salud permanente en el ser humano. En este sentido se puede hablar sin regateos de una implementación intercultural de las técnicas y tradiciones en salud. ${ }^{276}$ Esta referencia es importante porque -reiteran los profesores de la carrera- la importancia del trabajo del CEDEHC es un antecedente de la estructura curricular de la carrera, además de las experiencias particulares de los profesores que laboraron en Morelos. Llama también la atención que éste sea un trabajo ciudadano sin financiamiento gubernamental. En este sentido, la construcción del mapa curricular no partió de la novedad, sino de una práctica madurada con los años. Los miembros de la academia no incluyeron un tronco común y por ende no iniciaron clases sin contenidos

\footnotetext{
${ }^{275}$ La aprobación de la Dirección General de Profesiones a las carreras para aspirar a la emisión del título profesional ocurrió en 2006 para la licenciatura en Desarrollo Sustentable, y en 2007 para las licenciaturas en Lengua y Cultura y Comunicación Intercultural.

${ }^{276}$ Es increíble, la convergencia en el campo de la salud, en términos de las experiencias interculturales, es decir de la convivencia de varios métodos curativos, sin importar su origen cultural. En el Gobierno Federal destaca la creación de la Dirección de Medicina Tradicional al interior de la Secretaría de Salud, cuya misión es impulsar la aceptación y respeto a las distintas tradiciones curativas del país. Al margen de las naturales resistencias, culturales y burocráticas, destaca en las bases de política pública de esta Dirección, facilidad de convivencia entre medicina tradicional mexicana, acupuntura china y japonesa, reiki, masajes, musicoterapia, aromaterapia o cualquier técnica factible de producir salud. La mentad convergencia se refiere a la convivencia horizontal, pero simultáneamente, la debilidad en términos de conservación de las culturas originarias, por el acercamiento a una cultura global, holística y new age de la salud. De esto que el centro del expediente intercultural en salud, opera con base en la eficacia y no en el origen cultural; todas las tradiciones culturales valen lo mismo si curan, esto desde luego incluye la mezcla homogénea de técnicas curativas en un mismo paciente. En ese sentido, la dilución de las culturas particulares en una cultura globalizada de la salud, opera en ámbitos que parecen distintos como la UIEM y la Secretaría de Salud.
} 
específicos, sino que se pusieron a trabajar desde el apertura de la carrera con una estructura mínima, que fueron complementando al parejo de las actividades.

El perfil de egreso de la licenciatura en Salud Interculturales el siguiente Formar profesionales con un alto sentido ético, con habilidades y conocimientos que coadyuven en la solución del déficit de atención y de la problemática de salud pública, social y comunitaria en las regiones indígenas, rurales y marginales urbanas, a través de prácticas de salud preventivas y holísticas tendientes a la plenitud bio-psico-social de la población que atiendan, en especial de sus comunidades y culturas originarias, a través de la vinculación comunitaria para el desarrollo, de forma acorde con el método de enseñanza de las Universidades Interculturales (Folleto informativo, s/f)

Del resultado destaca la presencia de un eje sobre medicina tradicional mesoamericana, uno sobre técnicas provenientes de otras tradiciones culturales, uno sobre aspectos emocionales de la salud, uno sobre salud comunitaria y finalmente uno sobre aspectos del saber científico "convencional”. Como había mencionado, los contenidos técnicos de salud incluyen dos semestres más que en las otras carreras por decisión expresa de los que diseñaron la currícula. Destaca negativamente la ausencia de contenidos sobre teoría antropológica y elementos culturales. La relación y proporción entres saber tradicional/saber científico es de nueva cuenta una decisión exógena y de carácter estatal. No se ignora el particular origen en prácticas provenientes de la sociedad civil, pero tampoco, que la estructura estatal, va normalizando y readecuando las propuestas, tanto por la necesaria aprobación de la CGEIB, de la Dirección General de Profesiones, como también del "CIFRHUS". La Comisión Interinstitucional para la Formación de Recursos Humanos para la Salud es la instancia estatal, encargada de aprobar las estructuras de formación de los profesionales dedicados al campo de la Salud. Refieren los profesores de la carrera de Salud que las negociaciones para la aprobación de su mapa curricular fueron duras y tardaron alrededor de un año, <<pues no querían aprobar la carrera pues son muy cerrados, hasta que los pudimos convencer $>$. No obstante esta referencia, una percepción: el CIFRHUS tiene normas para la emisión de calificaciones de competencias profesionales en Herbolaria, Acupuntura y Homeopatía, es decir, el Estado ya no es cerrado a otras visiones en salud, siempre y cuando, pasen por la certificación de dicho órgano. ${ }^{277}$ Es decir, después del proceso de construcción quedan nuevamente en evidencia las

\footnotetext{
277 El registro de la licenciatura en Salud Intercultural, quedó incluido en la Dirección General de Profesiones, a partir de 2011.
} 
determinaciones distintas respecto de las otras tres carreras. Sin embargo, son similares en cuanto a las disposiciones exógenas y por tanto, en el ejercicio de poder político en la educación intercultural en salud.

\section{El salón de clases y la vida interna}

Lo más conspicuo de los salones de clase en la UIEM, es su redondez. Al margen de toda la decoración y detalles alusivos a la tradición mesoamericana, el círculo de seis metros de diámetro impresiona por su rareza. Como se había expuesto, el diseño está anclado a todo el tema del origen prehispánico, la serpiente enroscada, la pirámide redonda, pero particularmente en este caso, la "circularidad" del conocimiento. La raíz mitológica que opone Mesoamérica/Occidente, Redondo/Cuadrado, Horizontal/Vertical e Intercultural/Hegemónico, y que permite todas las transformaciones entre estos pares, modela la idea de que en el salón de clase redondo el conocimiento circula de manera horizontal, sin jerarquías, de manera intercultural, borrando la hegemonía occidental y su conocimiento cuadrado, quedando como única posibilidad la dispersión intercultural del conocimiento y la igualación entre las culturas indígenas y la mestiza. Esta orden, impuesta exógenamente sobre maestros y alumnos tomó en la vida cotidiana varias características.

Se cuenta que el modelo redondo es una evocación del círculo de personas alrededor de la fogata -que es el conocimiento- y que ocurre de manera cotidiana en las comunidades; eso determina la ausencia de diferencias y por tanto de relaciones de poder. El primer resultado de ello es que se determinó no poner escritorio a los profesores para obligarlos a entrar en esta lógica y desplazarlos como foco de la clase y fuente del conocimiento. En la administración de la UIEM se produjo una gran frustración, pues los profesores se resistieron a comportarse según el diseño, exigieron escritorios y por ende, hubo que comprárselos; en este caso, el ejercicio de poder no ocurrió. Otro aspecto dirigido en sentido contrario al espíritu del modelo es la distorsión que introduce el pizarrón, pues determina ya una focalización no circular y una disposición tipo auditorio. ${ }^{278} \mathrm{El}$ modelo se complica si se utilizan medios audiovisuales, puesto que una televisión en el escritorio empuja a los alumnos al fondo -con foco en el dispositivo- o, si se usa el "cañón", dado que la pantalla que está frente al pizarrón, se genera una disposición en dos ejes paralelos y perpendiculares a la proyección.

\footnotetext{
${ }^{278}$ Todos los esquemas de las distintas disposiciones en el salón de clase están en el Anexo 9.
} 
Finalmente, en grupos grandes, ocurría que el profesor tenía que ocupar forzosamente el centro del salón al ser desplazado por los alumnos a su alrededor. La consecuencia de esto es la producción de eco que vuelve la exposición difícil de comprender en un salón abarrotado. Estas dinámicas particulares también tienen su expresión particular en los salones cuadrados; hay ventajas y desventajas, sin embargo, llaman la atención los problemas reales que impiden el expediente de la horizontalidad al nivel puramente operativo y que el salón redondo no puede resolver. Sin duda, el diseño es más la expresión de un expediente ideológico que funcional, por los problemas señalados y que impiden el modelo de fogata comunitaria. ${ }^{279}$ Más aún, destaca la contradicción con la arquitectura mesoamericana de abundantes plazas cuadradas, por lo que esta ortogonal, y vertical ontología está, de manera inusualmente sorpresiva, asociada únicamente con Occidente y su saber cuadrado. En todo caso, se logre o no la desasimetrización de las relaciones maestro/alumno, ambos se ven obligados, mediante el ejercicio de poder por control, a desarrollar sus actividades en un entorno circular. ${ }^{280}$

Esta condición impuesta de manera exógena, presiona a la reflexión sobre que lo intercultural, arranca desde el sitio mismo de aprendizaje. En los alumnos el relato es muy consistente: la disposición circular determina la igualación entre maestro y alumno, dado que ambos tienen conocimiento y <<ninguno vale más que otro $>$. Esta expectativa de horizontalidad y ausencia de poder en las clases se confronta con la realidad de la asimetría entre maestros y alumnos: la diferencia real en conocimiento y la capacidad certificadora del maestro. En una ocasión llegó una profesora a un grupo por primera vez; preguntando por qué estaban sentados en disposición radial, los alumnos le comentan sobre la mitología de todo el edificio y la pedagogía de lo redondo. La maestra señaló que no le molestaba el edificio, pero que se movieran a una disposición paralela con filas frente a frente. Dos alumnos protestan: <<eso no es interculturalidad pues siempre nos sentamos así >>. Como ella siempre trabaja así, ordena que se muevan; los alumnos se mueven de mala gana y la clase empieza.

\footnotetext{
${ }^{279}$ Un profesor lo expresó de manera transparente al preguntársele sobre estos temas: <<El diseño del edificio es un tema político y la política interna de la clase es independiente de la forma del salón〉>.

${ }^{280}$ La pertinencia de la educación intercultural en otras unidades del país no puede considerarse mermada por la ausencia de salones redondos; sin embargo se generan, como expuse, conductas y conceptualizaciones de apropiación distintas, por el contexto diferente. En una ocasión, en plena clase, un profesor se refirió a la Universidad Intercultural del Estado de Puebla:

$-¿$ Cómo creen que es el edificio? Es como el del tecnológico.

- ¿Cuadrado?

-Pues sí ¡cuadrado!
} 
Este pequeño ejemplo es un nexo entre la ideología intercultural, en la cual las culturas no pueden clasificarse como mejores o peores y por tanto son iguales, y las relaciones entre maestros y alumnos, que contienen evidentes asimetrías. Como en el caso de los mapas curriculares, el profesor determina de manera exógena, estructura y contenidos de la materia, definiendo la secuencia en la que los alumnos van a apropiarse del bien educativo. Esta asimetría se ve complementada con la capacidad certificadora, que impone la circunstancia de que los alumnos deben tener conductas $y$ conceptualizaciones mínimas y específicas, si desean una calificación aprobatoria. En varias ocasiones se constató que al inicio de los cursos, los profesores presentan de manera "tradicional" su programa de trabajo para el curso, y no existe ninguna presión en los alumnos para cambiar esta determinación; la asimetría del saber es aceptada en su componente general; simultáneamente se enuncian los criterios de calificación, que tampoco son cuestionados. A lo largo de los cursos siguen apareciendo frecuentemente, "recordatorios" de dicha realidad. Estas asimetrías, de saber y de certificación, que no tiene que ver en nada con las relaciones entre las culturas, caracterizan el fenómeno de la educación profesionalizada, pero pueden y deben ser matizadas en términos de lo que se expuso en el Capítulo 3: que resulta injusto extender diferencias de un ámbito, para ejercer poder en otro; es decir, que el poder que ejerce el profesor de manera legítima, no debe ser usado para clasificar los conocimientos de las diferentes culturas, como "buenos" o como "malos" y menos aún para desvalorizar a los muchachos por su condición de indígenas (hecho que desaparece en las clases con profesores indígenas, con la permanencia las asimetrías profesor-alumno). En eso reside el expediente intercultural. La ampliación de esta idea a toda relación asimétrica paraliza la vida política y la capacidad de conducir la acción social. En este caso particular se confunde la horizontalidad de la interculturalidad, con la horizontalidad en todos los aspectos de la vida escolar, lo que genera tensiones e inviabilidad en algunos ejes del proyecto. Estas complicaciones de lo que es y no es la interculturalidad se expondrán en adelante.

El tema de la interculturalidad como hecho real, instrumentado en una institución de educación superior, en una zona indígena, se contrapone con el mandato constitucional del artículo segundo, porque los tres órdenes de gobierno deberán: "Garantizar e incrementar los niveles de escolaridad, favoreciendo la educación bilingüe e 
intercultural". En la UIEM, este mandato no puede evidenciar de mejor manera el ejercicio de poder político del Estado, ya que desde el inicio se decidió, de manera exógena, favorecer únicamente la educación intercultural y eliminar la educación bilingüe; lo que se ofrece son clases de lengua indígena. Casi ocho años después, no hay evidencias de que esto pueda cambiar en el futuro. Como se expuso, un insumo central en este tema es la decisión de eliminar la idea de una universidad indígena e imponer la de una universidad intercultural. En segundo lugar, está la contundente realidad de que aproximadamente el $80 \%$ de los alumnos indígenas no dominan su lengua materna y sólo el resto estaría en capacidad de entender una clase en lengua indígena. De hecho, hasta 2009 las clases de "lengua originaria" se instrumentaban en ocho niveles, correspondientes a los ocho semestres; a la fecha lo que existe es un sistema de ubicación por competencia con sólo tres niveles: básico, intermedio y avanzado, más eficiente y acorde con la realidad. ${ }^{281}$ De manera adicional, el porcentaje de profesores que puede dar una clase en lengua indígena, que no sea de idioma, es parecido, sin considerar si quiera las complicaciones linguísticas ocasionadas por la ausencia de vocablos técnicos, cuya reflexión está presente en los profesores, pero en un nivel más anecdótico que de política educativa. Estas limitaciones reales a la implementación de un sistema bilingüe universitario, se acentúan al tomarse la decisión exógena, de no favorecerlo. Ello es evidente por la ausencia de un programa piloto o paralelo que impulse la implantación del espíritu constitucional; lo que es claro es que los alumnos que se insertan en la UIEM se apropian de un bien educativo intercultural no bilingüe.

Lo propiamente "intercultural" ha sido implantado, dispersado y aprehendido con éxito sorprendente. Los muchachos tienen claro que la interculturalidad significa la posibilidad y la obligatoriedad normativa de que las relaciones entre las culturas indígenas y la del resto de la nación -la occidental mestiza- sean de respeto, mutua comprensión, mutuo aprendizaje y perduración simultánea. Al mismo tiempo, que para lograr este futuro deseable y posible, los estudiantes indígenas y los mestizos deberán

\footnotetext{
${ }^{281}$ Esta convergencia con lo que ocurre en cualquier programa de enseñanza de idiomas contrasta con la sorprendente declaración de un profesor de la Universidad Intercultural de Yucatán en un foro nacional organizado en la UIEM, que en abierta oposición a "Occidente", declaraba que ellos no deberían utilizar la metodología <<de esas escuelas gringas>> y enseñar la lengua maya cómo se aprende en la realidad: con los discursos, oraciones y nombres que se dan en las 〈<casas mayas〉>. En su refractaria actitud hacia la metodología externa, este profesor no alcanza a ver o no quiere ver, que la metodología es tal, en virtud de que la lengua a enseñar, se enseña como segunda lengua, motivo por el cual, no se puede modelar cómo se aprende en cualquier casa, es decir, no enseñada sino vivida. Éste es un ejemplo de las dificultades en la construcción de una epistemología o metodología intercultural, pues desde este tipo de perspectivas "intercultural” es sinónimo de "indígena".
} 
compartir y dispersar el orgullo de ser indígenas o de disfrutar la herencia cultural indígena que conforma a México como nación. Esta visión política y normativa coincide plenamente con el proyecto multiculturalista $\mathrm{y}$, simultáneamente, con los supuestos generales que la CGEIB planteaba para la educación superior intercultural; ${ }^{282}$ nuevamente, el Estado actuando. El resultado más importante de todo este esfuerzo es que los alumnos indígenas refieren historias de su doble transformación: de sentirse apenados o negar su cultura a un orgullo naciente y creciente por manifestarla ante quien sea; y por otro lado, a reconstruir o reencontrarse con todos los elementos de su cultura que desconocen o que están olvidados. La cotidianidad de estas manifestaciones al interior de la UIEM es consistente y contundente. ${ }^{283}$

Otros efectos son imprevistos o manejados defectuosamente o dañinamente en la implantación exógena, pues no hay en la UIEM una implementación clara de lo que una política intercultural supone. Más allá de ideas de respeto, empatía, conocimiento e igualación, no existen lineamientos para la aplicación concreta de estrategias que hagan de la interculturalidad una palanca de aplicación de las políticas educativas entre indígenas. Es una queja común de los profesores que dentro de la capacitación que se les brinda o en los comentarios sobre el funcionamiento de la universidad, la interculturalidad aparece como un buen concepto pero que tiene poco que ver con la realidad concreta del proceso educativo o de las comunidades. La labor de coordinación y de generación de políticas por parte de la CGEIB en torno del tema de la interculturalidad, queda en un nivel un tanto abstracto y no aporta insumos específicos para la implementación cotidiana y a largo plazo. La indefinición entre lo que es y no es la interculturalidad crea una sobresaturación del término y sus alcances, aplicándose a todo. La primera consecuencia de tal debilidad es la dispersión de que en un mundo de interculturalidad plena, es decir, de relaciones horizontales entre las culturas, todas las relaciones serán horizontales. Ya se ha comentado en varios momentos la cándida suposición de que en un mundo intercultural, desaparecen las asimetrías, el poder y la política. Claro que los muchachos son inocentes de tal ideología, pues se expuso cómo existe una confusión muy extendida respecto al justo deseo de extirpar de las relaciones inter-culturales las asimetrías generadas por las diferencias culturales, pero que

\footnotetext{
${ }^{282}$ Como se expuso en los Capítulos 3 y 4.

${ }^{283}$ Conocer si esta realidad se vive de manera semejante, fuera de la UIEM, es decir en las comunidades o en el centro mestizo rector, donde las presiones a la identidad indígena ocurren, es motivo de una investigación diferente y desde luego de mediano plazo, pues la creación de una "masa crítica" de intelectuales indígenas es condición necesaria para romper el círculo vicioso de desprecio o negación de la cultura indígena; las condiciones se están alcanzando, los resultados son, no obstante, una interrogante.
} 
desemboca en pensar que las otras relaciones simultáneas a las diferencias culturales son necesariamente carentes de poder. Esta lógica errónea ha confluido en tensiones al interior de la UIEM, porque ocurre que ante la percepción de un ejercicio de poder en la universidad, y que no tiene que ver nada con el mundo de las relaciones entre culturas, los individuos refieran este hecho como carente de interculturalidad. Los casos más frecuentes ocurren entre maestros y alumnos, puesto que la inconformidad con disposiciones del proceso educativo, como puede ser horario, tipo de trabajo, materiales elegidos, criterios de evaluación, etcétera, es simbolizado y renombrado por los alumnos inconformes, como no intercultural. Esta presión desasimetrizadora se complementa con la expuesta debilidad de los profesores por la inseguridad laboral, lo que redunda en una baja conformidad del alumnado con la autoridad del maestro. Lo anterior sumado a la presión de no reprobar alumnos por los daños al proyecto, culmina en un bajo nivel y apatía del profesor al respecto. Esta pérdida del ejercicio de poder - vía la certificación que tiene el profesor- se debe en parte a la extensión "cósmica" e ilimitada del genuino deseo de suprimir las relaciones de poder con base en la diferencia cultural.

Una parte importante de esta errada percepción deriva de la baja calidad del conocimiento antropológico impartido en la UIEM, que dispersa la idea de que $<<$ las comunidades siempre han sido interculturales $>$ y por consecuencia, que las relaciones de poder no ocurren ahí. En las referencias sobre aspectos culturales de las comunidades, el común denominador es el una vida apacible y equilibrada con la naturaleza y los demás grupos, es decir, sin conflicto. Las oposiciones Indígenas/Occidente y no poder/ poder, da lugar a este discurso ideológico que tiene tinte "indigenista" y remite a la conocida visión de los indígenas como el "buen salvaje" de evidentes aires naturalistas. El problema no resuelto de la relación efectiva de los estudiantes con los elementos de la cultura occidental, se mantiene como el gran reto, pues si la autoadscripción fue una solución política para apoyar el fortalecimiento del orgullo por la pertenencia indígena, resulta problemático, al menos, en virtud de borrar las gradaciones y no permitir valorar el porcentaje de elementos culturales no indígenas que tienen los individuos. Un profesor indígena, en una actitud profundamente reflexiva sobre estos problemas declara: <<la verdad es que ni los profesores indígenas, ni los estudiantes, ni el Estado, estaban preparados para la construcción del modelo de educación intercultural $>$.

Como colofón a todos estos problemas, se presenta un caso observado que conjunta todas las buenas intenciones en torno de la educación intercultural y sus 
problemas no resueltos. Hay que tener en mente lo que se presentó arriba, respecto de la importancia del fogón, las tres piedras y el comal, como soporte del cosmos mazahua y la relevancia de lo circular del conjunto como centro de reunión y generador de un alimento esencial: las tortillas. Simultáneamente, el papel que este modelo cósmico jugó en el desarrollo arquitectónico de la universidad.

En una exposición de trabajos de alumnos, una muchacha desarrolla el tema de los daños y las desventajas que los fogones tradicionales acarrean a los miembros de las comunidades: son muy contaminantes, son poco eficientes y producen daños a la salud por la humareda que dispersan en la vivienda. La solución a todo ello es la estufa "Lorena", fogón cerrado hecho de adobe o concreto, de base cuadrada, con un hogar circular cerrado sobre el que se asienta el comal. Los gases se conducen a dos hornillas más pequeñas, cerradas, y de ahí se entuban hacia el techo de la vivienda. En la exposición salta a la vista que no se realiza una reflexión sobre los aspectos cosmogónicos de la transformación del fogón y por lo tanto la posible reinterpretación cultural sobre las tres hornillas presentes en la estufa "Lorena" y del dramático paso del molde redondo al cuadrado. A pesar de que la estudiante cuenta con la preparación antropológica mínima para hacer una reflexión de este tipo, y más por ser mazahua, lo que expone se define por el esfuerzo de ayudar a la población en sus problemas de eficiencia calórica y salud pulmonar. El caso es un problema típico de los expuestos en cualquier reflexión de antropología aplicada, pero, sobre lo que no se debe hacer. Si bien se pudiera considerar debilidad académica en la estudiante, dos profesores, uno con larga permanencia en el proyecto y el otro con nivel de doctorado, atestiguaron la propuesta sin mayor comentario. Como un refuerzo adicional a este impulso regional, en una visita que realicé a la asociación civil Pro Mazahua A. C., ubicada en una localidad serrana, quedé sorprendido por la presencia física en la entrada de una estufa "Lorena", que apoya permanentemente la sustitución de fogones de tres piedras por la moderna estufa.

Como se ve, hay una falta de reflexión en torno de los temas de la convivencia entre cultura y tradición, de problematización frente al cambio cultural y la pérdida de un elemento en ésta, de la consulta a los afectados en las soluciones que los impactan, de la presión de la tecnología sobre las soluciones menos eficientes y del paternalismo de siempre. Al no haber fortaleza en el diseño de las políticas de educación intercultural, donde principios claros orienten los esfuerzos de investigación y acción, los resultados del proyecto son disparejos. 
Los más pobres y marginados de los mazahuas son los que usan fogones de leña; son parte fundamental el núcleo duro de la cultura mazahua. Si la tecnología más eficiente sustituye sin más al fogón tradicional en esas poblaciones, ¿de dónde beberán su cultura los mazahuas urbanos y de estufa de gas? ¿todo es autoadscripción? ¿cómo se podrá enlazar el pasado milenario con el presente, si las sustituciones tecnológicas van más rápido que la planeación y diseño de políticas de preservación? La transformación cultural es un hecho de la vida y las sociedades humanas. La normatividad legal que pretenda frenarla o dirigirla está condenada al fracaso, si no se consideran en su aplicación los limites reales y teóricos del esfuerzo, los ejes de reflexión profunda sobre la vida y transformación de las culturas, y la conducción adecuada de los agentes factibles de lograrlo, a través de un ejercicio consciente y atinado del poder político, en virtud de modificar sus conductas y conceptualizaciones, en una dirección tal, que los resultados concuerden aceptablemente con las expectativas iniciales. Es decir, que en este caso la orientación de la CGEIB ha sido deficiente en introducir elementos exógenos para dar forma concreta a estas interrogantes y por ende, ha omitido ejercer el poder, como refirieron los profesores respecto de la falta de dirección y "coordinación" de la CGEIB.

Si lo normativo de la interculturalidad desde una perspectiva amplia tiene, tanto felices resultados como situaciones no resueltas, la valoración de la estructura del conocimiento impartido en las aulas es aún más compleja. En foros de expertos e involucrados, y en las aulas de la UIEM, el tema de la relación entre el conocimiento indígena y el "occidental", lo que se llama la epistemología intercultural, está aún en vías de construirse. En este nivel no queda duda, nuevamente, del éxito que han logrado todos los participantes en inyectar el espíritu del artículo segundo constitucional, que refiere el derecho de los pueblos indígenas a Preservar y enriquecer sus lenguas, conocimientos y todos los elementos que constituyan su cultura e identidad. Hay una actitud fuerte y generalizada de que los conocimientos indígenas deben conservarse y simultáneamente, reafirmar su valor frente a cualquier otro marco cultural, es decir, que no valen menos por ser indígenas, sino que precisamente por eso, deben ser preservados y equiparados. En las clases se discuten los elementos del conocimiento indígena, simultáneamente con los "occidentales" y se pasa de uno a otro sin la mayor dificultad. Esto es un gran 
principio, pues queda extirpada la idea de que el conocimiento indígena es inferior, por no estar confirmado por la "ciencia" o no estar conformado de acuerdo con las estructuras canónicas de "Occidente". En este punto, la UIEM ha cumplido con el mandato del segundo constitucional, que ordena: Definir y desarrollar programas educativos de contenido regional que reconozcan la herencia cultural de sus pueblos, de acuerdo con las leyes de la materia y en consulta con las comunidades indígenas. Impulsar el respeto y conocimiento de las diversas culturas existentes en la nación.

Como se ha visto, el cumplimiento de la Constitución, en términos de derechos de los pueblos indígenas, desemboca en ejercicio de poder político, al surgir la necesidad de darle forma y contenido concreto en el aula de educación superior. En esta dimensión, lo primero que destaca es la relación problemática con "Occidente". Ya se había expuesto de manera pormenorizada, en el Capítulo 4, la conflictiva relación que desde la CGEIB se estableció con las universidades tradicionales, occidentales, y su epistemología, ya que según su planteamiento: <<en sus métodos se privilegia la transmisión de conocimientos, no de procesos de pensamiento o discernimiento $>>$. Esta visión política, ideológica, y por ende sesgada de la Universidad como fenómeno humano, se difunde en la UIEM y tiende a imperar en las clases, al oponer constantemente en el discurso, los conocimientos indígenas con los occidentales. Se recurre en demasía a condenar el colonialismo científico, sin hacer una demarcación entre el uso político del conocimiento y el conocimiento por sí mismo. Más allá de que el rechazo discursivo de "Occidente" atente contra el espíritu intercultural, el asunto de fondo, es que el "ruido" ideológico impide la reflexión sobre la importancia, pertinencia y maravilla de los conocimiento generados desde esta tradición, que como los de cualquier otra cultura son productos del esfuerzo humano. Esta dificultad in situ, de ubicar la componente occidental en su justa dimensión nubla la integración de una epistemología intercultural como tal. Los profesores reiteran su adhesión al espíritu que ubica los conocimientos tradicionales al parejo de los conocimientos científicos, pero al surgir las confrontaciones no presentan argumentos para la creación de un sistema dual o complementario, sino que se desemboca en la sola valoración de lo indígena, dejando los conocimientos no indígenas como incidentales, en la sombra, pero que cada vez que son necesarios, se incorporan "por la puerta de atrás". ${ }^{284}$

\footnotetext{
${ }^{284}$ En una ocasión, un profesor de la UIEM me comentaba que la temporada de lluvia en la región se estaba retrasando demasiado (hay que aclarar que ese año, 2011, fue un fenómeno generalizado en toda la Mesa Central). No obstante la simultaneidad geográfica del fenómeno, me refirió que los campesinos del
} 
Desde luego que esta actitud en los estudiantes indígenas, es más que comprensible; incluso, se podría decir que hasta legítima. Lo que no se justifica es el papel que las instancias estatales y sus agentes juegan en la reafirmación de esta actitud o en su defecto, ser omisos en llevarlos a un punto diferente, intercultural. En este caso, el ejercicio de poder político es deficiente en los términos que se han expuesto: impulsar a los sujetos a tener conductas o conceptualizaciones que de otro modo no tendrían. Lo que es común es la construcción de un espacio político, una arena turneriana, donde se acompaña, y en ocasiones, se anima esta confrontación. Esto desemboca en una práctica casuística, en donde lo que ocurre no es la implementación de un sistema pedagógicoepistemológico intercultural, sino la presentación casuística y aislada de elementos de ambas tradiciones culturales, que están o pueden estar relacionados de manera horizontal. ${ }^{285}$ Algunos ejemplos de estas dificultades epistemológicas darán cuenta de la falta de maduración de este expediente y por ende, de la necesidad de una intervención exógena más vigorosa desde la CGEIB. El problema es que, según refieren los profesores, se les habla de manera general y no se les dan líneas operativas para resolver este gran problema.

El primer ejemplo es el sesgo en la caracterización del sujeto eje de la actividad de la universidad: el indígena. En el Capítulo 3, se expuso la forma en que tuvo lugar un paso sorprendente, en la transición del Convenio 107 al Convenio 169 en la OIT, al eliminar a las formas intermedias -los semitribales- como sujetos de los convenios. La aparición

\footnotetext{
lugar, achacaban la tardanza de la lluvia a que la empresa IUSA, con cientos de hectáreas de cultivo en invernadero, sobre todo de jitomate, estaba disparando "rayos láser" a las nubes para $<<$ evaporarlas $>>$, con el propósito de retrasar las lluvias y dañar las cosechas de temporal, elevando el precio de su mercancía, por la consecuente escases en el mercado. Más allá de la insostenible hipótesis económica, pues el fenómeno era casi nacional, y de la no conocida existencia de dispositivos tecnológicos tan poderosos, llama la atención que el profesor apoyaba la hipótesis de los cultivadores locales, pues había escuchado varias referencias sobre avistamiento <<de rayos y puntos rojos en el cielo $>$. Es notable la incapacidad de un profesionista, para comprender este pensamiento mágico de la gente del campo, y desecharlo sin más, por estar eminentemente errado. El fenómeno era simultáneo en todo el Valle de Toluca, en el Valle de México, y en las regiones vecinas de Michoacán, Hidalgo, Tlaxcala y Puebla. Al manifestar mi extrañeza sobre estos aspectos, el profesor refirió el respeto y credibilidad que se debe dar a la gente de las comunidades. En este contexto, la ausencia de una estructura clara de las relaciones entre formas de conocimiento, su campo de acción y utilidad impide procesar historias de esta naturaleza, para clasificarlas como insostenibles. Esta asignación no tiene nada que ver con el respeto u horizontalidad entre formas de conocimiento, ni con ejercicio de poder, sino claramente con una percepción equivocada de la realidad, anclada en el desconocimiento de las posibilidades y límites de la tecnología actual.

${ }^{285}$ Durante dos meses en el año 2009 y un mes en el 2011 se asistió a las clases de manera regular en las cuatro licenciaturas. Sin ser concluyentes los juicios sobre los aspectos presentados, llamó poderosamente mi atención la convergencia en los distintos temas. Hay buena intención de los profesores y receptividad en los alumnos, pero ante los conflictos que aparecen, la salida constante es privilegiar lo indígena, borrar lo "occidental" y evitar enfrentar el problema desde una óptica intercultural.
} 
de la idea de "autoadscripción" borró estas formas intermedias de acuerdo con legítimos intereses político-normativos, pero comprometiendo la existencia de realidades diferentes, que no son solamente transicionales de un estado $A$ a uno $B$, sino que en el proceso de vida de las culturas, son ya un estadio diferente: $C$. La categoría de "campesino", si bien tiene fuertes influencias ideológicas enraizadas en el ideario político de la Revolución Mexicana, también describe una realidad social y cultural de comunidades que no son indígenas, pero que además, muy probablemente, ya no lo serán. En la UIEM, todo el discurso de acción y de investigación apunta a los pueblos originarios o las comunidades indígenas, y difícilmente se imagina un sujeto rural que ya no es indígena, pero que además, no quiere serlo. La presión de la autoadscripción indígena para ser beneficiario de la acción gubernamental, empuja en esa dirección y distorsiona claramente las percepciones, en el sentido de que los indígenas son el único núcleo de la vida universitaria. ${ }^{286}$ En ese sentido es que debe fortalecerse la construcción intercultural de una epistemología que permita conocer, explicar y actuar en el medio rural mexicano, escapando del duro corsé que impone la autoadscripción política y económica, y permita comprender y respetar las culturas no indígenas de la región, pero que siguen siendo rurales.

Una de las características y de las complejidades de la epistemología intercultural está definida por el campo de conocimiento y acción. La especificidad de las carreras obliga a reflexiones diferentes sobre su materia de conocimiento y, en ese sentido, orientan la relación entre conocimiento tradicional y conocimiento científico de manera particular. Ya se había tocado de manera específica, la sorprendente facilidad con la que, en el tema de la salud, se incorporan no sólo la medicina indígena y la alópata o científica, sino cualquier otra tradición curativa, independientemente de su procedencia geográfica o cultural, o de su substrato de impacto: físico, emocional o "energético". La relación con la medicina científica está claramente demarcada en el discurso, al quedar sus conocimientos situados en el rubro de urgencias, de amenazas graves a la salud o de las

\footnotetext{
${ }^{286}$ Esta presión por fundir campesinos con indígenas, tiene en México una línea de gran fuerza en el discurso político de Guillermo Bonfil Batalla, expuesto en el libro México profundo (1994). Al margen de lo entrañable que resulta para todos los antropólogos la obra de Bonfil, es evidente su convicción tendiente a incluir en el "México profundo" a campesinos e indígenas por igual. Si bien tiene argumentos sólidos, también es cierto que hay una distancia insalvable e infranqueable, en donde indígenas y campesinos no son, y ya no serán, lo mismo. Al preguntarme los miembros de la UIEM sobre las críticas o problemas que veía en el proyecto, si les mencionaba mi extrañeza sobre la dominancia de lo indígena y la ausencia de la población rural no indígena -los campesinos-, su sorpresa era evidente, pues no se habían detenido a pensar que discursivamente, los campesinos están desaparecidos.
} 
técnicas de diagnóstico y análisis clínicos. El criterio instrumental en estos temas, la cura del paciente, deriva en una integración holística (término empleado de manera cotidiana) de los saberes. Si se observa el mapa curricular (Anexo 8), los ejes temáticos están claramente definidos con respecto a las tradiciones culturales: el " $\mathrm{B}$ " y el "C" se refieren a la tradición mesoamericana y de otras técnicas alternativas; y el "E" y el "'F" son sin duda cercanos a la medicina científica y gubernamental. Esta demarcación conceptual da cuenta de la posibilidad de ubicar las diferentes tradiciones culturales en espacios definidos y de que la integración surja de la vida en los salones y en la práctica profesional. En la cotidianidad de las clases, no se detectaron conflictos mayores al nivel de la convivencia entre saberes; la convivencia es en general armónica. Como ya se ha mencionado, llama la atención que el foco cultural de la carrera está ocupado por la coexistencia de todas las tradiciones, presionado por la visión holística que impera. Esta visión, contrasta con el mandato constitucional, cuyo espíritu surge de la necesidad de evitar la dilución "holística" de las culturas indígenas, derivada de las presiones de la globalización.

En la carrera de Desarrollo Sustentable, se detectó una convergencia con la estructura anterior, pues en general, dada la naturaleza de la materia abordada, hay pocas tensiones respecto de la convivencia entre conocimientos científicos y tradicionales regionales; a diferencia de "Salud", en donde conviven varias tradiciones. Si se observa el mapa curricular, no es discernible, a diferencia del anterior, dónde están las materias o las líneas sobre conocimiento tradicional. Casi todo el esquema refiere contenidos que pudieran encontrarse en carreras "clásicas" del área de atención al mundo rural. Dada esta característica, el tratamiento de las relaciones entre conocimientos se da al interior de las clases. Nuevamente, ahí es donde se observa la falta de una estructura clara de las relaciones entre epistemologías diferentes pues, como se refirió, en ese contexto lo que tiende a ocurrir es un manejo casuístico de métodos y técnicas tradicionales y no una relación orgánica con el conocimiento científico. Es evidente que el impulso estatal en este sentido cosecha resultados desiguales, pues desde el diseño de las UI se buscó que se trabajaran estas temáticas, pero los insumos bridados son insuficientes y el esfuerzo desplegado en los salones de clase, que es honesto y generoso, expone una falta de maduración en la instrumentación de la mentada epistemología intercultural. En los salones se habla sobre técnicas tradicionales en producción agrícola o pecuaria, pero se observan dificultades en relación con la escala, ya que al nivel de la producción masiva, estas técnicas tienen problemas de 
instrumentación. No obstante, se identifica una valoración genuina y una búsqueda por dispersar estos conocimientos para encontrar formas de aplicación útiles a la región. Uno de los grandes logros en esta carrera, es implantar en los muchachos la actitud de no colisionar con los saberes productivos de las comunidades, sino plantear las ventajas que aportan y también que muchas de las técnicas comerciales y contemporáneas, acarrean desventajas que frecuentemente no son valoradas. ${ }^{287}$

Así, a primera vista, el mapa curricular de la carrera de Comunicación Intercultural, no da indicios de la diferencia que existe con lo que se imparte en otras universidades. Al margen de la permanente clase de "Lengua originaria" y de la materia de "Comunicación Intercultural" que peculiarmente forma parte del tronco común, el resto del contenido no pone en evidencia la construcción de una convivencia de saberes. La incorporación de lo indígena o lo tradicional se enfoca más en el objeto de trabajo que en la estructura de conocimiento. En el perfil de egreso se insiste que el uso de todas las modalidades y tecnologías de comunicación e información, podrán ser usadas “...para difundir, proyectar y revitalizar la existencia, cultura y conocimiento de los pueblos indígenas de México ante el mundo global del siglo XXI”. Es claro aquí que la incorporación de las formas de conocimiento indígena están supeditadas a las técnicas contemporáneas de comunicación. Lo que cambia respecto de las carreras en otras universidades es el foco de acción. En ese sentido hay que destacar la abundancia de trabajos estudiantiles, de las tesis de grado, que incorporan reflexiones, análisis o difusión de las culturas originarias de la región, incluyendo la elaboración de materiales en lenguas indígenas. El éxito entonces deriva de la incorporación exógena de temáticas indígenas en las clases, aunque en el caso de Comunicación se detecta nuevamente un uso casuístico de los temas, con el objeto de ilustrar a manera de ejemplo problemas técnicos de la carrera. En este sentido, la idea sobre lo que es interculturalidad es en esta licenciatura, la más instrumental y de menor profundidad. ${ }^{288}$

\footnotetext{
${ }^{287}$ Una idea generalizada en este sentido es la presencia constante de juicios según los cuales todas las prácticas de los productores tradicionales son "ecológicas" y no dañinas al ambiente. Es pues notable que en las clases en la UIEM se hayan presenciado discusiones y lecturas, cuyo objetivo es ubicar el impacto en el ecosistema de dichos productores, con la idea central, que cualquier actividad humana es invasiva del entorno. Varios alumnos mostraron disposición a problematizar esta dimensión, aunque en otros casos, se presentaron las naturales y conocidas reticencias a pensar el tema, en función de que los daños reales, "siempre" proviene de fuera de las comunidades.

${ }^{288}$ Según reflexión de una comunicóloga en la materia de "Introducción a la Comunicación Intercultural": < la comunicación entre dos agentes, emisor y receptor, es desde luego una comunicación intercultural >> estas imprecisiones y desconocimiento llegan en este caso a trivializar lo intercultural.
} 
Finalmente, en la carrera de "Lengua y Cultura" el mundo de la epistemología intercultural es el más complejo. Las tres carreras anteriores, Salud, Desarrollo y Comunicación, implican conocimiento y técnicas para lograr "algo" y cuyos antecedentes "occidentales" suponen una asimetría respecto del mismo mundo entre los indígenas. En ese sentido, es pertinente hablar de una epistemología intercultural, que permita relacionar, combinar, armonizar o demarcar ambas tradiciones de manera interesada, respetuosa y horizontal. En el caso de la última licenciatura, la materia de trabajo es la Cultura y la Lengua indígena en sentido amplio. En este caso no hay posibilidad de instrumentar caminos intermedios. De lo que se trata es de formar agentes para que cumplan, de manera profesionalizada, con la expectativa constitucional que implica lograr la comprensión, el respeto y la conservación de los distintos elementos que componen las culturas indígenas, ya sea para darles presencia y legitimidad hacia el exterior, pero también para restaurar y fortalecer la identidad indígena. Este mandato, culminación de persistentes demandas indígenas, es procesado por los órganos del Estado para crear, de manera exógena, a la carrera en cuestión. El resultado es una estructura en la cual las teorías y técnicas impartidas están en línea con dicha idea. Nuevamente, el ejercicio de poder político es exitoso, en un nivel muy general, pues da forma al deseo de abordar estos temas. Sin embargo, una reflexión profunda e intercultural en términos epistemológicos consistiría, desde mi punto de vista, en buscar construir mecanismos que permitan aclarar el papel e importancia de la cultura indígena, en su convivencia cotidiana e indisoluble con la cultura mexicana $u$ occidental, en el vaso contenedor central, que es el individuo de las comunidades. Ya he mostrado cómo el concepto de autoadscripción, desempeña un papel político preponderante, pero en términos antropológicos es altamente problemático. El decir "soy indígena" al margen de una evaluación de la estructura cultural que carga el individuo es tan equivocado como el decir "no soy indígena", cuando una parte substancial de la cultura del individuo indica lo contrario. ${ }^{289}$ En estas complicaciones, la epistemología intercultural sentaría las bases para a resolver los fenómenos de convivencia y respeto entre culturas, desde el sujeto mismo del conflicto, pues los alumnos de la UIEM portan de entrada, un cúmulo de elementos culturales externos ("mexicanos" u occidentales) y una lengua no indígena. En las discusiones observadas

\footnotetext{
${ }^{289}$ Como se expuso en una nota anterior, Guillermo Bonfil (1994), señala atinadamente las consecuencias desde un lado, pero omite considerar la factibilidad de los fenómenos inversos, que en México, son harto frecuentes.
} 
se participa mucho refiriéndose a cómo sacar ventaja de lo externo, para mantener o reanimar la cultura indígena. Es decir, la Cultura externa, no indígena, se explica en la UIEM como meramente tecnológica, puramente instrumental, implicando por ello que su utilización, "no contamina" las culturas originarias. Esta visión claramente errónea de la Cultura Occidental, como únicamente tecnológica, soslaya los conocidos fenómenos de difusión cultural, en donde lo tecnológico dispersa significados profundos, aunque no siempre es necesario internalizar dichos insumos ideales para poder acceder a la tecnología. En todo caso, la cultura externa y occidental, siempre va atrás, es hegemónica, o acontece en la sombra. Como reafirmé, este comprensible efecto político no puede subsistir por siempre, si lo que se quiere es construir verdaderas formas de conocimiento intercultural. En este sentido, el ejercicio de poder político ha sido deficiente o fallido, puesto que no ha llevado a los individuos a obrar de otro modo al que lo harían, sino que ha robustecido y dado foro a las comprensibles actitudes políticas, olvidando las necesidades epistemológicas del proyecto de educación superior intercultural en regiones indígenas.

\section{Corolario}

La aplicación exitosa de los supuestos de una política pública pasa, en muchos aspectos, por el ejercicio del poder político. Se ha expuesto de manera pormenorizada todo el proceso que va desde la demanda ciudadana, pasa por la construcción administrativa y política de la unidad a implantar, por el desarrollo de los contenidos y la puesta en marcha de las clases en las aulas. El modelo teórico, planteado para el análisis del fenómeno, se mostró efectivo en este nivel, toda vez que al identificar el sistema clasificatorio que da sentido al ejercicio de poder por intercambio, fue relativamente sencillo analizar las formas en las que transcurren los efectos exógenos del proyecto de educación cultural. Los recursos que el Estado puso a disposición de la población de la zona, fueron apropiados en modos muy convergentes con la orden determinada para dicho proceso. En este sentido, el concepto de conductas y conceptualizaciones de apropiación es una herramienta adecuada para seguir el hilo conductor que arranca en la Constitución, pasa por las leyes secundarias, los criterios administrativos las adecuaciones prácticas, y los comportamientos en clase, al margen de que los efectos sean de orden material o inmaterial.

Se expuso de manera amplia, cómo es que los montos, tanto en asignación, naturaleza, calidad y monto, tienen un impacto característico; desde luego que dicho 
impacto está en concordancia con la intención diseñada en la apropiación de los bienes gubernamentales. Aquí fue clara la diferencia que existe entre una "auditoria" de los recursos y la determinación del impacto exógeno que generan los bienes apropiados por la población estudiantil. Las asimetrías: Estado con recursos/población sin recursos y capacidad certificadora/necesidad de certificación, son los núcleos del orden clasificatorio fundamental en la UIEM. Estas asimetrías son las centrales en el proceso de conducción social que el Estado desarrolla en cumplimiento del artículo segundo de la Constitución.

Las complejidades del proceso político de implementación, cuyos extremos son las demandas y los productos gubernamentales, lo que es conocido como la "caja negra" del sistema político, se exhibieron al "mirar" al interior de este espacio y exponer que independientemente de la influencia que tengan el Gobierno Federal, el Gobierno Estatal, el Rector o las Academias de la UIEM, la "salida" final en el aula, tiene potentes fuerzas normalizadoras que superan las peculiaridades locales y constituyen de manera efectiva lo que refiere el abstracto término "Estado". Es decir, la educación intercultural se encuentra en esta época en un estado determinado, cuya forma y fondo constitucional, es implantada de manera exógena por un grupo orgánico de instancias gubernamentales específicas: todo el conjunto y sus relaciones normativas internas y con la sociedad, es esquemáticamente lo que se denomina Estado. Si llegaran a ocurrir transformaciones que "asciendan" desde el nivel más bajo, incluso contrarias a las órdenes iniciales, su incorporación general al proceso, las torna exógenas para los recién incorporados, y por su generalidad y permanencia, se transforman en estatales por definición.

Dado el largo camino recorrido y la reiteración en todos los temas, sólo resta decir que la UIEM es el resultado de las presiones sociales que modificaron al Estado mexicano. Su nueva apariencia definió en muchos aspectos lo que iba a ser apropiado en San Felipe del Progreso, pero también determinó la intromisión del Estado en esa porción de la sociedad. Todos los insumos de la vida universitaria contienen órdenes de naturaleza estatal. La colocación y forma del edificio; la calidad del personal y sus formas de contratación; las estructuras curriculares; la estructura epistemológica; la composición cultural; la predominancia de lo intercultural sobre lo bilingüe; los horarios, los mecanismos de evaluación y titulación. En todos estos campos el ejercicio del poder político se mostró exitoso en general, pues se documentó el predominio y la concordancia entre la orden, y las conductas y conceptualizaciones implantadas. 
Los logros iniciales y de corto plazo también expusieron que las consecuencias a mediano o largo plazo de estos beneficios iniciales, no necesariamente producen efectos en línea con el espíritu constitucional. Estas discordancias, "clásicas" en el análisis de políticas, evidencian el peso de los efectos imprevistos o perversos. En este nivel se puede señalar que las incongruencias surgen, de una débil valoración de los efectos a mediano y largo plazo de los éxitos inmediatos del ejercicio de poder o de las naturales complicaciones de conducir "intencionalmente" la realidad; condiciones políticas inherentes y que Max Weber calificara de demoniacas. En todo caso, este nivel ya no incide en la valoración técnica del ejercicio del poder político, que en relación con las órdenes instrumentadas tuvo una efectividad por arriba de lo razonable. Más bien, se refiere a la generación de insumos erróneos, léase "exógenos", en la instrumentación de las políticas, que aun siendo exitoso el ejercicio de poder no cumple con las expectativas que movilizaron a toda la maquinaria gubernamental. Pero la evaluación fina y reposada de la materialización del espíritu del artículo segundo de la Constitución Mexicana en la Universidad Intercultural del Estado de México, se desplaza al futuro. Queda en el presente, la descripción eficaz del funcionamiento del poder político en el campo de la educación superior intercultural en regiones indígenas. 


\section{Conclusiones}

La Antropología es una vía sólida para el estudio del poder político. Esta sentencia es, de todas las hipótesis, conjeturas y búsquedas de este trabajo, la que mayor certeza produjo. Al inicio de este esfuerzo, me propuse construir unas bases para enfrentar los problemas que se generan en el estudio de los fenómenos de poder. Este propósito estaba inundado por una fuerte convicción: que era posible emprenderlo utilizando contenidos netamente antropológicos. Luego del diseño, desarrollo teórico y confrontación con los problemas concretos, la convicción se transformó en certeza. Desde luego que, a la luz del cuerpo histórico de nuestra disciplina, la declaración parecería una verdad de Perogrullo; sin embargo, su espíritu reside en que los cimientos de todo el planteamiento descansan en dos insumos "clásicos": los estudios clasificatorios y los fenómenos de intercambio a la luz del ensayo sobre los dones.

Sería ingenuo ignorar la necesidad de una serie de acompañamientos y complementos originados en otras disciplinas, y que dieron una dimensión real a los fundamentos antropológicos. Pero dicha complementariedad estuvo subordinada todo el tiempo, a determinaciones eminentemente antropológicas. El hecho de haber iniciado la búsqueda con esa convicción y haber completado sin sobresaltos el proceso que va de la teoría a la praxis es, como mencioné al inicio, una certeza de la mayor importancia. 
¿Cuáles son las bases para tal seguridad? el enfrentamiento del modelo al estudio de las políticas de educación superior que instrumenta el Estado mexicano en poblaciones indígenas y, concretamente, en la Universidad Intercultural del Estado de México. Una de las definiciones utilizadas en este trabajo, caracterizaba al ejercicio del poder como la ocurrencia de un fenómeno por el cual un actor llevaba a otro a conducirse en formas que no ocurrirían sin la concurrencia del primero, es decir, sin una intervención exógena. La exterioridad, necesaria para determinar un fenómeno como de poder, fue una "lupa" que se convirtió en fundamental para juzgar los mecanismos de instrumentación de las políticas de educación intercultural en el medio indígena. Se insistió a lo largo de todo el trabajo de análisis en que era muy importante ir separando la dimensión social y ciudadana del fenómeno para diferenciar el ejercicio del poder político, del ejercicio del poder soberano que la sociedad impone como norma al Estado. Esta separación se basó, como dije, en la obstinada búsqueda por esclarecer cuándo un fenómeno acontecía como voluntad soberana con acompañamiento gubernamental y cuándo se daba al margen de dicha soberanía o para ser más preciso, en la lógica más pura de lo que es el Estado.

Hay que destacar que aún antes de siquiera imaginar el estudio de caso que confrontaría todo el diseño, el modelo tenía un origen profundamente arraigado en la Cultura, producto de su modelación en los sistemas clasificatorios y en la visión global que Mauss imprimió a los fenómenos de intercambio cuando buscó superar el pensamiento puramente económico. Por ello resultó altamente satisfactorio verificar la pertinencia de un modelo antropológico para el estudio del poder, en el abordaje de políticas estatales que enfrentan problemas de relaciones asimétricas caracterizadas por la diferencia cultural. Como se pudo constatar, la cadena diferencia-asimetría-ejercicio de poder, resultó más que adecuada para enfrentar todo el esfuerzo nacional e internacional, que buscó y busca, producir relaciones armónicas, equitativas y justas entre las diferentes culturas del globo y particularmente, desde luego, neutralizar el fenómeno histórico de dominación coloniales sobre las culturas indígenas.

La acción del Estado en la UIEM produjo, como vimos, resultados dispares por la instrumentación de las políticas definidas en la reforma constitucional de 2001. Por un lado hay que anotar el feliz éxito que constituye el arranque y la implantación en el sitio, de las unidades. También la reafirmación de la identidad indígena y el creciente y vigoroso fortalecimiento del orgullo de pertenecer a una de las muchas culturas originarias del país. La educación superior, como vehículo de estos ejes no formativos, 
es muy productiva. Lo es también la vinculación de los muchachos con las comunidades, producto del orgullo y la identidad reafirmada. Se trabaja en y por los habitantes locales, tornando secundarias las preocupaciones por la movilidad fuera de la región como nicho de desarrollo profesional. Pero la construcción de lo que la "nueva" identidad indígena supone, entre lo tradicional que ya no es, y las complejidades de la dilución en la cultura urbana y globalizante, tiene varios problemas que están enraizados en la idea misma de los contenidos y ponderación de lo indígena frente a lo exterior, fundamentalmente en los planes y programas de estudio. Ahí es que el ejercicio del poder político se mostró problemático, porque el modelo "inyecta” desde su diseño estos problemas sin resolverlos. Como se condensará más adelante, el ejercicio exitoso del poder político no necesariamente conlleva alcanzar el efecto normativo imaginado de origen.

Más allá de estas reflexiones, el modelo se mostró altamente satisfactorio y con gran capacidad heurística para abordar la lógica que va de los cuerpos legales y las políticas integracionistas a las "multiculturalistas". Partiendo de poblaciones con culturas diferentes pero sobre todo, con desarrollo y ciudadanización diferente, se utilizó la intervención del Estado para aprovechar esas diferencias, paradójicamente, como medio de integración a la cultura mayoritaria y dominante; en este objetivo la acción exógena del Estado aparece como central. Luego del fracaso de expediente integracionista y de la progresiva conformación de los indígenas como agentes de su propio desarrollo, las políticas dejaron de ser integracionistas y se transformaron hacia una agenda que buscaba igualar desarrollo y ciudadanía, manteniendo la diferencia cultural original. En ambos momentos las herramientas antropológicas sirven, como aseveré, para el entendimiento de qué cosas de las culturas son diferentes y cómo se construyen y destruyen las asimetrías a partir de estas diferencias.

Lo anterior es un subproducto del trabajo, pues siempre que el Estado logre con éxito dispersar conductas y conceptos entre las poblaciones, de manera exógena, habrá ejercido el poder; y tengo la convicción de que con el modelo, se puede abordar cualquier caso de relaciones asimétricas. Sin embargo, las políticas que interesan o impactan la Cultura, son un ejemplo especialmente significativo, pues engloban un tema de particular interés para la comunidad antropológica, por la vigencia política del tema. Tal actualidad me llevó a reflexionar a lo largo del trabajo sobre algunas de las complicaciones que representa la intervención exógena en una cultura en particular, que avanza en el expediente de la mentada "conservación". Este tema se cruza de maneras 
complejas con la militancia política de amplios sectores y llama poderosamente la atención que, en varios casos, se esquivan temas sobre los que la Antropología tiene fuertes argumentos, apoyando dichas intervenciones o reprobándolas. El "indigenismo" posrevolucionario es un ejemplo de cómo miembros de una comunidad científica, al inyectar insumos para la intervención estatal, puede producir efectos en ambos sentidos. La relación entre poder, política y cultura es de tal complejidad que, en el estudio de fenómenos de poder político sobre las culturas, me llevó a distanciarme en gran parte del trabajo del mundo del deber ser, para concentrarme en explicar únicamente el de los hechos. Asimismo, también marqué mi distancia de los estudios de caso de políticas, en este sentido del tema educativo, con el objetivo de insistir en la pertinencia global que la Antropología Política tiene para el esclarecimiento de las políticas gubernamentales, sin llegar a grados de especificidad tal, que se pierda el sentido global, antropológico, de la política.

Todos estos puntos iniciales delinean de manera muy resumida la travesía y los resultados globales, producidos en el estudio de las políticas de educación intercultural en el la UIEM. Ahora bien, ¿cuáles son los resultados a detalle tanto del modelo como de su confrontación con todos los temas abordados?

Por lo que toca al corazón del modelo, la lógica clasificatoria, los resultados son muy alentadores. Desde un punto de vista analítico, se cuenta con una herramienta fuerte para caracterizar lo que axiomáticamente se planteó como el corazón de las relaciones de poder: la asimetría. Creí en un inicio, que la referencia a las relaciones de poder como "asimétricas" era débilmente seguida, ponderada y caracterizada en todas sus implicaciones, por la teoría existente sobre el tema; de ahí la base del modelo. Los sistemas clasificatorios permiten delinear cómo es la dinámica de la construcción humana, que define las entidades como diferentes. Esta característica, que empuja los razonamientos al mundo de lo simbólico, tiene a mi modo de ver tres controles y que fueron expuestos a lo largo de todo el trabajo. Primero, que la estructuración del modelo no busca justificar o explicar cómo "nace" el poder entre los hombres, sino cómo se utilizan sus herramientas. En este sentido, como segundo, las bases materiales o ideales de una diferencia no son distinguibles como herramientas ya simbolizadas en la cabeza de quien intenta ejercer el poder, esto es, no se busca una teoría simbólica del poder, 
sino explicar cómo dado un entorno material o simbólico, un actor percibe o intuye que está claramente en una relación asimétrica y ventajosa con su alter diferente. En todo el cuerpo del argumento se trataron las bases materiales o inmateriales de las asimetrías de manera indistinta con relación al procedimiento intencional, es decir, las conductas o conceptualizaciones de apropiación definidas. Esto es fundamental porque el poder no se ejerce por accidente, sino de manera intencional; de ahí que la conciencia de la posición táctica y/o estratégica que se ocupa es central para un ejercicio de poder exitoso. Y tercero: que definir una preeminencia de lo simbólico o de lo material, está completamente en contra de la realidad histórica del ejercicio de poder. Esta certeza, deriva de que no se consideró bajo ningún esquema, un sustrato duro e ineludible del poder, por lo tanto resulta irrelevante si la diferencia que estructura el poder es material o simbólica; solo la coyuntura define su culminación en ejercicio exitoso.

La modelación analítica de las diferencias como asimetrías en pares de oposición, resultó sorprendentemente útil para entender el proceso. Más allá de las críticas que la postura levi-straussiana suscita, su uso, acotado al proceso que definimos como de "empobrecimiento y exageración”, resulto más que adecuado para el análisis del fenómeno. En ello no se pierden de vista las advertencias que Max Weber delineó para los tipos ideales como modelos simplificados de la realidad.

En la movilización de las asimetrías, para ejercer el poder, la instrumentalidad y la visión de futuro juegan un papel determinante y resultaron centrales para constatar si se ejerció o no el poder. Acorde con todo el desarrollo, hay que recalcar que los caminos por los que se define la visión de futuro, con toda su carga normativa, son complementarios y no sustantivos para el ejercicio de poder. De ahí resultó, como producto del enfrentamiento con la realidad, un fortalecimiento del tema de lo exógeno del ejercicio de poder, es decir, que la imbricación real que en el mundo político tienen, medios, métodos y fines, nubla en muchas ocasiones la posibilidad de distinguir hechos de fines. Sólo los fenómenos exógenos pueden ser definidos como de poder; el reto metodológico consistió y consiste, en separarlos analíticamente. Esta dimensión no se consideró en toda su magnitud al inicio y corresponde a uno de los buenos resultados del trabajo empírico; habrá que fortalecerlo en su dimensión formal.

El otro tema que falta fortalecer es la construcción de un cuerpo más sólido y menos casuístico de los sistemas clasificatorios. A lo largo del desarrollo de este trabajo se ha recolectado evidencia teórica y empírica de otros sistemas clasificatorios cuya simiente no está en las reseñadas en el capítulo respectivo, sino en otras lógicas 
humanas, como pueden ser las clasificaciones espaciales, emotivas, fisiológicas, axiológicas, etcétera. Estoy cierto que estas ausencias no debilitan o transforman substancialmente la lógica diferencia-asimetría-ejercicio de poder, pero su incorporación fortalecerá la especificidad del campo social en el que se tejen las relaciones asimétricas entre individuos y grupos.

En cuanto al tema del poder por intercambio, los resultados fueron altamente satisfactorios. La asimetría resultante de la dupla tener/no tener, caracteriza esta forma tan human de poder y permite explicar una serie de fenómenos de gran amplitud. Sin duda, el resultado teórico más notable, fue el producido de la confrontación entre Marcel Mauss y Carlos Marx. Para ambos, el proceso de los intercambios es un continuum y los distintos resultados analíticos derivan de las bases de las que parten, pero también de la focalización analítica sobre quién y por qué inicia el fenómeno. Y en esto no queda duda: para Mauss el que inicia el fenómeno, lo inicia subordinando; en contraposición, para Marx el que inicia lo hace subordinándose. Para uno, dar más es subordinar más; para otro, dar más significa mayor subordinación. Para uno se habla de don; para otro, lo que llamé anti-don. Metodológicamente: para uno, el dominante aporta primero el "don" y luego viene la devolución; para el otro, el dominado primero devuelve el "anti-don" y luego se le da

Estas curiosidades teóricas y metafóricas, en realidad fueron resultado de una interrogante general y que venía desde el modelo inicial: si no hay substrato duro de poder, ¿por qué dar siempre subordinaba al receptor? En el esclarecimiento de lo anterior, la certeza de Godelier de que el don no sólo instaura una diferencia o desigualdad, sino que si ya existe previamente el don expresa y legitima lo ya existente, permitió superar la dificultad del contexto previo y "salirse" de la dinámica exclusivamente económica del hecho. La subordinación máxima en el dar Godelier la modela en los dones a los dioses, pero entre los hombres, el caso existe y Marx lo vio claramente entre capitalistas y asalariados. Esta complejidad llevó a generar el concepto de conductas y conceptualizaciones de apropiación, que define en dos momentos el ejercicio de poder por intercambio: alguien da y alguien toma; pero alguien define conductas o conceptualizaciones derivadas de la toma del bien. Analíticamente, resulta irrelevante saber quién toma o devuelve primero; lo central es saber, quien define las 
conductas o conceptualizaciones del otro, derivadas de la toma. No debe olvidarse que resultó muy útil definir a la expresión subjetiva de esas conductas o conceptualizaciones, como "la orden". Ese concepto busca superar las interpretaciones morales del enunciado, al construirse, no en base a la percepción del enunciante como no forzosa -en términos de petición o favor por ejemplo- sino con base en su carácter exógeno y colgado de conductas o conceptualizaciones determinadas.

Para el caso de las políticas gubernamentales, el flujo de recursos que llega a la sociedad lo hace con efectos internos o externos. Claramente, aquí lo que interesa es la forma en que el Estado modela la acción social de los actores, derivada y condicionada por la toma del bien y que de otro modo no harían, lo que caracteriza el fenómeno como netamente exógeno. Como se osbervó, este concepto fue utilizado y fortalecido para abordar las políticas educativas interculturales en sus dos momentos: como don (primero el bien educativo y luego el aprendizaje); como anti don (primero el rendimiento mínimo y luego la certificación).

Esta lógica teórica de aproximación fue completamente útil y reafirmó, como mencioné al inicio, mi certeza en la utilidad de la perspectiva antropológica. Con relación a las otras perspectivas sociales, se delinearon una serie de complementos y precauciones que buscaban entender y modelar las dinámicas económicas que, ciertamente, caracterizan al fenómeno del intercambio. Este aire disciplinar ni buscó eliminarse ni sobrevalorarse. La característica más provechosa de esta aproximación fue la reseñada diferencia entre los intercambios homogéneos y los heterogéneos, que al nivel de las reflexiones antropológicas se mostró débil y en ocasiones inadecuada. El concepto de conductas y conceptualizaciones de apropiación, supera estas dificultades al hacer suya la precisión económica y diferenciar si la influencia se produjo por un intercambio homogéneo o heterogéneo.

Quiero reseñar la importancia de algunos juicios provenientes de la Ciencia Política. Aquellos que definen que el ejercicio de poder no sólo consiste en lo que se produce como efecto positivo, sino como ausencia de efecto, es decir, que el ejercicio de poder busca limitar o impedir las conductas o las conceptualizaciones concretas de un actor, ya sea en su ejecución u ocurrencia o más aún, en la sola posibilidad de que el actor prefigure su ocurrencia. Estos importantes insumos fueron centrales para caracterizar los efectos de poder en las legislaciones en materia indígena y los modelos administrativos de la educación intercultural, ya que claramente definen la ilegalidad de las conductas o las conceptualizaciones que lesionan a los indígenas en términos de la 
diferencia cultural; si logran evitarse, devienen en el ejercicio del poder político eficaz. De manera simultánea, en términos de discriminación, se busca llegar al punto que tal tema "desparezca" de la vida pública. Las políticas que en ese sentido se aplicaron en la UIEM, mostraron como se expuso, un impacto desigual, a veces eficaz, a veces infructuoso. En cualquier caso, los ejes del modelo mostraron su eficacia explicativa. En particular destacaron las aportaciones de Jon Elster sobre los fenómenos de justicia local, que evidenciaron algunos de los problemas que enfrentaba la UIEM en virtud de su éxito en la región, pues comenzó a llamar la atención de la población que habita la zona urbana, mejor preparada, con las consecuentes presiones de desplazamiento sobre los estudiantes de la zona rural, paradójicamente, la base normativa del modelo. Es factible vislumbrar la necesidad mecanismos de discriminación explícitos, para dar efectividad real a las asimetrizaciones constitucionales, que buscaban privilegiar el carácter indígena de la institución y no, su novedad en términos regionales.

Hay en relación con estos puntos, dos ausencias notables. En primer lugar, desde la Sociología apareció como sorprendentemente necesario y útil, el concepto de isomorfismo institucional. Herramienta teórica que da cuenta de la fuerte difusión de formas institucionalizadas que afectan a las organizaciones de un nicho, ya sea porque las probabilidades de continuidad aumentan por la convergencia con formas imperantes y exitosas, ya por la facilidad de ajustarse a los cánones regulares, evitando las complicaciones de innovar o vencer las resistencias institucionales. No se incluyó en el diseño teórico para dar cuenta de las circunstancias que motivaron su aparición.

En segundo lugar está el de la incorporación de los fenómenos consubstanciales a lo Político y la Política: es decir, las lógicas de la caracterización de los actores como amigos o enemigos y el alto grado de intensidad y hostilidad que puede alcanzarse con los segundos; o por otro lado, el del mundo de la búsqueda de consensos y la contención de los conflictos, en un contexto normativamente regulado. Esta ausencia tiene una explicación. Si bien este trabajo se ha definido de manera convencida como de Antropología Política, ha sido evidente que se ha focalizado únicamente en modelar y explicar los fenómenos de poder en su determinación causal. Para ello se busca entender el contexto, necesariamente político, pero al margen de la política; ¿cómo es esto? En el corazón de los estudios de la Política, lo fundamental es la caracterización del contexto, pero fundamentalmente, las reglas de operación, transformación y dirección de dicho contexto; el sistema político diríase. En el estudio de las políticas aplicadas en la UIEM, se tocó tangencialmente esta dimensión, que en definitiva no es la central. Para ello se 
utilizaron los conceptos de campo y arena turnerianos, pero que no son suficientes para caracterizar lo político y la política. Hago la precisión, porque se recuerda que lo central es construir un modelo de explicación de lo fenómenos de poder, insumo básico, pero no único, en el abordaje de tan complejo campo.

La primera prueba a la que se sometió el modelo fue al análisis de los instrumentos nacionales e internacionales, que enmarcaban el desempeño del Estado en términos de políticas hacia los pueblos indígenas. Por ello se buscó reseñar las órdenes que el Estado iba a implementar en su población para abordar el tema indígena. En un primer momento (Convenio 107 de la OIT) se definían conductas y conceptualizaciones de funcionarios de gobierno, tendientes a integrar a las poblaciones culturalmente diferentes y minoritarias, pero también efectos exógenos sobre la población indígena, que los iban llevar a integrarse a la cultura mayoritaria.

Estas políticas estaban sustentadas en una búsqueda central: si las diferencias culturales y las asimetrías derivadas de esa característica estaban impidiendo el desarrollo, ciudadanización e integración a la cultura mayoritaria, todos los efectos de las políticas deberían apuntar a la eliminación de la diferencia cultural. Para ello se debían destinar recursos, que al ser apropiados por la población indígena, los llevaran a sumarse al "fluir" de la población mayoritaria.

Destacaron en este punto la utilidad de las herramientas sobre la descripción del proceso diferencia-asimetría-ejercicio de poder, porque fueron profundamente útiles en la caracterización de lo que los instrumentos internacionales definían como desigualdades. Ya en este nivel, las posibilidades heurísticas del modelo fueron evidentes, porque permitieron explicar el proceso legal, que desde la Declaración Universal de los Derechos del Hombre buscaba definir como ilegales pares opuestos de diferencias, que eran utilizados cotidianamente para ejercer el poder sobre los subordinados, ya impidiéndoles su acceso a los derechos ciudadanos, ya obligándolos a través de estas desventajas.

El C-107 definió como centrales las diferencias Estado/pueblos y resto de la población/indígenas. Estas claras asimetrías en términos de desarrollo y derechos, fueron la base para estructurara políticas que consideraban la integración, respetando la cultura, patrimonio y opiniones de los indígenas; sin embargo, las políticas de gasto 
estatal definían conductas o conceptualizaciones necesariamente integradoras como las políticas de capacitación laboral, de inserción al sistema capitalista, subordinación al orden jurídico estatal, al educativo nacional y al democrático-liberal. Es de notar, que las asimetrías que fundamentaron la conducción social de los indígenas a su integración, eran exógenas y surgían de la superioridad de recursos del Estado colonial o mestizo frente a los indígenas, pero también la simbólica y la tecnológica, que determinaban su incorporación a la cultura colonial como el único camino viable. Destaca la consideración de un estadio sociológico: los "semitribales", que desaparecerá para el C169.

El C-169 modificó las visiones de manera paradigmática. No se abundará más en éste. Basta mencionar que aquí se desarrollaron los conceptos de "desasimetrización” y “asimetrización” como el proceso jurídico que declara ilegales el uso diferencias humanas para impedir el acceso a derechos o ejercer el poder (el primero) o también, que "crea" por decreto, una situación de privilegio especial, en aquellos que en general se encuentran en desventaja general (el segundo). Este último caso es el de la llamada "acción afirmativa", pero que en concordancia con el planteamiento general del poder político claramente representa un acto de asimetrización. Las políticas del C-169 definen la acción del Estado como no integradora y declaran que el desarrollo y la ciudadanización plena de los indígenas puede lograrse sin borrar la diferencia cultural, pues el uso de tal diferencia define para conformar una asimetría se define como ilegal.

El expediente multiculturalista que se analizó en esa sección, mostró como los nuevos proyectos políticos sobre la diversidad cultural estaban colgados de tres ejes: la comprensión, el respeto y la conservación. En términos de políticas que impactaban a la cultura, como es el caso de la educación intercultural en el medio indígena, el C-169 (y posteriormente la Declaración de los Derechos de los Pueblos Indígenas de 2007), especificaba que el Estado Mexicano se comprometía a actuar con estos nuevos insumos, comprendiendo, respetando y preservando las culturas indígenas. Se expuso entonces que el ejercicio del poder político estatal, debía ocurrir llevando a la totalidad de las población a conducirse con esta nueva realidad. Esto no definía el fin de las relaciones de poder entre el Estado y los pueblos indígenas, sino que caracterizaba el fin de la integración y del uso de las diferencias culturales como asimetría hacia los indígenas. A propósito de esto fue que se expusieron los conflictos de tipo antropológico, entre la particularidad de una cultura y la incorporación de elementos externos. La acción exógena del Estado para “animar" la subsistencia de una cultura o 
sus elementos, era el punto más problemático y desde el multiculturalismo se resolvía con un expediente político de alcance hegemónico, pero que claramente exponía fallas de tipo antropológico.

La presión internacional, pero sobre todo la nacional -vía el EZLN-, caracterizó la transformación institucional del Estado en concordancia con el C-169. Lograda la reforma al segundo constitucional en 2001, y aclarada la distancia frente a los Acuerdos de San Andrés, se perfilan, ahora sí, las acciones que los tres órdenes de gobierno deben cumplir en términos constitucionales. Se delineó en el Apartado A del artículo, el conjunto de derechos inalienables que tienen los indígenas, con base en su diferencia cultural, declarando ilegales todas las asimetrías que el Estado y la población mestiza utilizan para frenar el acceso a tales derechos; es pues un proceso de desasimetrización. En el Apartado B se establecieron las obligaciones gubernamentales para instrumentar tales derechos y las políticas específicas para fortalecer su ejercicio; comporta un proceso de asimetrización. Recordemos que se despliegan las formas de acción y el uso de los recursos, que los tres órdenes de gobierno deberán instrumentar, y se hizo una precisión en términos de poder: que el Estado mexicano ya estaba imposibilitado de ejercer el poder mediante las diferencias culturales con los indígenas, pero que no estaba imposibilitado para ejercer el poder sobre los indígenas como sujetos con derechos constitucionales, de manera semejante a la que realiza con el resto de la población. En este sentido, el Estado es asimétrico, respecto de los indígenas y respecto del resto de la población por igual. Esta supremacía del Estado, se evidenció al caracterizar las maneras en las que las políticas públicas hacia los pueblos indígenas fueron instrumentadas. Esta particularidad se tocó en esta última sección a propósito del carácter exógeno del ejercicio del poder: que había que separar la dimensión social y ciudadana del actuar del Estado, de lo que este último realiza por mandato ciudadano, pero desde una lógica distinta. En ese tenor, y se hizo notar en los dos capítulos finales, no todos los indígenas están en posición real de ejercer sus derechos, ni tampoco de implementar las formas que tienen sus derechos y que sólo es capaz de operar el Estado. Al margen de los reclamos por la autonomía escamoteada, aun si hubiera sido estatuida constitucionalmente, los problemas estatales, tal cual, subsistirían, pues provienen de necesidades con forma y fondo estatal y sólo desde esa lógica pueden ser solventados. Con esta idea en mente es que se analizó el diseño concreto de las políticas de educación superior en las regiones indígenas. 
La Universidad Intercultural es la forma final y vigente que el Estado mexicano produjo para obedecer el mandato constitucional relativo a la educación superior en zonas con población indígena. Al margen de que se delineó la historia de las políticas educativas en poblaciones indígenas en concordancia con la migración de paradigmas -del integracionista al multiculturalista-, en este capítulo se expuso ya de manera concreta el diseño que enmarca el ejercicio de poder político para esta población. Este diseño está en consonancia con lo que se acaba de aseverar: que hay problemas de dimensión estatal que sólo desde esa lógica pueden prevalecer si se desea una aplicación de largo alcance. Esta idea, que se fue fortaleciendo a lo largo del trabajo, permite encuadrar de manera antropológica, algunos de los problemas más recurrentes en las complejas sociedades actuales, pues el Estado, como una forma histórica del desarrollo humano, es una respuesta a problemas concretos; su complejización deriva de responder a las intrincadas situaciones contemporáneas. Las tensiones entre el Estado Mexicano y los grupos indígenas incluidos de manera forzada en su interior, derivan justo de determinar los límites del Estado. El análisis de los instrumentos legales secundarios y los organismos resultantes puso en evidencia, cómo ahí se expone e impone la forma que debe tener (y que puede tener) la educación superior hacia los pueblos indígenas.

Varias son las características y las condicionantes surgidas del proceso de diseño institucional que se emprendió en 2001 y que culminó en diciembre de 2003, con el decreto de creación dela UIEM. Destacaron desde luego, las que definen las formas que tendrá dicha educación: será intercultural y no indígena; atenderá a población fundamental pero no exclusivamente indígena; tendrá una fuerte intención en la vinculación con la comunidad; creará carreras y programas diseñados y avalados conjuntamente con la CGEIB; no seleccionará a sus estudiantes con criterios de eficiencia académica; será una educación de alta calidad; tendrá un esquema institucional de organismo descentralizado de los gobiernos estatales; su presupuesto se construirá a partes iguales entre la Federación y las entidades federativas; su rector será nombrado por el gobernador del estado; el consejo directivo estará subordinado al control político del gobierno del estado; las formas de contratación y los salarios se regirán por una lógica determinada por la entidad federativa y no por la Federación; que sólo habrá una UI por estado, aunque podrá tener distintas unidades; y que serán instituciones no mayores a 3000 estudiantes. 
Este apretado resumen, compendia, como se ve, una serie de controles que enmarcan a las UI y que, inevitablemente, tendrían que existir en una forma u otra. Ya desde aquí se empieza a sentir la forma final que tendrá el bien gubernamental “educación” y que tendrá impacto profundo en las conductas y conceptualizaciones de apropiación desarrolladas por la población blanco: los estudiantes indígenas. En este punto es que el concepto de isomorfismo institucional, que no estaba previsto en el diseño inicial, mostró su pertinencia para dar cuenta de las presiones institucionales para mantener inercias educativas tradicionales, matizando los impulsos novedosos y subordinando de plano otros, que abiertamente dañaban el proyecto de las UI.

Hay que recordar tres cosas: que el diseño no ocurrió al margen de la participación de actores concretos (indígenas y no indígenas) interesados en el proyecto; que la forma final no es resultado puro de los intereses de la Federación; y que, en el caso de la UIEM, la voluntad y vetos del Gobierno del Estado de México también contribuyeron en el diseño. Mucho de ello estuvo más influido por la política interior del estado, que por una disputa en términos del interés académico.

La pujanza de los recursos movilizados por el Estado, ha logrado el cumplimiento constitucional en 12 estados diferentes, y probablemente uno más. En este proceso, el Estado determinó, desde el diseño, condicionantes en la apropiación del bien educativo. Este marco institucional, que bien pudiera denominarse la "gramática" de la orden, es el espacio donde se enuncian las órdenes concretas que dicta la UIEM, como institución de educación superior en el medio indígena. Todo esto constituye pues, ejercicio de poder político

Las características peculiares del ejercicio de poder político, en contextos de convivencia de culturas diferentes, que se había considerado a propósito del Multiculturalismo, reapareció nuevamente en el análisis de las políticas concretas, ahora en torno del papel que los antropólogos juegan en el análisis, diseño, crítica o instrumentación de las políticas de Estado. El motivo era aclarar (y aclararme) la complejidad que supone analizar el ejercicio del poder político, pero irlo confundiendo, progresiva o parcialmente con el mundo del deber ser. Este último aspecto tiene como consecuencia debilitar el análisis del fenómeno en sí. Ello vino a colación por las contribuciones de la Antropología y de los antropólogos para el desarrollo de la educación intercultural, que abren vías para la comprensión pero también para la concientización y movilización de los agentes en la conducción de su futuro. 
Esta veta comprometida plantea una antropología y una etnografía de la interculturalidad como medio para lograr tal expediente. Creo, y lo afirmé al inicio de estas conclusiones, que desde la Antropología Política se pueden exponer los mecanismos que el Estado utiliza para ejercer el poder político sin necesidad de realizar mayores adecuaciones, que siendo válidas son muy específicas. La comprensión profunda de los fenómenos concretos de la implementación de políticas educativas interculturales faculta y facilita en un segundo momento, hacer una crítica que beneficie a los actores involucrados, sin necesidad de adecuaciones metodológicas problemáticas, que hacen más borrosa la frontera entre el ser y el deber ser. Considero que tanto estas reflexiones, como las realizadas en el capítulo tres sobre el Multiculturalismo, son un intento por enunciar algunos controles a los naturales impulsos críticos que tiene cualquier investigador, que en el caso de aquellos que se enfocan en la comprensión de los fenómenos de poder, se tornan más complejos, porque como que el objeto de estudio es el predomino de lo exógeno sobre lo endógeno, criticar esta realidad, simplemente por ser tal, conduce desbocadamente a un callejón sin salida.

La confrontación específica del modelo con la realidad en la Universidad Intercultural del Estado de México siguió arrojando resultados aceptables. Centrado en las asimetrías que muestran al Estado como superordinado, tanto por los recursos que puede movilizar, como por su capacidad certificadora, el impacto de su actuación es patente. La demarcación entre lo que llega de fuera -lo exógeno estatal- y lo que se espera al interior -las demandas de cumplimiento de derechos constitucionales-, fue un mecanismo acertado para separar lo que es ejercicio de poder político, de lo que no es.

Se fueron desgranando, desde el inicio del proyecto en 2003, todos los efectos de las decisiones tomadas por las instancias estatales, en función de cómo se gastaron los recursos, dónde se gastaron, para quiénes estaba destinado ese gasto y para quiénes no. En estos efectos, las órdenes de apropiación mostraron una efectividad sorprendente, pues las conductas y conceptualizaciones derivadas de la toma de los bienes gubernamentales, convergen con el deseo inicial.

Los efectos del diseño general se replican en la dimensión más específica de la vida académica, en donde los efectos exógenos, tocan asuntos tan cotidianos como la forma y la ornamentación del edificio; el contenido, estructura y disposición temporal 
de las materias en el mapa curricular; el desarrollo al interior de los salones de clases, comenzando por el impacto del salón redondo; la decisión de privilegiar la interculturalidad por sobre lo bilingüe; la presión por interculturalizar toda la vida académica, pero también todas las asimetrías; y el proceso de construcción de una epistemología intercultural.

$\mathrm{Si}$ bien estos campos no abordan la totalidad de la vida académicoadministrativa de la UIEM, son ejemplos claros del impacto que tiene el ejercicio del poder político. Es decir, la consecución de los objetivos iniciales, definidos de forma concreta, fue altamente satisfactoria. El Estado en este caso mostró la efectividad del ejercicio del poder político, hacia el cumplimiento de los objetivos planteados en la Constitución. Sin embargo en este mismo capítulo, se problematizó que dicha efectividad, se daba al nivel de lo "concreto" o "definido", porque los efectos de segundo y tercer orden exponían ya problemas estructurales en la instrumentación de las políticas de educación superior intercultural. Estos problemas, surgían de que los efectos (o defectos) macroscópicos de los éxitos "microscópicos" tenían en varios aspectos, direcciones divergentes o contrarias a lo dispuesto constitucionalmente; los llamados efectos imprevistos o perversos. Pero la corrección o modificación del curso elegido pasa por una crítica técnica -sobre los medios empleados para ocasionar efectosy normativa -sobre los matices e intensidades de la consecución de los fines. Esa crítica, como se aclaró, pertenece a un tiempo y espacio distinto al del análisis, descripción y comprensión de los fenómenos de poder en la UIEM que, tengo la convicción, ha mostrado un nivel más que aceptable.

Para terminar. En todo trabajo de análisis respecto de lo social, las consideraciones sobre su utilidad para la comunidad estudiada aparecen todo el tiempo. En el presente trabajo, estas consideraciones también han sido "compañeras" de viaje. El predomino de lo analítico y explicativo ha dejado, en apariencia, poco espacio para enunciar contribuciones que mejoren los procesos de implementación de las políticas públicas, y que inciden en la dimensión cultural de los sujetos. Sin embargo, estoy plenamente convencido -lo enuncié al inicio y al final de este trabajo-, que la exaltación de la Antropología como una vía no sólo útil, sino notablemente potente en el abordaje de los fenómenos del poder político contemporáneo, no es exagerada. Hice alusión también, a la urgencia contemporánea por encontrar soluciones contundentes a los problemas que más dañan a las sociedades. Las demandas al Estado, para que actúe y modifique la 
situación "para mejor", son formidables. Estas demandas también exigen mayor participación de los involucrados. Así, la sociedad toda, está atrapada en la búsqueda de soluciones estatales, en medio de presiones anti-estatales.

El planteamiento de este trabajo es que existen formas en el ejercicio del poder que son, no solamente legítimas, sino profundamente ineludibles en la atinada conducción de la sociedad. Esta aseveración determina, necesariamente, la imposibilidad de que todos conduzcan el destino de todos. La centralización creciente es una solución consistente con la complejización creciente de la humanidad. En el fino proceso de la política, que supone descubrir el balance preciso entre concentrar y delegar soluciones, el fin de toda centralización no es una opción.

La Antropología, ciencia tejida en la consideración de las culturas humanas como un todo, impulsa a pensar los problemas cotidianos frente a un horizonte de "larga duración" cultural y faculta a quienes usan sus herramienta, a matizar o moderar las urgencias en la búsqueda de una mejor sociedad. Este descenso en la velocidad, se complementa con la convicción de las ventajas que el ejercicio del poder político tiene para resolver una gran cantidad de problemas sociales pero que por otro lado, expone notables incapacidades para otros vastos campos de la vida humana. Dar herramientas para pensar reposadamente ambos extremos es una de las virtudes de nuestra disciplina. Valga pues este esfuerzo, no como una dirección definitiva en la comprensión del fenómeno del poder, sino como una invitación a problematizar las ventajas y límites del poder político a la luz del faro antropológico, construido en la reflexión de los elementos que conforman la cultura humana, en la que el poder, es un elemento más. 


\section{BIBLIOGRAFÍA}

-Adams, Richard N. La red de la expansión humana. México, Ediciones de la Casa Chata, 1978.

------. El octavo día. La evolución social como auto organización de la energía. México, Universidad Autónoma Metropolitana, 2001.

-Agudo, Alejandro. "Conocimiento, lenguaje, poder e intermediación. Perspectivas contemporáneas en la antropología de las políticas públicas”, en: Estudios Sociológicos XXVII: 79, 2009.

-Aguirre Beltrán, Gonzalo. Regiones de refugio. México, Instituto Indigenista Interamericano-INI, 1967

-----. Teoría y práctica de la educación indígena. Obra polémica, X. México, Universidad Veracruzana-INI-FCE, 1992.

-Aguilar, Iñigo et allí. Educación interétnica. México, INAH, 1996.

-Alexander, Jeffrey. Las teorías sociológicas desde la Segunda Guerra Mundial. Barcelona, Gedisa, 2000.

-Alteridades. "Multiculturalismo derechos humanos y pueblos indígenas" (Dossier). Año 18, Num. 35, enero-junio 2008.

-Allen, Nicholas. "Marcel Mauss", en: Thomas Barfield (ed.). Diccionario de antropología. México, Siglo XXI, 2000.

-Amara, Guiuseppe. La violencia. México, Consejo Nacional para la Cultura y las Artes, 1998.

-Ansaldo, Juan (Editor). ¡Nunca más un México sin nosotros! El camino del Congreso Nacional Indígena. Compilación de documentos 1996-1998. México, Serie de los usos y costumbres, Ce Acatl, 1998.

-Asociación Antropológica Americana; Comité ejecutivo. "Statement on Human Rights”, en: American Anthropologist. Vol. 49, October-December, No. 4, 1947.

-Arrow, Kenneth. "Valores individuales y valores sociales", en: Lecturas de teoría política. Madrid, Ministerio de Economía y Hacienda, 1991.

-Asamblea General de las Naciones Unidas. Declaración Universal de los Derechos del Hombre. New York, 1948. En: www.un.org/es/documents/udhr consultada el 11 agosto de 2011.

-Bachrach, Peter y Morton Baratz. "Two Faces of Power”, en: The American Political 
Science Review. Vol. 56, No. 4, 1962.

-Baldwin, David. "Power and Social Exchange", en: The American Political Science Review. Vol. 72, No. 4, 1978.

-Barie, Cletus. Pueblos indígenas y derechos constitucionales en América Latina: Un panorama (2a ed.). Bolivia, Instituto Indigenista Interamericano/CDI, 2003.

-Barnes, Barry. La naturaleza del poder. Barcelona, Ediciones Pomares-Corredor, 1990.

-Barquín Cendejas, Alfonso. De la economía a la política: un tránsito difícil.

Intercambio y poder político en Anthony Downs, Charles Lindblom y Douglas North (Tesis de maestría). México, UNAM-FCPYS, 2006.

-----. Del poder y su desgaste. Un modelo para su estudio. México, INAH, 2007.

-Barret, Stanley. Culture Meets Power. Westport, Praeger, 2002.

-Bartolomé, Miguel Alberto. Gente de costumbre y gente de razón. Las identidades étnicas en México. México, INI-Siglo XXI, 1997.

-----. Procesos interculturales: antropología política del pluralismo en América Latina. México, Siglo XXI, 2006.

-----. La tierra plural. Sistemas interculturales en Oaxaca. México, INAH, 2008.

-Bengoa, José. La emergencia indígena en América Latina. México, FCE, 2000.

-Benveniste, Émile. Problemas de lingüística general, V. I, (7ª ed.). México, Siglo XXI, 1978.

-Bertely, María (Coord.). Sembrando nuestra educación intercultural como derecho: la nueva escuela intercultural en Chiapas. México, CIESAS-Ediciones Alcatraz, 2009.

-Blau, Peter. Exchange and Power in Social Life. New York, Wiley, 1964.

-Bobbio, Norberto. Estado, gobierno y sociedad. México, FCE, 1989.

-Bonfil Batalla, Guillermo. "Del indigenismo de la Revolución a la Antropología Critica", en: Andrés Medina y Carlos García Mora (Coords.). La quiebra política de la Antropología Mexicana. México, UNAM, 1983.

-----. "Lo propio y lo ajeno: Una aproximación al problema del control cultural”, en:

Pensar nuestra cultura. México, Alianza ed., 1991.

-----. México profundo. Una civilización negada. México, Grijalbo, 1994.

-----. (compilador). Utopía y revolución. El pensamiento político contemporáneo de los indios en América Latina. México, Nueva Imagen, 1981.

-Boulding, Kenneth. Las tres caras del poder. Barcelona, Paidós, 1993.

-Buchanan, James. Ensayos sobre economía política. México, Alianza Editorial 
Mexicana, 1990.

-----. y Gordon Tullock. El cálculo del consenso. Fundamentos lógicos de la democracia constitucional. Madrid, Espasa-Calpe, 1980.

-Burguete, Araceli. “Los indios y la Constitución”, en: México Indígena. Num. 23, Agosto, 1991.

-Calvo Pontón, Beatriz y Laura Donadieu. Una educación ;indígena bilingüe y bicultural? Capacitación diferencial de los maestros mazahuas? México, CIESAS, 1992.

-Castaingts Teillery, Juan. Simbolismos del dinero. Barcelona, Anthropos/UAM-I, 2002.

-----. El dilema del prisionero como solución al enigma del don. Mecanoescrito, 2007a.

-----. Economía política de la política económica. Mecanoescrito, 2007b.

-Castro Domingo, Pablo. Los que ya bailaron que se sienten: Cultura política, ciudadanía y alternancia electoral. México, Miguel Ángel Porrúa, 2006.

-Celote Preciado, Antolín. Cuando el sueño se hizo palabra. El nacimiento de la primera universidad intercultural de México. Edición digital en disco compacto. Toluca, s/f.

-Cipolla, Carlo. "Las leyes fundamentales de la estupidez humana", en: Allegro ma non tropo (2a ed.). Barcelona, Editorial Crítica, 1992.

-Claessen, Henry J.M. Antropología Política. México, Universidad Nacional Autónoma de México-Instituto de Investigaciones Jurídicas, 1979.

-Clastres, Pierre. La sociedad contra el Estado. Barcelona, Monte Ávila Editores, 1978.

-----. Arqueología de la violencia: la guerra en las sociedades primitivas. México, Fondo de Cultura Económica, 2004.

-Comas, Juan. La antropología social en México. Trayectoria y antología. México, Instituto Indigenista Interamericano, 1964.

-Collins, Randall. Cuatro tradiciones sociológicas. México, UAM-I, 1996.

-Colom, Francisco (Editor). El espejo, el mosaico y el crisol. Modelos políticos para el multiculturalismo. Barcelona, UAM/Anthropos, 2001.

-Congreso Nacional de Educación Indígena e Intercultural. Hacia la construcción de una educación indígena e intercultural desde los pueblos y para los pueblos. México, 2001.

-Constitución Política de los Estados Unidos Mexicanos. Vigente al 13 de octubre de 2011. Consultada en: www.ordenjuridico.gob.mx 
Coordinación General de Educación Intercultural Bilingüe. Experiencias innovadoras en educación intercultural. 2 volúmenes. México, SEP-CGEIB, 2004.

-----. Universidad intercultural. Modelo educativo. México, SEP-CGEIB, 2006a.

-----. El enfoque intercultural em educación. Orientaciones para maestros de primaria. México, SEP-CGEIB, 2006b.

-----. Modelo educativo del bachillerato intercultural. México, SEP-CGEIB, 2006c.

-----. Líneas de investigación en educación intercultural. México, SEP-CGEIB, 2009.

-Dahl, Robert. “The Concept of Power”, en: Behavioural Science. Vol. 2, Num. 3, July, 1957.

-Dalton, George (ed). Primitive, Archaic and Modern Economies Essays of Karl Polanyi. Boston, Beacon Press, 1969.

-De Jouvenel, Bertrand. El poder (2ª ed.). Madrid, Editora Nacional, 1974.

-Deance, Iván y Verónica Vázquez (coord.). Aulas diversas. Experiencias sobre educación intercultural en América. Quito, Ediciones Abya-Yala, 2012.

-Derrida, Jacques. De la gramatología (2a ed.). México, Siglo XXI, 1978.

-Diario Oficial de la Federación, 4 de diciembre de 1948. "Ley que crea el Instituto Nacional Indigenista”, en: INI (1978) op. cit.

-----. 28 de enero de 1992. "Decreto por el que se reforma el Artículo 4o. de la Constitución Política de los Estados Unidos Mexicanos". México, Secretaría de Gobernación.

-----. 22 de enero de 2001. “Acuerdo por el que se establece la Coordinación General de Educación Intercultural Bilingüe”. México, Secretaría de Gobernación.

-----. 14 de agosto de 2001. “Decreto...”. México, Secretaría de Gobernación.

-----. 31 de diciembre de 2010. “ACUERDO número 575 por el que se emiten las

Reglas de Operación del Programa Nacional de Becas y Financiamiento (PRONABES)"'. México, Secretaría de Gobernación.

-Díaz Polanco, Héctor. Autonomía regional. La autodeterminación de los pueblos indios. México, Siglo XXI/UNAM, 1991.

-----. La rebelión zapatista y la autonomía. México, Siglo XXI, 1997.

-----. Elogio de la diversidad. Globalización, Multiculturalismo y etnofagia. México, Siglo XXI, 2006.

-Dietz, Gunther. Multiculturalismo, interculturalidad y educación. Una aproximación antropológica. Granada, CIESAS-Universidad de Granada, 2003.

----- y Laura Mateos. Interculturalidad y educación intercultural en México. Un análisis 
de los discursos nacionales e internacionales en su impacto en los modelos educativos mexicanos. México, CGEIB, 2011.

-Dostoyevski, Fedor. Memorias del subsuelo. Barcelona, DVD Ediciones, 2005.

-Douglas, Mary. Pureza y peligro. Un análisis sobre los conceptos de contaminación y tabú. Madrid, Siglo XXI Editores, 1973.

-Downs, Anthony. Teoría económica de la democracia. Madrid, Aguilar, 1973.

-Elster, Jon. Justicia local. De qué modo las instituciones distribuyen bienes escasos y cargas necesarias. Barcelona, Gedisa, 1998.

-Engels, Federico. Anti-Dühring (2ª ed.). México, Editorial Grijalbo, 1968.

-Erasmus, Charles. “El síndrome 'encogido' y el desarrollo de la comunidad”, en: América indígena. Vol. XXIX, num. 1, Enero 1969

-Fábregas, Andrés. "La experiencia de la Universidad Intercultural de Chiapas", en: Daniel Matto (Coord.). Diversidad cultural e interculturalidad en educación superior. Experiencias en América Latina. Caracas, IESALC-UNESCO, 2008.

-Fix-Zamudio, Héctor. "Introducción al estudio de la defensa de la Constitución”, en: Boletín mexicano de Derecho Comparado. No. 1, 1968.

-----. y Salvador Valencia Carmona. Derecho Constitucional Mexicano y Comparado (6a ed.). México, UNAM/Editorial Porrúa, 2009.

-Florescano, Enrique. Los orígenes del poder político en Mesoamérica. México, FCE, 2009.

-Foucault, Michel. Microfísica del poder. ( $3^{\mathrm{a}}$ ed.). Madrid, Las Ediciones de la Piqueta, 1992.

-----. "El sujeto y el poder", en: Hubert L. Dreyfus y Paul Rabinow (comps.). Michel Foucault: más allá del estructuralismo y la hermenéutica. Buenos Aires, Ediciones Nueva Visión, 2001.

-Gaceta de Gobierno. Periódico Oficial del Gobierno del Estado de México. No. 115, 10 de diciembre de 2003. Consultado en línea en: www.edomexico.gob.mx/uiem/decreto.htm, el 16 de febrero de 2009.

-Gaceta Parlamentaria. 7 de diciembre de 1990 (Versión electrónica). Dirección General de Crónica Parlamentaria, Cámara de Diputados. Consultada en: http://gaceta.diputados.gob.mx consultada el 18 de mayo de 2010.

-Gaceta Parlamentaria. 25 de abril de 2001 (Versión electrónica). Cámara de Senadores. Consultada en: www.senado.gob.mx/index.php? ver=sp\&mn=2 el 19 de junio de 2010. 
-Galbraith, John Kenneth. Anatomía del poder. México, Edivisión, 1986.

-Gallino, Luciano. “Autoridad”, en: Luciano Gallino. Diccionario de Sociología. México, Siglo XXI, 1995.

-Galván de Terrazas, Luz Elena. La palabra mazahua (Documentos municipales para la historia de la educación indígena). Cuadernos de la Casa Chata \# 61. México, CIESAS, 1982.

-Garduño, Julio. El final del silencio. Documentos indígenas. México, Premia Ed., 1983.

-Gasparello, Giovanna y Jaime Quintana Guerrero (Coordinadores). Otras geografías. Experiencias de autonomías indígenas en México. México, UAM-I, 2009.

-Geist, Ingrid. “Introducción”, en: Ingrid Geist (comp.). Antropología del ritual. Victor Turner. México, INAH/ENAH, 2002.

-Giddens, Anthony. Las nuevas reglas del método sociológico ( $2^{\mathrm{a}} \mathrm{ed}$.). Buenos Aires, Amorrortu, 1997.

-Gilly, Adolfo. Chiapas, la razón ardiente. México, ERA, 1997.

-Gimate-Welsh, Adrián. Representación y deliberación en la LVIII Legislatura. A propósito de la Ley de Derechos y Cultura Indígenas. México, UAM-I/Miguel Ángel Porrúa, 2010.

-Gobierno del Estado de Chiapas. Los Acuerdos de San Andrés. México, Consejo Estatal para la Cultura y las Artes/Secretaría de Pueblos Indios, 2003.

-Gobierno del Estado de México. Universidad Intercultural del Estado de México. Julio 2003.

-Godelier, Maurice. Racionalidad e irracionalidad en economía ( $2^{\mathrm{a}}$ ed.). México, Siglo XXI, 1970.

-----. Lo ideal y lo material. Madrid, Taurus, 1990.

-----. El enigma del don. Barcelona, Paidós, 1998.

-González Alcantaud, José. El clientelismo político. Perspectiva socioantropológica. Barcelona, Anthropos, 1997.

-González Apodaca, Érica. Los profesionistas indios en la educación intercultural. Etnicidad, intermediación y escuela en el territorio mixe. México, UAM-I, Juan Pablos, 2008.

-González de la Rocha, Mercedes (Coord.). Procesos domésticos y vulnerabilidad. Perspectivas antropológicas de los hogares con Oportunidades. México, CIESAS-Publicaciones de la Casa Chata, 2006. 
-González Villaruel, Alejandro. Actores sociales y estructura de poder en operación en la cadena agroindustrial del limón (Tesis doctoral). México, Universidad Autónoma Metropolitana-Iztapalapa, 2005.

-Gouldner, Alvin. La sociología actual: Renovación y crítica. Madrid, Alianza, 1979.

-Gozzi, , Gustavo. "Estado contemporáneo", en: Norberto Bobbio et allí. Diccionario de Política (13 ${ }^{\mathrm{a}}$ ed.). México, Siglo XXI, 2002.

-Guerra, Juan. Historia personal de la COCOPA. México, Grijalbo, 1998.

-Gutiérrez, Daniel (compilador). Multiculturalismo. Desafíos y perspectivas. México, COLMEX/Siglo XII, 2006.

-Guzmán Gómez, Alba. Voces indígenas. México, INI-CNA, 1991.

-Habermas, Jürgen. La inclusión del otro. Estudios de teoría política. Barcelona, Paidós, 1999.

-Hale, Charles. "Rethinking Indigenous Politics in the Era of the "Indio Permitido", en: Report on the Americas. NACLA, Vol. 38, No 2, 2004.

-Hardt, Michael y Antonio Negri. Imperio. Barcelona, Paidós, 2002.

-Harvey, Neil. La rebelión de Chiapas. La lucha por la tierra y la democracia. México, ERA, 2000.

-Homans, George. "Social Behavior as Exchange", en: The American Journal of Sociology. Vol. 63, No. 6, 1958.

-INALI. Ley General de Derechos Lingüísticos de los Pueblos Indígenas. México, Instituto Nacional de Lenguas Indígenas, s/f.

-INFOMEX-CDI. Solicitud de información sobre los montos transferidos por la Comisión para el Desarrollo de los Pueblos Indígenas a la Universidad Intercultural del Estado de México. Fecha de respuesta vía digital: 9 de noviembre de 2011.

-INFOMEX-SEP. Solicitud de información sobre el convenio de colaboración entre la SEP y el Gobierno del Estado de México, para la creación de la Universidad Intercultural del Estado de México. Fecha de respuesta vía digital según folio 14 de junio de 2011.

-Instituto Nacional Indigenista (INI). Métodos y resultados de la politica indigenista. México, INI, 1954.

-----. INI 30 años después. Una revisión crítica. México, INI, 1978.

-Jiménez Naranjo, Yolanda. "Los enunciados de la escuela intercultural en el ámbito de los pueblos indígenas", en: Desacatos. Num. 35, enero-abril, 2011. 
-Juliano, Dolores. Educación intercultural. Escuelas y minorías étnicas. Madrid, EUDEMA, 1993.

-Kelsen, Hans. Compendio de Teoría General del Estado. México, Colofón, 2007.

-Kirchhoff, Paul. "Mesoamérica”, en: Una definición de Mesoamérica (2a ed.). México, Instituto de Investigaciones Antropológicas, 1992.

-Klesing-Rempel, Úrsula (Comp.). Lo propio y lo ajeno. Interculturalidad y sociedad multicultural. México, Plaza y Valdez, 1996.

-Koch, Howard. La guerra de los mundos. México, UAM, 1996.

-Kymlicka, Will. Ciudadanía multicultural. Barcelona, Paidós, 1996.

-Krotz, Esteban. "La fundamentación de la idea de Derechos Humanos en contextos multiculturales", en: Alteridades. Volumen 18, No. 35, 2008.

-Laclau, Ernesto y Chantal Mouffe. Hegemonía y estrategia socialista. Hacia una radicalización de la democracia (2a ed.).Buenos Áires, FCE, 2004.

-Lasalle, Ferdinand. ¿Qué es una constitución?. México, Colofón, 2002.

-Lévi-Strauss, Claude. El pensamiento salvaje. México, Fondo de Cultura Económica, 1964.

-----. Las estructuras elementales del parentesco. Barcelona, Paidós, 1969.

-----. Antropología estructural (6 ${ }^{\mathrm{a}}$ ed.). Buenos Aires, Eudeba, 1976.

-----. “Introducción a la obra de Marcel Mauss”, en: Marcel Mauss. Sociología y Antropología. Madrid, Tecnos, 1979.

-----. "Raza y cultura”, en: Raza y cultura. Introducción de Manuel Garrido. Madrid, Cátedra, 2000.

-Ley General de Educación. Vigente al 16 de noviembre de 2011. Consultada en: www.ordenjuridico.gob.mx

-Ley Orgánica de la Universidad Autónoma Indígena de Sinaloa. Consultada en: www.uaim.edu.mx , el 18 de octubre de 2011.

-Leyva, Xochitl. Neo-Zapatism: Networks of Power and War. Tesis de Doctorado. University of Manchester, 2001.

-Lindblom, Charles. Politics and Markets. New York, Basic Books, 1977.

-----. El proceso de elaboración de Políticas Públicas. México, Ministerio para las Administraciones Públicas-Miguel Ángel Porrúa, 1991.

-----. Democracia y sistemas de mercado. Estudio introductorio de Carlos Sirvent. México, Fondo de Cultura Económica, 1999. -Lindholm, Charles. "Mary Douglas", en: Thomas Barfield (ed.). Diccionario de 
antropología. México, Siglo XXI, 2000.

-López, Gerardo y Sergio Velazco. Aportaciones indígenas a la educación. Antología. México, SEP-Ed. El Caballito, 1985.

-Lowi, Theodore. "Políticas públicas, estudios de caso y teoría política", en: Luís Aguilar Villanueva. La hechura de las políticas. ( $3^{\mathrm{a}}$ ed.). México, Miguel Ángel Porrúa, 2000.

-Lowie, Robert. Historia de la etnología. México, Fondo de Cultura Económica, 1946.

-Luhman, Niklas. Poder. Barcelona, Anthropos-Universidad Iberoamericana, 1995.

-Lukes, Steven. Power. A Radical View (2 ed.). Great Britain, Palgrave MacMillan, 2005.

-Manzanilla, Linda. La construcción de la sociedad urbana en Mesopotamia. Un proceso en la historia. México, UNAM, 1986.

-Maquiavelo, Nicolás. El príncipe. Madrid, El Mundo-Unidad Editorial, 1999.

-Martuccelli, Danilo. "Las contradicciones políticas del Multiculturalismo", en: Daniel Gutierrez op. cit.

-Marx, Emmanuel. The Social Context of Violent Behavior. London, Routledge and Kegan Paul, 1976.

-Marx, Karl. Contribución a la crítica de la Economía Política (2a ed.). Madrid, Alberto Corazón Editor, 1976.

-----. Introducción general a la crítica de la economía política (14a ed.). México, Ediciones Pasado y Presente, 1980.

-----.El Capital. Crítica de la Economía Política (3a ed.). México, Fondo de Cultura Económica, 1999.

-----. y Federico Engels. Obras escogidas en dos tomos. Moscú, Editorial Progreso, s/f.

-Matto, Daniel (Coord.) Diversidad cultural e interculturalidad en educación superior. Experiencias en América Latina. Caracas, IESALC-UNESCO, 2008.

-Mauss, Marcel y Emile Durkheim. "De ciertas formas de clasificación primitiva”, en: Marcel Mauss. Instituciones y culto. Obras II. Barcelona, Barral Editores, 1971a.

-----. "Ensayo sobre los dones. Motivo y forma del cambio en las sociedades primitivas", en: Sociología y Antropología. Madrid, Tecnos, $1971 \mathrm{~b}$.

-Medina Peña, Luís. Hacia el nuevo Estado. México, 1920-1994 (2ª ed). México, FCE, 1995. 
-Moguel, Julio. Chiapas: la guerra de los signos. México, Juan Pablos Editor, 1998.

-Morgan, Lewis H. La sociedad primitiva. México, Ediciones Quinto Sol, 1984.

-Nietzsche, Federico. Genealogía de la moral. Madrid, Mestas Ediciones, 2001.

-North, Douglass. “A Transaction Cost Theory of Politics”, en: Journal of Theoretical Politics. 2 (4), 1990.

-----. Instituciones, cambio institucional y desempeño económico. México, Fondo de Cultura Económica, 1993.

-Nugent, David y Joan Vincent (Eds.). A Companion to the Anthropology of Politics. Oxford, Blackwell, 2004.

-Oemichen, Cristina. Reforma del Estado. Política social e indigenismo en México. 1988-1996. México, UNAM-IIA, 1999.

-Ordóñez, José Emilio. “Constitución y derechos étnico en México”, en: Derechos indígenas en la actualidad. Instituto de Investigaciones Jurídicas, Serie E: Varios, Num. 59. México, IIJ/UNAM, 1994.

-Parsons, Talcott. “On the Concept of Political Power", en: Sociological Theory and Modern Society. New York, The Free Press, 1967.

-----. "El aspecto político de la estructura y el proceso sociales", en: Easton, David (comp.). Enfoques sobre teoría política. Buenos Aires, Amorrortu, 1973.

-Pérez Ruiz, Maya Lorena. ¡Todos somos zapatistas! Alianzas y rupturas entre el EZLN y las organizaciones indígenas. Tesis de Doctorado. Universidad Autónoma Metropolitana-Iztapalapa, 2000.

-Portinaro, Pier Paolo. "Poder político", en: Germán Pérez Fernández del Castillo et alii (comps.). Léxico de la política. México, FCE-FLACSO, 2000.

-Poulantzas, Nicos. Poder político y clases sociales en el estado capitalista ( $8^{\mathrm{a}} \mathrm{ed}$.). México, Siglo XXI, 1974.

Powell, Walter y Paul DiMaggio (Comps.). El Nuevo institucionalismo en el análisis organizacional. México, FCE, 1999.

-Ramírez Castañeda, Elisa. La educación indígena en México. México, UNAM, 2006. -Rawls, John. Teoría de la justicia. México, FCE, 2002.

-Reygadas, Luís. “Las redes de la desigualdad: un enfoque multidimensional”, en: Cultura y política. Dimensiones de la desigualdad. No. 22, Otoño, 2004.

-Ricossa, Sergio. Diccionario de Economía (5ª ed.). México, Siglo XXI, 2007. -Rodríguez Miguel Angel (coord.). Testimonios de discriminación: historias vivas. México, CGEIB, 2006. 
-Rousseau, Juan Jacobo. “Discurso sobre el origen de la desigualdad”, en: El contrato social o principios de derecho político (13 ${ }^{\text {a }}$ ed.). México, Editorial Porrúa, 2002.

-Sáenz, Moisés. "La escuela rural mexicana” [1928], en: Juan Comas (comp.) La antropología social en México. México, Instituto Indigenista Interamericano, 1964.

-Santos, Boaventura de Sousa (Coord). Democratizar la democracia. Los caminos de la democracia participativa. México, FCE, 2004.

-----. y Cesar Rodríguez Garavito (Eds.). El Derecho y la globalización desde abajo. Hacia una legitimidad cosmopolita. Barcelona, Anthropos/UAM-Cuajimalpa, 2007.

-Sahlins, Marshal. Economía de la edad de piedra (2ª ed.). Madrid, Akal, 1983.

-----. Cultura y razón práctica (2ª ed.). Barcelona, Gedisa, 2007.

-Sarmiento, Sergio. "El consejo nacional de los Pueblos Indígenas y la política indigenista”, en: Revista Mexicana de Sociología. V. 47, No. 3, 1985.

-Sartori, Giovanni. La sociedad multiétnica. Pluralismo, Multiculturalismo y Etnofagia. Madrid, Taurus, 2001.

-----. La política. Lógica y método en las Ciencias Sociales (2 $2^{\mathrm{a}}$ ed.). México, Fondo de Cultura Económica, 2002.

-Saussure, Ferdinand de. Curso de lingüística general (4a ed.). México, Ediciones Nuevo mar, 1989.

-Schiera, Pierangelo. "Estado moderno", en: Norberto Bobbio et allí. Diccionario de Política (13 ${ }^{\mathrm{a}}$ ed.). México, Siglo XXI, 2002.

-Schmelkes, Sylvia. “Coordinación General de Educación Intercultural Bilingüe”, en: Educación superior para los pueblos indígenas de América Latina. Memorias del segundo encuentro regional. México, IESALC-CGEIB, 2004.

-----. "Creación y desarrollo inicial de la universidades interculturales en México: problema, oportunidades, retos", en: Daniel Matto (Coord.) Diversidad cultural e interculturalidad en educación superior. Experiencias en América Latina. Caracas, IESALC-UNESCO, 2008.

-Scott, James. Weapons of the Weak. Everyday Forms of Peasant Resistance. New Haven, Yale University Press, 1985.

-----. Los dominados y el arte de la resistencia. México, Editorial Era, 2000.

-Secretaria de Educación Pública. Programa Nacional de Educación 2001-2006. México, SEP, 2001. 
-Serrano, Enrique. Consenso y conflicto. Schmitt, Arendt y la definición de lo político. México, CEPCOM, 1998.

-Serrano Carreto, Enrique et al. Indicadores socioeconómicos de los pueblos indígenas de México. México, INI/PNUD/CONAPO, 2002.

-Sierra, Ma. Teresa. "Esencialismos y Autonomía: Paradojas de las reivindicaciones indígenas”, en: Alteridades. Volumen 7, No. 14, 1997.

-Sharma, Aradhana y Akhil Gupta (Eds.). The Anthropology of the State: A Reader. Oxford,Blackwell, 2007.

-Shepsle, Kenneth y Mark Bonchek. Las formulas de la política. Instituciones, racionalidad y comportamiento. México, Taurus-CIDE, 2005.

Shore, Cris y Susan Wright (Eds.). Anthropology of Policy: Critical Perspectives on Governance and Power. London, Routledge, 1997.

-Smith, Adam. La riqueza de las naciones. Madrid, Alianza Editorial, 1994.

-Stoczkowski, Wictor. “Claude Levi-Strauss y la UNESCO”, en: El Correo de la UNESCO, Número 5, 2008. Disponible en: www.unesco.org/es/courier/cls.

-Stoppino, Mario. "Poder" en: Norberto Bobbio et al. Diccionario de política (13 ${ }^{\mathrm{a}}$ ed.). México, Siglo XXI, 2002a.

-----. “Autoridad” en: Norberto Bobbio et al. Diccionario de política (13 ed.). México, Siglo XXI, 2002a.

-Stavenhagen, Rodolfo. Las clases sociales en las sociedades agrarias. México, Siglo XXI, 1969.

-----. "Los derechos indígenas: algunos problemas conceptuales", en: Nueva Antropología. XIII, 43, 1992.

-----. “Derecho internacional y derechos indígenas", en: Esteban Krotz (Ed.). Antropología jurídica: perspectivas socioculturales en el estudio del derecho. Barcelona, UAM-Anthropos, 2002.

-Suprema Corte de Justicia de la Nación. La jerarquía de los tratados internacionales respecto de la legislación general federal y local, conforme al artículo 133 constitucional. México, Suprema Corte de Justicia de la Nación, 2009.

-Swartz, M., Tuden, A., y Turner, V. "Antropología Política: Una Introducción" en: Alteridades. Año IV, Num. 8, 1994.

-Taylor, Charles. El multiculturalismo y “La política del reconocimiento” (2a ed.). México, Fondo de Cultura Económica, 2009.

-Tejera Gaona, Héctor. La antropología funcionalista. México, INAH, 1996. 
-Touraine, Alain. "Las condiciones de la comunicación intercultural”, en: Daniel Gutierrez op. cit.

-Turner, Victor. Dramas, Fields and Metaphors. Ithaca, Cornell University Press, 1974.

-----. La selva de los símbolos (4a ed.). México, Siglo XXI, 1999.

-----. "Dramas sociales y metáforas rituales", en: Ingrid Geist (comp). op. cit. 2002a.

-----. "Mukanda, circuncisión de los muchachos. Las políticas de un ritual no político", en: Ingrid Geist (comp). op. cit. 2002 b.

-UIEM. Acta del Consejo Directivo UIEM-005, 18 de abril de 2005.

-Uvalle Berrones, Ricardo. La responsabilidad política e institucional de la Administración Pública. Toluca, Instituto de Administración Pública del Estado de México, 2003.

-Uberoi, Singh. Politics of Kula Ring ( $2^{\mathrm{a}}$ ed.). Manchester, Manchester University Press, 1971.

-Valdivia, Teresa. "Políticas y reformas en materia indígena, 1990-2007”, en: Argumentos. Vol. 22, No. 59, 2009.

-Valladares, Laura. La lucha por las autonomías en México: Políticas multiculturales Movimiento indígena. Tesis de Doctorado. México, ENAH, 2009.

-Van Cott, Dona Lee. “Los movimientos indígenas y sus logros: La representación y el reconocimiento jurídico en los Andes”, en: América Latina Hoy. No. 36, Abril, 2004.

-Varela, Roberto. Expansión de sistemas y relaciones de poder. México, Universidad Autónoma Metropolitana-Iztapalapa, 1984.

-----. Cultura y poder. México, Anthropos-Universidad Autónoma Metropolitana, 2005.

-Villoro, Luis. Los grandes momentos del indigenismo en México. México, Ediciones de la Casa Chata, 1984.

-----. El poder y el valor. Fundamentos de una ética política. México, FCE, 1997.

-Warman, Arturo et al. De eso que llaman antropología mexicana. México, Nuestro Tiempo, 1970.

-Weber, Max. Economía y Sociedad (2a ed.). 2 t. México, Fondo de Cultura Económica, 1964.

-----. Ensayos sobre metodología sociológica. Buenos Aires, Amorrortu, 1973.

-----. El político y el científico. Introd. de Raymond Aron. Madrid, Alianza Editorial, 1998.

-White, Leslie. La ciencia de la cultura: un estudio sobre el hombre y la civilización. 
Barcelona, Ediciones Paidós, 1982.

-Wolf, Eric. Figurar el poder. Ideologías de dominación y crisis. México, CIESAS, 2001

-Womack, John. Chiapas, el Obispo de San Cristóbal y la revuelta zapatista. México, Cal y Arena, 1998.

-Zapata-Barrero, Ricard. Multiculturalidad e inmigración. Madrid, Editorial Síntesis, 2004.

-Zolo, Danilo. Cosmópolis. Perspectivas y riesgos de un gobierno mundial. Barcelona, Paidós, 2000.

-----. La justicia de los vencedores. De Nuremberg a Bagdad. Buenos Aires, EDHASA, 2007. 


\section{COORDINACIÓN GENERAL}

DE EDUCACIÓN INTERCULTURAL Y BILINGÜE

México, D. F., a 09 de Noviembre de 2011.

\section{A QUIEN CORRESPONDA:}

En atención a la solicitud recibida con No. de folio $\mathbf{0 0 0 1 1 0 0 4 2 2 2 1 1}$, dirigida a la Unidad de Enlace de la SECRETARÍA DE EDUCACIÓN PÚBLICA, con fundamento en el artículo 42 de la Ley Federal de Transparencia y Acceso a la Información Pública Gubernamental, el Dr. Fernando I. Salmerón Castro, Coordinador General de Educación Intercultural y Bilingüe, manifiesta lo siguiente:

- Referente al Monto del presupuesto asignado a la CGEIB por año desde su creación hasta el 2011; únicamente el total.

Respecto al No. de folio en mención, se presenta la información solicitada:

PRESUPUESTO AUTORIZADO 2002 AL 2011

\begin{tabular}{|c|c|c|c|c|}
\hline & $\begin{array}{c}\text { ASIGNACION } \\
\text { ORIGINAL }\end{array}$ & $\begin{array}{c}\text { AMPLIACIÓN } \\
\text { CAMARA DE } \\
\text { DIPUTADOS }\end{array}$ & $\begin{array}{c}\text { PRESUPUESTO } \\
\text { CDI }\end{array}$ & FOMEIM \\
\hline AÑO 2002 & $83,592,600.00$ & & & \\
\hline AÑO 2003 & $60,334,337.00$ & & & $4,835,560.02$ \\
\hline AÑO 2004 & $38,474,399.00$ & & & $4,881,488.00$ \\
\hline AÑO 2005 & $36,052,207.00$ & & $27,975,000.00$ & \\
\hline AÑO 2006 & $36,689,403.00$ & & $21,375,146.00$ & \\
\hline AÑO 2007 & $35,277,752.00$ & & & \\
\hline AÑO 2008 & $34,386,832.00$ & $11,500,000.00$ & & \\
\hline
\end{tabular}




\begin{tabular}{|c|c|c|c|c|} 
AÑO 2009 & $43,086,977.00$ & $8,000,000.00$ & $2,296,900.00$ & \\
\hline AÑO 2010 & $33,856,669.00$ & & $424,000.00$ & \\
\hline AÑO 2011 & $38,568,265.00$ & & $340,000.00$ & \\
\hline
\end{tabular}

Sin otro particular, reciba un cordial saludo.

\section{A T E NT A M E N T E}

Rachel Hernández Simancas

Enlace de Transparencia 


\section{Anexo 2}

\section{Nota Metodológica}

La presente nota, constituye un bosquejo sobre cómo utilizar los resultados teóricos delineados en los primeros dos capítulos de este trabajo, para la realización de una investigación empírica. El proceso de culminación de la investigación, supone poner a prueba los conceptos, las categorías y su articulación, con el objeto de evidenciar su pertinencia en la profundización del tema. En este caso, la manera en la que la educación superior intercultural, es materializada en la población, es decir, el caso de las Universidades Interculturales (UI) como una política pública.

I) El punto de partida de la investigación, se basa en un enunciado muy simple: existe una cantidad de recursos asignados, tanto para la creación como para el mantenimiento de cada unidad educativa en el país. Estos recursos buscan tener un efecto sobre los actores involucrados en el proceso educativo. Tales efectos son direccionados, es decir, hay un diseño previo y una intención predeterminada en muchos de los índices del presupuesto asignado. Se supone entonces, que el éxito del modelo de educación intercultural como política pública, ocurrirá si los agentes de destino, modifican su conducta y sus conceptualizaciones, de acuerdo con tales supuestos iniciales.

Lo anterior es lo que se definió como una forma de poder por intercambio, pues en el acto de tomar los recursos o servicios que ofrece el Estado, se busca que los individuos se comporten en una dirección definida, en este caso, en función de la apropiación de los recursos asignados. Lo que se llamó conductas y conceptualizaciones de apropiación. Así, sin matices, justo es lo que se pretende conocer: en qué medida el esfuerzo de los distintos órdenes de gobierno, va direccionando a los involucrados en torno a las universidades, para poder considerar dicha política educativa como eficaz o ineficaz.

Sin embargo, ningún proceso gubernamental ocurre aislado. Existe un contexto en torno a su desarrollo, que define la forma y el fondo de las políticas. En este caso en particular, se postuló como el marco que define la naturaleza asimétrica de las relaciones de poder, a los sistemas de clasificación. En un sistema específico, existen 
pares de oposición que delinean diferencias entre los actores involucrados en la relación. Estas diferencias asociadas a un proceso específico, se transforman en asimetrías, que colocan como más aventajado a uno sobre otro. Tal ventaja es factible utilizarla para ejercer el poder. En el caso de las UI, existen varias asimetrías fundamentales que definen la relación como de poder. Las dos más notables son, los recursos monetarios que facultan el proceso educativo y la capacidad de certificación de la educación adquirida.

Lo anterior es una versión esquemática y general de la investigación. El objetivo en adelante, será el de ir detallando las necesidades del proceso de investigación en términos metodológicos, es decir, cómo se va a proceder para instrumentalizar la teoría desarrollada en la primera fase.

II) Lo primero que interesa conocer son los supuestos en los que se basa la creación de las UIC. Estos supuestos son de varios tipos y no se presentan aquí de manera jerarquizada. En primer lugar, destaca el actor que genera las necesidades de las UI. La situación en la que se encuentran los pueblos y comunidades indígenas del país, es en general de bajo desarrollo. Factores de toda índole confluyen para que esta situación no se haya podido romper, no obstante los esfuerzos a lo largo de la historia de México. Particularmente, el acceso a la educación superior ha sido bajo y con malos resultados. Las UI buscan revertir esta situación. Por ello resulta fundamental conocer cómo se caracterizó el problema y cuáles fueron las soluciones propuestas. En esto importan, tanto las opiniones ciudadanas, las de expertos interesados, las de los indígenas mismos y las de las instancias de gobierno. En segundo lugar, está el cuerpo de regulaciones legales y administrativas con las que el Estado fundamenta la educación superior en estos planteles. Finalmente, se encuentra la población de destino, o sea, los alumnos que concurren actualmente a las UI.

En cada uno de los índices anteriores, existe un cuerpo de ideas, intenciones, visiones de futuro e ideologías, que soportan el lugar que ocupan las UI:; como un derecho a la educación; como un derecho de la población indígena; como una obligación de gobierno; o en todo caso, como una composición particular de estos tres puntos. Cada actor o eje, supondrá una organización jerárquica particular, de por qué se crearon y cómo deben operar estas universidades. Así, resulta fundamental ir conociendo, tanto el universo subjetivo como el objetivo que enmarca el origen referido. 
Para ello se realizarán entrevistas con los sujetos involucrados, de tal manera que se pueda conocer la particular organización que da cada actor al marco de origen de las UI. Al mismo tiempo, a través de la lectura de los documentos de fundamentación, certificación y operación de las UI, se podrá conocer la visión estatal que se plantea para la creación de las UI. Para esta investigación resulta central, conocer las convergencias y divergencias en torno a los principios que generaron las UI, pues mucho del éxito de tales unidades, suponemos, tendrá que ver con el balance positivo desde ambas visiones.

Como segundo punto general, destaca el proceso puramente gubernamental, es decir: qué mecanismos y actores operaron para la creación de las UIC; y cuáles son los puntos de correspondencia entre el marco legal y normativo inicial. Con lo anterior, se busca ir determinando, la lógica de instrumentación de la política de Estado, al nivel de política pública. En términos normativos, existen una serie de pasos o tareas a cumplir por todos los actores, sin embargo de manera general, estos marcos legales (Constitución Política de los Estados Unidos Mexicanos, Ley General de Derechos Lingüísticos de Los Pueblos Indígenas, Ley General de Educación, Convenios y declaraciones de rango internacional, Leyes estatales o municipales, Decretos de creación, Normas de operación, etcétera) comportan una cierta dimensión atemporal, es decir, regularmente prescriben o proscriben acciones, sin determinar plazos limite. Lo anterior deriva a menudo de la escala de aplicación, pues dado el marco de acción a nivel nacional, no se puede por decreto, enunciar el cumplimiento de todos y cada uno de los supuestos. Así que en ese nivel, interesa conocer la mayor cantidad de disposiciones que se generaron para culminar la instrumentación de la política pública, esto es, la puesta en funcionamiento de las unidades educativas en cada una de las localidades escogidas.

El tercer punto general, es determinar de manera presencial, los efectos que dichas unidades generan en los individuos objeto de la política: los estudiantes. En el proceso cotidiano de la educación, es donde se buscará constatar, si lo supuesto en las determinaciones normativas y en las administrativas, se cumple y en qué medida. Esta parte es la más importante de la investigación, pues implica conocer: lo que se hace; lo que se dice que se hace; o lo que se debería hacer. Esquemáticamente, representa el núcleo de la investigación, pues realizado el "mapa" de lo que se supone debería ocurrir (en concordancia con los dos puntos anteriores), se conocerá lo que verdaderamente ocurre, es decir: si la política de Estado ha sido implementada de manera adecuada y en qué medida. Dado que el interés de este esfuerzo, reside en los mecanismos por los 
cuales el Estado ejerce el poder, lo central es la determinación de cuánto de lo que se supone debe ocurrir, ocurre en términos de acciones y de conceptualizaciones.

¿Cómo se relacionan los apartados I y II para la realización de la investigación? En primer término está el supuesto básico que caracteriza a las relaciones de poder: la asimetría. La movilización y transformación de la acción social por parte de los órganos del Estado, tiene una parte substancial que plantea el ejercicio del poder político. Desde esta óptica, el núcleo característico es la idea de que el ejercicio de poder subyace en la detonación o transformación de conductas y conceptualizaciones en los actores, que de otro modo no harían. Esto es, que la motivación no es interna, endógena, sino que proviene de una influencia exterior, exógena, que es, necesariamente, intencional y direccionada. Con esto no se desdeña la motivación propia de los sujetos, sino que se busca caracterizar, hasta dónde peso más la influencia externa que la interna; hasta dónde el ejercicio de poder.

Se trata de buscar, cuáles son los reactivos, por los que se supone que los individuos en torno a las UI, desarrollarán o transformaran sus conductas y conceptualizaciones. Para la implementación de una política pública, resulta esencial el conocimiento adecuado de estos reactivos, pues una presunción errónea, tendrá como consecuencia el fracaso del plan propuesto. Así, se pretende caracterizar las asimetrías que suponen la actuación direccionada de los individuos, si ocurren como se planteaba, y si dichas actuaciones derivan de tales reactivos o las motivaciones se encuentran en otro lado. Para lo anterior, es fundamental delinear los sistemas clasificatorios que relacionan a todos los actores involucrados y conocer las asimetrías existentes entre cada uno de ellos. Estas clasificaciones y asimetrías, deberán ser determinadas en dos ámbitos generales: en términos estructurales y en términos subjetivos.

Lo primero, supone la determinación de las asimetrías que derivan de la relación objetiva entre actores. Ejes como la diferencia en recursos, conocimientos, legitimidades, derechos, fuerza, sacralidad, etnicidad, etcétera, serán básicos en la investigación a llevar a cabo. Tales ejes serán extraídos de la interpretación de los textos, de la observación del desarrollo de los procesos educativos y de las entrevistas con los actores involucrados. Este nivel es independiente de la percepción de los actores sobre la estructura de asimetrías; es fundamentalmente, una labor del investigador.

Lo segundo en cambio, supone la internalización de las asimetrías por los actores involucrados. De las entrevistas y la observación, se podrá conocer, hasta qué 
grado se perciben las asimetrías estructurales y si éstas son las que se tienen como motivaciones para la actuación social. Aquí vale la pena considerar, la posible articulación de las asimetrías en un relato que ponga en evidencia, la percepción del entorno de oposiciones que definen las asimetrías en las UI y que para darles sentido, es factible organizarlas en una estructura mitológica. Recabando varios de estos relatos, se fortalecerá o ampliará la estructura de poder que subyace al fenómeno de poder estatal.

Hay que tener en cuenta, que las actuaciones pueden ocurrir en efecto, por la movilización de las asimetrías por parte de los órganos y actores gubernamentales, y su internalización por parte de los actores elegidos. No obstante, puede ocurrir que aun sin subjetivizar las asimetrías, sean éstas las que impelen al actor a conducirse de determinada manera o en contraposición, que los actores gubernamentales las utilicen sin asumir su poder coactivo. Aquí no se neutraliza el requisito de la intencionalidad, que es, ontológicamente necesaria, para suponer un ejercicio de poder. Lo que ocurre es que el establecimiento de un escenario deseable por aquel que ejerce el poder, lo "imagina" como no coactivo, sino de libre elección para los involucrados. Esta situación no es metodológicamente complicada de resolver, pues no depende de los "buenos deseos" del funcionario o su postura política en favor de los involucrados en la política, sino, llanamente, de que la apropiación del bien gubernamental, este condicionado a la realización o introyección de conductas o conceptualizaciones de apropiación, que el funcionario desea o intuye que ocurrirán, independientemente, que introyecte o asuma su naturaleza coactiva. Finalmente, es factible la convergencia de asimetrías y motivaciones en los actores, de tal suerte que deberá considerarse de manera muy cuidadosa, si el ejercicio de poder ocurre en verdad.

Para este punto, hay que referir que desde los supuestos teóricos que se delinearon, los sistemas clasificatorios y por ende, las asimetrías resultantes, no estarán atadas a ningún substrato "duro". Ello quiere decir, que no se espera bajo ninguna circunstancia que el ejercicio de poder ocurra como hecho en los distintos niveles del proceso. Se busca conocer, hasta donde el cuerpo de intenciones que las UI suponen se logra, y que tanto de eso, proviene de una relación asimétrica. Es un hecho central, que puede ocurrir (y de hecho ocurrirá en varios índices), el fracaso de las presunciones de la política. Ello no afecta la investigación, pues lo que interesa no es demostrar a priori la existencia y funcionamiento de las relaciones de poder entre gobierno y ciudadanos, sino caracterizar las circunstancias de por qué ocurre o no, dicho ejercicio. 
En cuanto al otro gran supuesto: la ocurrencia de los fenómenos de poder mediante intercambio, es importante delinear las tareas básicas. Se trata de conocer las asignaciones de recursos y servicios que se implementan en cada nivel, para indagar si su apropiación, ocurre de acuerdo a lo dispuesto; es decir, si se dan las conductas y las conceptualizaciones de apropiación supuestas. Es de la mayor importancia aclarar, que en consonancia con todo el planteamiento teórico, el trabajo de investigación en este punto, no reviste en ningún modo, un trabajo de tipo economicista. En primer lugar, porque no se busca realizar fundamentalmente una labor de tipo cuantitativo, es decir, establecer una correlación directa entre asignaciones y efectos, de tal manera que resultara en la elaboración de un índice de eficiencia. Tal horizonte tendrá probablemente, de acuerdo al desarrollo de la investigación, algunos resultados en el trabajo. Mas no es los fundamental. Lo que se busca es conocer el efecto sociológico de la actividad del gobierno, es decir, la convergencia entre los supuestos que determinan el uso de recursos y las conductas y conceptualizaciones de apropiación. En este orden de ideas, resulta obvio que una aproximación al mundo de los recursos gubernamentales desde una perspectiva contable, está totalmente fuera de lugar. Sería un error seguir los recursos hasta sus últimas consecuencias, pues se caería en el mundo de la fiscalización, lo que está francamente lejos del "ojo" antropológico. No obstante resulta importante la aclaración, pues en términos metodológicos delinea una frontera que no se debe cruzar, ya que de otro modo se corre el riesgo de perder el objeto de investigación.

Dentro de los aspectos fundamentales, está el de valorar las características básicas de los intercambios no mercantiles, es decir, que no están mediados por el dinero en ambos sentidos. Para el caso de las UI, la movilización de la acción social no tiene como objetivo del intercambio, la devolución en términos monetarios; esto lo caracteriza como un intercambio heterogéneo. Las peculiaridades de este tipo, definen que la devolución esté siempre atada a una interpretación, tanto por el que da, pero sobre todo, por el que retribuye. Aparece así, el primer índice de incompatibilidad entre lo que se pide y lo que se hace. Hay que notar, que de acuerdo a lo que se planteó en el marco teórico, importarán tanto las conductas y conceptualizaciones que se busca provocar, como aquellas que se busca atenuar o disuadir. Dentro de los supuestos de las UI, se detectan provisionalmente, ambos aspectos: tanto lo que se definió como fenómenos convergentes -los provocantes-, como aquellos tratados de divergentes -los disuasivos. 
Un aspecto central será el de establecer, no solo lo que ocurre como términos pactados del intercambio (tanto objetivo como subjetivos), sino la caracterización de las circunstancias previas y posteriores al hecho en sí. De esta manera se conocerá cómo concurren las partes al intercambio y qué queda además de los efectos causados. Lo que se mencionó en términos de sistemas de clasificación y de relatos organizadores de asimetrías, cobra relevancia en este punto. Conocer la dimensión contextual de los intercambios, determina no sólo el valor efectivo de las asimetrías involucradas, sino también, cómo es que se asumen los individuos frente al intercambio. Aquí se quiere resaltar lo que es básico en el planteamiento teórico: que estos hechos ocurren no solo como fenómeno de don, sino como aquello que se mencionó como “anti-don”. Es decir, que la focalización analítica en los intercambios que fundamentan a las UI, se buscará tanto en los fenómenos donde el aporte ocurre primero y la devolución después, como en aquellos donde por la estructura del contexto, la devolución, va primero. Para ello, se debe determinar de manera general, el contexto total en el que se encuadran los hechos de intercambio, es decir, determinar lo que es conocido como el campo y si hay interacciones conflictivas, las arenas.

Finalmente, resalta la existencia de un marco estandarizado en el que ocurren los intercambios y las interacciones entre gobierno y ciudadanos. Para el caso de las UI, el modelo que se supone adecuado es el de la educación pública, obligatoria, gratuita y laica. En la vida de los individuos, hay, lo más probable, una historia de interacciones con este modelo, y un conjunto de opiniones sobre las conductas y conceptualizaciones que el individuo refiere al respecto. Tales interacciones habrán tenido como marco, tanto efectos de poder como de ausencia de poder. Hay un mundo normativo que supone la forma en la que se deben llevar a cabo esas interacciones y por tanto, orientarán en parte los efectos objetivos y subjetivos en los individuos. Pero también, han habido una serie de procesos administrativos y de gobierno, en los que el individuo ha tenido que adecuarse para -de acuerdo al supuesto general de esta tesis- apropiarse de los bienes que los gobiernos ponen a disposición de los ciudadanos.

Por último, es evidente que dentro del proceso de gobierno, los recursos disponibles para instrumentar políticas no son ilimitados. Generalmente se tiene que proceder, excluyendo a algunos miembros de la sociedad e incluyendo a otros. En estos lamentables pero necesarios cortes, aparecen criterios de justicia en la repartición de los bienes y en su apropiación. Los criterios pueden ser de tipo igualitario, es decir, todos tienen de origen derecho al bien gubernamental, o dinámicas como los sorteos, las filas 
o la repartición hasta que alcance, que resultan en la eliminación de unos sobre otros. En otros casos, hay criterios de redistribución que buscan igualar a los más desaventajados. Estos criterios de justicia, reparten los bienes en función de índices socioeconómicos, étnicos, lingüísticos, regionales o locales, por debilidades físicas, mentales, de salud, etcétera. En este segundo caso, una demanda excesiva del bien, resulta en la implementación de criterios selectivos. Las formas en las que se seleccionan a los que ingresarán a las UIC y los criterios con los que se reparten los recursos luego de la aceptación, constituyen un insumo importante en la determinación de la mecánica de los intercambios asimétricos, es decir, son básicos para la estructuración de los intercambios y para saber que ocurre primero: el don o la devolución. 
Anexo 3

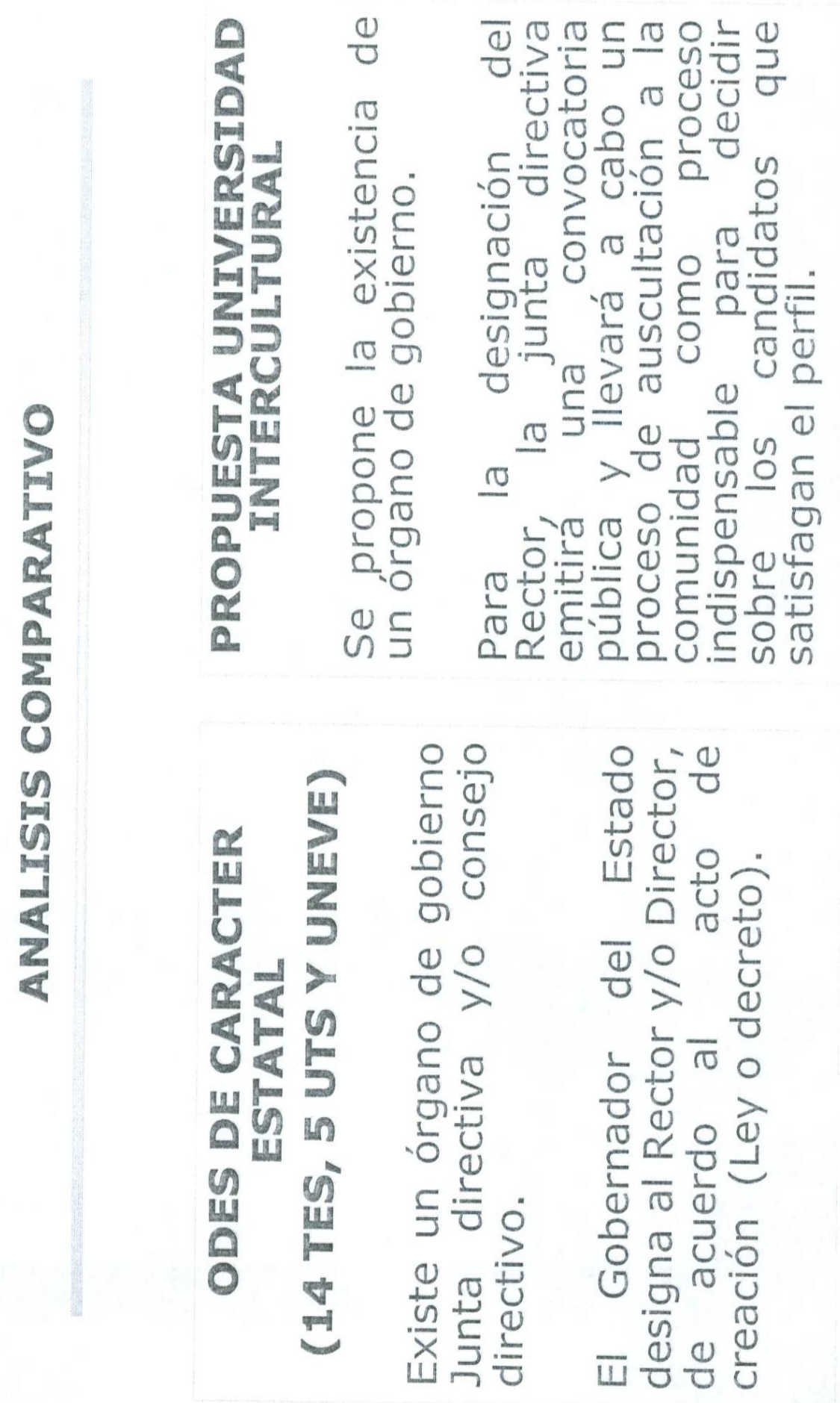




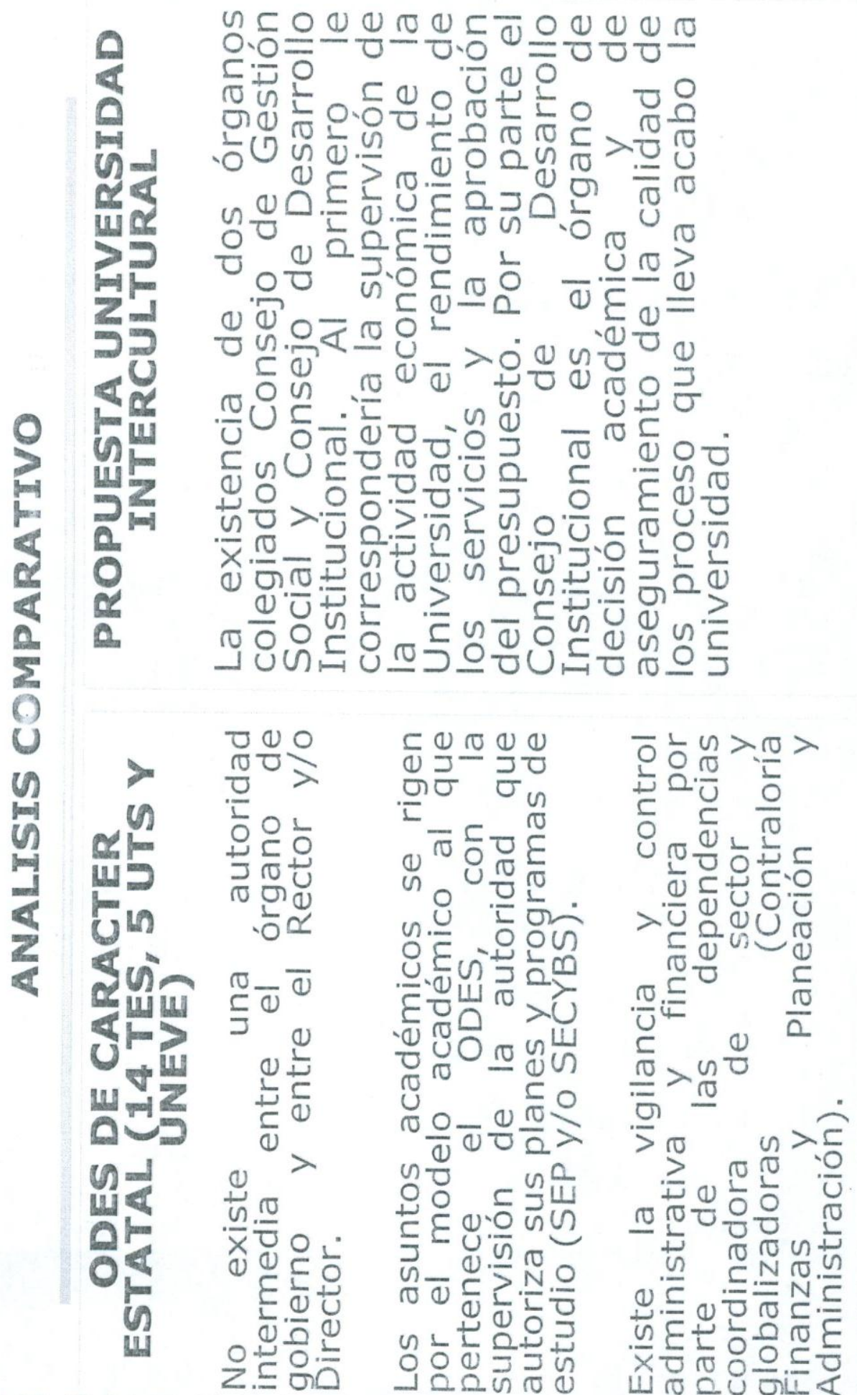




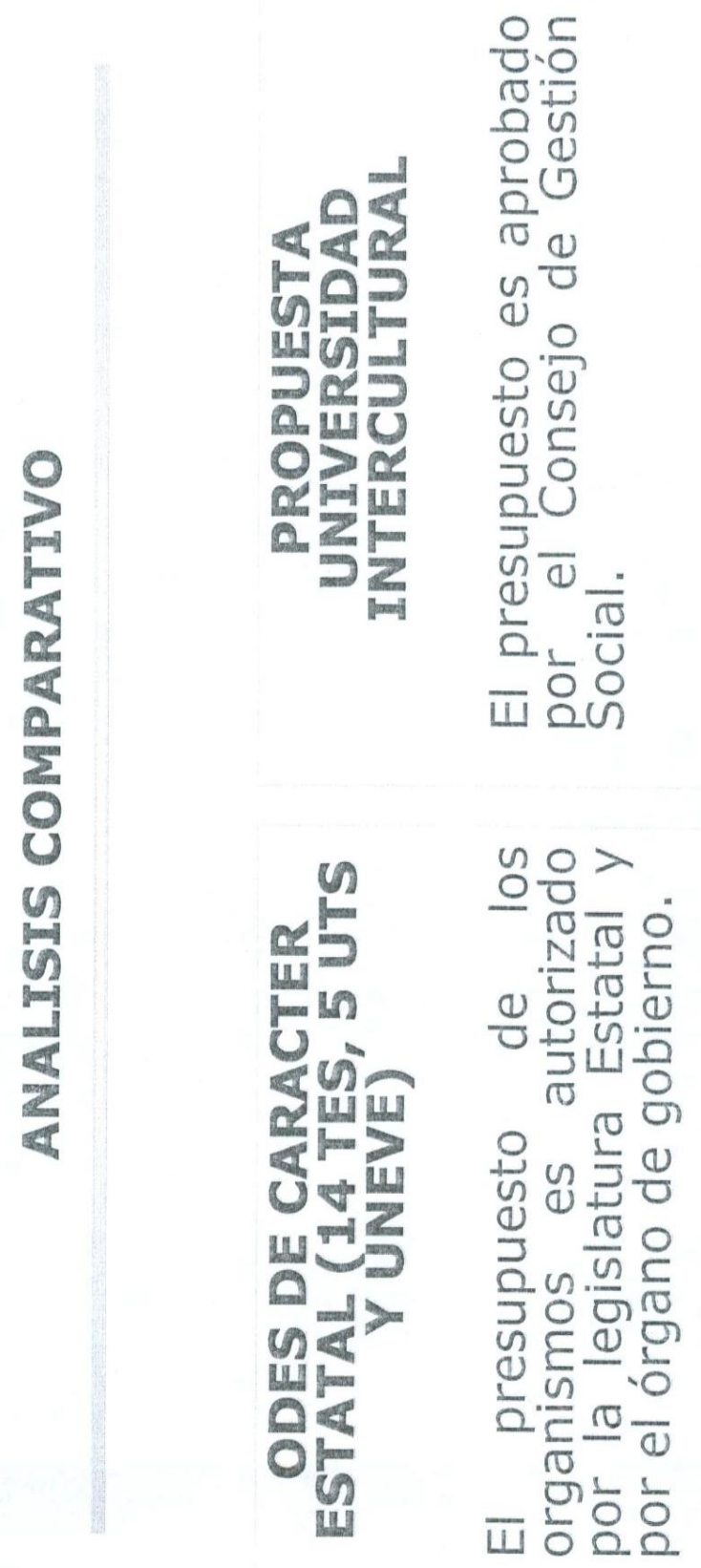




\section{Anexo 4}

\section{Transferencias desde la CDI a la UIEM}

\section{UNIVERSIDAD INTERCULTURAL DEL ESTADO DE MÉXICO}

\begin{tabular}{|c|c|c|}
\hline AÑO & $\mathrm{ACClON}$ & MONTO : \\
\hline \multirow[t]{2}{*}{2006} & $\begin{array}{l}\text { Construcción y equipamiento de la segunda etapa de la Universidad, con } \\
\text { capacidad instalada para } 500 \text { estudiantes. }\end{array}$ & $25,175,000.00$ \\
\hline & \begin{tabular}{|ll} 
& Subtotal \\
\end{tabular} & $25,175,000.00$ \\
\hline \multirow{8}{*}{2009} & $\begin{array}{l}\text { Propuesta de plan de estudios de la carrera de Ingeniería Energética y } \\
\text { Ambiental para las Universidades Interculturales }\end{array}$ & $500,000.00$ \\
\hline & $\begin{array}{l}\text { Diseño y puesta en marcha del Sistema de Información estadística de } \\
\text { educación intercultural y Bilingủe }\end{array}$ & $870,000.00$ \\
\hline & $\begin{array}{l}\text { Recuperación y fortalecimiento de expresiones culturales originarias para la } \\
\text { Producción de material didáctico de los propios Pueblos Indígenas }\end{array}$ & $536,500.00$ \\
\hline & $\begin{array}{l}\text { Centro de Salud Intercultural integrativa para la atención de la población de las } \\
\text { Comunidades Indígenas de los Pueblos Indígenas originarios y migrantes del } \\
\text { Estado de México: Mazahuas, HñaHñu, Tlahuica, Matlatzinca, Nahua, } \\
\text { Zapoteca, Mixteca y otros grupos étnicos. }\end{array}$ & $3,000,000.00$ \\
\hline & Creación del Laboratorio multimedia UIEM 2 da etapa del canal multimedia & $1,500,000.00$ \\
\hline & $\begin{array}{l}\text { Diseño, creación, construcción, equipamiento y operación de la cabina de radio } \\
\text { Indigena e Intercultural del canal UIEM }\end{array}$ & $450,000.00$ \\
\hline & $\begin{array}{l}\text { Tres estudios de factibilidad para la creación de Universidades Interculturales } \\
\text { en los Estados }\end{array}$ & $750,000.00$ \\
\hline & S $\quad$ Subtotal & $7,606,500.00$ \\
\hline \multirow{7}{*}{2010} & $\begin{array}{l}\text { Equipamiento de la primera etapa del edificio de Laboratorios de Ciencias y } \\
\text { Saberes tradicionales de la Universidad Intercultural del Estado de México. }\end{array}$ & $553,333.00$ \\
\hline & Laboratorio Multimedia Intercultural. & $1,000,000.00$ \\
\hline & $\begin{array}{l}\text { Módulo experimental de agroecosistemas sustentables de los grupos } \\
\text { originarios del Estado de México y capacitación comunitaria. }\end{array}$ & $600,000.00$ \\
\hline & $\begin{array}{l}\text { Creación de una base de información lingüística y cultural a partir de las } \\
\text { producciones escritas, orales y gráficas de alumnos de escuelas de las } \\
\text { regiones purepecha, Hñahñu, totonaco y urbano de Hidalgo y Distrito Federal } \\
\text { que operan el programa multimedia Uantakua. }\end{array}$ & $250,000.00$ \\
\hline & $\begin{array}{l}\text { Proyecto piloto de enseñanza y aprendizaje de la lengua y cultura mazahua y } \\
\text { tlahuica en telesecundaria de la Universidad Intercultural del Estado de México. }\end{array}$ & $750,000.00$ \\
\hline & Foro sobre medicina tradicional y Salud Intercultural. & $600,000.00$ \\
\hline & $\begin{array}{lll} & \end{array}$ & $3,753,333.00$ \\
\hline \multirow{5}{*}{2011} & Consolidación del laboratorio de Desarrollo Sustentable de la UIEM. & $1,360,000.00$ \\
\hline & $\begin{array}{l}\text { Sistema de enseñanza, conservación y difusión de la Medicina Tradicional para } \\
\text { el desarrollo de los pueblos originarios del Estado de México. }\end{array}$ & $850,000.00$ \\
\hline & $\begin{array}{l}\text { Aprovechamiento sustentable de la planta "Rejalgar" Symphoricarpos } \\
\text { microphyllum HBK, en las comunidades mazahuas. }\end{array}$ & $100,000.00$ \\
\hline & 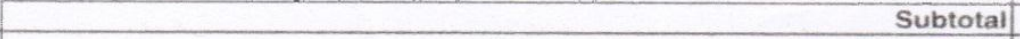 & $2,310,000.00$ \\
\hline & Gran Totai & $38,844,833.00$ \\
\hline
\end{tabular}


Anexo 5

Transferencias a la UIEM vías el convenio de colaboración

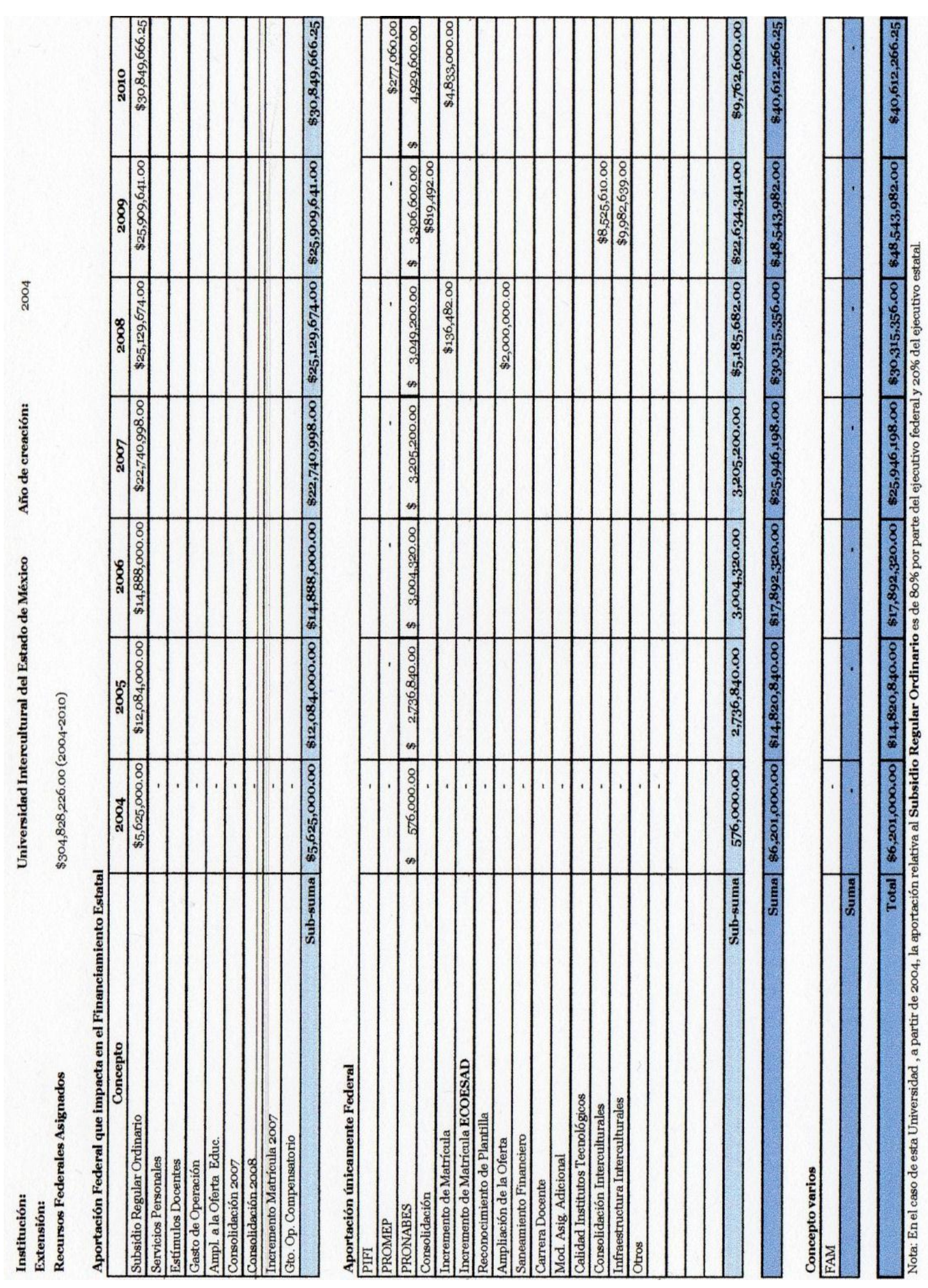


Anexo 6

Foto aérea de la UIEM

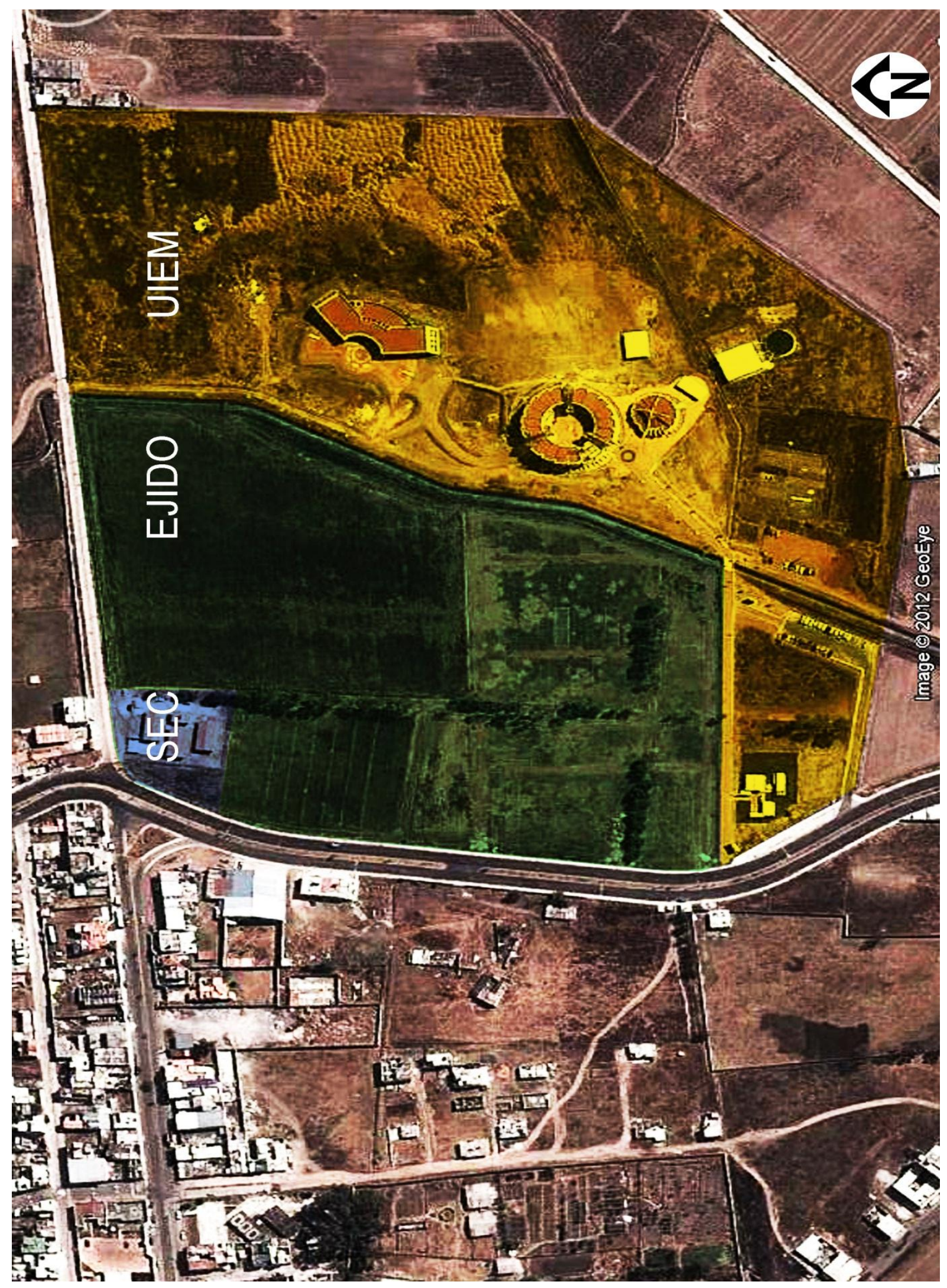


Anexo 7

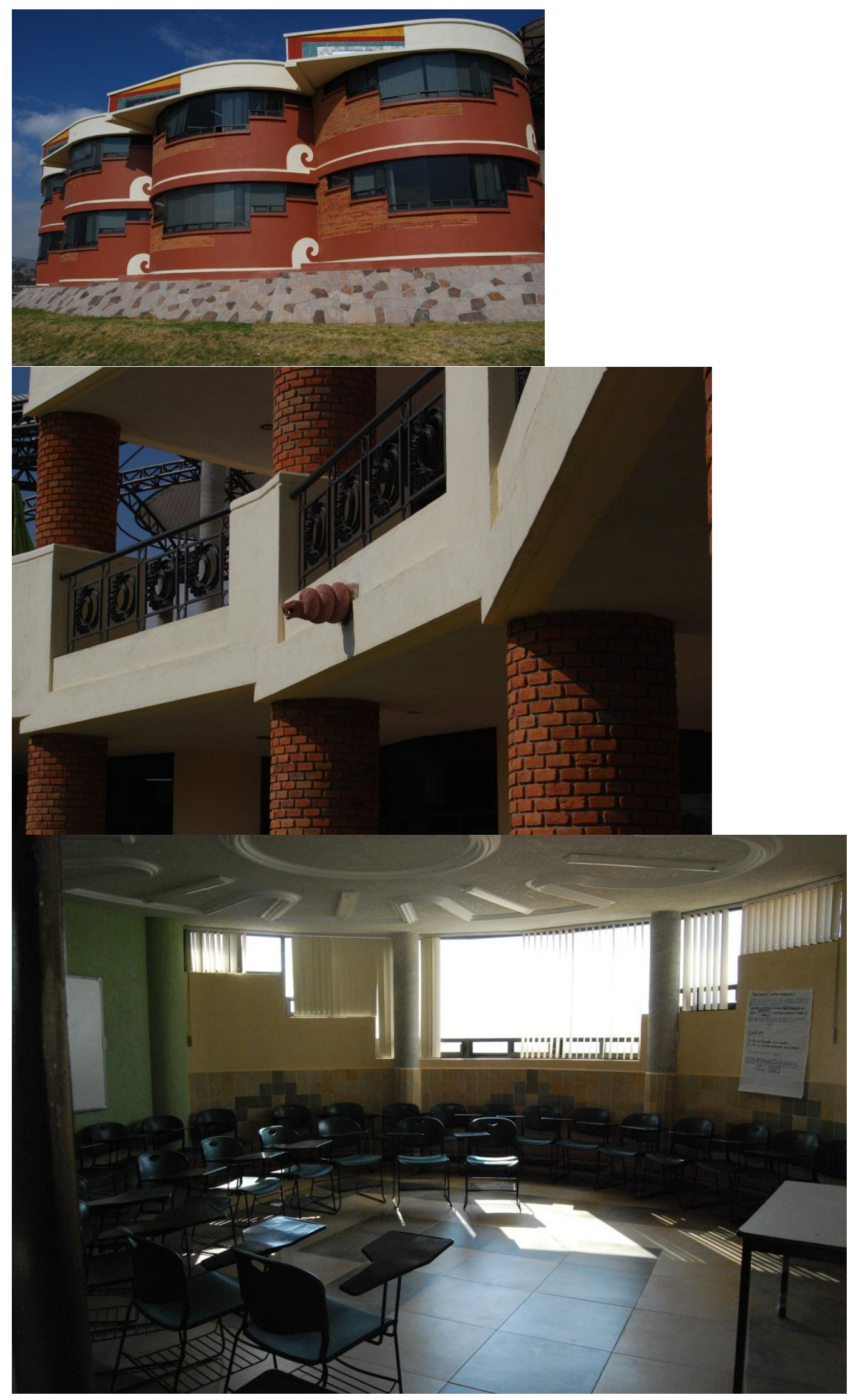



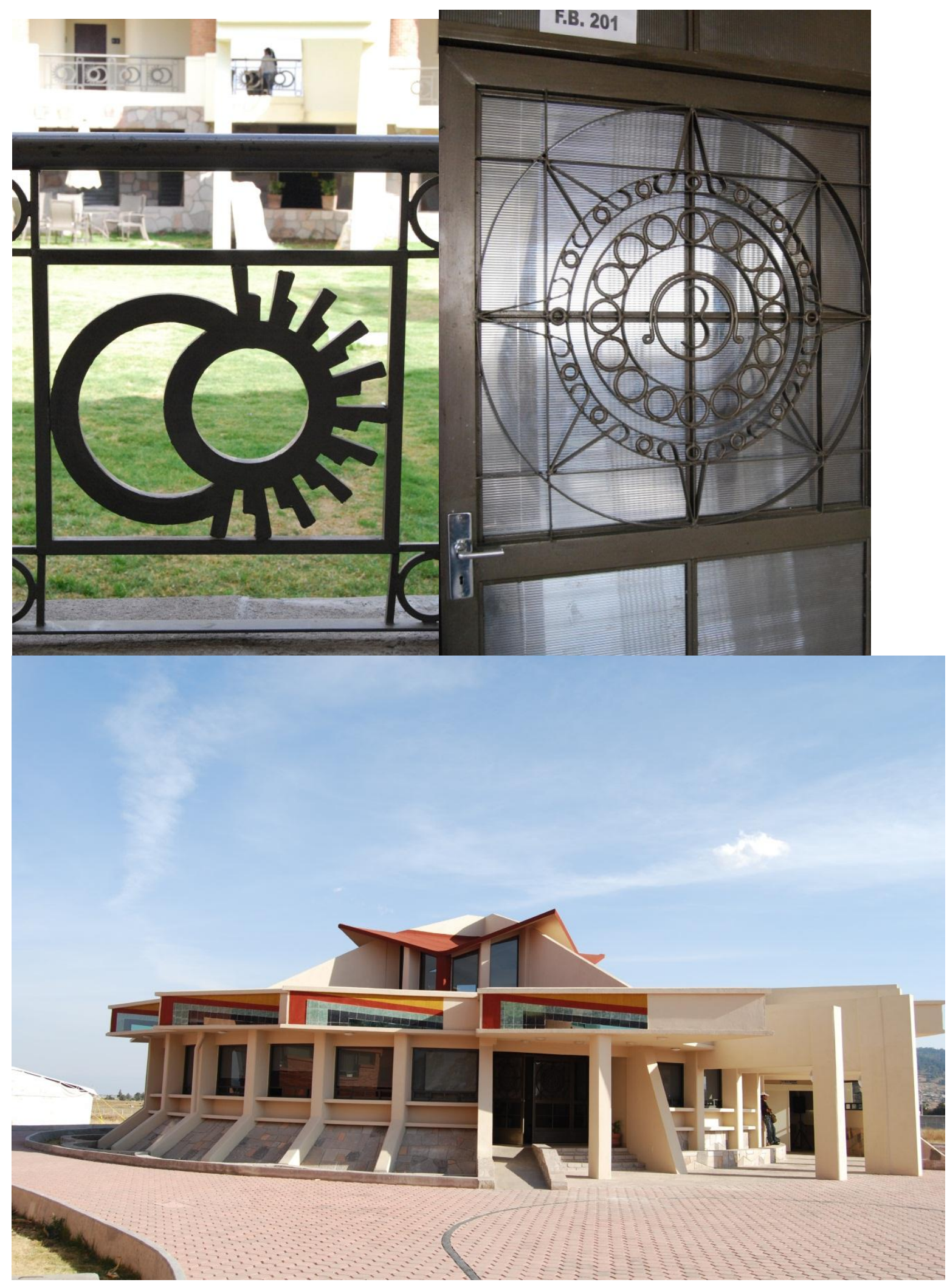

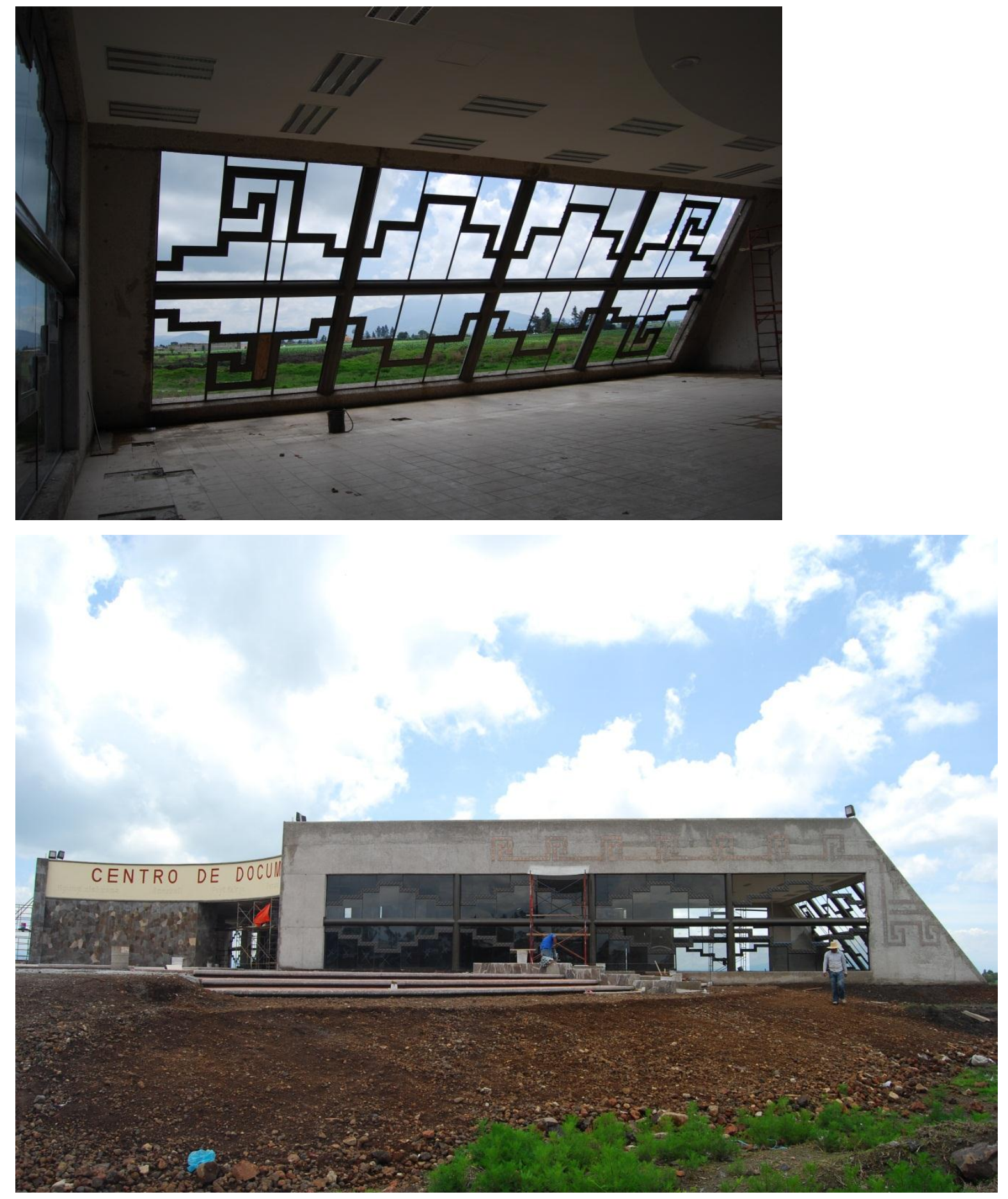
Anexo 8

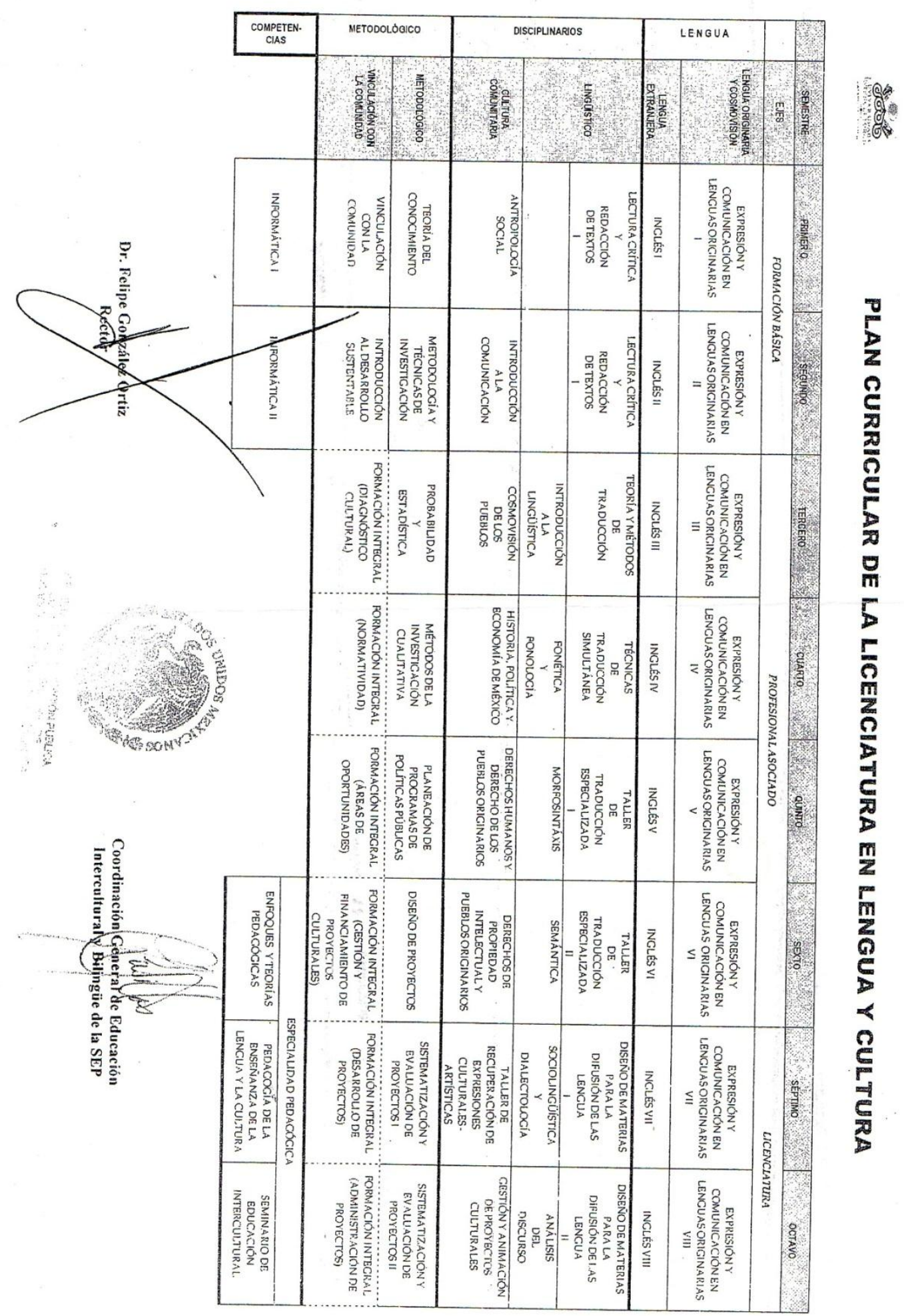




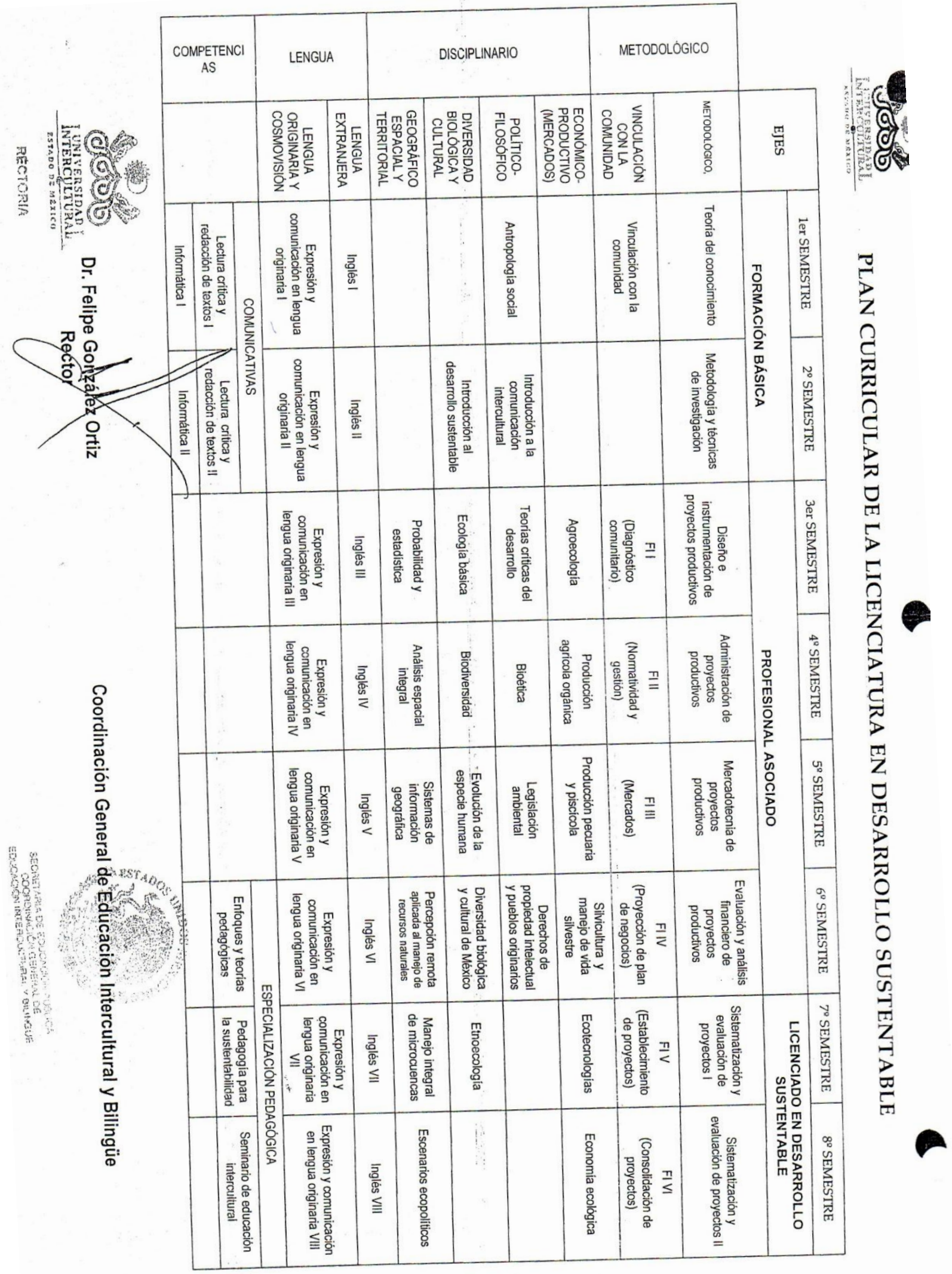




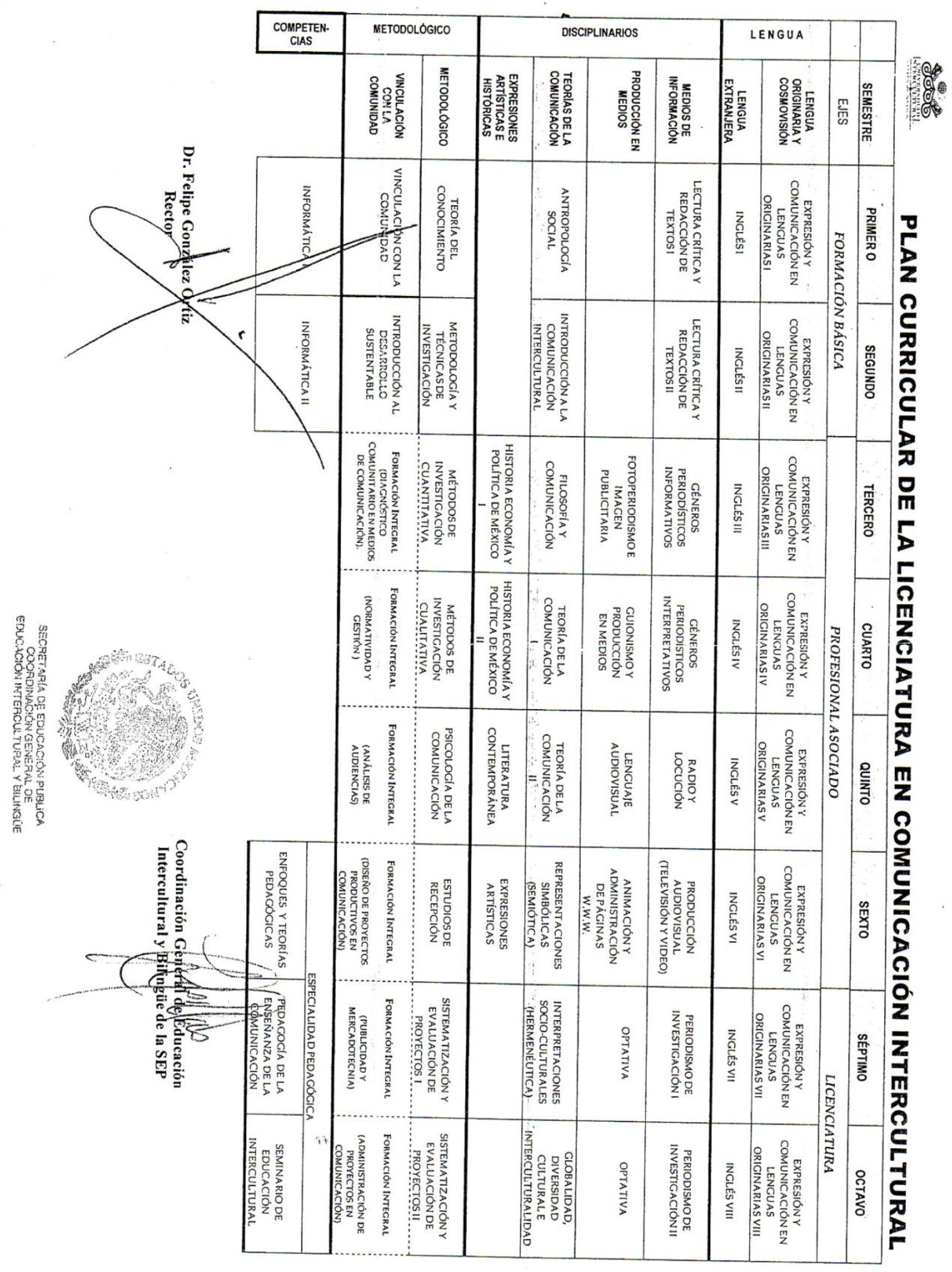




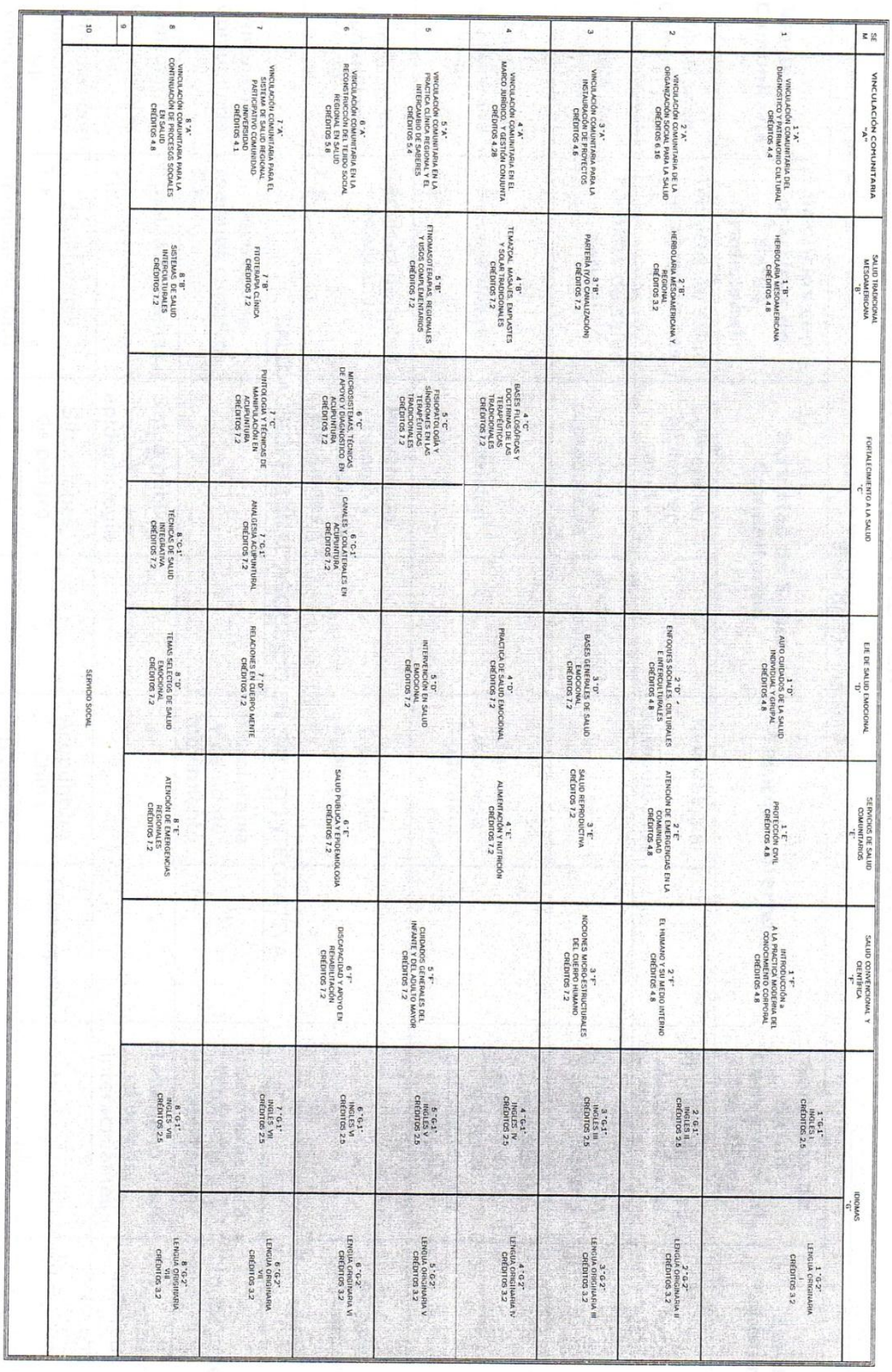


ANEXO 9

DISTRIBUCIÓN ESPACIAL EN SALONES
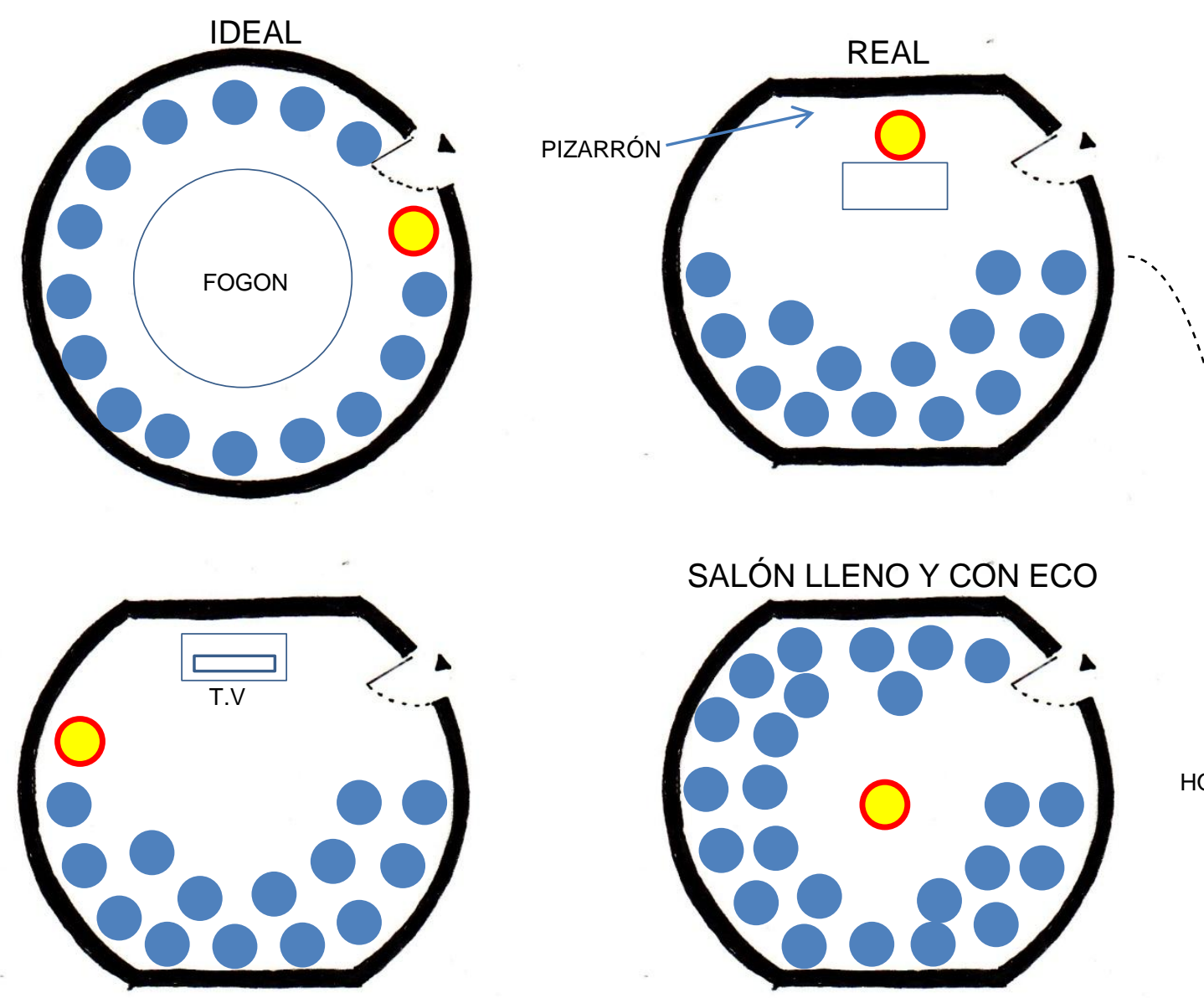

HOMOLOGÍA
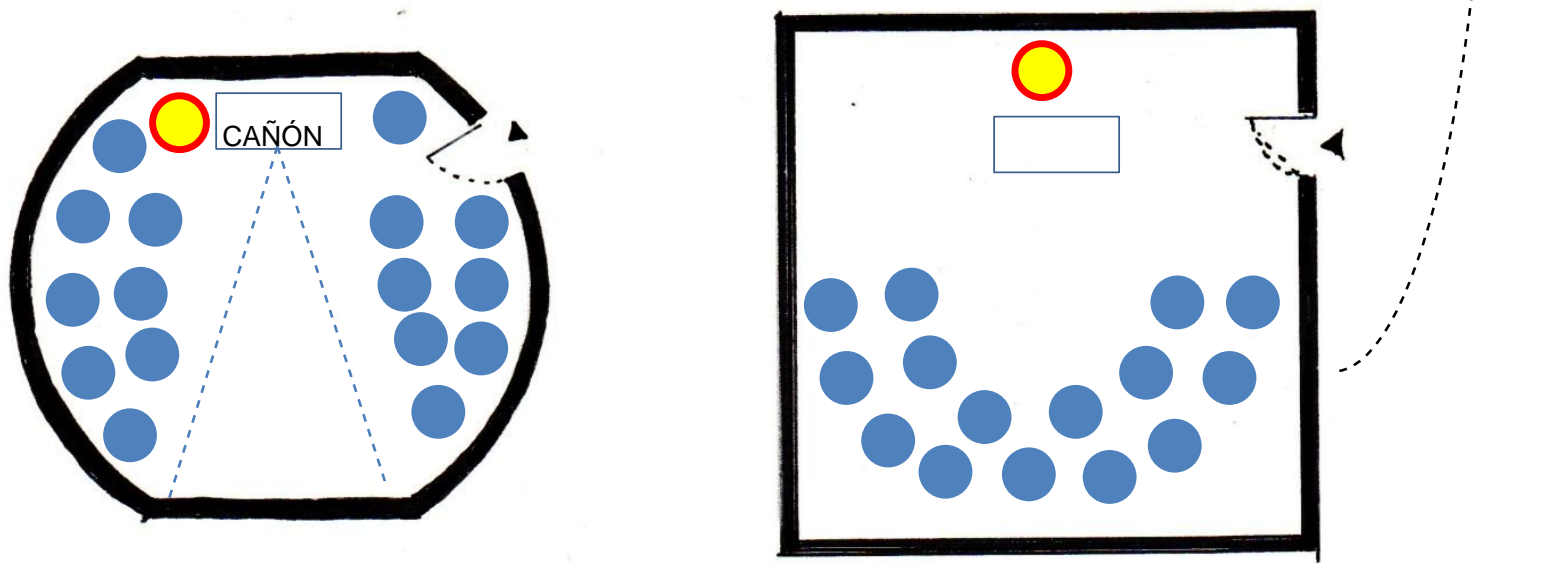

ALUMNO

ProfESOR 